Tobias Arens

Inter- und

intragenerative

Umverteilung im

deutschen Steuer-

Transfer-System 
Tobias Arens

\section{Inter- und intragenerative Umverteilung im deutschen Steuer-Transfer-System}

Mit einem Steuer-Transfer-Modell, das die Entwicklung seit 1950 abbildet, werden verschiedene Fragestellungen inter- und intragenerativer Umverteilung aus den Bereichen der Bildungsökonomie, der Familienpolitik und der Alterssicherung bearbeitet. Anders als in üblichen Ansätzen werden dabei Nettobelastungen des Lebenseinkommens verschiedener Kohorten unter Berücksichtigung der historischen Entwicklung bestimmt. Den bekannten Mehrbelastungen aus der Sozialversicherung für junge Kohorten stehen hiernach deutlich gesunkene Steuern und eine stark ausgeweitete Familienförderung gegenüber. Mit der zunehmenden Verlagerung von Umverteilung aus dem Steuersystem in die Sozialversicherung geht eine über die Kohorten deutlich sinkende Progression der Besteuerung ihrer Lebenseinkommen einher.

Tobias Arens studierte Volkswirtschaft und Psychologie an der Universität Münster. Er arbeitete am Fraunhofer Institut für angewandte Informationstechnik als Wissenschaftlicher Mitarbeiter an politökonomischen Fragestellungen und promovierte an der Deutschen Hochschule für Verwaltungswissenschaften Speyer. Der Autor ist im Bundesministerium für Arbeit und Soziales beschäftigt. 
Inter- und intragenerative Umverteilung im deutschen

Steuer-Transfer-System 


\section{FINANZWISSENSCHAFTLICHE SCHRIFTEN}

Herausgegeben von den Professoren

Konrad, Krause-Junk, Littmann, Oberhauser, Pohmer, Schmidt $\dagger$

Band 118

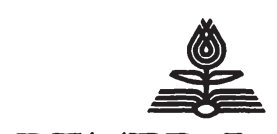

\section{PETER LANG}

Frankfurt am Main · Berlin · Bern · Bruxelles · New York · Oxford - Wien 


\section{Tobias Arens}

\section{Inter- und intragenerative Umverteilung im deutschen Steuer-Transfer-System}

Langfristige Wirkungen im Lebenszyklus

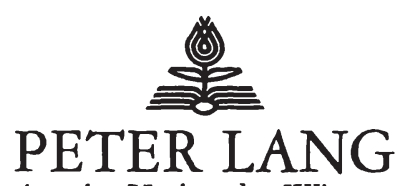

Internationaler Verlag der Wissenschaften 
Bibliografische Information der Deutschen Nationalbibliothek Die Deutsche Nationalbibliothek verzeichnet diese Publikation in der Deutschen Nationalbibliografie; detaillierte bibliografische Daten sind im Internet über <http://www.d-nb.de> abrufbar.

Zugl.: Speyer, Hochsch. für Verwaltungswissenschaften, Diss., 2009

Open Access: The online version of this publication is published on www.peterlang.com and www.econstor.eu under the international Creative Commons License CC-BY 4.0. Learn more on how you can use and share this work: http://creativecommons.org/licenses/ by/4.0.

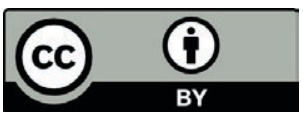

This book is available Open Access thanks to the kind support of ZBW - Leibniz-Informationszentrum Wirtschaft.

Gedruckt auf alterungsbeständigem, säurefreiem Papier.

ISSN 0170-8252

ISBN 978-3-631-59039-3

ISBN 978-3-631-75164-0 (eBook)

(C) Peter Lang GmbH

Internationaler Verlag der Wissenschaften

Frankfurt am Main 2009

Alle Rechte vorbehalten.

Das Werk einschließlich aller seiner Teile ist urheberrechtlich geschützt. Jede Verwertung außerhalb der engen Grenzen des Urheberrechtsgesetzes ist ohne Zustimmung des Verlages unzulässig und strafbar. Das gilt insbesondere für Vervielfältigungen, Übersetzungen, Mikroverfilmungen und die Einspeicherung und Verarbeitung in elektronischen Systemen.

\section{Printed in Germany 123457}

www.peterlang.de 


\section{Inhaltsverzeichnis}

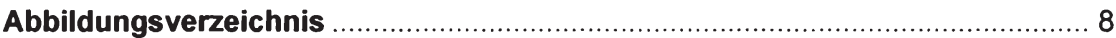

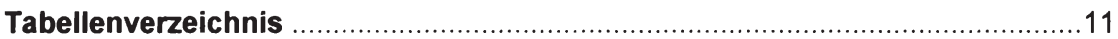

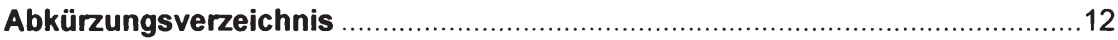

1 Einleitung: Untersuchungsgegenstände und -ansatz ..........................13

Teil 1: Grundlagen der Modellrechnungen:

Steuern, Transfers, Lebenseinkommen...............................19

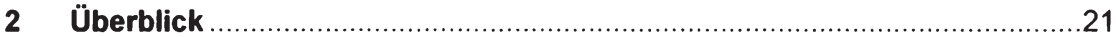

2.1 Bausteine der Modellrechnungen: Steuer-Transfer-Modell STM .............21

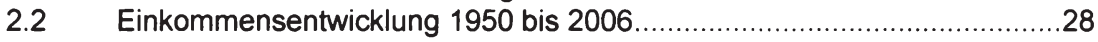

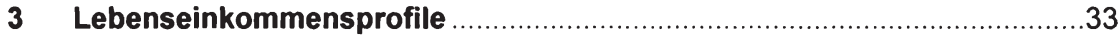

3.1 Schätzung von Einkommensprofilen ............................................. 33

3.2 Qualifikationswandel und Korrektur von Lebenseinkommensprofilen.......42

4 Steuern und Transfers: Entwicklungen seit 1950 .............................49

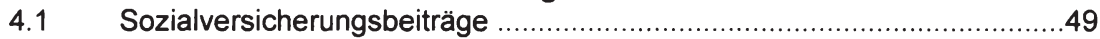

$4.2 \quad$ Einkommensteuer und Zuschlagsteuern .....................................54

4.2.1 Veranlagungsarten: Besteuerung von Ehegatten und Familien ...........54

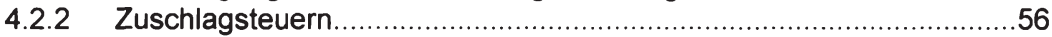

4.2.3 Eckwerte des Einkommensteuertarifs .........................................57

4.2.4 Entwicklung der Steuerbelastung bei Beziehern von Einkünften aus nichtselbständiger Arbeit ......................................................59

4.2.5 Besteuerung von Renten der gesetzlichen Rentenversicherung..........64

4.3 Kindergeld und kindbedingte Steuerentlastungen ................................69

4.3.1 Kinderfreibetrag und Kindergeld:

Familienleistungsausgleich im engeren Sinne ...........................69

4.3.2 Weitere kindbedingte Steuerentlastungen ...................................82

4.4 Leistungen im Anschluss an die Geburt eines Kindes:

Erziehungs- und Elterngeld ...................................................... 87

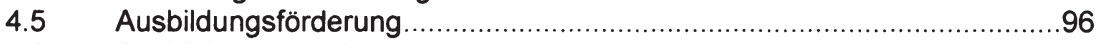

4.6 Ausbildungsgebühren............................................................

5 Gesetzliche Rentenversicherung: Entwicklungen seit 1992 ................113

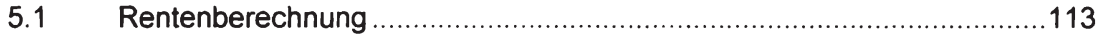

5.2 Transferelemente der gesetzlichen Rentenversicherung ...........................116 
Teil 2: Anwendung: Wirkungen des Steuer-Transfer-Systems im Lebenszyklus

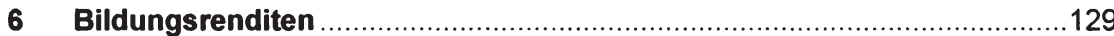

6.1 Zwei Ansätze zur Quantifizierung der Rentabilität von Bildung:

Das Mincer-Modell und interne Ertragsraten .......................................129

6.2 Ermittlung interner Ertragsraten mit dem STM ..................................137

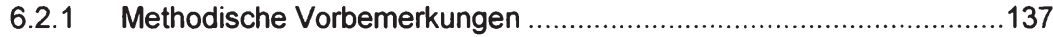

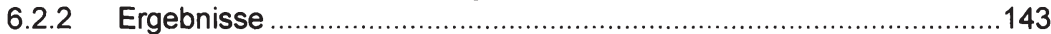

6.2.2.1 Entwicklung der Bildungsrenditen über die Kohorten

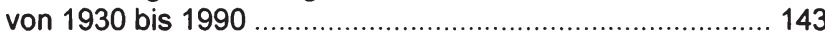

6.2.2.2 Renditeeffekte aktueller Studiengebühren ......................... 164

6.2.2.3 Vergleich verschiedener Ergebnisse zu internen Ertragsraten von Bildung ............................................. 166

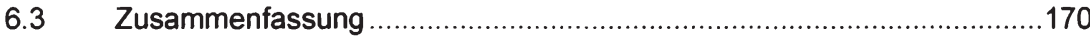

7 Inter- und intragenerative Umverteilung durch die gesetzliche

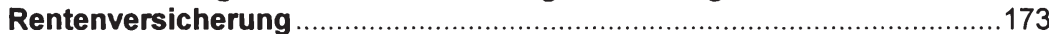

7.1 Umverteilung: Befunde, Methoden und Probleme ................................174

7.1.1 Renditeberechnungen auf der Basis von Eckrentnern .....................174

7.1.2 Berücksichtigung intragenerativer Unterschiede ............................182

7.2 Renditerelevante Merkmale: Ergebnisse des STM...............................191

7.2.1 Ausbildung und Einkommensprofil ..............................................192

7.2.2 Gesetzliche Altersgrenzen und Renteneintrittsalter ........................197

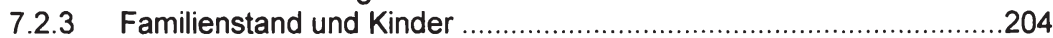

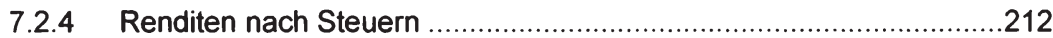

7.3 Renditeberechnungen mit dem STM: Gesamtwirkungen ....................219

7.4 Zusammenfassung und Schlussfolgerungen .....................................228

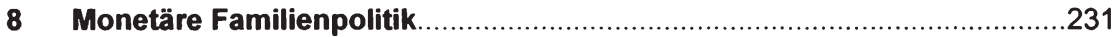

8.1 Familienpolitische Maßnahmen:

Umfang, Abgrenzung und ausgewählte Entwicklungen seit 1950 ..........233

8.1.1 Umfang insgesamt und Erfassung kindbedingter

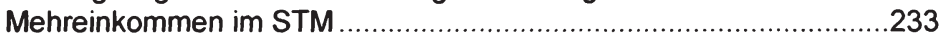

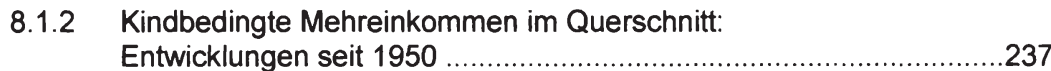

8.2 Kindbedingte Mehreinkommen im Lebenszyklus ................................243

8.2.1 OKonomische Begründungen monetärer Familienpolitik ..................244

8.2.2 Erfassung kindbedingter Mehreinkommen im Lebenszyklus .............249

8.2.2.1 Kindbedingte Mehreinkommen im Lebenszyklus von Eltern der Kohorten 1930 bis 1990 ............................. 256

8.2.2.2 Vergleiche nach dem Geburtsjahr der Kinder ..................... 265

8.2.3 Kindbedingte Mehreinkommen und Kosten von Kindern ..................269

8.3 Zusammenfassung und Schlussfolgerungen.......................................28 


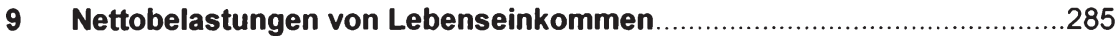

9.1 Ansätze intergenerativer Belastungsvergleiche ................................286

9.1.1 Generationenbilanzen und Lebensnettosteuersätze ........................286

9.1.2 Verknüpfung bestehender Ansätze im STM ................................290

9.2 Zukünftige Entwicklung: Annahmen im STM ......................................295

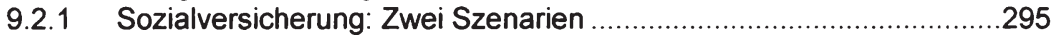

9.2.2 Besteuerung: Implikationen des geltenden Rechts .........................299

9.3 Bestimmung von Lebensnettosteuersätzen mit dem STM .....................302

9.3.1 Steuern und Sozialversicherung ..................................................304

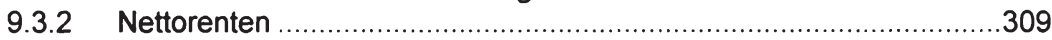

9.3.3 Lebensnettosteuersätze Alleinstehender .....................................315

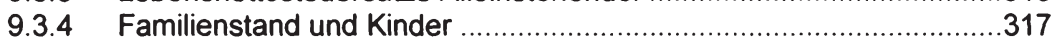

9.3.5 Rechenvarianten: Beitragssatzanstiege und Arbeitgeberanteile ........324

9.4 Gesamtbetrachtung und Schlussfolgerungen .......................................329

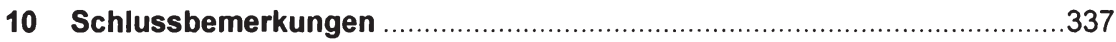

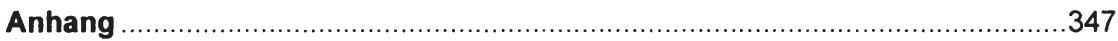

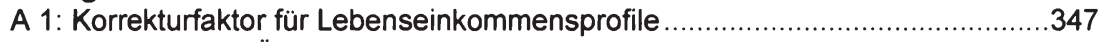

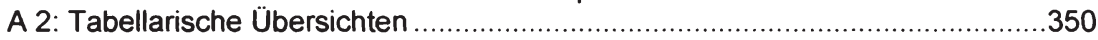

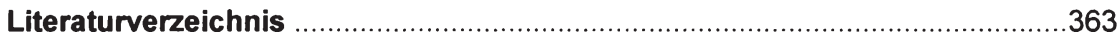




\section{Abbildungsverzeichnis}

Abbildung 1: Schema zur Berechnung von Einkommen- und Zuschlagsteuern im STM ............... 24

Abbildung 2: Durchschnittsentgelt der Rentenversicherung 1950 bis 2006 ................................. 29

Abbildung 3: Entwicklung verschiedener Durchschnittseinkommen

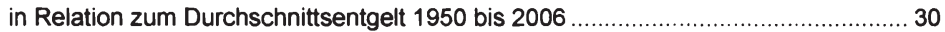

Abbildung 4: Geschätzte relative Einkommensprofile in Abhängigkeit von Geburtsjahr und

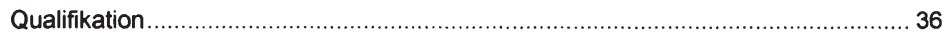

Abbildung 5: Einkommen in Abhängigkeit vom Alter in Quer- und Längsschnittbetrachtung .......... 38

Abbildung 6: Geschätzte nominale Einkommensprofile in Abhängigkeit von der Qualifikation

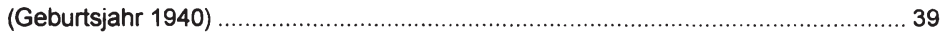

Abbildung 7: Qualifikationsstrukturen der Erwerbstätigen zwischen 1957 und 2003

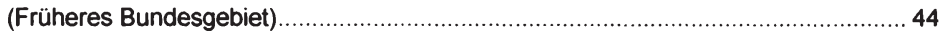

Abbildung 8: Interpolierte Qualifikationsstrukturen 1950 bis 2003 (Früheres Bundesgebiet) .......... 44

Abbildung 9: Korrekturfaktor der geschätzten Einkommen in Abhängigkeit vom Kalenderjahr....... 46

Abbildung 10: Geschätzte Einkommen ohne und mit Korrektur 1964 und 1974 .............................. 47

Abbildung 11: Beitragssätze der Sozialversicherung 1950 bis 2007

(Arbeitnehmeranteile, früheres Bundesgebiet) .................................................... 51

Abbildung 12: Beitragsbemessungsgrenzen der Sozialversicherung in Relation zum

Durchschnittsentgelt 1950 bis 2006 (früheres Bundesgebiet) .............................. 53

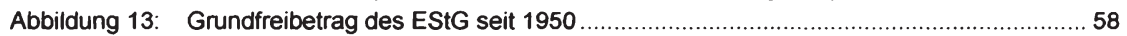

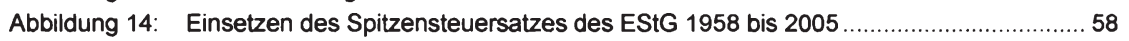

Abbildung 15: Wirkung von Steuervergünstigungen für ältere Steuerpflichtige 1950 bis 2005 ........ 59

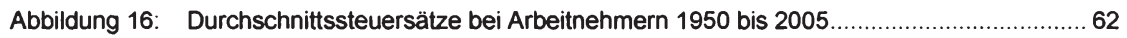

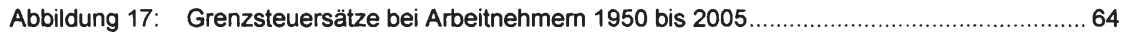

Abbildung 18: Steuerfreie Entgeltpunktsummen 1957 bis 2006 in Abhängigkeit von

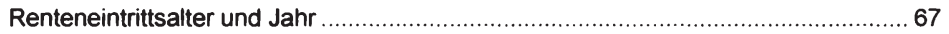

Abbildung 19: Kindergeld und Kinderfreibetrag nach Ordnungszahlen der Kinder 1950 bis 2006 ... 74

Abbildung 20: Entlastung durch den FLA 1950 bis 2006 (in Preisen des Jahres 2005) ................... 76

Abbildung 21: Wirkung des FLA 1995: Ohne und mit

„Entlastung bei niedrigen Erwerbseinkommen“ .................................................. 78

Abbildung 22: Ausgaben für das Kindergeld 1955 bis 2005: Insgesamt und je Kind ...................... 81

Abbildung 23: Steuermindereinnahmen durch Kinderfreibeträge 1982 bis 2006 .......................... 81

Abbildung 24: Erziehungsgeld in Abhängigkeit vom Einkommen zu verschiedenen Zeitpunkten ..... 91

Abbildung 25: Mutterschaftsurlaubs- und Erziehungsgeld:

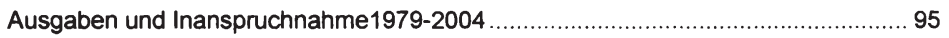

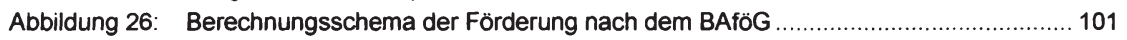

Abbildung 27: Ausbildungsförderung in Abhängigkeit vom Einkommen zu verschiedenen

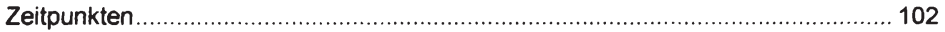

Abbildung 28: Entwicklung der Bedarfssätze und Freibeträge im Verhältnis zu

Lebenshaltungskosten und Einkommensentwicklung........................................ 104

Abbildung 29: Auszubildendenzahlen und Gefördertenquoten 1972 bis 2005

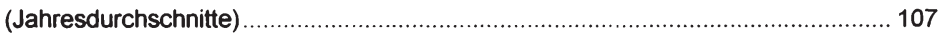

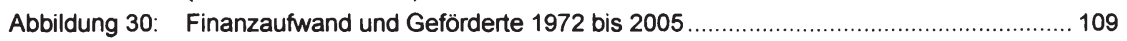

Abbildung 31: Höchstdauern bewerteter Anrechnungszeiten für schulische Ausbildungen............ 122

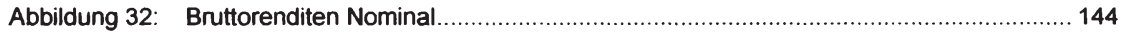

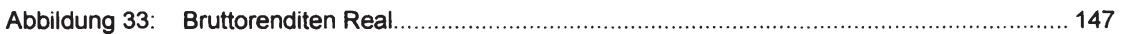


Abbildung 34: Bruttorenditen Real: Veränderung durch Korrektur der Einkommensprofile............ 149

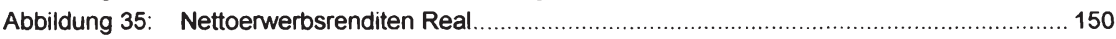

Abbildung 36: Partieller Renditeeffekt von Abgaben: Nettoerwerbsrenditen - Bruttorenditen ........ 151

Abbildung 37: Zusätzliche Renditeminderung durch Abgaben bei korrigierten Einkommen .......... 152

Abbildung 38: Partieller Renditeeffekt von Renten: Nettoerwerbs- - Nettolebensrenditen ............. 153

Abbildung 39: Partieller Renditeeffekt von Transfers an Eltern:

Renditen nach Transfers - Nettolebensrenditen („Mittelstandsloch ${ }^{4}$ )................... 154

Abbildung 40: Renditeeffekt von Transfers an Eltern: Differenzen zu mittlerem Einkommen ......... 155

Abbildung 41: Partieller Renditeeffekt von Transfers:

Transfers an Eltern und Ausbildungsförderung................................................ 156

Abbildung 42: Partieller Renditeeffekt von Ausbildungsgebühren ............................................ 158

Abbildung 43: Reale Brutto- und Gesamtrenditen bei beruflichen Abschlüssen .......................... 159

Abbildung 44: Reale Brutto- und Gesamtrenditen bei Hochschulabschlüssen ............................... 160

Abbildung 45: Reale Renditewirkungen des Steuer-Transfer-Systems (Berufliche Abschlüsse) .... 161

Abbildung 46: Reale Renditewirkungen des Steuer-Transfer-Systems (Hochschulabschlüsse) .... 162

Abbildung 47: Schätzungen der nominalen impliziten Rendite durch den Sachverständigenrat .... 177

Abbildung 48: Nominale implizite Renditen nach Rentenbezugsdauer (Eckrentner) .................... 179

Abbildung 49: Zunahme der ferneren Lebenserwartung für Geburtsjahre ab 1930 ...................... 180

Abbildung 50: Entgeltpunkte aus Transfers: Ausbildung …............................................... 193

Abbildung 51: Nominale implizite Renditen nach Qualifikation (Männer, alleinstehend) ................ 193

Abbildung 52: Renditevergleich mit dem Eckrentner (Eckrentner: 0\%) (Männer, alleinstehend) .... 194

Abbildung 53: Entwicklung von Durchschnittsentgelt und Beitragssätzen (Reale Größen)............ 196

Abbildung 54: Zugangsfaktoren in Abhängigkeit von Renteneintrittsalter und Geburtsjahr

nach dem RV-Altersgrenzenanpassungsgesetz ............................................. 199

Abbildung 55: Renditewirkung eines Vorziehens des Renteneintritts um zwei Jahre ................... 201

Abbildung 56: Entgeltpunkte aus Transfers: Kinder und Erwerbsbeteiligung ............................... 206

Abbildung 57: Renditevergleich mit Eckrentnerpaaren (Eckrentnerpaar: 0\%) (Paare, kinderlos) ... 207

Abbildung 58: Renditevergleich mit Eckrentnerpaaren (Eckrentnerpaar: 0\%) (Paare, 2 Kinder) .... 210

Abbildung 59: Renditewirkung von 2 Kindern: Paare mit zwei Kindern

gegenüber kinderlosen Paaren .................................................................... 211

Abbildung 60: Rentenversicherung und Steuerminder-/ -mehrbelastungen

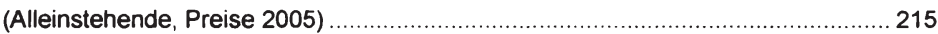

Abbildung 61: Renditen nach Steuern - Bruttorenditen (Männer, alleinstehend, nominal) ............ 217

Abbildung 62: Renditen nach Steuern - Bruttorenditen (Paare, nominal) .................................. 218

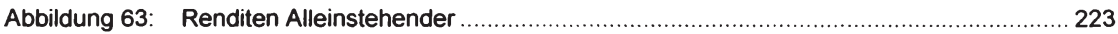

Abbildung 64: Renditen nach Steuern Alleinstehender: Abweichungen vom Eckrentner................ 224

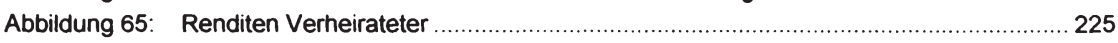

Abbildung 66: Renditen nach Steuern Verheirateter: Abweichungen vom Eckrentner................... 226

Abbildung 67: Intragenerative Renditedifferenzen (Renditen nach Steuern) ................................. 227

Abbildung 68: Nettoquoten nach Familientypen und Einkommen seit 1950 ................................ 239

Abbildung 69: Kindbedingte Mehreinkommen seit 1950:

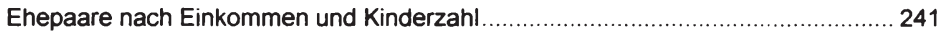

Abbildung 70: Kindbedingte Mehreinkommen seit 1950: Alleinerziehende nach Einkommen ........ 243

Abbildung 71: Kindbedingtes Mehreinkommen nach Lebensalter und Geburtsjahr ....................... 253

Abbildung 72: Kindbedingte Mehreinkommen und Lebenseinkommen nach Geburtsjahr

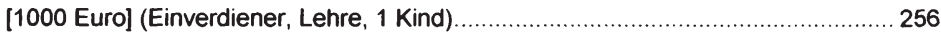

Abbildung 73: Kindbedingtes Mehreinkommen : Anteile am verfügbaren Lebenseinkommen

(Einverdiener, 1 Kind). 
Abbildung 74: Anteile am verfügbaren Lebenseinkommen:

Veränderung gegenüber Kohorte 1930 (Einverdiener, 1 Kind) ........................... 258

Abbildung 75: Kindbedingtes Mehreinkommen : Ausbildung (Einverdiener, 1 Student).................. 259

Abbildung 76: Kindbedingtes Mehreinkommen: Erwerbstätigkeit (1 Kind) ................................... 260

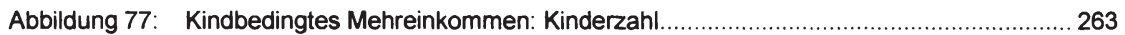

Abbildung 78: Anteile am verfügbaren Lebenseinkommen:

Veränderung gegenüber Kohorte 1930 (Einverdiener, 3 Kinder) ........................... 264

Abbildung 79: Kindbedingtes Mehreinkommen nach Qualifikation und Geburtsjahr des Vaters

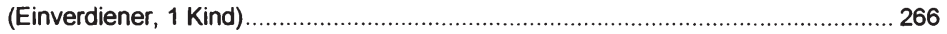

Abbildung 80: Kindbedingtes Mehreinkommen nach Qualifikation und Geburtsjahr des Kindes

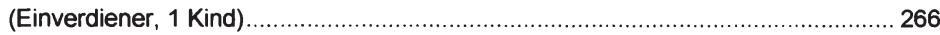

Abbildung 81: Kindbedingtes Mehreinkommen nach Qualifikation und Geburtsjahr des Kindes (Uni gegenüber Lehre) .................................................................... 268

Abbildung 82: Kompensierte Dauer nach Qualifikation und Geburtsjahr des Kindes (1 Kind) ........ 275

Abbildung 83: Vergleich von Indikatoren zur Entwicklung kindbedingter Leistungen ...................... 276

Abbildung 84: Kompensierte Dauer nach Qualifikation und Geburtsjahr des Kindes ( 3 Kinder) ..... 278

Abbildung 85: Kompensierte Dauer nach Qualifikation und Geburtsjahr des Kindes (3. Kind) ....... 278

Abbildung 86: Beitragssätze zur Sozialversicherung in zwei Szenarien (Arbeitnehmeranteile) ...... 299

Abbildung 87: Durchschnittssteuersätze in Vergangenheit und Zukunft (Arbeitnehmer) ................ 300

Abbildung 88: Durchschnittssteuersätze in Vergangenheit und Zukunft (Rentner) ......................... 301

Abbildung 89: Jährliche Durchschnittssteuersätze nach Qualifikation, Alter und Geburtsjahr ........ 305

Abbildung 90: Durchschnittssteuersätze nach Qualifikation: Erwerbsphase ...................................... 307

Abbildung 91: Abgabenquoten nach Qualifikation: Erwerbsphase .......................................... 308

Abbildung 92: Abgabenquoten nach Qualifikation: Rentenbezugsphase ................................. 310

Abbildung 93: Nettorenten in Prozent des Bruttolebenseinkommens........................................ 312

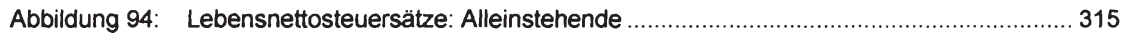

Abbildung 95: Lebensnettosteuersätze Alleinstehender: Intragenerative Unterschiede ................... 317

Abbildung 96: Ehebedingte Mehreinkommen (Einverdiener ohne Kinder) .................................... 319

Abbildung 97: Kindbedingte Mehreinkommen (Einverdiener, 2 Kinder) ....................................... 321

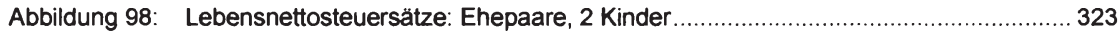

Abbildung 99: Lebensnettosteuersätze bei Durchschnittsverdienst (Lehre) nach Familienstand ... 323

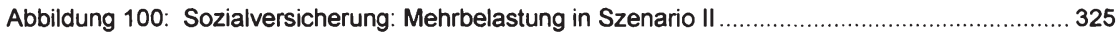

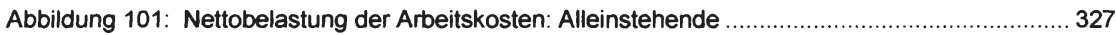




\section{Tabellenverzeichnis}

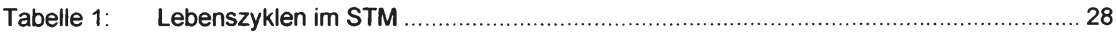

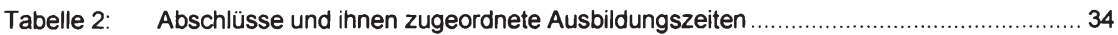

Tabelle 3: $\quad$ Ausgewählte Fälle bei Schätzung der Mincer-Gleichung .......................................... 35

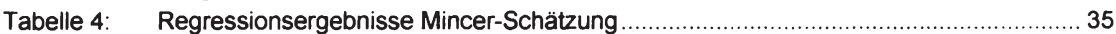

Tabelle 5: Ermittlung der Entgeltpunkte mit dem Rentenrechner des STM ............................... 114

Tabelle 6: Aufwertung von Zeiten beruflicher Ausbildung in der GRV ab 1991 ......................... 123

Tabelle 7: Nicht beitragsgedeckte Leistungen der Rentenversicherung [Mrd. Euro] .................... 126

Tabelle 8: Renditen nach dem Mincer-Ansatz (in Prozent) ................................................ 131

Tabelle 9: Befunde zu internen Ertragsraten von Bildung in Deutschland und ihrer Zusammensetzung (in Prozent) ....................................................... 135

Tabelle 10: Bestimmung von renditerelevanten Größen.............................................................. 139

Tabelle 11: Verschiedene Renditeabgrenzungen und jeweils enthaltene Größen ........................ 139

Tabelle 12: Reale partielle Renditeeffekte zukünftiger Studiengebühren

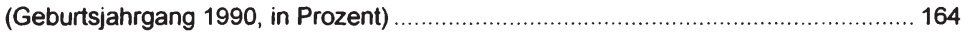

Tabelle 13: Vergleich von Befunden zu internen Ertragsraten von Bildung in

Deutschland und ihrer Zusammensetzung (in Prozent) ............................................ 167

Tabelle 14: Anteil der 20-Jährigen, die das 65. Lebensjahr vollenden (Männer)........................... 180

Tabelle 15: Entgeltpunkte aus Beiträgen der betrachteten Biographien ..................................... 191

Tabelle 16: Finanzvolumen familienpolitischer Maßnahmen mit Kindbezug 2004/ 2005 .............. 235

Tabelle 17: Summen kindbedingter Mehreinkommen je Kind: Vergleich von Ergebnissen ........... 254

Tabelle 18: Aufwendungen je Kind von der Geburt bis zum Altervon 18 Jahren [1000 Euro] ........ 271

Tabelle 19: Monetäre Familienpolitik im Lebenszyklus: Ergebnisse im Überblick........................ 280

Tabelle 20: Lebensnettosteuersätze in den USA nach Geburtsjahr .......................................... 290

Tabelle 21: Zusammensetzung der Nettobelastung von Lebenseinkommen [1000 Euro]

(Durchschnittseinkommen, in Preisen von 2005) .................................................. 331

Tabelle 22: Lebensnettosteuersätze in verschiedenen Varianten ................................................. 334

Tabelle 23: Sozialversicherung: Beitragssätze, Bemessungsgrenzen und Durchschnittsentgelte 1950 bis 2007 (Monetäre Werte in Euro/ Jahr, früheres Bundesgebiet) ........ 350

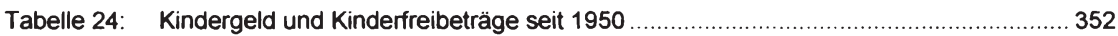

Tabelle 25: Altersgrenzen für Kindergeld und Kinderfreibeträge seit 1950 ............................... 353

Tabelle 26: Ausbildungsfreibeträge seit 1954 [Euro/ Jahr] ........................................................ 353

Tabelle 27: Abzugsbeträge für Alleinerziehende und Kinderadditive seit 1950 [Euro/ Jahr] .......... 354

Tabelle 28: Abzug von Kinderbetreuungskosten seit 1980 [Euro/ Jahr] ..................................... 354

Tabelle 29: Leistungsparameter von Mutterschaftsurlaubs- und Erziehungsgeld 1979 bis 2004 . . 355

Tabelle 30: Einkommensanrechnung beim Erziehungsgeld 1986 bis 2004 ............................... 355

Tabelle 31: Entwicklung der Förderung durch Mutterschaftsurlaubs- und

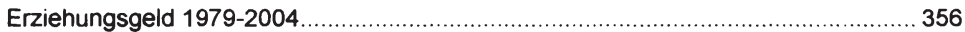

Tabelle 32: Bedarfe nach dem BAföG und dem Honnefer Modell [Euro/ Monat] .......................... 357

Tabelle 33: Sozialpauschalen und Freibeträge vom Elterneinkommen

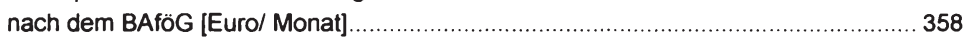

Tabelle 34: Darlehensregelungen für das Studenten-BAföG und das Honnefer Modell ................ 359

Tabelle 35: Entwicklung der Förderung nach dem BAföG 1972 bis 2005 (Studenten) .................. 360

Tabelle 36: Entwicklung der Förderung nach dem BAföG 1972 bis 2005 (Schüler und Gesamt).. 361

Tabelle 37: Ermittlung der Entgeltpunkte bei Altersrenten im STM ........................................ 362 


\section{Abkürzungsverzeichnis}

\begin{tabular}{|c|c|}
\hline AFBG & Aufstiegsfortbildungsförderungsgesetz \\
\hline AFG & Arbeitsförderungsgesetz \\
\hline AltEinkG & Alterseinkünftegesetz \\
\hline AVmEG & Altersvermögensergänzungsgesetz \\
\hline AVmG & Altersvermögensgesetz \\
\hline BAföG & Bundesausbildungsförderungsgesetz \\
\hline BEEG & Bundeselterngeld- und Elternzeitgesetz \\
\hline BErzGG & Bundeserziehungsgeldgesetz \\
\hline BGBI & Bundesgesetzblatt \\
\hline BKGG & Bundeskindergeldgesetz \\
\hline bzw. & beziehungsweise \\
\hline DM & Deutsche Mark (1 Euro = 1,95583 DM) \\
\hline EStG & Einkommensteuergesetz \\
\hline EVS & Einkommens- und Verbrauchsstichprobe \\
\hline FKPG & $\begin{array}{l}\text { Gesetz zur Umsetzung des Föderalen Konsolidierungs- } \\
\text { programms }\end{array}$ \\
\hline FLA & Familienleistungsausgleich \\
\hline GRV & Gesetzliche Rentenversicherung \\
\hline HBeglG & Haushaltsbegleitgesetz \\
\hline HEZG & Hinterbliebenenrenten- und Erziehungszeiten-Gesetz \\
\hline HStruktG & Haushaltsstrukturgesetz \\
\hline JStG & Jahressteuergesetz \\
\hline KGG & Kindergeldgesetz \\
\hline RRG & Rentenreformgesetz \\
\hline RVNG & Rentenversicherungs-Nachhaltigkeitsgesetz \\
\hline RVNG & Rentenversicherungsnachhaltigkeitsgesetz \\
\hline RVO & Reichsversicherungsordnung \\
\hline s. 0 . & siehe oben \\
\hline SGB VI & Sozialgesetzbuch (SGB) Sechstes Buch (VI) \\
\hline SOEP & Sozio-ökonomisches Panel \\
\hline StÄndG & Steueränderungsgesetz \\
\hline STM & Steuer-Transfer-Modell \\
\hline Tsd. & Tausend \\
\hline u. a. & unter anderem \\
\hline WFG & Wachstums- und Beschäftigungsförderungsgesetz \\
\hline ZVE & zu versteuerndes Einkommen \\
\hline
\end{tabular}




\section{Einleitung: Untersuchungsgegenstände und -ansatz}

Verteilungs- und Anreizeffekte der Steuer- und Sozialpolitik sind Gegenstand zahlreicher Fragestellungen aus verschiedenen ökonomischen Teilgebieten. Umverteilung wird dabei überwiegend als Querschnittsthema untersucht, wie etwa beim Vergleich der Einkommensverteilungen vor und nach staatlichem Eingriff. Unter den Eindrücken zunehmender staatlicher Verschuldung einerseits sowie bereits eingetretener und sich abzeichnender demographischer Veränderungen andererseits fand in den letzten Jahren jedoch auch die Längsschnittperspektive von Umverteilung zunehmend Beachtung. In der politischen und wissenschaftlichen Diskussion um die sozialen Sicherungssysteme, insbesondere um die Alterssicherung, nehmen intergenerative Belastungsvergleiche einen breiten Raum ein, Reformvorschläge orientieren sich häufig am Ziel einer möglichst gleichhohen Belastung verschiedener Kohorten, die als Indikator für eine gerechte Lastenverteilung herangezogen wird. Grundlage von Generationenbetrachtungen sind meist Salden der geleisteten und empfangenen Zahlungen innerhalb des gesamten Lebenszyklus bei bisherigen Kohorten, die mit mutmaßlichen zukünftigen Werten verglichen werden. Ein zentraler Befund solcher Längsschnittbetrachtungen ist eine zunehmende Abgabenbelastung junger und zukünftiger Generationen, die auf Grund fehlender Nachhaltigkeit der bisherigen Fiskalpolitik sowie einer alternden Bevölkerung erforderlich erscheint. Zu den wesentlichen Ergebnissen für Deutschland zählen Prognosen steigender Beitragssätze in einzelnen Zweigen der umlagefinanzierten Sozialversicherung als Folge des demographischen Wandels. Eine Zuspitzung finden solche Resultate in der Ansicht, jüngere Kohorten seien im Vergleich zu älteren benachteiligt.

Gängige Ansätze zur Untersuchung intergenerativer Umverteilung weisen allerdings verschiedene Beschränkungen auf, die der Ableitbarkeit derartiger Aussagen im Wege stehen. Zum einen wird eine Zeitpunktanalyse des Status Quo zu einem Längsschnitt umgedeutet, die tatsächliche Entwicklung der Vergangenheit bleibt jedoch ausgeblendet. Dieses Vorgehen ist etwa bei der Generationenbilanzierung üblich. Empirische historische Zahlungsreihen werden hauptsächlich in mikroökonomischen Analysen zur Rentenversicherung genutzt, dafür wird in diesen aber nur ein Teilbereich des Steuer-Transfer-Systems erfasst. Weiterhin befassen sich Längsschnittanalysen meist nur mit intergenerativen Unterschieden, von intragenerativen Unterschieden etwa zwischen niedrigen und hohen Einkommen oder zwischen Eltern und Kinderlosen wird abstrahiert. Letztere finden sich eher in Querschnittsbetrachtungen, in denen auch die zahlreichen Interdependenzen verschiedener Steuern und Transfers berücksichtigt werden.

Mit der in dieser Arbeit verwandten Methodik werden die skizzierten Probleme aufgegriffen, um zur Quantifizierbarkeit von langfristigen Wirkungen des Steuer-TransferSystems im Lebenszyklus beizutragen. Ein Schwerpunkt liegt dabei auf Vergleichen verschiedener Kohorten, wie insbesondere bei Arbeiten zur Rentenversicherung üblich. Ein weiterer zentraler Aspekt ist die Gegenüberstellung von Status Quo und früheren Rechtsständen, die unter anderem zur vergleichenden Beurteilung der geltenden familienpolitischen Maßnahmen vielversprechend erscheint. Hauptwerkzeug der Analyse ist ein Steuer-Transfer-Modell (STM), das Rechtsstände seit 1950 recht umfassend und detailliert abbildet. Das Modell ermittelt unter Vorgabe verschiedener 
exogener Merkmale aus Bruttoeinkommensgrößen das verfügbare Einkommen unter dem jeweils geltenden Recht. Eine zentrale Größe ist dabei das Lebenseinkommen vor und nach Umverteilung, dessen Abhängigkeit vom Geburtszeitpunkt und verschiedenen sozioökonomischen Merkmalen wie Kinderzahl und Einkommen bestimmt wird. Die zweite Grundlage des Ansatzes bilden typisierte Biographien, aus denen unter Berücksichtigung empirischer Zusammenhänge von Bildung und Einkommen (Brutto-)Lebenseinkommensprofile konstruiert werden. Zukünftige Rechtsstände basieren zum einen auf externen Projektionen zur Sozialversicherung, zum anderen auf einer Fortschreibung des geltenden Rechts, bei der bereits festgeschriebene aber noch nicht vollumfänglich wirksame Gesetzesänderungen (wie der sukzessive Übergang zur nachgelagerten Besteuerung von Alterseinkünften) berücksichtigt sind. Grundgedanke ist die mechanistische Anwendung der Gesetzesalgorithmen auf die empirisch gestützten biographischen Eingabegrößen, zu denen das Periodeneinkommen oder die Kinderzahl zählen. Als Ausgabegrößen liefert das STM dann unter anderem die zu leistende Einkommensteuer oder den Kindergeldanspruch. Einschränkungen bestehen beim hier gewählten Ansatz in der Konzentration auf ausgewählte Abgaben und Leistungen, deren Auswahl sich nach ihrer fiskalischen Relevanz und nach ihrer Anwendbarkeit in typisierenden Biographien richtet. Nicht in repräsentativen Biographien abbildbar erscheinen vor allem probabilistisch auftretende bedürftigkeitsorientierte Transfers oder Leistungen der Arbeitslosenversicherung. Analysiert werden Lebenseinkommensprofile sozialversicherungspflichtiger Arbeitnehmer, die sich in ihrer Qualifikation und in Folge dessen auch in ihren Einkommen unterscheiden. Mit diesem Ansatz werden Ergebnisse zu Fragestellungen aus den Bereichen der Bildungsökonomie, der Familienpolitik, der Alterssicherung sowie zu intergenerativen Belastungsvergleichen ermittelt und mit auf alternativen Methoden beruhenden Befunden verglichen. Schwerpunkt der hier gewählten Vorgehensweise sind langfristige Verteilungswirkungen des SteuerTransfer-Systems, die sich unter detaillierter Berücksichtigung der institutionellen Berechnungsvorschriften und ihrer historischen Entwicklung ergeben. Zwei Hauptvorteile zeichnen sich aus der Modellierung der Änderungen des Steuer-TransferSystems über Jahrzehnte ab: Erstens werden umfassendere Vergleiche älterer und jüngerer Kohorten ermöglicht als in den gängigen Betrachtungen, die sich auf intergenerative Unterschiede in der Alterssicherung konzentrieren. Zweitens lässt sich der Status Quo des Steuer-Transfer-Systems besser einordnen, indem langfristige Wirkrichtungen der Rechtsänderungen seit den 1950er Jahren herausgearbeitet werden.

Ausgangspunkt dieser Arbeit ist somit die Wahl einer methodischen Herangehensweise, die dann auf verschiedene Themen angewandt wird. Gemeinsamkeit der untersuchten Fragestellungen ist, dass gleichzeitig intra- sowie intergenerative Wirkungen des Steuer-Transfer-Systems seit 1950 herausgearbeitet werden. Als Ursachen intragenerativer Unterschiede werden hauptsächlich bildungsabhängige Einkommensverläufe sowie Familienstand und Kinderzahl betrachtet. Die intergenerativen Vergleiche beziehen sich auf die Geburtsjahre von 1930 bis 1990 . Eine Folge der recht umfassenden Abbildung von Leistungen und Abgaben ist, dass über Lebenszyklen gebildete Salden eine starke Verdichtung von zum Teil konträr wirkenden Einzelmaßnahmen mit sich bringen. Die im Modell abgebildeten rechtlichen Regelungen sind zudem themenübergreifend relevant, familienpolitische Maßnahmen 
etwa reichen sowohl in die Bildungspolitik als auch in die Alterssicherung hinein. Als Konsequenz der Analyse zum Teil identischer Maßnahmen in verschiedenen Kontexten gliedert sich diese Arbeit in zwei Hauptteile. Im ersten Teil werden die "Zutaten" vorgestellt, im zweiten Teil werden mit diesen verschiedene Fragestellungen untersucht. Zum ersten Teil zählen die Darstellung der im STM erfassten Gesetze, die Beschreibung der Konstruktion der Einkommensprofile sowie der Annahmen zur zukünftigen Entwicklung. Neben der historischen Entwicklung der rechtlichen Regelungen umfasst die Dokumentation im ersten Teil auch zahlreiche Querschnittsvergleiche zur einkommensabhängigen Wirkung verschiedener Rechtsstände. So werden unter anderem die historische Entwicklung der Steuertarife, des Erziehungsgelds und der Ausbildungsförderung nachgezeichnet. Die hierbei beschriebenen Verteilungswirkungen im Querschnitt dienen auch der Nachvollziehbarkeit der stark verdichtenden Lebenszyklusbetrachtungen im zweiten Teil. Die Kapitel des zweiten Teils bestehen aus in sich geschlossenen Betrachtungen zu vier Themengebieten. Auf die Darstellung von Details der dabei relevanten Steuer- und Transfergesetze wird im zweiten Teil weitgehend verzichtet, stattdessen wird dort auf die jeweiligen Abschnitte des ersten Teils verwiesen. Grundsätzlich kann der zweite Teil der Arbeit damit auch unabhängig vom ersten Teil gelesen werden, weitergehende Einzelheiten lassen sich dann bei Bedarf im ersten Teil nachschlagen. Auch bauen die einzelnen Kapitel des zweiten Teils nicht aufeinander auf, so dass sie nicht zwingend in der vorgegebenen Reihenfolge gelesen werden müssen. Allerdings führt das Kapitel 9 verschiedene Teilaspekte der drei anderen Kapitel zusammen, wodurch sich seine Lektüre als Abschluss anbietet. Die Längsschnittbetrachtungen der vier Kapitel des zweiten Teils kombinieren Elemente aus Generationenbilanzen, mikroökonomischen Lebenszyklusanalysen und typischerweise nur im Querschnitt eingesetzten SteuerTransfer-Modellen. Die Schlussbemerkungen am Ende der Arbeit fassen verschiedene markante Befunde noch einmal knapp zusammen, um daran anschließend einige gemeinsame Schlussfolgerungen aus den einzelnen Teilen zu ziehen. Die vier Kapitel des zweiten Teils behandeln die folgenden Themen:

(1) Bildungsrenditen: Bildungsbedingte Einkommensunterschiede sind vielfach untersucht worden. Methodische Grundlage ist überwiegend eine von Jacob Mincer hergeleitete Einkommensfunktion, deren Parameter sich unter bestimmten Voraussetzungen als Rendite von Humankapitalinvestitionen interpretieren lassen. Mit diesem Ansatz wurden seit den 1970er Jahren zahlreiche Schätzungen vorgenommen, die insgesamt auf recht stabile Bildungsrenditen in Deutschland während der letzten Jahrzehnte hindeuten. Bei den Berechnungen mit dem STM bilden Schätzergebnisse einer Mincer-Gleichung eine zentrale Inputgröße zur Bestimmung von Bildungsrenditen. Aus den MincerParametern sowie dem allgemeinen Lohnwachstum ergeben sich qualifikationsabhängige Bruttojahreseinkommen, aus denen das Modell die verfügbaren Einkommen ableitet. Über die Kapitalwertformel werden dann Bruttound Nettorenditen sowie die Renditewirkung einzelner Elemente des SteuerTransfer-Systems berechnet. Dabei zeigen sich deutliche Renditeschwankungen über die Kohorten von 1930 bis 1990, die Bruttorenditen für die Geburtsjahrgänge von 1930 bis 1945 liegen als Folge des starken Lohnwachstums zu Beginn des Betrachtungszeitraums um mehrere Prozentpunkte über den Renditen später Geborener. Als Renditeeffekte des Steuer-Transfer- 
Systems lassen sich zum einen die im Vergleich zu früheren Rechtsständen heute recht niedrige Ausbildungsförderung und zum anderen die abnehmende Besteuerung von Humankapitalinvestitionen hervorheben. Die in der jüngeren Vergangenheit in mehreren Bundesländern eingeführten Studiengebühren mindern in ihrer gegenwärtigen Höhe Bildungsrenditen nur in geringem Umfang.

(2) Gesetzliche Rentenversicherung: Die wiederholten Reformen der letzten Jahre zur Stabilisierung der umlagefinanzierten gesetzlichen Rentenversicherung wirken grundsätzlich in Richtung einer Lastenverschiebung von jüngeren zu älteren Kohorten. Ein gebräuchliches Kriterium zur Beurteilung verschiedener Maßnahmen ist die implizite Rendite, die die kohortenspezifischen Renten-Beitrags-Relationen an Hand des Eckrentners, eines stark typisierten Versicherungsverlaufs, erfasst. Mit diesem Vorgehen wird von verschiedenen Umverteilungselementen der Rentenversicherung abstrahiert, wodurch erstens intergenerative Vergleiche zum Teil ungenau sind und zweitens intragenerative Renditedifferenzen ignoriert werden. Mit dem STM berechnete Vergleiche von Eckrentnerrenditen mit den Werten, die sich für empirisch gestützte Biographien ergeben, zeigen zum einen, dass die Renditen der sich bereits im Rentenalter befindenden Kohorten üblicherweise unterzeichnet werden. Unter Berücksichtigung von verschiedenen nicht beitragsäquivalenten Leistungen sowie von Möglichkeiten der frühzeitigen Verrentung fallen die Renditen über die Kohorten von 1930 bis 1945 wesentlich stärker, als der Eckrentner zum Ausdruck bringt. Innerhalb der Kohorten von 1950 bis 1990 zeichnet sich ein Renditeminimum bei den um das Jahr 1965 Geborenen ab, für die sich aus den Übergangsregelungen zur Anhebung der Regelaltersgrenze auf 67 Jahre sowie zur nachgelagerten Besteuerung der Renten eine relativ ungünstige Position ergibt. Intragenerative Vergleiche weisen vor allem auf Renditenachteile von Akademikern hin, die aus ihrer ausbildungsbedingt verkürzten Erwerbsphase resultieren.

(3) Monetäre Familienpolitik: Anhaltend niedrige Geburtenraten und hohe private Kosten von Kindern haben zu einer starken Ausweitung familienpolitischer Leistungen in den letzten Jahren beigetragen, wobei trotz Finanzvolumina in einer Größenordnung von 150 Mrd. Euro jährlich weiterhin vielfach eine Benachteiligung von Familien im Steuer-Transfer-System beklagt wird. Zur Untersuchung der Entwicklung familienpolitischer Transfers während der letzten Jahrzehnte wird mit dem STM das Ausmaß kindbedingter Leistungen als Anteil am Lebenseinkommen von Eltern der Kohorten 1930 bis 1990 betrachtet. Die Lebenszyklusperspektive erlaubt dabei, die auf diverse Einzelmaßnahmen verteilten und in verschiedenen Lebensphasen anfallenden Transfers wie Kindergeld oder kindbedingte Rentenzuschläge in ihrer Gesamtwirkung erfassen zu können. Im intragenerativen Vergleich zeigt sich hiernach, dass der Umfang kindbezogener Leistungen überwiegend mit dem Elterneinkommen anstieg. Nur bei Kindern, die im Zeitraum von 1986 bis 2006 geboren wurden, empfangen Eltern mit niedrigerem Einkommen höhere Transfers. Hauptergebnis intergenerativer Vergleiche ist eine gemessen an der Einkommensentwicklung deutlich überproportionale Zunahme kindbezogener Leistungen. 
Besonders stark haben Familien mit wenigen Kindern und niedrigem Einkommen vom Ausbau monetärer Transfers profitiert. Hier hat sich der Anteil der kindbezogenen Mehreinkommen am Lebenseinkommen annähernd verfünffacht, bei Mehrkindfamilien und/ oder höheren Einkommen ergibt sich immer noch rund eine Verdoppelung. Obwohl die geltende Familienpolitik hiernach im historischen Vergleich sehr großzügig erscheint, deckt sie weiterhin nur einen kleinen Anteil der von Eltern getragenen Kosten ab, die vor allem auch Opportunitätskosten durch Erwerbseinschränkungen umfassen. Die für ein heute geborenes Kind gewährten Leistungen kompensieren je nach Einkommen der Mutter Verdienstausfälle aus Erwerbsunterbrechungen von etwa drei- bis vierjähriger Dauer.

(4) Lebensnettosteuersätze: Neben dem Renditeverfall in der Rentenversicherung dienen vor allem in Generationenbilanzen identifizierte Tragfähigkeitslücken als Indikator für eine intergenerative Umverteilung zu Lasten junger Generationen. Eine Größe zur Illustration von intergenerativen Belastungsunterschieden bilden dabei Lebensnettosteuersätze, definiert als Anteil des Steuer-Transfer-Saldos am Lebenseinkommen. Da Generationenbilanzen in der Regel jedoch nur die Zustände eines Basisjahres unter einer alternden Bevölkerung fortschreiben, geben sie keinen Aufschluss über die Belastungen realer Kohorten. In den Berechnungen mit dem STM werden hingegen Lebensnettosteuersätze unter Berücksichtigung der historischen Entwicklung sowie der zu enwartenden zukünftigen Beitragssatzanstiege in der Sozialversicherung bestimmt. Diese Ergebnisse weisen zwar unter anderem auf Grund fehlender Inzidenzprüfungen Beschränkungen auf. Über die Beitragssatzprojektionen wird jedoch ein Großteil der in Generationenbilanzen ermittelten Tragfähigkeitslücken dem Umlageverfahren entsprechend auf die betroffenen Generationen verteilt, so dass die wesentlichen Ursachen für die enwarteten Nachteile junger Generationen in innen erfasst sind. Aus den intergenerativen Vergleichen stechen hiernach zum einen die deutlich niedrigeren Belastungen der bis etwa 1940 Geborenen hervor, zum anderen ergeben sich überraschend geringe Unterschiede zwischen den Jahrgängen von etwa 1950 bis 1990. Während junge Generationen zwar mit weiterhin steigenden Abgaben an die Sozialversicherung zu rechnen haben (wobei die zukünftigen Anstiege im Rahmen der historischen Entwicklung eher moderat erscheinen), zeichnet sich für sie kompensierend eine sehr niedrige steuerliche Belastung ab, die unter anderem aus dem Übergang zur nachgelagerten Besteuerung von Alterseinkünften folgt. Durch diesen weiteren Rückbau der progressiven Besteuerung bei Ausweitung der proportional belastenden Sozialversicherung sind in den jüngeren Kohorten Bezieher höherer Einkommen relativ gut gestellt. Daneben weisen intragenerative Vergleiche darauf hin, dass mit dem im vorherigen Kapitel beschriebenen Ausbau der Familienförderung in den jüngeren Kohorten auch Personen mit Kindern relativ geringen Nettobelastungen ausgesetzt sind. 
Tobias Arens - 978-3-631-75164-0

Downloaded from PubFactory at 01/11/2019 07:33:05AM

via free access 


\section{Teil 1 Grundlagen:}

\section{Steuern, Transfers und Lebenseinkommen}


Tobias Arens - 978-3-631-75164-0

Downloaded from PubFactory at 01/11/2019 07:33:05AM

via free access 


\section{2 Überblick}

\subsection{Bausteine der Modellrechnungen: Steuer-Transfer-Modell STM}

Ausgangspunkt dieser Arbeit sind Zusammenhänge von Bruttoeinkommen und verfügbarem Einkommen seit dem Jahr 1950. Um diese zu erfassen, wurde ein integriertes Steuer-Transfer-Modell (STM) entwickelt, das die hierfür relevanten Gesetzesstände und -änderungen abbildet. Die Modellrechnungen in dieser Arbeit beruhen auf drei Hauptbausteinen:

(1) Steuer-Transfer-Rechner

(2) Rentenrechner

(3) Lebenseinkommensprofile

In den weiteren Kapiteln des ersten Teils dieser Arbeit werden diese Bausteine näher vorgestellt. Den größten Umfang nimmt dabei die Darstellung des Steuer-TransferRechners und der in inm abgebildeten Gesetze ein. Außerdem widmen sich jeweils ein Kapitel der Rentenberechnung und der Konstruktion von Lebenseinkommensprofilen. Diese beiden Bestandteile sind für den zweiten Teil der Arbeit von Bedeutung, in dem intergenerative Vergleiche zur Wirkung des Steuer-Transfer-Systems auf der Basis von Lebenszyklusbetrachtungen durchgeführt werden. Der Rentenrechner übernimmt dabei die Aufgabe, aus einer vorgegebenen Rentenbiographie den Rentenanspruch endogen zu ermitteln. Die geschätzten Lebenseinkommensprofile bilden schließlich die empirische Basis für (Brutto-)Einkommensverläufe im Lebenszyklus, auf die die Gesetzesmechanik des Steuer-Transfer-Rechners und des Rentenrechners angewandt werden.

Der Steuer-Transfer-Rechner bildet das Kernstück des Modells. Er lässt sich als integrierter Abgaben- und Transferrechner skizzieren, der aus der Vorgabe von Jahreszahl, Bruttoeinkommen und verschiedenen sozioökonomischen Merkmalen als exogenen Größen die zu entrichtenden Steuern und Sozialversicherungsbeiträge sowie Ansprüche auf Transfers als endogene Größen ermittelt. Die gesetzlich vorgegebenen Berechnungsvorschriften werden detailgetreu nachvollzogen, wobei folgende Regelungen erfasst sind:

- Einkommensteuergesetz (EStG)

- Zuschlagsteuern zur Einkommensteuer:

Ergänzungsabgabegesetz

Stabilitätszulagegesetz (StabZG)

Solidaritätszuschlaggesetz (SoIZG)

[ab 1950]

[1968-1974]

[1973-1974]

[ab 1991]

- Bundeskindergeldgesetz (BKGG) und Vorgängerregelungen

[ab 1950]

- Pflichtbeiträge zur Sozialversicherung

[ab 1950]

- Ausbildungsförderung:

Förderung nach dem Honnefer Modell

Bundesausbildungsförderungsgesetz (BAföG) 
- Leistungen im Anschluss an die Geburt eines Kindes:

Mutterschaftsurlaubsgeld

[1979-1985]

Bundeserziehungsgeldgesetz (BErzGG)

[1986-2006]

Elterngeld (BEEG)

[ab 2007]

\section{sowie}

- Ausbildungsgebühren:

$$
\begin{aligned}
& \text { Schulgeld } \\
& \text { Studiengebühren }
\end{aligned}
$$

[1950-1970

und $a b 2006$ ]

In Klammern sind die jeweiligen Zeiträume angegeben, deren Rechtsstände im Modell abgebildet sind. Diese entsprechen den Zeiträumen, in denen die verschiedenen Maßnahmen wirksam waren. Neben den aktuell geltenden Vorschriften umfasst das STM auch nur vorübergehend bestehende Gesetze wie das Ergänzungsabgabe- und Stabilitätszuschlaggesetz sowie Vorgänger heutiger Transfers wie die Förderung nach dem Honnefer Modell, deren Funktion dem Studenten-BAföG entsprach. Mit der Auswahl der berücksichtigten Regelungen wird auch das Anwendungsgebiet des STM abgesteckt, das sich auf folgende Inhalte und Fälle konzentriert:

Das Modell deckt (fast) ausschließlich monetäre Transfers ab. Realtransfers wie die unentgeltliche öffentliche Bereitstellung von Ausbildung oder Leistungen der gesetzlichen Krankenversicherung sind nicht erfasst. Für intergenerative Vergleiche ist diese Einschränkung soweit unschädlich, wie davon ausgegangen werden kann, dass die relative Bedeutung von Realtransfers intertemporal konstant ist. Zu Beginn des betrachteten Zeitraums sowie seit kurzem wieder werden allerdings Gebühren für Ausbildungen erhoben, die ansonsten unentgeltlich waren. Da diese Gebühren von unmittelbarer Bedeutung für die intergenerativen Vergleiche im zweiten Teil der Arbeit sind, insbesondere für die Berechnung von Bildungsrenditen, sind über den $\mathrm{Be}-$ reich der monetären Transfers hinausgehend Regelungen zu Ausbildungsgebühren typisierend in den Modellrechnungen erfasst.

Von den monetären Transfers berücksichtigt das STM weiterhin nur diejenigen, die in Standardfällen bezogen werden. Nicht zu diesem Standard werden Transfers gerechnet, die der Absicherung gegen spezielle Lebensrisiken wie Arbeitslosigkeit oder Erwerbsunfähigkeit dienen oder Armut entgegenwirken sollen. Erfasst sind indessen breit angelegte kindbedingte Transfers und Steuererleichterungen sowie Renten der gesetzlichen Rentenversicherung. Die in dieser Arbeit hauptsächlich betrachteten Wirkungen des Steuer-Transfer-Systems beziehen sich auf Unterschiede erstens zwischen Einkommensniveaus und zweitens zwischen Familien(-typen), sowie die Entwicklung dieser Unterschiede im Zeitverlauf.

Die hiermit zusammen hängende dritte Abgrenzung des Untersuchungsgegenstandes bezieht sich auf die Art der berücksichtigten Einkommen. Als typischer Erwerbstyp werden sozialversicherungspflichtige Arbeitnehmer betrachtet, so dass die vom STM erfassten Bruttoeinkommen Erwerbseinkommen aus sozialversicherungspflichtiger Tätigkeit und Renten der gesetzlichen Rentenversicherung sind. Ausgehend von sozialversicherungspflichtigem Bruttolohn und/ oder Brutto- 
renten werden für diese beiden Einkommensarten die zu entrichtenden Steuern und Sozialversicherungsbeiträge im Modell bestimmt.

Die grundlegende Abbildung des Steuer-Transfer-Rechners, die Abhängigkeit des verfügbaren Einkommens eines Kalenderjahres $y_{v}$ von Bruttoeinkommen und sozioökonomischen Merkmalen unter dem Rechtsstand eines Jahres $t$, lässt sich somit darstellen in der Form:

$y_{v}\left(y_{B}, R_{B}, m, t\right)=y_{B}+R_{B}-T_{t}\left(y_{B}, R_{B}, m\right)+S_{t}\left(y_{B}, R_{B}, m\right)$

mit $\quad y_{B} \quad$ Bruttolohn

$R_{B} \quad$ Bruttorente aus der gesetzlichen Rentenversicherung

$m$ Merkmalsvektor (Alter, Familienstand, Anzahl und Alter von Kindern ...)

$T_{t}[$.$] Abgabenfunktion$

$S_{t}[.$.$] Transferfunktion$

Die Abgabenfunktion $T_{t}$ gibt die Sozialversicherungsbeiträge sowie Einkommen- und Zuschlagsteuern wieder. Die Transferfunktion $S_{t}$ bildet kindbedingte Leistungen wie das Kindergeld und die Ausbildungsförderung $a b$, wobei die Abhängigkeit dieser Leistungen von den zu entrichtenden Abgaben im Modell ebenfalls berücksichtigt ist. In verschiedenen Kontexten interessierende intraindividuelle Unterschiede wie etwa eine kindbedingte Entlastung, die sich sowohl aus Steuerminderungen als auch aus Transfers zusammensetzt, ergeben sich als Differenz der verfügbaren Einkommen von Fällen, die sich nur in der Kinderzahl unterscheiden bei ansonsten identischen Bruttoeinkommen und sonstigen Merkmalen.

Während die Bestimmung der Sozialversicherungsbeiträge im Wesentlichen dem gleich bleibenden einfachen Prinzip folgt, von der Bruttogröße bis zu einem Maximalwert einen prozentualen Anteil abzuziehen, bestehen bei der Besteuerung zum einen gravierende Unterschiede im Zeitverlauf und zum anderen eine nicht unerhebliche Einzelfallabhängigkeit bei der Zuordnung der Bemessungsgrundlage zu einer Bruttogröße. In der Steuerberechnung des STM sind die gesetzlich fixierten pauschalen Abzugsbeträge erfasst (wie etwa der Arbeitnehmer-Pauschbetrag von derzeit 920 Euro), nur nachweisabhängig gewährte Abzüge sind hingegen nicht berücksichtigt. Neben wechselnden Steuertarifen verursachen vor allem Anpassungen, Einführungen und Streichungen von Pauschbeträgen die mit dem Modell ermittelbaren intertemporalen Unterschiede in der Besteuerung. Die dem Einkommensteuergesetz folgende Steuerberechnung des Modells ist in Abbildung 1 schematisch dargestellt. Auf die Gültigkeitsdauer verschiedener Frei- und Abzugsbeträge sowie wesentliche Entwicklungslinien in der Besteuerung seit 1950 wird im vierten Kapitel (s. Kapitel 4.2 Einkommensteuer und Zuschlagsteuern) eingegangen. Ausgegliedert aus diesem Kapitel sind kindbedingte Erleichterungen bei der Einkommensteuer, von denen die Kinderfreibeträge am bedeutsamsten sind. Auf Grund der engen funktionalen Verknüpfung von Kindergeld und Kinderfreibeträgen im Familienleistungsausgleich werden diese beiden Hauptinstrumente der Familienpolitik gemeinsam in einem eigenen Kapitel besprochen. Weitere im Einkommensteuergesetz verankerte familienpolitische Maßnahmen wie die Ausbildungsfreibeträge schließen sich in einem zu- 
sätzlichen Kapitel an. Das Kapitel zur Ausgestaltung von Steuern und Transfers seit 1950 (Kapitel 4) dient der Dokumentation der im Steuer-Transfer-Rechner erfassten gesetzlichen Entwicklung und der von ihr ausgehenden Implikationen in den Bereichen der Besteuerung, der Sozialversicherung und der familienpolitischen Transfers. Neben zum Teil eher technisch anmutenden Details der Gesetzgebung wird in zahlreichen vergleichenden Querschnitten herausgearbeitet, in welchen Jahren die Gesetzgebung unter Berücksichtigung der Einkommensentwicklung zu Einschnitten oder zu Erleichterungen führte. Dabei werden die Modellergebnisse auf der Mikroebene auch in Beziehung zur Entwicklung des Finanzvolumens der betrachteten Maßnahmen gesetzt. Auf den zweiten Teil der Arbeit vorgreifend wird die Darstellung um Hinweise ergänzt, welche Auswirkungen sich für die Längsschnittbetrachtungen von Lebenszyklen der Kohorten von 1930 bis 1990 abzeichnen.

\section{Abbildung 1: Schema zur Berechnung von Einkommen- und Zuschlagsteuern im STM}

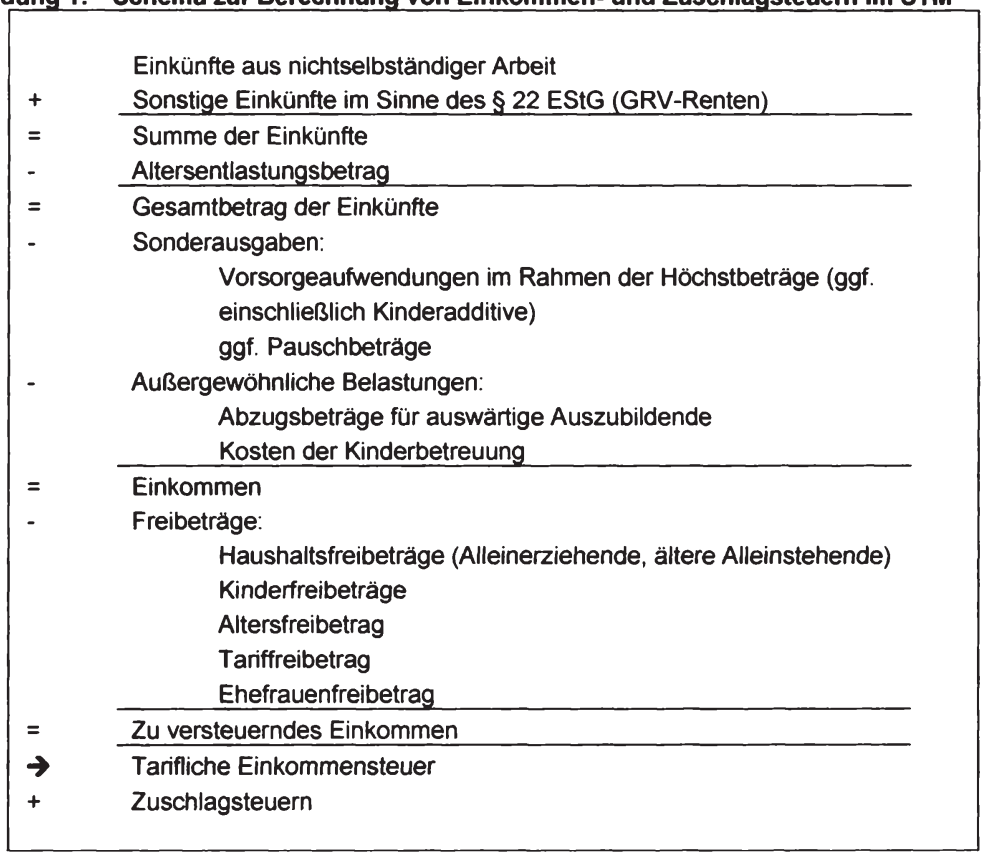

Die Funktionen des Rentenrechners als zweitem wesentlichem Baustein kommen nur bei Längsschnittanalysen zum Tragen. Seine Kernaufgabe ist die Bestimmung von mit Zugangsfaktoren gewichteten Entgeltpunkten auf der Grundlage von Rentenbiographien, die maßgeblich für den individuellen Rentenanspruch sind. Im Rahmen einer Lebenszyklusbetrachtung erfolgt diese Berechnung zum -exogen vorzugebenden- Renteneintrittszeitpunkt. Aus den während der Erwerbsphase erzielten Bruttolöhnen sowie weiteren berechnungsrelevanten Merkmalen bestimmt der Rentenrechner die Bruttojahresrente im Renteneintrittsjahr, die Rente der Folgejahre wird aus dieser an Hand der Entwicklung der aktuellen Rentenwerte fortgeschrieben. Bei 
Hinterbliebenenrenten wird analog vorgegangen: Zum einen werden einmalig, nämlich im Todesjahr, die Entgeltpunkte der Hinterbliebenenrente bestimmt, zum anderen werden aus diesen sowie aus der Entwicklung der aktuellen Rentenwerte die Bruttojahresrenten fortgeschrieben (wobei die Hinterbliebenenrenten gegebenenfalls um anzurechnende Einkommen gemindert werden). Sowohl bei der Berechnung von Renten aus eigenen Ansprüchen (Renten wegen Alters) als auch bei den Hinterbliebenenrenten (Renten wegen Todes) berücksichtigt der Rentenrechner detailliert die gesetzlichen Vorgaben des SGB VI. Die aus den biographischen Angaben ermittelte Rente umfasst dabei neben den beitragsäquivalenten Rentenbestandteilen auch verschiedene Transferelemente, wie sie sich unter anderem bei der Bewertung von Ausbildungszeiten ergeben. Der Rentenrechner ermittelt folglich Rentenansprüche als endogene Größe, die sich aus einer Rentenbiographie als exogener Vorgabe ergeben. Die zahlreichen Abhängigkeiten der Rentenbestandteile mit Transfercharakter vom Geburtsjahr sind im Rentenrechner berücksichtigt. Implementiert sind die Rechtsstände für Rentenzugänge ab 1992, so dass bei der Betrachtung von Kohorten ab 1930 auch Rentenbezüge vor Erreichen des (bisherigen) gesetzlichen Renteneintrittsalters von 65 Jahren nachvollzogen werden können. Im Kapitel zu den Renten der gesetzlichen Rentenversicherung (Kapitel 5) wird die Rentenberechnung näher vorgestellt. Die Auswahl der vom Rentenrechner abgebildeten Transferelemente folgt denselben Gesichtspunkten wie beim Steuer-Transfer-Rechner, auch hier beschränkt sich die Betrachtung auf Standardfälle.

Schließlich bilden die Lebenseinkommensprofile als dritter Baustein eine empirische Grundlage für die Längsschnittbetrachtungen des zweiten Teils der Arbeit. Sie beruhen auf einem Mincer'schen Ansatz und geben das Bruttojahreseinkommen in Abhängigkeit von Qualifikation und Lebensalter wieder. Von der Bildungsvariablen der Einkommensfunktion gehen bei den Lebenszyklusbetrachtungen dieser Arbeit neben den üblichen Einkommensunterschieden weitere Implikationen aus: Die modellierten gesetzlichen Regelungen nehmen zum Teil unmittelbar auf Bildungsbeteiligung Bezug; Beispiele sind die rentensteigernden Wirkungen von Ausbildungszeiten oder der verlängerte Kindergeldbezug bei Auszubildenden. Zum Teil sind diese Wirkungen von Bildungsbeteiligung originärer Bestandteil der untersuchten Fragestellungen, so liegt ein Erkenntnisinteresse bei der Berechnung von Bildungsrenditen gerade auf dem Einfluss des Steuer-Transfer-Systems auf die Rentabilität von Humankapitalinvestitionen. Für andere im zweiten Teil der Arbeit untersuchte Fragestellungen sind bildungsökonomische Zusammenhänge hingegen von untergeordneter Bedeutung. Hier stehen (intragenerative) Unterschiede zwischen Einkommensniveaus im Vordergrund, die Bildungsvariable übernimmt dann primär die Rolle eines Indikators des Einkommensniveaus, wobei längerdauernde Qualifikationsphasen mit höheren Einkommen einhergehen.

Für die Auswahl der berücksichtigten Ausbildungen sind diese beiden Funktionen der Bildungsvariablen ausschlaggebend, zum einen die rechtlichen Regelungen zur Bildungsförderung abzudecken und zum anderen ein angemessenes Spektrum der Einkommensskala zu erfassen. Für fünf Abschlüsse wurden Lebenseinkommensprofile geschätzt, die von Personen ohne beruflichen Abschluss und mit unterdurchschnittlichem Einkommen bis zu Universitätsabsolventen, die das höchste Einkommen erzielen, reichen. Eine Grundannahme bei den Lebenseinkommensprofilen ist, dass sich das Bruttoerwerbseinkommen unabhängig vom Geburtsjahr aus einer 
zeitlich invarianten Bildungsprämie und der Erfahrung ableiten lässt. Das Bruttojahreseinkommen bestimmt sich hiernach aus einer qualifikations- und altersabhängigen relativen Einkommensposition und einem Indikator des gesamtwirtschaftlichen Lohnniveaus, wofür die Zeitreihe des Durchschnittsentgelts der gesetzlichen Rentenversicherung herangezogen wird. Über die Fortschreibung folgen aus den konkaven Alters-Einkommens-Profilen der Mincer-Schätzung monoton steigende Lebenseinkommensprofile, bei denen die relativen qualifikationsabhängigen Einkommensunterschiede in allen Kohorten gleich sind. Im Kapitel zur Konstruktion von Lebenseinkommensprofilen (Kapitel 3), das eine Beschreibung der Vorgehensweise enthält, werden sowohl Befunde vorgestellt, die die getroffene Annahme konstanter Bildungsprämien rechtfertigen, als auch ein Ansatz hergeleitet, mit dem zusätzlich Einflüsse des Qualifikationswandels erfasst werden können. Als Ergebnisse bleiben zum einen qualifikationsabhängige Lebenseinkommensprofile, auf die im zweiten Teil der Arbeit regelmäßig zurückgegriffen wird, und zum anderen korrigierte Lebenseinkommensprofile, in denen auch Verschiebungen der Qualifikationsstruktur erfasst werden. Letztere werden bei der Berechnung von Bildungsrenditen aufgegriffen werden.

Als Grundmuster der Lebenszyklusbetrachtungen im zweiten Teil der Arbeit ergibt sich aus den drei Bausteinen des STM das -mit einem Zinssatz $z$ abdiskontierteverfügbare Lebenseinkommen LEK in Abhängigkeit von Qualifikation $q$, Geburtsjahr $j$ und weiteren Merkmalen $m$ typisierend in der Form:

$$
\begin{aligned}
\operatorname{LEK}(q, j, m)= & \sum_{t=t_{t}}^{t_{E}}\left[\hat{y}(q, t, j)-T_{t}\left(\hat{y}(q, t, j), m_{t}\right)+S_{t}\left(\hat{y}(q, t, j), m_{t}\right)\right]^{*}(1+z)^{-t} \\
& \left.+\sum_{t=t_{E}}^{t_{N}} R_{t}(q, t, j, m)-T_{t}\left(R_{t}(q, t, j, m), m_{t}\right)+S_{t}\left(R_{t}(q, t, j, m), m_{t}\right)\right]^{*}(1+z)^{-t}
\end{aligned}
$$

mit $\hat{y} \quad$ geschätzter Bruttolohn

$m$ Merkmalsvektor (Familienstand, Anzahl von Kindern ...)

$T_{t}[.$.$] Abgabenfunktion$

$S_{t}[.$.$] Transferfunktion$

$R_{t}[.$.$] Rentenfunktion$

$t_{E} \quad$ Renteneintrittsalter

$t_{N} \quad$ Todesalter

Der Zusammenhang zwischen Bruttoeinkommen und verfügbaren Einkommen einer Periode, wie er vom Steuer-Transfer-Rechner abgebildet wird, wird in der Lebenszyklusperspektive also auf empirisch gestützte Einkommensprofile einer Erwerbsphase angewandt, an die sich eine Rentenbezugsphase anschließt, deren Rente aus den Einkommen der Erwerbsphase sowie den weiteren Merkmalen endogen ermittelt wird. Die Dauer der Erwerbsphase richtet sich zum einen nach den Ausbildungsdauern je Qualifikation und zum anderen nach der Setzung eines Renteneintrittsalters. In der Regel wird von einem Renteneintritt mit 65 Jahren ausgegangen, im Kapitel zu den Renditen der gesetzlichen Rentenversicherung wird jedoch auch der Einfluss alternativer Alter vorgestellt. Die Berechnung von Steuern, Sozialabgaben und Transfers erfolgt stets unter Berücksichtigung exogen vorgegebener Merkmale 
wie Familienstand und Kinderzahl. Welche Variationen der exogenen Merkmale Familienstand und Kinderzahl (und mit innen einher gehender Erwerbsmuster) betrachtet werden, wird in den Kapiteln des zweiten Teils unterschiedlich gehandhabt, die jeweils getroffenen Annahmen werden dort im Einzelnen vorgestellt. Als empirische Stützpunkte der Bruttoeinkommen dienen die Zeitreihen des Durchschnittsentgelts sowie des aktuellen Rentenwerts. Die Annahmen zur Lebenserwartung schließlich fußen auf den Generationensterbetafeln des Statistischen Bundesamts. In Tabelle 1 ist aufgeführt, welche Funktionen die drei Bausteine des STM (Steuer-TransferRechner, Rentenrechner, Lebenseinkommensprofile) bei Lebenszyklusbetrachtungen wahrnehmen, die die drei Phasen der Ausbildung, der Erwerbstätigkeit und des Rentenbezugs abdecken. Ergänzend sind die weiteren Größen angegeben, die in die Konstruktion der Lebenszyklen einfließen.

Für die Analyse der bekannten Entwicklung bis zum Jahr 2007 greift das STM auf die tatsächliche Entwicklung von Gesetzen, Einkommen und Rentenwerten seit 1950 zurück. Welche Ergebnisse das Modell für in die Zukunft reichende Berechnungen liefert, hängt naturgemäß von diesbezüglichen Annahmen ab. Unter diesem Aspekt sind drei Arten von Parametern zu unterscheiden:

- Für Lohnwachstum, Beitragssätze zur Rentenversicherung und die aktuellen Rentenwerte nach $\$ 68$ SGB VI werden die Annahmen der Kommission zur Nachhaltigkeit in der Finanzierung der Sozialen Sicherungssysteme („Rürup-Kommission“) übernommen, deren Werte aus einem konsistenten Modellrahmen zur ökonomischen und demographischen Entwicklung abgeleitet sind. Ausgegangen wird von einer nominalen Lohnwachstumsrate von mittelfristig $3,0 \%$, die Inflationsrate liegt bei $1,5 \%{ }^{2}$

- Die Beitragssätze zur Arbeitslosen-, Kranken- und Pflegeversicherung werden in der Regel auf dem Stand von 2007 fixiert. Die zukünftige Höhe dieser Beitragssätze ist primär für die intergenerativen Vergleiche von Lebensabgabenquoten relevant. In dem sich hiermit befassenden Kapitel des zweiten Teils werden verschiedene Annahmen zu Prognosen dieser Beitragssätze aufgegriffen, ansonsten wird das heutige Niveau ab 2007 beibehalten.

- Steuern und Transfers sind mit dem Lohnwachstum indexiert, relative Beund Entlastungen sind hiernach grundsätzlich unabhängig vom gesamtwirtschaftlichen Lohnniveau. So bleibt ab dem Jahr 2007 beispielsweise unter sonst gleichen Umständen für jedes Einkommensniveau der Durchschnittssteuersatz konstant. Eine so genannte kalte Progression tritt also nicht auf, genauso entspricht das Kindergeld einem gleich bleibenden Anteil am Durchschnittslohn. Von dieser Indexierung ausgenommen sind für den Zeitraum nach 2007 bereits festgeschriebene Gesetzesparameter. Hierzu zählen die bis 2025 ansteigenden Anteile steuerlich abzugsfähiger Rentenversicherungsbeiträge und die bei Renteneintritten bis 2040 zu vergebenden nominal fixierten Rentenfreibeträge. ${ }^{3}$

S. Statistisches Bundesamt (2005a)

Bundesministerium für Gesundheit und Soziale Sicherung (Hrsg.) (2003), S. 55

Die gesetzlichen Übergangsregelungen zur sukzessiven steuerlichen Freistellung von Rentenversicherungsbeiträgen und der spiegelbildlich zunehmenden Rentenbesteuerung werden innerhalb des vierten Kapitels besprochen. 
Tabelle 1: Lebenszyklen im STM

\begin{tabular}{|c|c|c|c|}
\hline & \multicolumn{3}{|c|}{ Phase } \\
\hline & Ausbildung & Erwerb & Rente \\
\hline Dauer & $\begin{array}{l}\text { Lebensein- } \\
\text { kommensprofil }\end{array}$ & $\begin{array}{c}\text { bis Renteneintritt gemäß } \\
\text { exogener Vorgabe }\end{array}$ & gemäß Sterbetafeln \\
\hline $\begin{array}{l}\text { Bruttoein- } \\
\text { kommen }\end{array}$ & Null* & $\begin{array}{l}\text { Lebenseinkommensprofil } \\
\text { \& Durchschnittsentgelt }\end{array}$ & $\begin{array}{c}\text { Rentenrechner } \\
\text { \& aktueller Rentenwert }\end{array}$ \\
\hline $\begin{array}{l}\text { Verfügbares } \\
\text { Einkommen }\end{array}$ & $\begin{array}{c}\text { Steuer-Transfer- } \\
\text { Rechner }\end{array}$ & Steuer-Transfer-Rechner & Steuer-Transfer-Rechner \\
\hline & $\begin{array}{l}\text { * Nur während } \\
\text { zubildenden } \\
\text { Durchschnitts }\end{array}$ & $\begin{array}{l}\text { ieblicher Ausbildungen wir } \\
\text { nommen (Ausbildungsvers } \\
\text { jelts beträgt. }\end{array}$ & $\begin{array}{l}\text { genes Einkommen des Aus- } \\
\text { ung), das stets } 20 \% \text { des }\end{array}$ \\
\hline
\end{tabular}

In Hinblick auf das Teilsystem der Rentenversicherung basieren die Berechnungen mit dem STM somit auf in sich geschlossenen Annahmen zur gesamtwirtschaftlichen Entwicklung unter Berücksichtigung der Budgetrestriktion. Bei den übrigen Teilbereichen des Steuer-Transfer-Systems wird hingegen von Fragen nach der Tragfähigkeit der gegenwärtigen Politik abstrahiert. Aufgezeigt werden stattdessen implizite langfristige Verteilungswirkungen des Status Quo aus einer mikroökonomischen Perspektive.

\subsection{Einkommensentwicklung 1950 bis 2006}

Als Grundlage für intertemporale Vergleiche der Be- und Entlastungen aus Steuern, Sozialversicherungsbeiträgen und Transfers wird in der weiteren Darstellung regelmäßig auf die jährlichen Durchschnittsentgelte der gesetzlichen Rentenversicherung nach Anlage 1 SGB VI zurückgegriffen werden (im Weiteren nur als Durchschnittsentgelt bezeichnet). Das Durchschnittsentgelt reflektiert auf Grund von $\S \S 68$ und 69 SGB VI (bzw. früher § 1255 RVO) im Wesentlichen die Entwicklung der Bruttolohnund -gehaltssumme je durchschnittlich beschäftigten Arbeitnehmer. Da die historische (sowie auch die für die Zukunft angenommene) Entwicklung des Durchschnittsentgelts wiederholt zur Deutung von Ergebnissen der Lebenszyklusbetrachtungen im zweiten Teil herangezogen wird, wird diese im Folgenden kurz vorgestellt. Insbesondere das starke Einkommenswachstum im Zeitraum von 1950 bis 1975 wird sich später wiederholt als wesentliche Ursache für intergenerative Unterschiede herausstellen. Zur Einordnung wird die Entwicklung des Durchschnittsentgelts ergänzend mit anderen Einkommenszeitreihen verglichen.

Das nominale Durchschnittsentgelt stieg seit 1950 monoton (Abbildung 2). Sein Wachstum ist durch verschiedene Rechtsänderungen geringfügig von der Zunahme der durchschnittlichen Bruttolöhne und -gehälter der volkswirtschaftlichen Gesamtrechnung abgekoppelt. Zuletzt bewirkte das Rentenversicherungs-Nachhaltigkeitsgesetz (RVNG) 2004 eine Änderung der Berechnungsvorschrift des Durchschnittsentgelts. Danach ist nicht mehr wie bis dahin die Lohnsumme insgesamt maßgeblich 
sondern ausschließlich das rentenbeitragspflichtige Einkommen. Entgelte oberhalb der Beitragsbemessungsgrenze und Beamtenbezüge werden aus der Berechnung eliminiert, wodurch die Ausgabenentwicklung der Rentenversicherung gedämpft werden soll. ${ }^{4}$

Abbildung 2: Durchschnittsentgelt der Rentenversicherung 1950 bis 2006

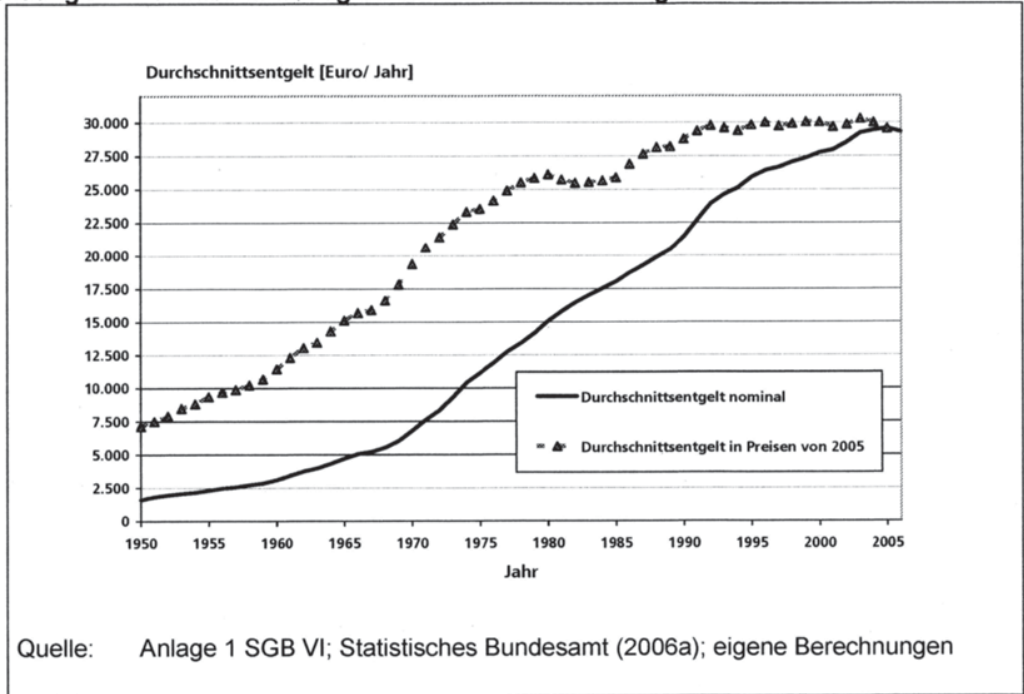

In den 1950er Jahren stieg das nominale Durchschnittsentgelt von 3.161 DM (1.616 Euro) auf 5.602 DM (2.864 Euro) um rund $77 \%$, womit die durchschnittliche jährliche Wachstumsrate $6,6 \%$ betrug, was bei der moderaten damaligen Preissteigerung einer preisniveaubereinigten Rate von 4,6\% entspricht. ${ }^{5}$ In den beiden folgenden Jahrzehnten bis 1979 beschleunigte sich die nominale Zunahme. In den 1960er Jahren lag die durchschnittliche jährliche Wachstumsrate bei 7,8\%, in den 1970er Jahren bei 8,9\%. Allerdings gingen die Entgeltsteigerungen der 1970er Jahre mit Preissteigerungsraten von bis zu etwa $7 \%$ einher, so dass die preisniveaubereinigte jahresdurchschnittliche Wachstumsrate des Durchschnittsentgelts in den 1960er Jahren mit $5,2 \%$ über dem Wert des folgenden Jahrzehnts von $3,8 \%$ lag. Nominal war das Durchschnittsentgelt in den 28 Jahren von 1950 bis 1978, der ersten Hälfte der hier betrachteten Vergangenheit, von 3.161 DM (1.616 Euro) auf 26.242 DM (13.417 Euro) und damit das 8,3-fache des Ausgangswerts angestiegen, in konstanten Preisen entspricht dies einer Zunahme auf das 3,6-fache. Das gegen Ende der 1970er Jahre

Hain, Lohmann, Lübke (2004), S. 334ff

Zur Preisniveaubereinigung wurde in dieser Arbeit stets auf den Preisindex für die Lebenshaltung von

- 4-Personen-Haushalten von Arbeitern und Angestellten mit mittlerem Einkommen (1950-1961)

- allen privaten Haushalten (1962-1999)

im früheren Bundesgebiet und ab 2000 auf den Verbraucherpreisindex für Deutschland zurückgegriffen. S. Statistisches Bundesamt (2006a) 
einsetzende Abschmilzen der Wachstumsraten setzte sich in den 1980er und 1990er Jahren fort, in denen durchschnittliche nominale Wachstumsraten von $3,8 \%$ bzw. $2,9 \%$ (preisniveaubereinigt $0,9 \%$ bzw. 0,6\%) zu verzeichnen waren. Durch die Berechnungsmodalitäten des Durchschnittsentgelts, das sich auf die Einkommen im früheren Bundesgebiet bezieht, werden die Werte nicht -zumindest nicht unmittelbar- von dem Strukturbruch durch die deutsche Wiedervereinigung beeinträchtigt. Seit Beginn des 21. Jahrhunderts lag die durchschnittliche Wachstumsrate bei rund $1,0 \%$ nominal, preisniveaubereinigt stagnierten die Einkommen. Für die zweite Hälfte des Zeitraums seit 1950 ergibt sich damit eine Zunahme des Durchschnittsentgelts auf das 2,2-fache des Wertes von 1978, unter Berücksichtigung der Preisentwicklung entspricht dies einem Anstieg um insgesamt etwa 16\%.

Abbildung 3: Entwicklung verschiedener Durchschnittseinkommen in Relation zum Durchschnittsentgelt 1950 bis 2006

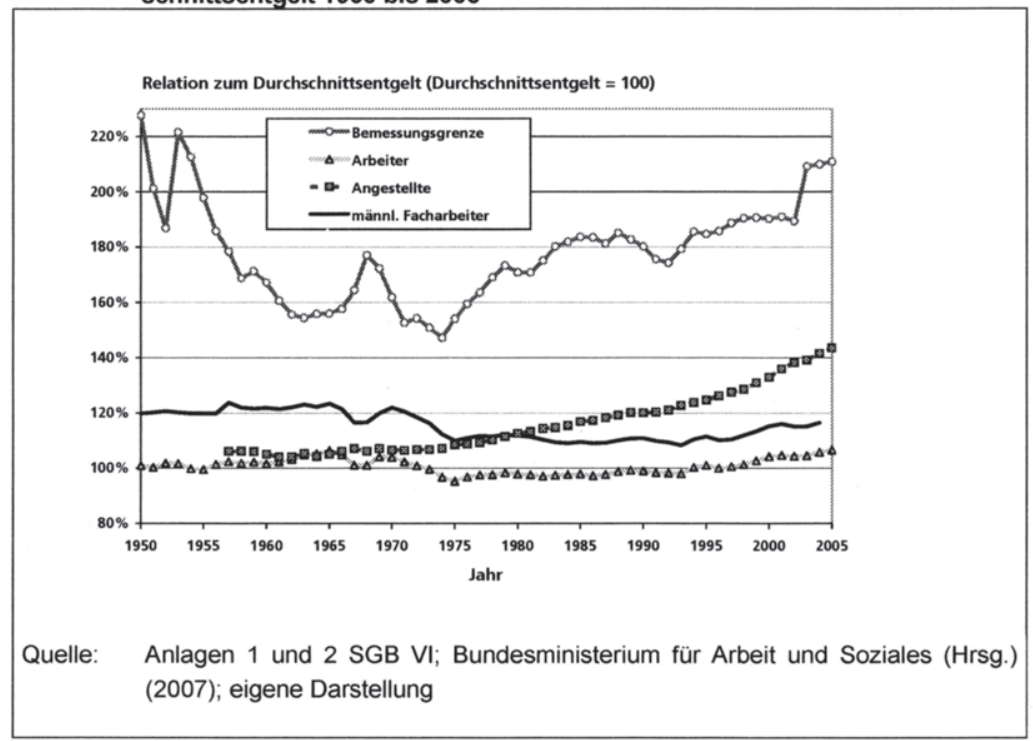

In Abbildung 3 ist die Entwicklung verschiedener Einkommen in Relation zum Durchschnittsentgelt dargestellt. ${ }^{6}$ Sämtliche Größen beziehen sich auf das frühere Bundesgebiet. Die Beitragsbemessungsgrenze nach Anlage 2 SGB VI betrug seit $1950 \mathrm{~min}-$ destens $147 \%$ des Durchschnittsentgelts und liegt seit 2003 bei etwa $210 \%$. Da die Beitragsbemessungsgrenze gemäß $§ 159$ SGB VI und das Durchschnittsentgelt gemäß § 69 SGB VI grundsätzlich entsprechend der Entwicklung derselben Größen der

6 Dargestellt sind die auf Jahreswerte hochgerechneten durchschnittlichen Bruttoverdienste von

- Arbeitern im Produzierenden Gewerbe

- Angestellten im Produzierenden Gewerbe; Handel; Instandhaltung und Reparatur von Kraftfahrzeugen und Gebrauchsgütern; Kredit- und Versicherungsgewerbe

- männlichen Facharbeitern im Produzierenden Gewerbe.

(S. Bundesministerium für Arbeit und Soziales (Hrsg.) (2007)) 
volkswirtschaftlichen Gesamtrechnung jährlich angepasst werden, ist zukünftig weiterhin mit einem Verhältnis in dieser Größenordnung zu rechnen. Die qualifikationsabhängigen Einkommensprofile für die Lebenszyklusbetrachtungen des zweiten Teils enthalten Bruttolöhne von bis zu knapp $190 \%$ des Durchschnittentgelts. Bei den jüngeren Kohorten ist daher von einer weiter reichenden Erfassung der Bruttoeinkommen durch die Sozialversicherungspflicht auszugehen. Die durchschnittlichen Bruttoverdienste von Arbeitern lagen durchgehend in ähnlicher Höhe wie das Durchschnittsentgelt, sie entsprachen seit 1950 zwischen rund $95 \%$ und $107 \%$ dessen Werts. Die Abgrenzung von Arbeitern entspricht weitgehend dem von der OECD für internationale Vergleichsanalysen definierten „average production worker", der einen typisierten Durchschnittsverdiener charakterisieren soll. ${ }^{7}$

Die Einkommen männlicher Facharbeiter schwankten bis in die 1970er Jahre um Werte von $120 \%$ des Durchschnittsentgelts, danach lagen sie recht konstant bei etwa $110 \%$. Spiegelbildlich wichen die Durchschnittseinkommen von Angestellten seit Mitte der siebziger Jahre des vergangenen Jahrhunderts zunehmend nach oben ab und betragen in den letzten Jahren mehr als $140 \%$ des Durchschnittsentgelts. Mögliche Gründe für die verschiedenen Verläufe, zu denen unter anderem geschlechtsspezifische Einkommensunterschiede, Verschiebungen in der Qualifikations- und Beschäftigungsstruktur und der Anteil von Teilzeitarbeit zählen, sollen hier nicht weiter verfolgt werden. Als Faustregel lässt sich festhalten, dass das Durchschnittsentgelt weitgehend das Durchschnittseinkommen von Arbeitern reflektiert, während die Einkommenssituation von Angestellten zunehmend nach oben von ihm abweicht.

Die Bruttojahreseinkommen aus den im nächsten Kapitel vorgestellten Einkommensprofilen bewegen sich je nach Qualifikation und Alter zwischen knapp 60\% und über $180 \%$ des Durchschnittsentgelts. Das durchschnittliche Bruttoeinkommen während der gesamten Erwerbsphase beläuft sich beim geringsten betrachteten Qualifikationsniveau auf knapp $79 \%$ des Durchschnittsentgelts, beim höchsten Abschluss liegt der Wert bei rund 168\%. Die Spannweite der betrachteten Einkommen reicht somit von recht niedrigen Werten unter dem Niveau durchschnittlicher Arbeiter bis zu höheren Einkommen oberhalb von durchschnittlichen Angestelltengehältern. Verschiedene Rechtsänderungen, die sich vor allem im Bereich hoher und höchster Einkommen auswirken, schlagen sich entsprechend nur begrenzt in den Lebenszyklusbetrachtungen des zweiten Teils nieder. Einige Hinweise auf intertemporale Unterschiede bei Höchsteinkommen finden sich vor allem in der Darstellung des Einkommensteuermoduls des Steuer-Transfer-Rechners im ersten Teil.

Der „average production worker" wird als männlicher oder weiblicher Arbeiter in der Industrie mit Vollzeittätigkeit abgegrenzt. S. Bahle, Maucher (2003), S. 22 
Tobias Arens - 978-3-631-75164-0

Downloaded from PubFactory at 01/11/2019 07:33:05AM

via free access 


\section{Lebenseinkommensprofile}

Ein wesentliches Merkmal bei der Unterscheidung verschiedener Biographien in dieser Arbeit ist der berufliche Abschluss, der sich einerseits auf verschiedene Transfers auswirkt und andererseits signifikanter Prädiktor des Erwerbseinkommens ist. Der verbreiteteste Ansatz zur Beschreibung und Erklärung der Einkommensverteilung geht auf humankapitaltheoretische Arbeiten Mincers (1958) zurück und stellt Einkommen in Abhängigkeit von Bildung und Berufserfahrung dar. Wiederkehrendes Ergebnis von auf Mincers Modell ${ }^{8}$ beruhenden Untersuchungen ist ein umgekehrt uförmiges Alters-Einkommens-Profil, das seit langem gebiets- und zeitübergreifend zu beobachten ist. ${ }^{9} \mathrm{Da}$ das Hauptanliegen dieser Arbeit darin besteht, den zeitlichen Verlauf des Zusammenhangs von empirisch gestützten Markteinkommen und den sich durch das Steuer-Transfer-Modell daraus abgeleiteten verfügbaren Einkommen zu untersuchen, wozu vorrangig eine geeignete Beschreibung statt einer weiterreichenden Erklärung der Einkommensverteilung benötigt wird, werden trotz verschiedener Kritikpunkte an ihren humankapitaltheoretischen und methodischen Grundlagen aus einer einfachen Mincer-Funktion abgeleitete Erwerbseinkommen in das Modell eingespeist. ${ }^{10}$ Für diese Vorgehensweise spricht zum einen, dass ein Vergleich mit Ergebnissen früherer Publikationen möglich ist, deren Datengrundlagen bis in die 1970er Jahre zurückreichen. Zum anderen bietet der Ansatz unter pragmatischen Gesichtspunkten einige Vorzüge: Mit der geschätzten Einkommensfunktion lassen sich recht einfach Perioden- und Lebenseinkommen verschiedener Kohorten für die Berechnungen vorgeben, wobei zusätzlich die Möglichkeit besteht, bei $\mathrm{Er}$ werbsunterbrechungen nicht nur den unmittelbaren Einkommensverlust zu berücksichtigen, sondern auch Mindereinkommen bei späterer Wiederaufnahme von Erwerbstätigkeit, die aus der geringeren Berufserfahrung im Vergleich zu durchgehend erwerbstätigen Gleichaltrigen resultieren.

\subsection{Schätzung von Einkommensprofilen}

Ausgangspunkt der Lebenseinkommensprofile ist eine Mincer-Funktion, deren $\mathrm{Pa}$ rameter mit Daten der Einkommens- und Verbrauchsstichprobe 2003 (EVS) geschätzt wurden:

$\ln \hat{y}_{1}=\beta_{0}+\beta_{1} e+\beta_{2} e^{2}+\beta_{l m i} a_{l^{\prime} m}+\beta_{l \cdot I} a_{F \cdot H}+\beta_{M} a_{M}+\beta_{L} a_{l}$

mit $\quad$ s zu schätzende Parameter

a Dummy-Variablen für die Ausbildungsabschlüsse Hochschule (Uni), Fachhochschule (FH), „Meister" (M), „Lehre" (L), wobei

Zur Modellspezifikation Mincers s. Mincer (1974)

Blaug (1973), S. 25ff

10 Als weitere Erklärungen des Zusammenhangs von Bildung und Einkommen neben der Humankapitaltheorie sind der Signaling-Ansatz von Spence und die Screening-Hypothese (Spence (1973), Thurow (1975)). Methodische Kritikpunkte beziehen sich insbesondere auf die SelbstSelektivität bei Bildungsentscheidungen (vgl. hierzu Maddala (1983), S. 257ff.). 


\section{$a_{i}=1, \quad$ wenn Person i den Abschluss i aufweist 0 sonst \\ e potenzielle Berufserfahrung}

Personen ohne abgeschlossene Berufsausbildung bilden die Referenzgruppe. Zur vereinfachten Übertragbarkeit auf verschiedene Kalenderjahre wurde das Einkommen in Relation zum Durchschnittsentgelt ausgedrückt ( $y_{i}=$ Bruttoeinkommen / 28.938, bei einem Durchschnittsentgelt 2003 von 28.938 Euro). Ein geschätztes Einkommen von 1,0 entspricht damit dem Durchschnittsentgelt (sowie auch einem Entgeltpunkt der gesetzlichen Rentenversicherung). Die potenzielle Berufserfahrung $e$ wird wie üblich aus dem Lebensalter, den Ausbildungsdauern und der Zeit bis zur Einschulung abgeleitet:

$\begin{array}{lll}\text { Berufserfahrung }=\quad & \text { Lebensalter } \\ & - & \text { qualifikationsabhängige Ausbildungsdauer } \\ & \text { Einschulungsalter }\end{array}$

Die Ausbildungsdauern ergeben sich zum Teil aus den Pflichtzeiten, zum Teil aus Durchschnittswerten (s. Tabelle 2). Ausgegangen wurde von zehn Jahren Pflichtschulzeit und drei Jahren für die Sekundarstufe II. Für ein Hochschulstudium wurde eine Dauer von sechs Jahren angenommen. Die 17 Jahre bis zum Fachhochschulabschluss entsprechen 12 oder 13 Schuljahren zuzüglich vier bzw. fünf Studienjahren. Die 13 Jahre für eine berufliche Ausbildung umfassen zehn Schul- und drei Lehrjahre, für den Abschluss an einer Fachschule (Meistertitel) wurde von zwei weiteren Ausbildungsjahren ausgegangen. Bei Personen ohne Abschluss wurde die Möglichkeit, nach neun Schuljahren die Schule zu verlassen nicht berücksichtigt.

Tabelle 2: Abschlüsse und ihnen zugeordnete Ausbildungszeiten

\begin{tabular}{|l|c|c|}
\hline \multicolumn{1}{|c|}{ Beruflicher Abschluss } & Abkürzung & $\begin{array}{c}\text { Ausbildungsdauer } \\
\text { [Jahre] }\end{array}$ \\
\hline Hochschulabschluss & Uni & 19 \\
\hline $\begin{array}{l}\text { Fachhochschulabschluss } \\
\text { (auch Ingenieurschulabschluss) }\end{array}$ & $\mathrm{FH}$ & 17 \\
\hline $\begin{array}{l}\text { Ausbildung an einer Fach-, Meister-, } \\
\text { Technikerschule, Berufs- Oder Fachakademie }\end{array}$ & $\begin{array}{c}\text { M } \\
\left.\text { (,Meister }{ }^{\prime}\right)\end{array}$ & 15 \\
\hline $\begin{array}{l}\text { Abschluss einer beruflichen Ausbildung (Leh- } \\
\text { re)oder gleichwertiger Berufsfachschulabschluss }\end{array}$ & $\begin{array}{c}\text { L } \\
\left.\text { (Lehre }{ }^{4}\right)\end{array}$ & 13 \\
\hline $\begin{array}{l}\text { kein beruflicher Abschluss und nicht in beruflicher } \\
\text { Ausbildung }\end{array}$ & Ohne & 10 \\
\hline
\end{tabular}

Alternative Annahmen zu durchschnittlichen Studiendauern oder der Zuordnung von Zeiten einer beruflichen Ausbildung, die sich bekanntlich auf Ausbildungszeiten im engeren Sinne und Zeiten berufspraktischer Tätigkeiten zusammensetzen, sind denkbar. ${ }^{11}$ Weiterhin wurde ein Einschulungsalter von sechs Jahren gesetzt. Da sich das STM auf sozialversicherungspflichtige Normalbeschäftigungen konzentriert, wur-

11 So unterstellen Bellmann, Reinberg und Tessaring beispielsweise 18 (Uni)/ 15 (FH)/ 15,125 (M)/ 12,125 (L) und 10 (Ohne) Jahre. (Bellmann, Reinberg, Tessaring (1994), S. 50) 
den weder Beamte und Selbstständige noch Teilzeiterwerbstätige in die Schätzung aufgenommen (Tabelle 3). Ohne die Bedingungen der Vollzeitbeschäftigung und ohne den Ausschluss von (bei Vollzeitbeschäftigten unplausiblen) Niedrigsteinkommen beträgt der durchschnittliche errechnete Jahresbruttolohn des so abgegrenzten Samples 28.415 Euro und entspricht damit annähernd dem Durchschnittsentgelt des Jahres 2003 von 28.938 Euro. Die Schätzergebnisse sind in Tabelle 4 dargestellt. ${ }^{12}$

Tabelle 3: Ausgewählte Fälle bei Schätzung der Mincer-Gleichung

\begin{tabular}{|l|l|}
\hline \multicolumn{1}{|c|}{ Variable } & berücksichtigte Ausprägungen \\
\hline Staatsangehörigkeit & Deutsch \\
\hline Soziale Stellung & Arbeiter oder Angestellter \\
\hline Beschäftigungsverhältnis & Vollzeitbeschäftigung \\
\hline Alter & zwischen 18 und 65 Jahren \\
\hline Bruttolohn & $>5.000$ Euro/ Jahr \\
\hline
\end{tabular}

Tabelle 4: Regressionsergebnisse Mincer-Schätzung

\begin{tabular}{|l|c|c|c|c|}
\hline Variable & $\begin{array}{c}\text { Nicht standar- } \\
\text { disierte Koeffi- } \\
\text { zienten }\end{array}$ & $\begin{array}{c}\text { Standard- } \\
\text { fehler }\end{array}$ & $\begin{array}{c}\text { t-Sta- } \\
\text { tistik }\end{array}$ & $p$ \\
\hline Konstante $\left(\beta_{0}\right)$ & $-1,3833$ & 0,089 & $-15,6$ & $<0,0001$ \\
\hline Erfahrung $\left(\beta_{1}\right)$ & 0,0264 & 0,002 & 18,3 & $<0,0001$ \\
\hline quadrierte Erfahrung $\left(\beta_{2}\right)$ & $-0,0004$ & 0,000 & 16,6 & $<0,0001$ \\
\hline Uni $\left(\beta_{\text {uni }}\right)$ & 0,7642 & 0,086 & 14,6 & $<0,0001$ \\
\hline $\mathrm{FH}\left(\beta_{\mathrm{FH}}\right)$ & 0,6224 & 0,086 & 12,5 & $<0,0001$ \\
\hline $\mathrm{M}\left(\beta_{\mathrm{M}}\right)$ & 0,4444 & 0,086 & 10,7 & $<0,0001$ \\
\hline $\mathrm{L}\left(\beta_{\mathrm{L}}\right)$ & 0,2569 & 0,086 & 8,6 & $<0,0001$ \\
\hline korrigiertes $\mathrm{R}^{2}$ & & 0,348 & \\
\hline Standardfehler des Schätzers & 0,566 \\
\hline Fallzahl & 22.143 \\
\hline Quelle: EVS 2003, eigene Berechnungen \\
\hline
\end{tabular}

Unter der Annahme zeitlich invarianter Bildungs- und Erfahrungsrenditen ${ }^{13}$ $\left(\left(\beta_{i t} \mid t\right)=\beta\right.$, für verschiedene Kalenderjahre $t$ und $i \epsilon\{1,2$, Uni, $\left.F H, M, L\}\right)$ lässt sich aus den Koeffizienten und den Durchschnittsentgelten $d$ für jede Kombination aus Qualifikation $q$, Kalenderjahr $t$ und Geburtsjahr $j$ das geschätzte Bruttojahreseinkommen $\hat{b}$ bilden:

12 Wird statt des in Relation zum Durchschnittsentgelt ausgedrückten Bruttolohns der nominale Bruttolohn als abhängige Variable gewählt, ergibt sich als Konstante $\beta_{0}{ }^{\prime}=\beta_{0}+\ln (28.938) \approx 8,89$ bei ansonsten gleichen Koeffizienten.

Hier wird zunächst die in der Literatur verbreitete Gleichsetzung der geschätzten transformierten Parameter mit einer Bildungsrendite (Rendite $(q)=e^{\beta_{u \prime}}$ ) übernommen. Im Kapitel zu Bildungsrenditen wird hingegen für einen differenzierteren Renditebegriff plädiert werden, der unter anderem auch Bildungskosten berücksichtigt. (Vgl. Heckman, Lochner, Todd (2003), S. 1f) 


$$
\begin{aligned}
\hat{b}(q, t, j) & =d(t)^{*} \hat{y}(q, t, j) \\
& =d(t)^{*} \operatorname{Exp}\left[\beta_{0}+\beta_{1} e(q, t, j)+\beta_{2} e(q, t, j)^{2}+\beta_{q}(q)\right]
\end{aligned}
$$

Es ergeben sich somit für alle betrachteten Qualifikationen geburtsjahrunabhängige relative Lebenseinkommensprofile. Für Universitätsabsolventen jeder Kohorte resultiert beispielsweise ein Einkommen zu Beginn des Erwerbslebens (im Alter von 25 Jahren) von etwa $125 \%$ des Durchschnittsentgelts des jeweiligen Kalenderjahres, im Altersbereich um 55 Jahre beträgt ihr Bruttoeinkommen annähernd 190\% des Durchschnitts (vgl. Abbildung 4). Personen mit abgeschlossener beruflicher Ausbildung (Lehre) weisen am Anfang der Erwerbsphase Einkommen unterhalb des Durchschnittsentgelts (85\%) auf, später steigt ihr relatives Einkommen über dieses (bis zu knapp $115 \%)$. Bei Personen ohne Abschluss bewegt sich das Einkommen stets unterhalb des Durchschnittsentgelts (je nach Lebensalter etwa $70 \%$ bis $90 \%$ ).

Abbildung 4: Geschätzte relative Einkommensprofile in Abhängigkeit von Geburtsjahr und Qualifikation

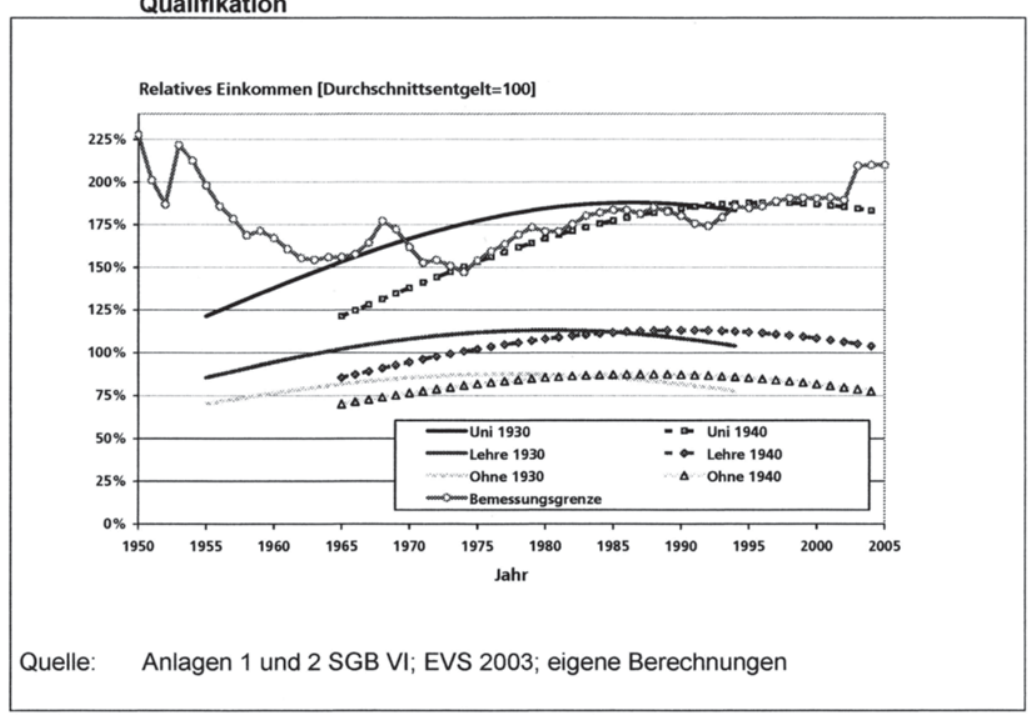

In Abbildung 4 ist weiterhin die Beitragsbemessungsgrenze der gesetzlichen Rentenversicherung dargestellt. Es deutet sich an, dass nach den Schätzergebnissen für Personen mit Universitätsabschluss aus älteren Kohorten zwischen den 1970er und 1990er Jahren Teile des Bruttoeinkommens nicht mit Sozialversicherungsbeiträgen belastet wurden. Für jüngere Kohorten gilt dies auf Grund des Anstiegs der Bemessungsgrenze auf rund $210 \%$ des Durchschnittsentgelts nicht mehr. Die so konstruierten und nach der Qualifikation differenzierten Lebenseinkommensprofile führen somit zu fünf jeweils konkaven relativen Einkommensverläufen, wobei mit höheren $A b-$ schlüssen (Universität, Fachhochschule, Meister) Verdienste deutlich oberhalb des Durchschnittsentgelts assoziiert werden. Beim Abschluss Lehre ergibt sich über die 
Erwerbsphase insgesamt ein leicht überdurchschnittliches Einkommen, für Personen ohne Abschluss resultiert ein unterdurchschnittlicher Wert in einer Größenordnung von rund $80 \%$ des Durchschnittsentgelts. Die Konkavität der Einkommensverläufe ist insbesondere für die Ableitung des verfügbaren Einkommens aus dem Bruttoeinkommen bei einem progressiven Steuertarif und der Sozialversicherungsfreiheit von Einkommen jenseits der Beitragsbemessungsgrenzen relevant.

Ein mögliches Missverständnis bei dieser Art der Konstruktion von Lebenseinkommensprofilen aus Querschnittsdaten bezieht sich auf das Absinken des Einkommens gegen Ende der Erwerbsphase, das vor allem in Widerspruch zu dem Befund nach unten starrer Löhne steht. Göbel (1983) weist auf den Unterschied von aus Querschnitten gewonnenen Alters-Einkommens-Profilen und Lebenseinkommensprofilen hin, zu deren Bestimmung Längsschnittdaten erforderlich sind. ${ }^{14}$ Für Geburtsjahrgänge zwischen 1900 und 1915 findet er auf der Grundlage von Längsschnittdaten der gesetzlichen Rentenversicherung -mit Ausnahme der Kriegszeiten in der ersten Hälfte der 1940er Jahre- durchgehend monoton steigende Nominaleinkommen, das aus Alters-EinkommensProfilen bekannte Absinken zum Ende der Erwerbsphase ist nicht zu beobachten. Deren umgekehrt u-förmiger Verlauf wird entsprechend mit einer Verschlechterung der relativen Einkommensposition bei höherem Lebensalter erklärt, der bei allgemeinen Einkommenssteigerungen mit nominal steigenden absoluten Einkommen vereinbar ist. ${ }^{15}$

Abbildung 5 zeigt die Unterschiede bei der Betrachtung des Einkommens in Abhängigkeit vom Alter im Quer- und Längsschnitt. Abgebildet ist jeweils der Mittelwert des nominalen Bruttojahreseinkommens verschiedener Altersgruppen (unter 20 Jahre, 20 bis 24 Jahre, 25 bis 29 Jahre, etc.), der auf der Grundlage verschiedener Wellen des Sozio-ökonomischen Panels (SOEP) bestimmt wurde. Der umgekehrt uförmige Verlauf zeichnet sich im oberen Teil der Abbildung für alle drei betrachteten Jahre $(1983,1993,2003)$ ab, die Niveauunterschiede der drei Alters-EinkommensProfile reflektieren die allgemeine nominale Einkommenssteigerung zwischen 1983 und 2003. Werden hingegen die durchschnittlichen Einkommen verschiedener Gruppen von Kohorten (1929-33, 1934-38 etc.) zu verschiedenen Zeitpunkten als QuasiLängsschnitt gegen das Lebensalter abgetragen wie im unteren Teil von Abbildung 5 (und im oberen Teil angedeutet durch die Verbindungspfeile), ergeben sich monoton steigende nominale Lebenseinkommensverläufe. ${ }^{16}$ Die relativen Verschlechterungen der Einkommensposition gegen Ende der Enwerbsphase bei den in Abbildung 4 dargestellten Lebenseinkommensprofilen ergeben durch die Kalibrierung an Hand der Durchschnittsentgelte mit Abbildung 5 kompatible nominale Profile, wie in Abbildung 6 für Personen des Geburtsjahrgangs 1940 exemplarisch dargestellt ist.

Die hier getroffene Annahme zeitübergreifend konstanter Parameter der Mincer-Gleichung bei der Berechnung von Lebenseinkommensprofilen ist zwar vor allem bei Kohortenvergleichen zum zukünftigen Sicherungsniveau im Alter nicht unüblich, ${ }^{17} \mathrm{er}-$

14 S. Göbel (1983), S. $174 \mathrm{ff}$

15 Vgl. hierzu Schmähl, Göbel (1983), S .139; Viebrok (1997), S. 103ff

16 Für eine ähnliche Darstellung zum Vergleich von umgekehrt u-förmigen Querschnitt- bei monoton steigenden Längsschnittprofilen bezogen auf das Sparverhalten s. Börsch-Supan, Lusardi (2003), S. $3 \mathrm{ff}$

17 So etwa Essig, Reil-Held (2003), S. $11 \mathrm{ff}$ und Himmelreicher, Viebrok (2003), S. $69 f$ 
scheint jedoch für das angestrebte Ziel, möglichst repräsentative intertemporale und intergenerative Belastungsvergleiche durchzuführen, gewagt. Insbesondere gravierende Verschiebungen der Qualifikationsstruktur der Erwerbstätigen seit den 1950er Jahren lassen Zweifel an dieser Annahme aufkommen.

Abbildung 5: Einkommen in Abhängigkeit vom Alter in Quer- und Längsschnittbetrachtung
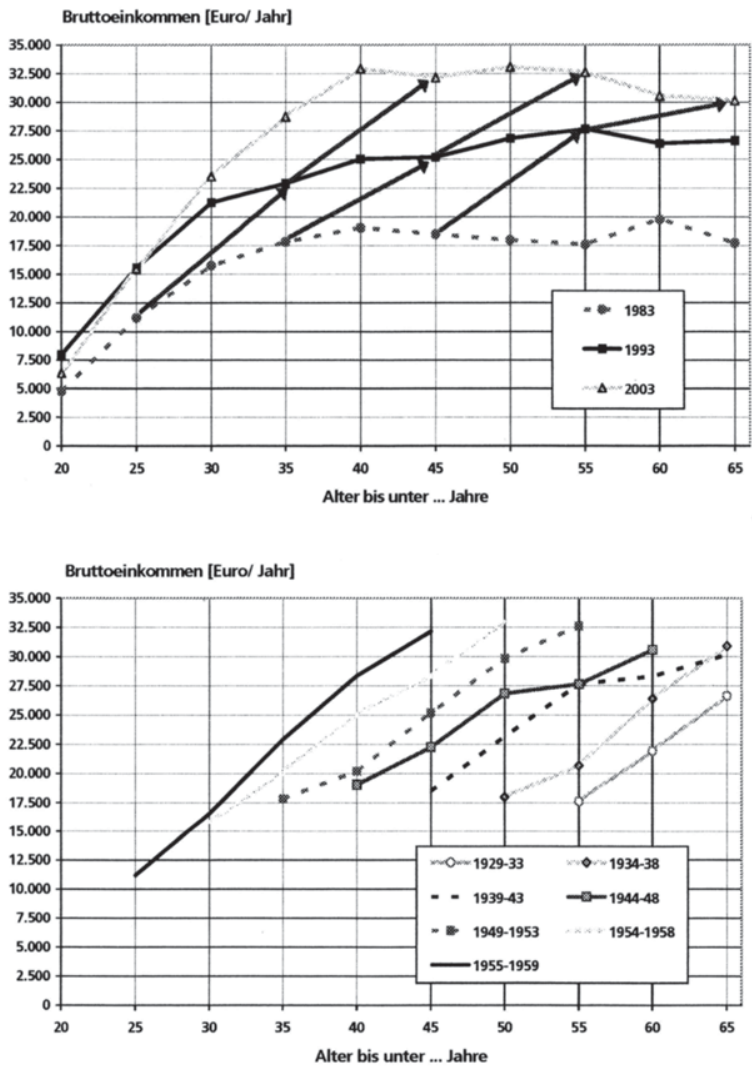

Quelle: SOEP; eigene Berechnungen

Zu ihrer Prüfung kommt grundsätzlich der Vergleich mit Ergebnissen von älteren Schätzungen ähnlicher Mincer-Modelle in Frage. Behindert wird dieses Vorgehen durch uneinheitliche methodische Ansätze, die unter anderem in unterschiedlichen Abgrenzungen einzelner Qualifikationen (z. B. Hochschulen insgesamt oder Fachhochschulen und Universitäten getrennt), der Untersuchungspopulation (mit oder oh- 
ne Differenzierung nach Geschlecht, Erwerbstätige insgesamt oder nur abhängig Beschäftigte etc.), der abhängigen Variablen (Brutto- oder Nettoeinkommen, Einkommen je Arbeitsstunde oder je Monat/ Jahr) und der unabhängigen Variablen (weitere Prädiktoren neben Bildungsdummies und Erfahrung, Schooling-Modelle mit Bildung als linearer statt kategorialer Variable) bestehen. ${ }^{18}$ Aus der Fülle empirischer Untersuchungen soll auf drei Studien eingegangen werden, die sich dadurch auszeichnen, für längere Zeiträume Schätzwerte bei gleich bleibenden Methoden und Daten zu bieten und zudem ähnliche Modellspezifikationen wie die hier gewählte aufweisen.

Abbildung 6: Geschätzte nominale Einkommensprofile in Abhängigkeit von der Qualifikation (Geburtsjahr 1940)

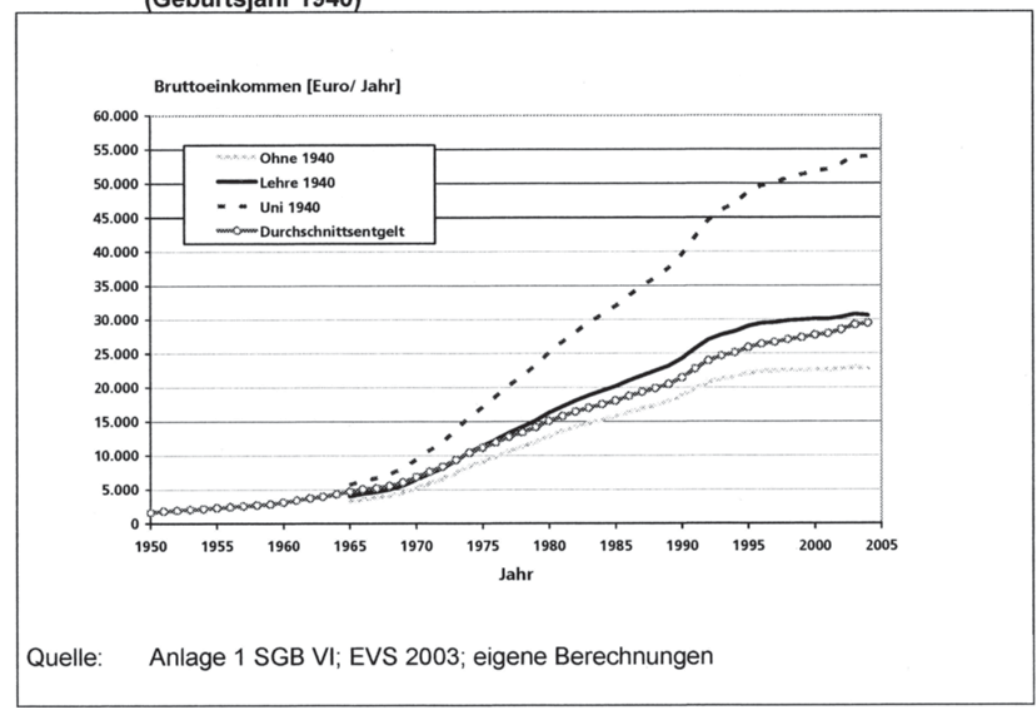

Erstens verglichen Bellmann, Reinberg und Tessaring (1994) für Jahre von 1976 bis 1987 Ergebnisse, die sie an Hand einer Stichprobe der Beschäftigtenstatistik ermittelten, die sozialversicherungspflichtig- und vollzeitbeschäftigte Männer umfasst, abhängige Variable waren Bruttomonatsverdienste. Zweitens untersuchten Lauer und Steiner (2000) die zeitliche Entwicklung der von innen geschätzten Parameter. Ihre Datenbasis ist das SOEP, der untersuchte Zeitraum reicht von 1984 bis 1997, abhängige Variable ist der reale Bruttostundenverdienst. Drittens schätzten Bellmann und Gartner (2003) für die Jahre von 1990 bis 2000 ein Mincer-Modell, wozu sie auf neuere Datensätze der auch von Bellmann, Reinberg und Tessaring (1994) genutzten Stichprobe zurückgriffen, dabei allerdings den Bruttotageslohn als Variable in das Modell aufnahmen. In allen drei Untersuchungen wird wie bei der hier durchgeführten Schätzung ein Dummy-Variablen-Modell eingesetzt.

18 Vgl. Lauer, Steiner (1999), S. 143 
Bellmann, Reinberg und Tessaring (1994) kommen zu dem Schluss, dass „auch längerfristig das steigende Angebot an Hochqualifizierten Arbeitskräften nicht oder kaum die qualifikatorische Einkommensverteilung aller Erwerbstätigen beeinflussen würde", ${ }^{19}$ ein Ergebnis, das sie sowohl aus der Entwicklung qualifikationsabhängiger Nettoeinkommen (ermittelt aus Mikrozensen) als auch aus ihren Analysen der Beschäftigtenstichprobe ableiten. Die Parameter des von innen geschätzten MincerModells für verschiedene Jahre deuten die Autoren als Hinweis auf einen im Zeitraum von 1976 bis 1987 leicht gewachsenen Einkommensabstand von Akademikern gegenüber anderen Qualifikationsgruppen, wobei sich dieser mögliche Trend ab Mitte der 1980er Jahre wieder umzukehren scheine. Für Absolventen von Universitäten und Fachhochschulen bewegen sich die $\beta_{\text {Uni }}$ und $\beta_{\mathrm{FH}}$ (s. 0.) entsprechenden Werte um 0,4 bei einem Minimum von 0,367 (1976) und einem Maximum von 0,443 (1985), die Unterschiede zwischen den beiden Hochschularten fallen dabei gering aus. Im Vergleich zu den hier geschätzten Parametern $\beta_{\text {Uni }}=0,7642$ und $\beta_{\mathrm{FH}}=0,6224$ (s.o.) sind diese Werte alarmierend niedrig. Nach diesen Ergebnissen beträgt das geschätzte Einkommen eines Universitätsabsolventen das 2,1-fache $\left(=e^{0,9642}\right)$ einer Person ohne Abschluss mit gleicher Erfahrung, nach Bellmann, Reinberg und Tessaring (1994) hingegen nur das 1,4- bis 1-6-fache. Erklärbar ist dieser Unterschied durch die Zensierung von Bruttoeinkommen in der Beschäftigtenstatistik. Diese enthält nur Einkommen bis zur maximalen Beitragsbemessungsgrenze, die zwischen 1976 und 1987 zwischen etwa $160 \%$ und $180 \%$ des Durchschnittsentgelts ausmachte (vgl. Abbildung 4). Hierdurch war von bis zu $66 \%$ der Universitätsabsolventen statt des tatsächlichen Einkommens nur bekannt, dass dieses mindestens der Bemessungsgrenze entsprach. ${ }^{20}$

Weißhuhn und Clement (1982) griffen zur Schätzung von Einkommensgleichungen der Mincer-Form ebenfalls auf die Beschäftigtenstatistik zurück, korrigierten jedoch die zensierten Einkommensverteilungen ihrer Ausgangsdaten und ordneten Einkommen in Höhe der Bemessungsgrenze unter verschiedenen Verteilungsannahmen höhere Werte $\mathrm{zu}^{21}$ Nach dieser Transformation finden sie für Männer mit Universitätsabschluss in den Jahren 1974 und 1977 Einkommen in der GröBenordnung des 2,1-fachen von Personen ohne Abschluss mit gleicher Erfahrung, was sich mit den aus der EVS 2003 generierten Werten deckt. Auch fällt der Unterschied zwischen Universitäts- und Fachhochschulabsolventen bei innen stärker aus als bei Bellmann, Reinberg und Tessaring (1994). Für letztere nennen sie eine Einkommensrelation von knapp 2,0, was den hier bestimmten Wert von 1,86 $\left(=e^{0,6224}\right)$ leicht übersteigt. Zwei Punkte sind aus diesen beiden Untersuchungen festzuhalten: Erstens deutet die Entwicklung der Parameter über die Stichprobenjahre bei Bellmann, Reinberg und Tessaring (1994) auf keine gravierenden Verschiebungen der qualifikationsabhängigen Einkommensverteilungen zwischen 1976 und $1987 \mathrm{hin}$. Zweitens legen die von Weißhuhn und Clement (1982) gewonnenen Parameter nahe, dass die auf Daten aus dem Jahr 2003 basierenden Werte auch für die 1970er Jahre die Relationen der Einkommen von Personen mit unterschiedlichen Abschlüssen geeignet abbilden. Beide Aspekte unterstützen die Vorgehensweise, die aus der EVS 2003 gewonnenen Werte als zeitlich invariant zu unterstellen.

\footnotetext{
Bellmann, Reinberg, Tessaring (1994), S. 56

Bellmann, Reinberg, Tessaring (1994), S. $43 f$

Weißhuhn, Clement (1982), S. 40
} 
Auch Lauer und Steiner (2000) gehen der Frage der zeitlichen Entwicklung von Bildungsrenditen nach. Als wesentliches Teilergebnis konstatieren sie bemerkenswert stabil gebliebene Renditen in den Jahren von 1984 bis 1997 von rund $8 \%$ bei Männern und $10 \%$ bei Frauen (jeweils je Ausbildungsjahr), wenngleich umfassendere Modellspezifikationen recht markante Unterschiede zwischen verschiedenen Teilgruppen aufzeigen ( $u$. a. Voll- gegenüber Teilzeit, öffentlicher und privater Sektor). ${ }^{22}$ Ihre dem hier geschätzten Parameter $\beta_{U n i}=0,7642$ vergleichbaren Werte bewegen sich zwischen 0,659 (1997) und 0,792 $(1987,1993)$ bei Männern, bei Frauen zwischen 0,794 (1997) und 0,946 (1990). ${ }^{23}$ Eine systematische Auf- oder Abwärtsbewegung im Zeitverlauf ist nicht auszumachen. Die aus der EVS 2003 abgeleitete Bildungsrendite für Universitätsabsolventen liegt damit innerhalb des Intervalls, das sich nach Lauer und Steiner (2000) für Männer in den 1980er und 1990er Jahren ergibt. Bei Fachhochschülern ergibt sich ein gleichartiger Befund.

Bellmann und Gartner (2003) hingegen finden „eine Zunahme der Prämien für Bildungsabschlüsse" in den 1990er Jahren, besonders bei akademischen Abschlüssen. ${ }^{24}$ Das Problem der zensierten Beobachtungen lösen sie, indem sie ein TobitModell statt eines linearen Modells wählten. Neben diesem methodischen Unterschied behindern auch inhaltliche Abweichungen einen direkten Vergleich ihrer Ergebnisse mit den aus der EVS 2003 abgeleiteten Parametern (Bellmann und Gartner weisen getrennte Ergebnisse für West- und Ostdeutschland aus und nehmen zusätzlich die dritte Potenz der Berufserfahrung als erklärende Variable auf). Die von innen angegebenen Bildungsrenditen liegen jedoch grundsätzlich in einer mit den hier präsentierten Parametern zu vereinbarenden Größenordnung. Für Universitätsabsolventen in Westdeutschland reicht die Spanne der Parameter von 0,71 (1992) bis 0,8211 (2000), die Renditen für Ostdeutschland liegen auf etwas geringerem Niveau. $\beta_{\text {Uni }}=0,7642$ entspricht annähernd dem Mittelwert der beiden für Westdeutschland genannten Werte. Bei Fachhochschulabsolventen ergibt sich ein ähnlicher Befund.

Insgesamt zeigen Vergleiche der aus der EVS 2003 gewonnenen Parameter mit anderen Untersuchungen, die Jahre von 1974 bis 2000 abdecken, dass sie geeignet wirken, die qualifikationsabhängigen Einkommensrelationen bis in die Mitte der 1970 er Jahre zurück relativ angemessen zu beschreiben. Demnach ist von der recht strikt anmutenden Annahme zeitlich invarianter Parameter keine wesentliche Beeinträchtigung der empirischen Aussagekraft der auf ihr beruhenden Ergebnisse zu erwarten. Für weiter zurück liegende Jahre muss diese Annahme mangels entsprechender Vergleichsmöglichkeiten hingegen ungeprüft bleiben. Auf einen Vorteil identischer qualifikationsabhängiger Lebenseinkommensverläufe verschiedener Kohorten ist noch hinzuweisen: Diese ceteris paribus-Bedingung führt zu Kohorten, die sich nicht in ihren relativen Markteinkommen unterscheiden. Abweichungen ihrer verfügbaren Einkommen beschränken sich damit auf den isolierten Einfluss des SteuerTransfer-Systems, der im Fokus der Betrachtung steht. ${ }^{25}$

22 Lauer, Steiner (2000), S. 1

23 Lauer, Steiner (2000), S. $27 \mathrm{f}$

24 Bellmann, Gartner (2003), S. 505

25 Auf eine verbleibende mögliche empirische Unzulänglichkeit dieses Ansatzes soll noch hingewiesen werden: Die für verschiedene Zeitpunkte festgestellte näherungsweise Übereinstimmung von qualifikationsabhängigen Alters-Einkommens-Profilen schließt nicht aus, dass bei 


\subsection{Qualifikationswandel und Korrektur von Lebenseinkommens- profilen}

Die Lebenszyklusbetrachtungen im zweiten Teil dieser Arbeit beruhen regelmäßig auf den Einkommensprofilen der soeben beschriebenen Form, wonach die qualifikationsspezifischen Verläufe und Durchschnittswerte unabhängig vom Geburtsjahr sind. Allerdings bringt dieser Ansatz ein mögliches Problem mit sich, das vorrangig Ergebnisse zur Rentabilität von Humankapitalinvestitionen beeinträchtigt. Im Kapitel zu Bildungsrenditen im zweiten Teil der Arbeit werden daher ergänzend korrigierte Einkommensprofile betrachtet, deren Herleitung hier vorgestellt wird.

Die vorangegangenen Ausführungen sollten Belege für recht stabile Einkommensrelationen der einzelnen Qualifikationsstufen liefern. Nicht gewährleistet ist indessen, dass konstante relative Lebenseinkommensprofile verschiedener Kohorten das Einkommensniveau zu unterschiedlichen Zeitpunkten reproduzieren, wie folgende Überlegungen illustrieren sollen: Das Durchschnittsentgelt, das grundsätzlich dem Mittelwert der Bruttoeinkommen eines Jahres entspricht, ergibt sich nach der MincerFunktion als mit der gemeinsamen Verteilung von Erfahrung und Qualifikation gewichteter Mittelwert der individuellen Einkommen. ${ }^{26}$ Die Kalibrierung der Lebenseinkommensverläufe verschiedener Kohorten über das Durchschnittsentgelt impliziert nun, dass die Alters-Qualifikations-Struktur der Erwerbstätigen verschiedener Jahre konstant ist. Im Jahr 2003, für das von einem Anteil der Personen ohne beruflichen Abschluss an den Erwerbstätigen von unter 15\% auszugehen ist, liegt deren geschätztes durchschnittliches Einkommen bei unter $80 \%$ des Durchschnittsentgelts. Wenn sich für Universitätsabsolventen in etwa der doppelte Wert ergibt, folgt für diese entsprechend ein Durchschnitt von rund $160 \%$. In einem fiktiven früheren Jahr, in dem fast die Gesamtheit der Erwerbstätigen über keinen Abschluss verfügt, würde sich -bei identischer Altersverteilung- auf der Grundlage der Parameter des Jahres 2003 ein geschätztes Durchschnittsentgelt $\hat{d}_{t}$ der gesamten Volkswirtschaft ergeben, das nur rund $80 \%$ des tatsächlichen Werts beträgt. Auch wenn die qualifikationsspezifischen Einkommensrelationen in diesem fiktiven Jahr denen des Jahres 2003 gleichen, wird das Einkommensniveau systematisch unterschätzt, da der Gesamtdurchschnitt nahezu demjenigen der Personen ohne Abschluss entspricht. Würde stattdessen dieselbe Mincer-Funktion auf der Grundlage von Daten dieses hypothetischen Jahres geschätzt, müsste für Personen ohne Abschluss ein durchschnittliches Einkommen in Höhe von $100 \%$ des Durchschnittsentgelts resultieren, für Universitätsabsolventen ceteris paribus von $200 \%$. Die Annahme gleicher qualifikationsspezifischer Einkommensrelationen gilt zwar weiterhin, das Einkommensniveau der Gesamtwirtschaft dieses Jahres liegt jedoch höher, als die Parameter des Jahres 2003 implizieren.

Längsschnittanalysen Kohorteneffekte auftreten. Erklärungsansätze hierfür können divergierende Kohortengrößen und Qualifikationsstrukturen von Kohorten sein, so dass ungleiche Knappheiten für verschiedene Alter und Alters-Qualifikations-Kombinationen existieren, aus denen sich kohortenspezifische Bildungsrenditen ableiten lassen. (S .Boockmann, Steiner (2000), S. 2ff)

26 In der folgenden Argumentation wird vereinfachend vom Alter statt von der Erfahrung gesprochen. Eine formale Darstellung enthält der Anhang A1 (Korrekturfaktor für Lebenseinkommensprofile). 
Dieses fiktive Jahr hat zwar in der Geschichte der Bundesrepublik nicht existiert, dennoch hat sich die Qualifikationsstruktur der Erwerbstätigen seit den 50er Jahren des 20. Jahrhunderts, als bis zu $50 \%$ formal unqualifiziert waren, massiv verbessert. Für Brutto-Bildungsrenditen, bei denen nur die Verteilung der Erwerbseinkommen betrachtet wird, ist eine daraus resultierende Niveauverzerrung weniger relevant. Renditen, die sich auf das aus Modellrechnungen abgeleitete verfügbare Einkommen beziehen, werden bei einem progressiven Steuersystem indessen um so stärker systematisch überschätzt, je weiter das Qualifikationsniveau unter dem des Basisjahres 2003 liegt. Eine Relation qualifikationsspezifischer Einkommen vor Steuern von beispielsweise 2,0 kann -je nachdem, ob es sich um einen Gering- und einen Normalverdienst oder um einen Normal- und einen Hochverdienst handelt- zu nennenswerten Unterschieden der Relationen der verfügbaren Einkommen führen. Um hierauf zurückgehende Verzerrungen beim Vergleich verschiedener empirisch gestützter Kohorten zu verhindern, bedarf es demnach einer Korrektur des Einkommensniveaus zu verschiedenen Zeitpunkten, die Abweichungen von der Qualifikationsund Altersstruktur des Basisjahres 2003 berücksichtigt. Anders ausgedrückt ist die bei Mincer-Schätzungen üblicherweise nicht weiter beachtete Konstante $\beta_{0}$ für die hier gewählte Form intertemporaler Vergleiche anzupassen.

Abbildung 7 zeigt die Qualifikationsstruktur der Erwerbstätigen für einige Jahre zwischen 1957 und 2003. Auf Grund verschiedener Diskrepanzen bei Abgrenzung und Aggregation einzelner Qualifikationen sind zeitliche Vergleiche nur eingeschränkt möglich. Es zeichnet sich jedoch eine wesentliche Verschiebung der Anteile einzelner Qualifikationsniveaus im Zeitverlauf ab, bei der der Rückgang formal nicht Qualifizierter und die Zunahme von akademischen Abschlüssen hervorstechen. Der Anteil von Universitätsabsolventen an den Erwerbstätigen hat sich zwischen 1964 und 2003 von rund $3 \%$ auf über $10 \%$ mehr als verdreifacht. Etwa $40 \%$ bis $50 \%$ der Erwerbstätigen verfügten bis 1964 über keinen beruflichen Abschluss, seitdem ist ihr Anteil kontinuierlich auf rund 13\% im Jahre 2003 zurückgegangen. Dominierend ist fast durchgängig der hier als "Lehre" charakterisierte Abschluss, dessen Anteil bis in die 1970 er bei etwa $40 \%$ bis $50 \%$ lag und seitdem auf bis zu $60 \%$ anstieg. Aus den verfügbaren Daten, die bis in die Mitte der 1970er Jahre nur sehr grob gegliedert und recht undifferenziert sind, wurde eine kontinuierliche Zeitreihe der Qualifikationsstruktur in der hier getroffenen Abgrenzung der Abschlussarten abgeleitet. Neben den in Abbildung 7 dargestellten Stützjahren wurden weitere Werte aus den zu Abbildung 7 genannten Quellen herangezogen; für den Zeitraum ab 1996 wurde die Qualifikationsstruktur auf der Grundlage der Mikrozensen berechnet. Für Jahre vor 1957 wurde die Qualifikationsstruktur 1957 als konstant gesetzt, im Zeitraum danach wurden fehlende Werte linear interpoliert. Ab 1976 liegen Ausgangswerte mit maximal zweijährigen Abständen vor. 
Abbildung 7: Qualifikationsstrukturen der Erwerbstätigen zwischen 1957 und 2003 (Früheres Bundesgebiet)

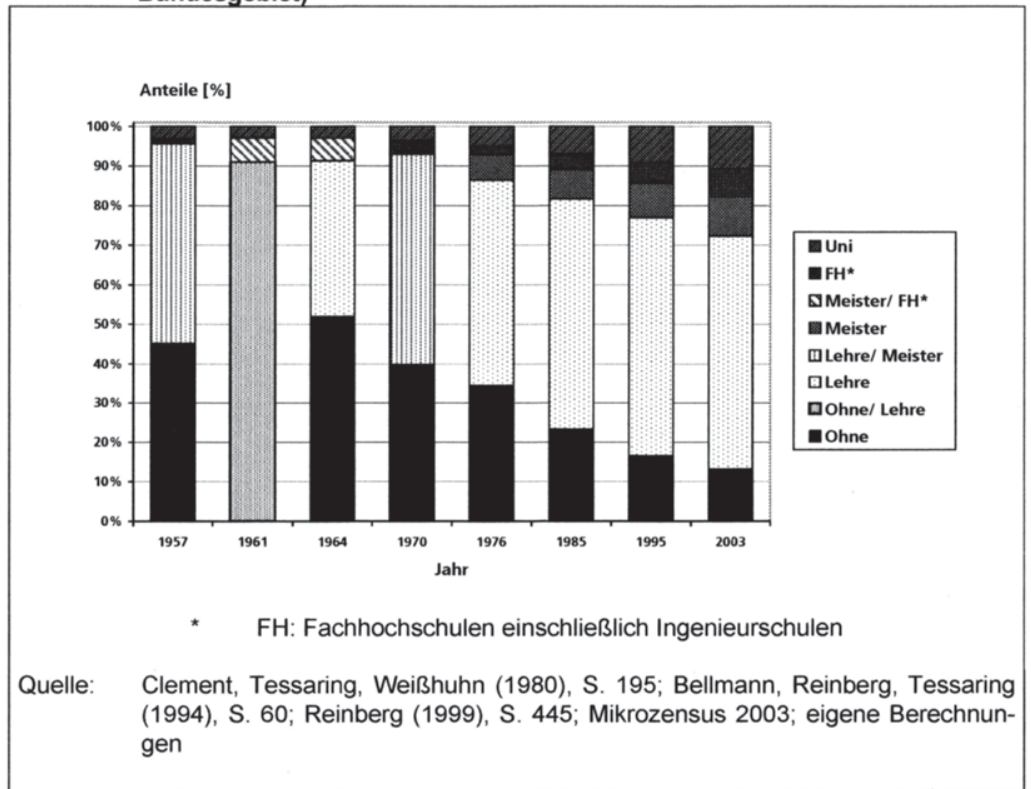

Abbildung 8: Interpolierte Qualifikationsstrukturen 1950 bis 2003 (Früheres Bundesgebiet)

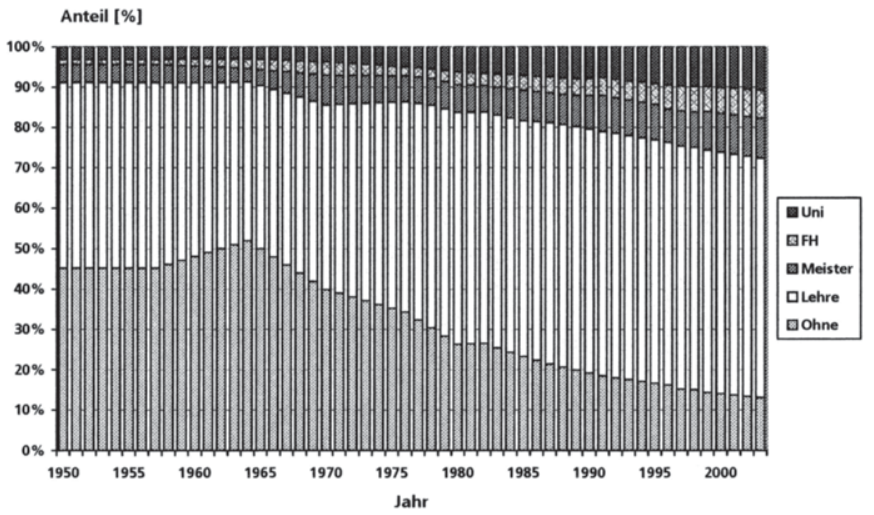

Quelle: wie Abbildung 7 ; Mikrozensus 1996-2003; eigene Berechnungen 
Die so unter zwangsläufig recht starken Vereinfachungen gewonnene, die wesentlichen Tendenzen aber enthaltende Zeitreihe gibt Abbildung 8 wieder, die eine Grundlage für die geforderte Niveaukorrektur bieten kann. Im Idealfall wäre nicht nur die Entwicklung der Qualifikationsstruktur bekannt sondern auch der gemeinsamen Alters- und Qualifikationsstruktur. Da aber bereits erstere nur mit Unsicherheit bestimmbar ist und für letztere insbesondere vor 1976 kaum valide Anhaltspunkte vorliegen, soll im Folgenden eine Korrekturmöglichkeit auf der Basis der in Abbildung 8 gezeigten Qualifikationsverschiebung vorgestellt werden. Als Ursache des Korrekturbedarfs der nach dem Mincer-Modell geschätzten und mit dem Durchschnittsentgelt kalibrierten Einkommen früherer Jahre wird hier ausschließlich auf die gewandelte Qualifikationsstruktur Bezug genommen, vereinfachend wird von der Altersstruktur abstrahiert. Grundsätzlich wird ein korrigiertes geschätztes Bruttoeinkommen $\hat{b}^{k}(q, t, j)$ in Abhängigkeit von Qualifikation $q$, Kalenderjahr $t$ und Geburtsjahr j gesucht, das das Ausmaß der Abweichung der Qualifikationsstruktur in $t$ von der des Basisjahres 2003 quantifiziert:

$\hat{b}^{h}(q, t, j)=k(t) * \hat{b}(q, t, j)$

$k(t)$ ist dabei der gesuchte Korrekturfaktor, bzw. in der Notation der MincerGleichung gilt $\beta_{0}{ }^{k}=\beta_{0}+\ln (k(t))$. Als Lösung ergibt sich: ${ }^{27}$

$$
k(t)=\frac{\sum_{q=1}^{5} r_{4}{ }^{*} w(2003, q)}{\sum_{4=1}^{5} r_{4}{ }^{*} w(t, q)}
$$

$$
\begin{aligned}
& \text { mit } r_{q} \quad \text { "Bildungsrendite" von Qualifikation q } \\
& w(t, q) \quad \text { Anteil von Qualifikation } q \text { an den Erwerbstätigen im Jahr } t
\end{aligned}
$$

Der Faktor entspricht damit der mit den Einkommensrelationen der Abschlüsse gewichteten Qualifikationsstruktur im Verhältnis zum entsprechenden Wert des Jahres 2003. Zur Herleitung von $k(t)$ wurde neben der bereits oben diskutierten Annahme zeitlich invarianter Bildungsrenditen der geschätzten Mincer-Gleichung die Einkommensneutralität der Entwicklung der Altersstruktur unterstellt. Entsprechend ist $k(t)$ in dieser Form sicherlich nur begrenzt geeignet, die Einkommensverteilung im Zeitverlauf empirisch zu beschreiben, sollte jedoch eine verbesserte Anpassung der konstruierten Lebenseinkommensprofile an beobachtbare Werte bieten. Abbildung 9 zeigt die zeitliche Entwicklung des Korrekturfaktors, die derjenigen der Qualifikationsstruktur folgt. Die korrigierten Einkommen $\hat{b}^{k}(q, t, j)$ entsprechen bis in die Mitte der 1960er Jahre etwa dem 1,17- bis 1,19-fachen ihrer unkorrigierten Partnereinkommen (ein unkorrigiertes geschätztes Einkommen in Höhe des Durchschnittsentgelts beispielsweise entspricht also einem korrigierten Wert von rund $118 \%$ des Durchschnittsentgelts). Danach fällt der Korrekturfaktor weitgehend linear, bis er im Jahr

27 Zur Herleitung von $k(t)$ und den dazu getroffenen Annahmen siehe Anhang A1 (Korrekturfaktor für Lebenseinkommensprofile). 
2003 definitionsgemäß 1,0 beträgt. Generell wäre für zukünftige Einkommen ebenfalls eine analoge Korrektur möglich. Bei einer weiteren Verbesserung der Qualifikationsstruktur würden dann Werte von unter 1,0 resultieren. Da einerseits aber weniger starke Veränderungen als in der Vergangenheit zu erwarten sind und andererseits dazu zusätzlich ungesicherte Annahmen über die zukünftige Entwicklung erforderlich wären, wird hierauf verzichtet. Der Korrekturfaktor für Jahre ab 2003 entspricht damit 1,0, so dass die korrigierten Einkommen ab dann mit den unkorrigierten übereinstimmen.

Abbildung 9: Korrekturfaktor der geschätzten Einkommen in Abhängigkeit vom Kalenderjahr

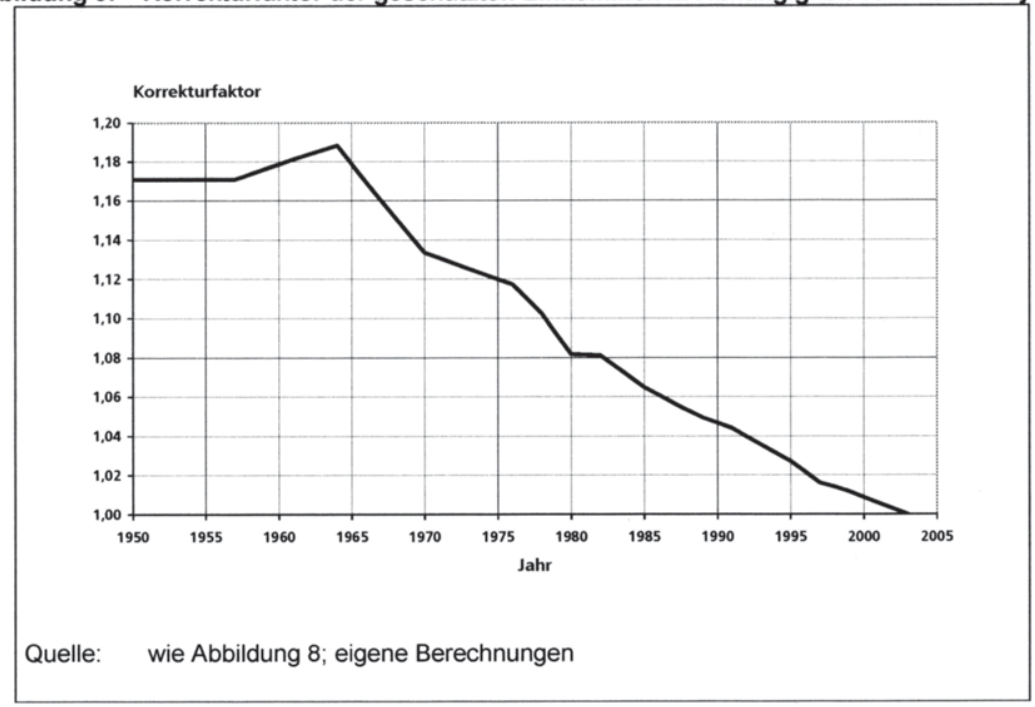

Die Wirkung der Einkommenskorrektur ist an Hand von Daten der Jahre 1964 und 1974, für die der Korrekturfaktor 1,19 bzw. 1,12 beträgt, in Abbildung 10 dargestellt. Von diesen beiden Jahren liegen nach Qualifikationen und Altersgruppen aufgeschlüsselte Durchschnittseinkommen vor, die neben den korrigierten und unkorrigierten geschätzten Alters-Einkommens-Profilen ebenfalls abgetragen sind.

Für das Jahr 1964 stammen die Vergleichswerte von Schmidt und Baumgarten (1967), die die Verteilung der Nettoeinkommen nach dem Mikrozensus 1964 untersuchten. Die für einen Vergleich mit den Schätzergebnissen wünschenswertere Verteilung der Bruttoerwerbseinkommen liegt nicht vor. Die für das Jahr 1974 publizierten Ergebnisse von Clement, Tessaring und Weißhuhn (1980) hingegen decken sich fast vollständig mit der hier getroffenen Abgrenzung der Substichprobe der EVS 2003: Sie betrachteten die Durchschnittseinkommen deutscher vollzeitbeschäftigter Arbeiter und Angestellter in der Beschäftigtenstatistik, wobei sie das Problem der zensierten Daten ähnlich wie Weißhuhn und Clement (1982) (s.o.) lösten. 
Abbildung 10: Geschätzte Einkommen ohne und mit Korrektur 1964 und 1974

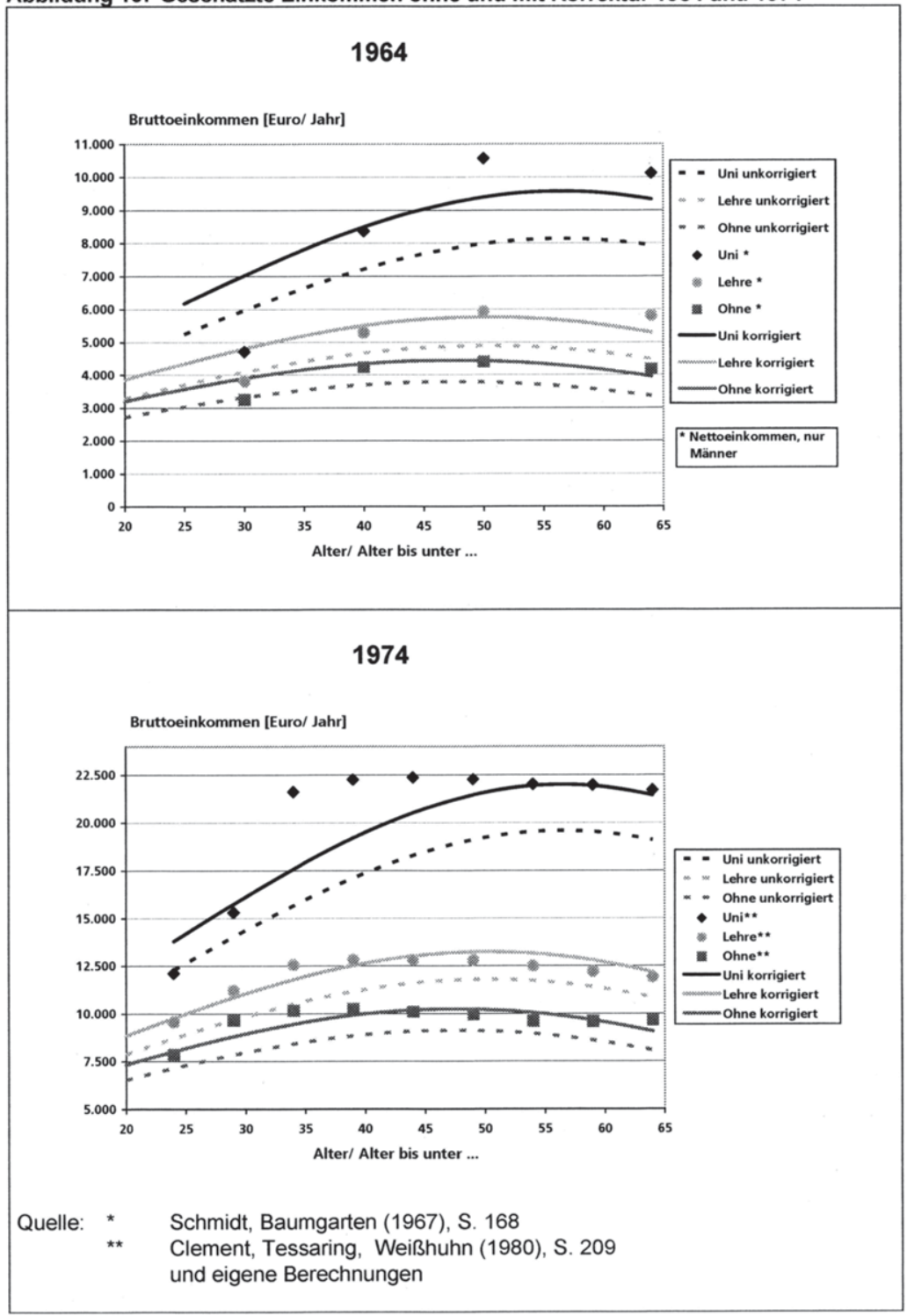


Für beide Jahre zeigt sich, dass die unkorrigierten Alters-Einkommens-Profile außer in den jüngsten Altersklassen durchgängig die Vergleichswerte unterschreiten. Für die korrigierten Profile zeichnet sich hingegen die erwartete bessere Anpassung an die damaligen Einkommensverteilungen ab. Insbesondere die Korrektur für das Jahr 1974, für das sich aus den Daten von Clement, Tessaring und Weißhuhn (1980) eine sehr gute Vergleichsmöglichkeit ergibt, stützt die Annahme, dass die gewählte Art der Korrektur eine verbesserte Anpassung an frühere Einkommensverteilungen bietet, ohne die tatsächlichen Verhältnisse zu überschätzen.

Im Weiteren werden zwei Arten von Lebenseinkommensprofilen für Kohortenvergleiche herangezogen: Erstens wird das Steuer-Transfer-System regelmäßig bei (unkorrigierten) Profilen angewandt, deren Jahreseinkommen sich aus den geschätzten Parametern der Mincer-Gleichung und der Zeitreihe der Durchschnittsentgelte ergeben. Auf diesen fußende Ergebnisse lassen sich als ceteris paribus-Vergleich verschiedener Einkommensniveaus auffassen, wobei höhere Einkommen mit höherer formaler Qualifikation einhergehen. Sie geben damit Aufschluss über intertemporale Unterschiede in den Längsschnittwirkungen des Steuer-Transfer-Systems bei gleichartigen Individuen verschiedener Geburtsjahre, wobei sich die Gleichartigkeit auf die relative Einkommensposition bezieht. Zweitens werden bei der Besprechung von Bildungsrenditen auch korrigierte Lebenseinkommensprofile betrachtet, bei denen die relativen Einkommenspositionen im Zeitverlauf konstant sind, die Einkommensniveaus hingegen nicht. Sie bieten demnach nicht den Vorteil, den isolierten Einfluss verschiedener Gesetzesstände abzubilden. Stattdessen zeichnen sie sich dadurch aus, die im Zeitverlauf nicht konstanten Einkommensniveaus der betrachteten Abschlüsse empirisch besser zu erfassen. 


\section{Steuern und Transfers: Entwicklungen seit 1950}

Die im Steuer-Transfer-Rechner als Hauptmodul des STM erfassten Regelungen seit 1950 sind in den folgenden Unterkapiteln dokumentiert. Abrisse der historischen Entwicklung mit ihren wesentlichen Rechtsänderungen werden dabei um vergleichende Querschnitte ergänzt, die mit dem Steuer-Transfer-Rechner berechnet wurden. Mit der Darstellung sollen die sich effektiv ergebenden Wirkungen unter Berücksichtigung der Einkommensentwicklung herausgearbeitet werden. Zum einen handelt es sich bei den folgenden Unterkapiteln damit um in sich geschlossene Darstellungen einzelner Teilbereiche des Steuer-Transfer-Systems, in denen der zeitliche Verlauf von $\mathrm{Be}$ - und Entlastungen nachvollzogen wird. Zum anderen wird in Hinblick auf die Längsschnittbetrachtungen im zweiten Teil das Ziel verfolgt, dessen bisweilen stark verdichtete Ergebnisse besser nachvollziehbar zu machen. Entsprechend werden Hinweise gegeben, wie sich einzelne Rechtsänderungen auf die betrachteten Kohorten von 1930 bis 1990 unterschiedlich auswirken.

\subsection{Sozialversicherungsbeiträge}

Neben Einkommensteuer und Zuschlagsteuern bilden die Beiträge zur Sozialversicherung die in der Analyse der Steuer-Transfer-Systems abgebildeten Belastungen. Von der Leistungsseite der Sozialversicherung werden ausschließlich die Renten der gesetzlichen Rentenversicherung betrachtet, die endogen berechnet und später dargestellt werden. Die Höhe der individuellen Sozialversicherungsbeiträge bestimmt sich seit 1950 durchgehend aus den beitragspflichtigen Einkommen, den Beitragssätzen und den Beitragsbemessungsgrenzen. Als beitragspflichtige Einkommen ergeben sich im STM Erwerbseinkommen von Arbeitnehmern und Renten aus der gesetzlichen Rentenversicherung. Die Beitragsbemessungsgrenzen, die den Höchstbetrag des der Abgabenpflicht unterliegenden Einkommens markieren, decken sich im Bereich der Krankenversicherung meist mit der Versicherungspflichtgrenze, bei deren Überschreiten ein Austritt aus der gesetzlichen Krankenversicherung zulässig ist. Im STM wird diese Option nicht berücksichtigt, betrachtete Fälle gelten stets als gesetzlich versichert. Auch Sonderregelungen der jüngeren Vergangenheit zu geminderten Sozialversicherungsbeiträgen bei niedrigen Einkommen (so genannte Mini- und Midi-Jobs mit monatlichen Bruttolöhnen von bis zu 400 bzw. 800 Euro) kennt das Modell nicht, da sich diese bei den betrachteten Arbeitsverhältnissen und daraus resultierenden Einkommensniveaus (in der Regel Vollzeiterwerbstätigkeit) nicht auswirken. Bei vier das Bruttoerwerbseinkommen belastenden Zweigen der Sozialversicherung (Kranken-, Pflege-, Arbeitslosen- und Rentenversicherung), von denen zwei auch eine Beitragspflicht bei Rentenbezug begründen (Kranken- und Pflegeversicherung) ergeben sich die Sozialversicherungsbeiträge SV im STM demgemäß durchgängig in der Form: 


$$
\begin{aligned}
& S V=\sum_{i=1}^{4}\left(s_{i}{ }^{4}+z_{i}\right)^{*} \operatorname{Min}\left(b^{4}, b m g_{i}\right)+\sum_{z=1}^{2}\left(s_{i}^{R}+z_{i}\right)^{*} \operatorname{Min}\left(b^{R}, b m g_{i}\right) \\
& \text { mit } \quad s_{i} \quad \text { Beitragssatz zu Versicherung } i \\
& \text { b beitragspflichtige Einnahmen } \\
& \text { wobei } A / R \quad \text { Arbeiter und Angestellte/ Rentner } \\
& z_{i} \quad \text { Zuschläge zum Beitragssatz von Versicherung } i \\
& b_{m g} \quad \text { Beitragsbemessungsgrenze von Versicherung } i
\end{aligned}
$$

Zuschläge $z_{i}$ existieren erst seit 2005 und umfassen zum einen den Pflegeversicherungszuschlag für Kinderlose und den Zusatzbeitrag zur Krankenversicherung für Zahnersatz. Ersterer beträgt $0,25 \%$, ist von Kinderlosen ab 23 Jahren zu entrichten und folgt einer Vorgabe des Bundesverfassungsgerichts, die Pflegeversicherungsbeiträge von Eltern und Kinderlosen zu differenzieren ${ }^{28}$ Mit letzterem entspricht seit Juli 2005, als von der vormals paritätischen Finanzierung der gesetzlichen Krankenversicherung durch Arbeitgeber und -nehmer abgewichen wurde, der vom Arbeitnehmer zu tragende Anteil an den Beiträgen zur Krankenversicherung nicht mehr dem halben Beitragssatz der jeweiligen Kasse. Der Zusatzbeitrag wird in Form eines zusätzlichen und nur vom Arbeitnehmer zu tragenden Beitragssatzes in Höhe von $0,9 \%$ erhoben. ${ }^{29}$

Eine von den Bruttorenten abzuführende Eigenbeteiligung der Rentner an ihren Krankenversicherungsbeiträgen wurde erstmals mit dem HBeglG 1983 begründet. Ab Juli 1983 wurden Beitragssätze von zunächst 1\% eingeführt, die bis 1996 stufenweise auf bis zu 6,7\% angehoben wurden. Seit 1997 entspricht der Beitragssatz der Rentner dem allgemeinen Satz ihrer Versicherung und stimmt damit mit dem von Erwerbseinkommen zu entrichtenden Anteil überein. ${ }^{30}$ Bei Einführung der gesetzlichen Pflegeversicherung 1995 wurden auch Renten der Beitragspflicht unterworfen. Bis zum Ende des ersten Quartals 2004 wurde der halbe allgemeine Beitragssatz, der seit 1997 durchgängig 1,7\% beträgt, von der Bruttorente einbehalten. Seitdem wird der gesamte Pflegeversicherungsbeitrag von der Bruttorente abgeführt, womit zur Konsolidierung der bis dahin die andere Hälfte tragenden Rentenversicherung beigetragen werden soll.

Der weitgehend monotone Anstieg der Summe der Beitragssätze zu den Sozialversicherungszweigen (Abbildung 11), kombiniert mit auf die zukünftige demographische Entwicklung gestützten Prognosen weiterer Steigerungen, zählt zu den wesentlichen Grundlagen in der Diskussion um die Zukunft der sozialen Sicherungssysteme und um eine gerechte Lastenverteilung zwischen Generationen. In der Abbildung sind für die Renten-, Arbeitslosen- und Pflegeversicherung die gesetzlich

28 S. Deutscher Bundestag (2004a). Vgl. kritisch hierzu Wagner (2002), S. $43 f$

29 Nach dem Gesetz zur Anpassung der Finanzierung von Zahnersatz vom 15.12.2004 (BGBI I S 3445) müssen seit dem 01.07.2005 die Mitglieder der gesetzlichen Krankenversicherungen diesen Zusatzbeitrag entrichten. Auf Grund der zeitgleichen Verpflichtung der Versicherungen, ihre Beitragssätze um ebenfalls $0,9 \%$ abzusenken, wurden Arbeitnehmer effektiv um $0,45 \%$ stärker belastet als zuvor, Arbeitgeber wurden im selben Umfang entlastet. Vgl. Sachverständigenrat zur Begutachtung der gesamtwirtschaftlichen Entwicklung (2005), S. 73

30 S. zur Beitragssatzentwicklung in der Kranken- und Pflegeversicherung der Rentner: Bundesministerium für Gesundheit und Soziale Sicherung (Hrsg.) (2005), S. 338ff; Verband deutscher Rentenversicherungsträger (2005), S. 11 
festgeschriebenen Beitragssätze wiedergegeben, für die Krankenversicherung durchschnittliche Werte (bei Pflege- und Krankenversicherung ohne die beiden genannten Zuschläge). Die Gesamtbeitragssätze (einschließlich Arbeitgeberanteile) entsprechen durchgehend dem Doppelten der dargestellten Arbeitnehmeranteile. ${ }^{31}$

Abbildung 11: Beitragssätze der Sozialversicherung 1950 bis 2007 (Arbeitnehmeranteile, früheres Bundesgebiet)

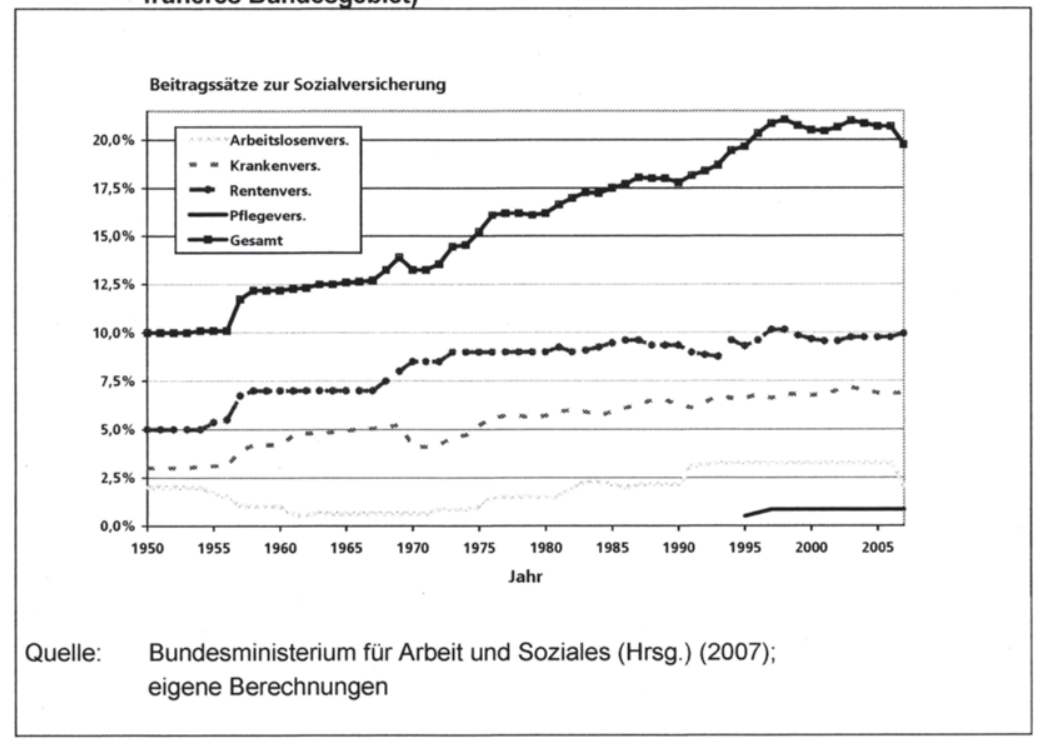

Die stärksten Anhebungen des Beitragssatzes zur Rentenversicherung der Arbeiter und Angestellten sind in den Jahren 1957 (von 5,5\% auf 7,0\%) und 1968 bis 1973 (sukzessive von $7,0 \%$ auf 9,0\%) zu verzeichnen. ${ }^{32}$ Zwischen 1973 und 1980 blieb der Satz stabil, danach ergaben sich verschiedene Erhöhungen und Senkungen, die insgesamt zu einer Aufwärtsbewegung führten. Der Beitragssatz schwankte zwischen $8,75 \%$ und 10,15\%, seit 2007 liegt er bei 9,95\%, knapp unter dem Zweifachen des bis 1954 gültigen Ursprungswerts von 5,0\%. Die durchschnittlichen Beitragssätze der Krankenversicherung sind ab 1957 meist jährlich gestiegen. Der starke Rückgang 1970 von $5,25 \%$ auf $4,1 \%$ ist vornehmlich auf das Inkraftreten des Lohnfortzahlungsgesetzes zurückzuführen, durch das Zahlungen an krankheitsbedingt arbeitsunfähige Arbeitnehmer verstärkt von den Arbeitgebern statt von den Krankenversicherungen zu leisten waren. ${ }^{33}$ Zwischen 1950 und 1969 stieg der durchschnitt-

31 Die der Abbildung zu Grunde liegenden Werte sind in Tabelle 23 im tabellarischen Anhang (Anhang A2) einsehbar.

32 Zur historischen Entwicklung von Rechtsänderungen im Bereich der Sozialversicherung s. Frerich, Frey (1996)

33 Mit dem Gesetz über die Fortzahlung des Arbeitsentgelts im Krankheitsfalle (Lohnfortzahlungsgesetz) vom 27. Juli 1969 (BGBI. I S. 946) wurden die Ansprüche von Arbeitern gegenüber dem Arbeitgeber weitgehend an die bis dahin nur für Angestellte bestehenden Regelungen angepasst. 
liche Beitragssatz von $3,0 \%$ auf $5,25 \%$, in den Jahren von 1970 bis 2005 von $4,1 \%$ auf $6,85 \%$, wobei zuletzt auch Änderungen des Leistungsumfangs die Entwicklung abdämpften.

Die Beitragssätze zur Arbeitslosenversicherung, die zu Beginn der 1950er Jahre bei $2,0 \%$ gelegen hatten, wurden in den Folgejahren auf bis zu jahresdurchschnittlich $0,5 \%$ gesenkt und verharrten auf einem ähnlich niedrigen Niveau bis in die 1970er Jahre hinein. Die stärksten Erhöhungen fielen in den Jahren 1975, 1982 (jeweils um $0,5 \%)$ und im Anschluss an die deutsche Wiedervereinigung $1991(1,0 \%)$ an. Senkungen oder Anhebungen des Beitragssatzes zur Arbeitslosenversicherung trafen wiederholt mit gegengerichteten Änderungen im Rentenbereich zusammen, eine Koinzidenz, die bei der Bewertung der Verteilungswirkungen der Rentenversicherung noch aufzugreifen sein wird. 2007 wurde der Beitragssatz zur Arbeitslosenversicherung zum Jahresbeginn von 3,25\% auf 2,1\% stark gesenkt (und ab 2008 auf $1,65 \%$ noch weiter herabgesetzt), gleichzeitig stieg der Beitragssatz zur Rentenversicherung leicht um 0,2 Prozentpunkte.

Insgesamt haben sich die Arbeitnehmerbeiträge zur Sozialversicherung von anfänglich $10,0 \%$ des Bruttoeinkommens auf bis zu rund $21 \%$ mehr als verdoppelt. Nach einem sprunghaften Anstieg 1957/58 auf 12,2\% und recht stabilen Sätzen in den 1960 er Jahren ist die weitere Entwicklung bis in die Mitte der 1990er Jahre, als in etwa das heutige Niveau erreicht wurde, von kontinuierlichen Zunahmen geprägt. Die Annahmen zur zukünftigen Entwicklung richten sich in dieser Arbeit im Rentenbereich nach den Projektionen der Nachhaltigkeitskommission („Rürup-Kommission"), wonach bis in die 2030er Jahre ein Anstieg des Beitragssatzes von derzeit 9,9\% auf etwa 11,5\% zu enwarten ist. Verschiedene Prognosen zur Entwicklung in den übrigen Sozialversicherungszweigen werden in Kapitel 9 (Nettobelastungen des Lebenseinkommens) im zweiten Teil diskutiert.

Im Gegensatz zu den Beitragssätzen wirken sich die Beitragsbemessungsgrenzen der Sozialversicherung nicht primär auf die intergenerative sondern auch auf die intragenerative Verteilung von Belastungen innerhalb des Kollektivs der Beitragszahler aus. Während bis zur Bemessungsgrenze Einkommen und Beiträge proportional sind, sinkt nach ihrem Überschreiten die durchschnittliche Belastung, wodurch die Sozialversicherung eine regressive Umverteilungskomponente enthält. Inwieweit durch die Bemessungsgrenzen eine geringere relative Belastung erfolgt als die Beitragssätze vermuten lassen, hängt von der Höhe der Bemessungsgrenzen in Relation zum Durchschnittsentgelt ab. Bis in die Mitte der 1970er Jahre, als die Bemessungsgrenzen noch nicht dynamisch an die Einkommensentwicklung angepasst wurden, ergaben sich bei hohen nominalen Einkommenssteigerungen wiederholt gravierende relative Rückgänge der Bemessungsgrenzen (Abbildung 12). ${ }^{34}$ So blieb etwa die Beitragsbemessungsgrenze der Arbeitslosenversicherung von 1957 bis 1966 unverändert bei 9.000 DM (4.602 Euro), während das Durchschnittsentgelt nominal um $96 \%$ anstieg. Damit entsprach die Bemessungsgrenze zu Beginn dieses Zeitraums 178\% des Durchschnittsentgelts, zu dessen Ende 91\%. Auch in der Krankenversicherung unterschritt die Bemessungsgrenze zeitweise das Durchschnittsent-

34 Für die entsprechenden Werte s. Tabelle 23 im tabellarischen Anhang (A2). Anfänglich stimmte die Bemessungsgrenze der Arbeitslosen- mit derjenigen der Krankenversicherung überein, ab 1970 wurde sie dem Wert der Rentenversicherung angepasst. 
gelt (1964, 1965 mit dem Tiefststand von knapp 86\%, 1968 und 1969). Seit den 1980er Jahren fallen die Schwankungen der Relationen von Bemessungsgrenzen und Durchschnittsentgelt geringer aus, nur noch für Bezieher deutlich überdurchschnittlicher Einkommen resultiert eine Kappung inrer Beiträge durch die Höchstwerte. In den 1960er Jahren und in der ersten Hälfte der 1970er Jahre hingegen ergaben sich bereits bei durchschnittlichen oder leicht überdurchschnittlichen Einkommen faktische Entlastungen durch die Beitragsbemessungsgrenzen. Inwieweit mit dem Überschreiten der Bemessungsgrenze zur Rentenversicherung, deren Leistungen vom STM abgebildet werden, eine Entlastung zu assoziieren ist, hängt von der später noch näher zu betrachtenden Renten-Beitrags-Relation ab.

Abbildung 12: Beitragsbemessungsgrenzen der Sozialversicherung in Relation zum Durchschnittsentgelt 1950 bis 2006 (früheres Bundesgebiet)

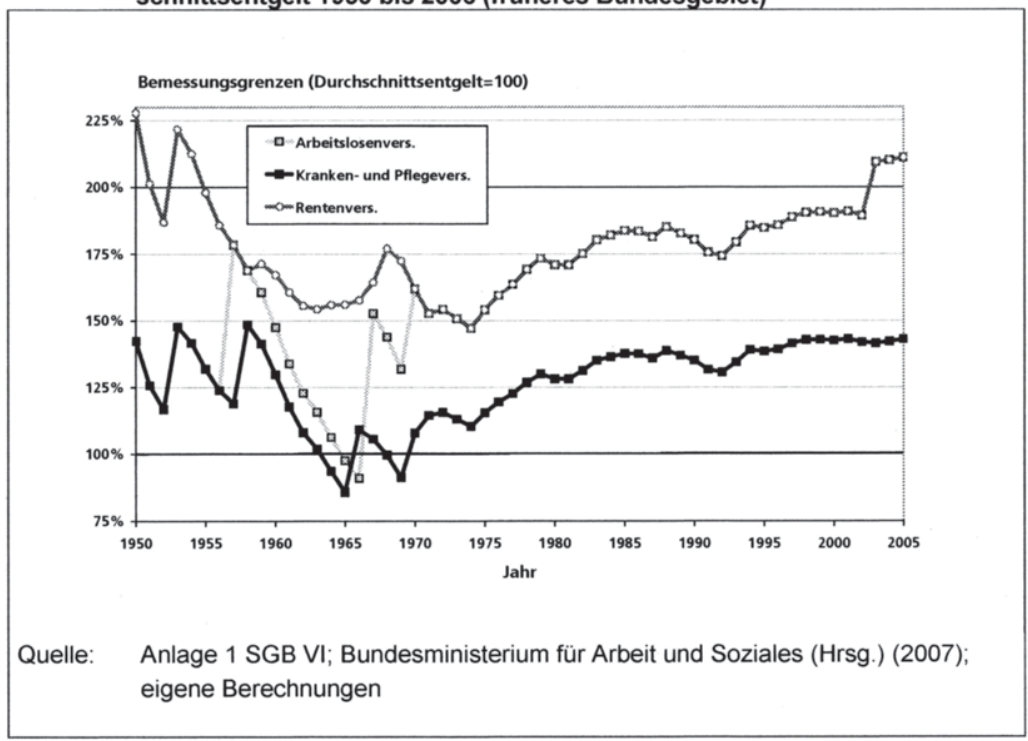

Die zeitliche Entwicklung der Beitragssätze zeigt letztlich eine deutliche Zunahme der Belastung der Einkommen durch Sozialversicherungsbeiträge. Die zusätzliche Betrachtung der Beitragsbemessungsgrenzen deutet darüber hinaus an, dass Bezieher hoher Einkommen aus jüngeren Kohorten davon doppelt betroffen sind: Neben den gestiegenen Beitragssätzen trifft sie die reale Anhebung der zu belastenden Höchstwerte, wobei die unstete Entwicklung in den 1950er und 1960er Jahren generellen Aussagen über das Ausmaß dieser doppelten Zunahme im Wege steht. 


\subsection{Einkommensteuer und Zuschlagsteuern}

In den folgenden Unterabschnitten werden einige wesentliche Änderungen bei der Einkommensbesteuerung seit 1950 und die aus der Einkommensteuer abgeleiteten Zuschlagsteuern betrachtet. Die Darstellung beschränkt sich auf die beiden im STM berücksichtigten Einkunftsarten

- Einkünfte aus nichtselbständiger Arbeit

- Renten der gesetzlichen Rentenversicherung als sonstige Einkünfte im Sinne des $§ 22$ EStG.

Nach einer kurzen Darstellung der verschiedenen Formen der Besteuerung von Ehepaaren und Familien werden die Tarife skizziert. Neben den Tarifen sind für die Steuerbelastung zu verschiedenen Zeitpunkten pauschale Abzugsbeträge bei der Ermittlung der Einkünfte, der Abzug von Sonderausgaben und außergewöhnlichen Belastungen und diverse Freibeträge ausschlaggebend, die im Zusammenhang mit den beiden Einkunftsarten besprochen werden. Die steuerliche Berücksichtigung von Kindern wird in einem eigenen Kapitel später aufgegriffen werden.

\subsubsection{Veranlagungsarten: Besteuerung von Ehegatten und Familien}

Die heute geltende Besteuerung von Ehegatten nach $\S 26$ EStG mit der Wahlmöglichkeit zwischen getrennter Veranlagung einerseits und Zusammenveranlagung unter Anwendung des Splittingtarifs ( $\$ 32$ a EStG) andererseits besteht im Wesentlichen seit 1958. Ursprünglich waren Ehegatten ausschließlich zusammen zu veranlagen, wobei die Einkünfte der beiden Partner zusammenzurechnen waren $(\S 26$ EStG 1951: Haushaltsbesteuerung: Ehegatten), ohne dass ein progressionsmilderndes Splitting vorgesehen war. ${ }^{35}$ Eine steuerliche Entlastung ergab sich aus dem in die damaligen Steuerklassen eingearbeiteten Ehefrauenfreibetrag (zwischen 1950 und 1956: 600 bis 900 DM (307 bis 460 Euro); 1957 einschließlich Hausfrauenfreibetrag bis zu 1.500 DM (767 Euro)), womit die Ehegattenbesteuerung einem typisierenden Realsplitting ähnelte, wie es heute bei getrennt lebenden Partnern angewendet werden kann. Da diese Form der Ehegattenbesteuerung bei einem progressiven Tarif zu einer Erhöhung der Steuerschuld als Folge der Eheschließung führen konnte, wurde $\S 26$ EStG 1951 als ehediskriminierend und damit verfassungswidrig verworfen; ab 1958 kannte das EStG einen Splittingtarif. Als Reaktion auf die Rechtssprechung räumte §26 EStG 1957 die Möglichkeit der rückwirkenden Neufestsetzung der Einkommensteuer unbeschränkt zusammen veranlagter Ehegatten für die Veranlagungszeiträume 1949 bis 1957 ein. ${ }^{36} \mathrm{Ob}$ aus der dabei ermöglichten getrennten Veranlagung, die den Verlust ehebedingter Abzugsbeträge mit sich brachte, eine geringere Steuerschuld resultiert, hängt von den Umständen des Falles ab.

35 Ausgenommen waren nach $§ 43$ EStDV lediglich „Einkünfte aus nichtselbständiger Arbeit der Ehefrau in einem dem Ehemann fremden Betrieb".

36 Vgl. Köhler (1958), S. 152 ff. 
Das STM geht bei Ehepaaren durchgängig von einer Zusammenveranlagung aus. Diese führt unter dem seit 1958 bestehenden Splittingtarif bei Partnern, die der von der Rechtssprechung angenommenen vollkommenen Wirtschaftsgemeinschaft entsprechen, regelmäßig zur Maximierung des gemeinsamen verfügbaren Einkommens. Die für die Jahre vor 1957 potenziell günstigere getrennte Veranlagung bleibt unberücksichtigt, womit die Steuerbelastung unter Umständen überzeichnet wird. Für die betrachteten Fälle sozialversicherungspflichtiger Arbeitnehmer ab Geburtsjahrgang 1930 wird hieraus jedoch kein wesentlicher Fehler erwartet: Erstens ist bei Einverdienerpaaren die Zusammenveranlagung vorteilhaft, zweitens unterliegen bei Doppelverdienern die Erwerbseinkünfte der Ehefrau nicht der Zusammenveranlagung (§ 43 EStDV 1951).

Eine zweite Form der Zusammenveranlagung, die durch die Rechtssprechung als Verstoß gegen den grundgesetzlichen Schutz von Ehe und Familie gewertet wurde, betrifft die Zuordnung der Einkünfte von Kindern eines Steuerpflichtigen. Letztmalig für den Veranlagungszeitraum 1964 sah § 27 EStG die Zusammenveranlagung eines Steuerpflichtigen mit seinen Kindern vor, soweit inm für diese Kinderfreibeträge nach $\S 32$ EStG zustanden. An die steuerliche Begünstigung durch einen Kinderfreibetrag knüpfte folglich die Pflicht der Zusammenveranlagung an, von der nur Einkünfte des Kindes aus nichtselbständiger Arbeit ausgeschlossen waren. Die von der damaligen Bundesregierung geäußerte Befürchtung, ohne die Zusammenveranlagung nach $\S 27$ EStG missbrauchsanfällige bürgerlich-rechtliche Gestaltungsmöglichkeiten zu eröffnen, indem Einkünfte leistungsfähigkeitsfremd auf Familienmitglieder aufgeteilt werden können, wurde gerichtlich als nicht hinreichend verworfen. ${ }^{37}$ Entsprechend entfiel § 27 EStG ab 1965, kompensierend wurde in § 32 EStG als Bedingung für die Gewährung des Kinderfreibetrags erstmals die Voraussetzung eingeführt, dass die eigenen Einkünfte und Bezüge eines volljährigen Kindes einen Grenzwert nicht überschreiten. Tatsächlich wurde die Option steuermindernder Übertragung von Einkünften, die vor allem bei Kapitaleinkünften gegeben erscheint, frühzeitig von der steuerberatenden Literatur aufgenommen. ${ }^{38}$

Für die bei den Berechnungen mit dem STM herangezogenen Fälle markiert die Rechtsänderung 1964/65 keine einschneidende Veränderung. Kinder erzielen dabei typisierend kein Einkommen oder nur geringes Erwerbseinkommen (Ausbildungsvergütungen), das bis 1964 aus der Zusammenveranlagung mit den Eltern ausscheidet und ab 1965 niedrig genug ist, um den Wegfall kindbedingter Entlastungen (Kinderfreibetrag, Kindergeld) bei höheren Einkünften oder Bezügen volljähriger Kinder zu vermeiden. ${ }^{39}$

37 Vgl. BVerfG-Beschluss vom 30. Juni 19641 BvL 16-25/62, BVerfGE 18, 97

38 Vgl. Dresdner Bank AG (Hrsg.) (1966), S. $120 f$

39 Zeitweise galt die Einschränkung bereits für Kinder nach Vollendung des 16. Lebensjahrs (vgl. das Unterkapitel zum Familienleistungsausgleich im engeren Sinne, Kapitel 4.3.1). Die Einkommensgrenze lag 1965 bei 7.200 DM (3.681 Euro) je Jahr und wurde bis 2005 wiederholt angehoben, zuletzt auf 7.680 Euro (§32 EStG). Ausbildungsvergütungen und Einkünfte aus Nebenerwerbstätigkeiten von Auszubildenden in üblichen Größenordnungen waren damit für die Gewährung von Kinderfreibeträgen überwiegend unschädlich. 


\subsubsection{Zuschlagsteuern}

Als auf die Einkommensteuer aufsetzende Zuschlagsteuern sind im STM die Ergänzungsabgabe (wirksam in den Veranlagungszeiträumen 1968 bis 1974), die Stabilitätszulage (wirksam 1973 und 1974) und der Solidaritätszuschlag (wirksam 1991, 1992 und seit 1995) abgebildet. ${ }^{40}$ Auf die Modellierung des in den Jahren 1970 und 1971 erhobenen Konjunkturzuschlags, der zur Preisniveaustabilisierung eingeführt und 1972 unverzinst zurückgezahlt wurde, wurde vereinfachend verzichtet, da von diesem nur marginale Mehrbelastungen ausgingen. ${ }^{41}$ Auch die sich nach der Einkommensteuer bemessende jedoch nicht staatlichem Abgabenzwang unterliegende Kirchensteuer bleibt im STM unberücksichtigt. Für alle drei unter dem Begriff Zuschlagsteuern zusammengefasste Steuerarten bildet grundsätzlich die veranlagte Einkommensteuer die Bemessungsgrundlage, eine Zusatzbelastung tritt jeweils erst bei Überschreiten von Freibeträgen ein. Bei Steuerpflichtigen, denen Kinderfreibeträge gewährt werden, gilt für den Solidaritätszuschlag seit Einführung des Optionsmodells beim Familienleistungsausgleich im Jahr 1996 abweichend die fiktive Einkommensteuer, die sich bei Abzug sämtlicher Kinderfreibeträge ergeben würde, als Bemessungsgrundlage (§ 3 Abs. 2 SolZG).

Während der Stabilitätszuschlag zur konjunkturellen Steuerung eingesetzt wurde, dienten die Ergänzungsabgabe und der Solidaritätszuschlag explizit der Erzielung von Mehreinnahmen, beim Solidaritätszuschlag insbesondere zur Deckung der Zusatzbelastungen durch die deutsche Wiedervereinigung. Die Ergänzungsabgabe betrug bei einem zu versteuernden Einkommen oberhalb von 16.020 DM (8.191 Euro, Verdoppelung bei Verheirateten) $3 \%$ der Einkommensteuer, der Stabilitätszuschlag von 5\% wurde bei einer Einkommensteuer ab 5.887 DM (3.010 Euro, Verdoppelung bei Verheirateten) fällig. ${ }^{42}$ Für den Solidaritätszuschlag galten seit 1991 verschiedene Berechnungsmodalitäten. Der Prozentsatz belief sich auf 3,75\% (1991, 1992), 7,5\% (1995-1997) bzw. 5,5\% (seit 1998). Seit 1995 besteht eine Freigrenze, zudem wirkt sich seitdem in unteren Einkommensbereichen eine Minderungsvorschrift aus, durch die nicht der volle Prozentsatz zur Anwendung gelangt ( $\$ 4$ SolZG).

40 Gesetz über eine Ergänzungsabgabe zur Einkommensteuer und zur Körperschaftsteuer - Ergänzungsabgabegesetz vom 21.12.1967 BGBL. I, S. 1254

Stabilitätszuschlaggesetz - StabZG vom 26. Juni 1973 BGBI I, S. 676

Eingeführt durch: Gesetz zur Einführung eines befristeten Solidaritätszuschlags und zur Änderung von Verbrauchsteuer- und anderen Gesetzen - Solidaritätsgesetz (SoIZG) vom 24.06.1991 BGBL I, S. 1318

41 Konjunkturzuschlagsgesetz vom 23.07.1970 BGBI I, S. 1125

42 Der volle Satz von $5 \%$ wurde erst ab einer Einkommensteuer von 3.895 Euro erhoben, darunter waren Sätze zwischen $0,5 \%$ und $4,5 \%$ zu entrichten. 


\subsubsection{Eckwerte des Einkommensteuertarifs}

In den Jahren von 1950 bis 1954 enthielt das EStG einen Stufentarif, innerhalb vorgegebener Einkommensklassen waren die Grenzsteuersätze konstant und betrugen $10 \%$ bis $95 \% .{ }^{43}$ Der 1955 eingeführte logarithmische Formeltarif mit bis zum Spitzensteuersatz streng monoton steigenden Grenzbelastungen ${ }^{44}$ wurde 1958 von einem linear-progressiven Tarif mit mehreren Proportional- und Progressionszonen abgelöst, an dem seither festgehalten wurde. Nach 1958 wurde der Tarif insgesamt fünfzehn mal geändert, davon achtmal seit $1996 .{ }^{45}$ Zur kurzen Charakterisierung der Tarife gibt Abbildung 13 die seit 1950 geltenden Grundfreibeträge wieder, Abbildung 14 zeigt die zu versteuernden Einkommen, ab denen der Spitzensteuersatz Anwendung findet. Auf die Darstellung der der maximalen Grenzbelastung unterliegenden Einkommen vor 1958, die einem Mehrfachen des 1958 geltenden Wertes entsprechen, wurde verzichtet. Neben den nominalen Beträgen sind für den intertemporalen Vergleich die Werte auch in konstanten Preisen und in Relation zum Durchschnittsentgelt der gesetzlichen Rentenversicherung des jeweiligen Jahres angegeben.

Der tarifliche Grundfreibetrag, der das Einsetzen der faktischen Steuerpflicht markiert, wurde seit 1950 unregelmäßig erhöht. Mit der Einkommensteuerreform 1958 wurde ein Grundfreibetrag von 1.680 DM (859 Euro) festgesetzt, der rund $31,5 \%$ des damaligen Durchschnittsentgelts entsprach. Bei einem bis 1975 unveränderten Grundfreibetrag, starken Einkommens- und moderaten Preisniveausteigerungen wurden niedrige Einkommen zunehmend von der Steuerpflicht erfasst. Von 1975 bis 1995 spiegelten wiederholte Anhebungen des Grundfreibetrags in etwa die Entwicklung von Löhnen und Preisen wider, der reale Grundfreibetrag blieb recht stabil und entsprach rund $11 \%$ bis $14 \%$ des Durchschnittsentgelts. Im Rahmen der Steuerreform 1996 wurde der Grundfreibetrag drastisch heraufgesetzt, um verfassungsgerichtliche Vorgaben zur Steuerfreistellung des Existenzminimums zu erfüllen. ${ }^{46}$ Mehrere Anpassungen danach bewirkten weitere geringfügige reale Entlastungen. Der Grundfreibetrag belief sich ab 1996 auf etwa 23\% bis 26\% des Durchschnittsentgelts.

Im Gegensatz zum Grundfreibetrag ist der untere Grenzwert der oberen Proportionalzone, von dem an der Spitzensteuersatz wirkt, seit 1958 nur einmal angehoben worden und liegt nach mehreren Absenkungen mit derzeit 52.152 Euro unter dem 1958 gültigen Wert (Abbildung 14). Die vertikale Differenzierung durch den Steuertarif im Bereich hoher und höchster Einkommen nahm im Betrachtungszeitraum damit beständig ab. Während der Spitzensteuersatz 1958 erst bei zu versteuernden Ein-

43 Ab 1951 galt nach § 32 Abs. 1 EStG als Einschränkung des maximalen Grenzsteuersatzes, dass der Durchschnittssteuersatz höchstens $80 \%$ beträgt. Zur Steuerberechnung bis 1954 vgl.: o.V. (1952)

44 Die Grenzbelastung nach dem logarithmischen Formeltarif hatte bei äußerst hohen Einkommen eine Sprungstelle, an der der Grenzsteuersatz von rund $63,5 \%$ auf $55 \%$ fiel. Zur Einkommensteuerberechnung unter dem logarithmischen Formeltarif vgl.: Beck'sche Textausgaben (1957)

45 Vgl. zur historischen Entwicklung der Einkommensteuertarife: Zimmerer (1996); Deutscher Bundestag (1997a), S. 11ff; Bundesministerium der Finanzen (2007a), S. 56

46 2 BvL 5, 8, 14/91 BVerfGE 87 
kommen in Höhe des 20,6-fachen des Durchschnittsentgelts anzuwenden war, greift er im Jahr 2005 bereits bei dessen 1,8-fachem Wert.

\section{Abbildung 13: Grundfreibetrag des EStG seit 1950}

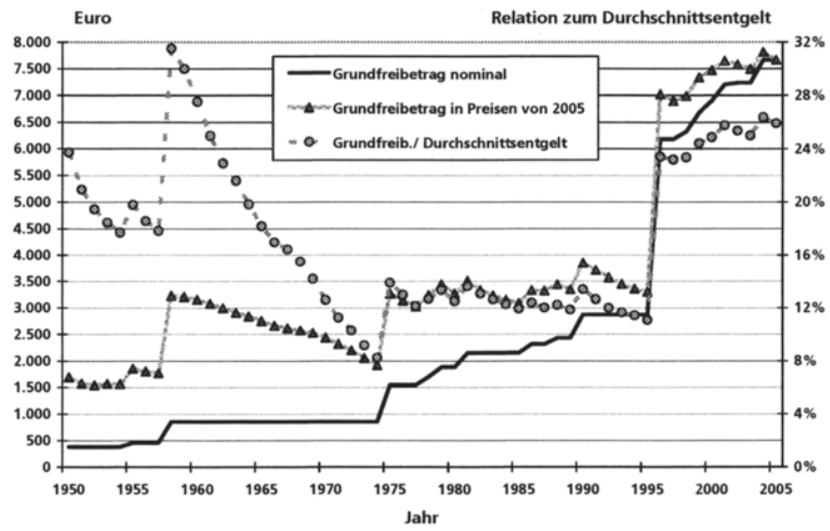

Quelle: EStG, SGB VI; eigene Berechnungen

Abbildung 14: Einsetzen des Spitzensteuersatzes des EStG 1958 bis 2005

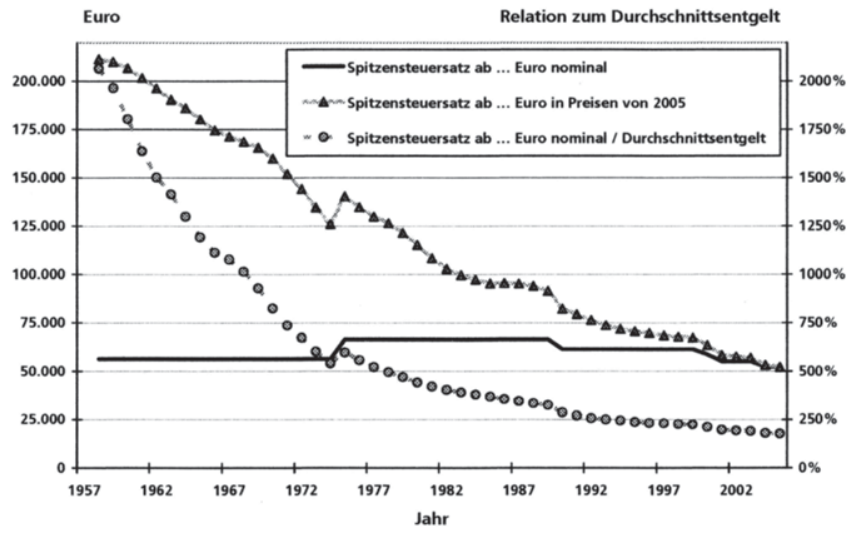

Quelle: EStG, SGB VI; eigene Berechnungen 


\subsubsection{Entwicklung der Steuerbelastung bei Beziehern von Einkünften aus nichtselbständiger Arbeit}

Während Grundfreibetrag und Spitzensteuersatz zwar gängige Merkmale zur Beschreibung verschiedener Tarife sind, ist für die faktische Belastung mittlerer Einkommen der dazwischen liegende Tarifverlauf ausschlaggebend. Im Folgenden soll die Belastung durch Einkommen- und Zuschlagsteuern im Zeitverlauf für sozialversicherungspflichtige Arbeitnehmer diskutiert werden. Betrachtet werden dabei Bruttolöhne in Höhe von $100 \%$ und $200 \%$ des Durchschnittsentgelts, weiterhin werden die Fälle allein stehender und verheirateter Steuerpflichtiger (Einverdienerpaare) unterschieden. Zusätzlich erweist sich die Setzung eines Alters von unter 50 Jahren als ergebnisrelevant, da verschiedene altersabhängige Abzugsbeträge einen nicht unerheblichen Einfluss auf die zu entrichtende Einkommensteuer ausüben. Bei allein stehenden kinderlosen Steuerpflichtigen wirkten sich je nach Rechtsstand ein Sonderbzw. Haushaltsfreibetrag (1950 bis 1981, Mindestalter 55 bzw. 50 Jahre), ein Altersfreibetrag (1954 bis 1989, Mindestalter 70 bzw. 65 Jahre), ein Altersentlastungsbetrag (seit 1975, Mindestalter 64 Jahre) und verdoppelte Höchstbeträge bei begrenzt abzugsfähigen Vorsorgeaufwendungen (1950 bis 1975, Mindestalter 50 Jahre) aus (vgl. Abbildung 15). ${ }^{47}$ Die Abbildung gibt die Durchschnittssteuersätze (Einkommensteuer plus Zuschlagsteuern) allein stehender Arbeitnehmer wieder, die ausschließlich Bruttoeinkommen aus nichtselbständiger Arbeit in Höhe des Durchschnittsentgelts beziehen.

Abbildung 15: Wirkung von Steuervergünstigungen für ältere Steuerpflichtige 1950 bis 2005

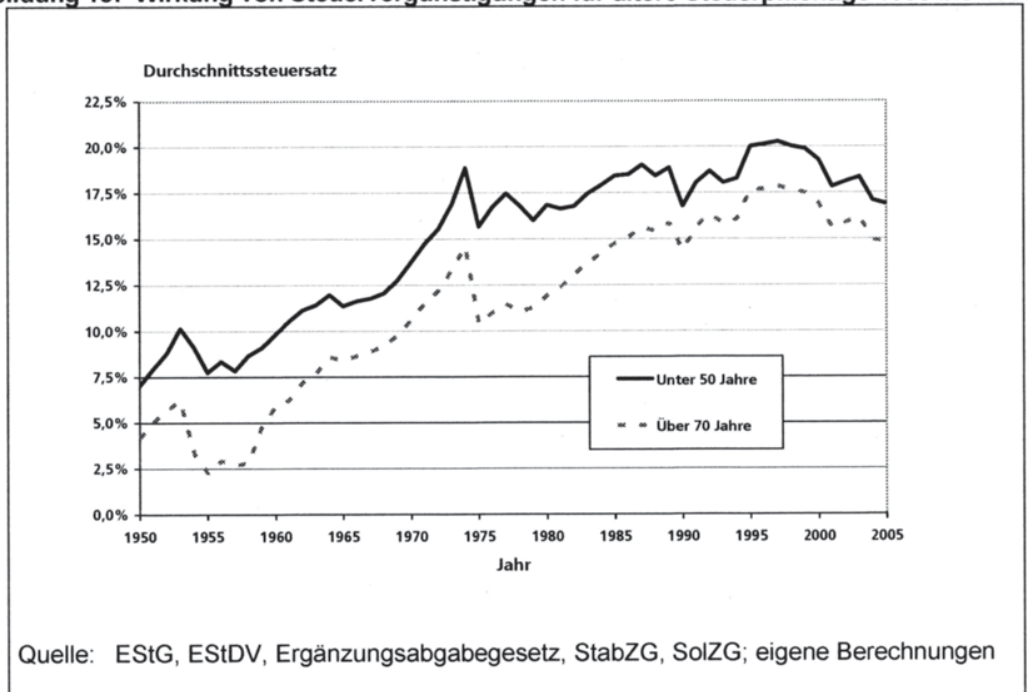

47 Vgl. zu altersabhängigen Steuervergünstigungen: Frerich, Frey (1996) 
Die Darstellung in Abbildung 15 zielt darauf ab, die möglichen kumulativen Wirkungen altersbezogener Vergünstigungen zu verdeutlichen, so dass zur lllustration der untypische Fall eines Arbeitnehmers im Alter von 70 Jahren dargestellt ist. Die zum Teil mit Kriegsfolgen, zum Teil sozialpolitisch begründeten Steuervergünstigungen für ältere Steuerpflichtige führen bei Durchschnittsverdienst zu Reduzierungen der Durchschnittsbelastung von bis zu 6,0 Prozentpunkten (1977), seit den 1990er Jahren von 2,0 bis 2,4 Prozentpunkten. Nach geltendem Recht ist ein schrittweiser Abbau des noch bestehenden Altersentlastungsbetrags vorgesehen, der ab 2040 vollständig entfallen soll ( $\$ 24$ a EStG). Aus der Kombination der Mindestalter und der Zeiträume der Anwendbarkeit der altersbezogenen Vergünstigungen folgt, dass diese mit Ausnahme des Altersentlastungsbetrags für Kohorten ab 1930 keine Entlastung bewirken. Wesentlich stärker begünstigt waren hingegen ältere Kohorten, deren Abgabenbelastung hier allerdings nicht weiter untersucht wird.

Weiteren Einfluss auf die Belastung durch Einkommensteuer und Zuschlagsteuern neben der Einkommensentwicklung und den Steuertarifen üben verschiedene Abzüge von der Bemessungsgrundlage aus:

- Pauschbeträge bei der Ermittlung der Einkünfte: Bei der Ermittlung der Einkünfte aus nichtselbständiger Arbeit sind seit 1950 durchgängig und bis 1989 kumulativ wirksame Pauschbeträge abzuziehen (Werbungskostenpauschale für Arbeitnehmer (1950 bis 1989), Weihnachtsfreibetrag (1951 bis 1989), Arbeitnehmerfreibetrag (1965 bis 1989), Arbeitnehmer-Pauschbetrag (seit 1990)).

- Sonderausgaben: Bis 1974 bestand für Arbeitnehmer ein recht hoher Pauschbetrag für Sonderausgaben, der auch Vorsorgeaufwendungen -die hier ausschließlich die Pflichtbeiträge zur Sozialversicherung umfassen-abdeckte. Alternativ waren nachgewiesene höhere Beträge bei der Einkommensteuerveranlagung im Rahmen von Höchstbeträgen abzugsfähig (§ $10 \mathrm{EStG}$ ). Faktisch ab 1961 wurde zusätzlich der zu kürzende Vonwegabzug gewährt. Die Einführung der Vorsorgepauschale im Jahr 1975 ( $\$ 10$ c EStG) brachte neben deutlich verbesserten Abzugsmöglichkeiten vor allem eine Angleichung der bei der Lohnsteuer berücksichtigten und der zu veranlagenden Vorsorgeaufwendungen mit sich, wodurch die Abweichung von Lohn- und veranlagter Einkommensteuer reduziert wurde. Gleichzeitig wurde der Pauschbetrag für Sonderausgaben, der nun nicht mehr der Abgeltung der Vorsorgeaufwendungen diente, deutlich gesenkt. Schließlich sieht das AltEinkG ab 2005 bis zum Jahr 2040 ansteigende Abzugsmöglichkeiten für Vorsorgeaufwendungen vor, ab 2040 sollen Alterseinkünfte dann vollständig einer nachgelagerten Besteuerung unterliegen. ${ }^{48}$

48 Bis zum Jahr 2019 gilt zudem eine Übergangsregelung, nach der die abzugsfähigen Vorsorgeaufwendungen nach der für das Kalenderjahr 2004 geltenden Fassung des $\S 10$ Abs. 3 EStG zu bestimmen sind, soweit dies für den Steuerpflichtigen günstiger ist ( $\$ 10$ Abs. 4 a EStG). Zusammen mit dem Vergleich von Zulagen und Steuerminderungen bei zusätzlichen Altersvorsorgebeträgen ( ${ }_{n}$ Riester-Sparen ${ }^{4}$ ) nach $\S 10$ a Abs. 2 EStG einerseits und Kindergeld und -freibetrag nach $\S 31$ EStG andererseits enthält das EStG damit bis zu drei von der Finanzverwaltung vorzunehmende Günstigerprüfungen, die das STM ebenfalls nachvollzieht. Bei Steuerpflichtigen mit mehreren Kindern sind die verschiedenen Prüfungen gegebenenfalls wiederholt zu durchlaufen. 
- Sonstige Abzüge: Für die Jahre von 1978 bis 1980 wird der damalige Tariffreibetrag von 510 DM (261 Euro) abgezogen. Außerdem ist die Entlastung bei niedrigen Erwerbseinkommen für die Jahre 1993 bis 1995 berücksichtigt (§ 32 c EStG 1993, § 32 d EStG 1994). Grundsätzlich im STM abgebildete weitere Frei- oder Abzugsbeträge wirken sich bei den in diesem Kapitel verglichenen Fällen von Kinderlosen nicht aus. Neben den altersabhängigen Steuervergünstigungen fallen hierunter außergewöhnliche Belastungen, die jedoch nur bei Steuerpflichtigen mit Kindern wirksam werden (Betreuungskosten, Ausbildungsfreibeträge).

Einige markante Befunde zur Belastung durch Einkommen- und Zuschlagsteuern seit 1950 bei Bruttoeinkommen in Höhe des Durchschnittsentgelts $\left(1^{*} d\right)$ oder des doppelten Werts $\left(2^{*} d\right)$ sind (vgl. Abbildung 16$)$ :

- In den Jahren vor der großen Reform der Ehegattenbesteuerung (1950 bis 1957) lag der Durchschnittssteuersatz von Ehepaaren bei gleichem Pro-KopfEinkommen wesentlich über dem Wert von Alleinstehenden (Vergleich von Allein $\left(1^{\star} d\right)$ und Verheiratet $\left(2^{*} d\right)$ ). Allerdings waren die ehebedingten Freibeträge hinreichend hoch, um die Durchschnittsbelastung auch ohne Splittingvorteil im Vergleich zur reinen Individualbesteuerung nennenswert zu senken (Vergleich von Verheiratet $\left(2^{*} d\right)$ und Allein $\left(2^{*} d\right)$ ). Ab 1958 ergeben sich Unterschiede in der Durchschnittsbelastung bei gleichem Pro-Kopf-Einkommen ausschließlich aus den Abzugsbeträgen von der Bemessungsgrundlage (A/lein $\left(1^{*} d\right)$ gegenüber Verheiratet $\left(2^{*} d\right)$ ). Die etwas höhere Durchschnittsbelastung der Einverdienerpaare resultiert aus den pauschalierten Werbungskosten, deren Wirkung partiell durch ihre verdoppelten Höchstbeträge beim Abzug der Vorsorgeaufwendungen kompensiert wird. Bei Sozialversicherungsbeiträgen, die seit Ende der 1960er Jahre die abziehbaren Vorsorgeaufwendungen in zunehmendem Umfang übersteigen, folgt seitdem eine zusätzliche Begünstigung der Ehe. ${ }^{49}$

- In den Jahren von 1958 bis 1974 stieg die Durchschnittsbelastung für alle vier Fallkonstellationen fast kontinuierlich an, einzige Ausnahme bildet die Steuerreform 1965, von der am stärksten Bezieher höherer Einkommen (Allein $\left(2^{\star} d\right)$ ) profitierten. Der Durchschnittssteuersatz hatte sich zwischen 1958 und 1974 in allen Fällen mindestens verdoppelt.

- Zwischen 1975 und 1989 ergibt sich für verschiedene Einkommensniveaus ein differenzierteres Bild. Für geringere Einkommen (Verheiratet (1*d)) blieb der Durchschnittssteuersatz recht stabil, er streute nur geringfügig innerhalb eines Intervalls von $10,2 \%$ bis $11,6 \%$. Bei mittleren Einkommen führten die verschiedenen Rechtsstände zu einer leichten Belastungszunahme um etwa 2,5 bis 3 Prozentpunkte (von $15,7 \%$ auf $18,9 \%$ (Allein $\left(1^{*} d\right.$ )) bzw. von $17,2 \%$ auf $19,5 \%$ Verheiratet $\left(2^{\star} d\right)$ ). Für höhere Einkommen Allein $\left(2^{\star} d\right)$ ) entsprach der Durchschnittssteuersatz bis zu 32,2\% (1987) nach 28,1\% im Jahr 1975.

- Die Steuerreform 1990 senkte die Steuerbelastung in allen vier Fällen, am stärksten fiel die relative Entlastung bei höheren Einkommen aus. Von der

49 Vgl. zum sinkenden Anteil steuerlich abziehbarer Sozialversicherungsbeiträge bei Ledigen und Verheirateten für die Zeiträume von 1980 bis 1996 bzw. von 1960 bis 2005: Bundesministerium der Finanzen (Hrsg.) (1997); Bundesministerium der Finanzen (Hrsg.) (2003), S. 131 
Steuerreform 1996 mit der starken Anhebung des Grundfreibetrags profitierten hingegen primär niedrigere Einkommen, für die seitdem die durchschnittliche Belastung weiter kontinuierlich sank. Bei den anderen Einkommensniveaus liegen indessen zwei gegenläufige Entwicklungen vor: Steigenden Steuerquoten bis zur Jahrtausendwende folgten danach wiederholte Absenkungen.

- Die Quote der zusätzlichen Belastung durch Zuschlagsteuern hängt wesentlich vom Einkommensniveau ab. Die Freibeträge bei der Ergänzungsabgabe 1968 bis 1974 verschonten niedrigere und mittlere Einkommen, erst bei höherem Einkommen setzte die Abgabenpflicht ein. Von der Stabilitätszulage 1973 und 1974 blieben hingegen nur Bezieher von geringeren Einkommen effektiv freigestellt. Ähnliches galt zuletzt für den Solidaritätszuschlag. Nachdem zunächst auch bei niedrigeren Einkommen der Zuschlag anfiel, bleiben diese in den letzten Jahren unter der Freigrenze.

Abbildung 16: Durchschnittssteuersätze bei Arbeitnehmern 1950 bis 2005

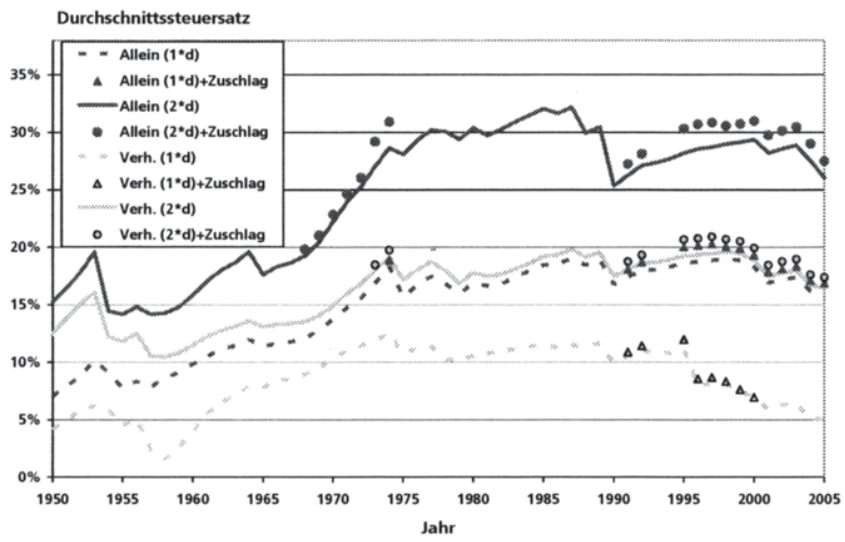

Quelle: EStG, EStDV, Ergänzungsabgabegesetz, StabZG, SolZG; eigene Berechnungen

- Vereinfachend lassen sich die Durchschnittssteuersätze seit den 1970er Jahren als umgekehrte u-Kurve beschreiben, deren Krümmung allerdings erheblich zwischen Einkommensniveaus variiert. ${ }^{50}$ Für höhere und mittlere Einkommen entspricht die Durchschnittsbelastung aus Einkommen- und $\mathrm{Zu}$ -

50 Corneo (2005) diskutiert ebenfalls die Entwicklung der Einkommensbesteuerung an Hand der Durchschnittssteuersätze verschiedener Einkommenslevel. Seine aus den Statistischen Jahrbüchern empirisch abgeleiteten Verläufe decken sich mit Abbildung 16, allerdings betrachtet er auch Höchsteinkommen (, the rich"), die bis zum 50-fachen des durchschnittlichen Pro-Kopf-Einkommens betragen. Für diese zeigt sich eine besonders starke Steuerentlastung durch die Steuerreformen seit dem Jahr 2000 mit inren wiederholten Absenkungen des Spitzensteuersatzes. Für "the rich" ergibt sich im Jahr 2005 ein historischer Tiefstwert der Steuerbelastung. (Corneo (2005), S. 162f) 
schlagsteuern im Jahr 2005 von rund $27,5 \%$ bzw. 17,0\% in etwa dem Wert des Jahres 1973, dazwischen ergaben sich fast immer höhere Steuerquoten. Für niedrigere Einkommen wurde die aktuelle Quote von rund $5 \%$ zuletzt im Jahr 1960 unterschritten.

Festzuhalten bleibt, dass im Zeitraum seit 1950 die Steuerbelastung für die hier betrachteten Einkommensklassen vor allem von der Mitte der 1950er bis zum Ende der 1960 er Jahre relativ gering war, die 1970er und 1980er Jahre hingegen vor allem für höhere und niedrigere Einkommen Hochsteuerphasen waren. Für Kohorten, die ab etwa 1970 in die Erwerbsphase eintraten, deutet sich damit eine recht hohe Lebenssteuerlast an: Die moderate Besteuerung früherer Jahre nutzte innen nicht, die Steuersenkungen der letzten Jahre wirken nur während des letzten Drittels der Erwerbsphase. Für die ältesten Kohorten mit Geburtsjahren ab 1930 zeichnen sich zwei gegensätzliche Effekte ab. Bei konkaven Lebenseinkommensprofilen unterliegen die relativ geringen Einkommen der ersten Hälfte des Erwerbslebens nur einer gemäßigten Besteuerung, die höheren Einkommen späterer Jahre fallen jedoch in Zeiten hoher Belastungsquoten. Durch die Fortschreibung des derzeit geltenden Steuerrechts für zukünftige Jahre ergibt sich für junge Kohorten, die erst seit kurzem erwerbstätig sind, tendenziell eine schlechtestenfalls mittlere Position. Ihre Lebenssteuerlast wird von im historischen Vergleich durchaus niedrig erscheinenden Steuerquoten geprägt.

Zur abschließenden Einordnung der betrachteten Einkommensniveaus innerhalb der Tarife einzelner Jahre gibt Abbildung 17 die Grenzsteuersätze wieder. Zum einen zeigt sich bei höheren und mittleren Einkommen ein im wesentlichen gleichgerichteter Verlauf von Grenz- und Durchschnittssteuersätzen. Nur bei niedrigeren Einkommen sind die Grenzsteuersätze recht konstant geblieben, ein starker Anstieg 1996 traf mit einer deutlichen Absenkung der Durchschnittsbelastung zusammen. Die Kombination niedriger Durchschnitts- und relativ hoher Grenzsteuersätze in unteren Einkommensbereichen in den letzten Jahren lässt auf verschlechterte Arbeitsanreize schließen. ${ }^{51}$ Nach unregelmäßigen Verläufen unter dem Stufen- und Formeltarif der Jahre bis 1957 war zwischen 1958 und 1965 für breite Schichten der Steuerpflichtigen der Eingangssteuersatz von $20 \%$ bzw. $19 \%$ maßgeblich. Während für höhere Einkommen bereits in diesen Jahren die Grenzbelastung beständig anstieg, unterlagen ab 1966 auch mittlere Einkommen zunehmend der Progression des Steuertarifs. Bei niedrigeren Einkommen entsprach indessen bis 1990 der Grenzsteuersatz stets dem Eingangssteuersatz von bis zu 22\%. Ab 1975 flacht die Kurve der Grenzsteuersätze mittlerer und höherer Einkommen $a b$, bei letzteren hatte sie sich auf bis zu unter fünf Prozentpunkte an den Spitzensteuersatz von 56\% angenähert. Mit der Steuerreform 1990 sanken für mittlere und höhere Einkommen die Grenzsteuersätze im Vergleich zum Spitzensteuersatz stark, die vertikale Differenzierung oberhalb der hier als höher eingestuften Einkommen nahm entsprechend zu. Die 2005 gültigen Grenzsteuersätze von 30,5\% bzw. 42,0\% ähneln den Werten zu Beginn der 1970er Jahre, als allerdings der Spitzensteuersatz noch $53 \%$ bis $56 \%$ betrug. Die sich in Abbildung 14 bereits andeutende abnehmende Progression in sehr hohen Einkommensbereichen lässt sich folglich auch auf der Grundlage der Entwicklung der Grenzsteuersätze nachzeichnen.

51 Corneo (2005), S. 164 
Abbildung 17: Grenzsteuersätze bei Arbeitnehmern 1950 bis 2005

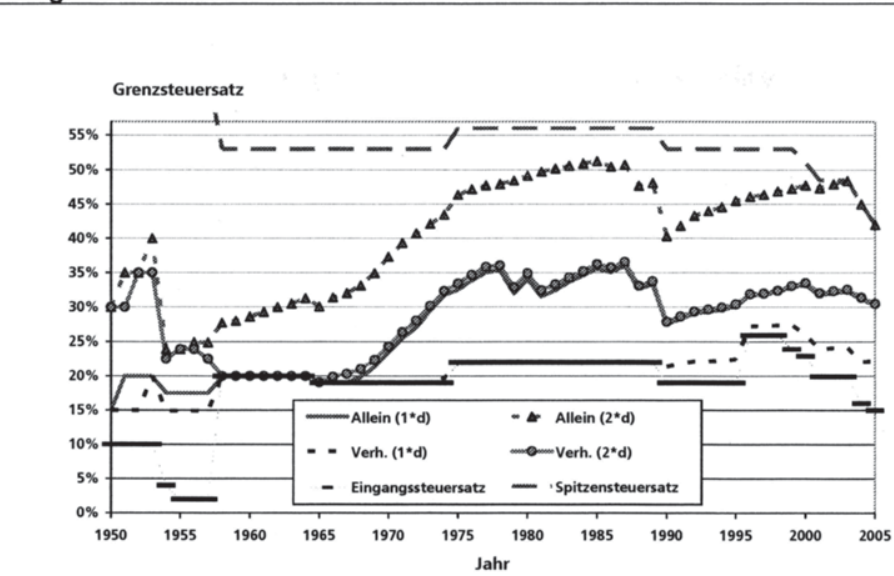

Quelle: EStG, EStDV; eigene Berechnungen

\subsubsection{Besteuerung von Renten der gesetzlichen Rentenversicherung}

Renten der gesetzlichen Rentenversicherung zählten im Betrachtungszeitraum durchgehend zu den sonstigen Einkünften im Sinne des § 22 EStG. Von 1955 bis 2005, als mit dem AltEinkG ein sukzessiver Übergang von der vor- zur nachgelagerten Besteuerung der Renten eingeleitet wurde, unterlag ausschließlich der Ertragsanteil einer Rente der Besteuerung. Dieser vom Lebensalter beim Erstbezug abhängende Anteil wird in den Ertragsanteilstabellen des $§ 22$ EStG ausgewiesen, deren Werte finanzmathematisch aus der ferneren Lebenserwartung von Männern und einem Referenzzinssatz abgeleitet werden. Die Berechnung greift auf die Fiktion einer Leibrente als Gegenleistung für eine zum Renteneintrittszeitpunkt erfolgende Einmalzahlung zurück, womit unter steuersystematischen Gesichtspunkten eine Zahlung aus versteuertem Einkommen impliziert wird. ${ }^{52}$ Der Ertragsanteil steigt nach diesem im EStG gewählten Ansatz mit der aus den Sterbetafeln abgeleiteten ferneren Lebenserwartung und fält bei zunehmendem Referenzzins. Die Ertragsanteils-

52 Bemängelt werden an der Ertragsanteilsbesteuerung nach $§ 22$ EStG neben der unzureichenden Differenzierung nach dem Anteil des aus versteuertem Einkommen gebildeten Rentenanspruchs die unstete Anpassung an Änderungen der relevanten Rechengrößen (Lebenserwartung, Zinsniveau) und die stark vereinfachte Typisierung des Sterblichkeitsrisikos. Vgl. zu dem Grundgedanken der typisierenden Ertragsanteilsbesteuerung mit kritischen Anmerkungen: Homburg (1996), S. 96; Bundesministerium der Finanzen (Hrsg.) (2003), S. 34f, S. $107 \mathrm{ff}$.

Für eine kritische Würdigung sowohl von Problemen der Ertragsanteilsbesteuerung als auch von Inkonsistenzen in der steuerlichen Behandlung verschiedener Formen von Alterseinkünften s. Färber (1997), 189ff 
tabelle für diese typisierende -und unter ökonomischen Gesichtspunkten eine äuBerst ausgeprägte Bereitschaft zur Pauschalierung offenbarende- Form der Rentenbesteuerung blieb zwischen 1955 und 1982 unverändert, mit dem 2. HStruktG 1982 erfolgte erstmals eine Anpassung. ${ }^{53}$ Zwischen 1955 und 1981 betrug der Ertragsanteil einer erstmals im Alter von 65 Jahren bezogenen Rente 20\%. Zwischen 1982 und 1993 lag dieser Wert als Folge der Anpassung des Gesetzes an die gestiegene Lebenserwartung bei 24\%, ab 1994 bis 2004 wurde mit dem FKPG ein entsprechender Anteil von $27 \%$ festgesetzt. ${ }^{54}$ Von dieser bereits seit den 1960 er Jahren als reformbedürftig angesehenen Art der Rentenbesteuerung wurde erst seit 2005 Abstand genommen. ${ }^{55}$

Nach dem AltEinkG unterliegen Renten der gesetzlichen Rentenversicherung ab 2005 nicht mehr der Ertragsanteilsbesteuerung sondern werden in wiederum typisierender Form einem schrittweisen Übergang zu einer nachgelagerten Besteuerung unterworfen. Für gesetzliche Renten wird nun ein nominal konstant bleibender steuerfreier Teil ermittelt, der bei Erstbezug der Rente bis einschließlich $200550 \%$ des Rentenzahlbetrags des Jahres 2005 entspricht, und bei Renteneintritten zwischen 2006 und 2040 sukzessive auf $0 \%$ absinkt ( $\$ 22$ Nr. 1 Satz 3 Buchstabe a Doppelbuchstabe aa EStG) ${ }^{56}$ Für Bestandsrenten der gesetzlichen Rentenversicherung wirkt sich diese Änderung im Jahr 2005 wie die Einführung eines altersunabhängigen Ertragsanteils von $50 \%$ aus. Da der Freibetrag nominal fixiert ist, schrumpft der steuerfreie Anteil der Rente bei steigenden Rentenwerten über die Rentenbezugsphase. Daneben wurde mit dem AltEinkG für weiterhin der Ertragsanteilsbesteuerung unterliegende Renten eine neue Tabelle in § $22 \mathrm{EStG}$ aufgenommen, nach der sich für einen Erstbezug im Alter von 65 Jahren ein Ertragsanteil von 18\% statt wie bisher 27\% ergibt. Die durchgehend deutliche Herabsetzung der altersabhängigen Ertragsanteile reflektiert die Wahl eines niedrigeren Referenzzinssatzes von $3,25 \%$ statt wie bis dahin von $5,5 \%$, dessen Wirkung durch die weiterhin gestiegene Lebenserwartung nicht kompensiert wird. Mit dem alternativen Zinssatz sollte das aktuell niedrige Zinsniveau Berücksichtigung finden. ${ }^{57}$ Die neue Bemessung der Ertragsanteile entlastet Bezieher von Leibrenten, deren Einzahlungen aus versteuertem Einkommen stammen. Da Beiträge zur gesetzlichen Rentenversicherung durch die Steuerfreiheit der Arbeit-

53 2. Haushaltsstrukturgesetz vom 22.12.1981 BGBL I, S. 1523

54 Gesetz über Maßnahmen zur Bewältigung der finanziellen Erblasten im Zusammenhang mit der Herstellung der Einheit Deutschlands, zur langfristigen Sicherung des Aufbaus in den neuen Ländern, zur Neuordnung des bundesstaatlichen Finanzausgleichs und zur Entlastung der öffentlichen Haushalte (Gesetz zur Umsetzung des Föderalen Konsolidierungsprogramms - FKPG) vom 23.06.1993 BGBII, S. 944

55 Bereits 1967 thematisierte der wissenschaftliche Beirat beim Bundesministerium der Finanzen Alternativen bei der Besteuerung von Renten und Pensionen (Bundesministerium der Finanzen (Hrsg.) (1967)). Zu Mängeln der Ertragsanteilsbesteuerung in verfassungsrechtlicher und steuersystematischer Hinsicht s. a. Bundesministerium der Finanzen (Hrsg.) (1986).

56 Bei mehreren Renten kann die Berechnung verschiedener nominal konstanter Freibeträge erforderlich sein. In dieser Arbeit ist dieser Umstand bei Bezug von Witwen- oder Witwerrenten neben einer Rente aus eigenen Ansprüchen relevant und wird vom STM berücksichtigt. Bei Erstbezug einer eigenen Rente im Jahr 2002 und einer zusätzlichen Witwenrente ab 2010 beispielsweise beträgt der steuerfreie Rentenanteil zum einen 50\% der eigenen Rente des Jahres 2005 und zum anderen $40 \%$ der Witwenrente des Jahres 2010.

S. zur Besteuerung von Renten nach dem Alterseinkünftegesetz und zur Ermittlung des nominal konstanten steuerfreien Rententeils Kirchhof (2005), § $22 \mathrm{Nr}$. 27-27h

57 Vgl. Bundesministerium der Finanzen (Hrsg.) (2003), S. 34ff 
geberbeiträge und die begrenzte Abzugsfähigkeit der Arbeitnehmerbeiträge als Vorsorgeaufwendungen zumindest teilweise unversteuert bleiben, ist von Renten der gesetzlichen Rentenversicherung seit 2005 nicht mehr nur der Ertragsanteil zu versteuern. ${ }^{58}$

Flankiert von verschiedenen Abzugsbeträgen für ältere Steuerpflichtige im Allgemeinen und für Empfänger von wiederkehrenden Bezügen im Besonderen, führte die Ertragsanteilsbesteuerung nach $\S 22 \mathrm{EStG}$ dazu, dass Rentner in den zurückliegenden Jahrzehnten überwiegend keine Einkommensteuer zu entrichten hatten, soweit sie nicht zusätzlich höhere Einkünfte anderer Art erzielten. Zur ungefähren Beschreibung der Wirkung der Ertragsanteilsbesteuerung lässt sich die Entgeltpunktsumme EPS bestimmen, aus deren Überschreiten eine Rente folgt, deren Ertragsanteil den steuerlichen Grundfreibetrag des jeweiligen Jahres übersteigt: ${ }^{59}$

$$
\begin{array}{rll}
E P S=g /\left(e^{*} R^{*} 12\right) & \\
\text { mit } & g & \text { Grundfreibetrag des Steuertarifs } \\
& e & \text { altersabhängiger Ertragsanteil } \\
& R & \text { aktueller Rentenwert }
\end{array}
$$

EPS soll als Indikator herangezogen werden, bis in welche Einkommensbereiche Rentenbezieher keine Einkommensteuer zu entrichten hatten. Bei Einführung der dynamisierten Rente durch die Rentenreform 1957, mit der die Altersversorgung von einer Maßnahme zur Armutsvermeidung zu einem Lohnersatz aufgewertet wurde, ${ }^{60}$ entsprach der Ertragsanteil einer GRV-Rente in Höhe von 2.301 Euro/ Jahr, die erstmals im Alter von 65 Jahren bezogen wurde, dem damaligen Grundfreibetrag von rund 460 Euro. Bei einem aktuellen Rentenwert 1957 von 5,35 DM (2,74 Euro) waren für eine Jahresrente von 2.301 Euro rund 70,1 Entgeltpunkte erforderlich. ${ }^{61}$ Nach der Anhebung des Grundfreibetrags stieg dieser Wert 1958 auf rund 123 Entgeltpunkte und fiel in der Folgezeit bis 1974, als der Grundfreibetrag bei steigenden Rentenwerten unverändert blieb, kontinuierlich auf knapp 38 Entgeltpunkte (Abbildung 18). In den Jahren zwischen 1975 und 1981 schwankte die Entgeltpunktsumme, mit der ein Ertragsanteil in Höhe des Grundfreibetrags verbunden war, um Werte von 55, die neue Ertragsanteilstabelle 1982 führte zu einer Absenkung auf ein Niveau von etwa 45 Entgeltpunkten. Mit der erstmals 1994 gültigen Ertragsanteilstabelle fiel die Summe weiter auf etwa 38 Entgeltpunkte. Die massive Erhöhung des Grundfreibetrags

58 S. Brall, Bruno-Latocha, Lohmann (2004), S. $421 \mathrm{ff}$

59 Im Jahr 2002 galt zum Beispiel ein Grundfreibetrag von 7.235 Euro, der Ertragsanteil einer erstmals im Alter von 65 Jahren bezogenen Rente betrug 27\%, der aktuelle Rentenwert 25,86 Euro. Aus einer individuellen Entgeltpunktsumme von 86,35 folgt damit eine Jahresrente von 26.796 Euro ( $=25,86$ Euro* $86,35^{*} 12$ ). Bei einem Ertragsanteil von $27 \%$ ergibt sich hieraus eine steuerlich zu berücksichtigende Rente von rund 7.235 Euro, die damit dem Grundfreibetrag entspricht, so dass bei Renten, die auf nicht mehr als 86,35 Entgeltpunkten beruhen, die zu entrichtende Einkommensteuer null ist, so lange keine weiteren Einkünfte vorliegen. EPS beträgt im Jahr 2002 für bei Erstbezug 65-jährige Rentner somit 86,35 . Hockerts (1990), S. 94

61 Entgeltpunkte als Rechengröße zur Bestimmung der individuellen Rentenhöhe wurden erst mit dem RRG 1992 eingeführt, zuvor bemaß sich die Rente nach Werteinheiten, wobei 100 Werteinheiten 1,0 Entgeltpunkt entsprechen. S. Müller, Nachtigal, Hansen (1990), S. 69 
durch die Steuerreform 1996 bewirkte schließlich auch für Höchstrenten mit 79 oder mehr Entgeltpunkten eine Steuerfreistellung. Würde ab 2005 weiterhin nur der Ertragsanteil der GRV-Renten besteuert werden, so läge nach der Herabsetzung der Ertragsanteile im Rahmen des AltEinkG die Entgeltpunktsumme zuletzt bei über 135 Entgeltpunkten.

Abbildung 18: Steuerfreie Entgeltpunktsummen 1957 bis 2006 in Abhängigkeit von Renteneintrittsalter und Jahr

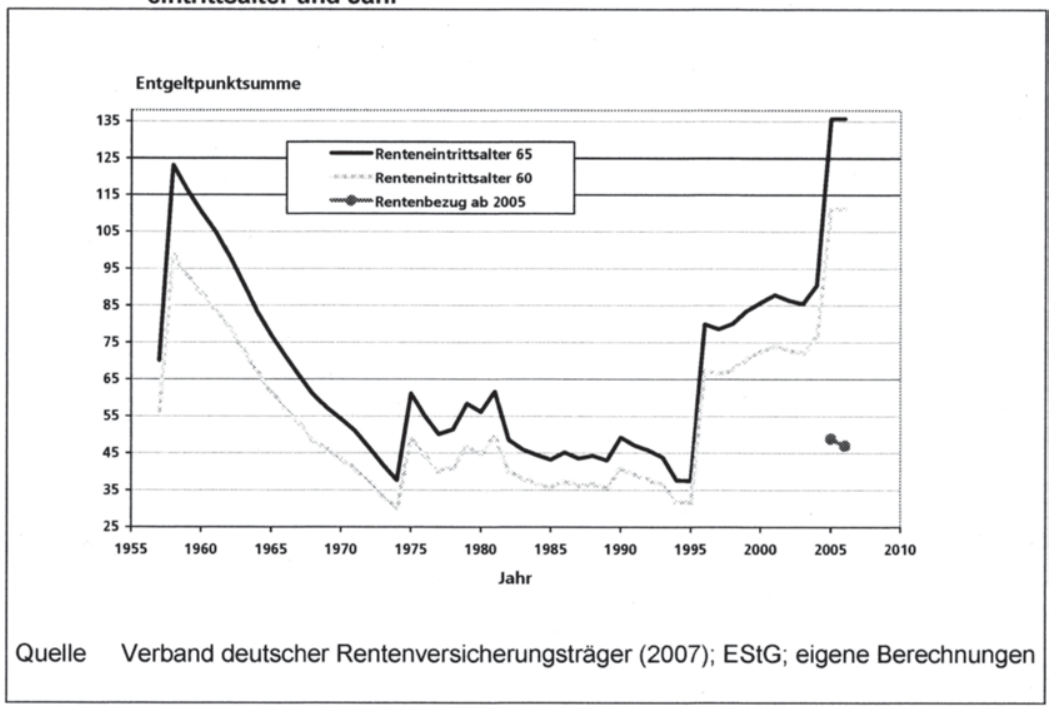

Die bisher genannten Beträge gelten für Renten, die erstmals im Alter von 65 Jahren bezogen wurden. Bei einem früheren Renteneintritt im Alter von 60 Jahren waren stets um 5 Prozentpunkte höhere Ertragsanteile anzusetzen, woraus eine geringere Entgeltpunktsumme folgt, deren niedrigste Werte bei rund 30 (1974) und 32 (1994, 1995) Entgeltpunkten lagen. Für die Jahre 2005 und 2006 ist neben der bei den GRV-Renten nicht mehr anzuwendenden Ertragsanteilsbesteuerung auch die neue Rechtslage nach dem AltEinkG abgebildet (Datenreihe Rentenbezug ab 2005). Da demgemäß faktisch ein Ertragsanteil von 50\% (Renteneintritte bis einschließlich 2005) bzw. 52\% (Renteneintritte 2006) wirkt, liegt die mit den früheren Jahren vergleichbare Entgeltpunktsumme bei etwa 48,9 (2005) bzw. 47,0 (2006). Zukünftig wird dieser Wert insbesondere für Neurenten bis zum Jahr 2040 tendenziell kontinuierlich abschmilzen. Spiegelbildlich zum zunehmenden steuerlichen Zugriff auf GRV-Renten werden die anspruchsbegründenden Beiträge schrittweise von der Besteuerung freigestellt.

Aus der Entwicklung der in Abbildung 18 aufgeführten Entgeltpunktsummen ist nur auf den zeitlichen Verlauf der Bedeutung der Gesetzesparameter des EStG zur Rentenbesteuerung zu schließen. Das Rentenniveau, bei dem effektiv eine Besteuerung frühestens einsetzt, ist nicht ersichtlich und liegt stets über den dargestellten Entgeltpunktsummen. Weitere Parameter, die das Niveau über die angegebenen Entgelt- 
punktsummen anheben, sind Pauschbeträge für Werbungskosten bei wiederkehrenden Bezügen (durchgängig seit 1950 gemäß § 14 EStDV bzW. § 9 a EStG), Pauschbeträge für Sonderausgaben bei wiederkehrenden Bezügen (bis $1974 \S 15$ EStDV bzw. $\S 10$ c EStG), Sonderausgaben-Pauschbeträge (§ 10 c EStG ab 1975) und nach den Umständen des Falles ein Haushaltsfreibetrag für allein stehende ältere Steuerpflichtige (bis 1981 § 32 Abs. 3 EStG) und ein Altersfreibetrag (§ 32 Abs. 2 EStG 1969 bis 1989). Allein stehende Steuerpflichtige im Alter von 65 Jahren, die ausschließlich Einkommen aus einer hohen Rente mit 67,5 Entgeltpunkten (1,5facher Wert der Standardrente) bezogen, hatten nach Ergebnissen des STM im Zeitraum von 1950 bis 2004 nur in den Jahren 1982 bis 1985 und 1992 bis 1995 Einkommensteuer zu entrichten, die zudem maximal 0,9\% der Bruttorente entsprach. Im Jahr 2005 blieb eine Bruttorente von bis zu knapp 18.900 Euro steuerfrei, für die rund 60,2 Entgeltpunkte erforderlich waren (1,3-facher Wert der Standardrente).

Insgesamt führte die Rentenbesteuerung nach dem EStG bis 2004 damit nur zu einer äußerst schwachen vertikalen Differenzierung zwischen Rentenbeziehern. Sowohl von Niedrigstrenten als auch von hohen bis höchsten Renten war meist keine Einkommensteuer abzuführen, solange keine größeren weiteren Einkünfte vorlagen. Nach Schätzungen des BMF wären im Jahr 2005 bei Fortbestehen des alten Rechts $14 \%$ der Rentenempfänger steuerbelastet, wobei diese mehrheitlich ihre Renten übersteigende andere Einkünfte erzielen (85\%). Mit dem durch das AltEinkG geschaffenen neuen Recht stieg der Anteil steuerbelasteter Rentenbezieher auf $23 \%$, bei denen weiterhin andere Einkünfte die dominierende Einkommensquelle bilden $(55 \%) .{ }^{62}$ Zukünftig ist von einem beständig zunehmenden Anteil Einkommensteuer entrichtender Rentner auszugehen.

Für den modellhaften Belastungsvergleich verschiedener Kohorten ab 1930 ist primär die Entwicklung der Rentenbesteuerung ab etwa 1990 relevant. Für Erwerbsverläufe mit niedrigen bis gehobenen Einkommen zeichnet sich nach Abbildung 18 durchgehende Steuerfreiheit während der Rentenbezugsphase auch in den ersten Jahren nach Inkrafttreten des AltEinkG ab. Bei hohen Erwerbseinkommen, die in den hier betrachteten Modellfällen mit akademischen Abschlüssen einhergehen, ist nach den Umständen des Falles zum einen in der ersten Hälfte der 1990er Jahre Einkommensteuer von Rentenempfängern zu entrichten, zum anderen wirkt sich bei ihnen die Verschärfung durch das AltEinkG unmittelbar ab 2005 aus.

62 Bundesministerium der Finanzen (2004), S. $7 f$ 


\subsection{Kindergeld und kindbedingte Steuerentlastungen}

Als Familienleistungsausgleich (FLA) werden in dieser Arbeit die einkommensteuerlichen Kinderfreibeträge und Zahlungen von Kindergeld betrachtet, womit ein FLA im engeren Sinne abgegrenzt ist. Statt daneben unter einem FLA im weiteren Sinne zusätzlich andere familienpolitische Leistungen zusammenzufassen, wird hierfür der allgemeinere Begriff der kindbedingten Leistungen gewählt. ${ }^{63} \mathrm{Zu}$ diesen zählen neben den in diesem Kapitel dargestellten steuerlichen Maßnahmen unter anderem auch das Elterngeld, kindbezogene Rentenzuschläge oder die Minderung des Solidaritätszuschlags als mittelbare Folge der Kinderfreibeträge. Gegenstand der Darstellung hier sind Regelungen des Einkommensteuergesetzes seit 1950 mit familienpolitischer Bedeutung. Im nächsten Unterkapitel wird zunächst die Entwicklung von Kindergeld und -freibeträgen dargestellt. Diese beiden wichtigsten familienpolitischen Instrumente sind gemeinsam zu besprechen, da die Wirkungen der beiden Leistungen seit 1950 wiederholt voneinander abhingen. Andere Abzugsmöglichkeiten des Einkommensteuergesetzes, die auf die Entlastung von Eltern abzielen, werden hieran anschließend vorgestellt.

\subsubsection{Kinderfreibetrag und Kindergeld: Familienleistungsausgleich im engeren Sinne}

Bis zur Reform durch das Jahressteuergesetz (JStG) 1996 wurde der FLA als Familien/astenausgleich bezeichnet, durch die Umbenennung sollten die von Familien erbrachten Leistungen stärker hervorgehoben werden ${ }_{1}^{64}$ ohne dass damit eine grundlegende konzeptionelle Änderung einher ging. Ob und inwieweit von Familien Leistungen erbracht werden, die eine ökonomische Begründung für den FLA bieten, wird recht kontrovers beurteilt, worauf im zweiten Teil noch einzugehen sein wird. Seit Bestehen der Bundesrepublik wurde der FLA durch Kindergeld und -freibeträge wiederholt grundlegend modifiziert. Signifikante Unterschiede zwischen verschiedenen Rechtsständen ergeben sich in Hinblick auf die Staffelung der Beträge nach der Kinderzahl, auf die relative Bedeutung des Kindergelds im Vergleich zu den Freibeträgen, die Einkommensabhängigkeit des Kindergelds und die Substitutionsbeziehung zwischen den beiden Instrumenten. Meist existierte ein dualer FLA, in dem Kindergeld und Kinderfreibeträge gleichzeitig gewährt wurden, die beiden Instrumente also additiv wirkten. Für die Betrachtung in dieser Arbeit sind vor allem zwei Unterscheidungsmerkmale relevant:

63 Der hier verwandte enge Begriff des FLA orientiert sich somit an der seit 1996 in § 31 EStG getroffenen Abgrenzung und bezieht sich ausschließlich auf die hierunter fallenden familienpolitischen Instrumente, ohne damit eine inhaltliche Aussage zu ihrer Wirkung, ihren Zielen oder ihrer Beurteilung zu treffen. Eine inhaltlich geprägte Klassifizierung von familienpolitischen Instrumenten zu einem FLA im engeren oder weiteren Sinne nehmen unter anderem Lüdeke und Werding (1996) vor. 
- Horizontale Differenzierung: Hierunter wird die Staffelung von Parametern nach der Kinderzahl verstanden. Seit 1953 differenzierte der FLA permanent nach der Ordnungszahl der Kinder, wobei die Leistungen mit der Kinderzahl überproportional stiegen. So wird beispielsweise heute in Vierkindfamilien für das vierte Kind ein höheres Kindergeld gezahlt als für das erste bis dritte Kind. Während Begründbarkeit, Ziele und anzustrebender Umfang des FLA in der Literatur umfangreich erörtert werden, bleibt die Frage nach den Implikationen einer horizontalen Differenzierung meist unberücksichtigt.

- Einkommensabhängigkeit: Die Höhe des von Kindergeld und -freibeträgen ausgehenden Mehreinkommens hängt seit 1950 fast durchgängig vom Einkommensniveau der Eltern ab. Es wird sich zeigen, dass überwiegend ein positiver Zusammenhang zwischen Einkommen und Entlastungswirkung des FLA besteht, Eltern mit höherem Einkommen mithin stärker vom FLA profitieren.

Kinderfreibeträge wurden bereits in den vierziger Jahren des 20. Jahrhunderts für jedes Kind gewährt, ein allgemeines Kindergeld wurde erstmals 1955 eingeführt und zunächst nur ab dem dritten Kind gezahlt. Ab 1961 folgte das Kindergeld für zweite Kinder, seit 1975 besteht grundsätzlich für jedes Kind ein Kindergeldanspruch. Mit Ausnahme des Zeitraums von 1975 bis 1982, als der FLA ausschließlich über Kindergeldzahlungen erfolgte, existierten die beiden Elemente seit 1955 parallel. Geprägt wurde die Ausgestaltung des FLA von sich wandelnden gesellschaftspolitischen Leitbildern und verfassungsgerichtlicher Rechtssprechung. ${ }^{65}$ Neben dem anzustrebenden Umfang der Begünstigung von Familien wurde insbesondere die relative Gewichtung des Kindergelds innerhalb des FLA politisch kontrovers bewertet. Wie sonstige Freibeträge führt auch ein Kinderfreibetrag in einem progressiven Steuersystem zu einer mit dem Einkommen zunehmenden Entlastung, das Kindergeld ist indessen grundsätzlich einkommensunabhängig und überwiegend sozialpolitisch motiviert. Die politische Debatte in der Geschichte der Bundesrepublik um das Spannungsverhältnis von Kindergeld und -freibetrag reflektiert entsprechend zumindest implizit die Frage, ob die Entlastungswirkung des FLA positiv, negativ oder nicht vom Einkommen abhängen soll.

Mit dem FLA wurden distributive, allokative und steuerrechtliche Ziele verfolgt, wobei diesen in verschiedenen Phasen unterschiedliches Gewicht zukam. Eine zentrale Begründung für Kinderfreibeträge folgt aus der Steuerrechtslehre. Der Grundsatz horizontaler Steuergerechtigkeit zielt darauf ab, Steuerpflichtige gleicher Leistungsfähigkeit gleich hoch zu besteuern. Kernpunkt ist damit die Quantifizierung der Leistungsfähigkeit unter Berücksichtigung individueller Merkmale eines Steuerpflichtigen. $\mathrm{Zu}$ formulieren ist entsprechend die Zuordnung einer steuerlichen Bemessungsgrundlage (im EStG: das zu versteuernde Einkommen ZVE) in Abhängigkeit von einem Einkommensbegriff $y$ und einem Merkmalsvektor $m$ :

65 Übersichten über die Entwicklungen von Leitbildern und Instrumenten der Familienpolitik und der intendierten Wirkungen des FLA mit Bezügen zur politischen Situation und zur Rechtssprechung geben:

Bundesministerium für Familie, Senioren, Frauen und Jugend (Hrsg.) (2001), S. 15-43; Frerich, Frey (1996), S. 113ff, S. 327ff 
$Z V E=f(y, m)$

Operationalisiert ist dieser Grundsatz im EStG in Hinblick auf die Kinderzahl eines Steuerpflichtigen durch die Kinderfreibeträge $b_{i}$ (mit $i$ als Ordnungszahl eines Kindes). Mit einem Merkmalsvektor $m_{0}$, der dem um die Anzahl der Kinder reduzierten Vektor $m$ entspricht, lässt sich das Prinzip in Abhängigkeit von der Kinderzahl $n_{K}$ ausdrücken als:

$$
Z V E=f\left(y, m_{0}, n_{K}\right)=f\left(y, m_{0}\right)-\sum_{i=1}^{n_{4}} b_{i}
$$

Horizontale Steuergerechtigkeit im Rahmen des FLA bezieht sich damit ausschließlich auf den Vergleich von Steuerpflichtigen, die bei gleichem Einkommen identische Merkmale aufweisen und sich nur in der Kinderzahl unterscheiden. Die Summe der Kinderfreibeträge entspricht dabei den typisierten zwangsläufigen Aufwendungen für verschiedene Anzahlen von Kindern, die als indisponibles Einkommen gilt. Verschiedene Autoren betonen daher, dass von Kinderfreibeträgen ausgehende Steuerminderungen kein originär familienpolitisches Instrument sondern vollständig aus der Steuerrechtslehre abzuleiten sind. ${ }^{66}$ Aussagen darüber, wie sich das verfügbare Einkommen nach Steuern von Kinderlosen im Vergleich zu demjenigen von Eltern oder wie sich die kindbedingten Entlastungen von Eltern unterschiedlicher Leistungsfähigkeit zueinander verhalten sollen, lassen sich aus der steuersystematischen $\mathrm{Be}$ trachtung nicht ableiten. Seit den 1990er Jahren gewann das Argument horizontaler Steuergerechtigkeit, ausgelöst von Urteilen des Bundesverfassungsgerichts, stark an Bedeutung für die Begründung des FLA ${ }^{67}$ Da bei progressiven Steuertarifen, wie in der Bundesrepublik durchgängig gegeben, die Entlastungswirkung eines Freibetrags mit der Bemessungsgrundlage steigt, wirken Kinderfreibeträge zumindest innerhalb der Gruppe der Eltern regressiv. Dieser Wirkung liegen jedoch keine normativen Urteile zu Grunde, sie ist vielmehr Begleiterscheinung einer derartig definierten Besteuerung nach der Leistungsfähigkeit. Weder das Niveau kindbedingter Entlastungen noch das Ausmaß ihrer Einkommensabhängigkeit lassen sich auf Grund des horizontalen Gerechtigkeitsprinzips bestimmen, lediglich die Untergrenze des Freibetrags wird durch die Höhe des kindbedingt indisponiblen Einkommens festgelegt. Die konkrete Entlastungswirkung hängt dann nicht nur von der Höhe der Feibeträge sondern auch von der Ausgestaltung des Steuertarifs ab.

Für einen explizit auf Umverteilung abzielenden FLA, der in der Regel auf dem Argument der Bedarfsgerechtigkeit fußt, ist hingegen die Quantifizierung der kindbedingten Entlastung zentral. Ausgehend von dem Befund eines mit der Familiengröße zunehmenden materiellen (Mindest-)Bedarfs wird nach diesem Ansatz eine staatliche Korrektur der Verteilung der Markteinkommen angestrebt. Unterscheiden lassen sich eine generelle Umverteilung zugunsten von Eltern gegenüber Kinderlosen einerseits und eine primär auf Familien im unteren Einkommensbereich ab-

66 Ott (2002), S. 17ff; Lüdeke, Werding (1996), S. $421 \mathrm{f}$

67 Vgl. zur Rechtssprechung: Ott (2002), S. 18; Tipke, Lang (2002), § 9 Rz. $92 f$ 
zielende Redistribution andererseits. ${ }^{68}$ Erstere orientiert sich am von Kindern ausgehenden Mehrbedarf, letztere an der Differenz von verfügbarem Einkommen ohne Umverteilung und Gesamtbedarf. Beide Ansätze wurden und werden als Begründung für die Zahlung von Kindergeld als "zentrale Generalnorm einer familienpolitisch orientierten Einkommenspolitik" herangezogen. ${ }^{69}$ Ein mehrbedarfsorientierter FLA legt ein einheitliches und einkommensunabhängiges Kindergeld nahe, bei einem vorrangig Fehlbeträge ausgleichenden FLA ist hingegen eine Konzentration der Leistungen auf Familien mit niedrigen Einkommen indiziert. Fragwürdig bleibt bei letzterem Ansatz allerdings, inwieweit eine Generalnorm wie der FLA zur Mindestsicherung von Kindern beitragen kann, wenn diese Funktion auch von speziellen Transfers (wie dem Sozialgeld bzw. Arbeitslosengeld II) übernommen wird, bei denen das Kindergeld auf den Anspruch angerechnet wird, so dass das Kindergeld im untersten Einkommensbereich andere Transfers substituiert und folglich nicht das verfügbare Familieneinkommen erhöht. ${ }^{70}$

Allokativ orientierte Ansätze als dritte Begründungsform für einen FLA verweisen regelmäßig auf von Kindern ausgehende externe Effekte, zu deren Internalisierung der FLA beitragen soll. Dieser Punkt wird im zweiten Teil dieser Arbeit im Kapitel zur Familienpolitik ausführlicher behandelt werden.

Seit den 1950er Jahren wurden Kindergeld und -freibeträge in sehr unregelmäßigen Abständen angehoben (s. Abbildung 19). ${ }^{71}$ Die Entwicklung des FLA seit damals lässt sich in fünf Phasen unterteilen:

1. Phase: Einkommensunabhängiger additiver FLA überwiegend durch (1950 bis 1960) Kinderfreibeträge, zunehmende horizontale Differenzierung, Von 1950 bis 1952 war für jedes Kind ein einheitlicher Freibetrag von 600 DM (307 Euro) in die Einkommensteuertabellen eingearbeitet. 1953 wurde erstmals horizontal differenziert, der Freibetrag für dritte und weitere Kinder stieg auf zunächst $740 \mathrm{DM}$ (378 Euro) und in den Jahren danach auf bis zu 1.800 DM (920 Euro), das Doppelte des dann gültigen Freibetrags für erste Kinder. Ab 1957 wurde zusätzlich zwischen ersten und zweiten Kindern differenziert, die Freibeträge für zweite Kinder wurden annähernd auf das Niveau von Kindern höherer Ordnungszahl angehoben. Zu einer weiteren horizontalen Spreizung zwischen Familien unterschiedlicher Kinderzahl trug das 1959 eingeführte Kindergeld bei, das ab dem dritten Kind gewährt wurde und von anfänglich $300 \mathrm{DM}$ (153 Euro) auf 480 DM (245 Euro) je Jahr anstieg.

68 Vgl. Bundesministerium für Familie, Senioren, Frauen und Jugend (Hrsg.) (2001), S. $61 f$ In älteren Arbeiten wird zusätzlich die Möglichkeit der Angemessenheit eines aus distributiven Gründen regressiven FLA diskutiert. Grundüberlegung ist, dass mit dem Einkommen auch die Aufwendungen für Kinder steigen, so dass eine zunehmende Kompensation erforderlich ist. Vgl. Diehl (1971), S. 23

70 Vgl. Henman (2002), S. $42 f$

71 Die der Abbildung zu Grunde liegenden Daten sind mit einigen Anmerkungen in Tabelle 24 im tabellarischen Anhang A2 aufgeführt. 
2. Phase: $\quad$ Moderat einkommensabhängiger additiver FLA, steigende

(1961 bis 1974) Bedeutung eines horizontal differenzierten Kindergelds

Die Kinderfreibeträge für zweite und weitere Kinder blieben zwischen 1961 und 1974 konstant bei 1.680 DM für zweite Kinder bzw. 1.800 DM für dritte und weitere Kinder ( 859 bzw. 920 Euro), der Betrag für erste Kinder wurde in diesem Zeitraum einmal angehoben (1962 von 900 auf 1.200 DM, 460 auf 614 Euro). Das Kindergeld wurde indessen zunehmend nach der Kinderzahl gestaffelt. 1961 wurde Kindergeld für zweite Kinder von 300 DM je Jahr (153 Euro) eingeführt, das allerdings bei Überschreiten einer Einkommensgrenze von anfänglich 7.200 DM (3.681 Euro) entfiel. ${ }^{72}$ Bis 1974 wurde die Einkommensgrenze in mehreren Schritten auf 18.360 DM (9.387 Euro) angehoben. Für dritte und weitere Kinder war das Kindergeld einkommensunabhängig. Zwischen 1964 und 1974 existierten bis zu fünf nach der Ordnungszahl gestaffelte Kindergeldsätze, ab dem dritten Kind betrug das Kindergeld mindestens 480 DM jährlich (245 Euro).

3. Phase: FLA ausschließlich durch einkommensunabhängiges horizontal (1975 bis 1982) differenziertes Kindergeld

Ab 1975 wurden Kinderfreibeträge aus dem EStG herausgenommen. Im Gegenzug wurde das Kindergeld stark erhöht und bereits ab dem ersten Kind unabhängig vom Einkommen gezahlt. Das Erstkindergeld belief sich in diesem Zeitraum durchgehend auf $600 \mathrm{DM}$ jährlich (307 Euro), für zweite und weitere Kinder wurde das Kindergeld hingegen wiederholt angehoben. 1981 war das Kindergeld für das zweite Kind mit 1.440 DM (736 Euro) mehr als doppelt so hoch wie beim ersten Kind, der Jahresbetrag für dritte und weitere Kinder entsprach mit 2.880 DM (1.473 Euro) annähernd dem Fünffachen des Erstkindergeldes. Im Jahr 1982 erfolgte durch das Neunte Gesetz zur Änderung des BKGG die bislang einzige Kürzung der nominalen Kindergeldsätze. Betroffen waren zweite und dritte Kinder, deren Anspruch um jeweils 240 DM (123 Euro) herabgesetzt wurde. ${ }^{73}$

4. Phase: $\quad F L A$ mit einheitlichen Kinderfreibeträgen und einkommensab(1983 bis 1995) hängig gestaffeltem Kindergeld, ergänzt durch Kindergeldzuschläge Seit 1983 werden bei der Einkommensteuer wieder Kinderfreibeträge berücksichtigt. Als Kompensation der partiellen Kürzungen beim Kindergeld im Jahr 1982 wurden 1983 zunächst geringe einheitliche Freibeträge von 432 DM (221 Euro) für jedes Kind gewährt, die 1986 massiv erhöht wurden auf 2.484 DM (1.270 Euro) und sich ab 1992 auf 4.104 DM (2.098 Euro) beliefen. Das weiterhin stark horizontal differenzierte Kindergeld blieb bis 1991 zwar nominal konstant, allerdings wurde es nun ab dem zweiten Kind einkommensabhängig gemindert. Als neues Element wurde durch das 11. Gesetz zur Änderung des BKGG ab 1986 ein Kindergeldzuschlag in $\S 11$ a BKGG eingeführt. ${ }^{74}$ Der nur im unteren Einkommensbereich wirksame Zuschlag war so ausgestaltet, dass bei einkommensschwächeren Eltern faktisch die fehlende Entlastungswirkung der Kinderfreibeträge nachgeahmt wurde. ${ }^{75}$ Das recht komplizierte Wechselspiel

S. Schieckel (1965), S. 9, S. 25

Neuntes Gesetz zur Änderung des Bundeskindergeldgesetzes, BGBI I 1981, S. 1566

11. Gesetz zur Änderung des Bundeskindergeldgesetzes, BGBII 1985, S. 1251

Vgl. Wickenhagen, Krebs (1994), § 11 a, Anm. 1. 3 
des Instrumentenmix aus Kinderfreibeträgen, einkommensabhängigem Kindergeld und Kindergeldzuschlägen führte schließlich -von gesetzgeberischen Versäumnissen bei der Abstimmung von EStG und BKGG zwischen 1993 und 1995 abgesehen - zu einer einkommensunabhängigen Entlastung bis in gehobene Einkommensbereiche, darüber hinaus stieg sie mit dem Grenzsteuersatz.

Abbildung 19: Kindergeld und Kinderfreibetrag nach Ordnungszahlen der Kinder 1950 bis 2006

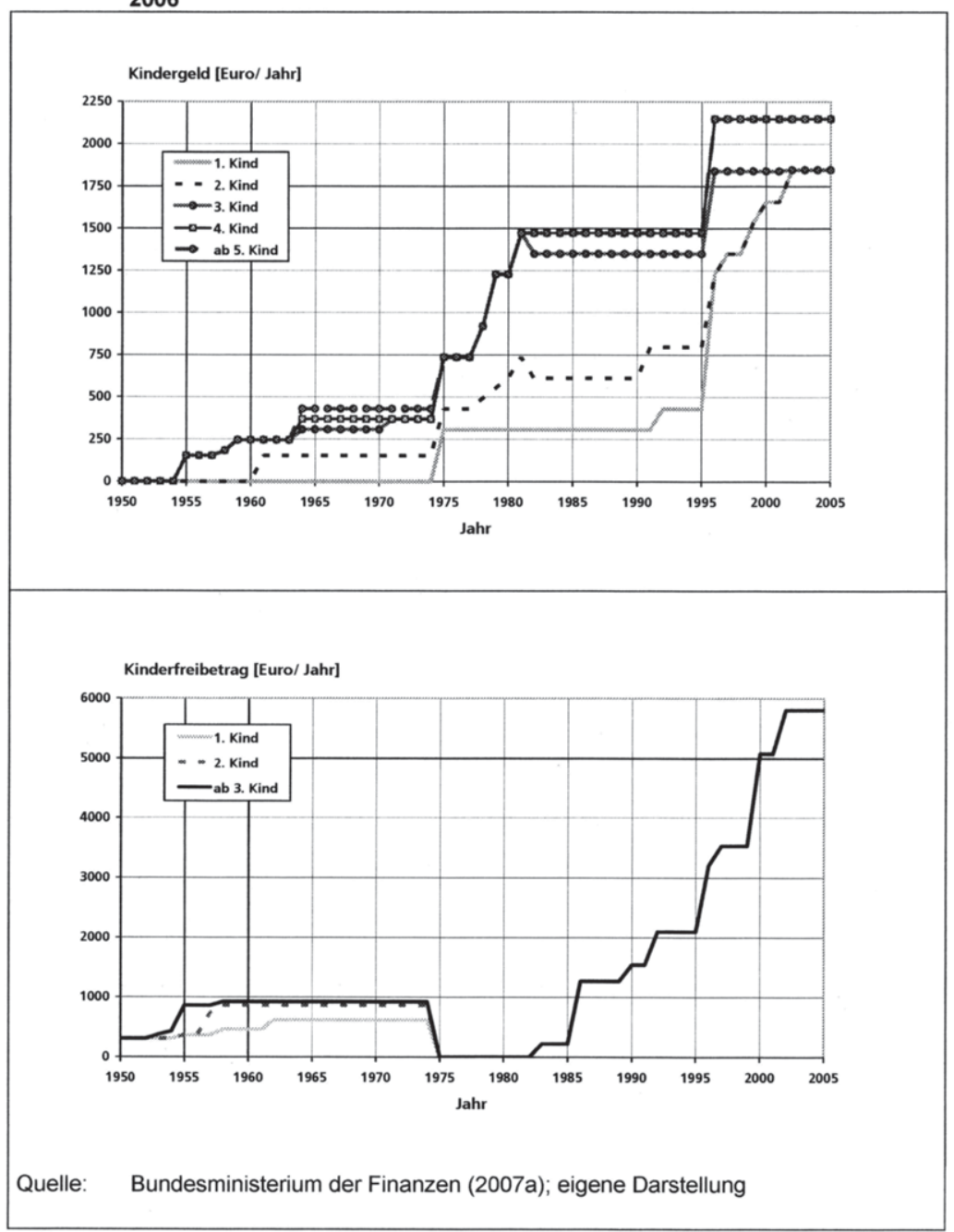


5. Phase: (seit 1996)

Alternative Gewährung von Kindergeld oder Kinderfreibeträgen (Optionsmodell), Leistungsanstiege, abnehmende horizontale Differenzierung

1996 wurde das Kindergeld massiv erhöht, insbesondere die Leistung für erste Kinder stieg von 840 DM (429 Euro) auf 2.400 DM je Jahr (1.227 Euro). Zudem blieb das Kindergeld seitdem unabhängig vom Einkommen. Auch die weiterhin einheitlichen Freibeträge wurden 1996 um über 50\% heraufgesetzt, womit der Gesetzgeber Vorgaben des Verfassungsgerichts nachkam, das die unzureichende steuerliche Freistellung des Existenzminimums von Kindern durch den zuvor bestehenden FLA kritisiert hatte. ${ }^{76}$ Das so genannte Optionsmodell, nach dem Kindergeld und die Entlastung durch Kinderfreibeträge miteinander zu verrechnen sind, löste den bis dahin bestehenden dualen FLA ab, bei dem die beiden Elemente formal unabhängig voneinander waren und somit additiv wirkten. ${ }^{77}$ Die Regelungen zur Einkommensanrechnung beim Kindergeld seit 1983 waren allerdings derart auf die Tarife des EStG abgestimmt, dass trotz wesentlicher Neuerungen in der gesetzlichen Ausgestaltung der FLA mit dem bis heute geltenden Optionsmodell grundsätzlich vergleichbare einkommensabhängige Wirkungen wie zwischen 1983 und 1995 erzeugte. Für die primär an den effektiven Einkommensdifferenzen interessierte Betrachtung dieser Arbeit resultieren die wesentlicheren Änderungen aus den 1996 stark gestiegenen Kindergeldsätzen und -freibeträgen und die reduzierte horizontale Differenzierung. Seit 2002 sind nur noch zwei Kindergeldbeträge vorgesehen von 1.848 Euro je Jahr (bis zum dritten Kind) bzw. 2.148 Euro für weitere Kinder, der Freibetrag beläuft sich stets auf 5.808 Euro.

Insgesamt führen die verschiedenen Rechtsstände zu einem recht unsystematischen Verlauf der Entlastung durch den FLA in Abhängigkeit vom Einkommen der Eltern und von der Ordnungszahl eines Kindes. Auffällige Ergebnisse der Entwicklung von 1950 bis 2006 sind (Abbildung 20):

- Abgebildet ist die (nicht kumulierte) preisniveaubereinigte Entlastung durch den FLA (Kindergeld einschließlich eventueller Kindergeldzuschläge plus Steuerminderung durch den Kinderfreibetrag) für ein erstes, drittes und fünftes Kind bei verschiedenen Einkommensniveaus. Ausgangspunkt der Abbildung ist jeweils ein Einverdienerehepaar, das ausschließlich Bruttoeinkommen aus nichtselbständiger Arbeit bezieht. Die Einkommen sind als Vielfache der jeweiligen jährlichen Durchschnittsentgelte der Rentenversicherung angegeben und reichen von geringen $(50 \%$ des Durchschnitts) bis zu Hochverdiensten (400\%). Beim dritten und fünften Kind ist als Vergleichswert zusätzlich die Entlastung durch den FLA für das erste Kind eines Durchschnittsverdieners aus dem ersten Teil der Abbildung erneut abgetragen.

Vgl. hierzu Tipke, Lang (2002), §9 Rz. $92 f$.

Seit 2000 ist der bis dahin einheitliche Kinderfreibetrag aus juristischen Gründen in zwei Freibeträge zerlegt worden, nämlich den Freibetrag für das sächliche Existenzminimum eines Kindes (Kinderfreibetrag) und den Freibetrag für den Betreuungs- und Erziehungsbedarf (später zusätzlich: "oder Ausbildungsbedarf") eines Kindes. Abgesehen von sich nur geringfügig auswirkenden Unterschieden bei der steuerlichen Behandlung von Kindern bis 16 Jahren einerseits und älteren Kindern andererseits in den Jahren 2000 und 2001 bleibt diese Neuerung für die Entlastungen durch Kinderfreibeträge irrelevant, so dass auch für die Rechtsstände ab 2000 weiterhin der Begriff Kinderfreibetrag verwendet wird, der ab dann zwei Komponenten umfasst. 
Abbildung 20: Entlastung durch den FLA 1950 bis 2006 (in Preisen des Jahres 2005)

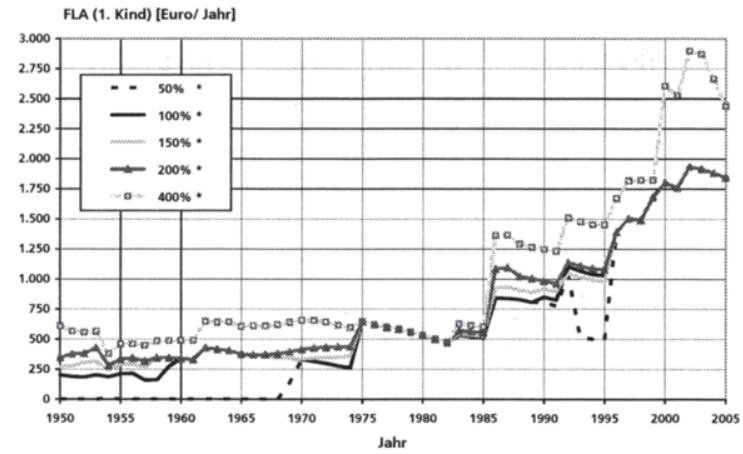

FLA (3. Kind) [Euro/ Jahr]
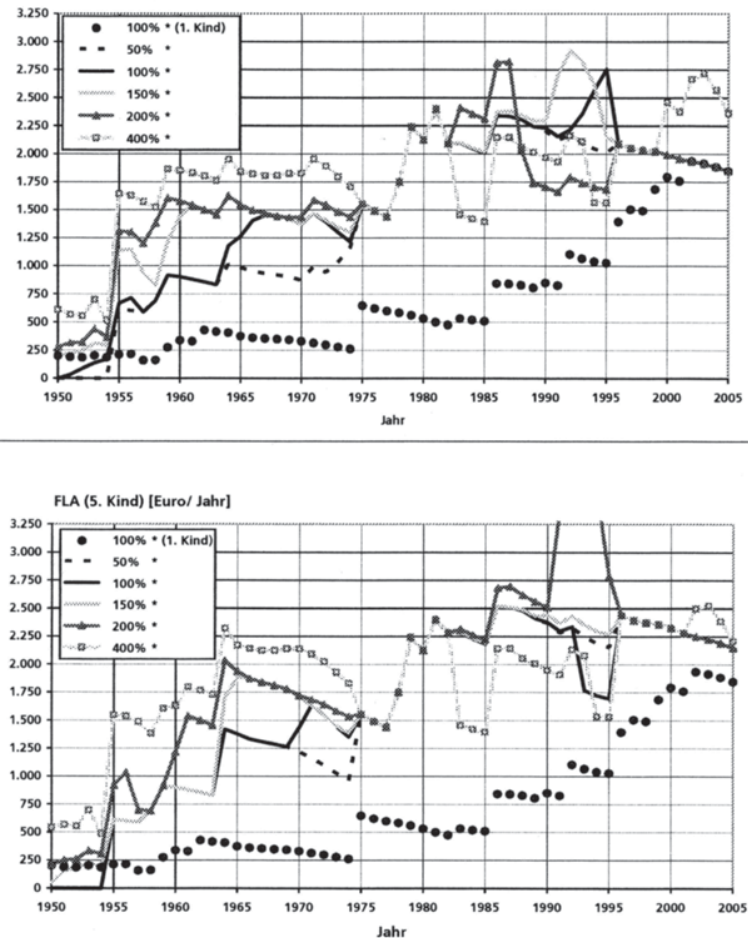

* Einkommen in Prozent des Durchschnittsentgelts der GRV der jeweiligen Jahre Quelle: $\quad$ eigene Berechnungen 
- Grundsätzlich stieg die nominale Entlastung durch den FLA für erste Kinder im Zeitverlauf für alle dargestellten Einkommensgruppen überwiegend monoton an, wobei meist ein positiver Zusammenhang von Einkommen und Entlastung durch den FLA bestand. Preisniveaubereinigt blieb die Wirkung von 1950 bis 1974 recht konstant, vor allem im unteren bis mittleren Einkommensbereich bedeutete die Einführung des Erstkindergeldes 1975 dann eine deutliche Verbesserung gegenüber der vorherigen Freibetragslösung; die Entlastung durch den FLA verdreifachte sich nahezu im Vergleich zum Vorjahr. Auch für Höchstverdiener (400\% des Durchschnittsentgelts) überstieg das neue Erstkindergeld von 307 Euro die Steuerminderung aus dem Jahr 1974 um rund 15\%. Der nächste Leistungssprung erfolgte 1986 mit der deutlichen Anhebung des Freibetrags für erste Kinder. Damit einher ging eine wieder zunehmende Spreizung der Wirkung über die Einkommensskala, wie sie auch bis 1974 bestanden hatte. Durch wiederholte Anhebungen von Kindergeld und -freibeträgen ab 1992 wurde die Wirkung des FLA für erste Kinder in den letzten 15 Jahren stark ausgeweitet. Auch führt das Optionsmodell seit 1996 da$\mathrm{zu}$, dass über weite Teile der Einkommensskala eine gleich hohe Leistung resultiert, eine über das Kindergeld hinausgehende Entlastung durch den Freibetrag ergibt sich erst bei hohen Einkommen. ${ }^{78}$ Nominal sinkende Entlastungen treten in zwei Fällen auf: Zum einen ergab sich bei Geringverdienern eine deutliche Verschlechterung von 1993 bis 1995, die Folge gesetzgeberischer Versäumnisse war, die weiter unten kurz erläutert wird. Zum anderen schlägt sich die reduzierte Wirkung eines Freibetrags im Fall von Tarifsenkungen bei hohen Einkommen in den Jahren nach 2003 nieder: Der fallende Grenzsteuersatz durch die Reformen des EStG nach 2003 bewirkt eine abnehmende nominale Entlastung bei unverändertem Kinderfreibetrag. Preisniveaubereinigt zeigen sich auch bei den darunter liegenden Einkommensniveaus leichte Rückgänge, die aus der fehlenden Anpassung der Leistungsparameter des FLA an die Preisentwicklung der letzten Jahre folgen.

- Im Vergleich zu den Wirkungen bei ersten Kindern fällt beim FLA für dritte Kinder zunächst das über weite Zeiträume wesentlich höhere Niveau auf. Bis zur Jahrtausendwende bewirkte der FLA für dritte Kinder eine deutlich stärkere Entlastung, die bis 1985 rund dem drei- bis vierfachen des FLA für erste Kinder entsprach. Während die derzeitige Regelung des FLA für erste Kinder im historischen Vergleich großzügig erscheint, zeichnet sich bei dritten Kindern über die letzten Jahrzehnte eher eine Seitwärtsbewegung ab. Preisniveaubereinigt ergibt sich eine recht konstante Wirkung seit Beginn der 1980er Jahre bei jedoch starken Schwankungen je nach Einkommensniveau. Im Vergleich zu den Effekten im Zeitraum vor 1975 sind die heutigen Entlastungswirkungen des FLA allerdings auch für dritte Kinder deutlich stärker. Als Zeiten mit erheblichen Leistungszunahmen für jede Einkommensstufe sind das Jahr 1955 und die zweite Hälfte der 1970er Jahre zu nennen. Bis 1975 besteht ein positiver Zusammenhang von Einkommen und Entlastung durch den FLA für dritte Kinder, zwischen 1983 und 1995 ergibt sich durch Kindergeldzuschläge und die Minderung des Kindergelds bei höheren Einkommen

78 Zur Wirkung des Optionsmodells und zur Aufteilung des Kindergelds in Steuerentlastung und Sozialtransfer in Abhängigkeit vom Grenzsteuersatz s. Althammer (2000), S. $41 f$ 
ein äußerst heterogenes Bild. Seit der Mitte der 1990er Jahre glich die Wirkung des FLA für dritte Kinder zunehmend derjenigen für erste Kinder.

- Der Verlauf der Entlastung durch den FLA bei fünften Kindern ähnelt demjenigen von dritten Kindern. Allerdings liegen die Werte wiederholt auf einem nochmals höheren Niveau.

Die irregulären Verläufe in den Jahren 1993 bis 1995 sind auf eine fehlende Harmonisierung von EStG und BKGG zurückzuführen. Nach dem erstmals durch das FKPG für den Veranlagungszeitraum 1993 wirksamen § 32 c EStG (Entlastung bei niedrigen Erwerbseinkommen, ab Veranlagungszeitraum 1994 § 32 d EStG) war in unteren Einkommensbereichen eine geringere als die tarifliche Einkommensteuer nach $\S 32$ a EStG anzusetzen. ${ }^{79}$ Da das BKGG, dessen Parameter zur Einkommensanrechnung auf das EStG in seiner ursprünglicheren Form abgestimmt waren, die Steuerrechtsänderung nicht nachvollzog, ergaben sich zwischen 1993 und 1995 nicht intendierte und auf Unverständnis stoßende Entlastungsmuster (Abbildung 21). ${ }^{80}$ In der Abbildung ist die Wirkung für ein erstes Kind dargestellt. Die Leistungsspitzen bei Einkommen um 20.000 Euro ergeben sich dadurch, dass ein Ehepaar nur durch den Kinderfreibetrag in den Bereich der „Entlastung bei niedrigen Erwerbseinkommen" fällt. Mit der Ordnungszahl der Kinder steigt der Einkommensbereich, in dem der Kinderfreibetrag zu einer Besteuerung unterhalb des tariflichen Werts führt und damit auch die Lage der Entlastungsspitze.

Abbildung 21: Wirkung des FLA 1995: Ohne und mit „Entlastung bei niedrigen Erwerbseinkommen"

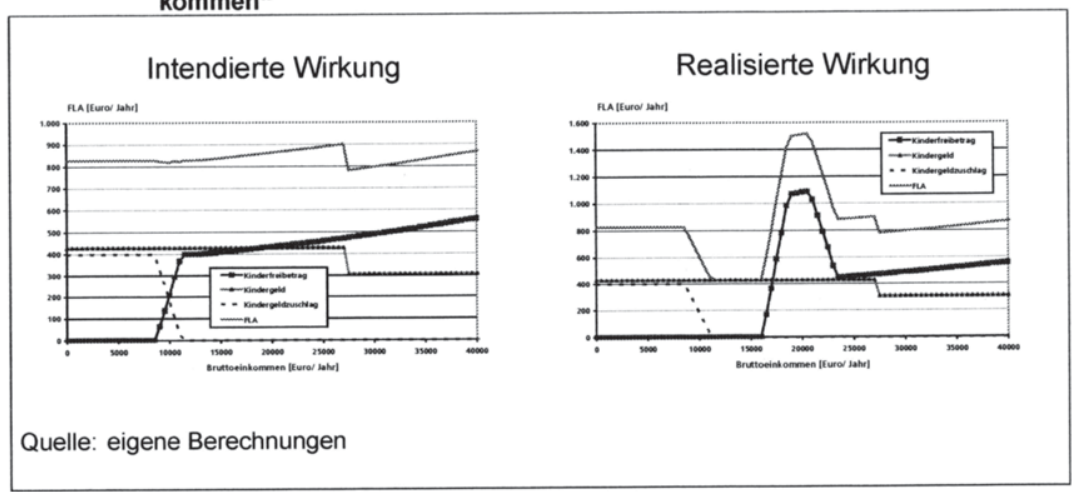

Im langfristigen Vergleich mit früheren Regelungen sticht beim FLA in seiner derzeit geltenden Fassung erstens ein relativ hohes Leistungsniveau hervor. Die Leistungsausweitungen seit den 1950er Jahren folgen dabei vor allem aus einer zunehmenden

79 Gesetz über Maßnahmen zur Bewältigung der finanziellen Erblasten im Zusammenhang mit der Herstellung der Einheit Deutschlands, zur langfristigen Sicherung des Aufbaus in den neuen Ländern, zur Neuordnung des bundesstaatlichen Finanzausgleichs und zur Entlastung der öffentlichen Haushalte (Gesetz zur Umsetzung des Föderalen Konsolidierungsprogramms - FKPG), BGBL | 1993, S. 944

80 Vgl. Kowalski (1994), S. 149 
Anhebung von Kindergeld und -freibeträgen für erste und zweite Kinder, für Kinder höherer Ordnungszahl sind die preisniveaubereinigten Entlastungswirkungen hingegen deutlich moderater gestiegen. In seiner Gesamtwirkung hat sich der FLA damit von einer schwerpunktmäßig auf Mehrkindfamilien ausgerichteten Förderung zu einer allgemeineren familienpolitischen Maßnahme entwickelt. Zweitens führt der heutige FLA zu einer relativ geringen Spreizung der kindbedingten Leistungen über die Einkommensskala. Wie seit 1950 fast durchgehend-Ausnahme ist der Zeitraum von 1975 bis 1982- ergibt sich auch heute aus den einzelnen Elementen des FLA insgesamt eine mit dem Einkommen steigende Entlastung, anders als früher dominiert jedoch der Effekt des einkommensunabhängigen Kindergelds.

In einer Längsschnittperspektive resultiert aus der über lange Zeiträume sehr ausgeprägten horizontalen Differenzierung im FLA ein ergänzender Einflussfaktor auf den kindbedingten Einkommensvorteil, der bei einer Zeitpunktbetrachtung verborgen bleibt. Da Kinder nur bis zu einem Höchstalter im FLA berücksichtigt werden, ergeben sich bei identischen Kinderzahlen aber abweichenden Altersabständen unterschiedliche Entlastungswirkungen. Von drei Geschwistern, die innerhalb von drei Jahren geboren werden, trägt das Jüngste typischerweise bis zum Ende seines 16. Lebensjahrs die Ordnungszahl drei, wenn das Älteste bei Vollendung des 18 . Lebensjahrs aus dem FLA ausscheidet. Anschließend ist die Ordnungszahl des dritten Kindes zwei und fällt im Jahr darauf auf eins. Wird das dritte Kind unter sonst gleichen Umständen erst zehn Jahre später geboren, ist seine Ordnungszahl nur bis zum Ende des sechsten Lebensjahres drei, vom achten bis zum vollendeten 18. Lebensjahr beträgt sie eins. Zwar werden in beiden Fällen drei Kinder über insgesamt 54 Jahre im FLA berücksichtigt, die horizontale Differenzierung führt jedoch zu tendenziell höheren Wirkungen bei rascher Geburtsfolge.

Ein zweiter nur bei einer Längsschnittbetrachtung zu Tage tretender Effekt folgt aus im Zeitverlauf unterschiedlichen Altersgrenzen für den FLA. Der FLA kannte durchgängig zwei für diese Arbeit relevante Altersgrenzen. Zum einen bestand eine allgemeine Grenze von meist 18 Jahren, zum anderen eine höhere Altersgrenze für Kinder in Ausbildung, die überwiegend bei 27 Jahren lag. Von 1955 bis 1974 wurde für Auszubildende bis zur Vollendung des 25. Lebensjahres Kindergeld gezahlt, danach galt durchgängig die höhere Altersgrenze von 27 Jahren. Zwischen 1955 und 1981 war die allgemeine Altersgrenze für das Kindergeld die Vollendung des 18. Lebensjahrs, zwischen 1982 und 1995 galt das 16. Lebensjahr. Seit 1996 wurde wieder das ursprüngliche Alter eingesetzt. Die Höchstalter für Kinderfreibeträge entwickelten sich weitgehend gleichartig. Allerdings galt zwischen 1955 und 1964 eine großzügigere Regelung bei Auszubildenden (27. statt 25. Lebensjahr), auch die Herabsetzung der allgemeinen Grenze auf das 16 . Lebensjahr erfolgte ein Jahr später (1983) und wurde drei Jahre früher revidiert (1992). Die letzte Änderung erfolgte mit Wirkung ab dem Veranlagungszeitraum 2007. Nach einer Übergangsregelung wird die Altersgrenze für Kindergeld und -freibeträge für Auszubildende nun wieder auf den niedrigeren Wert von 25 Jahren herabgesetzt ${ }^{81}$ Eine tabellarische Übersicht der Entwicklung der Altersbeschränkungen des FLA ist im tabellarischen Anhang A2 angefügt (Tabelle 25).

81 Steueränderungsgesetz 2007 vom 19.07.2006 BGBI I, S. 1652 
Die an Hand der Entlastungen bei Einzelfällen dargestellten Phasen des FLA schlagen sich auch in der Gesamtbetrachtung ihrer fiskalischen Bedeutung nieder. Die Entwicklung der Ausgaben für das Kindergeld wird überwiegend von den Kindergeldsätzen und der Größe der Bevölkerung im Alter von bis zu 18 Jahren geprägt (Abbildung 22). Daneben ging mit einer steigenden Bildungsbeteiligung Volljähriger ein Anstieg der durchschnittlichen Bezugsdauer einher. Von nachrangiger Bedeutung war die Einführung einer Einkommensgrenze ab 1965, durch die für grundsätzlich zu berücksichtigende Auszubildende, die die allgemeine Altersgrenze überschritten hatten, bei zu hohen eigenen Einkünften und Bezügen kein Kindergeld gezahlt wurde. Sprunghafte Ausgabenanstiege folgten aus der Einführung des Zweitkindergeldes 1961, der Gewährung des Erstkindergeldes bei gleichzeitiger Anhebung sämtlicher Sätze 1975 und den wiederholten Leistungsverbesserungen unter dem Optionsmodell ab 1996.

Die leicht zurückgehenden Ausgaben in den 1980er Jahren ergaben sich bei fallenden Kinderzahlen, die Niveauverschiebung 1991 aus der deutschen Wiedervereinigung. Da einheitliche Zeitreihen zu sämtlichen Kindergeldkindern nicht existieren, sind in Abbildung 22 Kindergeldzahlungen an Beschäftigte des öffentlichen Dienstes nicht enthalten, so dass die absolute Höhe der Ausgaben nur bedingt Aussagen zum Gesamtumfang zulässt. Seit 1996 sind die Ausgaben gemäß Abbildung 22 kontinuierlich von 19,2 auf 29,2 Mrd. Euro im Jahr 2004 um knapp 53\% angestiegen. Die Kindergeldausgaben unter Einschluss des öffentlichen Dienstes lagen seit 1996 um rund $20 \%$ über diesen Werten ${ }^{82}$ und betrugen zwischen 2002 und 2007 rund 34,5 bis 35,0 Mrd. Euro. ${ }^{83}$ Die Entwicklung der durchschnittlichen Ausgaben je Kind weicht von der Gesamtentwicklung vor allem im Jahr 1975 ab. Damals stiegen die Ausgaben von 1,7 auf 6,0 Mrd. Euro um 265\%, die Anzahl der Kindergeldkinder von 5,2 auf 14,1 Mio. um 171\%. Da hierunter der Anteil von Kindern mit der Ordnungszahl eins und entsprechend niedrigeren Sätzen hoch war, wuchs der durchschnittliche Jahresbetrag nur um $35 \%$ von 319 auf 430 Euro.

Für die auf Kinderfreibeträge zurückzuführenden Steuermindereinnahmen sind seit deren Wiedereinführung im Jahr 1983 drei Phasen auszumachen (Abbildung 23). Bei den geringen Freibeträgen von 221 Euro in den Jahren 1983 bis 1985 beliefen sich die Mindereinnahmen auf etwa 920 Mio. Euro/ Jahr. Als die Freibeträge 1986 nahezu versechsfacht wurden und bis 1992 weitere Anhebungen folgten, bewegten sich die Werte zwischen 4,0 und 8,4 Mrd. Euro. In den ersten Jahren des Optionsmodells ging von den in Relation zu den Kindergeldsätzen niedrigen Freibeträgen kaum eine zusätzliche Entlastung aus, erst mit den höheren Freibeträgen ab 2000 wuchs wieder der Anteil der Eltern, für die die Steuerminderung höher ausfiel als das Kindergeld auf etwa $12 \%$ bis $15 \% .{ }^{84}$ Die Steuermindereinnahmen erreichten damit eine Größenordnung von rund 1,5 Mrd. Euro.

32 Vgl. Deutscher Bundestag (2001a), S. 344

83 Bundesministerium der Finanzen (2007a), S. 63

84 Vgl. Bundesministerium der Finanzen (2007a), S. 57. Für 1970 werden Steuermindereinnahmen von 2,4 Mrd. Euro genannt. (Bundesministerium für Jugend, Familie und Gesundheit (Hrsg.) (1971), S. 47) 
Abbildung 22: Ausgaben für das Kindergeld 1955 bis 2005: Insgesamt und je Kind

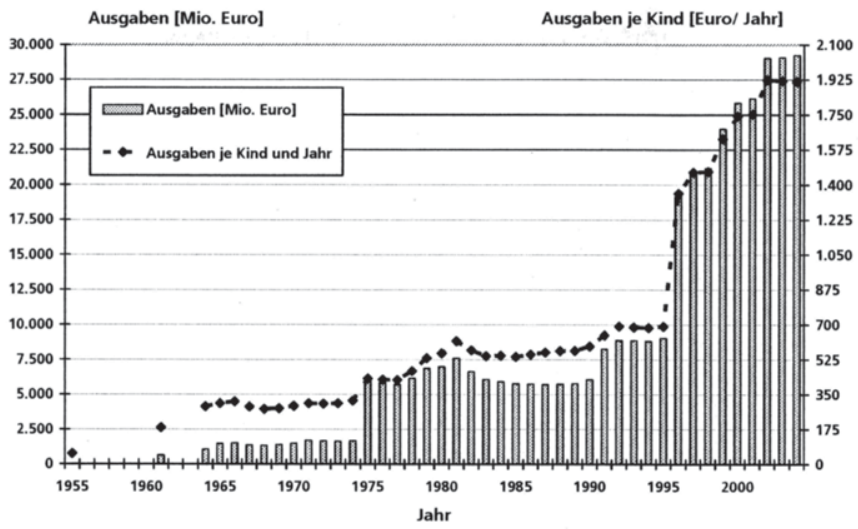

Alle Werte ohne Kindergeld im öffentlichen Dienst, ab 1964 einschließlich Verwaltungskosten (bis 1991 früheres Bundesgebiet, danach Deutschland)

Quelle: $\quad$ Frerich, Frey (1996); Bundesministerium für Arbeit und Soziales (Hrsg.) (2007); eigene Berechnungen

Abbildung 23: Steuermindereinnahmen durch Kinderfreibeträge 1982 bis 2006

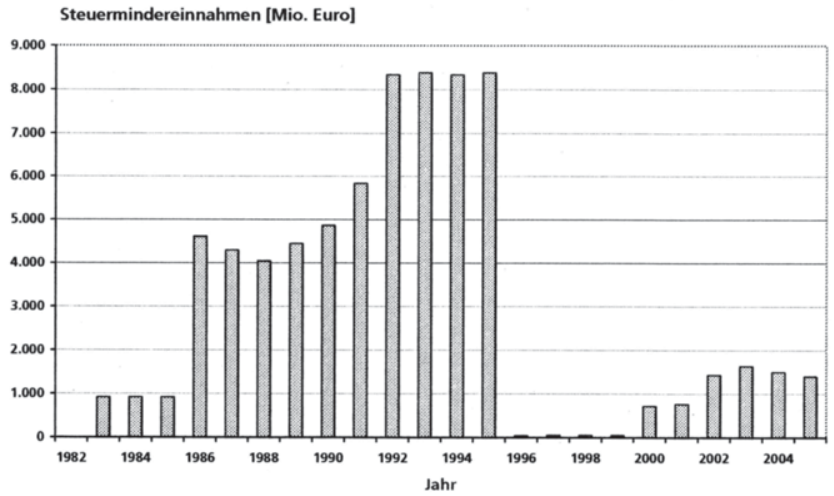

bis 1991 früheres Bundesgebiet, danach Deutschland

Quelle: Bundesministerium der Finanzen (2007a).; eigene Darstellung 


\subsubsection{Weitere kindbedingte Steuerentlastungen}

Neben den dem FLA zugeordneten Kinderfreibeträgen ergeben sich aus dem EStG weitere kindbedingte Entlastungen durch Ausbildungsfreibeträge oder die Absetzbarkeit von Betreuungskosten, die sowohl die zu entrichtende Einkommensteuer als auch von dieser abgeleitete Zuschlagsteuern mindern. Zudem standen Eltern phasenweise höhere Abzugsbeträge für Vorsorgeaufwendungen zu (so genannte Kinderadditive) und die zumutbare Belastung im Falle außergewöhnlicher Belastungen ist nach der Kinderzahl gestaffelt. Daneben existieren weitere steuerrechtliche Regelungen mit Kindbezug, die wegen ihrer geringen fiskalischen Bedeutung oder ihrer ausgeprägten Einzelfallabhängigkeit im STM nicht abgebildet sind (wie Freibeträge für die Beschäftigung von Haushaltshilfen oder die Abzugsfähigkeit von Schulgeld an Ersatzschulen als Sonderausgabe). Die kindbezogenen Regelungen galten zum Teil durchgängig seit 1950 (wie die Haushaltsfreibeträge) oder nur phasenweise (wie Kinderbetreuungskosten) ausschließlich für Alleinerziehende. Im Einzelnen umfassen die kindbedingten Entlastungen bei der Einkommensteuer:

- Ausbildungsfreibeträge

- Abzugsbetrag für Alleinerziehende

- Abzug von Kinderbetreuungskosten

- Kinderadditive bei begrenzt abzugsfähigen Vorsorgeaufwendungen

\section{Ausbildungsfreibeträge}

Der Begriff des Ausbildungsfreibetrags wurde 1977 in $\S 33$ a Abs. 2 EStG (Außergewöhnliche Belastungen in besonderen Fällen) eingeführt. Steuerpflichtigen, denen Aufwendungen für die Berufsausbildung eines Kindes erwuchsen, wurde auf Antrag ein Freibetrag vom Gesamtbetrag der Einkünfte abgezogen, dessen Höhe von Alter (unter/ ab 18 Jahren) und Unterbringung (auswärtig/ bei den Eltern) des Kindes abhing. Allerdings sah $\S 33$ a Abs. 2 EStG bereits seit 1954 Abzugsbeträge gleicher Wirkung vor, ohne den Begriff des Ausbildungsfreibetrags explizit zu gebrauchen. ${ }^{85}$ Ab dem Jahr 2002 wich der Begriff im Zusammenhang mit der Neuordnung der Freistellung des Existenzminimums von Kindern wieder aus $\S 33$ a Abs. 2 EStG, der nun einen Freibetrag zur Abgeltung eines Sonderbedarfs in Folge von Ausbildung beinhaltet. ${ }^{86}$ Gemeinsam ist allen drei Fassungen, dass der jeweilige Freibetrag nur für Kinder gewährt wurde, für die auch Anspruch auf einen Kinderfreibetrag bestand. Da $\S 33$ a Abs. 2 EStG in allen drei Zeiträumen gleichartige Entlastungen mit sich brachte, wird hier vereinfachend für alle Rechtsstände von Ausbildungsfreibeträgen gesprochen. Unterschiede bestanden in der Art der Kinder, für die ein Ausbildungsfreibetrag in Betracht kam, und in der Anrechnung eigener Einkommen des Kindes. Grundsätzlich sollten die Beträge den typischen Mehrbedarf von Kindern in Ausbildung steuerlich abdecken, der über den Kinderfreibetrag hinausging.

Zwischen 1954 und 1976 war ein Ausbildungsfreibetrag für Kinder vorgesehen, die während der Ausbildung auswärtig untergebracht waren. Anders als bei außergewöhnlichen Belastungen üblich war der Betrag nicht um die zumutbare Belastung zu kürzen, auch eigenes Einkommen des Auszubildenden blieb unberücksichtigt. Der

85 Gesetz zur Neuordnung von Steuern 1954, BGBL | 1954, S. 373

86 Schmidt (Hrsg.) (2002), § 33 a Rz 52 
Freibetrag belief sich bis 1957 auf 480 DM (245 Euro) und wurde bis 1976 dreimal erhöht, zuletzt 1961 von 900 auf 1.200 DM (von 460 auf 614 Euro). ${ }^{87}$ Die Ausbildungsfreibeträge ab 1977 unterschieden erstens zwischen minder- und volljährigen Kindern und zweitens zwischen Arten der Unterbringung (auswärtig/ bei den Eltern). Neu war die Einführung eines Freibetrags für volljährige Auszubildende, die bei den Eltern wohnten. Gegenüber 1976 wurden die Beträge massiv erhöht. Für Minderjährige, für die weiterhin nur bei auswärtiger Unterbringung der Freibetrag anzusetzen war, stieg der Wert um 50\% auf 1.800 DM (920 Euro), für Volljährige auBerhalb des Elternhauses galt nun ein um das 2,5-fache erhöhter Wert von 4.200 DM (2.147 Euro). Im Gegenzug wurden ab 1977 die Ausbildungsfreibeträge in Abhängigkeit vom Einkommen des Kindes gemindert. Im Rahmen von Konsolidierungsbemühungen wurden die Beträge 1984 durch das HBeglG 1983 halbiert, von 1988 bis 2002 waren wieder die Werte des Jahres 1977 wirksam. Ab 2002 sollte der Ausbildungsbedarf in der Regel durch die deutlich angehobenen Kinderfreibeträge abgedeckt sein, so dass seitdem nur noch für auswärtig untergebrachte volljährige Auszubildende ein Ausbildungsfreibetrag von 924 Euro besteht. Zu Beginn der 1980er Jahre, vor der Halbierung, beliefen sich die Steuermindereinnahmen durch Ausbildungsfreibeträge auf etwa 400 Mio. Euro jährlich. Für die zweite Hälfte der 1990er Jahre sind Werte von rund 650 Mio. Euro zu verzeichnen, nach 2002 gingen sie auf rund 180 Mio. Euro zurück. ${ }^{88}$

Bei den Berechnungen im zweiten Teil dieser Arbeit sind hauptsächlich die Ausbildungsfreibeträge für volljährige Auszubildende von Interesse, da minderjährige Auszubildende eher nicht auswärtig untergebracht sind und somit kein Abzug für sie in Betracht kommt. Die seit 1977 geltenden Vorschriften zur Minderung bergen für die modellhaften Analysen mit dem STM ein Problem, das geringfügige Rechenungenauigkeiten mit sich bringt: Während der Einfluss eigener Einkünfte von Auszubildenden keine Verzerrungen bewirkt, ist die Anrechnung von Zuschüssen nach dem BAföG (und anderer Ausbildungshilfen aus öffentlichen Mitteln) tückisch. Bei der Berechnung der Einkommensteuer der Eltern ist der Ausbildungsfreibetrag zu berücksichtigen, der seinerseits vom BAföG des Kindes abhängt. In dessen Berechnung fließt jedoch die von den Eltern entrichtete Einkommensteuer ein. Während die Reihenfolge der Schritte im Verwaltungsvollzug dadurch geklärt ist, dass beim BAföG die Einkommensverhältnisse der Eltern aus Vorjahren maßgeblich sind, ist die Berechnung im STM, das hiervon abstrahiert, rekursiv. Abweichend vom grundlegenden Ansatz des STM, alle Ergebnisgrößen aus den Einkommensverhältnissen des jeweils betrachteten Jahres abzuleiten, wird daher zunächst für die Berechnung des BAföG die Einkommensteuer zu Grunde gelegt, die sich ohne Ausbildungsfreibetrag ergibt, anschließend wird die Einkommensteuer erneut und dann mit dem gegebenenfalls um Zuschüsse nach dem BAföG gekürzten Ausbildungsfreibetrag berechnet.

Von diesem technischen Problem abgesehen irritiert die Regelung des §33 a Abs. 2 EStG, nur den Zuschussanteil des BAföG auf den Ausbildungsfreibetrag an-

87 Die verschiedenen Ausbildungsfreibeträge und die Phasen ihrer Geltung sind in Tabelle 26 im Anhang aufgelistet.

88 Vgl. Bundesministerium der Finanzen (2007b), S. 48; Bundesministerium der Finanzen (2007a), S. 63 
zurechnen, auch inhaltlich. ${ }^{89}$ Leistungen nach dem BAföG erhöhen die wirtschaftliche Leistungsfähigkeit der Familie im Jahr der Förderung in vollem Umfang, unabhängig davon, ob sie aus Darlehen oder Zuschuss bestehen. Eine Darlehenskomponente bei der Förderung beeinträchtigt die wirtschaftliche Leistungsfähigkeit allerdings dann, wenn die Tilgung einsetzt. Die Rückzahlung obliegt jedoch nicht den Eltern, sondern dem geförderten Auszubildenden selbst, mindert demnach seine wirtschaftliche Leistungsfähigkeit in späteren Jahren und nicht die seiner Eltern während der Förderung. Für „egoistische Eltern“ wäre ein BAföG-Volldarlehen optimal, da dieses den Ausbildungsfreibetrag nicht mindert und so ihre steuerlichen Abzugsmöglichkeiten maximiert, während sie selbst durch das Darlehen nicht belastet werden. Soll die Darlehenskomponente des BAföG steuerlich erfasst werden, erscheint es angemessener, dies zu dem Zeitpunkt und bei dem Zensiten zu tun, bei dem sie tatsächlich wirksam wird. Dies würde bedeuten, dass Rückzahlungen eines ehemals Geförderten steuermindernd wirken.

\section{Abzugsbetrag für Alleinerziehende}

Wie auch bei den Ausbildungsfreibeträgen wechselten die Begriffe für einen weiteren Abzugsbetrag von der Bemessungsgrundlage, der speziell Alleinerziehenden zu Gute kam. Ursprünglich in die Steuertabellen eingearbeitet und von 1958 bis 1974 als Sonderfreibetrag für die Halbfamilie bezeichnet, bestand bis 2004, als der Gesetzgeber mit seiner Abschaffung verfassungsgerichtliche Vorgaben erfüllte, durchgängig ein Freibetrag nach $\S 32$ EStG, seit 1975 Haushaltsfreibetrag genannt. ${ }^{90}$ Als Ausgleich für dessen Wegfall wurde ab 2004 der neue $\S 24$ b EStG geschaffen mit einem Entlastungsbetrag für Alleinerziehende, der vergleichbare Effekte wie die früheren Freibeträge erzeugt. ${ }^{91}$ Im Sinne einer einheitlichen Terminologie wird in dieser Arbeit Abzugsbetrag für Alleinerziehende als Oberbegriff gewählt.

In den Veranlagungszeiträumen vor 1958 bestand für Alleinerziehende eine eigene der damaligen Steuerklassen, was der Wirkung eines Abzugsbetrags von anfänglich 150 DM (77 Euro) entsprach, ab 1953 wurde dieser Wert mehr als verfünffacht. Wesentliche weitere Erhöhungen folgten 1975, nachdem der Betrag zuvor 17 Jahre lang konstant geblieben war, und 1982. Zwischen 1982 und 1995 entsprach der Abzugsbetrag mit seinen Werten von 4.212 bis 5.616 DM (2.154 bis 2.871 Euro) dem tariflichen Grundfreibetrag und sollte damit einen Ausgleich für die Verdoppelung der Nullzone beim Splittingverfahren bieten. ${ }^{92}$ Der neue Abzugsbetrag nach $\S 24$ b EStG liegt mit 1.308 Euro weit unter den vorherigen Beträgen nach § 32 EStG. Die jeweiligen Abzugsbeträge der betrachteten Veranlagungszeiträume sind in Tabelle $27 \mathrm{im}$ Anhang aufgeführt. Die Steuermindereinnahmen durch den Haushaltsfreibetrag er-

89 Zur Förderung als Zuschuss und/ oder Darlehen beim Studenten-BAföG siehe das Kapitel zur Ausbildungsförderung (Kapitel 4.5).

90 Vgl. Dresdner Bank AG (1976), S .124; Deutscher Bundestag (1999), S. 2

91 Der Begriff des Alleinerziehenden wird beim Entlastungsbetrag im Vergleich zum Haushaltsfreibetrag strenger abgegrenzt, auch wird er anders als sein Vorgänger von der Summe der Einkünfte statt vom Einkommen abgezogen. Beide Aspekte sind für den hier gegebenen Kontext jedoch ohne Belang.

92 Althammer (2000), S. 38 
reichten in den letzten Jahren rund 1 Mrd. Euro, beim Entlastungsbetrag sanken die Werte ab 2004 auf knapp 0,4 Mrd. Euro. ${ }^{93}$

\section{Abzug von Kinderbetreuungskosten}

Kinderbetreuungskosten waren erstmals im Veranlagungszeitraum 1980 steuerlich absetzbar ${ }^{94}$ Die verschiedenen Rechtsstände seitdem unterscheiden sich gravierend bezüglich der Voraussetzungen, der maximalen Höhe des Abzugsbetrags und der Einkommensanrechnung. In den Jahren von 1980 bis 1982 konnten sowohl von Ehepaaren als auch Alleinerziehenden für Kinder unter 18 Jahren Kinderbetreuungskosten als außergewöhnliche Belastung nach $\S 33$ a Abs. 3 EStG geltend gemacht werden. Nachgewiesene Kosten von bis zu 600 DM (307 Euro) je Kind waren berücksichtigungsfähig, ohne Nachweis wurden pauschal 300 DM (153 Euro) anerkannt, bei Splittingfällen verdoppelten sich diese Beträge.$^{95}$ Nachdem 1983 und 1984 keine Betreuungskosten steuerlich anerkannt worden waren, wurden ab 1985 ausschließlich Alleinerziehenden recht hohe Abzugsmöglichkeiten für Kinder, die das 16. Lebensjahr noch nicht vollendet hatten, eingeräumt ( $\$ 33 \mathrm{c} \mathrm{EStG).} \mathrm{Bis} \mathrm{zu} 4.000 \mathrm{DM}$ (2.045 Euro) waren für das erste und 2.000 DM (1.023 Euro) für jedes weitere Kind absetzbar. Allerdings waren die Aufwendungen um die zumutbare Belastung nach $\S 33$ EStG zu kürzen. Mindestens wurde allerdings auch ohne Nachweis ein pauschaler Abzugsbetrag von 480 DM (245 Euro) gewährt. Mit der Reform der Kinderfreibeträge im Jahr 2000, durch die nun über $\S 32$ Abs. 6 EStG explizit auch der Betreuungsbedarf abgedeckt werden sollte, entfielen die Betreuungskosten nach $\S 33$ c EStG. Ab 2002 entschloss sich der Gesetzgeber jedoch, in einem neuen $\S 33 \mathrm{c}$ EStG zusätzlich je Kind unter 14 Jahren den Abzug nachgewiesener enwerbsbedingter Kinderbetreuungskosten von bis zu 1.500 Euro außerhalb des FLA zu ermöglichen, soweit diese den Betreuungsfreibetrag von 1.548 Euro übersteigen. Bei Ehepaaren kann sich diese Regelung folglich nur für Doppelverdiener auswirken.

Die letzte Änderung ist seit dem Jahr 2006 wirksam. Zum einen werden weiterhin enwerbsbedingte Kinderbetreuungskosten anerkannt, nun jedoch als Werbungskosten (bzw. Betriebsausgaben) statt als außergewöhnliche Belastung (§ 9 Abs. 5 EStG, der auf $\S 4 \mathrm{f} \mathrm{EStG} \mathrm{verweist).} \mathrm{Zum} \mathrm{anderen} \mathrm{besteht} \mathrm{unabhängig} \mathrm{vom} \mathrm{Erwerbs-}$ status die Möglichkeit, entsprechende Kosten als Sonderausgaben geltend zu machen ( $\$ 10$ Abs. 1 Nr. 5 EStG). Relevant ist die Unterscheidung von enwerbsbedingten und nicht erwerbsbedingten Betreuungskosten für die Altersspanne des Kindes, innerhalb derer die Kosten abzugsfähig sind. Bei erwerbstätigen Eltern reicht die Spanne vom nullten bis zur Vollendung des 14. Lebensjahres, nicht erwerbsbedingte Betreuung wird nur für das Kindergartenalter von drei bis unter sechs Jahren berücksichtigt. Im Vergleich zur Regelung bis 2005 wurde der maximale Abzug von 1.500 auf 4.000 Euro deutlich heraufgesetzt, außerdem werden nun auch die Betreuungskosten unterhalb von 1.548 Euro abgezogen. Allerdings sind die Aufwendungen nicht vollständig sondern nur zu zwei Dritteln anzusetzen, so dass der maximale Abzug bei Kinderbetreuungskosten von mindestens 6.000 Euro eintritt. Gegenüber dem

93 Bundesministerium der Finanzen (2007a), S. 63

94 Zur Entwicklung der Abzugsmöglichkeiten siehe auch Tabelle 28 im Anhang.

95 Willeke, Onken (1990), S. 418 
Rechtsstand bis 2005 ergibt sich mit der Neuregelung aus Sicht des Zensiten stets eine Verbesserung.

Die Abzugsmöglichkeiten für Ehepaare und Alleinerziehende zu Beginn der 1980er Jahre brachten Steuerausfälle von gut 1 Mrd. Euro jährlich mit sich, ${ }^{96}$ die ausschließlich Alleinerziehende betreffende Regelung bis 1999 führte zuletzt zu Steuermindereinnahmen von etwa 100 Mio. Euro. Nach 2002 ergaben sich Werte von bis zu 170 Mio. Euro, ${ }^{97}$ ab 2006 ist mit einem erheblichen Anstieg zu rechnen. Für die Modellrechnungen im zweiten Teil dieser Arbeit stellt sich die Frage, wie mit dem nachweisabhängigen Abzug von Kinderbetreuungskosten umzugehen ist. Die pauschalen Mindestbeträge zwischen 1980 und 1999 gehen selbstverständlich in die Einkommensteuersimulation ein, darüber hinausgehende nachzuweisende Beträge werden dem Prinzip folgend, nur typisierte Beträge zu berücksichtigen, nicht angesetzt.

\section{Kinderadditive bei begrenzt abzugsfähigen Vorsorgeaufwendungen}

Von 1950 bis 1985 galten für Eltern großzügigere Höchstbeträge bei den als Sonderausgaben begrenzt abzugsfähigen Vorsorgeaufwendungen nach $\S 10 \mathrm{EStG}$. Für jedes Kind erhöhte sich der maximale Abzugsbetrag um 400 DM (1950 bis 1954), 500 DM (1955 bis 1974) bzw. 600 DM (1975 bis 1985) (205, 256 bzw. 307 Euro). ${ }^{98}$ In Kombination mit den sonstigen Regelungen zum beschränkten Abzug von Vorsorgeaufwendungen erhöhte sich der effektiv abzugsfähige Betrag um bis zu $50 \%$, so dass für jedes Kind bis zu 900 DM anzusetzen waren. Hatte ein Steuerpflichtiger das 49. Lebensjahr vollendet, so verdoppelten sich bis 1975 die Werte. 1986 entfielen diese so genannten Kinderadditive, als gleichzeitig die Kinderfreibeträge massiv von 221 auf 1.270 Euro stiegen. Die Kinderadditive sollten dem Umstand Rechnung tragen, dass Eltern im Rahmen ihrer gesetzlichen Unterhaltspflicht auch Vorsorgeaufwendungen zum Schutz ihrer Kinder zu treffen haben, ${ }^{99}$ ein Argument, das angesichts recht breit angelegter beitragsfreier Leistungen für Kinder in den verschiedenen Zweigen der gesetzlichen Sozialversicherung nur bedingt greift. Der Wegfall der Kinderadditive bei höheren Kinderfreibeträgen wurde primär mit Vereinfachungen begründet, daneben sollten Familien mit geringen Einkommen, von denen die Höchstbeträge für Vorsorgeaufwendungen nicht ausgeschöpft wurden, stärker begünstigt werden. ${ }^{100}$

\footnotetext{
96 Vgl. Bundesministerium der Finanzen (2007b), S. 42, S. 48

97 Bundesministerium der Finanzen (2007a), S. 63

98 S. a. Tabelle 27 im Anhang.

99 Vgl. Beschluss des BVerfG vom 8. Juni 19771 BvR 265/ 7

100 Deutscher Bundestag (1985), S. 96, S. 100
} 


\subsection{Leistungen im Anschluss an die Geburt eines Kindes: Erzie- hungs- und Elterngeld}

Spezifische Transfers während der ersten Lebensjahre oder -monate eines Kindes, die mitunter als Elemente eines phasenspezifischen Familienleistungsausgleichs dargestellt werden, existieren seit 1979, als das Mutterschaftsurlaubsgeld eingeführt wurde. An dessen Stelle trat ab 1986 das einem erweiterten Berechtigtenkreis zugängliche Erziehungsgeld nach dem Bundeserziehungsgeldgesetz (BErZGG) ${ }^{101}$ Mit dem Elterngeld nach dem Bundeselterngeld- und Elternzeitgesetz (BEEG) existiert nun seit Beginn des Jahres 2007 eine dritte Variante der Ausgestaltung dieser Form von Transfers. Erheblichster Unterschied zwischen Mutterschaftsurlaubs- und Erziehungsgeld ist, dass ersteres sich im Wesentlichen auf vor der Geburt sozialversicherungspflichtige Arbeitnehmerinnen beschränkte, letzteres hingegen allen Müttern (und gegebenenfalls auch Vätern) unabhängig vom Erwerbsstatus offen stand. Vom Elterngeld, das sich an dieselben Berechtigten richtet wie das Erziehungsgeld, gehen vor allem Leistungsverbesserungen für vor der Geburt erwerbstätige Elternteile einher, deren Einkommensverluste partiell kompensiert werden.

\section{Mutterschaftsurlaubsgeld}

Anstoß für das Mutterschaftsurlaubsgeld gab das Bemühen, Konflikte zwischen Beruf und Schwangerschaft zu mildern, die angesichts steigender Frauenerwerbstätigkeit und fallender Geburtenraten zunehmend dringlich erschienen. ${ }^{102}$ Es bestand bei seiner Einführung 1979 aus lohnabhängigen Zahlungen in Höhe von bis zu 25 DM je Tag (383 Euro monatlich) für die Dauer von bis zu sechs Monaten. Entsprechend betrug die maximale Gesamtleistung rund 2.301 Euro. Durch das HBeglG 1984 wurde der Leistungswert in den Jahren 1984 und 1985 auf 17 DM je Tag (entsprechend 261 Euro monatlich) gekürzt, analog fiel der Maximalbetrag auf 1.565 Euro. Das durchschnittlich gezahlte Mutterschaftsurlaubsgeld entsprach stets nahezu dem gesetzlichen Höchstwert. ${ }^{103}$ Voraussetzung für die Zahlung von Mutterschaftsurlaubsgeld war die Unterbrechung der Erwerbstätigkeit. Von Anfang an war die Inanspruchnahme hoch, knapp $89 \%$ bis $93 \%$ der berechtigten Mütter nutzten das Angebot, in fast allen Fällen über die gesamte Dauer von sechs Monaten. ${ }^{104}$ Die jährlichen Ausgaben schwankten zwischen 1980 und 1983 zwischen 427 und 473 Mio. Euro, vor allem die Leistungskürzung durch das HBeglG führte in den beiden Folgejahren zu deutlich niedrigeren Werten.

101 Vom Mutterschaftsurlaubsgeld nach dem Mutterschaftsurlaubsgesetz und der Reichsversicherungsordnung (RVO), das in den Modellrechnungen ermittelt wird, ist das bereits seit den 1960er Jahren fortlaufend bestehende Mutterschaftsgeld nach dem Mutterschutzgesetz und der RVO zu unterscheiden. Dieses wird im Modell nicht abgebildet, da es zum einen durch die kurze Bezugsdauer von geringer quantitativer Bedeutung ist und zum anderen auf das Mutterschaftsurlaubsgeld bzw. auf das Erziehungsgeld angerechnet wird, so dass sein Ausschluss nur zu vernachlässigbaren Ungenauigkeiten führt. Zur Entwicklung der Mutterschutzgesetzgebung, die neben monetären Leistungen auch Beschäftigungs- und Kündigungsschutz umfasst, vgl. Frerich, Frey (1996), S. 113f

102 Frerich, Frey (1996), S. 330

103 Deutscher Bundestag (1986a), S. 7

104 Deutscher Bundestag (1981a), S. 2; Deutscher Bundestag (1986a), S. 5 


\section{Erziehungsgeld}

Aus der Einführung des Erziehungsgelds im Jahre 1986 folgte in mehrerlei Hinsicht eine Leistungsausweitung: ${ }^{105}$ Erstens ging nun wie erwähnt von jedem Neugeborenen ein Leistungsanspruch aus, ${ }^{106}$ zweitens verlängerte sich die Bezugsdauer auf bis zu zehn Monate, und drittens betrug das Erziehungsgeld bis zu $600 \mathrm{DM}$ je Monat (307 Euro), was einer Verbesserung gegenüber 1985 entsprach, jedoch unter dem ursprünglichen Niveau des Mutterschaftsurlaubsgelds blieb. Konzeptionell unterscheidet sich das Erziehungsgeld grundlegend von seinem Vorgänger. Während das Mutterschaftsurlaubsgeld als Lohnersatzleistung ausgestaltet war und daher mit dem Einkommen der Mutter stieg (wobei die gesetzliche Begrenzung zu einer faktisch nahezu fixen Leistung in Höhe des Maximalbetrags führte, s.o.), hing die Höhe des Erziehungsgelds in den ersten sechs Lebensmonaten nicht und danach negativ vom Einkommen ab. Bedingung für den Erziehungsgeldbezug war, dass ein Elternteil nach der Geburt nicht oder nur eingeschränkt erwerbstätig war. Die Einkommensunabhängigkeit und die Bedingung der eingeschränkten Erwerbstätigkeit, während der ein Kündigungsschutz bestand (Erziehungsurlaub), sind aus den Zielen des $\mathrm{Ge}$ setzes abgeleitet, mit dem

1) die prägende Entwicklung in der ersten Lebensphase über die Betreuung durch eine feste Bezugsperson gefördert,

2) die Familientätigkeit als einer der Erwerbstätigkeit gleichwertige Aufgabe anerkannt und

3) Familien finanziell entlastet werden sollten. ${ }^{107}$

Zum ersten Ziel wurde nachdrücklich auf wissenschaftliche Erkenntnisse hingewiesen, nach denen insbesondere in den ersten drei Lebensjahren eine Erziehung im häuslich-familiären Umfeld die besten Entwicklungschancen eröffne. Der wissenschaftliche Beirat für Familienfragen empfahl 1989 unter entwicklungspsychologischen Gesichtspunkten eine Bezugsdauer von drei Jahren, eine darüber hinausgehende Ausdehnung hingegen behindere potenziell die Wiederaufnahme einer Erwerbstätigkeit. ${ }^{108}$ Das Erziehungsgeld sollte folglich explizit Anreize setzen, auf Erwerbstätigkeit zu Gunsten der Betreuungstätigkeit zu verzichten. Das zweite Ziel, die gesellschaftliche Anerkennung von Erziehungsleistungen, führte dazu, dass das Erziehungsgeld weitestgehend nicht auf alternative Ansprüche angerechnet wird und auch steuerlich irrelevant ist. Leistungen nach dem BErzGG werden folglich additiv zu anderen Sozialleistungen erbracht. Das zweite Ziel wird auch mit der Internalisierung positiver externer Effekte assoziiert. ${ }^{109}$

${ }^{105} \mathrm{Zu}$ vorhergehenden regional begrenzten Modellversuchen zur Erprobung des Erziehungsgelds S. Bundesministerium für Jugend, Familie, Frauen und Gesundheit (Hrsg.) (1989), S. 69ff

106 Für Geburten bis Juli 1989 konnte Erziehungsgeld nicht für mehrere Kinder gleichzeitig in Anspruch genommen werden (vgl. Kaltenborn (1998), S. 31). Diese bei Mehrlingsgeburten oder rascher Geburtsfolge relevante Einschränkung bleibt für die Modellrechnungen mit dem STM jedoch ohne Auswirkungen.

107 Vgl. die Begründung des Gesetzesentwurfs: Bundesrat (1985), S. If

108 Vgl. Bundesministerium für Jugend, Familie, Frauen und Gesundheit (Hrsg.) (1989), S. 22, S. $220 \mathrm{ff}$

109 Bundesministerium für Familie, Senioren, Frauen und Jugend (Hrsg.) (2001), S. 31 
Das maximale monatliche Erziehungsgeld ist seit 1989 nominal quasi konstant geblieben, der anfängliche Wert von 600 DM galt durchgehend bis 2004 (mit der Euro-Einführung 2002 wurde der gleich hohe Betrag von 307 Euro festgelegt), als eine geringfügige Absenkung auf 300 Euro erfolgte. Leistungserweiterungen ergaben sich stattdessen durch die Verlängerung der Bezugsdauer, die nach den anfänglichen 10 Monaten später 12 (ab 1988), 18 (ab 1990) und ab 1993 schließlich 24 Monate betrug. Diese Werte setzten sich stets aus einer sechsmonatigen ersten Phase und einer zweiten Phase über die verbleibende Zeit zusammen. Relevant ist die Phaseneinteilung für die Einkommensanrechnung, die in der zweiten Phase restriktiver ist. Seit 2001 sah das BErzGG eine neue Wahlmöglichkeit vor: Statt der weiterhin bestehenden so genannten Regelleistung konnte alternativ das Budget genutzt werden, nach dem der Leistungssatz um 50\% höher lag (450 Euro seit 2004), die Bezugsdauer jedoch nur bis zu 12 statt 24 Monate betrug. Das Budget ist tendenziell vorteilhaft, wenn beide Elternteile spätestens ein Jahr nach der Geburt erwerbstätig sind. Ab 2004 war die Option auf das Budget jedoch nur bei Einhaltung sehr niedriger Einkommensgrenzen gegeben. ${ }^{110}$

Die Einkommensanrechnung beim Erziehungsgeld wurde im Laufe seines Bestehens zunehmend verschärft. Bis 1993 einschließlich wurde in der ersten Phase einkommensunabhängig gefördert, in der zweiten Phase wurde das Erziehungsgeld bei Überschreiten des maßgeblichen Jahreseinkommens von 29.400 DM bei Verheirateten (15.032 Euro) um 3,3\% des übersteigenden Betrages gemindert. ${ }^{111}$ Diese mit dem oben genannten zweiten Ziel konfligierende Anrechnung erfolgte weniger aus sachlichen Erwägungen als aus fiskalpolitischen. Maßgebliches Einkommen im Sinne des BErzGG war die Summe der positiven Einkünfte, von der bis 1994 die entrichtete Einkommensteuer und die steuerlich anerkannten Vorsorgeaufwendungen abgesetzt wurden. Seit 1995 wurde stattdessen vereinfachend ein pauschaler Abzug von $27 \%$ (bis 2003) bzw. 24\% (ab 2004) vorgenommen. ${ }^{112}$ Ab 1994 wurde dann auch für die erste Phase Einkommen berücksichtigt. Bei maßgeblichen Jahreseinkommen ab 100.000 DM (51.129 Euro) entfiel der Anspruch. Anders als in der zweiten Phase existierte also kein Übergangsbereich, bis zur Einkommensgrenze wurde Erziehungsgeld in voller Höhe und danach gar nicht geleistet. Bis 2004 wurden diese Grenzbeträge von einer leichten Erhöhung 2001 abgesehen -bei der im Gegenzug der Minderungssatz auf 4,2\% anstieg- nicht verändert. Ab 2004 trat dann eine deutliche Verschärfung in Kraft, die Einkommensgrenze der ersten Phase fiel auf 30.000 Euro, der pauschale Abzug sank von 27\% auf 24\% und der Minderungssatz wurde zudem auf 5,2\% erhöht. Einige markante Auswirkungen leistungsrelevanter Größen

110 Die Entwicklung der Leistungsparameter von Mutterschaftsurlaubs- und Erziehungsgeld ist in Tabelle 29 im Anhang wiedergegeben.

111 Die Formulierung in $\S 5$ Abs. 3 BErzGG sah bis 2001 eine Minderung um „den zwölften Teil von 40 von Hundert des die Grenze übersteigenden Einkommens vor", was rund 3,3\% entspricht. Für Geschwister des Neugeborenen erhöhte sich die Grenze. Die verschiedenen Rechtsstände zur Einkommensanrechnung sind in Tabelle 30 im Anhang skizziert.

112 Für nicht sozialversicherungspflichtige Arbeitnehmer gelten niedrigere Anteilswerte. Vorteil der Pauschalregelung ist die vereinfachte Einkommensermittlung, die unter anderem ermöglichte, das Einkommen des Geburtsjahres statt früherer Jahre zu Grunde zu legen. In den Modellrechnungen wird durchgängig das Einkommen des Geburtsjahres herangezogen, tatsächlich war nach verschiedenen Rechtsständen des BErzGG hingegen zeitweise das Einkommen des letzten bzw. vorletzten Jahres vor der Geburt maßgebend. 
unter diesen verschiedenen Rechtsständen zeigen sich bei der Darstellung des Erziehungsgelds in Abhängigkeit vom Einkommen (Abbildung 24):

- Ausgangspunkt der Abbildung ist jeweils ein Einverdienerehepaar mit einem Neugeborenen ohne Geschwister, das ausschließlich Bruttoeinkommen aus nichtselbständiger Arbeit bezieht. Der Partner strebe während der ersten beiden Lebensjahre keine Erwerbstätigkeit an, wodurch üblicherweise der Regelbetrag des Erziehungsgelds vorteilhaft ist, da im Vergleich zum seit 2001 möglichen Budget die längere Bezugsdauer den niedrigeren Monatsbetrag überkompensiert. Unterstellt ist weiterhin, dass das Ehepaar immer die retrospektiv optimale Wahl zwischen Regel- und Budgetleistung trifft. Abgetragen ist jeweils das gesamte Erziehungsgeld über die vollständige Bezugsdauer.

- Äußerst deutlich ist der Effekt der Verlängerung der Bezugsdauer von 10 auf bis zu 24 Monate, wodurch bei weitgehend konstanten monatlichen Beträgen die maximale Gesamtförderung von 3.068 Euro beim Rechtsstand 1986 (10 Monate mit jeweils 307 Euro) auf bis zu 7.363 Euro (Rechtsstände 1993 bis 2001: 24 Monate mit jeweils 307 Euro) anstieg. Von dieser profitieren Eltern, die innerhalb der Höchstdauer beide vollzeiterwerbstätig sind, allerdings nicht. In Hinblick auf das erstgenannte Ziel, die Förderung der Erziehung innerhalb der Familie, ist diese Einschränkung jedoch unbedeutend.

- Für alle Rechtsstände lassen sich drei Einkommensintervalle unterscheiden, ab 1994 tritt ein viertes hinzu: Im ersten Intervall folgt aus dem Bruttolohn ein Einkommen unterhalb der Einkommensgrenze der zweiten Phase, wodurch der monatliche Höchstwert über die gesamte Dauer gezahlt wird. Seit 1986 lag diese Schwelle für die betrachtete Fallkonstellation recht konstant bei etwa 22.000 Euro, von 2001 bis 2003 ergab sich ein etwas höherer Wert von 23.500 Euro. Im anschließenden Intervall greift die Minderungsregel für die zweite Phase, das Erziehungsgeld fällt mit steigendem Einkommen, bis ein Anspruch in der zweiten Phase verwirkt ist. Das Höchsteinkommen für dieses Intervall entsprach bis 2004 einem Jahresbruttolohn von etwa 33.500 Euro, danach von etwa 30.200 Euro. Bei Einkommen im dritten Intervall besteht ein Anspruch auf Erziehungsgeld über eine Dauer von sechs Monaten (1. Phase), das nicht gemindert wird. Ab dem unteren Wert des vierten Intervalls schließlich, das seit der Einführung einer Einkommensgrenze auch für die erste Phase im Jahre 1994 existiert, entfällt das Erziehungsgeld vollständig. Zwischen 1994 und 2003 lag die Schwelle, ab der ein Erziehungsgeld von Null resultierte, bei einem Bruttojahreslohn von rund 71.500 Euro (in der Abbildung nicht dargestellt), 2004 bei einem Bruttolohn von 40.500 Euro.

- Insgesamt hat die Streuung des Erziehungsgelds in Abhängigkeit vom Einkommen stark zugenommen. Während sich 1986 über die gesamte Einkommensskala Beträge von 1.841 bis 3.068 Euro ergaben, womit das Mindesterziehungsgeld $60 \%$ des Höchstwertes entspricht, folgt für das Jahr 2004 bei Jahresbruttolöhnen von bis zu etwa 40.500 Euro ein Anteil von $25 \%$ (mindestens 1.800, höchstens 7.200 Euro). Bei Übersteigen dieses Bruttolohns ist das Erziehungsgeld null. Die Diagnose einer verstärkten Einkommensabhängigkeit liegt vor allem an dem zunehmenden Gewicht der zweiten Phase, für die immer eine Einkommensbegrenzung galt. Hinzu treten die ebenfalls wiederholt angehobenen Minderungssätze, wodurch das Einkommensintervall, in dem 
ein positiver Anspruch auch während der zweiten Phase bestand, gestaucht wird.

Abbildung 24: Erziehungsgeld in Abhängigkeit vom Einkommen zu verschiedenen Zeitpunkten

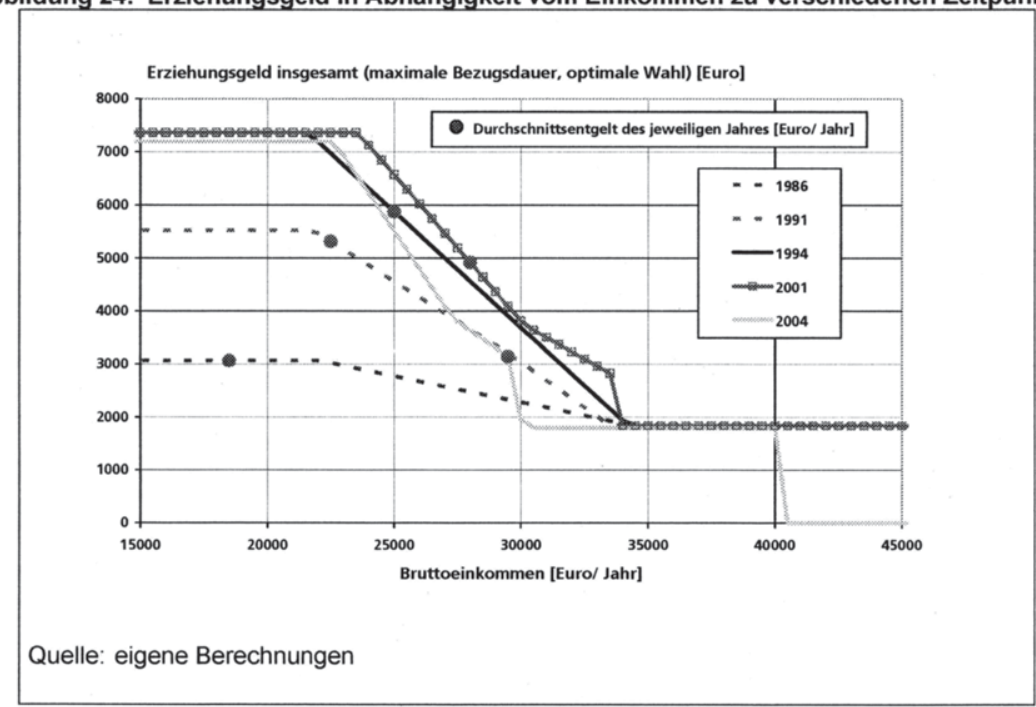

- Bei den Rechtsständen 2001 und 2004 ergeben sich im zweiten Intervall, in dem die Minderungsvorschriften wirksam sind, Sprungstellen. Ausschlaggebend hierfür ist, dass die annahmegemäß retrospektiv optimale Wahl zwischen Budget- und Regelleistung zu einkommensabhängig unterschiedlichen Entscheidungen führt. Trotz der beim betrachteten Familientyp unterstellten dauerhaften Nichterwerbstätigkeit eines Partners existiert ein Einkommensabschnitt, ${ }^{113}$ in dem die Wahl des Budgets das Gesamterziehungsgeld maximiert, was als Hinweis auf einen Harmonisierungsbedarf bei den Einkommensgrenzen und Minderungsvorschriften von Regel- und Budgetleistung hindeutet. Durch die retrospektive Ermittlung des Erziehungsgelds in den Modellrechnungen des STM werden potenzielle Verzerrungen durch Fehlentscheidungen vermieden.

- Würde in Abbildung 24 von einem Neugeborenen mit Geschwistern ausgegangen, so würden die Einkommensschwellen, ab denen gemindert wird oder die Förderung ausläuft für jedes zusätzliche Kind je nach Rechtsstand um etwa drei- bis viertausend Euro höher liegen. Bei einem allein Erziehenden Elternteil sinken die jeweiligen Schwellenlöhne um etwa $25 \%$ bis $30 \%$ im Vergleich zu Verheirateten.

113 Beim Rechtsstand 2001 reicht dieser Einkommensabschnitt für den betrachteten Fall von etwa 30.200 bis 33.700 Euro, 2004 von 27.400 bis 29.900 Euro. 
In Abbildung 24 sind auch die jährlichen Durchschnittsentgelte der gesetzlichen Rentenversicherung der jeweils betrachteten Jahre markiert, um einen Bezug zur Einkommensentwicklung herstellen zu können. 1986 ergab sich für ein Einverdienerehepaar mit dem damaligen Durchschnittsentgelt von 18.727 Euro ein ungemindertes Erziehungsgeld in Höhe von 3.068 Euro insgesamt. In den späteren abgebildeten Jahren fällt ein derartig definierter Durchschnittsverdienst zunehmend in das der Minderung unterliegende Einkommensintervall. 1991/92 entsprach das Erziehungsgeld dieses Typs von Ehepaar mit 5.320 Euro 96\% des Maximalbetrags von 5.522 Euro, in den weiteren Jahren sank dieser Anteil über Werte von $80 \%$ (1994) und $67 \%$ (2001) auf 44\% im Jahr 2004. Dieser Anteil für 2004 resultiert, wenn das Paar wie angenommen die Budgetlösung wählt (Bezug von bis zu 450 Euro über 12 Monate statt 24 Monate mit bis zu 300 Euro), seine Regelleistung entspricht nur noch rund $33 \%$ des Maximalbetrags von 7.200 Euro. Im Jahr 2004 lag ein Verdienst von nur einigen hundert Euro über dem Durchschnittsentgelt von 29.060 Euro (2004) im dritten Einkommensintervall, in dem Erziehungsgeld ab dem siebten Monat entfällt. Diese Ergebnisse zeigen auf, dass die Einkommensgrenzen und -anrechnung des BErzGG im Zeitverlauf zu einer zunehmenden Konzentration der Förderung auf Bezieher geringerer Einkommen hinwirkten. Dies entspricht einer Abkehr vom Ansatz, Erziehungsleistungen unabhängig von der ökonomischen Situation der Familie anzuerkennen (s. o. zweites Ziel), hin zu einer stärker bedarfsorientierten Sozialleistung. $^{114}$

\section{Elterngeld}

Mit der vielfach als Paradigmenwechsel bezeichneten Einführung des Elterngelds im Jahr 2007 erlischt dieser Sozialleistungscharakter. Technisch betrachtet stellt das Elterngeld eine Kombination von Merkmalen des Mutterschaftsurlaubsgelds und des Erziehungsgelds dar. Wie das Mutterschaftsurlaubsgeld ist es grundsätzlich als Lohnersatzleistung ausgestaltet. Als alternativer Anspruch besteht ein einkommensunabhängiger Förderbetrag wie beim frühen Erziehungsgeld von 1986 bis 1994. Der Bruch gegenüber den Vorgängerregelungen besteht weniger in der Konzeption des Elterngelds als solcher sondern primär in den Ausprägungen der leistungsrelevanten Parameter. Die Höhe des Elterngelds richtet sich nach dem zuvor bezogenen Nettoerwerbseinkommen, in Anlehnung an das Arbeitslosengeld wurde eine Lohnersatzrate von grundsätzlich $67 \%$ festgelegt ( $\$ 2$ Abs. 1 BEEG). Das Elterngeld beträgt in der Regel maximal 1.800 Euro je Monat, so dass eine Kompensation für Ausfälle von Nettoeinkommen bis zu 2.700 Euro erfolgt. ${ }^{115}$ Anders als beim Mutterschaftsurlaubs-

114 Vgl. Bundesministerium für Familie, Senioren, Frauen und Jugend (Hrsg.) (2001), S. 31

115 Bei Mehrlingsgeburten erfolgt auch über 1.800 Euro hinaus ein einkommensunabhängiger $\mathrm{Zu}$ schlag von 300 Euro für das zweite und jedes weitere Kind. Ältere Geschwister von bis zu sechs Jahren können ebenfalls zu einer Anhebung des Elterngelds führen, gegebenenfalis auch über 1.800 Euro hinaus.

Im BEEG wird als maßgebliches Einkommen das monatliche Einkommen aus Erwerbstätigkeit festgelegt ( $\$ 2$ Abs. 1 BEEG). Dieses entspricht dem Nettoeinkommen aus unselbständiger Arbeit mit der Ausnahme, dass neben Steuern und Sozialversicherungsbeiträgen zusätzlich der Arbeitnehmer-Pauschbetrag (von derzeit 920 Euro je Jahr) vom Bruttolohn abzuziehen ist ( $\$ 2$ Abs. 7 $B E E G)$. Das Elterngeld ist dadurch um in der Regel rund 51 Euro je Monat niedriger $\left(51 \approx 920 / 12{ }^{*} 0,67\right)$ als bei einer auf den Nettolohn in der üblichen Abgrenzung abstellenden Be- 
geld, bei dem der niedrige Maximalbetrag zu einer faktisch weitgehend einkommensunabhängigen Leistung führte, ist beim Elterngeld eine Differenzierung zu Gunsten höherer Einkommen zu erwarten, wie dies für eine Lohnersatzleistung charakteristisch ist. Aufgeweicht wird dieses Prinzip durch die Anhebung der Ersatzrate bei Nettoeinkommen unterhalb von 1.000 Euro ( $\$ 2$ Abs. 2 BEEG). Für Nettoerwerbseinkommen von bis zu 340 Euro ergibt sich eine Ersatzrate von $100 \%$, die bei darüber hinaus gehenden Einkommen linear gemindert wird, bis bei 1.000 Euro der Wert von $67 \%$ erreicht ist. Unabhängig vom Einkommen vor oder nach der Geburt sieht das Elterngeld einen Mindestbetrag von 300 Euro je Monat vor (§ 2 Abs. 5 BEEG).

Während das Erziehungsgeld also höchstens 300 Euro je Monat betrug (bei niedrigen Einkommen nach der Geburt) und bei mittleren und höheren Einkommen null war, beläuft sich das Elterngeld auf mindestens 300 Euro je Monat (bei Nichtenwerbstätigkeit oder niedrigen Einkommen vor der Geburt) und steigt mit dem Nettolohn vor der Geburt auf bis zu 1.800 Euro. Bei niedrigen Einkommen beträgt die monatliche Leistung sowohl beim Erziehungs- als auch beim Elterngeld entsprechend 300 Euro, Verbesserungen ergeben sich vor allem bei höheren (entfallenden) Einkommen, wo ein Erziehungsgeld von tendenziell null Euro durch ein Elterngeld von bis zu 1.800 Euro ersetzt wird. In Hinblick auf die monatliche Leistungshöhe sind Schlechterstellungen durch den Regimewechsel weitgehend ausgeschlossen, allerdings beträgt die Bezugsdauer des Elterngelds bis zu 12 Monate (unter Umständen bis zu 14 Monate) und unterschreitet damit die Anspruchsdauer des Erziehungsgelds von bis zu 24 Monaten. Die maximale Leistung über die gesamte Laufzeit hat sich im Vergleich zum Erziehungsgeld auf 21.600 Euro verdreifacht.

Mit der minimalen Leistung von 3.600 Euro ergibt sich für diejenigen Familien eine Halbierung der Leistung, die zuvor über 24 Monate einen Erziehungsgeldanspruch aufwiesen. Eine zweite Verschärfung gegenüber dem Erziehungsgeld folgt aus einer weiteren Parallele von Arbeitslosen- und Elterngeld, beide unterliegen dem Progressionsvorbehalt nach $\S 32 \mathrm{~b}$ EStG. Das Elterngeld ist nicht zu versteuern, allerdings erhöht es den Steuersatz, der auf das zu versteuernde Einkommen anzuwenden ist, wodurch nach den Umständen des Falles die Steuerschuld ansteigen kann. Wie beim Erziehungsgeld besteht kein Elterngeldanspruch bei voller Erwerbstätigkeit. Die Aufnahme einer Teilzeitbeschäftigung während des Bezugs von Elterngeld führt durch das Lohnersatzprinzip zu einem Absinken des Anspruchs in gleichem Umfang. Wenn etwa auf Grund einer Teilzeiterwerbstätigkeit statt des vollen Nettoeinkommens nur das halbe Einkommen entfällt, reduziert sich der Elterngeldanspruch ebenfalls um die Hälfte.

Als zweite wesentliche Neuerung neben dem positiven Zusammenhang von Einkommen und Transfervolumen folgt aus dem Elterngeld eine starke Abhängigkeit der Leistungshöhe vom Geburtsabstand, die sich in Längsschnittbetrachtungen offenbart. Bemessungszeitraum für das entfallende Nettoerwerbseinkommen ist grundsätzlich das Jahr unmittelbar vor der Geburt, ausgenommen sind unter anderem Monate mit Elterngeldbezug. Falls solche Monate vorliegen, werden statt dieser Zeit die letzten Monate vor der ansonsten geltenden Jahresfrist berücksichtigt. Durch diese Regelung gehen vom zeitlichen Abstand zwischen Geburten und vom Timing von

rechnung. Vereinfachend wird hier dennoch der Begriff des Nettolohns für das Elterngeld verwandt. 
Erwerbsunterbrechungen wesentliche Effekte auf das Transfervolumen aus, wobei vor allem stärkere Enwerbseinschränkungen im Jahr vor der Geburt eines Kindes aus Sicht der Eltern nachteilig sind. Für Mehrkindfamilien ergeben sich hieraus zwei Varianten, die das Elterngeld insgesamt annähernd maximieren: Erstens führt bei ursprünglich Vollzeiterwerbstätigen ein kurzer zeitlicher Abstand zwischen Geburten von rund einem Jahr zu einem hohen Elterngeld. In diesem Fall bleibt das Vollzeiteinkommen aus der Zeit vor der ersten Geburt für die Höhe des Anspruchs maßgeblich. Zweitens ist bei größeren Abständen ein Wechsel von Phasen der Kinderbetreuung und der (Vollzeit-)Erwerbstätigkeit vorteilhaft. Verschiedene Beobachtungen sprechen jedoch dafür, dass beide Varianten wenig typisch sind. Während ein recht hoher Anteil der Mütter vor der Erstgeburt vollzeiterwerbstätig ist, liegt die Quote der nicht oder eingeschränkt Erwerbstätigen vor der Geburt zweiter und weiterer Kinder deutlich höher. Weiterhin überschreitet der durchschnittliche Geburtsabstand drei Jahre. ${ }^{116}$ Zusammen deuten diese Befunde darauf hin, dass sich das Elterngeld für zweite und weitere Kinder unter den bisherigen Fertilitäts- und Erwerbsmustern überwiegend nicht nach einem Vollzeiteinkommen richten wird.

Die Inanspruchnahme des Erziehungsgelds war wie schon beim Mutterschaftsurlaubsgeld durchgängig sehr hoch, Leistungen nach dem BErzGG fielen in den Jahren zwischen 1986 und 2003 für etwa $91 \%$ bis $97 \%$ der Geburten an (Abbildung 25). ${ }^{117}$ Da mit der Einführung des Erziehungsgelds 1986 aus jeder Geburt ein Leistungsanspruch erwuchs, ging mit der ähnlich hohen Inanspruchnahme wie beim Mutterschaftsurlaubsgeld, bei dem rund die Hälfte der Mütter bezugsberechtigt war, eine drastische Zunahme der Leistungsfälle einher. Als Inanspruchnahme ist in Abbildung 25 die Relation von bewilligten Erstanträgen und Geburten eines Jahres ausgewiesen. ${ }^{118}$ Ausschlaggebend für die Bewilligung ist die Einhaltung der Einkommensgrenze der ersten Phase sowie der Bedingung der eingeschränkten Erwerbstätigkeit mindestens eines Elternteils. Da die Einkommensgrenze für die sechsmonatige erste Phase bis 2004 mit 51.129 Euro für Verheiratete (einem Bruttojahreslohn von etwa 71.500 Euro entsprechend) recht hoch angesetzt war, ging von ihr nur eine schwach restringierende Wirkung aus, so dass die Zahl der bewilligten Erstanträge primär von den Geburtenzahlen geprägt wurde. Die für das Erziehungsgeld ab dem siebten Monat maßgeblichen niedrigeren Einkommensgrenzen schlagen sich indessen nicht in der so definierten Inanspruchnahme nieder. Verschiedene Umstellungen im BErzGG -unter anderem die Einführung der Budgetlösung 2001- und daran anknüpfend auch in den Statistiken zum Erziehungsgeld verhindern eine vergleichbare Darstellung der stärker von der Einkommensentwicklung geprägten Inanspruchnahme in der zweiten Phase. Allerdings deutet sich der nach Abbildung $24 \mathrm{zu}$ erwartende vermehrte Ausschluss von Eltern vom Erziehungsgeld ab dem siebten

116 Der durchschnittliche zeitliche Abstand der Geburtstage zweier Geschwister (Geburtenabstand) variiert mit der Ordnungszahl der Kinder und beträgt für zweite Kinder rund 3,6 Jahre, für dritte Kinder 4,4 Jahre. (Statistisches Bundesamt (2006b), Tabelle 2.14)

117 Tabelle 31 im Anhang gibt die der Abbildung zu Grunde liegenden Werte wieder.

118 Seit 1995 muss das Erziehungsgeld für das zweite Lebensjahr eines Kindes separat beantragt werden. Für den regelmäßig niedrigeren Anteil der bewilligten Zweitanträge ist neben der strengeren Einkommensgrenze auch der mit dem Lebensalter der Kinder zunehmende Anteil von erwerbstätigen Eltern verantwortlich. Zudem entfällt seit 2001 die Möglichkeit eines Zweitantrags bei denjenigen Eltern, die die Budgetleistung wählen. 
Monat zumindest für einige Eckjahre an: 1994 wurden rund $86 \%$ der bewilligten Erstanträge über den sechsten Lebensmonat hinaus bewilligt, bis 1996 fiel dieser Anteil auf $84 \%$, ${ }^{119}$ im Jahr 2002 lag er noch bei knapp $79 \% .{ }^{120}$

Abbildung 25: Mutterschaftsurlaubs- und Erziehungsgeld: Ausgaben und Inanspruchnahme 1979 bis 2004

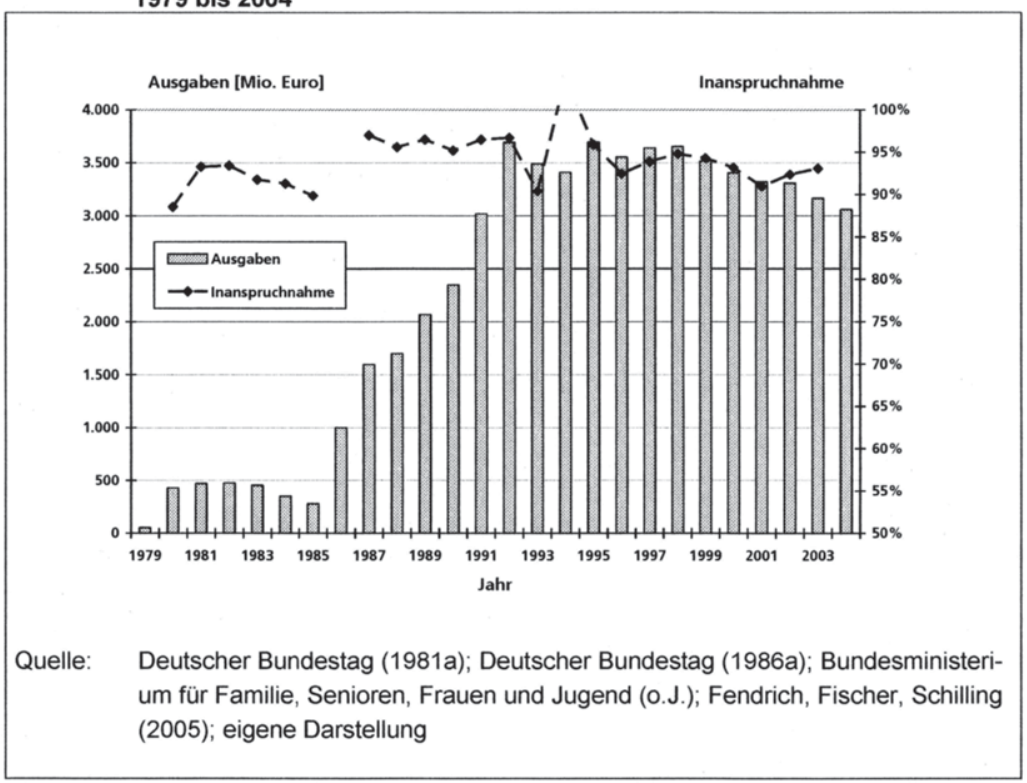

Durch die gestiegenen maximalen Bezugsdauern einerseits und die verschärft wirkende Einkommensanrechnung andererseits ergeben sich zwei gegenläufige Tendenzen für die Gesamtausgaben nach dem BErzGG. Zwischen 1987 und 1990, als die maximale Bezugsdauer schrittweise von 10 auf 18 Monate angehoben wurde, stiegen die Ausgaben bei moderat zunehmenden Geburtenzahlen massiv von 1.596 Mio. Euro auf 2.347 Mio. Euro an. In den folgenden Jahren wurde ein Ausgabenniveau von bis zu 3.698 Mio. Euro erreicht, was zum einen auf die Enweiterung der Berechtigtenzahlen durch die deutsche Wiedervereinigung und zum anderen auf die erneute Verlängerung der Bezugsdauer auf 24 Monate ab 1993 zurückzuführen ist. Seit 1995 zeigt sich eine stagnierende bis fallende Ausgabenentwicklung, die mit sinkenden Geburtenzahlen einhergeht. Reale Leistungsverschlechterungen beim $\mathrm{Er}$ ziehungsgeld in der zweiten Hälfte der 1990er Jahre durch unterbleibende Anpassungen der Gesetzesparameter (monatlicher Betrag, Einkommensgrenzen) wurden vom Gesetzgeber zwar anerkannt und als familienpolitisch unerwünscht gekennzeichnet, entsprechende Änderungen unterblieben jedoch auf Grund der Haushalts-

119 Deutscher Bundestag (1998), S. 11ff

120 Bundesministerium für Familie, Senioren, Frauen und Jugend. (o.J.), S. 6 
lage. ${ }^{121}$ Durch die gesetzlichen Einschnitte im Jahr 2004 wurde das Volumen des Erziehungsgelds zusätzlich eingeschränkt. Nach Ausgaben von knapp 3,1 Mrd. Euro 2004 wurden 2005 noch 2,9 Mrd. Euro aufgewendet, wobei für die Folgejahre ein weiter fallender Trend enwartet wurde. ${ }^{122}$ Mit der Ablösung des Erziehungsgelds durch das Elterngeld ab dem Jahr 2007 wird hingegen mit der Neuausrichtung des Förderprinzips auch eine Ausweitung der Transfers an Familien mit Neugeborenen angestrebt. Die erwarteten Ausgaben liegen mittelfristig bei 4,05 Mrd. Euro je Jahr, ${ }^{123}$ wobei nach den Ergebnissen für das Jahr 2007 eher mit höheren Werten zu rechnen ist. Im Vergleich zum Fortbestehen des Erziehungsgelds entspricht dies einer Zunahme der Leistungen um über $40 \%$.

\subsection{Ausbildungsförderung}

In der Geschichte der Bundesrepublik wurden verschiedene öffentlich finanzierte Förderungsmöglichkeiten für Bildungsteilnehmer geschaffen, die überwiegend auf eine höhere Bildungsbeteiligung und eine Verminderung sozialer Selektion beim Bildungszugang abzielen. Im Bereich beruflicher Bildung weisen die Förderung von Auszubildenden und von Arbeitslosen nach dem SGB III (bis 1998 nach dem Arbeitsförderungsgesetz AFG) eine lange Tradition auf, seit 1996 bietet zusätzlich das häufig als Meister-BAföG charakterisierte Aufstiegsfortbildungsförderungsgesetz (AFBG) Unterstützung bei Höherqualifizierungen. Für die hier betrachteten typisierenden Biographien ist hingegen die Förderung von Schülern und Studenten von größerer Bedeutung. Im Vergleich zu diesen ist der Anteil der Geförderten an den Auszubildenden im dualen System marginal. ${ }^{124}$ Ausbildungsförderung wurde und wird zum einen in Form von Gebührenerlassen (Schulgeld, Studiengebühren) und zum anderen durch Geldtransfers für den Lebensunterhalt gewährt. Eine breit angelegte Ausbildungsförderung existiert seit Beginn der siebziger Jahre des vergangenen Jahrhunderts durch das BAföG, für Studenten wurden ähnlich wirkende Vorgängerregelungen bereits in der zweiten Hälfte der fünfziger Jahre in Kraft gesetzt. Abgesehen von verschiedenen Programmen der Begabtenförderung und in der Zeit nach dem zweiten Weltkrieg eingeführten Förderangeboten für Kriegsfolgengeschädigte war eine Schülerförderung auf Bundesebene bis 1970 nicht vorgesehen. ${ }^{125}$ Vom STM werden die Studentenförderung nach dem Honnefer Modell und die Förderung von Schülern und Studierenden nach dem BAföG berechnet. Wesentlich für die Ent-

121 Deutscher Bundestag (1998), S. 2, S. 7

122 Deutscher Bundestag (2006a), S. 5

${ }^{123}$ Deutscher Bundestag (2006b), S. 17

124 Die bei Ausbildungen im dualen System potenziell gewährte Berufsausbildungsbeihilfe nach $\S 59$ ff SGB III bzw. von 1969 bis 1998 nach $\S 40$ ff AFG ist ähnlich wie das BAföG konzipiert. Vor allem die bei betrieblichen Ausbildungen gezahlten Ausbildungsvergütungen führen jedoch dazu, dass wegen des eigenen Einkommens des Auszubildenden kein Förderungsanspruch besteht (vgl. Arens, Quinke (2003), S. 64ff).

Für die zur aktiven Arbeitsmarktpolitik zählende Förderung beruflicher Weiterbildung nach dem SGB III bzw. zuvor nach dem AFG werden zwar durchaus erhebliche Mittel eingesetzt, die jedoch überwiegend Leistungen der Arbeitslosenversicherung sind und daher hier ausgeblendet bleiben.

125 Vgl. Dahnen (1970), S. $73 f$ 
lastungswirkung von Ausbildungsförderung sind erstens die Förderungsvoraussetzungen, zu denen die Abgrenzung der betroffenen Ausbildungsarten und persönliche Voraussetzungen wie die individuelle Eignung zählen, und zweitens die $\mathrm{Be}-$ messung der individuellen Höhe der Förderung. Relevante Parameter für letztere sind:

- Bedarfssätze: Die betrachteten Regelungen orientieren sich am typisierten monatlichen Bedarf eines Auszubildenden zur Deckung seines Lebensunterhalts. Die Bedarfssätze bestimmen den Maximalbetrag der Förderung.

- Einkommensanrechnung: Öffentliche Ausbildungsförderung in der Bundesrepublik war stets als Subsidiärleistung ausgestaltet, die nur bei unzureichenden sonstigen Einkommen gewährt wird. Bedeutsam ist insbesondere die üblicherweise erfolgende Anrechnung des Elterneinkommens, das vorrangig zur Finanzierung heranzuziehen ist. Freibeträge vom Einkommen eines Auszubildenden und inm Unterhaltsverpflichteter sowie die Bedarfssätze sind die Hauptdeterminanten des individuellen Förderungsbetrags.

- Art der Förderung: Förderung wird als nicht zurückzuzahlender Zuschuss oder als Darlehen gewährt. Die Förderungsart bleibt ohne Auswirkung auf das Einkommen während der Ausbildung, Darlehen mindern jedoch späteres Einkommen.

\section{Das Honnefer Modell}

Nach dem so genannten Honnefer Modell wurden ab dem Jahr 1957 Studierende an wissenschaftlichen Hochschulen unterstützt. Förderungsvoraussetzungen waren gute Eignung, die nach einer Anfangsförderung durch eine Prüfung an der Hochschule nachzuweisen war, und Bedürftigkeit, die ähnlich wie bis heute geltend als Differenz zwischen Bedarf (damals als Fördermessbetrag bezeichnet) und anzurechnendem Einkommen ermittelt wurde ${ }^{126}$ Neben monatlichen Zahlungen für den Lebensunterhalt umfasste die Förderung im Allgemeinen auch den Erlass der damals erhobenen Studiengebühren. Für Studierende an Fachhochschulen bestanden vergleichbare Fördermöglichkeiten nach dem Rhöndorfer Modell, das allerdings im Gegensatz zum von Bund und Ländern gemeinsam finanzierten Honnefer Modell ausschließlich von den Ländern getragen wurde und keine bundeseinheitlichen $\mathrm{Be}-$ rechnungsvorschriften aufwies. ${ }^{127} 1971$ wurden das Honnefer und das Rhöndorfer Modell durch das BAföG abgelöst.

Im Zeitraum von 1957 bis 1961 betrug die monatliche Höchstförderung 200 DM (rund 102 Euro), später wurde dieser Betrag wiederholt angehoben auf bis zu 350 DM (179 Euro) im Jahr 1971. Für Studierende, die bei ihren Eltern wohnten, galten bis 1961 um 70 DM (36 Euro) und danach um 30 DM (15 Euro) niedrigere Beträge. Auf den Bedarf anzurechnen war das Einkommen des Auszubildenden, soweit es einen Freibetrag von $125 \mathrm{DM}$ je Monat (64 Euro) überstieg. Für das ebenfalls anzurechnende Einkommen der Eltern galten Freibeträge von bis zu 750 DM (383 Euro) im Jahr 1971, bei allein stehenden Elternteilen lag der entsprechende Wert bei 490 DM (251

126 Stephany (1968), S. 35ff

127 Rothe, Blanke (1994), Einführung, Rn. 3 
Euro). Zusätzlich blieben für Geschwister des Auszubildenden Einkommen in Höhe von jeweils bis zu 240 DM (123 Euro) anrechnungsfrei. Vom die Freibeträge übersteigenden Einkommen der Eltern wurden 50\% auf den Bedarf angerechnet. Die im Honnefer Modell getroffene Unterscheidung von Anfangsförderung während der ersten drei Semester und der daran gegebenenfalls anschließenden Hauptförderung wirkte sich auf den Förderungsanspruch während der vorlesungsfreien Zeit und die Förderungsart aus. Während der ersten drei Semester unterblieb eine Förderung in der vorlesungsfreien Zeit. ${ }^{128}$ Die Hauptförderung umfasste im Gegensatz zur vollständig als Zuschuss gewährten Anfangsförderung einen Darlehensanteil von ursprünglich $50 \%$ und ab 1964 von $40 \%$. Die Darlehen waren zinslos und nur bis zu einem Höchstbetrag von 2.500 DM (1.278 Euro) zurückzuzahlen, der bei erfolgreicher Abschlussprüfung auf 1.500 DM (777 Euro) gekürzt wurde.

Die Anzahl der nach dem Honnefer Modell Geförderten bewegte sich zwischen 1957 und $1971 \mathrm{im}$ Bereich von 30 bis 45 Tsd. Studierenden je Jahr, was Gefördertenquoten von etwa $14 \%$ bis knapp $20 \%$ entsprach. Als Gefördertenquote wird der Anteil der Geförderten an der relevanten Studentenpopulation verstanden. Bezogen auf das Honnefer Modell sind dies deutsche Studierende an wissenschaftlichen Hochschulen ohne Gasthörer. Während die Gefördertenquote in der zweiten Hälfte der fünfziger Jahre des vergangenen Jahrhunderts zwischen rund $17 \%$ und $19 \% \mathrm{lag}$, sank sie in der ersten Hälfte der sechziger Jahre auf bis zu $14,4 \%$ ab, ${ }^{129}$ um schließlich wieder Werte von bis zu knapp $20 \%$ zu erreichen. ${ }^{130}$ Die Mittelaufwendungen nahmen weitgehend kontinuierlich zu und erreichten nach anfänglich etwa 30 Mio. Euro je Jahr bis 1965 Werte von bis zu 58 Mio. Euro. ${ }^{131}$

\section{Bundesausbildungsförderungsgesetz (BAföG)}

Nachdem die ursprüngliche Planung, ein sämtliche Ausbildungsbereiche abdeckendes Gesetz zu schaffen, an Mittelknappheit scheiterte, trat als Vorläufer des BAföG am 1.7.1970 das Ausbildungsförderungsgesetz (AföG) in Kraft, das sich auf eine Förderung an weiterführenden allgemein bildenden und berufsbildenden Schulen beschränkte, da die bestehenden Regelungen in diesen Bereichen als besonders unzureichend empfunden wurden. In das im Folgejahr verabschiedete BAföG wurde dann auch die Studentenförderung aufgenommen, für die bis dahin das Honnefer und das Rhöndorfer Modell weiterhin gültig blieben. ${ }^{132}$

Die Einführung des BAföG brachte in mehrerlei Hinsicht bedeutende Neuerungen mit sich: Erstmals wurden für weite Teile des Bildungssystems bundeseinheitliche Förderungskriterien geschaffen. Anders als beim auf Richtlinien beruhenden Honnefer Modell wurde mit dem BAföG die Ausbildungsförderung auf eine Gesetzesgrundlage gestellt. Damit bestand von nun an ein Rechtsanspruch auf Förderung, während frühere Maßnahmen überwiegend Ermessensleistungen darstellten. Schließlich genügte die so genannte schlichte Eignung als Förderungsvoraussetzung. Von der unter anderem im Honnefer Modell geforderten besonderen Eignung, die Züge einer

\footnotetext{
28 Onken (1993), S. 166

129 Deutscher Bundestag (1965), S. 66

130 Deutscher Bundestag (1974b), S. 99

131 Deutscher Bundestag (1966), zitiert nach Onken (1993), S. 167.

132 Rothe, Blanke (2005), Einführung, Rn. $4 f$
} 
Begabtenförderung aufwies, wurde Abstand genommen. ${ }^{133}$ Als Eignungsnachweis im Sinne des BAföG genügte die Erfüllung der formalen Zulassungskriterien der einzelnen Ausbildungsstätten.

Das BAföG ging auf zwei Hauptmotive zurück: Erstens sollte nach dem grundgesetzlich verankerten Sozialstaatsprinzip berufliche Chancengleichheit junger Menschen über soziale Schichten hinweg gewährleistet werden. Zweitens sollte ein verbesserter Bildungszugang zu einem höherqualifizierten Arbeitsangebot führen, das die wirtschaftliche Entwicklung stärken sollte. Die Förderung nach dem BAföG umfasst hauptsächlich monatliche Zahlungen während der Ausbildungszeit, die zur Finanzierung des Lebensunterhalts und der Ausbildungskosten beitragen sollen. $\mathrm{Da}$ fast zeitgleich mit der Einführung des BAföG Studiengebühren gestrichen wurden und Schulgeldzahlungen im Jahr 1961 von Rheinland-Pfalz als letztem Bundesland abgeschafft worden waren, machen Ausbildungsgebühren anders als beim Honnefer Modell nur einen geringen Teil der BAföG-Zahlungen aus; sie fallen hauptsächlich bei Auslandsförderungen an. Die Grundausrichtung des BAföG ist seit seiner Entstehung weitgehend konstant geblieben. Insbesondere verschiedene Gesetzesstände zur Förderungsart im Hochschulbereich (Zuschuss oder Darlehen), zu persönlichen Förderungsvoraussetzungen von Schülern und zur Gestaltung von Bedarfssätzen und Einkommensanrechnung führten jedoch zu erheblichen Schwankungen der individuellen Entlastung im Einzelfall und des öffentlichen Finanzaufwands im Zeitverlauf.

Die Liste der in $\S 2$ BAföG genannten Ausbildungsstätten, für deren Besuch eine Förderung geleistet werden kann, unterlag in der Geschichte des BAföG nur geringfügigen Änderungen, die unter anderem die Förderung des 10. Schuljahres an verschiedenen Schulformen betrafen. Im allgemein bildenden Schulbereich erstreckte sich die Förderung überwiegend auf die Sekundarstufe II (Gymnasien, Gesamtschulen) und Schulen des zweiten Bildungswegs, die den nachträglichen Erwerb eines mittleren Bildungsabschlusses oder einer Hochschulzugangsberechtigung ermöglichen (Abendschulen, Kollegs). Im BAföG erfasste berufliche Schulen sind Vollzeitschulen, an denen ein berufsqualifizierender Abschluss vermittelt wird (hauptsächlich Berufsfachschulen) oder die eine auf einem beruflichen Abschluss autbauende Weiterqualifizierung ermöglichen (Fachschulen, Fachoberschulen). Im Hochschulbereich werden sämtliche Ausbildungen gefördert, mit denen ein berufsqualifizierender Studienabschluss angestrebt wird (Universitäten, Fachhochschulen).

Wie im Honnefer Modell wurde und wird die Ausbildungsförderung nach dem BAföG nach dem Subsidiaritätsprinzip dann gewährt, wenn dem Auszubildenden die für Lebensunterhalt und Ausbildung erforderlichen Mittel anderweitig nicht zur Verfügung stehen. Vorrangig sind Vermögen und/ oder Einkommen des Auszubildenden, seines Ehegatten und seiner Eltern einzusetzen. Wenn diese Mittel nicht ausreichen, wird der Fehlbetrag als Ausbildungsförderung gewährt. Abweichend vom Honnefer Modell sieht das BAföG seit 1974 Ausnahmen von der Anrechnung des Elterneinkommens vor, die im Wesentlichen darauf abstellen, dass die Eltern ihre Unterhaltspflicht bereits abgegolten haben. Elternunabhängig gefördert werden typischer-

${ }^{133}$ Zur Bedeutung der Eignungsfeststellung für das Honnefer Modell s. Oehler, Scheuch (1965), S. $5 \mathrm{ff}$ 
weise Auszubildende mit mehrjähriger Berufserfahrung und an Schulen des zweiten Bildungswegs. Nachdem die elternunabhängige Förderung bis zum Ende der achtziger Jahre des 20. Jahrhunderts zunehmend an Bedeutung gewonnen hatte, wurde sie, Vorschläge des Beirats für Ausbildungsförderung aufgreifend, ab 1990 stark eingegrenzt. ${ }^{134}$

Die Berechnung der Förderung geht zunächst von dem jeweiligen Bedarf aus $(\S 12$ und $\S 13$ BAföG), der nach der Art der Ausbildungsstätten und der Unterkunft (bei den Eltern/ nicht bei den Eltern) gestaffelt ist. Das BAföG kennt vier Bedarfssatzgruppen, wobei der Bedarf in etwa das typische Alter der Auszubildenden reflektiert. Für Schüler gelten niedrigere Bedarfssätze als für Studenten; Auszubildende, die nicht bei ihren Eltern wohnen, weisen einen erhöhten Bedarf auf. Weiterhin existieren verschiedene Zuschläge zum Bedarf für eine eigenständige Kranken- (seit 1975) und Pflegeversicherung (seit 1995), für Fahrtkosten (1973 bis 1981) und für Mietkosten (seit 1974).

Die Berechnungsvorschriften zum Einkommen und Vermögen der $\S \S 21$ bis 30 BAföG behandeln hauptsächlich die Bestimmung des Einkommens im Sinne des BAföG und die darauf aufsetzende Ableitung des anrechenbaren Einkommens. ${ }^{135}$ Primär zur Verwaltungsvereinfachung geht das BAföG vom einkommensteuerrechtlichen Konzept der Summe der positiven Einkünfte aus, von der die gezahlte Einkommensteuer und Vorsorgeaufwendungen abzuziehen sind. ${ }^{136}$ Für letztere werden in $\S 21$ Abs. 4 BAföG so genannte Sozialpauschalen angegeben, mit denen Pflichtbeiträge zur Sozialversicherung und zu funktionsgleichen privaten Versicherungen in pauschalierter Form berücksichtigt werden. Während beim Auszubildenden das um absolute Freibeträge verminderte Einkommen vollständig anzurechnen ist, werden vom Eltern- und Ehegatteneinkommen jeweils nur die zusätzlich um relative Freibeträge geminderten Einkommen einbezogen. Als relative Freibeträge, die sich aus $\S 25$ Abs. 4 BAföG ergeben, werden die Anteile des die Freibeträge überstei-

134 Bis 1990, als durch das Zwölfte Gesetz zur Änderung des Bundesausbildungsförderungsgesetzes (12. BAföGÄndG vom 22.05.1990) die Voraussetzungen für die elternunabhängige Förderung nach $\S 11$ Abs. 3 BAföG verschärft und die gelockert elternabhängige Förderung nach $\S 25$ a BAföG gestrichen wurde, hatte sich durch die Häufung von Mehrfachqualifikationen (vor allem Studium nach einer Lehre) die Förderung zunehmend vom Elterneinkommen entkoppelt. 1986/87 erfolgte bei rund $40 \%$ der geförderten Studenten keine oder nur eine verminderte Anrechnung des Elterneinkommens. (Bundesministerium für Bildung und Wissenschaft (Hrsg.) (1988), S. 64). Im Jahr 2004 wurden etwa $11 \%$ der BAföG-Empfänger elternunabhängig gefördert.

135 Faktisch bis 1997 wurden neben dem Vermögen des Auszubildenden auch die Vermögen seines Ehegatten und seiner Eltern berücksichtigt, deren Anrechnung sich an die Vermögensteuer anlehnte, die auf Grund verfassungsgerichtlicher Rechtsprechung ab 1997 entfiel. Da der notwendige Verwaltungsaufwand einer Erfassung der Vermögen von Eltern und Ehegatten nach Wegfall der Vermögensteuer in Relation zum Einsparpotenzial unverhältnismäßig erschien, ist seit dem AföRG 2001 nur noch das Vermögen des Auszubildenden anzurechnen (s. Rothe, Blanke (2005), $\S 26$, Rn.1.6f). Auf die Betrachtung in dieser Arbeit wirkt sich diese Rechtsänderung nicht aus, da auf Grund hoher Vermögensfreibeträge auch bis 1997 die Vermögensanrechnung bei typisierten Fällen keine Auswirkungen hatte.

136 Bis 1981 wurde stattdessen der Gesamtbetrag der Einkünfte zu Grunde gelegt. Mit dem durch das 7. BAföGÄndG vollzogenen Wechsel zur restriktiveren Summe der positiven Einkünfte sollten Einnahmen in erweitertem Maße als anrechenbares Einkommen erfasst werden. (Bundesministerium für Gesundheit und Soziale Sicherung (Hrsg.) (2005), S. 766) Bei den Modellfällen dieser Arbeit stimmen Gesamtbetrag und Summe der positiven Einkünfte überein. 
genden Einkommens verstanden, die anrechnungsfrei bleiben. Abbildung 26 stellt die Berechnung der Förderung schematisch dar. Die Leistungsparameter, die Freibeträge und die Sozialpauschalen sind gemäß $§ 35$ BAföG alle zwei Jahre zu überprüfen und gegebenenfalls neu festzusetzen, wobei der Einkommens- und Preisentwicklung sowie der finanzwirtschaftlichen Entwicklung Rechnung zu tragen ist. §35 wirkt damit zumindest wie eine eingeschränkte Selbstbindung des Gesetzgebers, Leistungen nach dem BAföG nicht durch Preisniveausteigerungen erodieren zu lassen. Allerdings unterblieben grundsätzlich als notwendig erachtete Anpassungen wiederholt auf Grund fehlender Haushaltsmittel. ${ }^{137}$ Die zeitliche Entwicklung verschiedener zentraler Gesetzesparameter ist im tabellarischen Anhang dargestellt (Tabelle 32 bis Tabelle 34).

Abbildung 26: Berechnungsschema der Förderung nach dem BAföG

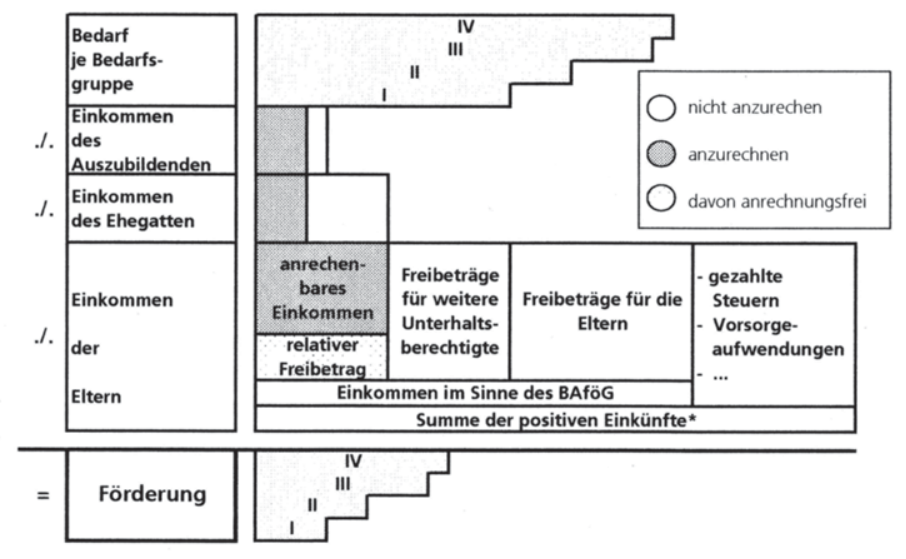

Bis zum 7. BAföGÄndG (1981): Gesamtbetrag der Einkünfte

Quelle: eigene Darstellung

Die Bedeutung förderungsrelevanter Größen und einige markante Gesetzesänderungen sollen an Hand von Abbildung 27 diskutiert werden:

- Ausgangspunkt der Abbildung ist jeweils ein Einverdienerehepaar mit einem Kind, das ausschließlich Bruttoeinkommen aus nichtselbständiger Arbeit bezieht. Ausbildungsförderung kommt für einen Studenten ohne eigenes Einkommen in Betracht, der nicht bei den Eltern wohnt und eine recht hohe Miete aufweist. Hierdurch ergibt sich abgesehen von Zuschlägen für eigene Versicherungen der maximale Bedarf unter den jeweiligen Rechtsständen.

- Die Höchstförderung, die sich bei anzurechnenden Einkommen von Null ergibt und dem Gesamtbedarf entspricht, wurde diskontinuierlich angehoben. Im Jahr 1966 betrug die Förderung nach dem Honnefer Modell bis zu rund 1.800

137 Vgl. Deutscher Bundestag (1983), S. 24; Deutscher Bundestag (1987), S. 21 
Euro/ Jahr, der höhere Bedarf 1970 führt zu einer Ausweitung auf bis zu knapp 2.150 Euro. Das BAföG 1971 sah deutlich höhere Bedarfssätze mit einer Förderung von bis zu 2.577 Euro/ Jahr vor, durch das 2. BAföGÄndG stieg dieser Wert 1974 auf 3.313 Euro. Bis zum Jahr 2002, als die bisher letzte Anhebung erfolgte, wurden die Bedarfssätze regelmäßig in zwei- bis dreijährigen Abständen angehoben, seitdem beträgt die Förderung bis zu 6.360 Euro/ Jahr.

- Die Einkommensschwelle, ab der Elterneinkommen auf den Bedarf anzurechnen ist, wird hauptsächlich von den absoluten Freibeträgen bestimmt. Sie markiert den Übergang von der Vollförderung (anzurechnendes Einkommen von Null) zur Teilförderung (anzurechnendes Einkommen größer als Null). Neben den absoluten Freibeträgen wirken sich auch der Einkommensteuertarif und die Sozialpauschalen auf ihre Höhe aus. Auf Grund ebenfalls regelmäßiger Anhebungen der absoluten Freibeträge stieg die Einkommensschwelle von einem Jahresbruttoeinkommen von rund 7.400 Euro im Jahr 1971 über Werte von 10.800 Euro (1977), 16.350 Euro (1988) und 17.700 Euro (1998) auf den heute gültigen Wert von etwa 23.400 Euro.

Abbildung 27: Ausbildungsförderung in Abhängigkeit vom Einkommen zu verschiedenen Zeitpunkten

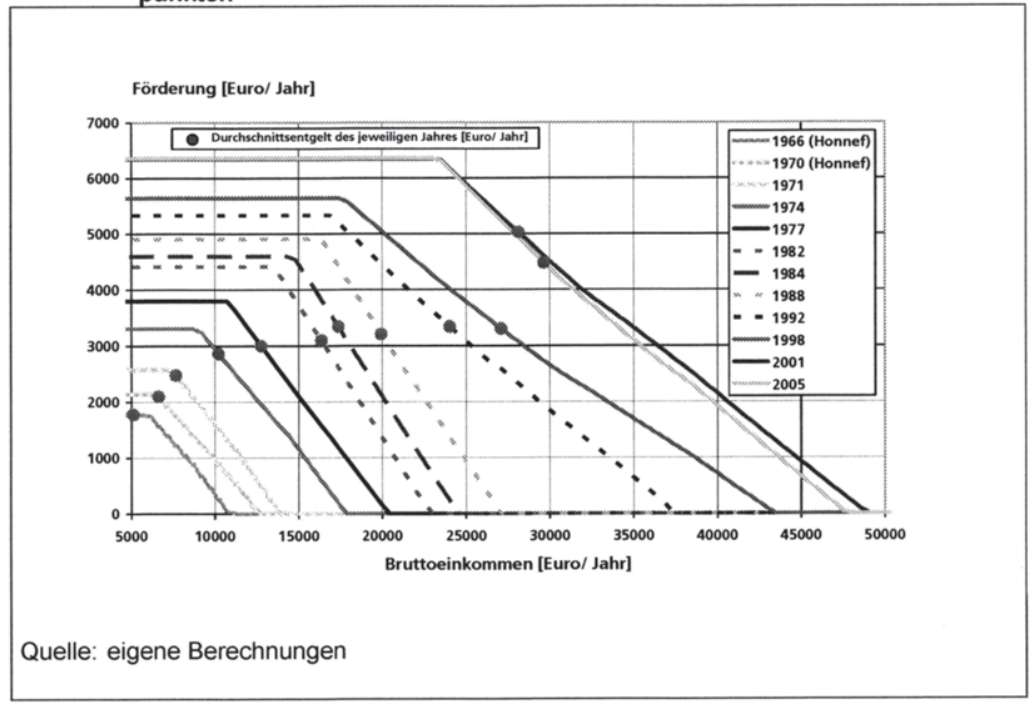

- Die Transferentzugsrate des BAföG, die der (negativen) Steigung der Förderung in Abhängigkeit vom Bruttoeinkommen entspricht, wird im Bereich der Teilförderung primär von den relativen Freibeträgen bestimmt. Nachdem diese beim Honnefer Modell bei $50 \%$ gelegen hatten, galten seit Bestehen des BAföG relative Freibeträge von $40 \%$ (von 1971 bis 1975), $25 \%$ (1976 bis 1989) und seit 1990 von 50\%. Die Verdoppelung des relativen Freibetrags vom 
Elterneinkommen ab 1999 wird in Abbildung 27 beim Vergleich der einkommensabhängigen Förderung in den Jahren 1988 und 1992 deutlich.

- Neben dem starken Anstieg der Leistungsparameter durch das AförG gelten seit 2001 zusätzlich zwei Änderungen bei der Einkommensanrechnung: An die Eltern gezahltes Kindergeld zählt seitdem nicht mehr zum Einkommen im Sinne des BAföG. Im Gegenzug wurden die Freibeträge vom Einkommen der Eltern für BAföG-berechtigte Kinder gestrichen. Insgesamt wirken die beiden Faktoren wie eine weitere Anhebung des absoluten Freibetrags vom Elterneinkommen.

- Im Jahr 2005 liegt die Vollförderung mit 6.360 Euro/ Jahr geringfügig über dem Wert für das Jahr 2001 von rund 6.350 Euro. Übersteigt das Elterneinkommen jedoch die Freibetragsgrenze, kehrt sich die Rangfolge um, ohne dass entsprechende Änderungen im BAföG erfolgten. Ausschlaggebend sind die Steuerreformen der Jahre 2003 bis 2005. Da die gezahlte Einkommensteuer das Einkommen im Sinne des BAföG mindert, werden die Steuerentlastungen der Eltern zum Teil über das BAföG kompensiert. Da das STM von der der Verwaltungsvereinfachung dienenden Regelung des $§ 24$ Abs. 1 BAföG abstrahiert, nach der das Elterneinkommen des vorletzten Jahres anzusetzen ist, schlagen sich Steueränderungen in den Modellrechnungen unmittelbar statt mit zweijähriger Verzögerung nieder.

- Würde in Abbildung 27 von einem Auszubildenden mit Geschwistern ausgegangen, hätte dies zwei Effekte: Erstens läge wegen der absoluten Freibeträge für die Geschwister die Einkommensschwelle zur Teilförderung höher. Zweitens würden die relativen Freibeträge für die Geschwister, die in der Geschichte des BAföG $5 \%$ oder $10 \%$ betrugen, zu einer geringeren negativen Steigung der Graphen im Teilförderungsbereich führen.

Als Bezugspunkt der in Abbildung 27 dargestellten Nominalgrößen zur Einkommensentwicklung sind die jährlichen Durchschnittsentgelte der gesetzlichen Rentenversicherung der jeweils betrachteten Jahre angegeben. ${ }^{138}$ Die derart markierten Förderbeträge ergeben sich folglich bei Einverdienerehepaaren mit Durchschnittsverdienst. Auffällig ist, dass für ein studierendes Kind derart definierter Durchschnittsverdiener in den acht Jahren zwischen 1966 und 1974 die Förderung von etwa 1.800 auf rund 2.860 Euro/ Jahr um nahezu $59 \%$ zunahm, im dreimal so langen Zeitraum von 1974 bis 1998, also in den 24 Jahren danach, jedoch nur um etwa 450 auf 3.310 Euro anstieg (16\%). Zwischen 1984 und 1998 blieb die nominale Förderung bei diesem Einkommensniveau weitgehend konstant und schwankte um Werte von 3.300 Euro. Erst mit dem AförG 2001 ergab sich wieder eine deutlichere Leistungsverbesserung, die in der betrachteten Konstellation zu einem Jahresförderbetrag von etwa 5.030 Euro führt. Während ein studierendes Kind von Durchschnittsverdienern unter den dargestellten Rechtsständen des Honnefer Modells eine Vollförderung (100\% des Bedarfs) erhielt, entsprach seine (Teil-)Förderung 1998 nur noch 59\% des Bedarfs (2001: 79\%). Diese Entwicklung weist darauf hin, dass trotz der regelmäßigen Anpassung der leistungsrelevanten Parameter die Förderungs-

138 In den Berichten nach $\S 35$ BAföG wird zur Überprüfung des Anpassungsbedarfs der Gesetzesparameter stattdessen auf die Entwicklung der Bruttolöhne und -gehälter je Arbeitnehmer Bezug genommen. Diese wichen bis zum Strukturbruch durch die deutsche Wiedervereinigung nie um mehr als $4 \%$ vom Durchschnittsentgelt der gesetzlichen Rentenversicherung ab. 
bedingungen seit Bestehen des BAföG für Bezieher mittlerer Einkommen zunehmend restriktiver wirkten. Eine Gegenbewegung zeichnet sich erst mit dem AförG $2001 \mathrm{ab}$.

Der zeitliche Verlauf der Indices zentraler Kennwerte der Berichte nach § 35 BAföG gibt weitere Anhaltspunkte für die Ursachen dieses Befunds (s. Abbildung 28). Auffällig ist die Entwicklung des Bedarfs, die seit Beginn der 80er Jahre des vergangenen Jahrhunderts nicht die Preisniveausteigerungen bei den Lebenshaltungskosten nachvollzog. Hieraus folgt für alle BAföG-berechtigten Auszubildenden eine reale Abnahme der Förderung im Zeitverlauf. Zusätzlich wichen die absoluten Freibeträge vom Elterneinkommen bis in die zweite Hälfte der neunziger Jahre von der Entwicklung der durchschnittlichen Bruttoeinkommen der Arbeitnehmer deutlich nach unten ab. Während Auszubildenden mit geringen Elterneinkommen hieraus keine Nachteile erwuchsen, wurden Eltern mit mittlerem und höherem Einkommen zunehmend zur Finanzierung der Ausbildung herangezogen.

Abbildung 28: Entwicklung der Bedarfssätze und Freibeträge im Verhältnis zu Lebenshaltungskosten und Einkommensentwicklung

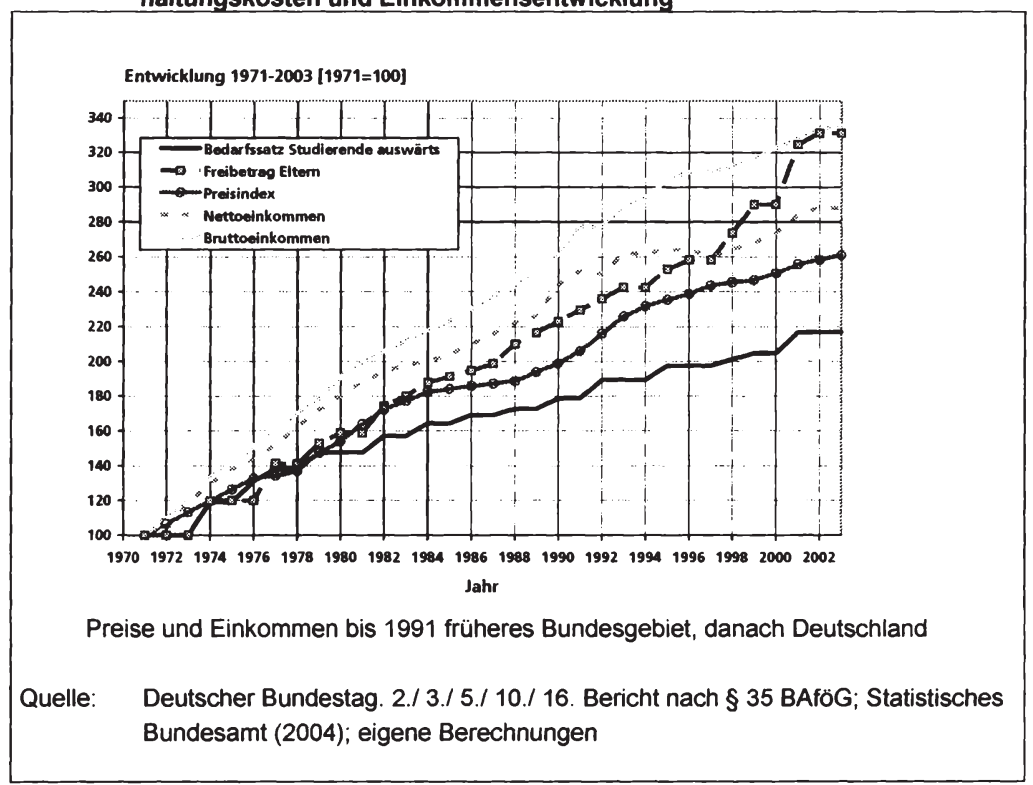

Eine isolierte Betrachtung von Unterperioden, die nicht von den relativ großzügigen Regelungen der frühen 70er Jahre beeinflusst sind, relativiert allerdings den Eindruck eines kontinuierlichen Leistungsabbaus. Im Vergleich zu 1991 zeichnet sich für 2003 keine reale Leistungskürzung ab, was überwiegend auf die BAföG-Reform 2001 zurückzuführen ist. ${ }^{139}$ Auch ist mit Wirkungsbeginn ab Herbst 2008 eine weitere BAföG-

139 Vgl. Deutscher Bundestag (2005), S. $33 f$ 
Reform beschlossen, deren Hauptelemente eine Anhebung der Bedarfe um rund $10 \%$ und der Freibeträge um $8 \%$ sind. Die Auswirkungen hieraus sind in den Berechnungen dieser Arbeit, die für die Zukunft den Rechtsstand des Jahres 2007 beibehält, jedoch nicht erfasst. Insgesamt erinnert die Entwicklung der Leistungsparameter beim BAföG an die Situation beim Erziehungsgeld (s. o.). Bei Einführung der Leistungen in den Jahren 1971 (BAföG) bzw. 1986 (Erziehungsgeld) ergaben sich im zeitlichen Vergleich relativ großzügige Förderungen, die in den Folgejahren jedoch zunehmend absackten.

Neben den Gesetzesänderungen zu den Berechnungsparametern der Förderung ergaben sich beim Schüler-BAföG insbesondere bei den Förderungsvoraussetzungen und beim Studenten-BAföG bei den Darlehensanteilen massive Unterschiede zwischen verschiedenen Rechtsständen:

- Zwischen 1970 und 1982 war der Besuch der gymnasialen Oberstufe ohne einschränkende Bedingungen förderungsfähig. Mit dem HBeglG erfolgte dann ab 1983 eine der weitest reichenden Zäsuren beim Schüler-BAföG. Vom Schuljahr 1983/4 an erfolgte eine Förderung an weiterführenden allgemein bildenden Schulen nur noch, wenn der Auszubildende notwendigerweise nicht bei seinen Eltern untergebracht war. Diese Bedingung der notwendigen auswärtigen Unterbringung, zu deren Erfüllung eine entsprechende Ausbildungsstätte nicht in angemessener Zeit erreichbar sein durfte, entsprach weitgehend der Abschaffung einer flächendeckenden Förderung in der Sekundarstufe II.

- Während das Schüler-BAföG durchgehend vollständig aus Zuschüssen bestand, unterlag die Förderungsart der Studenten wiederholt Änderungen. Der im Honnefer Modell enthaltene Darlehensanteil entfiel zunächst beim Studenten-BAföG (1971 bis 1973). Zwischen 1974 und 1982 wurde dann auf eine Darlehensförderung umgestellt, wobei die Darlehen jedoch nur bis zu einem monatlichen Maximalbetrag, der mit den Bedarfssätzen wiederholt angehoben wurde, zu tilgen waren. Im Jahr 1974 beispielsweise waren bis zu $80 \mathrm{DM}$ (41 Euro) des monatlichen Förderungsbetrages zurückzuzahlen, was bei der Höchstförderung von 540 DM (276 Euro) einem effektiven Darlehensanteil von knapp 15\% entsprach. Auch hier brachte das HBeglG 1983 eine gravierende Verschärfung: Die Höchstgrenze des Darlehensbetrags entfiel, so dass die Förderung ab dann als Volldarlehen erfolgte. Ab 1990 wurde der Darlehensanteil dann von $100 \%$ auf $50 \%$ gesenkt, ab 2001 wurde zusätzlich ein Höchstbetrag von 10.000 Euro (bis zur Währungsumstellung: rund 10.226 Euro) eingeführt. Dieser bezieht sich auf die Gesamtförderung und entspricht bei einer über fünf Jahre erfolgenden Vollförderung nach geltendem Recht einem effektiven Darlehensanteil von rund $31 \% .{ }^{140}$ Die BAföG-Darlehen wiesen stets recht moderate Rückzahlungsbedingungen und daraus folgend einen hohen Subventionierungsanteil auf. Zum einen bleiben sie unverzinst, und die Tilgung setzt erst einige Jahre nach Ausbildungsende ein. Zum anderen sind in Abhängigkeit von Dauer und Erfolg des Studiums Teilerlasse des Darlehens

140 Fünf Jahre Vollförderung führen bei den Bedarfen 2007 zu einer Gesamtförderung eines nicht bei den Eltern wohnenden Studierenden mit Mietkostenzuschuss von 31.800 Euro $(31.800=$ $5 * 12 * 530)$. 
vorgesehen, auch aus sozialen Gründen (Kinderbetreuung, niedriges Einkommen) können Rückzahlungen ausgesetzt oder erlassen werden.

- Weitere Rechtsänderungen, die zum Teil starke fiskalische Bedeutung aufwiesen, für die Betrachtung typisierter Fälle jedoch weniger relevant sind, betrafen die Förderung von Zweitausbildungen und die Förderungsdauern. $A b$ 1982 wurde durch das 7. BAföGÄndG die zuvor großzügiger gestaltete Förderung weiterer Ausbildungen auf Ausnahmefälle beschränkt. Grundsätzlich wird die Förderung seit 1971 für die Dauer der Ausbildung gewährt, wobei jedoch im Hochschulbereich Förderungshöchstdauern nach §15a BAföG wirksam werden, die meist der Regelstudienzeit entsprechen, so dass Studierende üblicherweise bis zu fünf Jahre gefördert werden können. Die früher außerhalb des Gesetzes geregelten und in zahlreiche Einzelfälle aufgesplitteten Höchstdauern gerieten weniger wegen Einschnitten im Gesetz als wegen der zunehmenden Diskrepanz von Regel- und Durchschnittsstudienzeiten in die Kritik. Erstmals wurde daher durch das 12. BAföGÄndG ab 1990 in $\S 15$ eine Studienabschlussförderung aufgenommen, durch die nach Ablauf der Höchstdauer für bis zu 12 Monate eine weitere Förderung beantragt werden kann. Hierauf beruhende Zahlungen sind vollständig und -im Gegensatz zu den sonstigen BAföG-Darlehen- verzinst zurückzuzahlen. Ausschlag für die zunächst zeitlich begrenzte Einführung der Studienabschlussförderung war der niedrige Anteil Studierender, der ein Studium in der Regelstudienzeit beendete. Da entgegen der ursprünglichen Erwartungen dieser Anteil in der Folgezeit nicht stieg, besteht die Regelung seitdem fort. ${ }^{141}$

Die seit der Einführung des BAföG zunehmend restriktiver wirkende Einkommensanrechnung wie oben diskutiert schlägt sich auch in den Gefördertenquoten nieder. Sie bestimmen sich grundsätzlich als

\section{Gefördertenquote $=$ Geförderte $/$ Berechtigte}

und werden als Indikator der Bedeutung des BAföG für die Finanzierung des Lebensunterhalts von Auszubildenden genutzt. Bis 1982 wurden sowohl für Schüler als auch für Studierende Gefördertenquoten in den Berichten nach $\S 35$ BAföG publiziert, nach dem "Kahlschlag"142 beim Schüler-BAföG durch das HBeglG entfiel diese Angabe für Schüler. Gewandelt hat sich zudem die Definition der Anzahl der Berechtigten bei Studierenden. Während ursprünglich in den Berichten nach $§ 35$ BAföG die Gesamtheit der Studierenden als Bezugsgröße gewählt wurde, wurde im 6 . Bericht erstmals ergänzend und seit dem 10. Bericht ausschließlich der Anteil an den Anspruchsberechtigten ausgewiesen. Diese stellen die Teilgruppe der Studierenden, die dem Grunde nach förderungsberechtigt ist, womit unter anderem diejenigen Studierenden entfallen, die die Förderungshöchstdauer überschritten haben oder für die wegen ihres Alters eine Förderung nicht möglich ist.

Begründet wurde diese Umstellung mit dem zunehmenden „Verzerrungseffekt" des ursprünglichen Verfahrens auf Grund steigender Anteile der für eine Ausbildungs-

141 S. Rothe, Blanke (2005), § 15, Rn.1.3

142 Zum Vorwurf des "Kahlschlags" bei der Schülerförderung durch das HBegıG s. Deutscher Bundestag (1982). 
förderung grundsätzlich nicht in Betracht kommenden Studenten. ${ }^{143}$ Tatsächlich war der Anteil der Anspruchsberechtigten an den Studierenden zwischen 1980 und 1986 von $74,0 \%$ auf $69,8 \%$ gefallen, 1977 hatte er noch $80,8 \%$ betragen. Ob die neuere Definition der Gefördertenquote sachdienlicher ist oder ob dadurch in erster Linie geschönte Quoten erzeugt werden, ${ }^{144}$ hängt von der Fragestellung ab. Die ältere Konzeption reflektiert die Gesamtwirkung der zur Nichtförderung führenden Faktoren, durch die Revision wird weitgehend der isolierte Effekt monetärer Größen abgebildet, der an Hand von Abbildung 27 und Abbildung 28 oben dargestellt wurde. Eine zunehmende Abweichung zwischen der Gesamtheit der Studierenden und den Anspruchsberechtigten weist auf eine verstärkte Wirkung der nichtmonetären Restriktionen der Studentenförderung hin, zu denen vor allem die Förderungshöchstdauer zählt, die bei steigenden Studiendauern einen wachsenden Anteil der Studenten von der Förderung ausschloss.

Abbildung 29: Auszubildendenzahlen und Gefördertenquoten 1972 bis 2005 (Jahresdurchschnitte)

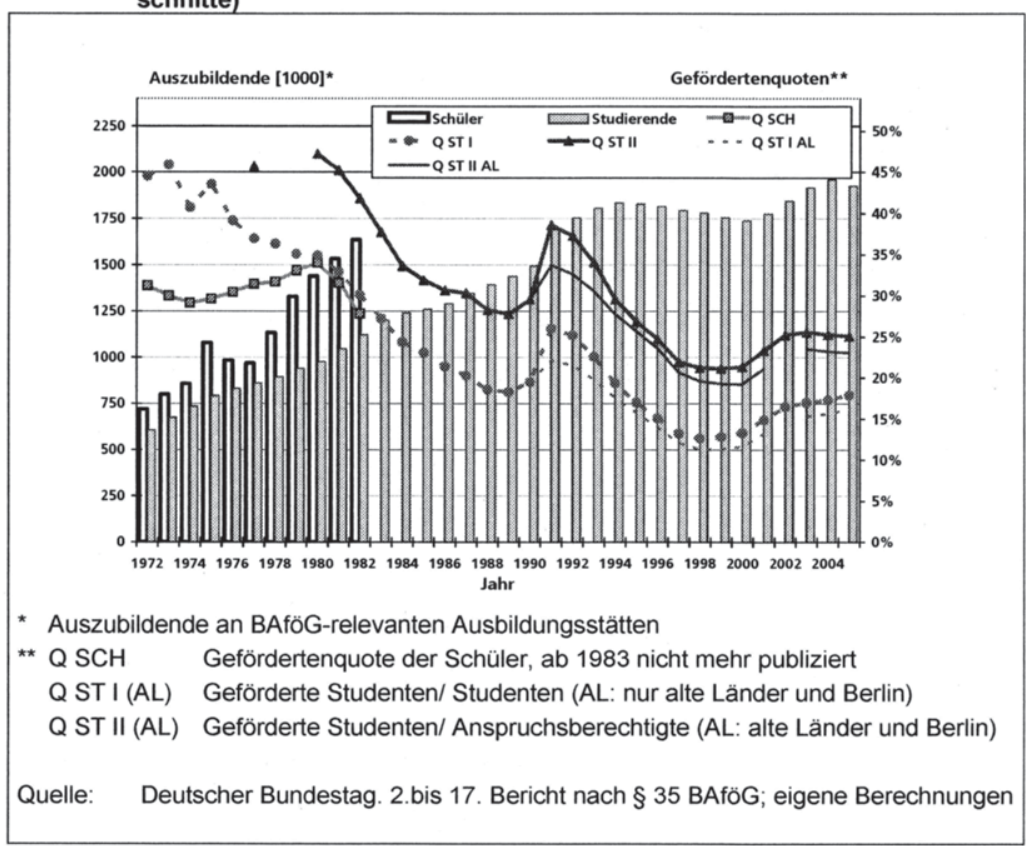

Die Gefördertenquote der Schüler stieg nach einem anfänglichen Absinken zwischen 1974 und 1980 von $29,1 \%$ auf $34,0 \%$ moderat an, wozu auch die Erweiterung des Berechtigtenkreises ab 1978 durch das 5. BAföGÄndG beitrug (Abbildung 29). ${ }^{145}$ Von

\footnotetext{
143 Deutscher Bundestag (1986b), S. 7

144 Onken (1993), S. $11 f$

145 Die zu Grunde liegenden Daten sind in Tabelle 35 und Tabelle 36 im Anhang dargestellt.
} 
1980 bis 1982, dem letzten Jahr einer breit angelegten Schülerförderung, fiel sie parallel zur Quote der Studenten und erreichte 1982 den bis dahin niedrigsten Wert von $27,8 \%$. Im Hochschulbereich wurden zu Beginn der 70er Jahre des vergangenen Jahrhunderts bis zu 45,9\% aller Studenten gefördert (1973). Im Vergleich zum Honnefer Modell wurde die Gefördertenquote (ältere Definition) damit mehr als verdoppelt. ${ }^{146}$ Aus den Förderungsbedingungen lässt sich der sprunghafte Anstieg bei Einführung des BAföG, das "keine einschneidenden materiellen Verbesserungen brachte", nur begrenzt erklären. ${ }^{147}$ Als mögliche Ursachen gelten die gelockerten Eignungsvoraussetzungen und der mit dem BAföG geschaffene Rechtsanspruch auf Förderung.

Von der Mitte der 1970er Jahre an fiel die Gefördertenquote monoton bis zum Jahr 1989, als noch 18,3\% der Studierenden gefördert wurden. Der anschließende Anstieg auf Werte von bis zu 26,0\% (1991) ist wesentlich auf die deutsche Wiedervereinigung zurückzuführen, als Studierende aus den neuen Ländern mit einem niedrigeren Einkommensniveau sowohl die Zahl als auch die strukturelle Zusammensetzung der BAföG-Berechtigten massiv veränderten. Daneben wirkte sich jedoch auch die BAföG-Reform des Jahres 1990 (12. BAföGÄndG) positiv auf die Gefördertenquote aus, wie die für die alten Länder und Berlin getrennt ausgewiesene Quote in Abbildung 29 zeigt. 1990 wurde der relative Freibetrag vom Einkommen der Eltern auf $50 \%$ verdoppelt, wodurch Studierende von Eltern mit mittleren bis höheren Einkommen einen positiven BAföG-Anspruch auf eine Teilförderung erwarben. Da eine vergleichbar großzügige Anhebung der Bedarfssätze nicht erfolgte, ergab sich für das Jahr 1990 die paradoxe Entwicklung einer steigenden Gefördertenquote bei einem fallenden durchschnittlichen monatlichen Förderungsbetrag. ${ }^{148}$ Von 1991 bis 1998 , als die historisch niedrigste Quote von $12,6 \%$ zu verzeichnen war, ist dann wiederum ein kontinuierlicher Rückgang der Gefördertenquote festzustellen. Eine weitere Abwärtsbewegung wurde mit der Reform 2001 vermieden, durch die bis zum Jahr 2003 17,0\% aller Studenten gefördert wurden.

Die Gefördertenquote der Studenten nach der neueren Definition, in der die Anspruchsberechtigten statt der Studenten insgesamt die Bezugsgröße bilden, zeigt einen weitgehend gleichgerichteten Verlauf bei einer deutlichen Niveauverschiebung. Bis 1998 fällt der Anteil der Anspruchsberechtigten an den Studierenden tendenziell, danach ist ein Wiederanstieg festzustellen. In den verschiedenen Berichten nach $\S 35$ BAföG sind Anteile von über $70 \%$ bis zu rund $60 \%$ der Studenten des jeweiligen Bezugsjahres verzeichnet. Entsprechend führt die neuere Definition zu Gefördertenquoten, die um rund ein bis zwei Drittel über den Werten nach der älteren Abgrenzung liegen. Unabhängig von der Art der Definition lassen sich überwiegend Phasen fallender Quoten ausmachen, wobei die BAföG-Reformen 1990 und 2001 die wesentlichen Ausnahmen verursachen. Bezogen auf die Anspruchsberechtigten wurde 2005 etwa jeder Vierte (25,1\%) gefördert, durch die BAföG-Reform ab Herbst 2008 wird ein Anstieg der Quote auf gut $29 \%$ erwartet. Insgesamt lässt sich festhalten, dass der im Zeitverlauf tendenziell fallende Anteil der grundsätzlich Anspruchsberechtigten auf eine zunehmende Bedeutung der nicht ökonomischen Förderungsvoraussetzungen hindeutet, wozu auch steigende Studiendauern ohne entsprechen-

146 Deutsches Studentenwerk (Hrsg.) (1969), S. $86 f$

147 Deutscher Bundestag (1974b), S. 98. Vgl. auch Abbildung 27.

148 Deutscher Bundestag (1992b), S. 3, S. 20 
de BAföG-Anpassungen zählen. Der Verlauf der Gefördertenquote im neueren Sinne zeigt darüber hinaus, dass die monetären Gesetzesparameter ebenfalls zu einer abnehmenden Reichweite des BAföG beitrugen.

Abbildung 30: Finanzaufwand und Geförderte 1972 bis 2005

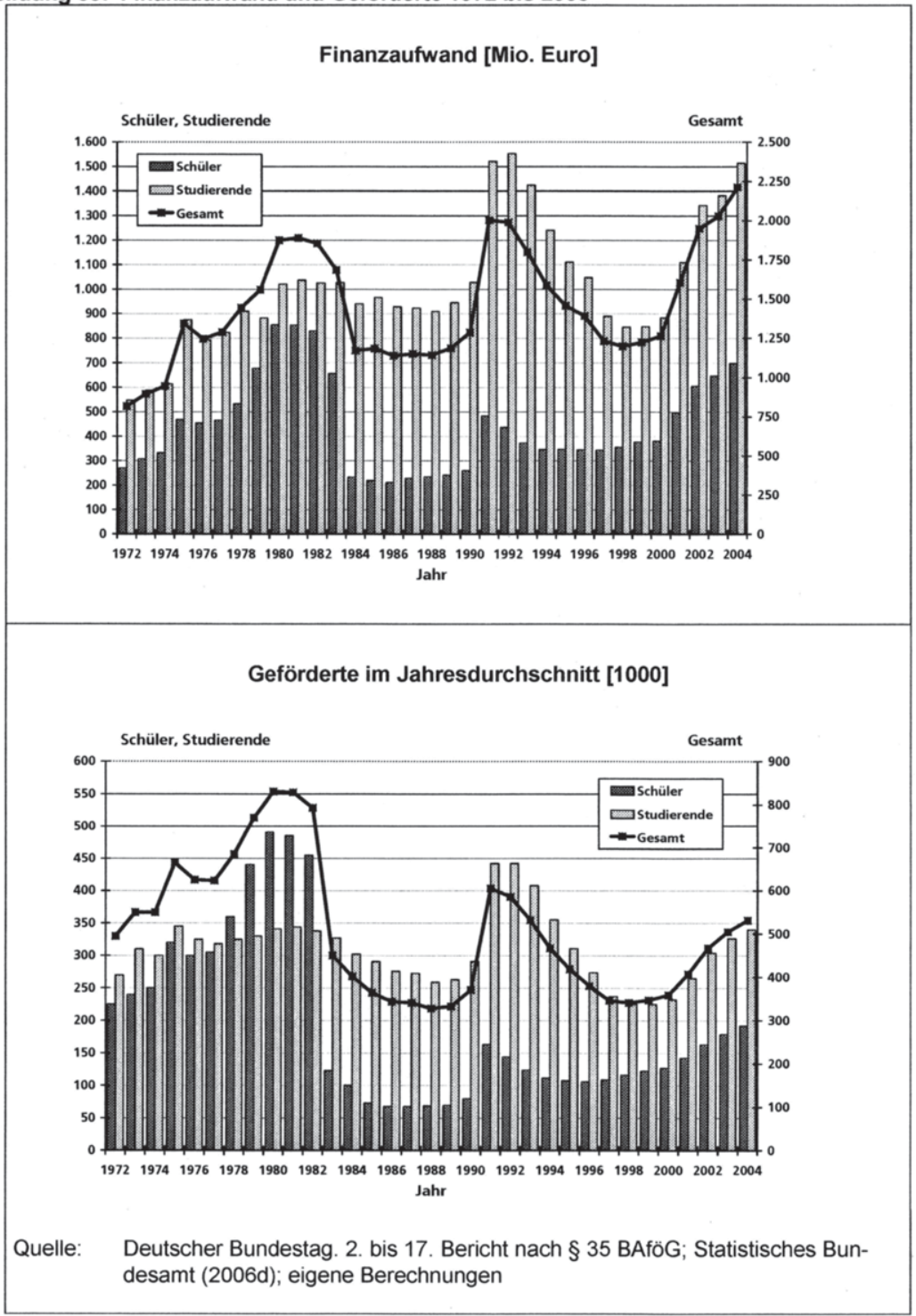


Die Gefördertenzahlen und der Finanzaufwand hingegen zeigen eine von den Gefördertenquoten stark abweichende Entwicklung (Abbildung 30). ${ }^{149}$ Zwischen 1972 und 1980 nahm der Finanzaufwand von 817 auf 1.874 Mio. Euro/ Jahr um fast $130 \%$ zu, die Zahl der Geförderten im Jahresdurchschnitt stieg im selben Zeitraum von 495 auf 831 Tsd. um rund $68 \%$. Getrieben wurde dieses Wachstum von den Auszubildendenzahlen an BAföG-relevanten Ausbildungsstätten, die wegen einer steigenden Bildungsbeteiligung und zudem wegen einer Enweiterung des Berechtigtenkreises des Schüler-BAföG von etwa 1,3 auf 2,4 Mio. um $82 \%$ zunahmen (vgl. Abbildung 29). Um das Jahr 1980 stellten Schüler mit bis zu 59\% die Mehrheit der Geförderten, ihr Anteil am Finanzaufwand lag auf Grund der niedrigeren Bedarfssätze des SchülerBAföG bei bis zu etwa 45\%. Die ab 1980/81 erfolgenden Leistungseinschnitte, unter denen die Bedingung der notwendigen auswärtigen Unterbringung für Schüler an allgemein bildenden Schulen hervorzuheben ist, führten zu einem massiven Ausgabenrückgang ab 1983. Die Zahl der geförderten Schüler fiel innerhalb eines Jahres von 455 Tsd. auf 123 Tsd. um 73\%. Ab 1984 bis 1990 gingen die Gefördertenzahlen leicht zurück, das Ausgabenvolumen blieb nominal recht konstant bei Werten von 1,2 bis 1,3 Mrd. Euro. Da die Studierendenzahlen im Jahresdurchschnitt, die zu Beginn der 1970er Jahre bei etwa 600 Tsd. gelegen hatten, weiterhin von etwa 1,24 Mio. (1984) auf 1,49 Mio. (1990) wuchsen, ging hiermit die oben skizzierte fallende Gefördertenquote einher. Bei in etwa stagnierenden Studierendenzahlen nach der deutschen Wiedervereinigung entwickelten sich der Finanzaufwand und die Gefördertenzahlen des Studenten-BAföG ähnlich wie die Gefördertenquote. Sowohl bei Schülern als auch bei Studenten sind starke Zuwächse seit der BAföG-Reform 2001 zu verzeichnen.

\subsection{Ausbildungsgebühren}

Nach der grundsätzlichen Ausrichtung dieser Arbeit beschränkt sich die Betrachtung auf monetäre Transfers. Ein Aspekt, der bei intergenerativen Vergleichen dadurch ignoriert würde, sind die unterschiedlichen privaten Beiträge zur Bildungsfinanzierung in den letzten Jahrzehnten, die vorrangig für die Berechnung von Bildungsrenditen im zweiten Teil dieser Arbeit von Interesse sind. Die bis vor kurzem geltende weitgehende Gebührenfreiheit bei Ausbildungen an staatlichen Schulen und Hochschulen existierte in dieser Form bundesweit seit 1970/71. Bis dahin wurden in der Regel Studiengebühren erhoben, seit dem Jahr 2006 wurden diese in mehreren Bundesländern wieder eingeführt. Schulgeldzahlungen an weiter führenden allgemein bildenden Schulen (Realschulen und Gymnasien) waren zuletzt 1961 zu entrichten, Pflichtschulbesuche bis zum Hauptschulabschluss waren in der Bundesrepublik stets gebührenfrei. Um die verschiedenen Gebührenregelungen in die Lebenszyklusbetrachtungen des zweiten Teils dieser Arbeit integrieren zu können, werden im STM durchschnittliche Belastungen von Auszubildenden bzw. von ihren Eltern angesetzt. Die Herleitung der hierbei gewählten Beträge wird im Folgenden vorgestellt. Auf Grund der heterogenen Regelungen zwischen Bundesländern und auch zwischen einzelnen Bildungseinrichtungen wird mit diesen typisierenden Richt-

149 Die zu Grunde liegenden Daten sind in Tabelle 35 und Tabelle 36 im Anhang dargestellt. 
werten von einer erheblichen Spannweite der früher erhobenen Gebühren abstrahiert.

In Bremen und Hessen blieb der Schulbesuch seit Bestehen der Bundesrepublik gänzlich gebührenfrei, in den übrigen Bundesländern wurde das Schulgeld an Gymnasien und Realschulen zwischen 1948 und 1961 abgeschafft. Bis dahin waren Beträge von etwa 15 bis 20 DM monatlich (92 bis 123 Euro je Jahr) üblich. ${ }^{150}$ Riphahn (2004) führt Werte an, die zwischen 1946 und 1959 von etwa 13\% auf 5\% der damaligen Durchschnittsentgelte der gesetzlichen Rentenversicherung fallen, was bei drastischen Einkommensanstiegen nominal recht konstanten Jahresbeträgen in einer Größenordnung von 100 bis 140 Euro entspricht. ${ }^{151}$ Ausschlaggebend für diese sinkende relative Belastung durch Schulgeld sind Übergangsregelungen in mehreren Bundesländern, die zu einem sukzessiven Abbau des Schulgeldes führten. Während die Setzung einer typisierenden Höhe des Schulgelds von durchgängig 110 Euro je Jahr nach diesen Angaben nicht unangemessen erscheint, muss die Annahme eines bundeseinheitlichen Zeitpunkts der Abschaffung von Schulgeldern notwendigerweise von den stark divergierenden Einzelregelungen der Länder abstrahieren. Hierfür wird das Jahr 1957 vorgeschlagen, für das auf Grund der Bevölkerungsanteile davon ausgegangen werden kann, dass erstmals für mehr als die Hälfte der Schüler Schulgeldfreiheit verwirklicht war. Nicht aufgenommen sind bei dieser Betrachtung verschiedene Schulgeldnachlässe für kinderreiche Familien oder für begabte Schüler, durch die eine soziale Staffelung in den Schulgeldregelungen bestand.

Bis zum Beschluss der Ministerpräsidenten der Länder vom 16. April 1970, im Zuge der Hochschulreform ab dem Wintersemester 1970/71 einheitlich auf die Erhebung von Studiengebühren zu verzichten, war der Hochschulbesuch in der Bundesrepublik überwiegend kostenpflichtig. Eine Ausnahme bildete Hessen, das bereits früher Landeskinder von der Gebührenpflicht an hessischen Hochschulen entbunden hatte. In der Zeit bis 1970 fielen Gebühren in verschiedenen Formen an, zu denen neben den auch danach noch erhobenen Sozialbeiträgen Kolleg- oder Hörergelder, Grund- und Prüfungsgebühren zählten. Kolleg- oder Hörergelder waren anders als die sonstigen Komponenten für jede belegte Veranstaltung einzeln zu entrichten und flossen größtenteils den Lehrenden zu. ${ }^{152}$ Auch in Hinblick auf die Studiengebühren gilt das Bestreben, repräsentative Durchschnittswerte zu ermitteln, ohne die sich regional vielfältig unterscheidenden Einzelregelungen $\mathrm{zu}$ erfassen. In frühen Sozialerhebungen des Deutschen Studentenwerks der Jahre 1956 und 1967 werden unter den monatlichen Ausgaben der Studierenden jeweils Studiengebühren von rund 30 DM monatlich angegeben (184 Euro je Jahr). ${ }^{153}$ Bei monatlichen Gesamtausgaben von 228 DM (1956) bzw. 404 DM (1967) entsprachen diese Werte etwa 13\% (1956) bzw. 7\% (1967) des mittleren Budgets der damaligen Studenten. Kath (1967) nennt als Ergebnis einer Befragung von 1.500 Studierenden an wissenschaftlichen Hoch-

\footnotetext{
150 In den bevölkerungsreichsten Bundesländern erfolgte dieser Schritt zwischen 1949 (Bayem), 1957 (Baden-Württemberg) und 1960 (Nordrhein-Westfalen), zuletzt in Rheinland-Pfalz 1961. (S. Ehmann (2003), S. 57f)

151 Riphahn (2004), S. 39

152 Haug (1999), S. $113 \mathrm{ff}$

153 Deutsches Studentenwerk (Hrsg.) (1957), S. 51

Deutsches Studentenwerk (Hrsg.) (1969), S. 71
}

Tobias Arens - 978-3-631-75164-0 
schulen im Wintersemester 1965/66 Studiengebühren in einer vergleichbaren GröBenordnung von typischerweise 30 bis 35 DM je Monat (184 bis 215 Euro je Jahr). ${ }^{154}$ Andere Autoren erwähnen zum Teil höhere Gebühren von etwa 256 Euro für Jahre um 1970. ${ }^{155}$ Ehmann (2003) diskutiert hingegen niedrigere Werte von bis zu $160 \mathrm{DM}$ je Semester (164 Euro je Jahr), die zudem vom Ende der 1940er Jahre bis 1970 recht konstant blieben. ${ }^{156}$

Für die in dieser Arbeit vorgenommenen Auswertungen erscheint auf Grund dieser Angaben die Annahme von Studiengebühren in einer gleich bleibenden Höhe von 200 Euro je Jahr für den Zeitraum bis 1970 als geeignete Näherungslösung. Insbesondere die Ergebnisse der auf umfangreichen Befragungen basierenden Sozialerhebungen, die mit den Jahren 1956 und 1967 sowohl den Beginn als auch das Ende des hier relevanten Zeitraums näherungsweise erfassen und auf nominal konstante Gebührenhöhen hindeuten, lassen diese Setzung angemessen erscheinen. Da gleichzeitig die Einkommen zwischen 1950 und 1970 deutlich zunahmen, resultiert eine sinkende relative Belastung durch Studiengebühren im Zeitverlauf. Weiterhin ist der mit der Förderung nach dem Honnefer Modell einher gehende Erlass der Studiengebühren in den Modellrechnungen berücksichtigt. ${ }^{157}$

Zwischen 1970 und 2005 wurden bundesweit keine Studiengebühren erhoben. Nachdem das Bundesverfassungsgericht im Jahr 2005 dann ein bundeseinheitliches Studiengebührenverbot für nichtig erklärt hatte ${ }^{158}$ wurde in mehreren Bundesländern die (Wieder-)Einführung allgemeiner Studiengebühren beschlossen. Die ab dem Jahr 2006 von Studienbeginn an zu entrichtenden Gebühren belaufen sich mehrheitlich auf einen Betrag von 500 Euro je Semester, ${ }^{159}$ wobei verschiedene Darlehens-, Erlass- und Stipendienmodelle geplant sind, die durch die Staffelung der Belastung von Studierenden einer sozialen Selektion beim Hochschulzugang entgegenwirken sollen. ${ }^{160}$ Für die in dieser Arbeit betrachteten Modellfälle irrelevante Langzeit- oder Zweitstudiengebühren in einer Größenordnung von 500 bis 650 Euro je Semester, die bereits seit einigen Jahren in verschiedenen Bundesländern erhoben werden, sollen überwiegend durch die allgemeinen Gebühren ersetzt werden. Ausgehend von den gegenwärtigen Studierendenzahlen werden ab dem Jahr 2008 voraussichtlich rund $70 \%$ der Studierenden an deutschen Hochschulen allgemeine Studiengebühren in einer Größenordnung von 500 Euro je Semester zu entrichten haben.

154 Kath (1967), S. $52 f$

155 Becker, Fenge (2005), S. 18

156 Ehmann (2003), S. $81 \mathrm{ff}$

157 Vgl. Deutsches Studentenwerk (Hrsg.) (1964), S. 61

158 BVerfG, 2 BvF 1/ 03 vom 26.1.2005

159 Insgesamt sieben Bundesländer, auf die rund $70 \%$ der Studierenden an deutschen Hochschulen entfallen, wollten zwischen den Wintersemestern 2006/ 2007 und 2007/ 2008 allgemeine Studiengebühren einführen. Während vier dieser Länder landeseinheitliche Gebühren von 500 Euro je Semester vorsahen (Baden-Württemberg, Hamburg, Hessen, Niedersachsen), soll in den anderen drei Ländern die Hochschule den Betrag selbst festlegen können (Bayern, Nordrhein-Westfalen, Saarland), wobei 500 Euro je Semester die Obergrenze bilden.

Vgl. zu den Modalitäten in den einzelnen Ländern Deutsches Studentenwerk (2008)

160 Vgl. hierzu Strate, Meyer (2006) 


\section{Gesetzliche Rentenversicherung: Entwicklungen seit 1992}

Renten der gesetzlichen Rentenversicherung werden vom STM detailgetreu den gesetzlichen Vorgaben folgend endogen berechnet. ${ }^{161}$ Diese Aufgabe übernimmt der Rentenrechner als drittes Modul des STM, der aus den Angaben von Geburtsjahr, Jahreseinkommen und verschiedenen sozioökonomischen Merkmalen als Bestandteilen einer Rentenbiographie den Rentenanspruch ermittelt. Abgebildet sind die Rechtsstände seit dem Rentenreformgesetz 1992 (RRG 1992), der ersten Änderung des SGB VI, mit der bereits seit den 1960er Jahren diskutierte „demographische Herausforderungen" für die Alterssicherung angenommen werden sollten. ${ }^{162}$ Bei Rentenbezug vor 1992, der bei der ältesten der in die Analyse einbezogenen Kohorten (Geburtsjahrgang 1930) einem Renteneintritt vor Vollendung des 62. Lebensjahres entspricht, wird vereinfachend der Rechtsstand 1992 angesetzt, allerdings ohne die erst mit dem RRG 1992 eingeführten Abschläge beim Zugangsfaktor anzuwenden (siehe unten). Die im STM abgebildeten Rentenarten umfassen Renten wegen Alters (Regelaltersrente, Altersrente für Frauen, Altersrente für langjährig Versicherte) und Renten wegen Todes (Witwen- und Witwerrenten). Andere Renten wie etwa die Altersrente wegen Arbeitslosigkeit, Renten wegen Erwerbsminderung oder Waisenrenten werden wegen fehlender Relevanz für Standardbiographien nicht betrachtet. Im Weiteren werden zum einen die vom Rentenrechner des STM nachempfundenen Berechnungsschritte zur Ermittlung der Renten dargelegt und zum anderen Umverteilungselemente in der Rentenversicherung unter verschiedenen Rechtsständen erörtert, die sich auf die Verteilung der Renten sowohl innerhalb von Kohorten als auch zwischen ihnen auswirken.

\subsection{Rentenberechnung}

\section{Renten wegen Alters}

Wie vom SGB VI vorgesehen wird bei Renten wegen Alters der individuelle Rentenanspruch aus den sich zum Renteneintrittszeitpunkt ergebenden Entgeltpunkten ermittelt, gewichtet mit dem Zugangs- und Rentenartfaktor. Die für die weitere Ableitung des verfügbaren Einkommens zu bestimmende Bruttojahresrente folgt dann nach der Rentenformel: ${ }^{163}$

Bruttojahresrente $=($ Entgeltpunkte * Zugangsfaktor * Rentenartfaktor $)$ * aktueller Rentenwert * 12

Die Berechnung der Renten setzt sich also aus zwei Schritten zusammen: Erstens werden einmalig im Jahr des Renteneintritts die Entgeltpunkte, der Zugangsfaktor

161 Alternativ können selbstverständlich auch Bruttorenten exogen vorgegeben werden, aus denen dann vom Steuer-Transfer-Rechner das verfügbare Einkommen abgeleitet wird.

162 Heine (1990), S. $141 f$

163 Bei Rentenbezug vor Vollendung des 65. Lebensjahrs wird die angegebene Rente gegebenenfalls um anzurechnende weitere Einkommen gekürzt. 
und der Rentenartfaktor festgelegt. ${ }^{164}$ Zweitens wird für jedes Jahr des Rentenbezugs die Bruttojahresrente unter Hinzuziehung des aktuellen Rentenwerts bestimmt. Für den ersten Schritt werden biographische Daten vom Beginn des belegungsfähigen Gesamtzeitraums (ab dem 16. bzw. 17. Lebensjahr, gegebenenfalls verlängert um frühere Beitragszeiten) bis zum Renteneintritt ausgewertet. Dabei berücksichtigte Merkmale sind rentenversicherungspflichtige Bruttoeinkommen, Ausbildungszeiten, Geburten von Kindern, das Geschlecht und das Alter sowie das Kalenderjahr. Eine Rentenbiographie umfasst Daten aus üblichenweise bis zu etwa 50 Kalenderjahren.

Das STM unterteilt die Entgeltpunkte einer Rente in drei Komponenten (s. Tabelle 5). (I) umfasst die Entgeltpunkte, die vollständig aus von Erwerbseinkommen abgeführten Rentenversicherungsbeiträgen stammen. Bei $n$ Jahren der Erwerbstätigkeit entspricht (I) den mit den Durchschnittsentgelten $d_{t}$ gewichteten Jahreseinkommen $y_{l}$, soweit diese nicht über der Beitragsbemessungsgrenze $b_{t}$ liegen:

$$
E P_{I}=\sum_{t=1}^{n} \operatorname{Min}\left(y_{t}, b_{t}\right) / d_{t}
$$

Tabelle 5: Ermittlung der Entgeltpunkte mit dem Rentenrechner des STM

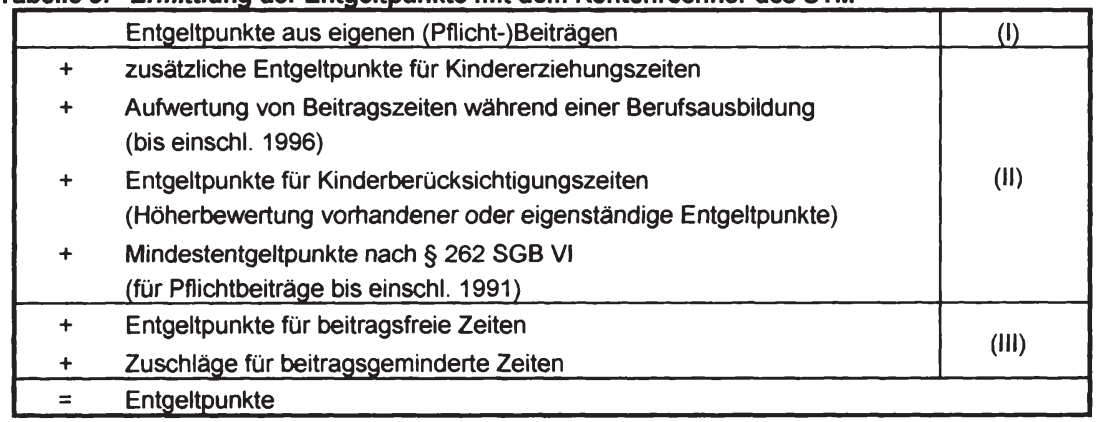

Die sich hieraus ergebende Rente bildet den Rentenzahlbetrag eines Rentenversicherungssystems $a b$, das keinerlei versicherungsfremde Transferelemente kennt. Die Summe aus (I) und (II) entspricht dem gesetzlichen Konzept der Entgeltpunkte aus Beitragszeiten, das sich als Zwischengröße bei der Rentenberechnung aus dem SGB VI ergibt. Anders als nach dem Gesetz erforderlich zerlegt das STM damit die Entgeltpunkte aus Beitragszeiten in einen durch eigene Beiträge gedeckten Teil und einen Transferteil, der aus gesetzlichen Zuschlägen oder Übertragungen von Beitragsäquivalenten resultiert. So beinhalten etwa die unter (II) aufgeführten zusätzlichen Entgeltpunkte für Kindererziehungszeiten nur diejenigen Teilwerte, die während der entsprechenden Zeiten rentensteigernd zu eigenen Entgeltpunkten hinzukommen (vgl. auch unten additive und substitutive Entgeltpunkte für Kindererzie-

${ }^{164}$ Eine Ausnahme bilden Renten, die Entgeltpunkte für Kindererziehungszeiten enthalten. Deren auch rückwirkende Aufwertung macht eine Neuberechnung der Entgeltpunkte im Zeitraum von 1998 bis 2000 erforderlich (siehe auch unten). 
hungszeiten). (III) schließlich enthält weitere Transferelemente der Rente, die sich aus der Gesamtleistungsbewertung nach § $71 \mathrm{ff}$ SGB VI ergeben. Mit dem (zu begrenzenden) Gesamtleistungswert werden Ausbildungszeiten (höher-)bewertet, in denen kein (beitragsfreie Zeiten) oder nur geringes (beitragsgeminderte Zeiten) Einkommen erzielt wird. Tabelle $37 \mathrm{im}$ Anhang gibt einen ausführlicheren schematischen Überblick über die Ermittlung der Entgeltpunkte.

Der Zugangsfaktor ( $§ 77$ SGB VI) einer Altersrente wird vom STM nach Prüfung der rentenrechtlichen Voraussetzungen festgelegt. Ausgehend vom exogen vorgegebenen Alter bei Renteneintritt, ermittelt das Modell aus den biographischen Daten, auf welche Arten von Altersrenten ein Anspruch besteht (Regelaltersrente, Altersrente für Frauen, Altersrente für langjährig Versicherte). Von den Rentenarten, deren Bezugsbedingungen erfüllt sind (u. a. Erfüllung von Wartezeiten, Mindestalter), wählt das Modell anschließend diejenige aus, die unter den im jeweiligen Kalenderjahr geltenden Altersgrenzen den höchsten Zugangsfaktor aufweist, eventuelle Zuoder Abschläge sind dabei berücksichtigt. Das Modell greift damit die vom Gesetz eingeräumten Optionen bei den Altersrenten auf und gewährleistet eine im Sinne des Rentners optimale Wahl der Rentenart. Der Einfluss verschiedener Renteneintrittszeitpunkte auf Ergebnisgrößen (wie die Renditen der Rentenversicherung im zweiten Teil dieser Arbeit) kann durch Variation des exogenen Renteneintrittsalters untersucht werden.

Der Rentenartfaktor ( $\$ 67$ SGB VI) beträgt bei den Renten wegen Alters durchgängig 1,0. Die historischen und zukünftigen aktuellen Rentenwerte (§ 67 SGB VI), auf die sich seit dem RVNG 2004 über den Nachhaltigkeitsfaktor auch die demographische Entwicklung auswirkt, zählen zu den exogenen Parametern, wobei die Entwicklung nach 2007 den Annahmen der Nachhaltigkeitskommission (RürupKommission") folgt.

\section{Renten wegen Todes}

Für die Höhe der Witwen- und Witwerrenten, die neben anderen Renten wegen Todes der Hinterbliebenensicherung dienen, sind die -mit dem Zugangsfaktor gewichteten- Entgeltpunkte der anspruchsauslösenden Rente des Verstorbenen, die Kinderzahl (frühestens ab 2002) und das Einkommen des Hinterbliebenen ausschlaggebend:

Bruttojahres-

rente $($ Witwe $)=($ Bruttojahresrente $($ Verstorbener $)+$ Entgeltpunkte $($ Kinder $)){ }^{\star}$ Rentenartfaktor(Witwe $)$ - anzurechnendes Einkommen

Bis zum Jahr 2001 betrug der Rentenartfaktor der Witwen- und Witwerrenten grundsätzlich 0,6 , kindbedingte zusätzliche Entgeltpunkte waren nicht vorgesehen. ${ }^{165} \mathrm{Oh}$ ne anzurechnendes Einkommen beläuft sich diese damit auf $60 \%$ der Rente des Ver-

165 Vereinfachend werden hier Witwen- und Witwerrenten stets mit großen Witwen-/ Witwerrenten gleichgesetzt. Die kleine Witwen-I Witwerrente mit ihrem Rentenartfaktor 0,25, die unter Umständen gezahlt wird, wenn der Hinterbliebene jünger als 45 Jahre ist, findet in den typisierenden Biographien keine Anwendung.

Weiterhin wird im Folgenden in Übereinstimmung mit den überwiegenden Sterblichkeitsmustern ausschließlich die weibliche Form dieser Hinterbliebenenrente genannt. 
storbenen. Für die Übergangszeit der ersten drei Monate nach dem Tod beträgt der Rentenartfaktor der Witwenrente allerdings unter allen betrachteten Rechtsständen 1,0. Mit dem AVmEG wurde ab 2002 einerseits der Rentenartfaktor von 0,6 auf 0,55 herabgesetzt, andererseits erhalten Witwenrenten seitdem einen von der Dauer der Erziehung von Kindern abhängigen Zuschlag an Entgeltpunkten (§ 78a SGB VI). ${ }^{166}$ Die gesetzliche Regelung bewirkt faktisch einen (mit dem Rentenartfaktor 1,0 zu gewichtenden) Zuschlag von 2,0 Entgeltpunkten für das erste und 1,0 Entgeltpunkten für weitere Kinder. Ob die Regelung nach dem AVmEG zu einer Verbesserung oder Verschlechterung für Hinterbliebene führt, richtet sich nach den Entgeltpunkten des Verstorbenen und der Kinderzahl. Für Kinderlose folgt immer eine Schlechterstellung im Vergleich zum älteren Recht, bei Hinterbliebenen mit einem Kind ist die Neufassung günstiger, wenn die Entgeltpunkte des Verstorbenen weniger als 40 betragen, für jedes weitere Kind erhöht sich dieser Wert um 20 Entgeltpunkte. Allerdings wird auf Grund von $\S \S 255,264$ b SGB VI, die für vor 1962 geborene Ehepartner eine Übergangsregel festlegen, bis in die 2020er Jahre hinein die alte Berechnung für die Mehrzahl der Witwenrenten anzuwenden sein.

Eine weitere Neuerung ergab sich ab 2002 durch die Möglichkeit eines Rentensplittings ( $§ 120$ a SGB VI), bei dem die Entgeltpunkte von Ehepartnern als eine Art von Versorgungsausgleich zwischen diesen aufgeteilt werden; im Gegenzug entfällt der Anspruch auf eine Witwenrente. Diese nur in seltenen Fällen eine Besserstellung bewirkende Option wird vom STM ignoriert, ohne dass hierdurch bedeutsame Verzerrungen zu erwarten sind. ${ }^{167}$ Als Einkommen sind durchgängig eigene Versorgungsbezüge und Erwerbseinkommen von Hinterbliebenen zu berücksichtigen ( $\S 18 \mathrm{a}, 18 \mathrm{~b}$ SGB IV), soweit sie einen an den aktuellen Rentenwert gekoppelten und von der Kinderzahl abhängenden Freibetrag überschreiten ( $97 \mathrm{SGB}$ VI). Durch verschiedene absolute und insbesondere relative Abzugsbeträge nimmt die Witwenrente bei steigendem Einkommen nur moderat ab. Eine hierbei relevante Verschärfung ergibt sich ab dem Jahr 2002, seit dem insbesondere auch Einkommen aus Vermögen anzurechnen sind.

\subsection{Transferelemente der gesetzlichen Rentenversicherung}

Grundsätzlich ist für die gesetzliche Rentenversicherung wie für jede Versicherung eine Umverteilungsabsicht konstituierend. Das Primäranliegen, Armutsrisiken bei Langlebigkeit abzusichern (und damit von Kurz- zu Langlebenden umzuverteilen), wird in der gesetzlichen Rentenversicherung jedoch von verschiedenen nicht aus dem Versicherungsprinzip ableitbaren Elementen der Leistungsbestimmung über-

${ }^{166}$ Eine ausführlichere Beschreibung der Reform der Hinterbliebenenversorgung durch das AVmEG und späterer Änderungen bieten: Stahl, Stegmann (2001)

167 Die Nutzung des Splittings enweist sich dann als vorteilhaft, wenn die Entgeltpunktdifferenz der Partner groß ist und zudem hohe andere Alterseinkünfte vorliegen. Da außerdem als Voraussetzung für das Rentensplitting beide Partner mindestens 25 Jahre rentenrechtlicher Zeiten aufweisen müssen, ist von ihm kein wesentlicher Einfluss auf die hier betrachteten Fälle zu enwarten (s. Grub (2005), S. 30f, S. 156ff). 
lagert. ${ }^{168}$ Intergenerative Unterschiede bei der Umverteilung durch die Rentenversicherung ergeben sich zum einen aus gesamtwirtschaftlichen Rahmendaten, deren Auswirkungen zumindest teilweise integraler Bestandteil des Umlageverfahrens sind, wie beispielsweise die Kopplung der Renten an die Lohnentwicklung. Zum anderen entspringen Unterschiede zwischen Kohorten jedoch auch politischen Setzungen, zu denen etwa das gesetzliche Renteneintrittsalter zählt. Daneben führt die Rentenversicherung auch zu weniger intensiv diskutierten intragenerativen Umverteilungsmustern, indem Rentenanwartschaften ohne äquivalente Beitragszahlungen begründet werden (Bewertung oder Höherbewertung verschiedener rentenrechtlicher Zeiten wie Ausbildungszeiten). Letztlich wirken jedoch auch diese auf Grund verschiedener Rechtsänderungen nicht intertemporal neutral, für Versicherte mit Kindern etwa zeigen sich zunehmende Verbesserungen seit 1992, Ausbildungszeiten werden indessen strenger bewertet. Im Weiteren werden einige Umverteilungselemente der Rentenversicherung dargestellt, deren Wirkung von den bei den Berechnungen mit dem STM variierten Merkmalen abhängt. ${ }^{169}$ Verteilungsrelevante Entwicklungen, die eher einer makroökonomischen Perspektive zuzuordnen sind, wie die zukünftige Demographie und die Finanzierung aus Versicherungsbeiträgen oder aus Steuermitteln bleiben außer Betracht.

\section{Geburtsjahr}

Als ausschließlich vom Geburtsjahr und nicht von weiteren Merkmalen abhängige Umverteilungselemente wirkten bei Renteneintritten ab 1992 die Pauschalzeit, die pauschale Anrechnungszeit, Altersgrenzen und mit innen verbundene $A b$ - oder $Z u$ schläge beim Zugangsfaktor:

- Bei Renteneintritten bis zum Jahr 2000 wurden rentenrechtliche Lücken innerhalb der Jahre bis einschließlich 1991 durch eine Pauschalzeit ganz oder teilweise geschlossen ( $§ 263$ Abs. 2 und Anlage 18 SGB VI bis 2004). Mit ihr sollten Schlechterstellungen durch die mit dem RRG 1992 erstmals eingeführte Gesamtleistungsbewertung, die das Erfordernis der Halbbelegung ablöste, abgemildert werden. ${ }^{170}$ Begründet wurde die Pauschalzeit als Vertrauensschutzregelung, die ein starkes Absinken der Bewertung beitragsfreier und beitragsgeminderter Zeiten bei unsteten Versicherungsverläufen verhindern sollte. Diese Zeiten werden seit 1992 grundsätzlich mit dem individuellen Gesamtleistungswert bewertet, der sich ungefähr als individueller Durchschnittsverdienst des Zeitraums vom Beginn der Rentenbiographie bis zum Renteneintritt bestimmt:

\section{Gesamtleistungswert $=($ Summe der Entgeltpunkte) $/$ (belegungsfähige Monate)}

168 Vgl. zum Versicherungsprinzip und zu Umverteilungswirkungen der Rentenversicherung KöhlerRama (2003); Börsch-Supan (1997), S. 200ff

169 Bei verschiedenen der im Weiteren beschriebenen Regelungen differenziert das SGB VI nach dem Geburtsdatum. Diese sind in der Darstellung hier soweit möglich in Renteneintrittsjahre ${ }_{n}$ übersetzt". Die Renteneintrittsjahre ergeben sich dabei aus der Kombination von Geburtsjahren, Altersgrenzen und den Jahren der Gültigkeit verschiedener Rechtsstände.

170 Für eine ausführliche Darstellung zu den Änderungen durch die Rentenreform 1992 s. Müller, Nachtigal, Hansen (1990). 
Mit der Pauschalzeit wurde der Einfluss von Lücken beschränkt, indem die belegungsfähigen Monate um bis zu $36 \%$ der Beitragszeiten reduziert wurden. Nach den Plänen des RRG 1992 sollte die Pauschalzeit von 36\% auf 0\% der Beitragszeiten in den Jahren von 1992 bis 2003 linear abgesenkt werden, mit dem WFG 1997 wurde die Übergangszeit so verkürzt, dass letztmals 2000 eine Pauschalzeit zu berücksichtigen war. ${ }^{171}$ Die Pauschalzeit wirkt sich dann relativ stark auf die individuelle Rentenhöhe aus, wenn erstens längere mit dem Gesamtleistungswert zu bewertende Zeiten vorliegen, zweitens in den Beitragszeiten ein recht hohes Einkommen erzielt wird und drittens die Rentenbiographie Lücken aufweist. Bei den in dieser Arbeit untersuchten Biographien wird das letzte Kriterium bei Ehepartnern mit Erwerbsunterbrechungen (mit oder ohne Kinder) erfüllt sein. Zusammen mit den beiden anderen Kriterien zeichnet sich ab, dass in erster Linie für Akademikerpaare die Pauschalzeit relevant ist, da sich für diese vergleichsweise lange beitragsfreie Ausbildungszeiten und hohe Einkommen ergeben. Insgesamt führt die Pauschalzeit jedoch auch bei dieser Konstellation nur zu gemäßigten Erhöhungen der Rentenzahlungen, maximal resultieren bis zu etwa 1,5 zusätzliche Entgeltpunkte, was unter anderem auf die begrenzte Gesamtleistungsbewertung bei Ausbildungszeiten zurückzuführen ist.

- Auch durch die pauschale Anrechnungszeit (§ 253 SGB VI) werden rentenrechtliche Lücken geschlossen, in diesem Fall allerdings um Benachteiligungen durch unvollständige Nachweise zu vermeiden. Fehlzeiten vor 1957 werden daher unter Umständen wie beitragsfreie Zeiten behandelt, für die entsprechende Entgeltpunkte vergeben werden. ${ }^{172}$ Bei den Berechnungen mit dem STM kann diese Vergünstigung ignoriert werden, da die Biographien als lückenlos dokumentiert in das Modell eingespeist werden.

- Zu- oder Abschläge beim Rentenzugangsfaktor wurden mit dem RRG 1992 in das SGB VI aufgenommen. Bis dahin betrug der Zugangsfaktor der hier betrachteten Renten wegen Alters stets 1,0 , soweit die jeweiligen Zugangsvoraussetzungen erfüllt waren. Abgesehen von dem Verzicht auf den Erwerb weiterer Entgeltpunkte blieb ein frühzeitiger Renteneintritt ohne Folgen für die Rentenhöhe. Eine diese Möglichkeit beschneidende Neuerung durch das RRG 1992 bestand in der Einführung einer zweiten Altersgrenze für verschiedene Rentenarten: Die bisherigen Altersgrenzen bestanden zumindest übergangsweise fort, um die Zugangsvoraussetzungen zu definieren. Daneben wurden höhere Altersgrenzen eingeführt, deren Erreichen Voraussetzung für eine Rente ohne Abschläge war. Die Abschläge belaufen sich seitdem für alle Renten wegen Alters auf 0,003 für jeden Kalendermonat, so dass der Zugangsfaktor um 0,036 je Jahr des vorzeitigen Rentenbezugs sinkt ( $\$ 77$ SGB VI). Umgekehrt wurden mit dem RRG 1992 auch Zuschläge eingeführt. Für jeden Monat ab Erreichen der Regelaltersgrenze (bisher also ab der Vollendung des 65. Lebensjahres), in dem Rentenansprüche nicht geltend gemacht werden, erhöht sich der Zugangsfaktor um 0,005. Bei einem Lebensalter in Jahren a und 1992 neu eingeführten Altersgrenzen $a_{\min }$ ist der Zugangsfaktor ZF demgemäß:

171 Vgl. Deutscher Bundestag (1996), S. 26

172 S. hierzu Bundesministerium für Gesundheit und Soziale Sicherung (Hrsg.) (2005), S. $292 f$ 
$Z F=1-\operatorname{Max}\left(0, a_{\min }-a\right)^{*} 0,036+\operatorname{Max}\left(0, a-a_{R . L K}\right) * 0,06$

Je nach Lebensalter bei Renteneintritt beträgt der Zugangsfaktor somit 1,0 $\left(a=a_{\min }\right)$ oder wird um einen Abschlag (wenn $a<a_{\text {min }}$ ) oder Zuschlag (wenn $a>a_{R A R}$ ) korrigiert. Für diese Arbeit sind primär die empirisch bedeutsameren Abschläge von Interesse. Zuschläge werden nur bei den seltenen Renteneintritten nach Überschreiten der Altersgrenze der Regelaltersrente $a_{R A R}$ gewährt.

- Die Altersgrenzen der gesetzlichen Rentenversicherung wirken sich zum einen auf die Berechtigung zum Rentenbezug und zum anderen auf die Rentenhöhe aus, da der Zugangsfaktor aus der Differenz von Lebensalter und Altersgrenze abgeleitet wird. Die Altersgrenze für die Regelaltersrente liegt seit dem frühen 20. Jahrhundert unverändert bei der Vollendung des 65. Lebensjahres, für zukünftige Renteneintritte steigt dieses Alter nach dem RV-Altersgrenzenanpassungsgesetz sukzessive auf 67 Jahre. Eine detailliertere Darstellung der Übergangsregelung und ihrer Auswirkungen auf verschiedene Kohorten erfolgt im Kapitel zur Rentenversicherung im zweiten Teil (s. Kapitel 7.2.2). Die seit 1972 bestehende Altersrente für langjährig Versicherte, für die mindestens 35 Versicherungsjahre erforderlich sind, konnte bis zum Jahr $2000 \mathrm{ab}$ Vollendung des 63. Lebensjahrs ohne Abschlag bezogen werden. Bei Renteneintritten zu Beginn des Jahres 2001 lag die Altersgrenze für eine abschlagsfreie Rente um ein Jahr höher, seit 2002 fällt sie mit dem Wert der Regelaltersrente von 65 Jahren zusammen, womit die Altersrente für langjährig Versicherte ab 2002 nur noch als Option auf einen frühzeitigen Renteneintritt mit Abschlägen relevant ist. Bis zum Jahr 2009 ist der Bezug dieser Rente mit Abschlägen ab dem Alter von 63 Jahren möglich, danach soll die Altersgrenze in einer kurzen Übergangsperiode bis 2012 auf das Alter von 62 Jahren fallen. ${ }^{173}$ Die Höhe des Abschlags bleibt demnach bei einem Renteneintrittsalter von 63 Jahren unverändert bei $7,2 \%$, bei Inanspruchnahme der herabgesetzten Grenze von 62 Jahren beträgt der Abschlag 10,8\%. Die typisierten Biographien in dieser Arbeit erfüllen bei durchgehender Enwerbsbeteiligung stets die Voraussetzung, bei Beginn des 62. Lebensjahrs mindestens 35 Beitragsjahre aufzuweisen. Ein Rentenbezug mit Abschlägen ist damit immer spätestens ab dem Lebensalter von 63 Jahren möglich. Für bis einschließlich 1937 Geborene ergibt sich damit die Möglichkeit einer abschlagsfreien Rente ab 63 Jahren (Zugangsfaktor 1,0), für den Geburtsjahrgang 1938 sinkt der Zugangsfaktor in diesem Fall auf 0,964, für alle Kohorten danach auf 0,928.

\section{Geschlecht (Altersrente für Frauen)}

Mit der Altersrente für Frauen erleichtert das SGB VI diesen den Rentenzugang (§ 39 SGB VI bis zum RRG 1999, seitdem § 237 a SGB VI). Die 1957 eingeführte Begünstigung bestand aus der Möglichkeit des Renteneintritts nach Vollendung des 60 . statt 65. Lebensjahres. Voraussetzung des Bezugs ist neben der Einhaltung der Altersgrenze eine Wartezeit von 15 oder mehr Jahren, wobei nach Vollendung des 40 . Lebensjahres mindestens 10 Jahre mit Pflichtbeitragszeiten belegt sein müssen. Die

${ }^{173}$ Eine Übersicht der Altersgrenzen verschiedener Rentenarten seit den 1990er Jahren und die geplanten Übergangsregelungen verschiedener Rentenreformen findet sich in Manzke (2002), S. $62 f$ 
Kombination der Bedingungen weist darauf hin, dass die Maßnahme auf typisierte Biographien abzielte, die von den drei Phasen der Erwerbstätigkeit, der Kindererziehung und der Wiederaufnahme der Erwerbstätigkeit geprägt sind. Seit dem Jahr 2001 wurden durch das RRG 1999 die Altersgrenzen der Altersrente für Frauen in mehreren Stufen angehoben. Die Altersgrenze für eine abschlagsfreie Rente steigt zwischen 2001 und 2009 von 60 auf 65 Jahre, mit Abschlägen ist weiterhin ein Rentenbezug ab dem Alter von 60 Jahren möglich. Der Abschlag beträgt damit bis zu 0,18 . Die Altersrente für Frauen unter Inkaufnahme von Abschlägen kann letztmalig im Renteneintrittsjahr 2011 Anwendung finden.

Für diese Arbeit, in der unstete Erwerbsverläufe stets mit Kindern verbunden sind, wirkt sich die Altersrente für Frauen primär bei Ehepaaren aus. Für diese ergibt sich im Fall von Renteneintritten vor Erreichung der Regelaltersgrenze von 65 Jahren die stärkste relative Begünstigung bei den bis 1940 geborenen Kohorten. Bei diesen ist der Bezug einer abschlagsfreien Altersrente für Frauen ab dem Alter von 60 Jahren möglich.

\section{Kinder}

Im betrachteten Zeitraum wurden die aus Kindererziehung folgenden Rentenbestandteile zunehmend großzügiger gestaltet. Mit dem HEZG wurde 1986 die Bewertung von Kindererziehungszeiten eingeführt. Das erste Lebensjahr eines Kindes galt als Kindererziehungszeit, für das dem erziehenden Elternteil -in der Regel der Mutter- bis zu 0,75 Entgeltpunkte (75\% des Durchschnittsverdiensts) gutgeschrieben wurden ( $\$ 70$ Abs. 2 SGB VI), eventuell vorhandene Entgeltpunkte aus eigenen Beiträgen wurden auf diesen Wert angerechnet. Mit dem RRG 1992 wurde die Kindererziehungszeit für ab 1992 geborene Kinder von einem auf drei Jahre ausgedehnt (§ 56 Abs. 1 SGB VI, § 249 Abs. 2 SGB VI). Bei rascher Geburtsfolge beginnt die Kindererziehungszeit für das jüngere Kind erst nach dem Ende der vorhergehenden Kindererziehungszeit, womit gewährleistet wurde, dass für jedes nach 1991 geborene Kind bis zu 2,25 Entgeltpunkte gutgeschrieben werden konnten. Zudem wurden mit dem RRG 1992 Kinderberücksichtigungszeiten eingeführt (§54 Abs. 1 Nr. 3 SGB VI), die zwar keine unmittelbar rentensteigernde Wirkung entfalteten, jedoch rentenrechtliche Lücken schlossen und durch eine Bewertung mit bis zu 0,75 zusätzlichen EP im Rahmen der Gesamtleistungsbewertung zu einem höheren Rentenanspruch führen konnten ( $\$ 71$ Abs. 3 SGB VI). Als Kinderberücksichtigungszeit gelten seit damals die ersten 10 Jahre nach der Geburt eines Kindes ( $\$ 57$ Abs. 1 SGB VI). Anders als Kindererziehungszeiten verlängern sich Kinderberücksichtigungszeiten nicht bei schneller Geburtsfolge. Mit dem RRG 1999 wurden die Entgeltpunkte für Kindererziehungszeiten im Zeitraum von 1998 bis 2000 auch rückwirkend für Bestandsrenten schrittweise von $75 \%$ auf $100 \%$ des Durchschnittsentgelts angehoben und außerdem additiv zu eventuell gleichzeitig erzielten Entgeltpunkten aus Beiträgen gewährt (höchstens jedoch bis zur Beitragsbemessungsgrenze). Letztere Änderung wirkt sich bei während der Kindererziehungszeit erwerbstätigen Erziehenden positiv aus, für die unter der Regelung des RRG 1992 nur die Differenz zwischen den aus eigenen Beiträgen erzielten Entgeltpunkten und 0,75 ausgeglichen wurde. ${ }^{174}$

174 Die Ersetzung der substitutiven durch die additive Berücksichtigung von Kindererziehungszeiten war gemäß verfassungsgerichtlicher Rechtsprechung erforderlich. S. Bundesministerium für Familie, Senioren, Frauen und Jugend (Hrsg.) (2001), S. 33 
Daneben wurden die Entgeltpunkte für Kinderberücksichtigungszeiten im Rahmen der Gesamtleistungsbewertung durch das RRG 1999 von 0,75 auf 1,0 angehoben. Eine wesentlichere Verbesserung erfuhren Kinderberücksichtigungszeiten durch das AVmEG, das für nach 1991 geborene Kinder eine Aufwertung von während dieser Zeiten erzielten Entgeltpunkten aus Pflichtbeiträgen vorsieht ( $\$ 70$ Abs. 3a SGB VI). Vorhandene Entgeltpunkte werden um 50\% aufgewertet, höchstens jedoch auf einen Gesamtwert von 1,0. Da die dreijährigen Kindererziehungszeiten bei Geburten ab 1992 bereits mit dem Durchschnittsentgelt bewertet werden, kommt eine Aufwertung in der Regel erst für die Zeit nach dem dritten Lebensjahr eines Kindes in Betracht. Bei sich überschneidenden Kinderberücksichtigungszeiten für mehr als ein Kind greift außerdem die Zusatzregelung, dass auch ohne Entgeltpunkte aus eigenen Beiträgen eine Gutschrift von 0,3336 Entgeltpunkten erfolgt, jedoch auch höchstens zu einem Gesamtwert von 1,0. Jahre der gleichzeitigen Erziehung mehrerer mindestens drei- und höchstens zehnjähriger Kinder werden dadurch immer mit mindestens 0,3336 Entgeltpunkten bewertet.

\section{Ausbildung}

Auf die individuelle Rentenhöhe wirken sich Zeiten einer beruflichen Ausbildung (Lehrzeit) als beitragsgeminderte Zeiten aus, Zeiten schulischer Ausbildungen, zu denen der Besuch von allgemein bildenden oder beruflichen (Vollzeit-)Schulen, Fachschulen und auch Hochschulen zählt, sind als Anrechnungszeiten beitragsfrei. Art und Umfang der Berücksichtigung von Ausbildungszeiten in der GRV wurden 1992 und später wiederholt geändert. Zwar geht von ihnen unter jedem Gesetzesstand grundsätzlich eine rentensteigernde Wirkung aus, diese wurde im Zeitverlauf jedoch weitgehend kontinuierlich abgebaut. Berücksichtigungsfähig waren Ausbildungszeiten stets ab dem Beginn des belegungsfähigen Gesamtzeitraums $(\$ 72$ Abs. 2 SGB VI), der bis 1996 der Vollendung des 16. Lebensjahrs entsprach. Ab 1997 wurde diese Altersgrenze um ein Jahr erhöht, wodurch die Anzahl der rentenwirksamen Ausbildungsjahre in der Regel um ein Jahr reduziert wurde.

\section{Zeiten schulischer Ausbildung}

Mit dem RRG 1992 wurde zum einen die Dauer anrechenbarer schulischer Ausbildungszeiten von vormals maximal 13 auf sieben Jahre begrenzt, zum anderen wurde die Höchstbewertung von Ausbildungsjahren von $90 \%$ des Durchschnittsverdiensts auf $75 \%$ herabgesetzt. Nach recht langen Übergangszeiten einer sukzessiven $A b-$ schmelzung sollten diese Minderungen erst bei Renteneintritten ab dem Jahr 2004 voll wirksam werden, Renteneintritte im Jahr 1992 blieben verschont ( $\$ 252$ Abs. 4 SGB VI, §263 Abs. 3 SGB VI). Überholt war diese Planung ab dem Jahr 1997, als mit dem WFG Anrechnungszeiten wegen schulischer Ausbildungen wiederum auf nunmehr drei Jahre reduziert wurden ( $\$ 58$ SGB VI) und daneben eine wesentlich straffere Übergangsregelung in Kraft trat. Mit deren Auslaufen sollten bei Renteneintritten ab 2001 nur noch bis zu drei Jahre mit maximal 75\% des Durchschnittsverdiensts bewertet werden. Zudem blieben ab 1997 Ausbildungszeiten vor Vollendung des 17. statt wie bis dahin des 16. Lebensjahrs unberücksichtigt. ${ }^{175}$ Durch das

175 Sowohl das RRG 1992 als auch das WFG brachten allerdings auch sich grundsätzlich positiv auf die Rentenansprüche auswirkende Änderungen in Hinblick auf schulische Ausbildungszeiten mit sich, die jedoch weder empirisch noch für die Modellrechnungen von wesentlicher Bedeutung wa- 
AVmEG wurden diese Einschnitte bereits 2002 partiell revidiert: Die Anrechnungszeit für schulische Ausbildungen wurde von drei auf acht Jahre ausgedehnt, von denen allerdings unverändert nur drei bewertet wurden. Die übrigen bis zu fünf Jahre wirken sich lediglich durch die Schließung rentenrechtlicher Lücken auf den Gesamtleistungswert aus. Schließlich gewann die Unterscheidung der schulischen Ausbildungsarten mit dem RVNG eine zusätzliche Bedeutung. Während Fachschulzeiten weiterhin wie zuvor behandelt werden, entfällt die Bewertung von Schul- und Hochschulzeiten vollständig für Renteneintritte ab 2009, zwischen 2005 und 2008 greift für diese eine Übergangsregelung. Ebenfalls neu ist die mit dem RVNG eingeführte gemeinsame Anrechnung von Zeiten schulischer und beruflicher Ausbildung auf den Dreijahreszeitraum (s. 0.). ${ }^{176}$

\section{Abbildung 31: Höchstdauern bewerteter Anrechnungszeiten für schulische Ausbildungen}

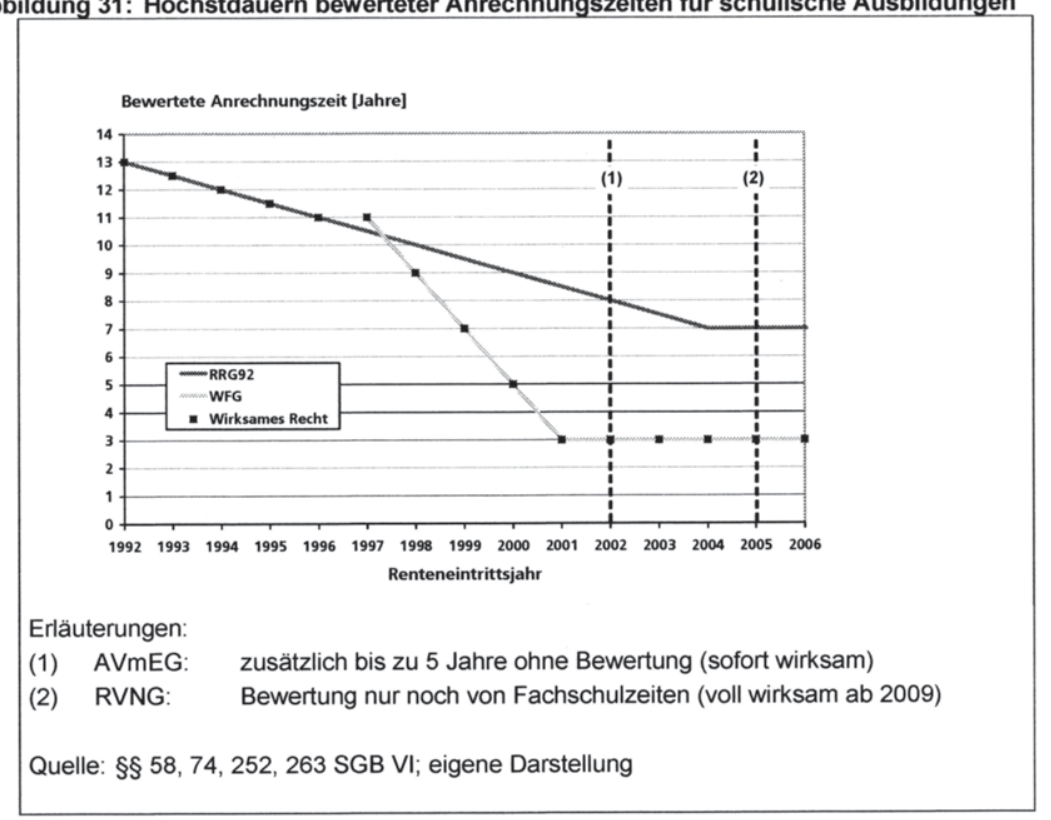

Abbildung 31 gibt einen Überblick über die Änderungen bei der Bewertung von schulischen Ausbildungszeiten in der GRV seit 1992, die abgesehen vom AVmEG fast ausschließlich zu einer restriktiveren Rentenberechnung führten. Eine Ausnahme be-

ren: Die bis zu 13-jährige Anrechnungszeit vor dem RRG 1992 setzt sich aus jeweils vier Jahren mit Schul- und Fachschulzeiten und einer Hochschulzeit von fünf Jahren zusammen. Die Begrenzung auf sieben Jahre des $\S 58$ Abs. 1 Nr. 4 in der Fassung des RRG 1992 unterscheidet hingegen nicht zwischen diesen Ausbildungsarten, so dass ab 1992 beispielsweise sieben statt vier Schuljahre anrechenbar wurden. Mit dem WFG entfiel für die Anrechnung von Fachschul- und Hochschulzeiten die Bedingung, dass diese Ausbildungen erfolgreich abgeschlossen waren.

176 Für eine ausführlichere Darstellung der Änderungen bei der Behandlung von Ausbildungszeiten durch das RVNG und ihrer Folgen s. Dünn, Lohmann, Stahl, Stegmann (2004). 
trifft den Renteneintrittsjahrgang 1997, der im Gegensatz zu späteren Jahrgängen durch das WFG eine geringfügige Besserstellung gegenüber der ursprünglichen Planung des RRG 1992 erfuhr.

Tabelle 6: Aufwertung von Zeiten beruflicher Ausbildung in der GRV ab 1991

\begin{tabular}{|c|c|c|c|c|c|c|}
\hline \multirow{3}{*}{$\operatorname{Jahr}(e)$} & \multirow{3}{*}{$\begin{array}{l}\text { Rechts- } \\
\text { stand }\end{array}$} & \multicolumn{2}{|c|}{ Aufwertung [Jahre] } & \multicolumn{3}{|c|}{ Bewertung nach } \\
\hline & & \multirow{2}{*}{ Pauschal $^{(1)}$} & \multirow{2}{*}{$\begin{array}{l}\text { mit Nach- } \\
\text { weis }^{(2)}\end{array}$} & \multirow{2}{*}{$\begin{array}{c}\text { Durchschnitts- } \\
\text { entgelt }^{(5)}\end{array}$} & \multicolumn{2}{|c|}{ Gesamtleistungswert $^{(6)}$} \\
\hline & & & & & mit Nachweis & ohne Nachweis \\
\hline vor 1992 & & 5 & $\infty$ & 90 & -- & - \\
\hline $1992-1996$ & $\begin{array}{l}\text { RRG } \\
1992 \\
\end{array}$ & 4 & $\infty$ & 90 & -- & -- \\
\hline 1997 & \multirow{8}{*}{ WFG } & 3 & $\infty$ & -- & 91 & 91 \\
\hline 1998 & & 3 & $\infty$ & -- & 87 & 87 \\
\hline 1999 & & 3 & $\infty$ & -- & 83 & 83 \\
\hline 2000 & & 3 & $\infty$ & -- & 79 & 79 \\
\hline 2001 & & 3 & $\infty$ & -- & 75 & 75 \\
\hline 2002 & & 3 & $\infty$ & -- & 75 & 75 \\
\hline 2003 & & 3 & $\infty$ & -- & 75 & 75 \\
\hline 2004 & & 3 & $\infty$ & - & 75 & 75 \\
\hline 2005 & \multirow{5}{*}{ RVNG } & 3 & $3 / \infty^{(3)}$ & -- & 75 & 75 \\
\hline 2006 & & 3 & $3 / \infty^{(3)}$ & -- & 75 & 56,25 \\
\hline 2007 & & 3 & $3 / \infty \infty^{(3)}$ & -- & 75 & 37,50 \\
\hline 2008 & & 3 & $3 / \infty^{(3)}$ & -- & 75 & 18,75 \\
\hline$a b 2009$ & & 0 & $3^{(4)}$ & - & 75 & 0 \\
\hline
\end{tabular}

$\infty$ keine Begrenzung

- nicht vorgesehen

(1) Pauschale Aufwertung der ersten ... Pflichtbeitragsjahre bis zum vollendeten 25. Lebensjahr

(2) Aufwertung von bis zu ... Jahren nachgewiesener beruflicher Ausbildung

(3) Aufwertung wie nachgewiesene/ nicht nachgewiesene berufliche Ausbildung

(4) Berufliche und schulische Ausbildung insgesamt

(5) Bewertung mit ... \% des Durchschnittsentgelts des jeweiligen Jahres

(6) Bewertung mit ... \% des Gesamtleistungswerts, höchstens jedoch mit ... \% des Durchschnittsentgelts des jeweiligen Jahres

\section{Zeiten beruflicher Ausbildung}

Die mit dem RRG 1992 neu geregelten Pflichtbeitragszeiten für eine Berufsausbildung sahen nach $\S 70$ Abs. 3 SGB VI eine pauschale Aufwertung der während einer Lehrzeit erzielten Entgeltpunkte auf $90 \%$ des Durchschnittsverdiensts vor, wenn der tatsächliche Verdienst zu einem geringeren Wert führte. Diese Regel wurde stets auf die ersten vier Jahre (bis 1991: bis zu fünf Jahre) mit Pflichtbeiträgen vor Vollendung des 25. Lebensjahrs angewandt (Berufsausbildung ohne Nachweis), auf Antrag ebenfalls auf darüber hinausgehende nachgewiesene Berufsausbildungszeiten ( 256 Abs. 1 SGB VI). Ab 1997 wurden Zeiten beruflicher Ausbildung durch das WFG den Anrechnungszeiten ( $\$ 58$ SGB VI) zugeordnet, wodurch die pauschale Bewertung mit mindestens 0,9 Entgeltpunkten durch den individuellen Gesamtleistungswert abgelöst und gemäß § 74 SGB VI nach einer 2001 abgeschlossenen Übergangsregelung ( $\$ 263$ Abs. 3 SGB VI) auf maximal 0,75 Entgeltpunkte begrenzt 
wurde. Weiterhin verkürzte sich der Zeitraum, der ohne Nachweis als Berufsausbildung galt, auf drei Jahre. Weitere Rechtsänderungen aus dem Zeitraum zwischen 1997 und 2005 wirken sich nicht auf die Bewertung beruflicher Ausbildungszeiten in den Modellrechnungen des STM aus, erst durch das RVNG folgen für Renteneintritte ab 2006 weitere Einschnitte, deren Auswirkungen sich nach einer Übergangszeit bis 2009 voll niederschlagen ( $\S \S 54,263$ SGB VI): Zum einen entfällt die pauschale Anerkennung einer Berufsausbildung ohne Nachweis ab 2009, zum anderen werden höchstens drei Jahre nachgewiesener beruflicher Ausbildungszeiten aufgewertet. Darüber hinaus werden Zeiten beruflicher und schulischer Ausbildung, für die bis dahin separate Regeln gelten, ab 2009 für nur noch bis zu drei Jahre insgesamt höher bewertet. Tabelle 6 fasst die im Modell abgebildeten Rechtsstände zusammen.

\section{Einkommen (Rente nach Mindesteinkommen, Mindestentgeltpunkte)}

Nach § 262 SGB VI können Entgeltpunkte aus Pflichtbeitragszeiten um bis zu 50\%, höchstens jedoch auf einen Durchschnittswert von 0,75 Entgeltpunkten aufgewertet werden. Voraussetzung für die Anwendung dieser Mindestentgeltpunkte-Regelung sind 35 oder mehr Jahre mit rentenrechtlichen Zeiten. Für einen Versicherten mit einem Bruttoeinkommen in durchgängiger Höhe von bis zu $50 \%$ des Durchschnittsentgelts bewirkt die Regelung eine Anhebung seiner Rente um 50\% (auf das 1,5-fache des ansonsten gültigen Werts). Bei höheren Verdiensten sinkt der prozentuale Anteil der der Mindestentgeltpunkte an der Rente. Durch die mit dem RRG 1992 eingeführte Beschränkung der Aufwertung auf Pflichtbeiträge, die in den Jahren bis einschließlich 1991 erbracht wurden, profitieren vorrangig ältere der hier betrachteten Kohorten von $§ 262$ SGB VI. Allerdings folgt aus den geschätzten Lebenseinkommensprofilen (s. Kapitel 3), nach denen kaum Jahre mit weniger als 0,75 Entgeltpunkten bei Vollzeitbeschäftigten zu verzeichnen sind, dass Mindestentgeltpunkte für typisierte Biographien durchgehend Erwerbstätiger weitestgehend bedeutungslos sind. Gravierender Einfluss kann von ihnen hingegen bei unterbrochenen Enwerbsbiographien mit Teilzeitbeschäftigung ausgehen. Während die Altersrente für Frauen explizit auf das Geschlecht abstellt, wirkt die Rente nach Mindesteinkommen nicht gesetzlich aber empirisch geschlechtsabhängig. Tatsächlich entfaltete die 1972 eingeführte Rente nach Mindesteinkommen erhebliche materielle Wirkungen, rund $12 \%$ aller damaligen Renten wurden angehoben, wobei etwa $80 \%$ der Begünstigten Frauen waren. ${ }^{177}$ In den Ergebnissen des STM schlägt sich § 262 SGB VI primär bei Ehepartnern mit verminderter Erwerbstätigkeit nieder, wobei die gesetzliche Beschränkung auf Beitragszeiten bis 1991 zu einer erheblichen Besserstellung von Angehörigen älterer Kohorten unter sonst gleichen Umständen führen kann.

177 Hermann (1990), S. 121 


\section{Anteil der Transferelemente an den Rentenausgaben}

Auf den vorgestellten Transferelementen, die auch als nicht beitragsgedeckte oder versicherungsfremde Leistungen zusammengefasst werden, beruhten im Jahr 2003 Ausgaben der Rentenversicherung der Arbeiter (ArV) und Angestellten (AnV) in Höhe von etwa 37 Mrd. Euro, was rund 19\% des Gesamtvolumens von 195,7 Mrd. Euro entspricht (Tabelle 7). Zusammen mit weiteren derartigen Leistungen („Sonstige“, u. a. West Ost-Transfers und Elemente der Hinterbliebenensicherung als quantitativ bedeutsamste Größen) von 40,5 Mrd. Euro, die sich nicht in den Ergebnissen des STM widerspiegeln, ergibt sich ein Transferanteil von 77,4 Mrd. Euro (39,6\% der Rentenausgaben). ${ }^{178^{\prime}}$

Die oben geäußerten Wirkungen der Umverteilungselemente bei verschiedenen Kohorten zeigen sich auch in den prognostizierten Werten der Bundesregierung in Tabelle 7. Fehlende oder geringe Abschläge verlieren an Bedeutung, bleiben jedoch weiterhin ausgabenrelevant. Zu berücksichtigen ist dabei, dass sich die angegebenen Ausgaben auf den Rentenbestand beziehen, der stark von früheren Rentenzugängen geprägt ist. Bei Betrachtung der Renteneintritte tritt ein wesentlich schnellerer Abbau ein. Ebenfalls rückläufig werden Rentenzahlungen auf Grund von höherbewerteten Berufsausbildungen und von Anrechnungszeiten sein, zu denen Zeiten der schulischen Ausbildung zählen, sowie Renten nach Mindesteinkommen. Für Kindererziehungszeiten wird hingegen eine Zunahme erwartet, wobei die angegebenen Werte von 5,2 bis 9,5 Mrd. Euro das Volumen kindbedingter Rentenzahlungen aus mehreren Gründen unterschreiten: Seit 1999 erfolgt für Kindererziehungszeiten nicht mehr eine Erstattung des Bundes an die Rentenversicherung. Stattdessen übernimmt der Bund die Beitragszahlungen während der Kindererziehungszeiten, sein Haushalt wird dadurch nicht mehr in den Jahren des Rentenanspruchs sondern in den Jahren nach der Geburt des anspruchsbegründenden Kindes belastet. Die vom Bund gezahlten Beiträge für Kindererziehungszeiten beliefen sich im Jahr 2005 auf rund 11,7 Mrd. Euro. ${ }^{179}$ Zudem sind rentensteigernde Kinderberücksichtigungszeiten in der Tabelle nicht erfasst. ${ }^{180}$ Neben den an Hand der Rechtsstände bereits besprochenen zukünftig zu erwartenden Entwicklungen der Umverteilungskomponenten der Rentenversicherung weist Tabelle 7 noch auf einen weiteren Umstand hin: Insgesamt ist von einem schrumpfenden Anteil nicht beitragsgedeckter Leistungen der Rentenversicherung auszugehen, zukünftige Renten werden demnach stärker dem Äquivalenzprinzip entsprechen.

178 Die Bundeszuschüsse an die Rentenversicherung in den drei in der Tabelle dargestellten Jahren decken gut $27 \%$ der jeweiligen Rentenausgaben und unterschreiten damit die nicht beitragsgedeckten Leistungen, wobei sich die Lücke allerdings schließt (0.V. (2004), S. 579).

180 Die aufgeführten Kindererziehungsleistungen wirken ähnlich wie Kindererziehungszeiten bei Geburten vor 1991. Mitglieder der Geburtsjahrgänge bis 1920 erhalten einen Entgeltpunkt je Kind, für die Kohorten ab 1921 wirken stattdessen Kindererziehungszeiten. 
Tabelle 7: Nicht beitragsgedeckte Leistungen der Rentenversicherung (ArV u. AnV) [Mrd. Euro]

\begin{tabular}{|l|r|r|r|}
\hline \multicolumn{1}{|c|}{ Art der Leistung } & \multicolumn{3}{|c|}{ Jahr } \\
\cline { 2 - 4 } & \multicolumn{1}{|c|}{2003} & 2007 & 2017 \\
\hline Anrechnungszeiten & 8,9 & 8,5 & 5,6 \\
\hline $\begin{array}{l}\text { Abschlagsfreie Altersrenten vor vollendetem 65. } \\
\text { Lebensjahr }\end{array}$ & 14,0 & 11,9 & 9,4 \\
\hline Kindererziehungszeiten bei Geburten vor 1992 & 5,2 & 6,2 & 9,5 \\
\hline Kindererziehungsleistungen (Kohorten vor 1921) & 0,8 & 0,5 & 0,1 \\
\hline Renten nach Mindesteinkommen & 3,3 & 2,6 & 2,5 \\
\hline Höherbewertung Berufsausbildung & 4,7 & 4,1 & 2,7 \\
\hline Sonstige & 40,5 & 36,0 & 48,1 \\
\hline Zusammen & 77,4 & 69,8 & 77,9 \\
\hline Rentenausgaben insgesamt & 195,7 & 204,2 & 280,3 \\
\hline Anteil nicht beitragsgedeckter Leistungen & $39,6 \%$ & $34,2 \%$ & $27,8 \%$ \\
\hline Quelle: o.V. (2004), S. 579; eigene Berechnungen & & & \\
\hline
\end{tabular}




\section{Teil 2 Anwendung:}

\section{Wirkungen des Steuer-Transfer-Systems im Lebenszyklus}


Tobias Arens - 978-3-631-75164-0

Downloaded from PubFactory at 01/11/2019 07:33:05AM

via free access 


\section{Bildungsrenditen}

Im Kapitel zur Herleitung der Lebenseinkommensprofile wurde bereits auf inhaltlich verschiedene Ansätze hingewiesen, deren Ergebnisse als Bildungsrenditen diskutiert werden. Die verbreiteteste Methode greift auf Regressionsergebnisse einer Einkommensgleichung Mincer'scher Form zurück, wobei die Einkommensrelation verschiedener Qualifikationen als Bildungsrendite aus den geschätzten Parametern abgeleitet wird. Dem humankapitaltheoretischen Grundgedanken, Bildungsentscheidungen als Investitionsproblem zu betrachten, wird empirisch eher die Bestimmung der internen Ertragsrate (interner Zinsfuß) von Ausbildungszeiten gerecht, wobei Kosten und Erträge von Bildung unter Berücksichtigung der Zeitpunkte ihrer Entstehung gegeneinander aufgerechnet werden. Ein dritter Ansatz besteht mit der short-cut-Methode, bei der unter stark vereinfachenden Annahmen ebenfalls eine interne Ertragsrate ermittelt wird und die hier nicht weiter betrachtet wird. ${ }^{181}$

\subsection{Zwei Ansätze zur Quantifizierung der Rentabilität von Bildung: Das Mincer-Modell und interne Ertragsraten}

Grundlage des Mincer'schen Ansatzes ist eine Einkommensgleichung mit Bildung und Erfahrung als erklärenden Variablen. In Mincers (1958) ursprünglichem Modell ist Bildung als lineare Variable formuliert, wobei der Umfang von Humankapitalinvestitionen über die notwendige Dauer zum Erreichen eines Abschlusses operationalisiert wird. In zahlreichen empirischen Arbeiten wurde dieses Schooling-Modell Mincers eingesetzt, als alternative Formulierung existiert ein Dummy-Variablen-Modell, das Bildung als kategoriale Variable erfasst. Mit letzterem Ansatz können heterogene Wirkungen verschiedener Ausbildungsarten auf das Einkommen abgebildet werden, die Annahme einer von der Anzahl der Ausbildungsjahre unabhängigen Bildungsrendite wird damit gelockert. Die Modellspezifikationen sind:

$$
\begin{array}{ll}
\text { Schooling-Modell: } & \ln \hat{y}_{t}=\beta_{0}+\beta_{1} e+\beta_{2} e^{2}+\beta_{3} s_{i} \\
\text { Dummy-Variablen-Modell: } & \ln \hat{y}_{t}=\beta_{0}+\beta_{1} e+\beta_{2} e^{2}+\sum_{j=3}^{k-11} \beta_{j} a_{t}
\end{array}
$$

$$
\begin{array}{ll}
\text { mit } \quad \begin{array}{l}
\boldsymbol{\beta} \\
a
\end{array} & \text { zu schätzende Parameter } \\
a_{i}= & 1, \quad \text { wennmy-Variablen für die Ausbildungsabschlüsse, wobei } \\
& 0 \text { sonst } \\
k & \text { Anzahl betrachteter Abschlüsse } \\
s_{i} & \text { Anzahl der Ausbildungsjahre für Abschluss } i \\
e & \text { potenzielle Berufserfahrung }
\end{array}
$$

181 S. zu den drei renditebezogenen bildungsökonomischen Ansätzen Psacharopoulos (1995) 
Beim Vergleich zweier Ausbildungen ergibt sich beim Mincer'schen Ansatz das relative Mehreinkommen nach dem Dummy-Variablen-Modell als:

$\hat{v}_{i, j}=\operatorname{Exp}\left[\hat{\beta}_{i}-\hat{\beta}_{j}\right]-1$

mit $\hat{v}_{i, j} \quad$ geschätztes relatives Mehreinkommen von Ausbildung $i$ gegenüber $j$

$\beta_{i} / \beta_{j} \quad$ Regressionskoeffizient für Ausbildung $i$ bzw. $j$

Die Rendite eines Ausbildungsjahrs $\hat{r}_{i, j}$ bestimmt sich dann in der Form:

$\hat{r}_{i, j}=\operatorname{Exp}\left[\hat{\beta}_{i}-\hat{\beta}_{j}\right]^{1 /\left(s_{i}-s_{j}\right)}-1$

mit $\quad s_{i} / s_{j} \quad$ Dauer von Ausbildung $i$ bzw. $j$

Für das Schooling-Modell, in dem Ausbildung als stetige Variable modelliert wird, so dass sich $\beta_{j}=0$ und $s_{j}=s_{i}-1$ setzen lässt, sind die beiden Ausdrücke $\hat{v}_{i, j}$ und $\hat{r}_{i, j}$ identisch. Sie reduzieren sich zu $\hat{r}_{i, 1+1}=\hat{v}_{t, i+1}=\operatorname{Exp}\left[\hat{\beta}_{i}\right]-1$. Die Rendite eines Ausbildungsjahres ergibt sich dann unmittelbar aus dem entsprechenden Koeffizienten des Regressionsmodells.

Für Deutschland wie für andere Länder liegen zahlreiche auf Mincers Modell fuBende Schätzungen von Einkommensgleichungen vor. ${ }^{182}$ Unterschiede in der Methode, der Modellspezifikation, den verwendeten Daten, den Untersuchungszeiträumen und der Abgrenzung der Stichprobe gehen mit einer nicht unerheblichen Spannweite der mit Modellen des Schooling-Typs für Deutschland gefundenen Mincer-Renditen einher. Ergebnisse für den Bildungsparameter des Schooling-Modells reichen von etwa 0,06 bis 0,11 ; häufige Angaben bewegen sich in einem Renditeintervall von etwa $7 \%$ bis $9 \%$. Wie bei der Konstruktion der Lebenseinkommensprofile bereits diskutiert, deuten sich in intertemporalen Vergleichen recht stabile Schätzergebnisse für Mincer-Modelle in Deutschland an, wie verschiedene Vergleichsuntersuchungen mit bis in die 1970er Jahre zurückreichenden Daten aufzeigen (vgl. Kapitel 3). Um die Ergebnisse von Schooling- und Dummy-VariablenModellen vergleichbar zu machen, werden wie dargestellt aus den Koeffizienten und den typisierenden Ausbildungsdauern Renditegrößen abgeleitet. Da beim DummyVariablen-Modell die Annahme eines linearen Zusammenhangs von Ausbildungsdauer und Rendite gelockert wird, tritt an die Stelle einer universellen Rendite eine nur den Vergleich zweier Ausbildungsarten beschreibende Rendite. Unter den hier getroffenen Annahmen führen die Ergebnisse der in Kapitel 3 vorgestellten Schätzungen zu Renditen der verschiedenen Abschlüsse zwischen $8,9 \%$ und $9,3 \%$ im Vergleich zu Personen ohne beruflichen Abschluss (Tabelle 8). Der ebenfalls gebräuchliche Vergleich mit dem nächstniedrigeren Abschluss (etwa tertiärer Bereich gegenüber Sekundarbereich II wie beim Vergleich von Uni und Lehre) führt überwiegend zu ähnlichen Werten. Die mit der EVS geschätzten Mincer-Parameter implizieren damit

182 Eine auch Deutschland umfassende umfangreiche internationale Übersicht geben Psacharopoulos, Patrinos (2004). Deutsche Studien werden verglichen in Lauer, Steiner (1999) 
für alle betrachteten Abschlüsse Bildungsrenditen in einer Größenordnung von etwa $9 \%$, ein mit anderen Ergebnissen für Deutschland kompatibler Wert.

Tabelle 8: Renditen nach dem Mincer-Ansatz (in Prozent)

\begin{tabular}{|l|c|c|c|}
\hline \multicolumn{1}{|c|}{ Abschluss } & Koeffizient & $\begin{array}{c}\text { Ausbildungsdauer } \\
\text { [Jahre] }\end{array}$ & Rendite \\
\hline Uni ggü. Ohne & 0,7642 & 19 & 8,9 \\
\hline FH ggü. Ohne & 0,6224 & 17 & 9,3 \\
\hline Meister ggü. Ohne & 0,4444 & 15 & 9,3 \\
\hline Lehre ggü. Ohne & 0,2569 & 13 & 8,9 \\
\hline Uni ggü. Lehre & & 8,8 \\
\hline Meister ggü. Lehre & & 9,8 \\
\hline Quelle: EVS 2003, eigene Berechnungen
\end{tabular}

Der Ansatz, (transformierte) Parameter aus Mincer-Gleichungen als Bildungsrenditen zu interpretieren, ist zwar verbreitet, trifft jedoch nur dann zu, wenn recht strenge Annahmen als erfüllt gelten können. Ein Modellrahmen, unter dem eine Interpretation der entsprechenden Regressionskoeffizienten der Mincer-Gleichung als Bildungsrenditen angemessen ist, wurde von Becker und Chiswick (1966) entwickelt. Danach beruht die Gleichsetzung der Koeffizienten mit Bildungsrenditen unter anderem auf der Annahme, dass die Investitionskosten einer Ausbildung mit dem entgangenen Einkommen übereinstimmen, das erzielt worden wäre, wenn an Stelle der Ausbildung einer (Vollzeit-)Erwerbstätigkeit nachgegangen worden wäre. ${ }^{183}$ Die Summe aus direkten Ausbildungskosten wie etwa Gebühren und Opportunitätskosten muss also dem entgangenen potenziellen Einkommen entsprechen, was beispielsweise der Fall ist, wenn Bildungsbeteiligung kostenlos ist und währenddessen kein Einkommen erzielt wird. Die Bedingung ist beispielsweise verletzt, wenn eine TeilzeitAusbildung absolviert und gleichzeitig Erwerbseinkommen erzielt wird. Üblicherweise unterbleibt jedoch bei der Gleichsetzung von Parametern des Mincer-Modells mit Bildungsrenditen der Hinweis, unter welchen Annahmen diese Deutung zulässig ist. $\mathrm{Zu}$ diesen zählt neben der genannten Bedingung eine hinreichend lange -eigentlich unendlich lange- Enwertsphase.

Unmittelbar aus den Parametern abgeleitete Renditen reflektieren damit primär die erste von zwei Implikationen der Mincer'schen Einkommensgleichung: Erstens lassen sich ihre Bildungsparameter zur Beschreibung der Arbeitsnachfrage heranziehen. Sie zeigen an, in welchem Umfang bildungsbedingte Produktivitätssteigerungen am Arbeitsmarkt honoriert werden. Zweitens geben ihre Bildungsparameter Anhaltspunkte zur Rentabilität von Humankapitalinvestitionen, jedoch nur falls strenge Bedingungen als erfüllt gelten können. ${ }^{184}$ Mincers Arbeiten bieten eine ausgereifte Theorie zur Analyse von Einkommensverteilungen, deren einschränkende Annahmen in der empirischen Anwendung jedoch häufig ignoriert werden. Eine Rendite im Sinne der Mincer-Gleichung bildet Bildungsentscheidungen unscharf $a b$, wenn das verfügbare Lebenseinkommen als Entscheidungsgröße zur Wahl zwischen

\footnotetext{
183 Vgl. Chiswick (2003), S. 11 ff

184 Vgl. Heckman, Lochner, Todd (2003), S. 1. Zur Herleitung und Interpretation der Parameter der Mincer-Gleichung s. a. Franz (2003), S. 90ff
} 
verschiedenen Bildungsalternativen durch die Ausblendung verschiedener Kostenund Ertragsgrößen unzutreffend modelliert ist.

Wesentliche Kostenkomponenten sind Opportunitätskosten durch Mindereinkommen während Ausbildungszeiten und direkte Kosten der Ausbildung wie Ausbildungsgebühren. Ebenso wirken in progressiven Steuersystemen Abgaben auf Bruttoeinkommen renditemindernd. ${ }^{185}$ Umgekehrt erfasst das Mincer-Modell renditesteigernde Wirkungen des Steuer-Transfer-Systems nicht, die sich aus bildungsbedingten Transfers und Mehreinkommen in der Rentenbezugsphase ergeben. Ebenfalls in diese Richtung wirken mit höherer Qualifikation abnehmende Arbeitslosigkeitsrisiken. Schließlich abstrahiert die Interpretation der Mincer-Parameter als Bildungsrendite von Investitionsrisiken (Ausbildungsabbrüche), der Abhängigkeit der Dauer der Erwerbsphase von der Bildungsbeteiligung (bzw. es wird eine unendliche Dauer als geeignete Annäherung angesehen) und von makroökonomischen Größen wie der Lohnwachstumsrate.

Einige neuere Arbeiten greifen verschiedene empirische Unzulänglichkeiten des Mincer-Ansatzes zur Schätzung von Bildungsrenditen auf und weisen unter weniger strengen Annahmen ermittelte Renditen aus. Heckmann, Lochner und Todd (2005) schätzen auf der Grundlage von Zensusdaten der Jahre von 1940 bis 1990 Bildungsrenditen für die USA mit einem nichtparametrischen Schätzverfahren. Bei ihrer Berechnung berücksichtigen sie Ruhestandsalter, Steuern und Ausbildungsgebühren. Zudem schätzen sie mit demselben Datenmaterial Bildungsrenditen nach dem Mincer-Ansatz. Zu ihren Hauptbefunden zählt zum einen, dass die Renditen deutlich geringer ausfallen, wenn Steuern und Ausbildungsgebühren in das Modell aufgenommen werden. Zum anderen schwanken die nichtparametrisch geschätzten Renditen im Zeitverlauf wesentlich stärker als das Mincer-Modell vermuten ließ. Bemerkenswert ist das erheblich höhere Niveau der sich nach dem nichtparametrischen Verfahren ergebenden Renditen. Diese liegen nahezu durchgängig mindestens fünf Prozentpunkte über den korrespondierenden Mincer-Werten, wobei dieser Niveauunterschied selbst dann resultiert, wenn Steuern und Gebühren in die Betrachtung einbezogen werden.

Eine andere Forschungsrichtung zur Quantifizierung von Bildungsrenditen, die vor allem für Ländervergleiche genutzt wird, zeichnet sich durch einen Rückgriff auf die einfache Barwertformel aus, von der ausgehend auch das Mincer-Modell unter starker Abstraktion abgeleitet wurde. Ziel ist, die Wirkung verschiedener institutioneller Rahmenbedingungen wie des Steuer- oder Rentensystems explizit in den Ergebnissen abzubilden und deren isolierte Effekte zu quantifizieren. Die Ergebnisse dieses Ansatzes, der ein zur empirischen Beurteilung privater Bildungsentscheidungen relevanteres Renditekonzept und Einschätzungen der Anreizwirkungen politischer Rahmenbedingungen auf Humankapitalinvestitionen verspricht, werden als (Netto-) Ertragsraten bezeichnet. Mit diesen wird zumindest eine Teilmenge der beim MincerAnsatz ignorierten -bzw. nur unter rigiden Annahmen unerheblichen- Auswirkungen

${ }^{185}$ Einflüsse des Steuer-Transfer-Systems auf Bildungsrenditen werden in manchen Studien (implizit) berücksichtigt, in denen Netto- statt Bruttoeinkommen die abhängige Variable bilden. Allerdings überlagern sich dann die Effekte des Steuer-Transfer-Systems und der Bildungsprämien des Arbeitsmarkts. 
von Bildung auf das (verfügbare) Lebenseinkommen berücksichtigt. ${ }^{186}$ Grundlage sind die in der Investitionstheorie üblichen Zahlungsreihen von abzudiskontierenden Kosten $K$ und Erträgen $E$, aus denen sich interne Ertragsraten ermitteln lassen. Dabei wird auf die Kapitalwertformel zurückgegriffen, die den Barwert $C_{0}$ einer Investition in Ausbildung $i$ im Vergleich zur Investition in Ausbildung $j$ in Abhängigkeit vom Zinssatz $z$ angibt: ${ }^{187}$

$$
\begin{aligned}
C_{0}(z)= & \sum_{t=t_{i,}}^{t_{v}}\left(E_{t}(i, j)-K_{t}(i, j)\right)^{*}(1+z)^{-t} \\
& =\sum_{i=t_{i,}}^{t}\left(y_{t}(i)-y_{t}(j)\right) *(1+z)^{-t}
\end{aligned}
$$

$y$ ist eine Einkommensgröße (z. B. Nettoperiodeneinkommen), $t_{0}$ bis $t_{N}$ die Zeitspanne, innerhalb derer die Höhe des verfügbaren Einkommens vom jeweiligen $A b$ schluss abhängt, die grundsätzlich vom Ende der Pflichtschulzeit bis zum Tod reicht. Die einzelnen Terme des Summenausdrucks entsprechen Mehr- $\left(y_{i}>y_{j}\right)$ oder Mindereinkommen $\left(y_{i}<y_{j}\right)$, die aus der gewählten Ausbildung $i$ im Vergleich zur betrachteten Alternative $j$ folgen. Die interne Ertragsrate oder Rendite $r$ nach diesem Ertragsratenansatz ist definiert als der Zinssatz, der zu einem Barwert von null führt:

$C_{0}(r)=0$

Während diese definitorischen Zusammenhänge zur Berechnung von Bildungsrenditen generell gültig sind, existieren zur Abgrenzung und Herleitung der Einkommens- und Kostengrößen keine einheitlichen Vorgaben. Je nach Datenverfügbarkeit und Untersuchungsziel fließen unterschiedlich definierte Größen in die Kapitalwertformel ein. Gemeinsam ist bisherigen Ansätzen, dass Einkommensprofile generiert werden müssen, die die Abhängigkeit des Einkommens von Lebensalter und Bildung erfassen und dass diesen korrespondierende Ausgabenprofile gegenüberzustellen sind, die die direkten Bildungskosten erfassen.

In einigen Arbeiten, die nach diesem Grundmuster angelegt sind, werden auch Ergebnisse für Deutschland angegeben. ${ }^{188}$ Als Inputgrößen werden sowohl mikroals auch makroökonomische Parameter genutzt, die Zusammenhänge von Bildung und Einkommen beschreiben sowie der Projektion der zukünftigen Entwicklung dienen. Zu den mikroökonomischen Parametern zählen Schätzwerte qualifikationsspezifischer Arbeitslosigkeitsrisiken und qualifikations- und erfahrungsbedingte Lohndiffe-

${ }^{186}$ Vgl. Sachverständigenrat zur Begutachtung der gesamtwirtschaftlichen Entwicklung (2004), S. $426 \mathrm{f}$. Allerdings ist der dortige Hinweis, dass die Mincer-Gleichung (Opportunitäts-)Kosten gänzlich ignoriert, unzutreffend. Der mögliche "Fehler" besteht nicht im Ausblenden der Kosten sondern in der vereinfachenden Gleichsetzung von Kosten und potenziellem Einkommen (s. o.).

Wenn die -in der Mehrzahl der empirischen Arbeiten implizit getroffenen- Annahmen des MincerModells im Zeitablauf konstanter Kosten und Erträge einer Bildungsbeteiligung, eines unendlichen Zeithorizonts und vollständiger Information erfüllt sind, lassen sich die Barwertformel und die Mincer-Gleichung ineinander überführen.

188 Die folgende Darstellung bezieht sich auf die vier Publikationen: (1) Blöndal, Field, Girouard (2002); (2) OECD (2003); (3) de la Fuente, Jimeno (2005); (4) Ammermüller, Kuckulenz, Lauer, Zwick (2005). 
rentiale. Letztere werden in Untersuchungen von de la Fuente und Jimeno (2005) sowie von Ammermüller, Kuckulenz, Lauer und Zwick (2005) über eine MincerSchätzung bestimmt. Die als Bildungsrendite bezeichnete Ergebnisgröße beim Mincer-Ansatz zählt hier also zu den (exogenen) Eingabegrößen. Daneben werden Durchschnittswerte für Ausbildungsdauern, das Renteneintrittsalter und die Lebenserwartung in die Berechnung der Ertragsraten eingespeist. Weitere Parameter, die politische Rahmenbedingungen skizzieren, sind Grenzsteuersätze und Lohnersatzraten der Arbeitslosen- und Rentenversicherung. Als direkte Ausbildungskosten werden durchschnittliche Kosten je Auszubildenden in verschiedenen Bildungseinrichtungen angesetzt, die auf Grund der weitgehend öffentlichen Finanzierung überwiegend den bildungsbedingten Transfers zugeschlagen werden. Zum Teil werden daneben auch monetäre Transfers an Auszubildende erfasst. Wichtige makroökonomische Inputgröße ist die reale Lohnwachstumsrate, mit der die Einkommen des Basisjahres fortgeschrieben werden. De la Fuente und Jimeno (2005) leiten her, wie die Ertragsrate von Bildung positiv von der Lohnwachstumsrate abhängt. ${ }^{189}$

Die dem Ertragsratenansatz zuzuordnenden Untersuchungen basieren also auf deskriptiven und mikroökonometrischen Analysen der Volkswirtschaft zu einem Zeitpunkt. Die Verhältnisse zu diesem Zeitpunkt werden unter Hinzuziehung einer Lohnwachstumsrate in die Zukunft projiziert, wobei die Parameter ansonsten konstant gesetzt werden. Unter diesem Datenkranz werden bildungsabhängige Einkommenspfade erstellt (Mindereinkommen während Ausbildungszeiten, Mehreinkommen in der Erwerbs- und Rentenbezugsphase bei höherer Qualifikation) und direkte Ausbildungskosten gegengerechnet. Für die Zeitreihe der Einkommensdifferenzen verschiedener Qualifikationen wird dann gemäß der Bedingung $C_{0}(r)=0$ die interne Ertragsrate bestimmt. Je nachdem, welche Einkommens- und Ausgabengrößen in die Zeitreihen aufgenommen werden, werden unterschiedlich abgegrenzte interne Ertragsraten angegeben. So genannte Raw-Returns umfassen eine rein marktlich erzielte Bruttorendite, die ausschließlich aus bildungsbedingten Differenzen der Bruttoeinkommen resultiert. Im Gegensatz hierzu umfassen die in den vier hier besprochenen Studien ausgewiesenen Gesamtrenditen sämtliche in die Renditeberechnung einbezogenen Ertrags- und Kostengrößen. Die Differenzen der verschieden abgegrenzten Renditebegriffe werden dann als Indikatoren der Bedeutung einzelner staatlicher Eingriffe (Besteuerung, Transfers etc.) für individuelle Bildungsentscheidungen gedeutet.

In Tabelle 9 sind Ergebnisse von vier Studien wiedergegeben, in denen interne Ertragsraten von Bildungsbeteiligung in Deutschland bestimmt wurden. Angegeben sind sowohl Vergleiche verschiedener Abschlüsse (z. B. Hochschule gegenüber Abitur) als auch der marginale Effekt eines zusätzlichen Ausbildungsjahres ( Die unter "Brutto" ausgewiesenen Renditen $(v=1)$ beziehen sich ausschließlich auf Erwerbseinkommen. In die weiteren Renditen fließen sequenziell zusätzliche Größen ein. Der partielle Renditeeffekt $p(v)$ einzelner Politikvariablen $v$ für die Erträge einer Ausbildung wird als Differenz der Rendite unter Einschluss dieser Variablen $r(v)$ und der nächst weniger umfassenden Renditevariante $r(v-1)$ angegeben:

${ }^{189}$ de la Fuente, Jimeno (2005), S. 17 
Ausbildungen und/ oder monetäre Transfers wie die Ausbildungsförderung nach dem BAföG. Ebenfalls uneinheitlich ist, ob Renten und Leistungen für Arbeitslose berücksichtigt sind. Daneben unterscheiden sich auch die Varianten, in die die Gesamtrendite aufgeschlüsselt wird, sowie die Reihenfolge der Varianten, aus der die partiellen Renditeeffekte abgeleitet werden.

Die Ergebnisse der vier auf einem identischen Grundkonzept basierenden, in mehreren Details jedoch Unterschiede aufweisenden Untersuchungen, die in Tabelle 9 aufgenommen wurden, zeigen einige Gemeinsamkeiten. Die Gesamtertragsraten liegen überwiegend höher als die rein marktlichen Ertragsraten, die sich aus der $\mathrm{Ge}$ genüberstellung bildungsabhängiger Bruttoeinkommensprofile ergeben. Diese Befunde sprechen für eine positive Gesamtwirkung des deutschen Steuer-TransferSystems auf die Rentabilität von Bildungsinvestitionen, Humankapitalinvestitionen werden demnach effektiv nicht besteuert sondern subventioniert. Renditemindernde Effekte des progressiven Steuersystems werden hiernach durch bildungsbedingte Transfers überkompensiert, die hauptsächlich in Form von gebührenfreier öffentlicher Ausbildung anfallen. Dieser Effekt tritt durchgehend bei Bildungsbeteiligung im Tertiärbereich auf, im Sekundarbereich II sind die Ergebnisse weniger einheitlich. Einschränkend ist für die Ergebnisse von Blöndal et al. (2002) und OECD (2003) anzumerken, dass bei diesen Arbeitslosigkeitsrisiken, die grundsätzlich marktliche statt politische Wirkungen von Bildung erfassen, nicht in den Bruttorenditen enthalten sind. Für Abschlüsse im Sekundarbereich II sinkt sowohl für Frauen als auch für Männer die Gesamtrendite unter die Bruttorendite, wenn die um Arbeitslosigkeitsrisiken korrigierten Bruttoeinkommen der marktlichen Rendite zugeschlagen werden. Allerdings blenden Blöndal et al. (2002) und OECD (2003) öffentliche Transfers bei der Analyse des Sekundarbereichs II aus. Unter ähnlichen Voraussetzungen führt der Vergleich verschiedener Abschlüsse von Ammermüller et al. (2005) bei niedrigeren Qualifikationsniveaus (Realschule gegenüber ohne Abschluss, Lehre gegenüber Realschule) zu Gesamtrenditen, die unter den jeweiligen Bruttorenditen liegen, während für ein Hochschulstudium die umgekehrte Relation gilt. Der von de la Fuente und Jimeno (2005) ausgewiesene Renditeabschlag von -0,8 Prozentpunkten für die Arbeitslosenversicherung folgt aus dem negativen Zusammenhang von Arbeitslosigkeit und Qualifikation, durch den geringer Qualifizierte Versicherungsleistungen verstärkt in Anspruch nehmen. Die höhere Erwerbstätigkeitswahrscheinlichkeit ist bei de la Fuente und Jimeno (2005) in der Bruttorendite enthalten.

Neben dem gemeinsamen Ergebnis, dass zumindest für den tertiären Bereich Gesamtertragsraten gefunden werden, die über der Bruttoertragsrate liegen, sind folgende Punkte aus Tabelle 9 noch festzuhalten: Die Bruttorenditen bewegen sich überwiegend in einem Bereich von $5 \%$ bis $10 \%$, wobei mehrere Autoren auf tendenziell sinkende (Grenz-)Renditen bei steigender Qualifikation hinweisen. ${ }^{190}$ Über Abgaben (Steuern und Sozialversicherungsbeiträge) werden die Bruttorenditen um etwa 1,5 bis 2 Prozentpunkte gemindert, Transfers erhöhen die Rendite in einer Größenordnung von etwa 3 Prozentpunkten.

190 Aus diesem Rahmen fällt der Wert von Ammermüller et al. (2005) für einen Realschulabschluss (Bruttorendite von 26\%), dessen Vergleich mit anderen Ergebnissen allerdings auch durch die unübliche Abgrenzung von Ausbildungsleveln erschwert wird, bei der allgemein bildende und berufliche Abschlüsse vermischt sind. 


\subsection{Ermittlung interner Ertragsraten mit dem STM}

\subsubsection{Methodische Vorbemerkungen}

Mit dem STM lassen sich ebenfalls dem Ertragsratenansatz zuzurechnende Bildungsrenditen ermitteln, wobei jedoch eine andere Schwerpunktsetzung erfolgt als bei den vorgestellten Studien. In diesen wird recht umfassend ein Status Quo einschließlich qualifikationsspezifischer Arbeitslosigkeit und Realtransfers in Form von öffentlichen Bildungsausgaben analysiert, das Steuer-Transfer-System wird eher rudimentär an Hand von Durchschnittssätzen beschrieben. Das STM beschränkt sich hingegen auf "Normalbiographien" ohne Arbeitslosigkeit und abstrahiert von Realtransfers, das Steuer-Transfer-System ist hingegen detailgetreu abgebildet. Übereinstimmend werden bildungsbedingte Einkommensdifferenzen in Form von MincerParametern als Inputgrößen genutzt und die zukünftige Entwicklung projiziert. Allerdings greift das STM auf eine wesentlich differenziertere Projektion institutioneller Rahmendaten zurück. Hierzu zählen zeitlich variable Beitragssätze zur Sozialversicherung und Rentenwerte sowie gesetzlich bereits fixierte zukünftige Änderungen wie etwa die Besteuerung nach dem Alterseinkünftegesetz.

Der Kohortenvergleich mit dem STM eröffnet zudem noch einen weiteren Untersuchungsaspekt: Die bisherigen Studien basieren auf Zeitpunktanalysen, die um eine Status Quo-Projektion ergänzt werden, woraus zukünftige Einkommens- und Ausgabenprofile abgeleitet werden. Die ermittelten Bildungsrenditen entsprechen damit den Werten, die für diejenigen Kohorten gelten, die zum Analysezeitpunkt potenziell in die Erwerbsphase eintreten, wobei politische Rahmenbedingungen wie etwa Durchschnittssteuersätze oder das Renten-Lohn-Verhältnis als zeitlich konstant angenommen werden. In Hinblick auf die jüngeren mit dem STM betrachteten Kohorten gilt einerseits vergleichbares. Auch für diese sind ihre Bildungsrenditen überwiegend Zukunftsprojektionen, die allerdings nicht auf eine reine Fortschreibung des Status Quo zurückgreifen. Für die älteren Kohorten wird mit historischen Zeitreihen zur Einkommensentwicklung gerechnet, und Rechtsänderungen im Steuer-Transfer-System seit 1950 sind berücksichtigt, so dass für diese retrospektive Bildungsrenditen ausgewiesen werden. Neben einer die beobachteten gegenwärtigen und mutmaßlichen zukünftigen Bedingungen erfassenden Bildungsrendite für die jüngsten Kohorten wird damit auch die Entwicklung der Renditen in der Vergangenheit in einem Längsschnittvergleich bestimmt.

In Übereinstimmung mit den vorgestellten Untersuchungen zu internen Ertragsraten werden verschiedene bildungsabhängige Einkommensdifferenzen sukzessive erfasst, womit sich zunehmend umfassendere Renditegrößen ergeben:

(1) Bruttolöhne: Bildungsbedingte Lohndifferenzen, die am Arbeitsmarkt erzielbare Bildungsprämien abbilden, gehen über die Bruttolebenseinkommensprofile, deren Konstruktionsprinzip in Kapitel 3 beschrieben wurde, in die Betrachtung ein. Für ausschließlich auf die während der Erwerbsphase erzielten Bruttoeinkommen abstellende Renditen bietet sich ein Vergleich mit den skizzierten Mincer-Renditen an. Die zur Herleitung der Lebenseinkommensprofile genutzten Parameter der Mincer-Schätzung sind hier eine zentrale exogene 
Größe für die Ermittlung der Ertragsraten. Die Bruttorenditen nach dem Ertragsratenansatz berücksichtigen im Gegensatz zum Mincer-Ansatz auch die Dauern der Erwerbsphase sowie die gesamtwirtschaftliche Lohnwachstumsrate.

(2) Abgaben: Das STM ermittelt aus den Bruttoeinkommen und abgabenrelevanten soziodemographischen Merkmalen das Nettoeinkommen. Als Abzüge vom Bruttoeinkommen ergeben sich Einkommen- und Zuschlagsteuern sowie Sozialversicherungsbeiträge. Bei Beschränkung auf die Erwerbsphase folgen hieraus Nettoenwerbsrenditen, die neben den Arbeitsmarktprämien auch die Besteuerung des Humankapitals erfassen.

(3) Renten: Nach der Erwerbsphase wirkt sich Bildung auch auf die Höhe des Ruhestandseinkommens aus. Zum einen folgen aus höheren Erwerbseinkommen höhere (Brutto-)Renten, zum anderen kennt das deutsche Rentensystem verschiedene bildungsbedingte Rentenzuschläge, die Transfercharakter aufweisen. Durch Einbeziehung der Rentenbezugsphase kommt es zu einer weiteren Vervollständigung des Renditebegriffs. Den den Abgaben zugerechneten Rentenversicherungsbeiträgen werden die auf sie zurückzuführenden Renten gegenübergestellt. Die sich so über den Lebenszyklus ergebenden Renditen werden im Weiteren als Nettolebensrenditen bezeichnet, wobei die durch das STM ermittelten, auf Renten zu entrichtenden Abgaben berücksichtigt sind.

(4) Bildungsbedingte Transfers: Aus Bildungsbeteiligung folgen verschiedene Ansprüche von Auszubildenden und/ oder ihren Eltern auf Transfers. Zum einen verlängert sich die Bezugsdauer kindbedingter Transfers für Eltern von Auszubildenden (insbesondere Kindergeld, Kinderfreibetrag, Ausbildungsfreibetrag), zum anderen kann der Auszubildende selbst gegebenenfalls Ausbildungsförderung erhalten (Schüler-BAföG, Studentenförderung nach dem Honnefer Modell oder dem BAföG). Die hiernach resultierenden Renditen werden als Renditen nach Transfers ausgewiesen.

(5) Gebühren: Ausbildungsgebühren (Schulgeld, Studiengebühren) werden unter zwei Gesichtspunkten betrachtet: Erstens erhöhen die Beachtung des bis in die 1950er Jahre erhobenen Schulgelds und die bis $1970 \mathrm{zu}$ entrichtenden Studiengebühren den empirischen Gehalt des Vergleichs verschiedener Kohorten (vgl. die Darstellung zu Ausbildungsgebühren in Kapitel 4.6). Zweitens wird der Einfluss unlängst eingeführter und möglicher zukünftiger Studiengebühren auf Bildungsrenditen untersucht. Die Berechnungen orientieren sich an den gegenwärtigen Größenordnungen allgemeiner Studiengebühren in mehreren Bundesländern. Die Gesamtrenditen umfassen neben den bisher genannten Größen auch die historischen Gebühren bzw. die für verschiedene Zukunftsszenarien angenommenen Gebühren.

Die hier gewählte Art der Bestimmung der einkommensrelevanten Größen und ihre Zuordnung zu den verschiedenen Renditebegriffen sind in Tabelle $10 \mathrm{bzw}$. Tabelle 11 zusammengefasst. Die Anzahl der zur Beurteilung von Bildungsentscheidungen bedeutsamen Größen in Tabelle 11 nimmt von den Bruttorenditen (1) zu den Gesamtrenditen (5) zu, der sequenzielle Vergleich der Renditen nach den einzelnen Abgrenzungen ermöglicht die Abschätzung der bildungsökonomischen Bedeutung verschiedener Elemente des Steuer-Transfer-Systems. Die Bruttorenditen reflektieren die 
marktliche Wirkung von Bildung, die sich ohne weitere staatliche Einflussnahme ergibt. Die Differenzen der verschiedenen Nettorenditen (2) bis (5) zeigen auf, in welchem Umfang sich einzelne Steuern und Transfers auf die Rentabilität auswirken. Abgesehen von probabilistischen Zusammenhängen zwischen Bildung und Einkommen sowie von Realtransfers decken die Gesamtrenditen (5) das deutsche Steuer-Transfer-System weitgehend ab. Als fehlende probabilistische Faktoren sind vor allem ein renditesteigerndes bildungsinduziert niedrigeres Arbeitslosigkeitsrisiko, dessen Effekt zum Teil durch Leistungen der Arbeitslosenversicherung kompensiert wird, und das renditemindernde Investitionsrisiko von Ausbildungsabbrüchen ohne Abschluss zu nennen. Bei den in dieser Arbeit betrachteten typisierenden Biographien verbleiben in mancherlei Hinsicht je nach exogener Setzung verschiedener Merkmale recht große Intervalle für renditerelevante Größen, so dass zusätzliche Fallunterscheidungen vorgenommen werden. Die Setzung einzelner renditerelevanter Größen richtet sich nach folgenden Vorgaben:

Tabelle 10: Bestimmung von renditerelevanten Größen

\begin{tabular}{|l|l|}
\hline \multicolumn{1}{|c|}{ Größen } & \multicolumn{1}{c|}{ Bestimmung } \\
\hline Dauem & $\begin{array}{l}\text { Institutionelle Vorgaben (Ausbildungszeiten, Renteneintrittsalter), } \\
\text { Durchschnittswerte (Lebenserwartung) }\end{array}$ \\
\hline Bruttolöhne & $\begin{array}{l}\text { Empirisch gestützt } \\
\text { (Mincer-Lohngleichung, Durchschnittsentgelte, Korrekturfaktor) }\end{array}$ \\
\hline Abgaben & Mechanistisch (STM) \\
\hline Nettorenten & Endogen aus Erwerbsbiographie, Abgaben auf Renten mechanistisch (STM) \\
\hline Transfers & Mechanistisch (STM) \\
\hline Gebühren & Historische Durchschnittswerte, Zukunftsszenarien \\
\hline
\end{tabular}

Tabelle 11: Verschiedene Renditeabgrenzungen und jeweils enthaltene Größen

\begin{tabular}{|l|c|c|c|c|c|}
\hline \multirow{2}{*}{ Enthaltene Größen } & \multicolumn{5}{|c|}{ Renditen } \\
\cline { 2 - 6 } & $\begin{array}{c}(1) \\
\text { Brutto }\end{array}$ & $\begin{array}{c}\text { (2) } \\
\text { Nettoerwerb }\end{array}$ & $\begin{array}{c}\text { (3) } \\
\text { Nettoleben }\end{array}$ & $\begin{array}{c}\text { (4) } \\
\text { Nach Transfers }\end{array}$ & $\begin{array}{c}\text { (5) } \\
\text { Gesamt }\end{array}$ \\
\hline Bruttolöhne & $\mathrm{Ja}$ & $\mathrm{Ja}$ & $\mathrm{Ja}$ & $\mathrm{Ja}$ & $\mathrm{Ja}$ \\
Abgaben auf Löhne & Nein & $\mathrm{Ja}$ & $\mathrm{Ja}$ & $\mathrm{Ja}$ & $\mathrm{Ja}$ \\
Nettorenten & Nein & Nein & $\mathrm{Ja}$ & $\mathrm{Ja}$ & $\mathrm{Ja}$ \\
bild. bedingte Transfers & Nein & Nein & Nein & $\mathrm{Ja}$ & $\mathrm{Ja}$ \\
Gebühren & Nein & Nein & Nein & Nein & $\mathrm{Ja}$ \\
\hline
\end{tabular}

Bruttolöhne: Für Enwerbstätige, die sich nicht in Ausbildung befinden, werden qualifikations- und erfahrungsabhängige Bruttolöhne gemäß der Lebenseinkommensprofile bzw. der korrigierten Lebenseinkommensprofile zu Grunde gelegt. Bei Auszubildenden wird grundsätzlich Erwerbslosigkeit unterstellt. Nur während betrieblicher Ausbildungen, die bei den Abschlüssen Lehre und Meister durchlaufen werden, wird eigenes Einkommen des Auszubildenden berücksichtigt, wobei stets Ausbildungsvergütungen von $20 \%$ des Durchschnittsentgelts des jeweiligen Jahres gesetzt werden, was 2007 einer monatlichen Ausbildungsvergütung von knapp 500 Euro entspricht. 
Bildungsbedingte Transfers: Als bildungsbedingter Transfer wird der Zuwachs an verfügbarem Einkommen der Eltern und des Auszubildenden durch das SteuerTransfer-System erfasst. Beim Vergleich zweier Ausbildungen $i$ und $j$ werden beispielsweise die Steuerminderung durch den Kinderfreibetrag und das Kindergeld den bildungsbedingten Transfers zugerechnet, das die Eltern des Auszubildenden $i$ in den Jahren beziehen, in denen der (ehemalige) Auszubildende $j$ bereits erwerbstätig ist, so dass für inn keine kindbedingten Vergünstigungen anfallen. Beim Vergleich der Ausbildungen Uni und Lehre kann dies beispielsweise das Kindergeld sein, das für den Studenten im Alter von 20 bis 24 Jahren gezahlt wird. Das Kindergeld für den Studenten im Alter von 18 bis 19 Jahren ist beim Vergleich mit dem Lehrling hingegen nicht renditerelevant, da auch dessen Eltern in diesem Zeitraum kindergeldberechtigt sind. Beim Vergleich von Uni und Ohne beeinflusst hingegen auch das Kindergeld für den 18- bis 19-Jährigen die Bildungsrendite, weil für Letzteren der Kindergeldanspruch spätestens mit der Volljährigkeit endet (vgl. zu kindbedingten Transfers an Eltern von Auszubildenden Kapitel 4.3). ${ }^{191}$

Neben die an Eltern gerichteten bildungsbedingten Transfers, die seit 1950, dem Beginn des Untersuchungszeitraums, durchgängig zu verzeichnen sind, treten $a b$ 1957 Maßnahmen der Ausbildungsförderung, deren Adressat der Auszubildende selbst ist. In den hier betrachteten Fällen schlägt sich die Förderung von Studenten an Universitäten oder Fachhochschulen nach dem Honnefer Modell (1957 bis 1970) und nach dem BAföG (ab 1971) nieder. Eine Schülerförderung wird für den Zeitraum von 1970 bis 1982 angenommen, als der Besuch weiterführender allgemein bildender Schulen ohne Einschränkungen gefördert werden konnte (vgl. Kapitel 4.5 zur Ausbildungsförderung). Die Ausbildungsförderung ist in zwei Phasen renditerelevant: Während der Ausbildungszeiten steigert die gezahlte Förderung Bildungsrenditen, in der Erwerbsphase wirken potenzielle Rückzahlungspflichten renditesenkend. Im Gegensatz zur Schülerförderung bestand und besteht die Studentenförderung zum Teil aus Darlehen. In den Renditeberechnungen sind die wiederholt geänderten Darlehensbedingungen berücksichtigt. Für die stets unverzinsten Darlehen wird in Übereinstimmung mit dem BAföG eine fünf Jahre nach Studienende beginnende Rückzahlung unterstellt, die Höhe der Raten und die Rückzahlungsdauer ergeben sich aus den gesetzlich festgeschriebenen Mindestraten und den Höchstdauern der Rückzahlung sowie der Höhe des zu tilgenden Darlehens.

Für die typisierende Quantifizierung renditerelevanter bildungsbedingter Transfers einer gegebenen Ausbildung bestehen erhebliche Freiheitsgrade. Ihr Umfang wird primär von Einkommen und Kinderzahl der Eltern des Auszubildenden determiniert. Auszubildende bleiben auch über die Volljährigkeit hinaus unterhaltsrechtlich ihren Eltern zugeordnet, wodurch neben den direkt an die Eltern gerichteten bildungsbedingten Transfers auch die Ausbildungsförderung weitgehend elternabhängig erfolgt. ${ }^{192}$ Seit Einführung der Ausbildungsförderung lassen sich unter den verschiedenen Rechtsständen drei Einkommensbereiche unterscheiden, in denen der Umfang bildungsbedingter Transfers

191 Im Zeitraum von 1982 bis 1995, als die allgemeine Altersgrenze für das Kindergeld die Vollendung des 16. Lebensjahres war, gilt beim Vergleich zum Abschluss Ohne auch das Kindergeld für den 16- oder 17-Jährigen (zukünftigen) Studenten als bildungsbedingt.

192 Für ein kritisches Fazit zu dieser Elternabhängigkeit sowie eine Darstellung alternativer Konzepte s. Färber (1996), S. 85ff. 
(1) weitgehend einkommensunabhängig ist,

(2) mit zunehmendem Einkommen fällt und

(3) mit dem Einkommen ansteigt.

Ursächlich sind die Wechselwirkungen von Ausbildungsförderung, Familienleistungsausgleich und weiteren kindbedingten Steuerminderungen. ${ }^{193} \mathrm{Um}$ die sich aus dem Steuer-Transfer-System ergebende Spannweite abzudecken, werden bei den Renditeberechnungen daher drei Einkommensniveaus von Eltern unterschieden:

Das niedrigste betrachtete Einkommen liegt bei der Volfförderungsgrenze des BAföG (bzw. des Honnefer Modells). Bei diesem Einkommen ist erstens die Ausbildungsförderung maximal (anzurechnendes Elterneinkommen von null). Zweitens profitieren die Eltern auf Grund der im Zeitverlauf überwiegend eher regressiven Wirkung kindbedingter Entlastungen stärker als bei darunter liegenden Einkommen von den innen zufließenden bildungsbedingten Transfers. Bei Einkommen an der Vollförderungsgrenze -die bei der betrachteten Familienkonstellation mit einem studierenden Kind je nach Rechtsstand des BAföG zwischen etwa $60 \%$ und $110 \%$ des Durchschnittsentgelts liegt- sind die bildungsbedingten Transfers maximal. ${ }^{194}$

Als zweites Einkommensniveau wird ein so genanntes Mitte/stands/och angegeben. Dieses zeichnet sich dadurch aus, dass das Elterneinkommen gerade bedarfsdeckend ist, so dass die Ausbildungsförderung genau null beträgt. Gleichzeitig profitieren diese Eltern nur in gemäßigtem Umfang von steuerlichen Abzugsbeträgen. Im Mittelstandsloch ist seit 1957, dem ersten Jahr einer breit angelegten Ausbildungsförderung, von minimalen bildungsbedingten Transfers auszugehen. Das Mittelstandsloch liegt unter der betrachteten Fallkonstellation je nach Rechtsstand bei $140 \%$ bis $200 \%$ des Durchschnittsentgelts der Rentenversicherung.

Beim dritten Einkommensniveau, Höchsteinkommen, bei dem Grenz- und Spitzensteuersatz identisch sind, wirken die steuerlichen Abzugsmöglichkeiten für Kinder in Ausbildung in höchstmöglichem Umfang. Hierdurch fallen die bildungsbedingten Transfers meistens höher aus als im Mittelstandsloch, liegen jedoch deutlich unter den Werten, die sich an der Vollförderungsgrenze ergeben. Die bildungsbedingten Transfers bei Höchsteinkommen bilden unter den meisten Rechtsständen die maximale Entlastung ab, wenn keine Ausbildungsförderung existieren würde.

Abgaben: Wie die bildungsbedingten Transfers hängen auch die Abgaben von exogen vorzugebenden Größen ab. Insbesondere die steuerliche Belastung wird von der Familienkonstellation (Alleinstehend oder Verheiratet, mit Kindern oder ohne) bestimmt. In Übereinstimmung mit den oben vorgestellten Untersuchungen zu internen Ertragsraten von Bildung wird von durchgehend Alleinstehenden ausgegangen. Dadurch fallen die aus Steuerzahlungen resultierenden Renditeminderungen tendenziell höher aus als bei der Annahme Verheirateter, wenn qualifikationsbedingtes Mehreinkommen über den Splittingvorteil überproportional entlastet wird.

${ }^{193}$ S. zu diesem Zusammenhang von Elterneinkommen und bildungsbedingten Transfers unter verschiedenen Rechtsständen zwischen 1986 und 2002: Kammann (1988), S. 74ff; Dohmen (1999), S. 261ff; Arens, Quinke (2003), S. 94ff

194 Bei Mehrkindfamilien können sich durch einen horizontal differenzierten FLA auch höhere Werte ergeben (vgl. Kapitel 4.3.1) 
Dauern: Die Lebenszyklen der typisierten Normalbiographien setzen sich aus den drei Phasen der Ausbildung, der Erwerbstätigkeit und des Ruhestands zusammen. Zwei Altersgrenzen sind festzulegen, die den Übergang in die Erwerbsphase bzw. in den Ruhestand markieren, zudem ist als dritter Wert die Lebensenwartung vorzugeben, um die Dauer der Rentenbezugsphase zu bestimmen. Für Bildungsrenditen ist vor allem der Übergang in die Erwerbsphase bedeutend, da die zu deren Beginn anfallenden Einkommen wesentlich schwächer abdiskontiert werden als die Einkommen gegen Ende des Lebenszyklus. Die zu Grunde gelegten Berufseintrittsalter ergeben sich aus den in Tabelle 8 angegebenen Ausbildungsdauern. Sie betragen unabhängig vom Geburtsjahr je nach Abschluss 16 Jahre (Ohne), 20 Jahre (Lehre), 22 Jahre (Meister), 24 Jahre (FH) oder 26 Jahre (Uni). Diese Alter liegen tendenziell unter empirischen Durchschnittswerten, die zu Grunde gelegten Ausbildungsdauern überschreiten im Hochschulbereich jedoch auf Regelstudienzeiten beruhende theoretische Mindestdauern und sind im Vergleich zu anderen Studien zu Ertragsraten von Bildung eher hoch angesetzt. ${ }^{195}$ Insgesamt führen die Annahmen zu den Ausbildungsdauern zu einer relativ vorsichtigen Schätzung der Rentabilität von Bildung. Die Setzungen des Renteneintrittsalters und der Lebenserwartung führen innerhalb realistischer Spannen nur zu geringfügigen Änderungen der Bildungsrenditen. Die im Weiteren vorgestellten Ergebnisse beruhen auf der Annahme eines konstanten Renteneintrittsalters von 65 Jahren, die Lebenserwartung wird mit durchgängig 84 Jahren sehr hoch angesetzt. Auf die Möglichkeit, diese beiden Werte in Übereinstimmung mit empirischen Durchschnittswerten kohortenspezifisch zu variieren, wurde wegen des geringen Einflusses dieser Parameter auf die Renditen verzichtet. ${ }^{196}$

Im Rahmen der so getroffenen Annahmen nimmt die Formel für den Barwert des Lebenseinkommens LEK in Abhängigkeit von Qualifikation $q$, Geburtsjahr $j$ und Zinssatz $z$ die Form an:

$$
\begin{aligned}
& \operatorname{LEK}(q, j, z)=\left\{\sum_{i=0}^{K(q)} \hat{y}_{i}^{b}(q, j)^{*}(1+z)^{-t}+\sum_{t=X(q)+1}^{64} \hat{y}_{i}^{b}(q, j)^{*}(1+z)^{-t}\right\} \\
& -\quad\left\{\sum_{i=0}^{X(q)} T_{j t}\left[\hat{y}_{t}^{b}(q, j)\right]^{*}(1+z)^{-t}+\sum_{t=Y(q)+1}^{64} T_{j+t}\left[\hat{y}_{t}^{b}(q, j)\right]^{*}(1+z)^{-t}\right\} \\
& +\quad\left\{\sum_{t=65}^{84} R_{j, r}\left[q, j, \sum_{t=0}^{64} \hat{y}_{t}^{b}(q, j)\right]^{*}(1+z)^{-t}\right\} \\
& +\left\{\sum_{t=0}^{x(q)} S_{j+r}\left[q, j, y^{E}\right]^{*}(1+z)^{-1}\right\} \\
& -\quad\left\{\sum_{i=0}^{x(q)} G_{j+t}[q, j]^{*}(1+z)^{-t}\right\}
\end{aligned}
$$

195 So legen Blöndal et al. (2002, S .18) und OECD (2003, S. 160) theoretische Mindestdauern zu Grunde; Ammermüller et al. (2005, S. 72) gehen von Ausbildungsdauern aus, die meist ein Jahr kürer sind als die hier genannten.

196 Wird etwa ein Renteneintrittsalter von 62 Jahren angenommen, verringern sich die realen Bruttorenditen um etwa 0,05 bis 0,15 Prozentpunkte gegenüber den Renditen bei einem Renteneintrittsalter von 65 Jahren. Die Effekte einer Variation der Lebenserwartung sind noch kleiner. 
Die Bildungsrendite $r$ einer Ausbildung $m$ im Vergleich zu einer Ausbildung $n$ folgt dann als Lösung der Gleichung:

$\operatorname{LEK}(m, j, r)-\operatorname{LEK}(n, j, r)=0$

Die fünf Ausdrücke in geschweiften Klammern entsprechen den in die jeweiligen Renditeabgrenzungen einbezogenen Größen. Die Bruttorendite umfasst nur den ersten Ausdruck, die Bruttoeinkommen. Diese bestehen erstens aus den während der Ausbildungszeiten von $t=0$ bis $t=X(q)$ erzielten Einkommen, wobei $X(q)$ die qualifikationsabhängige Ausbildungsdauer ist. Außer in Zeiten einer betrieblichen Ausbildung (Lehre) sind diese Einkommen null. Zweitens werden die Bruttoeinkommen während der Erwerbsphase, also bis zum Alter von 64 Jahren, hinzugerechnet. Um die Nettoenwerbsrenditen zu bestimmen, werden die auf die Löhne zu entrichtenden Abgaben (Steuern und Sozialversicherungsbeiträge) von den Bruttoeinkommen abgezogen (zweite geschweifte Klammer). Die Abgabenfunktion $T_{j+r}(.$.$) bildet dabei die jeweils$ gültigen Rechtsstände eines Kalenderjahres ab. Für die Nettolebensrenditen werden als dritter Ausdruck die Nettorenten $R_{j++}(.$.$) berücksichtigt. Diese ergeben sich aus$ den Bruttorenten, deren Höhe vom Bruttolebenseinkommen und qualifikationsspezifischen Rentenzuschlägen (etwa für Ausbildungszeiten) sowie dem aktuellen Rentenwert abhängt, abzüglich der auf die Bruttorenten entfallenden Abgaben. Die vierte geschweifte Klammer enthält die bildungsbedingten Transfers $S_{j+t}(.$.$) , deren$ Betrag vom jeweiligen Rechtsstand und dem unterstellten Elterneinkommen $y^{t}$ abhängt. Die bildungsbedingten Transfers sind in der Erwerbsphase negativ, wenn und so lange Ausbildungsdarlehen zurückgezahlt werden müssen (Rendite nach Transfers). Schließlich ergeben sich die Gesamtrenditen, wenn als fünfter Ausdruck zusätzlich Ausbildungsgebühren $G_{j+r}(.$.$) von den Einkommen subtrahiert werden.$

\subsubsection{Ergebnisse}

\subsubsection{Entwicklung der Bildungsrenditen über die Kohorten von 1930 bis 1990}

Die nominalen Bruttorenditen für verschiedene Kohorten, ermittelt aus den Bruttolohndifferenzen der Abschlüsse, zeigt Abbildung 32. Bei fünf Abschlüssen ergeben sich zehn paanweise Vergleiche, die jeweils aus den Differenzen der Einkommensprofile von zwei Abschlüssen folgen (Universitäts- gegenüber Fachhochschulabschluss, Uni gegenüber Meister, ..., Lehre gegenüber Ohne). Alle Renditekurven zeigen einen einheitlichen Verlauf. Für die Geburtsjahrgänge von 1930 bis 1945 schwanken die Renditen geringfügig und fallen danach bis zum Geburtsjahr 1960 stark ab. Die niedrigsten Renditen erzielen die Kohorten 1970 bis 1975, spätere Renditen liegen etwas höher, wobei in etwa dasselbe Niveau wie beim Geburtsjahrgang 1960 erreicht wird. Dieser zeitliche Verlauf tritt auf, obwohl die Abbildung 32 zu Grunde liegenden Lebenseinkommensprofile unter der Annahme zeitlich invarianter Bildungsrenditen im Sinne der Mincer-Gleichung gebildet wurden. Es sei noch einmal daran erinnert, dass sich 
die relativen Jahreseinkommen -die aus der Qualifikation $q$ sowie aus der aus Qualifikation, Kalenderjahr $t$ und Geburtsjahr $j$ abgeleiteten Erfahrung berechnet werdenverschiedener Kohorten nicht unterscheiden. Die relativen Lebenseinkommen und ihre Zusammensetzung hängen nur von der Qualifikation ab, nicht vom Geburtsjahr:

$$
\hat{b}(q, t, j)=d(t)^{*} \hat{y}(q, t, j)
$$

mit $\hat{b}(q, t, j) \quad$ geschätztes Bruttojahreseinkommen (in DM/ Euro)

$d(t) \quad$ Durchschnittsentgelt der gesetzlichen Rentenversicherung

$\hat{y}(q, t, j) \quad$ geschätztes relatives Bruttojahreseinkommen (in Entgeltpunkten)

Abbildung 32: Bruttorenditen Nominal

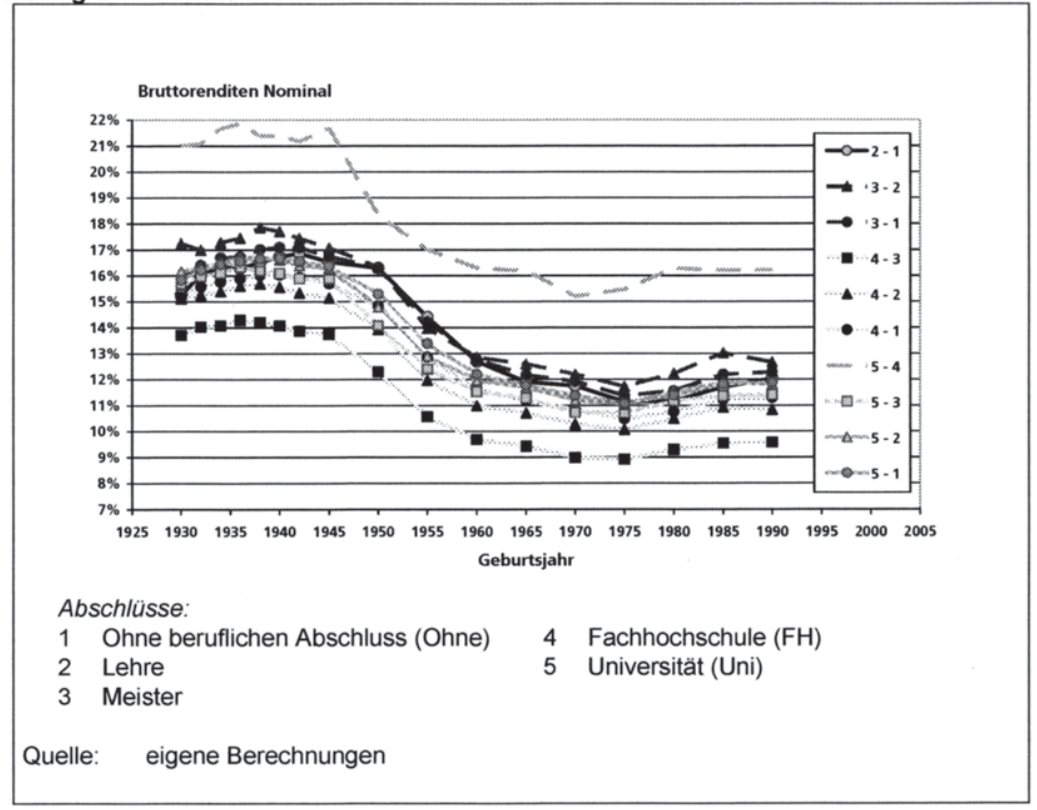

Trotz konstanter Mincer-Parameter und trotz gleichlanger Erwerbsphasen als Inputgrößen treten demnach deutliche Renditeunterschiede über die Kohorten auf. Die dargestellte Variation der Bruttorenditen über die Zeit ist folglich nicht über bildungsökonomische Parameter zu erklären sondern ausschließlich über die gesamtwirtschaftliche Lohnwachstumsrate, die hier über die Entwicklung des Durchschnittsentgelts erfasst ist. Der Verlauf der Bildungsrenditen spiegelt das hohe Lohnwachstum bis in die 1970er Jahre wider, dem bis 2006 deutlich gedämpfte Zunahmen folgten. Der leichte Anstieg über die jüngsten Kohorten ist Konsequenz der für die Zukunft angenommenen Wachstumsraten, die über den historischen Werten seit den 1980er Jahren liegen. Ein positiver Zusammenhang zwischen Bildungsrenditen und makroökonomischem Lohnwachstum resultiert daraus, dass mit der Bildungsbeteiligung 
einher gehende Einkommensverzichte zum potenziellen Beginn der Erwerbsphase unter den getroffenen Annahmen über zwei Faktoren kompensiert werden: Späteres Einkommen enthält erstens eine Bildungsprämie, zweitens fällt diese um so größer aus, je stärker der Durchschnittslohn nach Eintritt in die Erwerbsphase über dem Durchschnittslohn während der Bildungsbeteiligung liegt. Die Mindereinkommen in Ausbildungszeiten werden bei steigendem allgemeinem Lohnniveau faktisch geringer gewichtet. Werden nur die in Entgeltpunkten ausgedrückten geschätzten relativen Bruttojahreseinkommen betrachtet, ergibt sich für den Fall des Nullwachstums beispielsweise für ein Universitätsstudium im Vergleich zu einer Lehre eine Rendite von $8,6 \%$, ein Wert, der nahe bei dem entsprechenden impliziten Inputparameter aus der Mincerschätzung von $8,8 \%$ liegt (vgl. Tabelle 8 ). Bei einem konstanten Lohnwachstum von $3 \%$ beträgt dieselbe Rendite hingegen $11,8 \%$.

In Kapitel 3 wurden einige Hinweise auf im Zeitverlauf recht konstante Bildungsrenditen im Mincer'schen Sinne zusammengetragen. Der Verlauf der Bruttorenditen über die Kohorten deutet jedoch darauf hin, dass erhebliche intergenerative Unterschiede auf Grund der Stationaritätsannahme im Mincer-Modell unzutreffendenweise nicht erfasst werden. Dieses Ergebnis gravierender Unterschiede von MincerRenditen und internen Ertragsraten tritt ein, obwohl bei der Analyse stabile Modellparameter vorgegeben wurden. Die beim Mincer-Ansatz ausgeblendete Lohnwachstumsrate wirkt sich jedoch auf Grund der heterogenen Entwicklung während der zurückliegenden Jahrzehnte erheblich auf die Entwicklung der Bildungsrenditen in Deutschland aus, wobei ein positiver Zusammenhang zwischen Wachstumsrate und Anreizen für Humankapitalinvestitionen besteht. ${ }^{197}$

Abgesehen von dem Vergleich Uni-FH, der stets mit einem Abstand von 2 bis 4,5 Prozentpunkten zu den höchsten Renditen führt, und dem Vergleich FH-Meister, dessen Rendite durchgängig um knapp 1,5 Prozentpunkte unter dem zweitniedrigsten Wert liegt, sind die acht übrigen Renditen recht homogen, ihre Spannweite beträgt je nach Geburtsjahr 1,7 bis 2,4 Prozentpunkte. Die geringe Spannweite der Renditen deutet darauf hin, dass unter den zu Grunde gelegten Ausbildungsdauern die ähnlichen impliziten Mincer-Renditen (vgl. Tabelle 3) auch zu ähnlichen internen Brutto-Ertragsraten führen. Inwieweit der Fachhochschulabschluss im Vergleich zu den beiden anderen tertiären Abschlüssen (Uni, Meister) eine relativ ungünstige Position einnimmt, wird stark von den angenommenen Ausbildungsdauern geprägt. Bei einer ein Jahr länger dauernden Universitätsausbildung etwa sinken die Renditen für den Vergleich Uni-FH je nach Geburtsjahr um etwa 3 bis 5 Prozentpunkte. Üblich ist bei der Analyse interner Ertragsraten von Bildung, nur Renditen im Vergleich zum nächstniedrigeren Abschluss anzugeben (also etwa tertiärer Abschluss gegenüber Sekundarbereich II, Sekundarbereich II gegenüber Sekundarbereich I). Die hier vorgestellten Ergebnisse umfassen davon abweichend alle paarweisen Vergleiche der betrachteten Abschlüsse. In Übereinstimmung mit dem Schooling-Modell bestehen demnach nur geringe additive Effekte bei mehreren Abschlüssen. Auf einem mittleren Abschluss aufbauend ändert sich die Gesamtrendite gegenüber dem niedrigsten Qualifikationsniveau nicht mehr systematisch. Die Rendi-

197 Die Rendite $r$ ' in Abhängigkeit von der Lohnwachstumsrate ist bei exponentiellem Wachstum $r^{\prime}=r+g$, wobei $r$ die interne Ertragsrate bei Nullwachstum und $g$ eine konstante Lohnwachstumsrate ist (vgl. de la Fuente, Jimeno (2005), S. 4ff). Ein Anstieg der Lohnwachstumsrate erhöht also im selben Umfang die Rendite. Bei der hier vorgenommenen diskreten Betrachtung auf Jahresbasis ist $r^{\prime}=(1+r)^{*}(1+g)-1$. Bei kleinen Werten von $r$ und $g$ gilt dann näherungsweise $r^{\prime} \approx r+g$. 
ten der tertiären Abschlüsse (Meister, $\mathrm{FH}, \mathrm{Uni}$ ) gegenüber einem Abschluss der Sekundarstufe II (Lehre) und gegenüber einem darunter liegenden Abschluss (Ohne) unterscheiden sich kaum. So liegt etwa die Rendite Uni-Lehre in Abhängigkeit vom Geburtsjahr maximal 0,5 Prozentpunkte unter bzw. 0,3 Prozentpunkte über der Rendite Uni-Ohne. Gleichzeitig erreicht die Rendite Lehre-Ohne permanent eine ähnliche Größenordnung wie die Rendite Uni-Ohne.

Für die nominalen Bruttorenditen in Abbildung 32 deutet sich bereits an, dass der übliche Befund höherer Renditen von Humankapitalinvestitionen im Vergleich zu Sachinvestitionen auch hier resultiert. Nach Bildungsrenditen im Bereich von überwiegend $15 \%$ bis $17 \%$ für die Kohorten von 1930 bis 1945 bewegen sich die nominalen Bruttorenditen für Kohorten ab 1960 zwischen etwa 10\% und 12\%. Die nominale Kapitalmarktrendite lag seit den 1960er Jahren langfristig bei rund 7,1\%. ${ }^{198}$ Die angegebenen internen Brutto-Ertragsraten unterscheiden sich von Renditen im Mincer'schen Sinne und von anderen Veröffentlichungen zu internen Ertragsraten in mehrerlei Hinsicht: Im Vergleich zu Renditen im Mincer'schen Ansatz wirkt bei den angegebenen internen Brutto-Ertragsraten die Endlichkeit des Zeithorizonts renditemindernd, umgekehrt fällt die Rendite auf Grund des historischen und für die Zukunft projizierten gesamtwirtschaftlichen Lohnwachstums höher aus. Der Wachstumsparameter enthält allerdings anders als bei den oben genannten Studien zu internen Ertragsraten von Bildung neben dem realen Lohnwachstum auch die Preisniveausteigerung. Um mit anderen Ergebnissen zur Rentabilität von Bildung vergleichbare Ergebnisse zu erhalten, ist die Bestimmung preisniveaubereinigter Renditen angebracht, indem die Bruttoeinkommen unter einem konstanten Preisniveau angegeben werden. Ausgehend vom Jahr 2005 als Basisjahr werden die realen Renditen aus den um die Preisniveauentwicklung bereinigten Einkommen $\hat{b}(q, t, j)_{2 \times 15}$ bestimmt: ${ }^{199}$

$$
\begin{array}{lll}
\hat{b}(q, t, j)_{2005}=\hat{b}(q, t, j)^{*} P(2005) / P(t) \\
\text { mit } & P(2005) & \text { Preisindex } 2005 \\
& P(t) & \text { Preisindex des Kalenderjahrs } t
\end{array}
$$

Die hieraus ermittelten realen Bruttorenditen sind in Abbildung 33 dargestellt. Die zeitliche Entwicklung nominaler und realer Bruttorenditen folgt grundsätzlich demselben Muster. Die Renditen der Geburtsjahrgänge bis etwa 1945 liegen mit etwa $12 \%$ bis $14 \%$ deutlich über den späteren Werten, über die Kohorten zwischen 1945 und 1960 fallen sie stark ab, nach einem Minimum um das Geburtsjahr 1970 (rund $8 \%$ bis $10 \%$ ) tritt ein leichter Anstieg ein. Die Kohortenunterschiede fallen bei Betrachtung realer Renditen folglich geringer aus. Die nominalen Renditen liegen für die Geburtsjahrgänge von 1930 bis 1945 um etwa 3 bis 4 Prozentpunkte über den realen Renditen, nach dem Geburtsjahr 1960 unterschreiten die realen Renditen die nominalen zunächst um etwa 2 Prozentpunkte, in den jüngsten Kohorten entspricht die Differenz mit 1,6 Prozentpunkten in etwa der angenommenen zukünftigen Inflationsrate.

\footnotetext{
198 Deutsche Bundesbank (2001), S. 42

199 Der Preisindex ist aus dem Verbraucherpreisindex und seinen Vorgängern abgeleitet. Vgl. Statistisches Bundesamt (2006a)
} 
Die bei den nominalen Bruttorenditen zu beobachtenden Kohortenunterschiede werden durch Herausrechnung der Preisniveausteigerung demnach zum Teil eingeebnet, das Grundmuster bleibt jedoch erhalten. Die realen Bruttorenditen liegen durchgehend deutlich über der langfristigen realen Kapitalmarktrendite von rund 4\%, wobei hohes Reallohnwachstum bis in die Mitte der 1970er Jahre für die ältesten der betrachteten Kohorten zu realen Renditevorteilen in einer Größenordnung von etwa 3 bis 4 Prozentpunkten führt.

\section{Abbildung 33: Bruttorenditen Real}

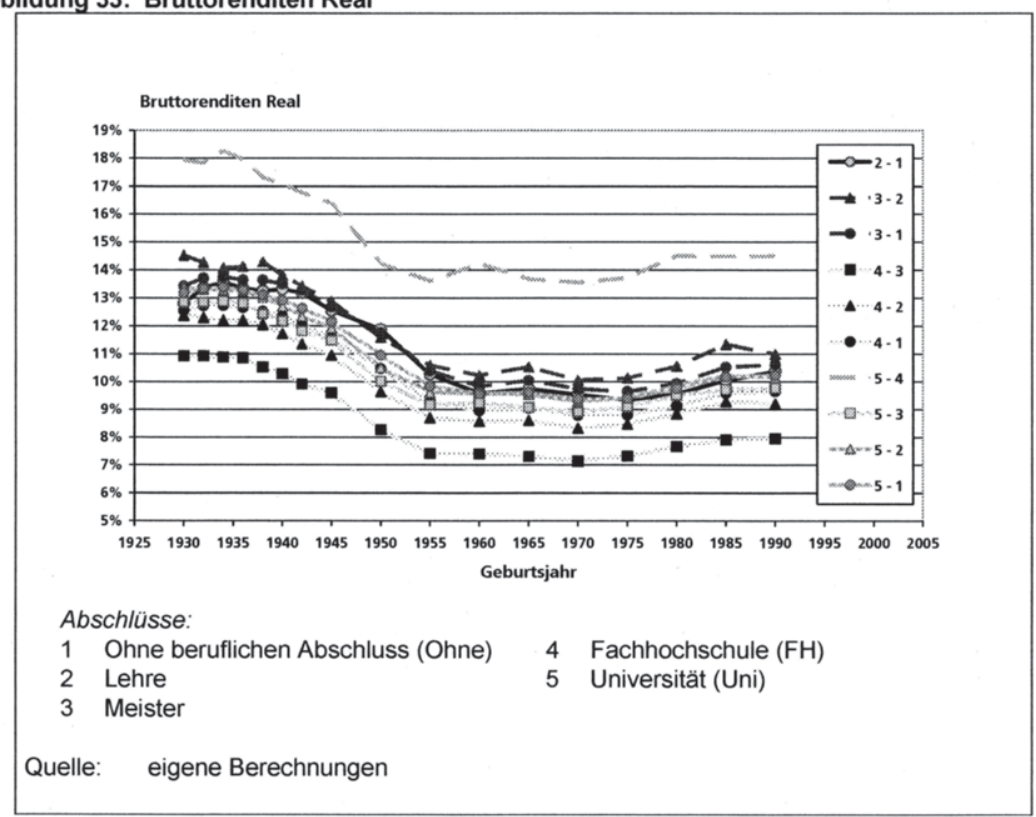

Neben dem Preisniveau kann allerdings noch ein zweiter Effekt verzerrend auf das Niveau und die Entwicklung der Bruttorenditen hinwirken. Im Kapitel zur Konstruktion von Lebenseinkommensprofilen wurde auf den Einfluss einer sich im Zeitverlauf verbessernden Qualifikationsstruktur auf die Schätzung von Bildungsrenditen hingewiesen, der trotz konstanter Bildungsprämien zu einer Überschätzung führen kann (vgl. Kapitel 3.2). Dort wurde ein Korrekturfaktor hergeleitet, der die Qualifikationsstruktur eines Kalenderjahres bei der Schätzung qualifikations- und erfahrungsabhängiger Bruttoeinkommen berücksichtigt. Dieser wirkt für Jahre mit einer schlechteren Qualifikationsstruktur als im Basisjahr 2003, für das die hier genutzten MincerParameter geschätzt wurden, wie ein additiver Zuschlag zum Absolutglied der Mincer-Gleichung. Durch den Korrekturfaktor bleibt das über die Zeitreihe der Durchschnittsentgelte der Rentenversicherung erfasste Lohnwachstum nicht eine rein exogene Variable sondern wird als Funktion der Qualifikationsstruktur partiell endogenisiert. Das geschätzte korrigierte Bruttojahreseinkommen in Preisen des Jahres 
2005, $\hat{b}(q, t, j)_{2005}^{k o n}$, ergibt sich als Produkt aus Korrekturfaktor und unkorrigiertem Pendant:

$\hat{b}(q, t, j)_{2005}^{k o 1 r}=k(t) * \hat{b}(q, t, j)_{2005}$

mit $\quad k(t) \quad$ Korrekturfaktor des Kalenderjahrs $t$

Da $k(t)$ durch die seit den 1950er Jahren weitgehend kontinuierlich verbesserte Qualifikationsstruktur von 1950 bis 2003 überwiegend monoton fällt, wirkt der Korrekturfaktor wie ein Korrektiv der globalen Lohnwachstumsrate. Anders ausgedrückt entsprechen korrigierte Einkommensprofile den bisherigen Profilen bei einer geringeren globalen Lohnwachstumsrate. Das Lohnwachstum wird nun teilweise auf den Qualifikationswandel zurückgeführt. Auf der Grundlage der korrigierten Lebenseinkommensprofile ist wegen des renditesteigernden Effekts des Lohnwachstums für die älteren Kohorten entsprechend eine geringere (reale) Bruttorendite zu erwarten, als die nicht korrigierten Profile zeigen. Für die jüngeren Kohorten ergibt sich indessen kein Unterschied, da die zukünftige Qualifikationsstruktur als konstant angenommen wird $(k(t)=1$ für $t \geq 2003$ ). Der Korrekturfaktor dient folglich dazu, Einflüsse des historischen Qualifikationswandels zu erfassen, um besser an die empirische Entwicklung angepasste Schätzungen der (weitgehend) retrospektiven Bildungsrenditen der älteren Kohorten zu bestimmen. Die Wirkung des Korrekturfaktors auf die Schätzung der realen Bruttorenditen ist in Abbildung 34 dargestellt. Abgetragen sind die Differenzen der Renditen bei korrigierten Einkommen und der in Abbildung 33 gezeigten Renditen bei nicht korrigierten Einkommen. Der Renditeeffekt des Korrekturfaktors hängt vor allem von dem Ausmaß des Qualifikationswandels während der Zeiten $a b$, in denen je nach Abschluss eine Erwerbstätigkeit oder eine Bildungsbeteiligung erfolgt.

Für die ältesten betrachteten Kohorten liegen die aus den korrigierten Einkommensprofilen ermittelten Renditen teilweise geringfügig über den nicht korrigierten Werten, was auf den vorübergehenden Anstieg des Korrekturfaktors zwischen 1957 und 1964 zurückzuführen ist, der mutmaßlich auf fehleranfälligen Daten zur Qualifikationsstruktur in diesem Zeitraum basiert. Am stärksten wirkt sich die Einkommenskorrektur für die Kohorten 1940 und 1945 aus, da sich die Qualifikationsstruktur zwischen 1965 und 1970, dem Zeitraum, in dem sich diese Kohorten je nach Qualifikation in Ausbildung oder Erwerbstätigkeit befanden, vergleichsweise stark verbesserte. Durch Berücksichtigung des Qualifikationswandels fallen die realen Bruttorenditen für diese Kohorten um bis zu rund 0,9 Prozentpunkte niedriger aus. Sowohl für ältere als auch jüngere Kohorten ergeben sich geringere Effekte. Auch nach Einbeziehung des Korrekturfaktors bleibt die zeitliche Entwicklung der realen Bruttorenditen weitgehend erhalten. Die höchsten Renditen erzielen die Kohorten bis 1945, allerdings sind die Renditen dieser Geburtsjahre nicht mehr annähernd konstant sondern fallen nun geringfügig. Der Renditerückgang über die Kohorten von 1945 bis 1960 wird leicht verstärkt, spiegelbildlich wird der Anstieg der Renditen für die jüngsten Geburtsjahre moderat erhöht. 
Abbildung 34: Bruttorenditen Real: Veränderung durch Korrektur der Einkommensprofile

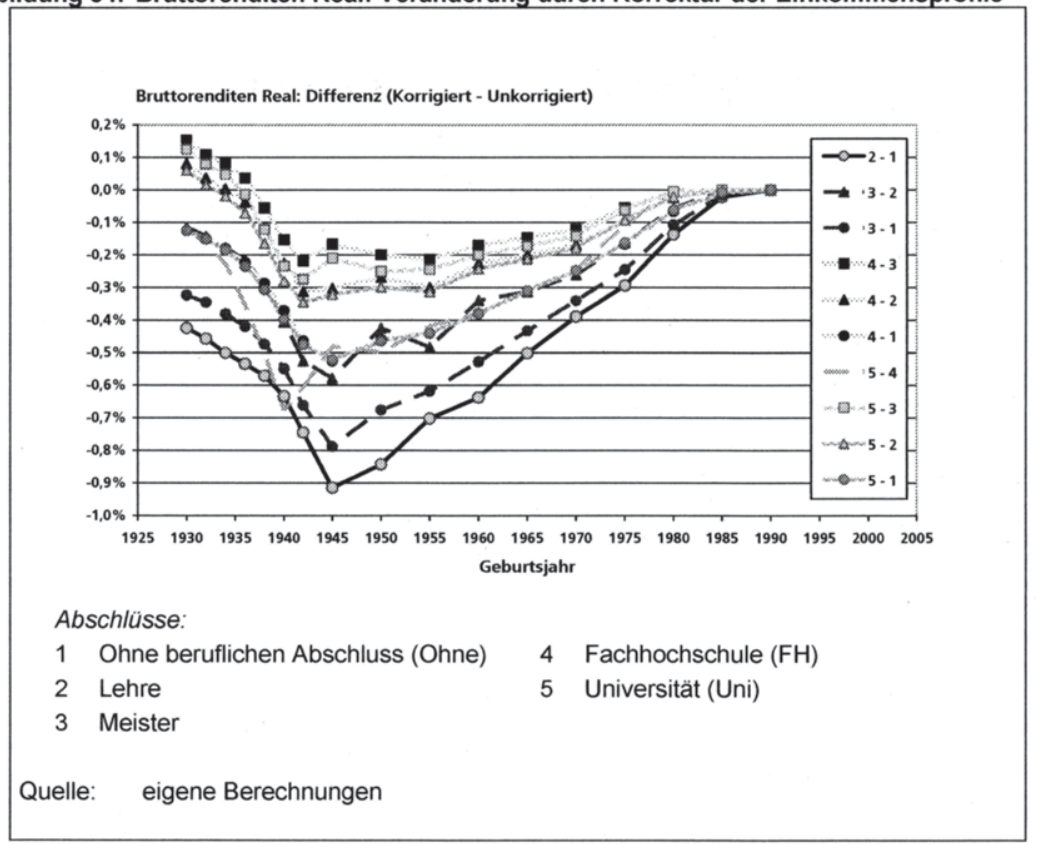

Für die Bruttorenditen bleibt festzuhalten, dass merkliche Renditeunterschiede über die Kohorten auftreten, obwohl zentrale Inputgrößen für ihre Berechnung wie die $\mathrm{Pa}$ rameter der zu Grunde liegenden Mincer-Schätzung als zeitlich invariant angenommen wurden. Konstante Renditen im Mincer'schen Sinne können folglich mit durchaus variablen internen Brutto-Ertragsraten einhergehen. Als Hauptursache treten im Zeitverlauf schwankende Lohnwachstumsraten auf, in geringerem Umfang trägt auch eine sich wandelnde Qualifikationsstruktur zu Renditeunterschieden zwischen Kohorten bei.

Gemäß der im vorherigen Unterkapitel vorgestellten Sequenz von Renditebegriffen folgen als zweite Abgrenzung die Nettoenwerbsrenditen, die aus den Differenzen der bis zum Ende der Erwerbsphase erzielten Nettoeinkommen (Bruttoeinkommen abzüglich Steuern und Sozialversicherungsbeiträge) gebildet werden. Im Fall einer im Zeitverlauf gleich bleibenden linearen Abgabenfunktion, bei der die Abgaben einen konstanten Anteil des Bruttoeinkommens bilden, sind Abgaben nicht renditerelevant, Bruttorenditen und Nettoerwerbsrenditen sind dann identisch. Ein solcher linearer Zusammenhang gilt innerhalb der Beitragsbemessungsgrenzen für die Sozialversicherungsbeiträge, die nur in geringem Maße die Renditen beeinflussen. Ihre Wirkung ergibt sich aus den im Zeitverlauf schwankenden Beitragssätzen und partiell nicht beitragspflichtigen bildungsbedingten Mehreinkommen, falls diese die Beitrags- 
bemessungsgrenzen überschreiten. Negative Effekte der Abgabenfunktion auf das Renditeniveau resultieren primär aus der Progression des Steuersystems. ${ }^{200}$

Abbildung 35 gibt die realen Nettoerwerbsrenditen wieder. Anders als die realen Bruttorenditen fallen diese recht monoton über die Kohorten von 1930 bis 1955 von Werten zwischen $10 \%$ und $12 \%$ auf etwa $6 \%$ bis $8 \%$ und verharren auf diesem Niveau für die Geburtsjahre von 1955 bis 1970. Danach steigen die Nettoerwerbsrenditen um durchschnittlich einen Prozentpunkt bis zum Geburtsjahrgang 1990 wieder an. Der Befund der höchsten Renditen bei den ältesten Kohorten und der niedrigsten Werte bei den mittleren Kohorten ergibt sich also sowohl für die Brutto- als auch für die Nettoerwerbsrenditen, allerdings unterscheiden sich die zeitlichen Verläufe.

Abbildung 35: Nettoerwerbsrenditen Real

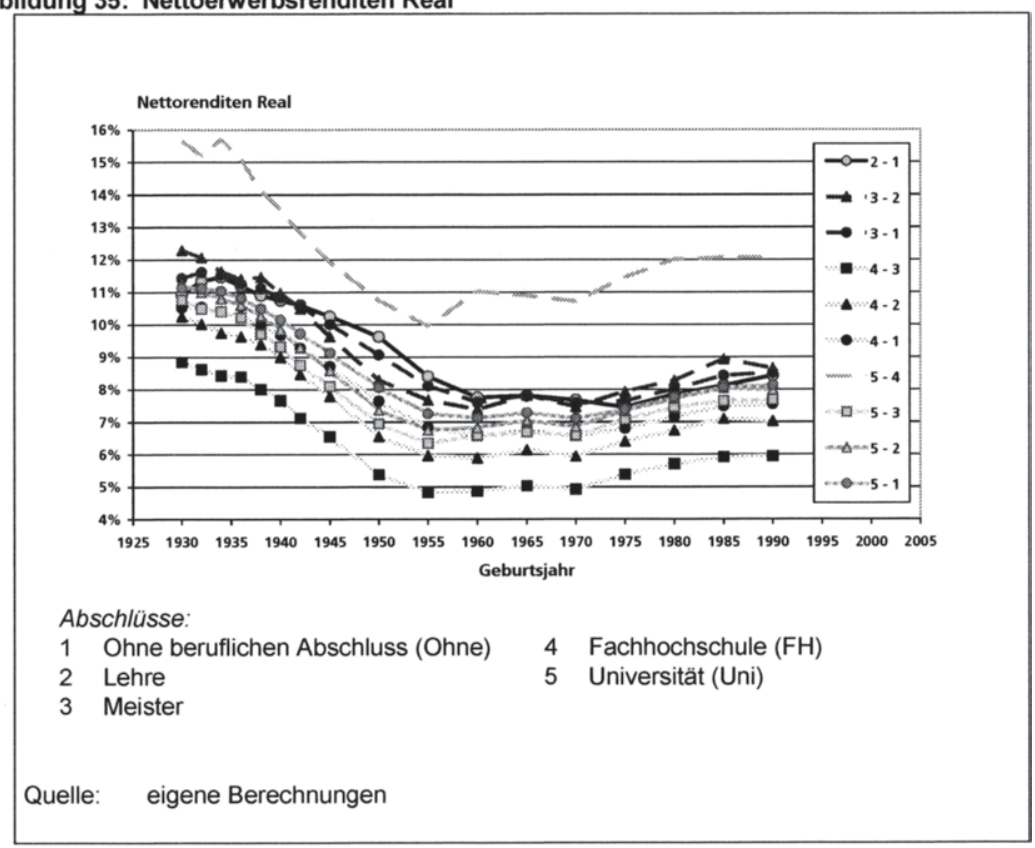

Der partielle Renditeeffekt der Abgaben, definiert als Differenz von Nettoenwerbsund Bruttorenditen, wird aus Abbildung 36 ersichtlich. Sowohl für die ältesten als auch die jüngsten Kohorten senken die Abgaben die Bildungsrendite um etwa -2 bis -2,5 Prozentpunkte, dazwischen ergibt sich für die meisten Vergleiche von zwei $A b-$ schlüssen ein etwa u-förmiger Verlauf. Der stärkste partielle Renditeeffekt tritt für die Kohorten 1945 bis 1950 auf mit etwa $-2,7$ bis zu -3,4 Prozentpunkten. Die Ent-

200 Die Aussage der Renditeneutralität einer linearen Abgabenfunktion gilt für die hier gewählte Sequenz der Renditebegriffe. Wenn hingegen etwa zunächst direkte Ausbildungskosten und danach proportionale Abgaben in die Einkommensprofile aufgenommen werden, gilt dieser Zusammenhang nicht. 
wicklung des Einflusses der Abgaben auf die Renditen ergibt sich vor allem aus dem Ausmaß der Steuerprogression in den betrachteten Einkommensbereichen. Grundsätzlich deuten geringe Renditeeffekte des Steuersystems auf eine mit dem Einkommen eher moderat zunehmende Durchschnittsbelastung hin. Entsprechend lassen die abgebildeten partiellen Renditeeffekte auf eine zu Beginn des Untersuchungszeitraums zunehmende Steuerprogression schließen, der eine Phase abnehmender Konvexität folgt.

\section{Abbildung 36: Partieller Renditeeffekt von Abgaben: Nettoerwerbsrenditen - Bruttorenditen}

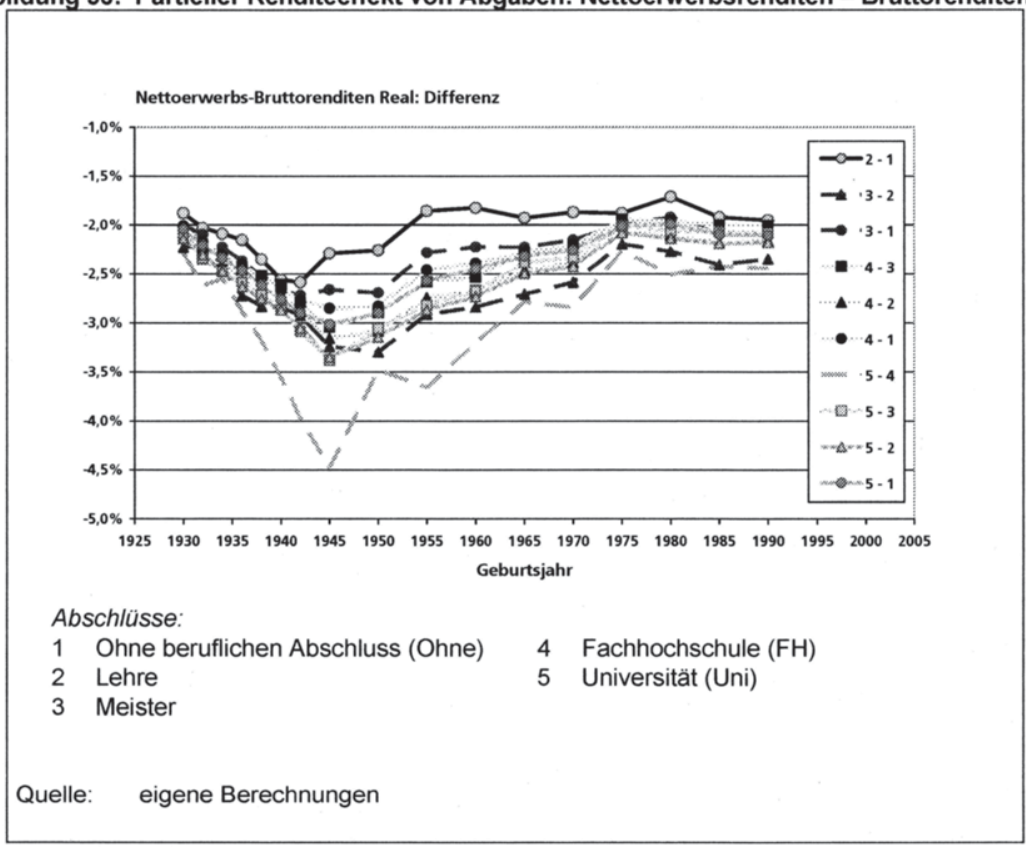

Die stärkste Renditewirkung entfalten die Abgaben über alle Kohorten hinweg bei dem Vergleich Uni-FH, am schwächsten fällt der Effekt durchgehend für den Vergleich Lehre-Ohne aus. Grundsätzlich ist dieser Befund bei einer progressiven Besteuerung zu erwarten. Sowohl die bildungsbedingten Mehreinkommen aus einer Lehre als auch eines Universitätsabsolventen im Vergleich zu einem Fachhochschüler betragen im Erwerbszyklus durchschnittlich etwa 20\% des Durchschnittsentgelts $(0,2$ Entgeltpunkte). Erstere fallen allerdings in den unteren Bereich der hier vertretenen Einkommensspanne von etwa $60 \%$ bis $190 \%$ der jeweiligen Durchschnittsentgelte, letztere in den Höchstbereich, so dass dieses Mehreinkommen einem höheren Grenzsteuersatz unterliegt. Abgesehen von grundsätzlichen Ausrichtungen des Steuersystems wird die zeitliche Entwicklung der partiellen Renditeeffekte der Abgaben auch durch die Zeitpunkte von Rechtsänderungen mitbestimmt, deren Effekte sich jedoch kaum systematisieren lassen. 
In Bezug auf die Bruttorenditen wurde ein moderat renditemindernder Effekt vorgestellt, wenn die Einkommen um Einflüsse des Qualifikationswandels korrigiert werden. Für die Renditeminderung durch Abgaben ist ein Anstieg bei den älteren Kohorten zu erwarten, wenn die Einkommen analog korrigiert werden. Durch die Korrektur steigt das bildungsbedingte Mehreinkommen und unterliegt tendenziell einer höheren Grenzbelastung. Über die Kohorten zeigt sich überwiegend eine geringe Zunahme des partiellen Renditeeffekts der Abgaben, wenn korrigierte Einkommensprofile betrachtet werden (Abbildung 37). Die dargestellte zusätzliche Renditeminderung ergibt sich als Differenz des partiellen Renditeeffekts von Abgaben bei unkorrigierten Einkommensprofilen und korrigierten Einkommensprofilen. Zu ihrer Bestimmung sind also zunächst sowohl die partiellen Renditeeffekte von Abgaben bei unkorrigierten als auch bei korrigierten Einkommensprofilen zu berechnen. Eine zusätzliche Renditeminderung (negatives Vorzeichen) zeigt demnach an, dass bei korrigierten Einkommensprofilen der Keil zwischen Brutto- und Nettoenwerbsrenditen größer ist.

\section{Abbildung 37: Zusätzliche Renditeminderung durch Abgaben bei korrigierten Einkommen}

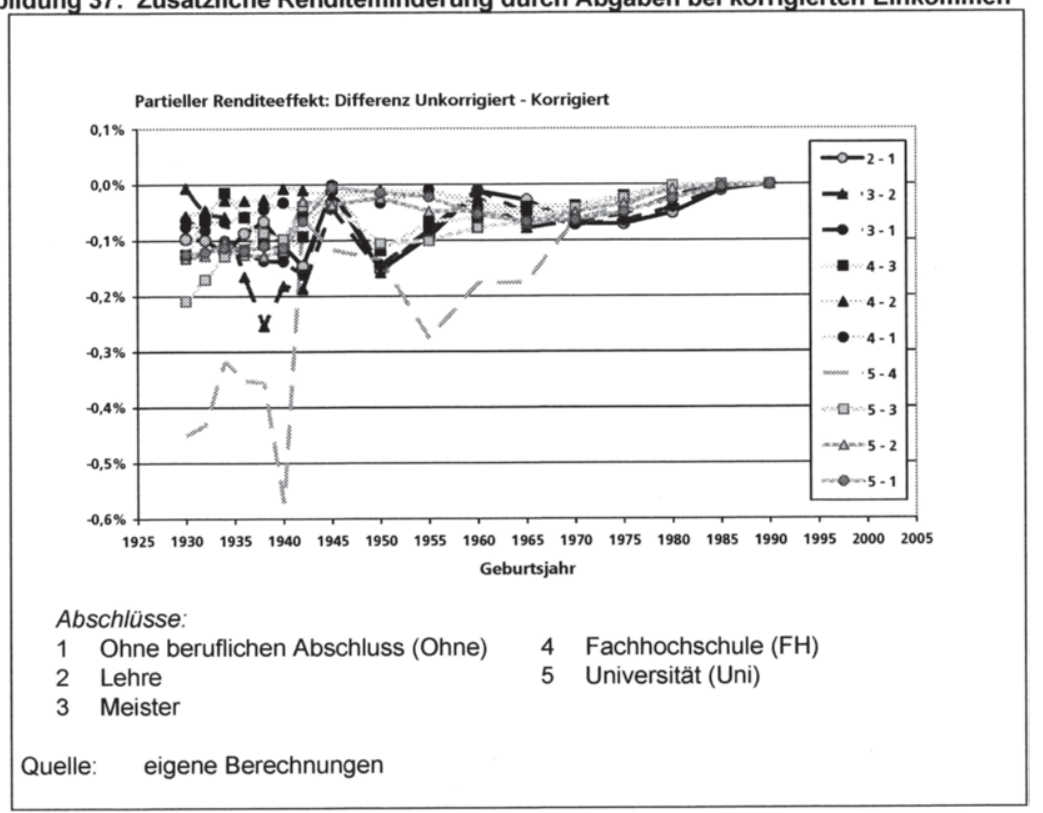

Abgesehen von dem Vergleich Uni-FH, der auch stets eine hohe Bruttorendite erzeugt, steigen die Absolutwerte der partiellen Renditeeffekte bei korrigierten Einkommensprofilen nur um bis zu etwa 0,2 Prozentpunkte an, mehrheitlich wird der Wert von 0,1 Prozentpunkten unterschritten. Die Einkommenskorrektur beeinflusst die Einschätzung der Wirkung von Steuern und Sozialversicherungsbeiträgen auf die Rentabilität von Humankapitalinvestitionen eher geringfügig. Insgesamt weist die vorgenommene Einkommenskorrektur damit darauf hin, dass interne Ertragsraten von Bildung für ältere Kohorten ohne Berücksichtigung des Qualifikationswandels 
leicht überschätzt werden können, wobei vor allem die Bruttorenditen zu hoch ausfallen. Grundlegende Änderungen bei Niveau und zeitlicher Entwicklung wurden jedoch nicht festgestellt. Die weitere Betrachtung bezieht sich daher vereinfachend nur noch auf die unkorrigierten Einkommensprofile.

Durch Einschluss der Nettorenten (Bruttorenten minus auf diese zu entrichtende Sozialversicherungsbeiträge und Steuern) als dritte Größe folgen die Nettolebensrenditen. Rentenzahlungen steigern die internen Ertragsraten nach den hier ermittelten Ergebnissen höchstens um 0,24 Prozentpunkte (Abbildung 38). Sowohl intertemporale als auch Querschnittsvergleiche sind nur vorsichtig zu interpretieren. Vergleiche werden zum einen durch verschiedene Rechtsänderungen seit dem RRG 1992 erschwert, die restriktivere Anrechnungen von Ausbildungszeiten auf Rentenansprüche mit sich brachten und zu erratisch wirkenden Renditeeffekten führen können. Zum anderen ist daran zu erinnern, dass positive partielle Renditeeffekte tendenziell je größer ausfallen, desto kleiner die zum Vergleich herangezogene weniger umfassende Rendite ist. So entspricht die Rangfolge der partiellen Renditeeffekte der Nettorenten weitgehend der umgekehrten Rangfolge der Nettoerwerbsrenditen. Die höchsten partiellen Renditewirkungen treten bei den mittleren Geburtsjahren 1955 bis 1970 auf, die gleichzeitig die geringsten Nettoerwerbsrenditen aufweisen, für die ältesten Kohorten gilt die umgekehrte Relation. Ebenso wirkt sich der Einschluss der Renten auf die Renditen des Vergleichs Uni-FH im Querschnittsvergleich minimal aus, beim Vergleich FH-Meister maximal. Diese beiden Vergleiche zeichnen sich jedoch genau entgegengesetzt durch die höchsten (Uni-FH) bzw. niedrigsten (FH-Meister) Nettoerwerbsrenditen aus.

Abbildung 38: Partieller Renditeeffekt von Renten: Nettoerwerbs- - Nettolebensrenditen

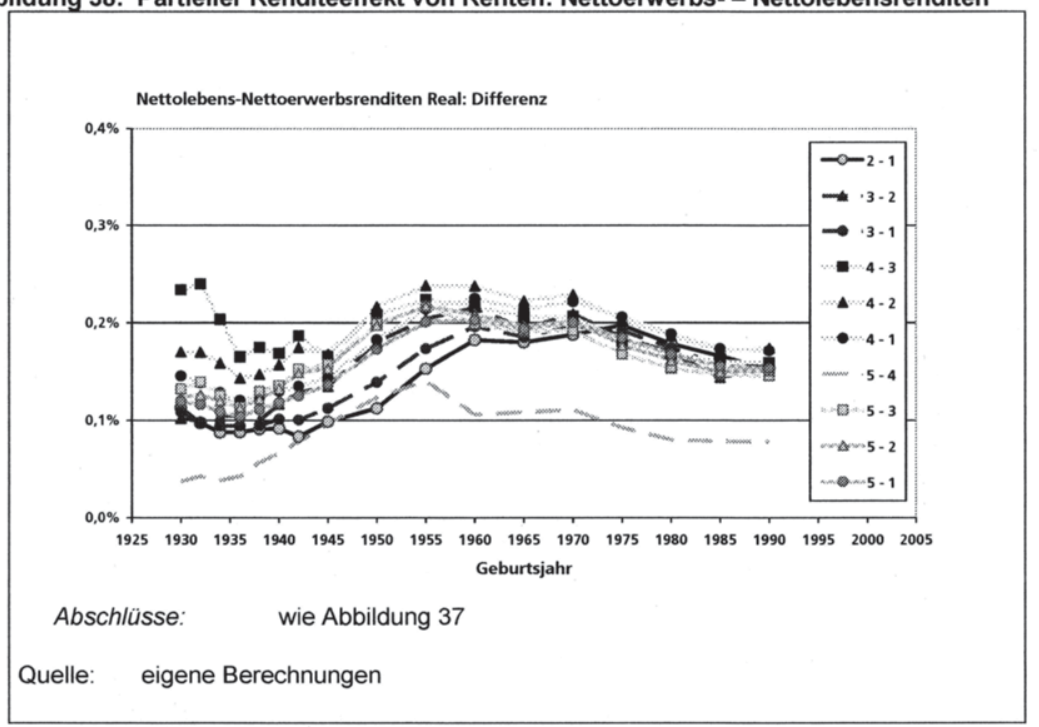


Für das Rentensystem bleibt als Fazit, dass es nach diesen Ergebnissen von untergeordneter Bedeutung für die Rentabilität von Humankapitalinvestitionen ist. Als typisierender Wert kann für die jüngeren Kohorten eine Renditesteigerung von knapp 0,2 Prozentpunkten gelten. Bei recht hohen Nettoerwerbsrenditen von meist über $6 \%$ und bis zu $12 \%$ werden die spät im Lebenszyklus anfallenden Rentenzahlungen zu stark abdiskontiert, um sich fühlbar auf die interne Ertragsrate auszuwirken.

Abbildung 39: Partieller Renditeeffekt von Transfers an Eltern:

Renditen nach Transfers - Nettolebensrenditen („Mittelstandsloch“)

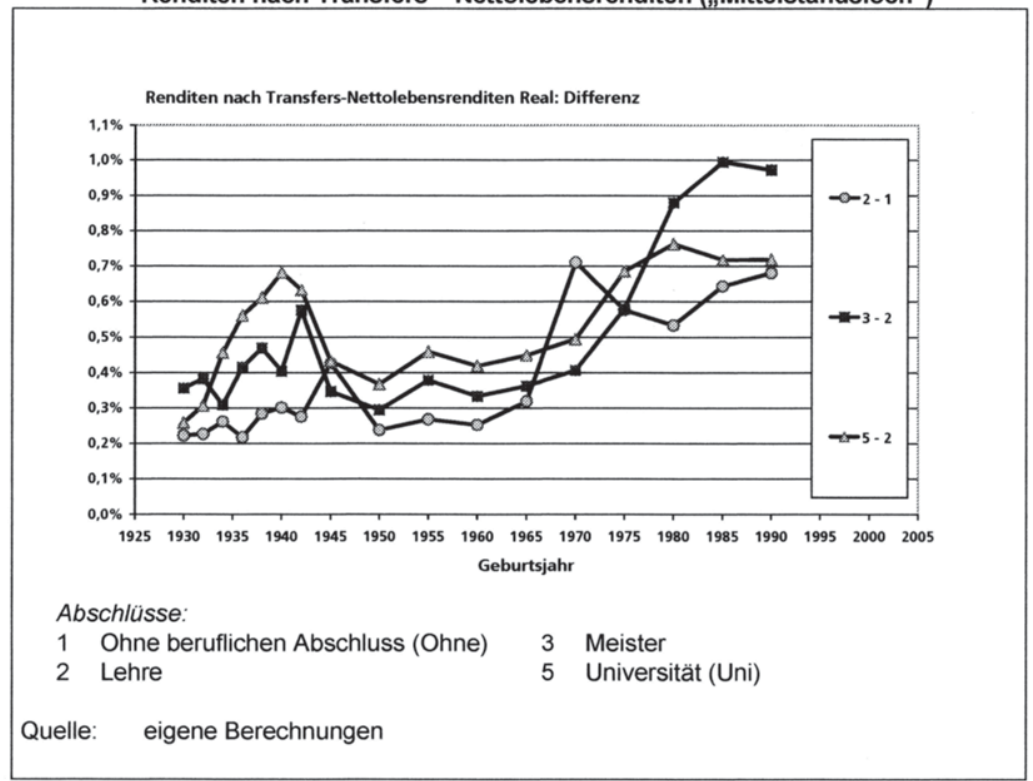

Zu den Renditen nach Transfers wurde bereits angemerkt, dass die Ausprägung von bildungsbedingten Transfers wesentlich vom unterstellten Elterneinkommen abhängt. Im Gegensatz zu den beiden anderen bisher auf ihre Renditerelevanz hin betrachteten Politikvarianten Abgaben und Renten, mit denen nicht unmittelbar bildungspolitische Ziele verfolgt werden, dient die Ausbildungsförderung explizit der Verstärkung von Bildungsanreizen. Bei den weiteren den bildungsbedingten Transfers zuzurechnenden Maßnahmen (verlängerter Anspruch auf Kindergeld, Ausbildungsfreibetrag etc.), die den Eltern von Auszubildenden zu Gute kommen, stehen eher familienpolitische Motive im Vordergrund. Wird zunächst die Ausbildungsförderung nach dem BAföG und dem Honnefer Modell ausgeblendet, zeigt sich bei mittleren Elterneinkommen („Mittelstandsloch") ein im historischen Vergleich hoher partieller Renditeeffekt der Transfers an Eltern von Auszubildenden für die jüngsten Kohorten von etwa 0,7 bis 1,0 Prozentpunkten (Abbildung 39). Die Abbildung beschränkt sich auf drei Ausbildungsvergleiche (Lehre-Ohne, Meister-Lehre, Uni-Lehre), die partiellen Renditeeffekte verlaufen bei den sieben übrigen Vergleichen ähnlich. Nach einem vorübergehenden Anstieg über die ältesten Kohorten betrug der partielle Rendite- 
effekt etwa 0,25 bis 0,45 Prozentpunkte für die Kohorten von 1945 bis 1965, danach wurde schrittweise das derzeitige Niveau von 0,7 bis 1,0 Prozentpunkten erreicht. Dieses Niveau und auch die zeitliche Entwicklung gelten für Elterneinkommen im so genannten Mittelstandsloch, dem Einkommen, bei dem kein Anspruch auf Ausbildungsförderung besteht, weil das Elterneinkommen gerade ausreicht, den Bedarf des Auszubildenden zu decken. ${ }^{201}$

Abbildung 40: Renditeeffekt von Transfers an Eltern: Differenzen zu mittlerem Einkommen

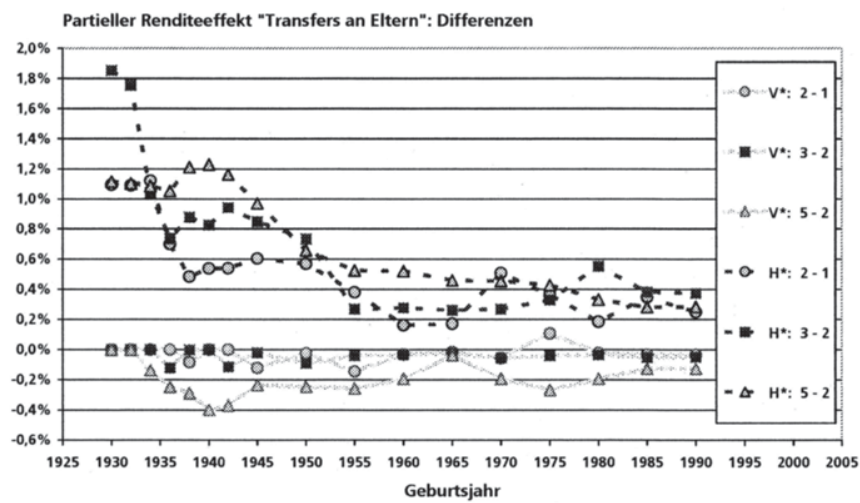

Abschlüsse: $\quad$ wie Abbildung 39

* V: Elterneinkommen an der Vollförderungsgrenze

$\mathrm{H}$ : Höchsteinkommen der Eltern

Quelle: eigene Berechnungen

Bei wesentlich höheren Elterneinkommen liegen die partiellen Renditeeffekte der an die Eltern adressierten bildungsbedingten Transfers stets deutlich über den Werten im Mittelstandsloch, bei niedrigeren Elterneinkommen fast immer darunter. Dieser Befund reflektiert den unter (fast) allen betrachteten Rechtsständen geltenden positiven Zusammenhang von Elterneinkommen und kindbedingten Entlastungen. Abbildung 40 zeigt die Abweichungen des partiellen Renditeeffekts von den in Abbildung 39 dargestellten Werten für Eltern mit Höchsteinkommen bzw. Einkommen an der Vollförderungsgrenze. Die partiellen Renditeeffekte für Elterneinkommen im Mittelstandsloch entsprechen in der Darstellung von Abbildung 40 also der Nullinie. Bei niedrigeren Elterneinkommen ergeben sich hauptsächlich für den Vergleich Uni-Lehre leichte Verschlechterungen der Bildungsrenditen, die mehrheitlich höchstens 0,2 Prozentpunkte betragen. Für sehr hohe Elterneinkommen sind die partiellen Renditeeffekte immer höher als bei mittlerem Einkommen, nach Abständen von über 1,0 Prozent-

201 Im Jahr 2007 liegt dieses Einkommen für verheiratete Eltern mit einem Studenten bei einem Jahresbruttolohn von knapp 50.000 Euro. 
punkten für die ältesten Kohorten fällt die partielle Wirkung für die Geburtsjahre ab 1955 um etwa 0,2 bis 0,5 Prozentpunkte höher aus als im Mittelstandsloch. Die zeitliche Entwicklung des partiellen Renditeeffekts bildungsbedingter Transfers für Eltern von Auszubildenden unterscheidet sich damit für verschiedene Einkommensniveaus. Für niedrige bis mittlere Einkommen nimmt der Renditeeffekt im Zeitverlauf tendenziell zu, für höchste Einkommen hingegen ab. Ein positiver Zusammenhang zwischen Elterneinkommen und Transfers bleibt zwar bestehen, die Spreizung über die Einkommensskala nimmt jedoch ab. Für die jüngsten Kohorten liegen die partiellen Renditeeffekte je nach Ausbildung und Elterneinkommen im Bereich von 0,5 bis 1,4 Prozentpunkten. Unter Renditeaspekten wirken sich die früh im Lebenszyklus anfallenden bildungsbedingten Transfers an Eltern demnach deutlich stärker aus als das Rentensystem.

Abbildung 41: Partieller Renditeeffekt von Transfers: Transfers an Eltern und Ausbildungsförderung

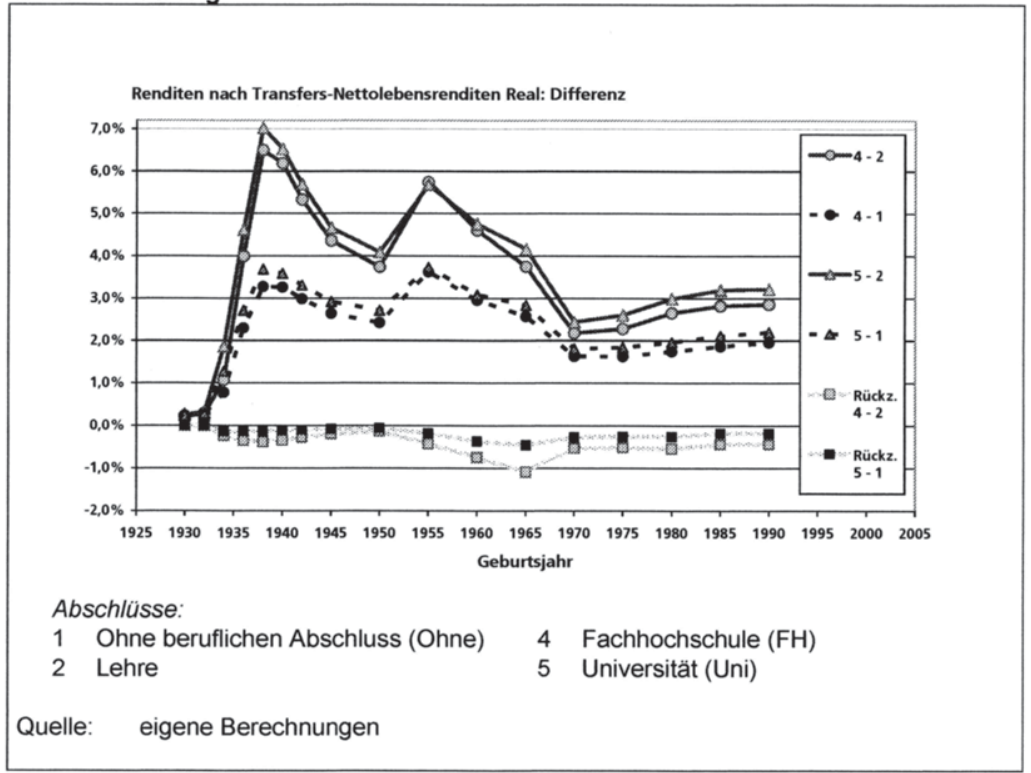

Vervollständigt man die bildungsbedingten Transfers um die Ausbildungsförderung, ergeben sich wesentlich stärkere partielle Renditeeffekte (Abbildung 41). Von der Ausbildungsförderung begünstigt werden bei den hier betrachteten Fällen Auszubildende an Fachhochschulen und Universitäten. Nachdem für die Kohorten um 1930 noch keine breit angelegte Ausbildungsförderung existierte, so dass für diese ausschließlich Transfers an Eltern zu bilanzieren sind, wirkte sich die Ausbildungsförderung nach dem BAföG und dem Honnefer Modell später fühlbar auf die Renditen aus. Zunächst steigen die partiellen Renditeeffekte bildungsbedingter Transfers über die Jahrgänge, für die nur während des letzten Teils der Ausbildung eine Förderung in Betracht kommt, stark an. Für den Geburtsjahrgang 1937, den ersten Jahrgang, der 
während des gesamten Studiums nach dem Honnefer Modell förderbar war, ergeben sich historische Höchstwerte der partiellen Renditeeffekte von bis zu 7,0 Prozentpunkten (Vergleich Uni-Lehre).

Im weiteren Verlauf erodieren die partiellen Renditeeffekte zunächst auf Grund nicht an die Einkommensentwicklung angepasster Leistungsparameter des Honnefer Modells. Die Einführung des BAföG 1971 führt danach zu einem Renditesprung, dem wiederum eine Leistungserosion folgt, die seit Mitte der 1990er Jahre zum Teil korrigiert wurde (vgl. Abbildung 41). Über die Kohorten von 1955 bis 1970 wirkt neben realen Verschlechterungen von Leistungsparametern auch der Wegfall der Schülerförderung in der Sekundarstufe II renditemindernd. In der Abbildung sind die Gesamtwirkungen bildungsbedingter Transfers an Eltern und Auszubildende dargestellt, wobei auf die Transfers an die Eltern beim angenommenen Einkommen an der Vollförderungsgrenze wie oben beschrieben etwa 0,2 bis 0,6 Prozentpunkte des partiellen Renditeeffekts entfallen. Rückzahlungen für Darlehen nach dem BAföG und dem Honnefer Modell wurden in der Abbildung berücksichtigt. Auf Universitäts- und Fachhochschulstudien wirkt die Ausbildungsförderung ähnlich, das Ausmaß hängt wesentlich von der Referenzausbildung ab. Im Vergleich zu Personen ohne Abschluss (FH-Ohne, Uni-Ohne) ergeben sich für die jüngsten Kohorten bei zuletzt leicht steigender Tendenz partielle Renditeeffekte von rund 2,0 Prozentpunkten, im Vergleich zu einer Lehre von etwa 3,0 Prozentpunkten (FH-Lehre, Uni-Lehre). Beide Werte sind im Vergleich zu vor 1970 geborenen Kohorten recht niedrig.

Die Graphen Rückzahlung 4-2 (FH-Lehre) und Rückzahlung 5-1 (Uni-Lehre) zeigen die in diesen Werten enthaltenen Auswirkungen der Darlehensrückzahlungen. Unter jedem Rechtsstand zehren die Rückzahlungen einen eher kleinen Teil der auf die Transfers zurückzuführenden Renditesteigerungen auf. Hierzu trägt neben den als Zuschuss erfolgenden Förderungsanteilen die Darlehenssubventionierung in Form von Zinslosigkeit und Karenzzeiten bei. Eine darlehensfreie Förderung würde die Renditen um höchstens 1,1 Prozentpunkte anheben (FH-Lehre, Geburtsjahr 1965), bei den jüngsten Kohorten liegen die entsprechenden Werte zwischen 0,2 und 0,4 Prozentpunkten. Vergleichsweise stark betroffen von Rückzahlungen ist der Geburtsjahrgang 1965, dessen BAföG-Förderung als Volldarlehen vergeben wurde. Insgesamt zeigt die Entwicklung der partiellen Renditeeffekte bildungsbedingter Transfers massive Reaktionen auf Gesetzesänderungen im Bereich der Ausbildungsförderung, über wenige Geburtsjahre sind Unterschiede von bis zu über 3,0 Prozentpunkten zu beobachten. Im Vergleich zu Abgaben und Renten wirkt sich die Ausbildungsförderung recht stark und unmittelbar auf die Bildungsrenditen aus. Dabei überkompensieren die bildungsbedingten Transfers bei Geförderten überwiegend die vom Abgabensystem ausgehende Renditeminderung. Über die Ausbildungsförderung, auf deren Ausgestaltung die Bildungsrenditen deutlich sensibler reagieren als auf Änderungen des Steuer- oder Rentensystems, steuert der Gesetzgeber recht direkt die Rentabilität von Humankapitalinvestitionen. Im historischen Vergleich gehen dabei von der gegenwärtigen Förderung nach dem BAföG eher bescheidene Bildungsanreize aus, wobei nach Wirksamwerden der jüngsten Reform ab Herbst 2008 ein positiverer Befund zu enwarten ist.

Um den Vergleich der Entwicklung der Bildungsrenditen über die Kohorten von 1930 bis 1990 abzuschließen, werden schließlich noch die historischen Schulgelder und Studiengebühren in die Lebenseinkommensprofile einbezogen. Da von Schulgeld- 
und Studiengebührenzahlungen letztmalig für die Kalenderjahre 1957 bzw. 1970 ausgegangen wird ( $\mathrm{vgl}$. Kapitel 4.6), sind die Geburtsjahrgänge bis 1940 vom Schulgeld und bis 1950 von Studiengebühren betroffen. Der Einfluss verschiedener Varianten unlängst eingeführter und möglicher zukünftiger Studiengebühren auf die Renditen der jüngsten Kohorten wird im folgenden Unterkapitel diskutiert. Für die Abschlüsse im beruflichen Bildungssystem Lehre und Meister wirken sich im Vergleich zum Qualifikationsniveau Ohne die historischen Schulgelder während des Erwerbs eines Realschulabschlusses aus, die die Renditen der betroffenen Kohorten um etwa 0,2 bis 0,3 Prozentpunkte mindern (Abbildung 42).

Abbildung 42: Partieller Renditeeffekt von Ausbildungsgebühren

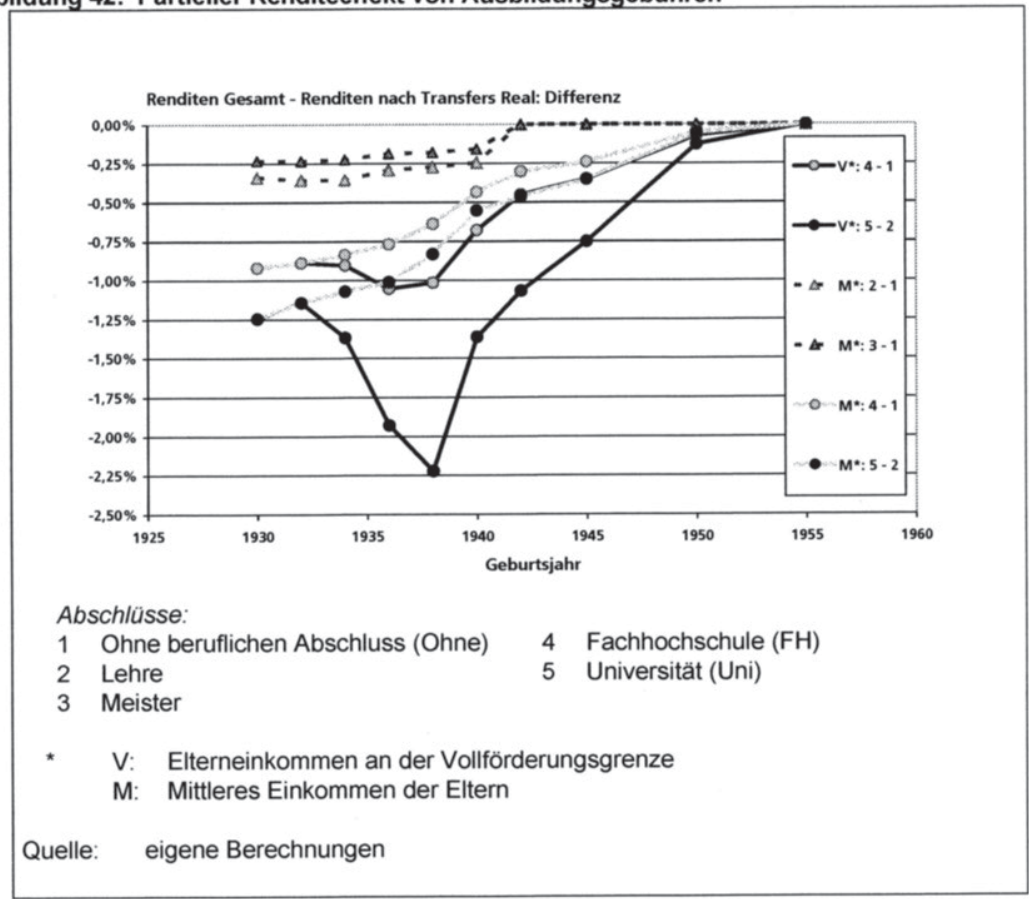

Für Abschlüsse an Hochschulen, bei denen neben Schulgeldern auch Studiengebühren anfallen, resultieren stärkere partielle Renditeeffekte, deren Ausprägung von der Höhe des angenommenen Elterneinkommens abhängt. Ausgehend von den höheren Renditen nach Transfers bei Elterneinkommen an der Vollförderungsgrenze liegen die partiellen Renditeeffekte der Ausbildungsgebühren bei bis zu -2,3 Prozentpunkten (Uni-Lehre, Geburtsjahr 1938). Dieselben Ausbildungsgebühren verringern die deutlich niedrigere Rendite nach Transfers im Mittelstandsloch für diese Konstellation hingegen nur um -1,0 Prozentpunkte. Abgesehen von mit den starken Schwankungen bei der Ausbildungsförderung einhergehenden Irregularitäten zeigt sich über die von Ausbildungsgebühren betroffenen Kohorten ein abnehmender 
Renditeeffekt, der mit der in Kapitel 4.6 begründeten Annahme nominal konstanter Ausbildungsgebühren bei steigenden Preisen korrespondiert. Die Renditeminderung nimmt bei mittlerem Elterneinkommen von etwa 1,3 bis 0,9 Prozentpunkten monoton ab auf Werte von zuletzt unter 0,4 Prozentpunkten.

Nach den einzelnen Effekten der in ihrer zeitlichen Entwicklung und ihrer Renditerelevanz recht unterschiedlichen politischen Variablen (Abgaben, Renten, Transfers, Ausbildungsgebühren) bleibt noch ihre Gesamtwirkung zu ermitteln, die sich aus der Differenz der Renditen ohne weitere staatliche Eingriffe (Bruttorenditen) und der Gesamtrenditen unter Einschluss aller betrachteter Größen ergibt. In Hinblick auf letztere wurde auf den Einfluss des Elterneinkommens hingewiesen, der vor allem bei geförderten Ausbildungen gravierend sein kann. Abbildung 43 und Abbildung 44 geben die Bruttorenditen (Brutto) und die Gesamtrenditen wieder, die sich mindestens (Gesamt min.) bzw. höchstens (Gesamt max.) ergeben. Die niedrigere Gesamtrendite gilt für minimale bildungsbedingte Transfers (bei mittleren Elterneinkommen), die andere für maximale (bei Elterneinkommen an der Vollförderungsgrenze).

Abbildung 43: Reale Brutto- und Gesamtrenditen bei beruflichen Abschlüssen
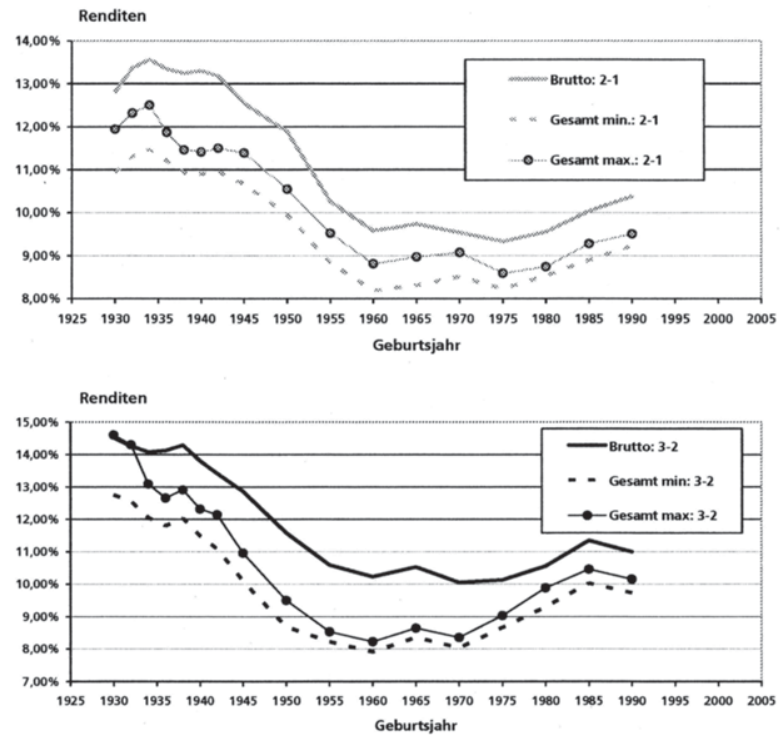

Abschlüsse:

1 Ohne beruflichen Abschluss (Ohne) 3 Meister

2 Lehre

Quelle: eigene Berechnungen 
Sowohl für berufliche als auch akademische Abschlüsse ähneln die zeitliche Entwicklung von Bruttorenditen und minimalen Gesamtrenditen einander. Die höchsten Renditen erzielen die ältesten Kohorten, danach fallen die Renditen über die $\mathrm{Ge}-$ burtsjahrgänge von 1940 bis 1955 stark ab, für die jüngsten Kohorten folgt ein leichter Anstieg. Als Hauptdeterminante von Schwankungen der Rentabilität von Humankapitalinvestitionen zeigt sich hiernach die höchstens mittelbar politisch steuerbare Lohnwachstumsrate, Änderungen von Politikvariablen wie der Steuerprogression oder der Familienförderung bewirkten in den letzten Jahrzehnten keine grundlegenden Abweichungen vom durch die Entwicklung der Markteinkommen vorgeprägten Verlauf. Der Anstieg der Bruttorenditen über die jüngeren Kohorten und der damit einher gehende Anstieg der Gesamtrenditen liegt primär an dem angenommenen zukünftigen Lohnwachstum von real 1,5\%, das über der Wachstumsrate der letzten beiden Jahrzehnte liegt. Markante Abweichungen der Entwicklung von Brutto- und Gesamtrenditen sind hingegen bei den maximalen Gesamtrenditen geförderter Ausbildungen festzustellen (Abbildung 44). Ihre Entwicklung wird stark von Gesetzesreformen im Bereich der Ausbildungsförderung geprägt, die vor allem für die Geburtsjahrgänge ab 1935 (Einführung des Honnefer Modells) und ab 1950 (Einführung des BAföG) Renditesprünge mit sich bringen.

Abbildung 44: Reale Brutto- und Gesamtrenditen bei Hochschulabschlüssen

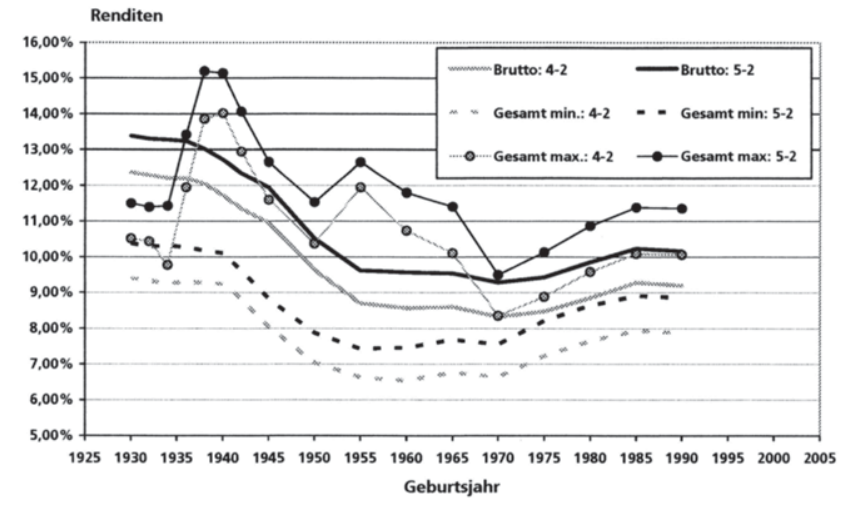

Abschlüsse:

2 Lehre

4 Fachhochschule (FH)

5 Universität (Uni)

Quelle: $\quad$ eigene Berechnungen

Die Betrachtung bis hierhin zeigt einen wesentlichen Einfluss der Entwicklung der Bruttorenditen auf die Gesamtrenditen. Zur weiteren Identifikation des Einflusses des Steuer-Transfer-Systems auf die intertemporalen Veränderungen sind in Abbildung 45 und Abbildung 46 die partiellen Renditeeffekte sämtlicher Politikvariablen dargestellt, die den Differenzen von Brutto- und Gesamtrenditen entsprechen. Die Rendite- 
wirkungen sind wiederum für maximale (Politik max.) und minimale bildungsbedingte Transfers dargestellt (Politik min.). Ergänzend sind als Spannweite die Absolutwerte der Differenzen dieser beiden partiellen Renditeeffekte abgebildet. Hohe Spannweiten zeigen eine starke Abhängigkeit der Gesamtrenditen vom Elterneinkommen und umgekehrt.

Abbildung 45: Reale Renditewirkungen des Steuer-Transfer-Systems (Berufliche Abschlüsse)

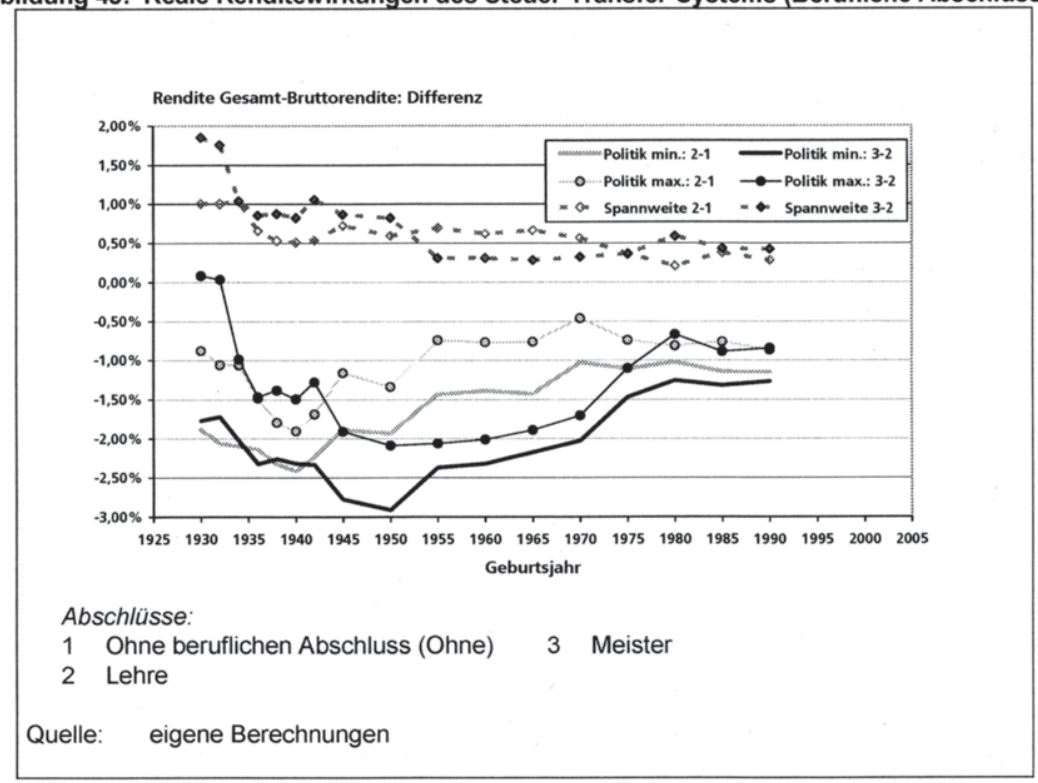

Beim Abschluss einer Lehre (Vergleich Lehre-Ohne) offenbart sich über die Kohorten von 1940 bis 1970 eine tendenziell abnehmende Renditeminderung durch das Steuer-Transfer-System. Während die Gesamtrendite für den Geburtsjahrgang 1940 höchstens 2,4 Prozentpunkte unter der Bruttorendite liegt (Politik min., 1940), ergeben sich für die Kohorten ab 1970 Werte zwischen 1,0 und 1,1 Prozentpunkten. Bei höheren bildungsbedingten Transfers fällt der Keil zwischen Brutto- und Gesamtrendite etwas niedriger aus, er schwankt zwischen 1,9 (Politik max., 1940) und 0,5 Prozentpunkten (Politik max., 1970). Die Spannweite der Wirkungen des SteuerTransfer-Systems über die Elterneinkommen nimmt dabei im Zeitverlauf ab, nach Werten von 1,0 Prozentpunkten für die ersten Kohorten resultieren zuletzt Beträge zwischen 0,2 und 0,3 Prozentpunkten. Zu beachten ist, dass beim Vergleich LehreOhne die bildungsbedingten Transfers in der Regel mit dem Elterneinkommen steigen, eine abnehmende Spannweite mithin schrumpfende Vorteile von Auszubildenden einkommensstarker Eltern bedeutet. Für den Abschluss einer Lehre ergeben sich für die jüngste Kohorte im historischen Vergleich recht geringe Renditeminderungen in einer Größenordnung von rund einem Prozentpunkt, bei einer Bruttorendite von $10,4 \%$ liegen die Gesamtrenditen zwischen 9,2\% und 9,5\%. Für einen auf einer Lehre aufbauenden höheren beruflichen Abschluss (Vergleich Meister- 
Lehre) gelten vergleichbare Aussagen. Auch hier ergeben sich sinkende Spannweiten, denen eine abnehmende Spreizung bildungsbedingter Transfers zu Gunsten höherer Elterneinkommen entspricht. Ebenfalls zeigen sich relativ moderate Renditeminderungen durch Steuern und Transfers für den Geburtsjahrgang 1990 von etwa 0,9 bis 1,3 Prozentpunkten, aus dessen Bruttorendite von $11,0 \%$ eine Gesamtrendite von $9,7 \%$ bis $10,1 \%$ folgt. Ab der Kohorte 1950, für die der Keil zwischen Brutto- und Gesamtrendite zwischen 2,1 und 2,9 Prozentpunkten betrug, werden die Renditen beim Vergleich Meister-Lehre durch das Steuer-Transfer-System in zunehmend geringerem Umfang geschmälert.

Gesamtrenditen von Hochschulabschlüssen gegenüber dem Abschluss einer Lehre (Fachhochschule-Lehre, Uni-Lehre) liegen für die ältesten betrachteten Kohorten bei niedrigen bildungsbedingten Transfers um rund 3,0 Prozentpunkte unter den Bruttorenditen (Politik min.). Über die Kohorten von 1945 bis 1975 fällt dieser Wert kontinuierlich und liegt für ab 1975 Geborene bei 1,2 bis 1,3 Prozentpunkten (Abbildung 46). Unter Renditegesichtspunkten haben negative Anreizwirkungen des Steuer-TransferSystems, auf eine Hochschulausbildung zu verzichten, damit für Auszubildende, die keinen Anspruch auf Ausbildungsförderung aufweisen, deutlich abgenommen.

Abbildung 46: Reale Renditewirkungen des Steuer-Transfer-Systems (Hochschulabschlüsse)

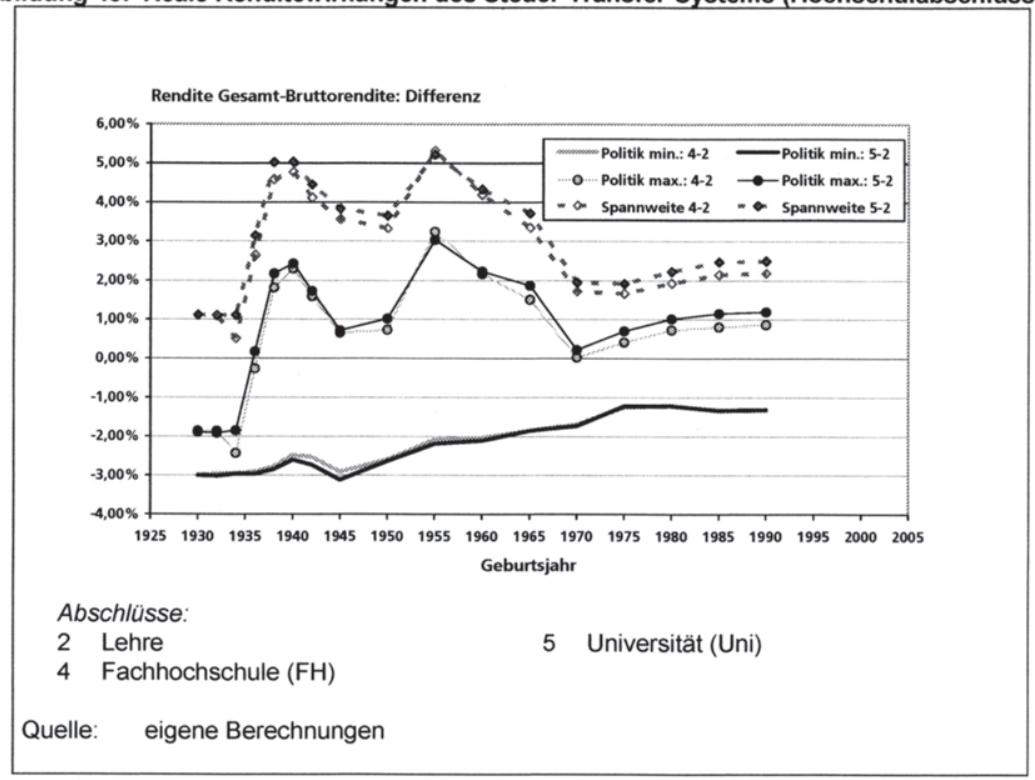

Bei niedrigeren Elterneinkommen, aus denen ein positiver Förderungsanspruch resultiert, folgt die uneinheitliche Entwicklung im Wesentlichen aus den verschiedenen Reformen der Ausbildungsförderung. Die Gesamtrenditen liegen seit deren Einführung durchgehend über den Bruttorenditen, die politische Gestaltung führt somit zu stärkeren Bildungsanreizen als die marktlichen Bildungsprämien allein (positive 
partielle Renditeeffekte in der Variante Politik max.). Nach einem Minimum von etwa plus 0,1 Prozentpunkten für den Geburtsjahrgang 1970 steigen die partiellen Renditeeffekte über die jüngsten Kohorten monoton an und liegen für 1990 Geborene bei etwa +1,0 Prozentpunkten. Im Vergleich zu den Kohorten vor 1970, für die sich Effekte von bis $z u+3,2$ Prozentpunkten ergeben, ist dieser Wert eher niedrig. Die Spannweiten der partiellen Renditeeffekte in Abhängigkeit vom Elterneinkommen liegen zuletzt bei etwa 2,2 bis 2,5 Prozentpunkten, die Gesamtrendite von Auszubildenden mit maximalen Transfers überschreitet die Rendite bei minimalen Transfers also um über 2 Prozentpunkte. Für Kohorten vor 1970 fiel diese Spreizung mit über drei und bis zu fünf Prozentpunkten deutlich höher aus. ${ }^{202}$ Eine relativ geringe Spannweite zu Gunsten von Auszubildenden mit niedrigerem Elterneinkommen weist auf eine weniger ausgeprägte Ausrichtung bildungsbedingter Transfers auf Einkommensschwächere hin. Unter dem geltenden Recht fallen die Gesamtrenditen von geförderten Auszubildenden zwar um gut zwei Prozentpunkte höher aus als bei Nichtgeförderten, so dass über bildungsbedingte Transfers ein selektiver zusätzlicher Ausbildungsanreiz geschaffen wird. Unter früheren Rechtsständen fiel dieser zusätzliche Anreiz jedoch größer aus, so dass die damalige Politikgestaltung tendenziell stärker auf eine höhere Bildungsbeteiligung von einkommensschwächeren Auszubildenden hinwirkte.

Aus den Entwicklungen der Bildungsrenditen über die Kohorten von 1930 bis 1990 lassen sich vorrangig zwei Ergebnisse festhalten: Die marktlichen Erträge von Bildungsinvestitionen fallen als Folge gesunkener Lohnwachstumsraten für die jüngsten Kohorten deutlich niedriger aus als für die ältesten, wobei die Bruttorenditen unter den angenommenen zukünftigen Lohnniveaus moderat ansteigen. Zusätzlich wirkt das Steuer-Transfer-System in abnehmendem Umfang renditemindernd, so dass die Gesamtrenditen stärker zunehmen als die Bruttorenditen. Ohne Berücksichtigung der Ausbildungsförderung wurde der Keil zwischen Brutto- und Gesamtrenditen für alle einbezogenen Ausbildungsniveaus über die betrachteten Geburtsjahre hinweg deutlich reduziert. Für die ältesten Kohorten waren Humankapitalinvestitionen nach diesen Ergebnissen vor allem auf Grund hohen Lohnwachstums rentabel, für die jüngeren Kohorten setzt verstärkt die sinkende Nettobelastung von bildungsbedingten Mehreinkommen Investitionsanreize. Bildungsbedingte Transfers kommen im Status Quo zwar vor allem Auszubildenden mit ärmeren Eltern zu Gute, allerdings wirken frühere Rechtsstände gezielter auf eine soziale Staffelung hin.

${ }^{202}$ Für die Kohorten bis etwa 1935, die nicht oder nur kurzzeitig Ausbildungsförderung erhalten konnten, besteht wie bei den beruflichen Abschlüssen ein positiver Zusammenhang zwischen Elterneinkommen und bildungsbedingten Transfers. Die Spannweiten für diese Jahrgänge von rund einem Prozentpunkt zeigen folglich eine um diesen Betrag höhere Gesamtrendite für Auszubildende mit einkommensstarken Eltem an. 


\subsubsection{Renditeeffekte aktueller Studiengebühren}

Wie bei den historischen Gebühren bis 1970 lässt sich prüfen, in welchem Umfang Bildungsrenditen von Hochschulabschlüssen bei zukünftiger Gebührenpflicht sinken. Hierfür wird zunächst der typische Betrag von 500 Euro je Semester angesetzt, der von verschiedenen Bundesländern angestrebt wird. Nach gegenwärtiger Planung ist davon auszugehen, dass rund $70 \%$ der Studierenden an deutschen Hochschulen ab dem Jahr 2008 allgemeine Studiengebühren dieser Größenordnung zu entrichten haben (vgl. Kapitel 4.6). Eventuelle landesspezifische Regelungen in Form von Erlassen oder subventionierten Darlehen -deren konkrete Ausgestaltungen bisher auch erst teilweise feststehen- bleiben unberücksichtigt, so dass die ermittelten Renditeminderungen eine Obergrenze bilden, die bei Fehlen kompensierender Maßnahmen gilt. Weiterhin wird unterstellt, dass die Gebühren mit der angenommenen Preissteigerungsrate von $1,5 \%$ in den nächsten Jahren wachsen. Für den Geburtsjahrgang 1990, bei dessen Hochschulbesuch ab dem Jahr 2010 in diesem Szenario durchgehend Studiengebühren von (fortgeschriebenen) 500 Euro je Semester anfallen, sinken die Gesamtrenditen eines Hochschulabschlusses gegenüber einer Lehre (Vergleiche FH-Lehre und Uni-Lehre) je nach Höhe der bildungsbedingten Transfers um rund 0,3 bis 0,5 Prozentpunkte (Tabelle 12). Die Gesamtrenditen für 1990 Geborene betragen nach Einführung der Gebühren bei minimalen Transfers 7,6\% (FH-Lehre) bzw. 8,5\% (Uni-Lehre), bei maximalen Transfers 9,6\% (FH-Lehre) bzw. 10,8\% (Uni-Lehre). Nahezu dieselben vier Gesamtrenditen ergeben sich für den Geburtsjahrgang 1980, der nicht von Studiengebühren betroffen war. Die Einführung von Studiengebühren in der diskutierten Höhe von 500 Euro je Semester bringt hiernach keine Einschnitte in einem Umfang mit sich, der nicht auch durch Schwankungen anderer renditerelevanter Einflüsse auftritt, zu denen neben dem Lohnwachstum die Steuerbelastung oder die Darlehenskonditionen des BAföG zählen.

Tabelle 12: Reale partielle Renditeeffekte zukünftiger Studiengebühren (Geburtsjahrgang 1990, in Prozent)

\begin{tabular}{|c|c|c|c|c|c|c|}
\hline \multirow{2}{*}{ Vergleich ${ }^{\star}$} & \multicolumn{2}{|c|}{ Renditen (real) } & \multicolumn{4}{|c|}{ Partieller Renditeeffekt: Gebühren von ... Euro } \\
\hline & Brutto & Gesamt** & 500 & 1.000 & 2.000 & 4.000 \\
\hline 4-2 (min.) & \multirow{2}{*}{9,2} & 7,9 & $-0,3$ & $-0,6$ & $-1,1$ & $-1,9$ \\
\hline 4-2 (max.) & & 10,1 & $-0,5$ & $-0,9$ & $-1,7$ & $-2,9$ \\
\hline $5-2(\min )$. & \multirow{2}{*}{10,2} & 8,9 & $-0,3$ & $-0,6$ & $-1,1$ & $-2,0$ \\
\hline $5-2(\max )$ & & 11,4 & $-0,5$ & $-1,0$ & $-1,8$ & $-3,1$ \\
\hline \multicolumn{7}{|c|}{$\begin{array}{l}2 \text { Lehre } \\
4 \text { Fachhochschule (FH) } \\
\text { * min./ max.: Renditen bei minimalen bzw. maximalen bildungsbedingten Transfers } \\
\text { ** Gesamtrendite ohne Gebühren }\end{array}$} \\
\hline
\end{tabular}

Im Vergleich zu den bis 1970 erhobenen Studiengebühren sind die partiellen Renditeeffekte von $-0,3$ bis $-0,5$ Prozentpunkten eher moderat. Für den Geburtsjahrgang 1945 resultieren aus den damaligen Gebühren etwas höhere Renditeeinbußen von 
$-0,4$ bis $-0,7$ Prozentpunkten, für ältere Kohorten ergeben sich stets stärkere Effekte durch Ausbildungsgebühren von häufig über -1,0 Prozentpunkten (vgl. auch Abbildung 42).

Neben dem die derzeitigen Gebührenpläne verschiedener Länder charakterisierenden Betrag von 500 Euro je Semester sind in Tabelle 12 auch die partiellen Renditeeffekte höherer Gebühren aufgeführt. Betrachtet wurden Werte von bis zu 4.000 Euro je Semester. Bei laufenden Grundmitteln von durchschnittlich rund 7.300 Euro je Studierenden im Jahr 2003 überschreiten Gebühren dieser Höhe geringfügig die öffentlich getragenen Ausbildungskosten, so dass ein Betrag von 4.000 Euro je Semester weitgehend einem privat finanzierten Studium entspricht. ${ }^{203}$ Eine Verdopplung der geplanten Gebühren auf 1.000 Euro je Semester führt hiernach zu einem näherungsweise ebenfalls doppelt so hohen partiellen Renditeeffekt von $-0,6$ bis $-1,0$ Prozentpunkten. Innerhalb des betrachteten Bereichs sinken die Gesamtrenditen jedoch unterlinear, kostendeckende Gebühren von 4.000 Euro je Semester senken die Renditen um -1,9 bis -3,1 Prozentpunkte. Ohne Ausbildungsförderung -also bei mittleren bis hohen Elterneinkommen- fallen in diesem Fall die Gesamtrenditen um rund zwei Prozentpunkte, bei geförderten Auszubildenden (Elterneinkommen bis zur Vollförderungsgrenze) um etwa drei Prozentpunkte.

Generell bewirken Gebühren ohne soziale Differenzierung eine abnehmende Spannweite der Gesamtrenditen über die vom Elterneinkommen abhängenden bildungsbedingten Transfers, der Renditevorteil von geförderten Auszubildenden sinkt. Während sich die Spannweite der Gesamtrenditen eines gebührenfreien Studiums für die 1990 Geborenen auf 2,5 Prozentpunkte (Vergleich Uni-Lehre) beläuft, beträgt der Wert bei Gebühren von 4.000 Euro je Semester 1,4 Prozentpunkte. Von der Einführung von Studiengebühren ohne soziale Komponente geht demnach ein unter Renditeaspekten größeres Investitionshemmnis für Transferempfänger aus, deren Bildungsrenditen stärker beeinträchtigt werden.

${ }^{203} \mathrm{Zu}$ den laufenden Grundmitteln s. Statistisches Bundesamt (2005b), S. 171. Der Betrag entspricht in etwa den Ausgaben für Hochschulen je Studierenden von 7.100 Euro (2003), der für Lehrtätigkeiten anfällt (s. Statistisches Bundesamt (2006c)). Studiengebühren von etwa 3.500 bis 4.000 Euro je Semester können entsprechend dann als angemessen gelten, wenn die auf die Ausbildung entfallenden Kosten der Hochschulen von den Studierenden selbst getragen werden sollen, während Forschungstätigkeiten anderweitig finanziert werden. Hierüber hinaus gehende Studiengebühren bedeuten eine überproportionale Beteiligung von Studierenden an der Finanzierung nicht ausbildungsbezogener Hochschulausgaben. Ein Modell Ausbildungskosten deckender Studiengebühren mit dem konstanten Durchschnittsbetrag von 3.500 bis 4.000 Euro impliziert allerdings auf Grund der zwischen Hochschularten und Fächergruppen stark variierenden Kosten massive Quersubventionierungen zwischen Studierenden. Je nach Art des Studiums wären zum Teil deutlich höhere oder niedrigere Gebühren erforderlich, wenn Studierende ihre Ausbildungskosten selbst tragen sollen. 


\subsubsection{Vergleich verschiedener Ergebnisse zu internen Ertragsraten von Bildung}

Für die Kohorte 1990 bietet sich ein Vergleich der Ergebnisse des STM mit anderen aktuellen Schätzungen von internen Ertragsraten an, die oben vorgestellt wurden. Wie in den wenigen Studien, die interne Ertragsraten von Bildung in Deutschland ausweisen, entsprechen die mit dem STM ermittelten Ergebnisse für den Geburtsjahrgang 1990 einer auf einer Zeitpunktanalyse fußenden Projektion der zukünftigen Entwicklung. Als Hauptunterschiede des hier gewählten Ansatzes zu bestehenden Untersuchungen ist einerseits die wesentlich detailliertere Abbildung institutioneller Regelungen im STM zu nennen. Andererseits sind in dessen Ergebnissen keine qualifikationsabhängigen Arbeitslosigkeitsrisiken und keine Realtransfers enthalten. Um vergleichbare Ergebnisse zur Wirkung von Transfers zu erhalten, wurden für die Kohorte 1990 vom sonst verfolgten Ansatz abweichend zusätzlich durchschnittliche öffentlich getragene Ausgaben für Bildungsteilnehmer den Transfers zugerechnet. Für ein Hochschulstudium wird ein Realtransfer von 7.300 Euro je Studienjahr angesetzt (vgl. hierzu Fußnote 203), Realtransfers während einer Lehre belaufen sich auf fortgeschriebene 2.100 Euro je Schuljahr. Dieser Betrag entspricht den offentlichen Ausgaben je Schüler an Berufsschulen im dualen System im Jahr 2002. ${ }^{204}$

In Tabelle 13 sind die Ergebnisse des STM den Werten aus den Untersuchungen von Blöndal et al. (2002), die mit von der OECD (2003) publizierten Werten nahezu identisch sind, und de la Fuente und Jimeno (2005) gegenübergestellt. ${ }^{205}$ Bei den mit dem STM betrachteten Transfers sind zum einen die bereits vorgestellten Unter- und Obergrenzen ausgewiesen, zum anderen wurden in einer dritten Variante zusätzlich die Realtransfers berücksichtigt. Für Abschlüsse auf dem Niveau der Sekundarstufe II sind die Renditen aus dem Vergleich Lehre-Ohne aufgeführt, für tertiäre $A b-$ schlüsse steht der Vergleich Uni-Lehre. Da das Ausmaß der partiellen Renditeeffekte einzelner Politikvariablen recht stark vom Niveau der Bruttorenditen und der Reihenfolge abhängen kann, in der Einkommens- und Kostengrößen in die Einkommensprofile einbezogen werden, sind Vergleiche zwischen verschiedenen Studien nur mit Vorbehalten zu interpretieren. Bei den Bruttorenditen ergeben sich beim STM zumindest für tertiäre Abschlüsse recht hohe Werte von $10,2 \%$, für einen Abschluss der Sekundarstufe II liegt der Wert von 10,4\% nahe bei dem Ergebnis von Blöndal et al. (2002). Die niedrigere Bruttorendite de la Fuentes und Jimenos (2005) von 8,3\% lässt sich zum Teil durch ihre Annahme einer Lohnwachstumsrate von 1,0\% (STM: 1,5\%) und die inrem Modell zu Grunde liegende Mincer-Rendite von 7,85\% (STM: rund $9 \%$ ) erklären.

204 Statistisches Bundesamt (2005b), S. 169. Die öffentlichen Ausgaben je Schüler für Berufsschulen im dualen System, an denen stets Teilzeitunterrichtet erteilt wird, liegen deutlich unter den öffentlichen Ausgaben an allgemein bildenden Schulen.

205 Die Werte von Blöndal et al. (2002), die nach dem Geschlecht differenzierte Renditen ausweisen, beziehen sich auf Männer. In die Tabelle sind aus den beiden Studien nur die Teilergebnisse aufgenommen worden, zu denen das STM Vergleichswerte bietet (vgl. Tabelle 9). 
Tabelle 13: Vergleich von Befunden zu internen Ertragsraten von Bildung in Deutschland und ihrer Zusammensetzung (in Prozent)

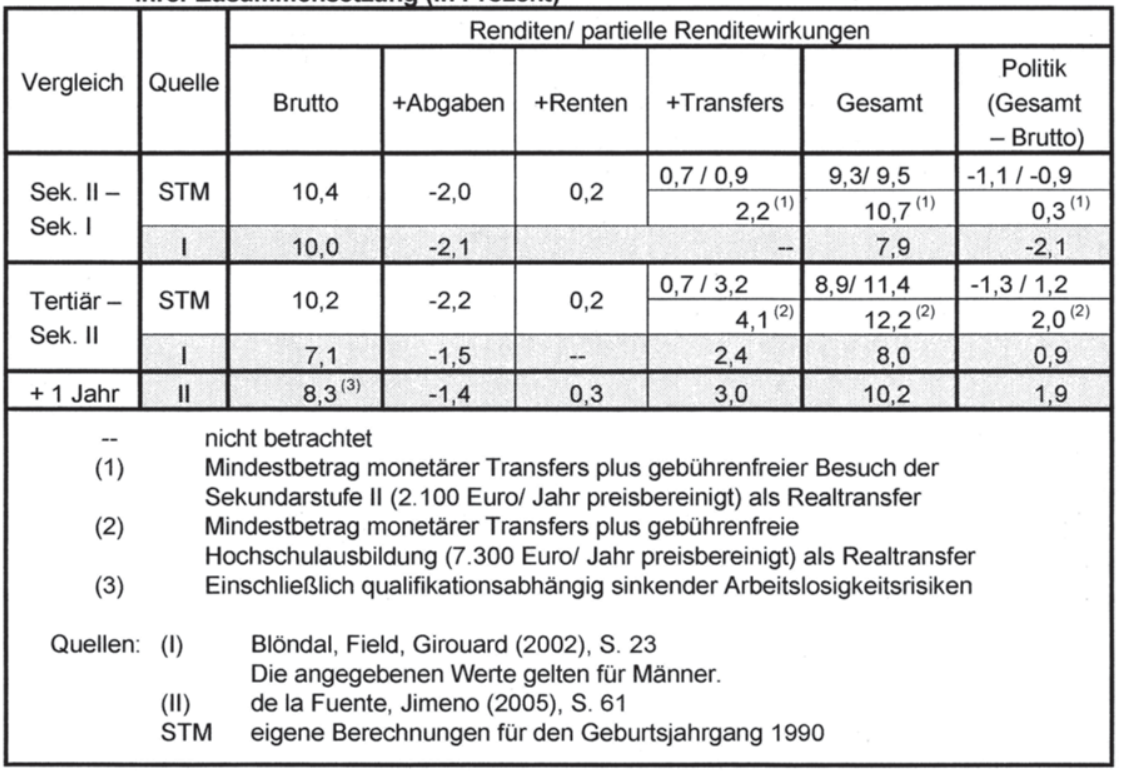

Die Renditeminderung durch Abgaben fällt beim STM für alle Qualifikationsniveaus recht homogen aus und liegt bei etwa $-2,0$ bis $-2,2$ Prozentpunkten. Der einem progressiven Steuersystem tendenziell zuwiderlaufende Befund von Blöndal et al. (2002) einer stärkeren Minderung bei niedrigerer Qualifikation (-1,5 Prozentpunkte bei tertiären Abschlüssen gegenüber -2,1 Prozentpunkten bei Abschlüssen der Sekundarstufe II) wird hier nicht repliziert. Im Vergleich zu Blöndal et al. (2002) und de la Fuente und Jimeno (2005), von denen letztere einen Wert von -1,4 Prozentpunkten angeben, deutet das STM auf einen größeren Einfluss des Steuersystems auf die Bildungsrenditen hin. In Hinblick auf die Bedeutung von Rentenzahlungen für Humankapitalinvestitionen ergibt sich übereinstimmend mit de la Fuente und Jimeno (2005) ein nur geringer Effekt ( $+0,2$ bzw. +0,3 Prozentpunkte).

Nach den Ergebnissen des STM erhöhen monetäre Transfers bei allen Ausbildungen die Bildungsrenditen um mindestens rund 0,7 Prozentpunkte, bei einer Förderung nach dem BAföG steigt der Effekt der monetären Transfers auf bis zu 3,2 Prozentpunkte. Zusammen mit Realtransfers liegt der partielle Renditeeffekt für den Sekundarstufe II-Abschluss bei mindestens 2,2 Prozentpunkten (davon 0,7 Prozentpunkte durch monetäre, 1,5 Prozentpunkte durch Realtransfers). Auf einen tertiären Abschluss wirken sich die Realtransfers noch weitaus stärker aus, insgesamt erhöhen die Transfers die Ertragsrate um mindestens 4,1 Prozentpunkte (davon 3,4 Prozentpunkte für Realtransfers). Das Ergebnis, dass Bildungsrenditen im Tertiärbereich stärker von Realtransfers begünstigt werden als im Sekundarbereich, ist auf Grund der tendenziell mit der Qualifikation ansteigenden öffentlichen Ausgaben je Ausbildungsjahr zu erwarten. De la Fuente und Jimeno (2005), die im Sinne des Schoo- 
ling-Modells von der Ausbildungsart unabhängige Renditen eines zusätzlichen Schuljahres betrachten, geben für das gesamte Bildungssystem einen partiellen Renditeeffekt von Transfers (monetäre Transfers und Realtransfers insgesamt) an, der mit 3,0 Prozentpunkten in etwa mittig zwischen den beiden Werten von 2,2 und 4,1 Prozentpunkten liegt, ${ }^{206}$ die hier ermittelten Ergebnisse erscheinen mit dem von de la Fuente und Jimeno (2005) grundsätzlich vereinbar. Allerdings weist die Betrachtung mit dem STM darauf hin, dass der globale Durchschnittswert für ein Ausbildungsjahr, den de la Fuente und Jimeno (2005) herleiten, je nach Qualifikationsniveau deutlich nach oben oder unten abweichen kann.

Blöndal et al. (2002) berücksichtigen als Transfers hingegen ausschließlich die Ausbildungsförderung („Public student support") von Studenten, Realtransfers oder bildungsbedingte Familientransfers bleiben ausgeblendet, Transfers für Ausbildungen im Sekundarbereich werden ignoriert. Als Nettoeffekt von Transfers bei tertiären Abschlüssen bestimmen sie einen Betrag von 2,4 Prozentpunkten, der sich aus einer Renditeminderung durch direkte Ausbildungskosten von - 0,3 Prozentpunkten und einer Renditesteigerung durch Ausbildungsförderung von 2,7 Prozentpunkten zusammensetzt, Darlehensrückzahlungen wurden in Rechnung gestellt. Durch die Ausbildungsförderung nach dem BAföG ergibt sich mit dem STM ein ähnlich hoher partieller Renditeeffekt von 2,5 Prozentpunkten (3,2 Prozentpunkte für monetäre Transfers insgesamt, davon 0,7 Prozentpunkte für Transfers an Eltern), ohne Darlehensrückzahlungen würde der Wert um rund 0,4 auf 2,9 Prozentpunkte ansteigen. Allerdings unterstellen Blöndal et al. (2002) Eltern mit Durchschnittseinkommen, während beim STM die mit unterdurchschnittlichem Elterneinkommen einhergehende Höchstförderung zu Grunde gelegt wurde. ${ }^{207}$ Der Befund von Blöndal et al. (2002) ist nach den hier ermittelten Ergebnissen mit der Annahme einer Vollförderung kompatibel, beim von Blöndal et al. (2002) angenommenen Einkommensniveau läge der partielle Renditeeffekt des BAföG deutlich unter ihrem Wert. Im Jahr 2006 betrug der durchschnittliche Förderungsbetrag des Studenten-BAföG von 375 Euro je Monat etwa 2/3 der mit dem STM betrachteten Vollförderung. ${ }^{208}$ Für eine Förderung in Höhe von 375 Euro - die bei dem Einkommensniveau von Blöndal et al. (2002) auch noch eher überzogen erscheint- sinkt der partielle Renditeeffekt des BAföG beim STM von 2,5 auf 1,6 Prozentpunkte. Die von Blöndal et al. (2002) und ebenfalls von der OECD (2003) angegebene partielle Renditewirkung der Ausbildungsförderung für die Bildungsrenditen in Deutschland lässt sich hiernach zwar grundsätzlich mit dem BAföG erzielen, allerdings nur bei maximaler Förderung, die nicht bei dem angegebenen sondern nur bei niedrigeren Elterneinkommen gewährt wird. Zudem ließe sich bei einer Gefördertenquote, die in den letzten Jahren bei maximal $25,6 \%$ lag, argumentieren, dass der Durchschnittsstudent als Nichtgeförderter zutreffend typisiert ist,

206 De la Fuente und Jimeno (2005) rechnen mit gewichteten Durchschnittsausgaben je Ausbildungsjahr, die 2/3 der Ausgaben im Sekundarbereich II plus 1/3 der Ausgaben im Tertiärbereich entsprechen. (de la Fuente, Jimeno (2005), S. 50)

207 Blöndal et al. (2002) definieren inr Durchschnittseinkommen als Einkommen von Doppelverdiendern, die jeweils den Lohn eines „average production worker" beziehen (Blöndal, Field, Girouard (2002), S. 19). In Deutschland entspricht dieser Lohn in etwa dem Durchschnittsentgelt der gesetzlichen Rentenversicherung, bei Doppelverdienern im Jahr 2002 mithin etwa 57.000 Euro.

208 Statistisches Bundesamt (2006d), Tabelle 1.1 
der mittlere Renditeeffekt des BAföG demnach bei null liegt. ${ }^{209}$ Insofern erscheint auch die Implikation unzutreffend, mit der Betrachtung von Kindern durchschnittlich verdienender Eltern ebenfalls die durchschnittliche Wirkung der Ausbildungsförderung zu erfassen.

Die Gesamtwirkung der betrachteten staatlichen Maßnahmen auf die Ertragsraten ist beim STM positiv, wenn Realtransfers in Form unentgeltlicher Ausbildung berücksichtigt werden. Für Abschlüsse auf Sekundarstufe II-Niveau liegt die Gesamtrendite leicht über der Bruttorendite (+0,3 Prozentpunkte), für tertiäre Abschlüsse mit mindestens +2,0 Prozentpunkten sogar recht stark. Die Ausgestaltung des Bildungs- und des Steuer-Transfer-Systems würde Humankapitalinvestitionen entsprechend stimulieren, wobei insbesondere Hochschulabschlüsse begünstigt werden. Auch de la Fuente und Jimeno (2005) kommen zu dem Ergebnis, dass Humankapitalinvestitionen in Deutschland -und ebenso in der Mehrzahl der von innen untersuchten EU-Länder- effektiv subventioniert werden, für das Bildungssystem insgesamt finden sie eine Renditesteigerung durch Abgaben, Renten und Transfers von 1,9 Prozentpunkten. ${ }^{210}$ Nach den Ergebnissen des STM liegt dieser Wert eher am oberen Rand der nach Ausbildungsarten differenzierten Renditen, für Abschlüsse im Sekundarbereich wurde hier ein deutlich niedrigerer Wert bestimmt. Das Resultat einer Subventionierung von Humankapital beruht dabei auf der weitgehend öffentlichen Finanzierung der direkten Ausbildungskosten, ohne Realtransfers liegen die Gesamtrenditen um etwa -1,3 bis -0,9 Prozentpunkte unter den Bruttorenditen, nur bei einer geförderten Ausbildung kehrt sich die Gesamtwirkung um (bis zu +1,2 Prozentpunkte).

209 Diese Gefördertenquote des Studenten-BAföG bezieht sich nur auf die Anspruchsberechtigten und nicht auf die Gesamtheit der Studierenden ( $v g l$. zur Abgrenzung der Anspruchsberechtigten Kapitel 4.5) (s. Deutscher Bundestag (2007a), S. 8). Da Blöndal et al. (2002) ausschließlich grundsätzlich Anspruchsberechtigte Studenten betrachten, erscheint diese Quote für inre Bezugspopulation durchaus angemessen.

210 Durch die mit dem STM nicht analysierte Arbeitslosenversicherung fällt dieser Wert um 0,8 auf 1,1 Prozentpunkte. Diese Renditesenkung beruht auf den nicht nach Risiken gestaffelten Beitragssätzen, während die Wahrscheinlichkeit der Leistungsinanspruchnahme mit zunehmender Qualifikation fällt. 


\subsection{Zusammenfassung}

Empirische Untersuchungen zur Rentabilität von Humankapitalinvestitionen basieren überwiegend auf einer auf Mincer zurückgehenden Regressionsgleichung, deren Parameter regelmäßig als Bildungsrenditen interpretiert werden. Schätzungen für Deutschland, die sich über den Zeitraum seit den 1970er Jahren erstrecken, deuten dabei auf recht stabile Renditen hin; ein auf Grund der deutlichen Höherqualifizierung über die letzten Jahrzehnte ( $\mathrm{vgl}$. Abbildung 8 ) tendenziell zu erwartender Renditerückgang zeichnet sich nicht ab. Nach diesem Ansatz bestimmte Bildungsrenditen weisen allerdings erstens regelmäßig den empirischen Nachteil auf, die von Mincer getroffenen restriktiven Annahmen ungeprüft als erfültt vorauszusetzen. Zweitens konzentrieren sie sich auf die marktlichen Wirkungen von Bildungsinvestitionen, ohne das Steuer-Transfer-System einzubeziehen. Mit den in diesem Kapitel dargestellten Bildungsrenditen wurden diese beiden Punkte aufgegriffen. Ausgehend von der Barwertformel wurden zunächst interne Brutto-Ertragsraten bestimmt und anschließend sequenziell renditerelevante Faktoren in die Barwertbildung einbezogen. Als politisch gesteuerte Einflüsse wurden die Renditewirkungen von Abgaben und verschiedenen Transfers untersucht. Im Zentrum der Berechnungen dieses Kapitels stehen die Fragen, welcher Einfluss von den einzelnen Elementen des Steuer-Transfer-Systems auf die Rentabilität von Humankapitalinvestitionen ausgeht und wie sich dieser über die letzten Jahrzehnte entwickelt hat. Eine Grundlage bilden dabei die in Kapitel 3 vorgestellten (Brutto-)Lebenseinkommensprofile für Angehörige der Kohorten von 1930 bis 1990, die auf eine Mincer-Schätzung zurückgreifen. Mit Verweis auf den Befund recht konstanter Mincer-Renditen in Deutschland werden deren Parameter als zeitlich invariant angenommen, so dass konstante Bildungsrenditen im Sinne einer Mincer-Gleichung zu den wesentlichen Inputgrößen bei der Bestimmung der Brutto- und Nettoertragsraten in diesem Kapitel zählen.

Trotz der konstanten Mincer-Parameter ergeben sich bereits bei den Bruttorenditen deutliche Unterschiede zwischen Angehörigen der Kohorten von 1930 bis 1990, die realen Renditen weisen eine Spannweite von etwa drei bis vier Prozentpunkten auf. Ursache dieser Streuung ist die Entwicklung der Lohnwachstumsrate: Die interne Ertragsrate von Bildungsinvestitionen setzt sich additiv zusammen aus einer Bildungsprämie, die bildungsbedingte Produktivitätsunterschiede am Arbeitsmarkt reflektiert, und der globalen Lohnwachstumsrate. Bei einem starken Wachstum fallen die für Bildungsentscheidungen typischen Opportunitätskosten zum potenziellen Beginn der Erwerbsphase geringer ins Gewicht. Mincer-Schätzungen auf der Grundlage von Querschnittsdaten erfassen jedoch nicht den Einfluss des Lohnwachstums, so dass der Befund recht konstanter Mincer-Renditen durchaus erhebliche Schwankungen der Rentabilität von Humankapitalinvestitionen verdeckt. Aus dem starken Lohnwachstum bis in die 1970er Jahre folgen Renditevorteile für die Kohorten von etwa 1930 bis 1945, die niedrigsten Werte ergeben sich bei den in den 1960er Jahren Geborenen, bei denen sich die geringen historischen Wachstumsraten seit den 1980er Jahren ungünstig auswirken. Von der nicht unmittelbar politisch steuerbaren Wachstumsrate gehen mithin wesentliche bildungsökonomische Effekte aus, wobei ein hohes Wachstum Anreize für Humankapitalinvestitionen impliziert, die über die aus Mincer-Schätzungen bekannten Bildungsprämien hinausgehen. 
Ein zweiter Faktor neben dem Lohnwachstum, dessen Einfluss bereits auf der Ebene der Bruttoeinkommen geprüft wurde, besteht im Qualifikationswandel. Grundgedanke hierfür ist die Abhängigkeit des gesamtwirtschaftlichen Lohnniveaus vom Qualifikationsniveau. Nach dem Konstruktionsprinzip der Lebenseinkommensprofile schlägt sich das Lohnwachstum in den Ertragsraten wie soeben beschrieben nieder. Gleichzeitig trägt jedoch eine Verbesserung der Qualifikationsstruktur des Arbeitsangebotes ihrerseits zur Lohnwachstumsrate bei. Unter dem zu beobachtenden Qualifikationswandel werden die Ertragsraten von Bildung mit dem hier gewählten Ansatz dadurch tendenziell überschätzt. Bei der Konstruktion der Lebenseinkommensprofile wurde daher ein Korrekturfaktor herleitet, über den die Abhängigkeit des Lohnwachstums vom Qualifikationswandel berücksichtigt wird. Mit dieser Korrektur ergeben sich geringfügig niedrigere Bildungsrenditen, ohne dass sich jedoch die vom Lohnwachstum vorgeprägte Entwicklung grundlegend verändert.

Inwieweit der Gesetzgeber über die marktlichen Effekte hinaus auf Bildungsanreize einwirkt, wurde über Nettorenditen ermittelt, die Abgaben (Steuern und Sozialversicherungsbeiträge), Nettorenten, bildungsbedingte Transfers, Ausbildungsgebühren und Realtransfers berücksichtigen. Das Steuer-Transfer-System beeinflusst die Renditen sowohl positiv als auch negativ, indem zum einen die Belastung von bildungsbedingten Mehreinkommen mit Abgaben renditemindernd wirkt und zum anderen verschiedene Formen von Transfers die Renditen anheben. Eine vor allem bei internationalen Vergleichen von Bildungssystemen untersuchte Frage ist dabei, ob Humankapitalinvestitionen effektiv belastet oder subventioniert werden. Über eine getrennte Betrachtung der verschiedenen Formen von Transfers für Bildungsteilnehmer wurde in diesem Kapitel hierüber hinaus untersucht, inwiefern bildungsfördernde Maßnahmen einkommensabhängig wirken, um so gegebenenfalls einer sozialen Selektion im Bildungssystem entgegenzuwirken. Zweiter Effekt dieser Trennung ist, die Bedeutung einzelner Maßnahmen sowohl im aktuellen Recht als auch in der historischen Entwicklung vergleichend gegenüber stellen zu können.

In Hinblick auf die Frage nach der Nettobelastung von Bildungsinvestitionen führen die Berechnungen hier zu dem auch in anderen Studien gefundenen Ergebnis, dass Bildung in Deutschland im Status Quo effektiv subventioniert wird. Vor allem im Hochschulbereich folgen aus Realtransfers in Form gebührenfreier -oder nicht kostendeckend bereit gestellter- Ausbildung zusammen mit monetären Transfers Nettorenditen, die über den rein marktlichen Bruttorenditen liegen. Die Renditeminderungen durch steuerliche Mehrbelastungen fallen geringer aus als die Wirkungen der Transfers. Auch bei beruflichen Ausbildungen ergibt sich tendenziell ein insgesamt positiver Effekt des Steuer-Transfer-Systems, der allerdings schwächer ausgeprägt ist.

Die Entwicklung und Zusammensetzung der Bildungsrenditen der Kohorten von 1930 bis 1990 gibt weiterhin Aufschluss, inwieweit sich die Bildungsanreize aus der geltenden Politik von früheren Rechtsständen unterscheiden. Von der Rentenversicherung gehen durchgängig nur geringe Effekte auf die Rentabilität von Humankapitalinvestitionen aus. Bildungsbedingt höhere Nettorenten fallen zu spät im Lebenszyklus an, um die Bildungsrenditen nennenswert zu beeinflussen. Großzügige bildungsbezogene Transfers im Bereich der Rentenversicherung, wie für in den 
1930er Jahren geborene Versicherte gewährt (vgl. Kapitel 7.2.1), erscheinen daher unter Anreizgesichtspunkten ungeeignet, die Bildungsnachfrage zu stimulieren. Wesentlichere Einflüsse gehen von Senkung und Streichung von Ausbildungsgebühren (Schulgeldern und Studiengebühren) im Zeitraum bis 1970 sowie vom Ausbau der Ausbildungsförderung aus. Neben diesen beiden unmittelbar auf eine erhöhte Bildungsnachfrage abzielenden Entwicklungsrichtungen schlagen sich in den kohortenspezifischen Renditen jedoch auch nicht oder nur mittelbar bildungspolitisch orientierte Reformen nieder. Zum einen wirkt sich der in Kapitel 8 ausführlich untersuchte Ausbau familienpolitischer Transfers aus, die Bildungsteilnehmern auch über die Volljährigkeit hinaus gewährt werden. Zum anderen zeigt sich im Kohortenvergleich für den Status Quo eine niedrige Renditeminderung durch die Besteuerung. Eine im historischen Vergleich nur schwach ausgeprägte Progression des Steuersystems im Status Quo (vgl. hierzu auch Kapitel 9.3.1) impliziert unter dem Aspekt der Rentabilität von Humankapitalinvestitionen ein relativ geringes Hemmnis der Bildungsnachfrage. Für die ältesten betrachteten Kohorten waren Humankapitalinvestitionen nach diesen Ergebnissen vor allem auf Grund eines hohen Lohnwachstums rentabel, für die jüngeren Kohorten folgen Investitionsanreize aus niedrigen Nettobelastungen von bildungsbedingten Mehreinkommen. Die derzeitige (Wieder-)Einführung von Studiengebühren schmälert die Renditen nur geringfügig.

Schließlich weist die separate Betrachtung von familienpolitischen Transfers, Ausbildungsförderung und Ausbildungsgebühren in diesem Kapitel auf einige markante Entwicklungen bei der sozialen Staffelung bildungsfördernder Maßnahmen hin. Zunächst wirken für die ältesten Kohorten keine besonderen Erleichterungen bei niedrigen Elterneinkommen, gegenteilig führt eine auf steuerliche Freibeträge konzentrierte Familienpolitik zu einem positiven Zusammenhang von Elterneinkommen und bildungsbedingten Entlastungen. Bei ihrer Einführung ist die Ausbildungsförderung vergleichsweise großzügig bemessen, was sich in großen Spannweiten der Bildungsrenditen in Abhängigkeit vom Elterneinkommen niederschlägt. Ebenso zeigen sich seit Einführung der Ausbildungsförderung aber auch die Wirkungen unsteter Anpassungen und sich abwechselnder expansiver sowie kontraktiver Gesetzeseingriffe. Die Bildungsrenditen förderungsberechtigter Auszubildender ändern sich bisweilen sprunghaft, wobei von der Förderung nach dem geltenden Recht im historischen Vergleich eher moderate Bildungsanreize ausgehen. Auch führen die jüngst eingeführten allgemeinen Studiengebühren zu einer Annäherung der Bildungsrenditen von Auszubildenden mit niedrigen und hohen Elterneinkommen, so dass zusätzliche Bildungsanreize für niedrige Einkommen tendenziell reduziert werden. In die umgekehrte Richtung wirkt die Anhebung des BAföG durch die ab Herbst 2008 wirksame jüngste Reform, deren Effekte hier allerdings nicht berücksichtigt wurden. Von ihr ist zwar ein unter Renditegesichtspunkten deutlicher zusätzlicher Anreiz zu erwarten, mit dem aber dennoch nicht das Niveau früherer Jahre erreicht wird. 


\section{Inter- und intragenerative Umverteilung durch die ge- setzliche Rentenversicherung}

Über Fragestellungen zur Ausgestaltung der umlagefinanzierten Rentenversicherung in Deutschland sind in den letzten Jahren zahlreiche Arbeiten auf der Grundlage von Rentenbiographien erstellt worden. Sowohl von verschiedenen Gesetzesänderungen stimuliert als auch ihrerseits diese stimulierend, sind vor dem Hintergrund des demographischen Wandels die Auswirkungen diverser Reformszenarien auf die Alterseinkünfte einzelner Kohorten untersucht worden. Ausgehend von dem Grundanliegen, die gesetzliche Rentenversicherung zu stabilisieren, wozu auf Grund sich verschiebender Beitragszahler-Rentner-Relationen Gesetzesanpassungen unerlässlich wirken, werden Reformoptionen regelmäßig an Hand intergenerativer Belastungsverschiebungen beurteilt. Als Maßstab eines gerechten Rentenrechts gilt dabei eine effektive Gleichbehandlung der Generationen, wozu eine Lösung des Zielkonflikts zwischen der Vermeidung von Beitragssatzanstiegen und der Sicherstellung eines hinreichenden Rentenniveaus gefunden werden muss. ${ }^{211}$ Die implizite Rendite der gesetzlichen Rentenversicherung ist dabei ein gebräuchlicher Indikator, inwieweit eine intergenerative Unleichbehandlung vorliegt (Entwicklung der absoluten Höhe der Renditen über Kohorten) und ob Reformmaßnahmen dieser entgegenwirken (Veränderung der Renditen für verschiedene Jahrgänge im Vergleich zur Beibehaltung des Status Quo). ${ }^{212}$ In der Reformdiskussion zur gesetzlichen Rentenversicherung dominiert der Aspekt intergenerativer Umverteilung, wobei zu deren Quantifizierung überwiegend auf das Konstrukt des Eckrentners zurückgegriffen wird. Dem Eckrentner liegt ein stark vereinfachter Versicherungsverlauf zu Grunde, bei dem von verschiedenen empirischen Befunden sowie renditerelevanten Berechnungsvorschriften zur Rentenversicherung abstrahiert wird.

In diesem Kapitel werden zunächst im anschließenden Unterkapitel einige Ergebnisse zu Umverteilungswirkungen der gesetzlichen Rentenversicherung vorgestellt. Zuerst wird eine Übersicht über Befunde und Probleme von Renditeschätzungen gegeben, die auf das Konstrukt des Eckrentners zurückgreifen. Anschließend werden einige Arbeiten besprochen, in denen neben dem Geburtsjahr weitere verteilungsrelevante Merkmale betrachtet werden, so dass in diesen neben intergenerativen zusätzlich intragenerative Unterschiede herausgearbeitet werden. Nach diesen Überblicken werden mit dem STM ermittelte Ergebnisse präsentiert. Im Vordergrund stehen dabei die Einflüsse von Rentenbestandteilen mit Transfercharakter sowie Effekte der Besteuerung. Als Ergänzung zu der gängigen Berechnung von Bruttorenditen werden hierzu Renditen nach Steuern bestimmt, die zum einen die Steuerminderung durch Rentenbeitragszahlungen und zum anderen die auf Renten zu entrichtenden Steuern berücksichtigen. Die Ergebnisse zielen auf zwei Fragestellungen ab: Erstens

211 Inwieweit die Ausgestaltung eines Rentenversicherungssystems als gerecht zu empfinden ist, ist primär eine Frage normativer Maßstäbe, auf die sich zumindest empirisch keine befriedigende Antwort finden lässt. Auf den im Zusammenhang mit der Rentenpolitik häufig herangezogenen Begriff der Generationengerechtigkeit wird hier bei der Darstellung intergenerativer Verteilungswirkungen der Rentenversicherung nicht zurückgegriffen. S. für Betrachtungen des Konstrukts der Generationengerechtigkeit und seiner Probleme: Börsch-Supan (2003); Rürup (2004); Schmähl (2004)

212 Sachverständigenrat zur Begutachtung der gesamtwirtschaftlichen Entwicklung (2003), S. 220 
wird geprüft, inwieweit sich die auf der Basis von Eckrentnern gewonnenen Befunde zu intergenerativen Unterschieden verschieben, wenn Renditen für sowohl empirisch als auch rentenrechtlich detaillierter modellierte Biographien bestimmt werden. Zweitens werden Renditeunterschiede innerhalb von Kohorten bestimmt, um zu untersuchen, in welchem Umfang die Rentenversicherung auch zu intragenerativer Umverteilung führt, die bei einer auf Eckrentner fokussierten Betrachtung ausgeblendet bleibt.

\subsection{Umverteilung: Befunde, Methoden und Probleme}

\subsubsection{Renditeberechnungen auf der Basis von Eckrentnern}

Die implizite Rendite folgt aus der Kapitalwertformel und ist im Kontext der Rentenversicherung der Zinssatz, bei dem der Barwert der Beitragszahlungen und der Barwert der Renten übereinstimmen. Gängiges Konstrukt zur Ermittlung der typisierten impliziten Rendite für ein Geburtsjahr $j$ ist der Standard- oder Eckrentner, der vom 21. Lebensjahr bis zum Erreichen der Regelaltersgrenze kontinuierlich das Durchschnittsentgelt der gesetzlichen Rentenversicherung verdient und eine durchschnittliche Lebenserwartung aufweist:

$\sum_{t=j, 21)}^{j+E(j)-1} d_{t}^{*} b_{t}^{*}(1+r)^{-t}=\sum_{t=j+E(j)}^{j+E(j)+T(j)} a_{t}^{k} *(E(j)-20)^{*}(1+r)^{-t}$

mit $t \quad$ Jahresindex

$d_{t} / a_{t}^{k}$ Durchschnittsentgelt aktueller Rentenwert (zuzüglich Leistungen zur Kranken- und Pflegeversicherung)

$b_{t} \quad$ Beitragssatz (Arbeitnehmer- und Arbeitgeberanteil)

E(j) Altersgrenze der (abschlagsfreien) Regelaltersrente

T(j) fernere Lebenserwartung

$r \quad$ implizite Rendite

Bei einer Altersgrenze von 65 Jahren für die Regelaltersrente weist der Eckrentner demnach 45 Entgeltpunkte auf, wodurch er über T(j)-65 Jahre eine Rente in Höhe der Standardrente bezieht. Von der Politik vorzugebende renditerelevante Parameter sind demnach die Regelaltersgrenze, der Beitragssatz und der aktuelle Rentenwert, wobei diese drei Werte durch die Budgetrestriktion der Rentenversicherung selbstverständlich interdependent sind, allerdings bestehen Freiheitsgrade bei der Festlegung nicht beitragsfinanzierter Leistungen (Bundeszuschüsse). Prognosen der impliziten Rendite des Eckrentners einer Kohorte $j$ fußen auf Annahmen zur Entwicklung der beitragspflichtigen Lohnsumme und der Altersstruktur, aus denen sich unter Berücksichtigung der Budgetrestriktion mögliche Kombinationen der renditerelevanten Parameter ergeben. Differenzierungen des Eckrentners in der skizzierten oder in ähnlicher Form nach dem Geschlecht oder dem Familienstand führen wegen der größeren Lebenserwartung zu höheren Renditen von Frauen als von Männern, 
die Renditen verheirateter Versicherter liegen auf Grund der Hinterbliebenenrenten über den Werten für Alleinstehende. Der Renditevorteil Verheirateter hängt dabei von den geschlechtsspezifischen Lebenserwartungen und den mittleren Altersunterschieden von Ehepartnern ab.

Auf dem Eckrentner beruhende Schätzungen der impliziten Rendite der gesetzlichen Rentenversicherung aus den 1990er Jahren zeigen regelmäßig einen monotonen Renditeverfall über die Geburtsjahrgänge von 1930 bis 1990. Schnabel (1998) etwa schätzt die reale Rendite für unverheiratete Frauen des Geburtsjahrgangs 1930 auf $3,0 \%$, wegen der geringeren Lebenserwartung liegt sein Wert für unverheiratete Männer dieses Jahrgangs bei 2,1\%. Für die Kohorte 1940 liegen die Renditen bereits deutlich darunter (Frauen 2,0\%; Männer 1,1\%), für 1980 Geborene sind seine Werte negativ $(-0,3 \%$ für Frauen; $-1,0 \%$ für Männer). Die von inm angegebenen Renditen für verheiratete Männer liegen durch die Hinterbliebenenversorgung um rund $1 \%$ bis $1,5 \%$ über den Werten für alleinstehende Frauen und bleiben auch für die jüngste betrachtete Kohorte leicht positiv. Der wissenschaftliche Beirat beim Bundesministerium für Wirtschaft (1998) ermittelte indessen für um 1980 geborene verheiratete männliche Versicherte eine mit etwa 1,6\% um gut 1,5 Prozentpunkte höhere reale Rendite. ${ }^{213}$ Für die Kohorte 1940 hingegen unterscheiden sich die Werte Schnabels und des Beirats für verheiratete Männer nur geringfügig (Schnabel 2,4\%; Beirat $2,7 \%)$.

Der Befund bisweilen erheblicher Spannweiten der in verschiedenen Publikationen angegebenen Renditeniveaus für dieselben Geburtsjahre und Versichertentypen ergibt sich auch beim Vergleich neuerer Studien. Neben Unterschieden in den Annahmen zu gesamtwirtschaftlichen Rahmendaten (Lohnwachstum, Bevölkerungsentwicklung, zu Grunde liegender Rechtsstand) enweist sich der Anteil der als renditerelevant erachteten Beitragszahlungen als eine wichtige Stellgröße. Mit dem Verweis auf einen Beitrag von Ohsmann und Stolz (2004) wird von verschiedenen Autoren ein Anteil von $80 \%$ als angemessene Größe zur Renditeermittlung angesehen, da rund $20 \%$ der der Beitragszahlungen nicht zur Absicherung des Langlebigkeitsrisikos dienen, sondern für andere Leistungen der Rentenversicherung wie Absicherung bei Erwerbsminderung oder Hinterbliebenenversorgung bei Tod des Versicherten im erwerbsfähigen Alter aufgewandt werden. ${ }^{214}$ Relevant erscheint diese Differenzierung insbesondere, wenn die Renditen der gesetzlichen Rentenversicherung mit Kapitalmarktrenditen verglichen werden sollen. Da die Rentenversicherung mehrere Leistungen abdeckt, sind für eine sachgerechte Gegenüberstellung nur die Beitragsanteile zu berücksichtigen, die für die von einem zum Vergleich herangezogenen Kapitalmarktprodukt ebenfalls gebotenen Leistungen anfallen. Auf Grund der recht sensiblen Reaktionen des Renditeniveaus auf die konkreten Berechnungsmodalitäten einer Untersuchung gilt weniger das Niveau als vielmehr die Veränderung der Renditen über die Geburtsjahre als relevantes Kriterium zur Beurteilung von Reformoptionen der Rentenversicherung. Während also deutliche Niveauunterschiede bei aus den 1990er Jahren stammenden Schätzungen der impliziten Renditen zu finden sind (ähnliches gilt auch für neuere Berechnungen), stimmen diese jedoch in dem Ergebnis eines durchgehenden Renditeverfalls über die Geburtsjahre

213 Bundesministerium für Wirtschaft (Hrsg.) (1998). Sinn (1999) kommt zu ähnlichen Renditeverläufen und -niveaus wie der wissenschaftliche Beirat. 
überein. Diesen Befunden lag durchgehend der Status Quo des damals geltenden Rentenrechts zu Grunde, der zu einem Anstieg der für die 2030er Jahre prognostizierten Beitragssätze auf bis zu über $30 \%$ beitrug. Jüngere Schätzungen zeigen hingegen zwar weiterhin ein rasches Absinken der impliziten Renditen über Geburtsjahre bis etwa 1955, danach stabilisieren sich die Renditen hingegen, wobei der Verlauf für Kohorten ab 1980 wesentlich vom zu Grunde liegenden Rechtsstand abhängt.

Die Erwartung, dass für nach 1960 Geborene kein monotoner Renditeverfall mehr eintreten wird, begründet sich wesentlich in zahlreichen Einschnitten bei den Leistungen der Rentenversicherung seit der Jahrtausendwende, zu denen unter anderem die Aussetzung von Rentenanpassungen, die Anhebung von Altersgrenzen und die Einführung des Nachhaltigkeitsfaktors in die Rentenanpassungsformel zählen. Flankiert wurden diese Maßnahmen von einer staatlichen Förderung privater Altersvorsorge ("Riester-Rente $).{ }^{215}$ Die rege gesetzgeberische Tätigkeit der letzten Jahre im Bereich der Alterssicherung trägt zu einer recht kurzen Gültigkeitsdauer von Renditeprognosen bei, exemplarisch sind in Abbildung 47 zwei Schätzungen des Sachverständigenrats aus den Jahren 2004 und 2006 wiedergegeben. Im Jahresgutachten 2004/ 05 wurden die Renditeverschiebungen durch das RVNG und ergänzende Maßnahmen betrachtet (unter anderem Übernahme des gesamten statt wie bis dahin des halben Pflegeversicherungsbeitrags durch die Rentenbezieher), daneben wurde die Rendite der gesamten Altersvorsorge bestimmt. Diese wurde unter der Annahme berechnet, dass die Differenz aus den niedrigeren Beitragszahlungen im Reformszenario und den höheren Beiträgen im Status Quo zum Aufbau einer kapitalgedeckten Zusatzrente angelegt wird. Auf Grund der höheren Kapitalmarktrendite (ausgegangen wird von 4\%) liegen die Renditen der gesamten Altersvorsorge über der impliziten Rendite der gesetzlichen Rentenversicherung.

Durch das RVNG und weitere Reformmaßnahmen sanken nach den Ergebnissen des Sachverständigenrats die impliziten Renditen der gesetzlichen Rentenversicherung für die Geburtsjahre bis 1975 , für jüngere Kohorten stiegen sie hingegen, wobei sich für einzelne Jahrgänge Veränderungen im Vergleich zum Status Quo-Szenario in einer Größenordnung von bis zu 0,2 Prozentpunkten ergeben. Für die Kohorten von 1955 bis 1985 bleiben die Renditen nach der Reform mit etwa 2,5\% (Männer) bzw. 3\% (Frauen) recht stabil, danach sinken sie bis zum Geburtsjahrgang 2010, der die niedrigsten impliziten Renditen erzielt, auf rund 2,2\% (Männer) bzw. 2,9\% (Frauen). Dem Reformszenario liegen Rentenversicherungsbeitragssätze von $22 \%$ bis $23 \%$ in den 2030 er Jahren zu Grunde. Im Jahresgutachten 2006 , in dem das Inkrafttreten des RVNG zum Status Quo zählt, wird als Reformszenario die Wirkung der sukzessiven Anhebung des gesetzlichen Renteneintrittsalters auf 67 Jahre als "der letzte noch ausstehende wichtige Schritt zur nachhaltigen Stabilisierung und Sicherung des Rentenversicherungssystems" untersucht, ${ }^{216}$ durch die Renditeverluste von maximal 0,34 Prozentpunkten (Männer, Geburtsjahr 1964) auftreten. Anders als im Jahresgutachten 2004 sind die Renditen über die Geburtsjahre von 1955 bis 1985 nicht konstant, stattdessen steigen sie sowohl im Status Quo- als auch im Reformszenario in diesem Bereich leicht an. Die jüngste Kohorte, 2010,

${ }^{215}$ S. zu den wesentlichen Änderungen durch das AVmEG, das AVmG und das RVNG: Verband deutscher Rentenversicherungsträger (Hrsg.) (2001a, 2001b, 2004)

216 Sachverständigenrat zur Begutachtung der gesamtwirtschaftlichen Entwicklung (2006), S. 241 
weist beim Status Quo Renditen von etwa 2,2\% (Männer) bzw. 2,8\% (Frauen) auf, ähnliche Werte gelten für 1975 Geborene.

Abbildung 47: Schätzungen der nominalen impliziten Rendite durch den Sachverständigenrat

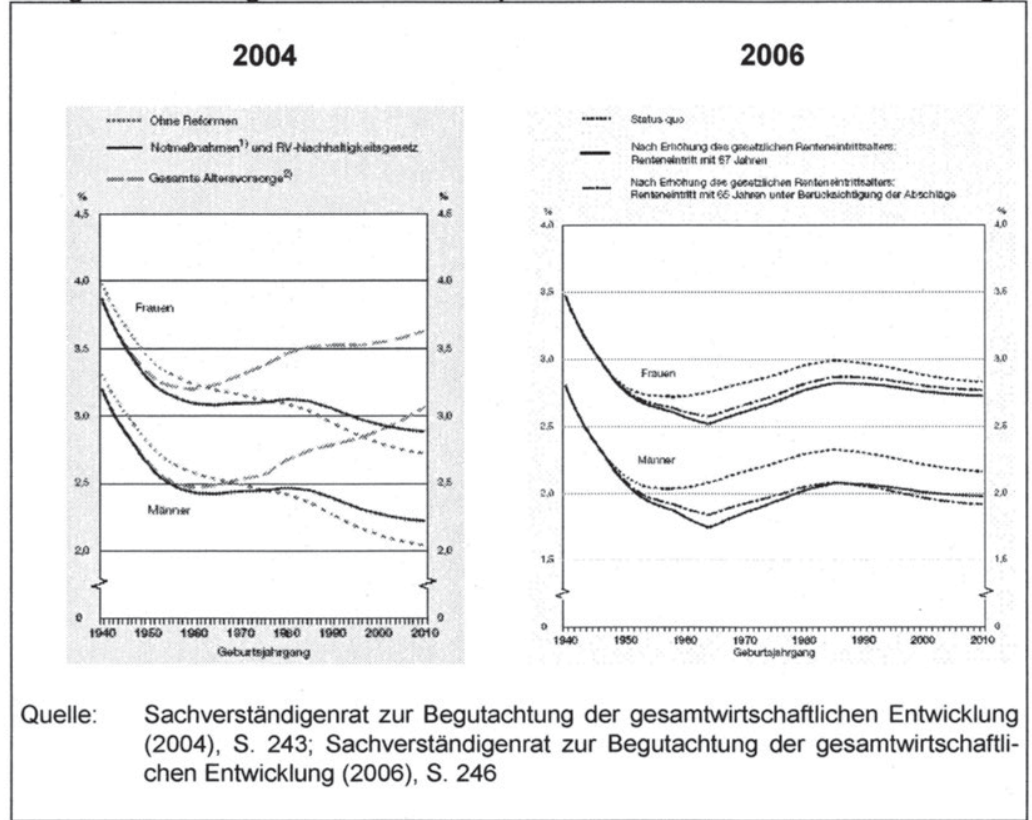

Mit diesem Überblick über verschiedene Untersuchungen zu impliziten Renditen der Rentenversicherung auf Basis von Standardrentnern sollte erstens verdeutlicht sein, dass je nach Annahmen und Setzungen erhebliche Niveauunterschiede auftreten können. Zweitens haben die Reformen der letzten Jahre zu wesentlichen Veränderungen der prognostizierten Renditen zu Gunsten junger und noch nicht geborener Kohorten geführt, wobei konkrete Verläufe stark von zukünftigen Entwicklungen abhängen werden. Drittens ist vorgreifend auf die bei der Betrachtung von Eckrentnern ausgeblendete intragenerative Umverteilung noch auf das Ausmaß von Renditeänderungen durch einzelne Reformschritte hinzuweisen: In den beiden vorgestellten Untersuchungen des Sachverständigenrats führten die jeweiligen Reformen zu Renditeveränderungen für einzelne Kohorten von höchstens rund 0,2 Prozentpunkten (Jahresgutachten 2004/05) bzw. gut 0,3 Prozentpunkten (Jahresgutachten 2006/ 07). Verschiebungen dieser Größenordnung folgen auch aus den Vorschlägen der Kommission zur Nachhaltigkeit in der Finanzierung der Sozialen Sicherungssysteme ("Rürup-Kommission"), die aus der Anhebung der Altersgrenzen und der Einführung des Nachhaltigkeitsfaktors Renditeeinbußen von insgesamt bis zu etwa 0,35 Prozentpunkten erwartete. ${ }^{217}$ Für ein Szenario ohne Anhebung der Altersgrenze

217 Bundesministerium für Gesundheit und Soziale Sicherung (Hrsg.) (2003), S. 108ff. 
ermittelte der Sozialbeirat 2004 Renditeminderungen von höchstens 0,17 Prozentpunkten. ${ }^{218}$ Die politische Bedeutung augenscheinlich eher geringfügiger Veränderungen der impliziten Renditen sollte also nicht unterschätzt werden. Hoch kontroverse Gesetzesänderungen wie die Anhebung des Renteneintrittsalters schlagen sich bei Renditeberechnungen in Veränderungen einer Größenordnung von bis zu rund einem Drittel Prozentpunkt nieder.

Neben den von der Politik vorzugebenden Parametern hängen die Ergebnisse bei der Renditeberechnung für Eckrentner von der angenommenen Rentenbezugsdauer $a b$, die ihrerseits über die mittlere Lebenserwartung bestimmt wird. Überwiegend wird hierzu die aus Sterbetafeln abgeleitete fernere Lebenserwartung bei gesetzlichem oder durchschnittlichem Renteneintrittsalter herangezogen, also etwa die fernere Lebenserwartung 65-Jähriger. Damit wird allerdings nicht die mittlere Rentenbezugsdauer einer gesamten Kohorte abgebildet, sondern nur die mittlere Dauer für diejenigen, für die der Versicherungsfall tatsächlich eintritt. Es handelt sich also nicht um den globalen Erwartungswert der Rentenbezugsdauer, sondern um den bedingten Wert für die Personen, die das 65. Lebensjahr vollenden. Die Rendite für eine Kohorte insgesamt liegt eher niedriger als bei Berechnungen auf der Basis der ferneren Lebenserwartung 65-Jähriger, da diese die Beiträge derjenigen ignoriert, die vor Renteneintritt versterben. Anders ausgedrückt werden mit der gängigen Betrachtung nicht die Renditen für das Versichertenkollektiv insgesamt berechnet sondern nur Renditen für den Teil der Versicherten, bei dem das versicherte Risiko -bei der Rentenversicherung also die Langlebigkeit- eintritt.

Abbildung 48 zeigt die mit dem STM berechneten nominalen impliziten Renditen für Eckrentner der Kohorten von 1930 bis 1990 in Abhängigkeit von der Rentenbezugsdauer. Die einzelnen Kurven entsprechen den vom Geburtsjahr abhängenden Renditen für eine gegebene Rentenbezugsdauer (von 10 bis 25 Jahren). Bei gleich bleibender (fernerer) Lebenserwartung würden die Renditen verschiedener Kohorten auf einer dieser Kurven verharren, deren Verlauf ausschließlich von der historischen und projizierten Entwicklung von Beiträgen und Rentenwerten abhängt. ${ }^{219}$ Für Männer des Jahrgangs 1930 etwa betrug die fernere Lebenserwartung im Alter von 65 Jahren 16,0 Jahre, woraus eine implizite Rendite von $4,5 \%$ folgt. ${ }^{220}$ Ein Rentenbezug über 16,0 Jahre führt bei Männern des Geburtsjahres 1990 zu einer Rendite von $1,4 \%$. Auf Grund steigender Lebenserwartung ist jedoch für diese Kohorte eine mittlere Rentenbezugsdauer von 19,1 Jahren anzunehmen, so dass die Rendite des Eckrentners 1990 stattdessen $2,1 \%$ beträgt.

In Abbildung 48 sind auch die Renditen für weibliche und männliche Eckrentner der einzelnen Geburtsjahre dargestellt, die sich aus den geschlechtsspezifischen ferneren Lebenserwartungen ableiten, wobei zur Illustration die fernere Lebenserwartung auf ganze Jahre gerundet wurde. "Sprünge" auf die nächsthöhere Renditekurve entsprechen somit einer Zunahme der Lebenserwartung um ein ganzes Jahr im Vergleich zur Kohorte 1930. Die auf der ferneren Lebenserwartung im Alter von 65 Jah-

${ }^{218}$ Deutscher Bundestag (2004b), S. 95

219 Rückwirkungen der Lebenserwartung auf den Rentenbestand und damit auf den Rentenwert und/ oder die Rentenbeiträge wurden hierbei also ignoriert.

220 Die Lebenserwartungen sind den Generationensterbetafeln des Statistischen Bundesamts entnommen und beziehen sich auf die zivile Kriegssterblichkeit für das gesamte Bundesgebiet (Statistisches Bundesamt (2005a)). 
ren beruhenden Kurven für Frauen und Männer (Lebenserwartung „65“) stimmen mit der gängigen Berechnungsmethode impliziter Renditen des Eckrentners überein. Wenn nicht von der ferneren Lebenserwartung bei Renteneintritt ausgegangen wird sondern von dem Erwartungswert 45-Jähriger (Lebenserwartung „45“), die gut die Hälfte der Beitragszahlungsphase durchlebt haben, liegen die impliziten Renditen vor allem für Männer niedriger. Wie stark die beiden Werte auseinanderklaffen, wird von der Sterblichkeit in der Altersspanne von 45 bis 65 Jahren geprägt. Je höher diese Sterblichkeit ist, desto größer fällt die Renditedifferenz aus. Analog überschreitet die auf der ferneren Lebenserwartung 65-Jähriger basierende Rendite einer Kohorte die Rendite ihres "typischen" Mitglieds umso mehr, je höher der Anteil ihrer vor dem Renteneintritt Verstorbener ist. Die zu erwartende Rendite einer repräsentativen Durchschnittsperson steigt mit jedem als vollendet angenommenen Lebensjahr $t$, da die Sterbewahrscheinlichkeit der Person im Jahr $t$ als null festgelegt wird.

Abbildung 48: Nominale implizite Renditen nach Rentenbezugsdauer (Eckrentner)

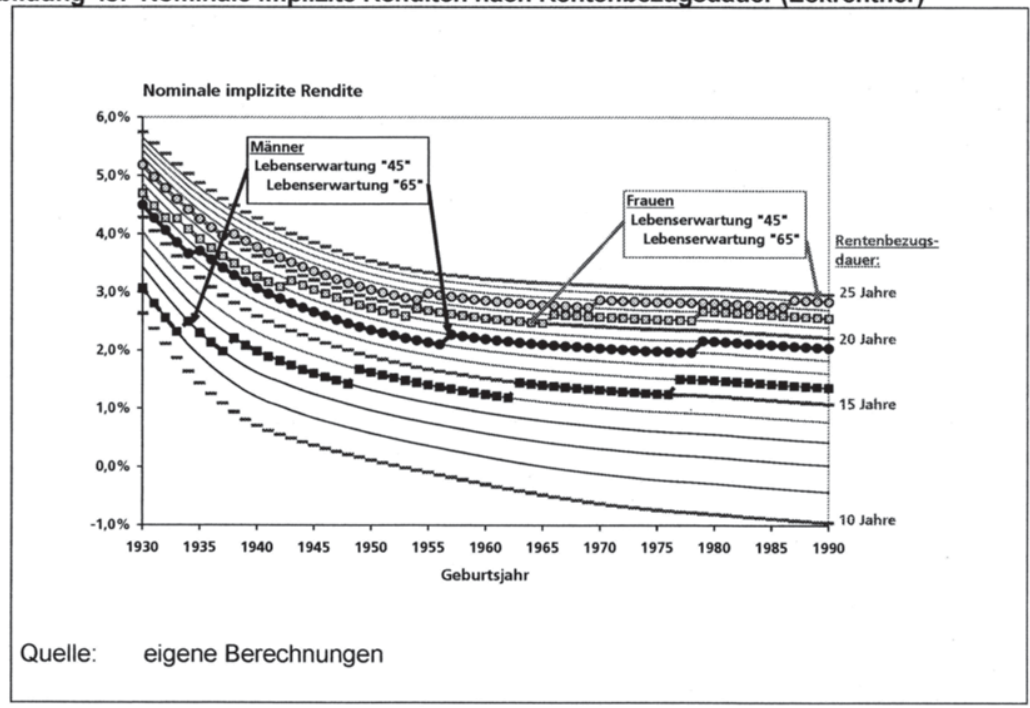

Für Männer mit Geburtsjahren um 1930 liegt die aus der ferneren Lebenserwartung im Alter von 45 Jahren folgende implizite Rendite mit 3,1\% um 1,4 Prozentpunkte unter dem Wert, der üblicherweise für den Eckrentner mit der bei Renteneintritt geltenden Lebenserwartung angegeben wird. Für die Kohorten um 1990 beträgt die Differenz indessen nur noch rund 0,7 Prozentpunkte. Die Abnahme der Differenz über die Kohorten ist Folge einer stärkeren Abnahme der Sterbewahrscheinlichkeiten ab dem Alter von 45 Jahren als im höheren Altersbereich allein (Abbildung 49). Während die fernere Lebenserwartung im Alter von 45 Jahren sowohl für Männer als auch für Frauen über die Kohorten von 1930 bis 1990 um über fünf Jahre zunimmt, steigt die fernere Lebenserwartung ab dem 65. Lebensjahr um 3,0 (Männer) bis 3,7 Jahre (Frauen). In der in Abbildung 48 gewählten Darstellungsform ergeben sich für Männer 
daraus entweder drei oder fünf "Sprünge" auf die nächsthöhere Renditekurve, je nachdem von welcher ferneren Lebenserwartung ausgegangen wird.

Abbildung 49: Zunahme der ferneren Lebenserwartung für Geburtsjahre ab 1930

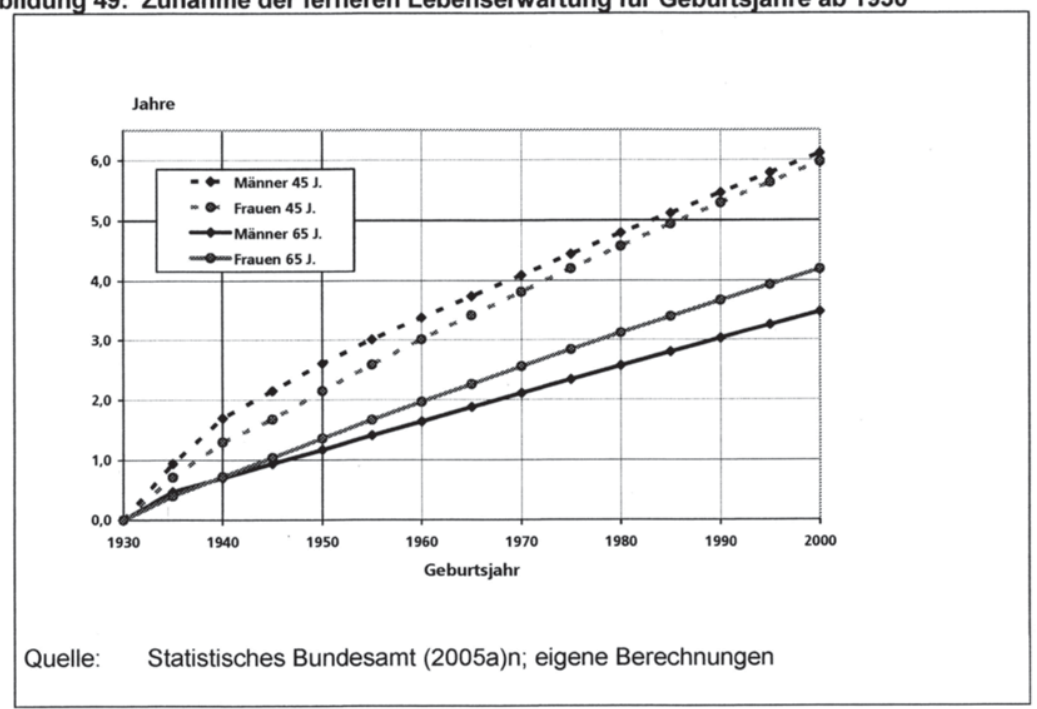

Tabelle 14: Anteil der 20-Jährigen, die das 65. Lebensjahr vollenden (Männer)

\begin{tabular}{|c|c|c|c|c|}
\hline Geburtsjahr & 1930 & 1950 & 1970 & 1990 \\
\hline Anteil & $76,1 \%$ & $83,0 \%$ & $86,6 \%$ & $89,2 \%$ \\
\hline Quelle: Statistisches Bundesamt (2005a); eigene Berechnungen \\
\hline
\end{tabular}

Aus den unterschiedlichen Rentenbezugsdauern je nach unterstellter fernerer Lebenserwartung folgt zum einen, dass die auf eine Eckrentnerbetrachtung zurückgreifenden impliziten Renditen bei empirischen altersbedingten Sterbewahrscheinlichkeiten eine Obergrenze der "wahren" Renditen darstellen. Die "wahre" Rendite, die sämtliche Beitragszahlungen und empfangene Leistungen einer Kohorte berücksichtigt, liegt darunter. ${ }^{221}$ Zum anderen, und dies ist bei der Diskussion intergenerativer Umverteilung der wichtigere Punkt, zeichnet sich ab, dass die Rendite für die jüngsten Kohorten weniger stark überschätzt wird, was Folge eines zunehmenden Anteils Versicherter ist, der das Renteneintrittsalter erreicht. So folgt aus der

221 Wilke (2005) greift dieses Problem auf und schätzt implizite Renditen auf der Grundlage von mit Überlebenswahrscheinlichkeiten gewichteten Zahlungsreihen von Durchschnittsverdienern. Neben den hier diskutierten Auswirkungen der Sterbewahrscheinlichkeiten vor Renteneintritt betrachtet sie auch die Absterbeordnung nach Renteneintritt. Nach ihren Ergebnissen führt die Berücksichtigung von Überlebenswahrscheinlichkeiten zu einem Absinken der Renditen bei alleinstehenden Männern um etwa 0,3 Prozentpunkte im Vergleich zur Standardbetrachtung des Eckrentners. 
Sterbetafel für Männer des Geburtsjahres 1930, dass 76,1\% der Mitglieder dieser Kohorte, die als 20-Jährige typisierend begannen, Versicherungsbeiträge zu entrichten, das 65. Lebensjahr vollendeten (Tabelle 14). Für den Geburtsjahrgang 1950 liegt dieser Anteil bei $83,0 \%$ und steigt bis zur Kohorte 1990 auf $89,2 \%$ an. Wenn bei einer Renditeberechnung an Hand des Eckrentners auf die fernere Lebenserwartung 65-Jähriger abgestellt wird, wird indessen implizit ein konstant bleibender Anteil unterstellt. Ein als Indikator für eine Schieflage des Rentensystems herangezogener Renditeverfall über die Geburtsjahre würde demnach überzeichnet, das Rentensystem wäre intergenerativ "gerechter" als die sich aus der ferneren Lebenserwartung 65-Jähriger ergebenden Renditen suggerieren. Welche Ausprägung der ferneren Lebenserwartung angemessen ist, die durchschnittlichen Beitragszahlungen und empfangenen Leistungen einer Kohorte insgesamt -also nicht nur der den Renteneintritt erlebenden Mitglieder- abzubilden, variiert über die Kohorten in Abhängigkeit von der Verteilung der jeweiligen Sterbewahrscheinlichkeiten während der Erwerbsphase. Die hier exemplarisch miteinander verglichenen ferneren Lebenserwartungen 45- und 65-Jähriger können als Hinweis aufgefasst werden, dass das Alter, aus dessen fernerer Lebenserwartung eine zutreffendere implizite Rendite abgeleitet werden kann, über die Geburtsjahre steigt.

Die Höhe der Differenzen der von der Rentenbezugsdauer abhängenden Renditen bei den hier diskutierten Modellfällen deutet darauf hin, dass die Wahl einer angemessenen ferneren Lebenserwartung wesentliche Auswirkungen auf die Bewertung intergenerativer Verteilungswirkungen der Rentenversicherung haben kann. Differenzen von bis zu 1,4 Prozentpunkten für die ältesten und 0,7 Prozentpunkten für die jüngsten betrachteten Männer übersteigen deutlich die oben vorgestellten Effekte von Gesetzesreformen der jüngeren Vergangenheit, die sich auf weniger als 0,4 Prozentpunkte belaufen. Die implizite Rendite für Frauen reagiert hingegen weniger anfällig auf die Spezifikation der Rentenbezugsdauer, da ausgehend von ihrer höheren Lebenserwartung weitere Anstiege zu geringeren Renditezuwächsen führen; die weit nach dem Renteneintritt anfallenden Leistungen werden stärker abdiskontiert. Allerdings schrumpft auch bei Frauen die Renditedifferenz in Abhängigkeit von der Ausprägung der ferneren Lebenserwartung. Bei den ältesten Geburtsjahren übersteigt die Rendite auf der Grundlage der ferneren Lebenserwartung im Alter von 65 Jahren mit 5,2\% den Wert bei der ferneren Lebenserwartung 45-Jähriger um 0,5 Prozentpunkte, bei den jüngsten Kohorten beträgt die Differenz noch rund 0,2 Prozentpunkte. 


\subsubsection{Berücksichtigung intragenerativer Unterschiede}

Die Problematik, eine angemessene Abbildung der zunehmenden Lebenserwartung finden zu müssen, tritt nicht nur für Eckrentnerbetrachtungen sondern grundsätzlich auf, wenn Renditeberechnungen zur Rentenversicherung an Hand typisierter Biographien durchgeführt werden sollen. Daneben bleiben in der Standardanwendung auf der Grundlage des Eckrentners jedoch weitere Effekte unberücksichtigt, die ihre Aussagekraft beschränken:

- Umverteilungselemente: Die dargestellten Renditeunterschiede zwischen Kohorten können als intergenerative Transfers aufgefasst werden. Deren Ausmaß wird jedoch anders als beim Eckrentner angenommen nicht nur von beitragsgedeckten Rentenbestandteilen bestimmt sondern auch von der Höhe versicherungsfremder Leistungen, durch die Entgeltpunkte ohne entsprechende Beiträge vergeben werden. Eine seit den 1990er Jahren zunehmend restriktivere Aufwertung von Entgeltpunkten lässt einen stärkeren Renditeverfall über die Geburtsjahre vermuten, als der Eckrentner zum Ausdruck bringen kann. Darüber hinaus können Rentenzuschläge, denen keine äquivalenten Beitragszahlungen vorausgehen, zu Renditedifferenzen innerhalb einer Kohorte führen, die sich als intragenerativer Transfer interpretieren lassen. Als weitere Ursache inhomogener Renditen eines Geburtsjahrgangs kommt die Verteilung der Periodeneinkommen über die Erwerbsphase in Betracht.

- Besteuerung: Für die gesetzliche Rentenversicherung ausgewiesene Renditen sind überwiegend Renditen vor Steuern, den Bruttobeiträgen werden die Bruttorenten gegenübergestellt. Angaben zu Renditen nach Steuern, die die auf Beitragszahlungen beruhenden Steuerminderungen in der Erwerbsphase und die auf Renten zu entrichtenden Steuern in Rechnung stellen, sind hingegen rar. Insbesondere durch den Übergang zur nachgelagerten Besteuerung von Alterseinkünften seit 2005 sind jedoch intergenerative Unterschiede beim Vergleich von Brutto- und Nettorenditen zu erwarten.

Während angetrieben von der demographischen Entwicklung die intergenerative Umverteilung durch die Rentenversicherung in zahlreichen Analysen untersucht wird, befassen sich nur wenige Arbeiten mit intragenerativen Verteilungswirkungen. Eine mögliche Ursache für die geringe Beachtung intragenerativer Unterschiede ist die relative Beitragsäquivalenz als konstituierendes Element der Rentenversicherung. Grundsätzlich wirkt die Rentenversicherung rangkonservierend, die durchschnittliche Einkommensposition in der Erwerbsphase und die Einkommensposition in der Rentenbezugsphase sind identisch. So führt etwa die Verdopplung eines (Lebenszyklus-)Erwerbseinkommens -innerhalb der Beitragsbemessungsgrenzen- zur Verdoppelung der Entgeltpunkte und damit auch der Renten, womit die implizite Rendite für die Mitglieder einer Kohorte unabhängig vom Einkommensniveau ist. ${ }^{222}$ Das Prinzip relativer Beitragsäquivalenz wird in der Rentenversicherung jedoch in vielerlei

222 Köhler-Rama (2003) bespricht dieses relative Äquivalenzprinzip, nach dem die Verteilung der gesetzlichen Renten grundsätzlich die Verteilung der versicherungspflichtigen Markteinkommen reproduziert, unter dem Begriff der Teilhabeăquivalenz (Köhler-Rama (2003), S. 3f). 
Hinsicht durchbrochen, was eine mögliche Ursache für intragenerative Renditedifferenzen schafft. Zahlreiche nicht beitragsgedeckte Leistungen wie die Hinterbliebenenversorgung und Rentenzuschläge für Ausbildungs- oder Kindererziehungszeiten, die im Jahr 2003 nahezu 40\% der Rentenausgaben ausmachten (vgl. Kapitel 5.2), lassen die Verdichtung der Rendite einer Kohorte auf einen einzelnen Wert wie beim Standardrentner, bei dessen Rente diese Transferelemente ausgeblendet bleiben, unbefriedigend erscheinen. Das Geschlecht und der Familienstand (alleinstehend oder verheiratet) sind zwei Merkmale, deren auch auf der Grundlage des Eckrentners ermittelbarer Einfluss auf die impliziten Renditen bereits angesprochen wurde. Dabei zeigen sich Renditevorteile zum einen von Frauen gegenüber Männern als Folge der unterschiedlichen Lebenserwartungen und zum anderen von Verheirateten gegenüber Alleinstehenden durch die Hinterbliebenenrenten.

Eine weitere mögliche Ursache für Renditeunterschiede innerhalb einer Kohorte ist die Verteilung der Periodeneinkommen über den Lebenszyklus. Da in der Rentenversicherung Beiträge nicht nach ihrem Einzahlungszeitpunkt gewichtet werden, sind die Renten im versicherungsmathematischen Sinn nicht fair. Zwei Rentenbiographien mit identischer Anzahl von Entgeltpunkten führen unabhängig von der Verteilung der Periodeneinkommen zu gleich hohen Renten, wodurch eine Biographie, in der spät im Lebenszyklus hohe Einkommen erzielt werden, potenziell Renditevorteile aufweist. Der Sachverständigenrat untersuchte den Effekt der Verteilung der Einkommen über den Lebenszyklus in seinem Jahresgutachten 2004/ 05, indem er neben dem Eckrentner auch eine Versichertenbiographie analysierte, die in den letzten 35 (statt 45) Jahren vor dem Renteneintritt 45 Entgeltpunkte erwirbt, folglich also über 35 Jahre jeweils rund 1,286 Entgeltpunkte erzielt. Für diesen gestauchten Einkommensverlauf, vom Sachverständigenrat als "Akademiker" skizziert, liegen die Renditen für die Geburtsjahrgänge von 1940 bis 1955 entgegen der Erwartung deutlich unter den Renditen des Eckrentners, für jüngere Kohorten hingegen zum Teil geringfügig höher. Als Grund wird auf die relativ niedrigen Beitragssätze der 1960er und 1970er Jahre verwiesen, wodurch die damaligen Standardrentner mit 45 Beitragsjahren im Gegensatz zu den Akademikern relativ günstig ihre ersten Entgeltpunkte enwerben konnten. Bei gegebenem Beitragssatz und gleichen Rentenzahlungen ist die implizite Rendite ansonsten jedoch umso größer, je zeitnäher am Rentenbeginn die Zahlungen getätigt werden, weshalb der Akademiker grundsätzlich Renditevorteile aufweist. ${ }^{223}$

In verschiedenen Arbeiten (und auch bei den im nächsten Abschnitt vorgestellten Berechnungen mit dem STM), die sich sowohl mit inter- als auch intragenerativen Verteilungswirkungen der Rentenversicherung befassen, wird wie beim Eckrentner auf die implizite Rendite zurückgegriffen, wobei jedoch mehrere Versichertenbiographien unterschieden werden. Deren Renten enthalten zum einen nicht beitragsgedeckte Zuschläge mit Transfercharakter und zum anderen weisen sie empirisch hergeleitete qualifikationsabhängige Lebenseinkommensprofile auf, um den Einfluss der Verteilung der Einkommen über die Erwerbsphase zu erfassen. Die der Renditeberechnung zu Grunde liegende Formel des Barwerts $C_{0}$ in Abhängigkeit vom Zinssatz $z$ nimmt dabei die Form an:

${ }^{223}$ Sachverständigenrat zur Begutachtung der gesamtwirtschaftlichen Entwicklung (2004), S. 243f. 


$$
C_{0}(z)=\sum_{t=0}^{E(j)}-\operatorname{Min}\left[B_{t}, \hat{y}_{t}^{b}(q, j)\right]^{*} b_{t}^{*}(1+z)^{-t}+\sum_{t=E(j)+1}^{T(j)} R_{j+t}\left[q, j, E(j), m, \sum_{t=0}^{E(j)} \hat{y}_{t}^{b}(q, j)\right]^{*}(1+z)^{-t}
$$

mit $t / j \quad$ Kalenderjahr/ Geburtsjahr

E(i) Alter bei Renteneintritt

$B_{t} \quad$ Beitragsbemessungsgrenze

$b_{t} \quad$ Beitragssatz (Arbeitnehmer- und Arbeitgeberanteil)

$\hat{y}_{1}^{b}(q, j)$ geschătztes Bruttojahreseinkommen nach Qualifikation $q$ und Alter

$t-j$

T(j) Lebenserwartung

$R_{j+1}[\ldots] \quad$ Bruttojahresrente

und die implizite Rendite $r$ ist der Zinssatz, für den gilt:

$$
C_{0}(r)=0
$$

Der erste Summenausdruck entspricht somit den Beitragszahlungen unter Berücksichtigung der Beitragsbemessungsgrenze. Der zweite Summenausdruck bildet die Renten $a b$, die ihrerseits von den Entgeltpunkten aus eigenen Pflichtbeiträgen (Summe der Bruttoeinkommen) sowie verschiedenen Rentenzuschlägen oder -abschlägen abhängen. Diese bestimmen sich nach dem Geburtsjahr $j$, über das die Anwendbarkeit verschiedener Vergünstigungen und die Altersgrenzen zu bestimmen sind, dem Renteneintrittsalter $E(j)$, das den Zugangsfaktor determiniert, der Qualifikation $q$ (Entgeltpunkte für Ausbildungszeiten), sowie weiteren Merkmalen $\mathrm{m}$ wie der Kinderzahl (Entgeltpunkte für Kindererziehungszeiten). Einzelheiten der Rentenberechnung und der im STM berücksichtigten Transferelemente sind in Kapitel 5 dargelegt. Im STM bildet die Rentenfunktion $R_{j+1}[.$.$] die institutionellen Rahmen-$ bedingungen der Rentenversicherung für die Rechtsstände seit 1992 detailgetreu ab. Ihr liegt die allgemeine Rentenformel

\section{Bruttojahresrente $=\left(\right.$ Entgeltpunkte ${ }^{*}$ Zugangsfaktor ${ }^{*}$ Rentenartfaktor $)$ *aktueller Rentenwert * 12}

zu Grunde, wobei die Entgeltpunkte in Entgeltpunkte aus Beiträgen und in Entgeltpunkte aus Transfers zerlegt werden. In der beim Eckrentner angewandten Grundform der Rentenberechnung speist sich die Rente hingegen ausschließlich aus früheren Beitragszahlungen, die verschiedenen als Transfer zu charakterisierenden Entgeltpunktzuschläge sind dort nicht erfasst. Die Differenz der Entgeltpunkte insgesamt und der Entgeltpunkte aus Beiträgen kommt als Ursache intragenerativer Umverteilung in Betracht. ${ }^{224}$ Die Entgeltpunkte aus Transfers, ergänzt um Entgeltpunkte aus versicherungsmathematisch inadäquaten Abschlägen beim Zugangsfaktor, entsprechen den nicht beitragsgedeckten Leistungen der Rentenversicherung, die ver-

${ }^{224}$ In dem kontrafaktischen Fall, dass die Entgeltpunkte aus Transfers EP(T) einen interindividuell konstanten Anteil der Entgeltpunkte aus Beiträgen $E P(B)$ bilden, so dass stets $E P(T)+E P(B)=t$ * $E P(B)$ gilt, wären die Transferelemente bei gegebenen Einnahmen der Rentenversicherung intragenerativ verteilungs- und renditeneutral. $E P(T)$ würde dann lediglich den aktuellen Rentenwert als Nummeraire absenken. 
einfachend als intragenerativer Transfer eingeordnet werden könnten. Der aktuelle Rentenwert wäre hingegen für den Umfang intergenerativer Transfers ausschlaggebend.

Diese Charakterisierung als intragenerativer Transfer ist allerdings nicht unproblematisch, da nicht zwingend eine Umverteilung zwischen den Mitgliedern derselben Kohorte von Rentenbeziehern vorliegen muss. Ausgehend von den drei vom Gesetzgeber bestimmbaren Parametern des (Bundes-)Zuschusses $Z$, des Beitragssatzes $b$ und des Rentenniveaus $v$, letzteres ausgedrückt als Anteil der Standardrente am Durchschnittsentgelt $\bar{y}$, ergeben sich die Einnahmen $E$ und Ausgaben $A$ der Rentenversicherung als:.225

$$
\begin{aligned}
& E=b^{*} \bar{y}^{*} N_{B}+Z \\
& A=v^{*} \bar{y}^{*}(1+\bar{T})^{*} \sum_{i=1}^{v_{k}} E P_{i}
\end{aligned}
$$

Die Einnahmen entsprechen dem Beitragsanteil der beitragspflichtigen Lohnsumme (Anzahl der Beitragszahler $N_{B}$ multipliziert mit dem Durchschnittsentgelt) plus $\mathrm{Zu}$ schuss. Die Ausgaben resultieren aus dem Produkt des aktuellen Rentenwerts $\left(v^{*} \bar{y}\right)$ mit der Summe der -mit Zugangs- und Rentenartfaktor gewichteten- Entgeltpunkte aller $N_{R}$ Rentner. $\bar{T}$ sei schließlich eine Skalierungsgröße, die die durchschnittlichen Entgeltpunkte aus Transfers erfasst. Die Gleichungen der Einnahmen und Ausgaben entsprechen damit der grundlegenden Darstellung einer umlagefinanzierten Rentenversicherung, enweitert um den Zuschuss einerseits und als Transfer einzuordnende zusätzliche Entgeltpunkte andererseits. Da die Einnahmen und Ausgaben der Budgetgleichung $E=A$ genügen müssen, bleiben zwei der drei politisch festzulegenden Parameter frei wählbar. Nimmt man nun als Referenzsituation das Versorgungsniveau $v_{0}$ und den Beitragssatz $b_{0}$ einer nicht durch Transfers und $\mathrm{Zu}$ schüsse überlagerten Rentenversicherung $(\bar{T}=0 ; Z=0)$, so können drei grundsätzliche Politikvarianten unterschieden werden, in denen die zusätzlichen Entgeltpunkte aus Transfers auf unterschiedliche Weise finanziert werden. In diesen drei Fällen lassen sich folgende Wirkungen der auf Transfers beruhenden Rentenanteile aus den Einnahmen- und Ausgabengleichungen ableiten:

- Vollständige Finanzierung der Transfers durch Zuschüsse

$\left(Z=v_{0}^{*} \bar{y}^{*} \bar{T} * \sum_{i=1}^{i_{k}} E P_{1}\right)$

In diesem Fall bleiben der aktuelle Rentenwert und der Beitragssatz im Vergleich zur Referenzsituation unverändert. Die Renten steigen jeweils um den individuellen Transferanteil; Schlechterstellungen von Rentnern, die keine Entgeltpunkte aus Transfers aufweisen, treten nicht auf. Die Rentenzuschläge werden nicht durch das Versichertenkollektiv finanziert (sondern z. B. aus Steuermitteln).

${ }^{225} \mathrm{~S}$. zu den grundsätzlichen Zusammenhängen von Einnahmen, Ausgaben, Beitragssatz und Rentenniveau im umlagefinanzierten Verfahren Homburg (1988), S. 18ff. 
- Vollständige Finanzierung der Transfers durch Beitragssatzerhöhungen $\left(b=(1+\bar{T})^{*} b_{0}\right)$

Hierbei bleibt der aktuelle Rentenwert konstant, der Zuschuss ist null. Wie im ersten Fall steigen die Renten jeweils um den individuellen Transferanteil, ohne dass es zu Schlechterstellungen kommt. Die Mehrausgaben werden vollständig von den Kohorten der Beitragszahler getragen.

- Vollständige Finanzierung der Transfers durch Absenkung des Rentenniveaus $\left(v=v_{0} /(1+\bar{T})\right)$

Der Beitragssatz ändert sich nicht, der Zuschuss ist null. Rentner, deren individueller Zuschlag niedriger ist als der Durchschnittswert $\bar{T}$, erfahren eine Schlechterstellung; Rentner mit einem überdurchschnittlichen Zuschlag verbessern sich im Vergleich zur Referenzsituation. Die Transfers bewirken ausschließlich eine Umverteilung zwischen Rentenbeziehern.

Selbstverständlich sind auch Mischformen dieser drei "reinen" Politikvarianten möglich. Verdeutlicht werden sollte, dass die als intragenerativ bezeichneten Transfers bei der Rentenbemessung nicht zwingend mit einer Umverteilung zwischen Rentenbeziehern einhergehen müssen, wie die Fälle 1 und 2 aufzeigen. In der ersten Politikvariante werden versicherungsfremde Leistungen nicht aus den Beitragseinnahmen erbracht, was einer Stärkung des Versicherungsprinzips entspricht. Es handelt sich also um eine Umverteilung zwischen Versicherten und Nicht-Versicherten (wobei etwa eine Steuerfinanzierung natürlich auch durch das Versichertenkollektiv mitgetragen wird). Der zweite Fall führt -zumindest bei im Zeitverlauf nicht konstantem Transferanteil $\bar{T}$ - zu einer intergenerativen Umverteilung von den Kohorten der Beitragszahler zu den Kohorten der Rentenbezieher. Nur im dritten Fall liegt eine intragenerative Umverteilung im engeren Sinne vor, die Transferanteile von Renten werden von anderen Rentnern finanziert. Um die verschiedenen versicherungsfremden Leistungen tatsächlich ausschließlich als intragenerativen Transfer einordnen zu können, müssen die Einnahmeparameter Zuschuss und Beitragssatz als festgelegt gelten können, so dass nur noch Leistungsverschiebungen zwischen Rentnern möglich sind.

Welcher Politikvariante die deutsche Gesetzgebung in welchem Umfang folgte, bleibt auf Grund der nicht beobachtbaren Referenzsituation letztlich unbestimmt. Die ausgabenorientierte Einnahmenpolitik, die auf die Sicherung des Rentenniveaus abzielt, und Bundeszuschüsse, die beständig unter dem Umfang der versicherungsfremden Leistungen liegen, deuten jedoch darauf hin, dass auch die Transferanteile der Renten zu intergenerativer Umverteilung führen. Verstärkt werden intergenerative Unterschiede zudem durch Gesetzeseingriffe, die zu ungleichmäßigen Begünstigungen verschiedener Kohorten durch Entgeltpunkte aus Transfers führen. Beispiele hierfür sind der rasche Abbau von bewerteten Anrechnungszeiten für schulische Ausbildungen über die Renteneintrittsjahre zwischen 2005 und 2009 oder die Rente nach Mindesteinkommen, durch die Beitragszahlungen aus Jahren bis 1991 potenziell aufgewertet werden. Insofern bleibt eine Trennung in inter- und intragenerative Umverteilung durch das Äquivalenzprinzip verletzende Rentenzuschläge unscharf. 
Ergebnisse zu intragenerativen Unterschieden in den Verteilungswirkungen der Rentenversicherung auf der Grundlage von Längsschnittbetrachtungen sind, abgesehen von den bekannten Einflüssen des Geschlechts und des Familienstands, äußerst rar. Zwar existieren zahlreiche Untersuchungen zur Einkommensverteilung von Rentnerhaushalten im Querschnitt, bei diesen werden jedoch die empfangenen Leistungen nicht zu den entrichteten Beiträgen in Beziehung gesetzt. Im Zusammenhang mit der 2002 eingeführten Förderung einer kapitalgedeckten Altersvorsorge ("Riester-Rente") wurden einige Längsschnittanalysen für verschiedene Biographietypen erstellt, die sich mit der gemeinsamen Wirkung von gesetzlicher und geförderter kapitalgedeckter Rente befassen. Ein Motiv für die Differenzierung verschiedener Modellfälle in diesen Arbeiten sind Gesetzesänderungen bei der Hinterbliebenenversorgung (verstärkte Anrechnung von Einkommen, Absenkung des Rentenartfaktors und Rentenzuschlag für Kindererziehung bei Witwenrenten, vgl. Kapitel 5) sowie die Förderkonditionen der kapitalgedeckten Rente, die nach der Familiengröße gestaffelte Förderbeträge (Sparzulagen) und Steuerminderungen beinhalten. Entsprechend ist von einer von der Kinderzahl und dem Einkommensniveau abhängenden Wirkung der Altersvorsorge auszugehen, so dass diese Merkmale über die betrachteten Fälle variiert werden. Gängige Elemente dieser Analysen sind die Annahmen eines konkaven Einkommensprofils des Mincer-Typs (vgl. Kapitel 3) und die Übernahme der von der Nachhaltigkeitskommission („Rürup-Kommission“) prognostizierten ferneren Lebenserwartung.

Essig und Reil-Held (2003) vergleichen die Absenkung des Rentenniveaus durch die Rentenreform 2001 mit der Höhe der Zahlungen aus einer Riester-Rente für den Geburtsjahrgang 1982. Sie betrachten vier alleinstehende Modellpersonen, die sich qualifikationsbedingt in ihren Einkommen und Erwerbseintrittsaltern unterscheiden. Die Nutzung der Fördermöglichkeiten in vollem Umfang, wozu jährlich $4 \%$ des Bruttoenwerbseinkommens in einen zertifizierten Vorsorgevertrag einzuzahlen sind, überkompensiert nach ihren Ergebnissen voraussichtlich die durch die Rentenreform 2001 und den -2004 mit dem RVNG beschlossenen- Nachhaltigkeitsfaktor entstandene Versorgungslücke bei allen vier Modellfällen. Dieser Befund gilt auch unter ungünstigen Bedingungen wie einer 10-jährigen Erwerbsunterbrechung und niedrigen Zinsszenarien, woraus die Autoren die Empfehlung ableiten, öffentliche Maßnahmen zur Erhöhung der Nachfrage nach privater Altersvorsorge zu veranlassen.

Himmelreicher und Viebrok (2003) sowie Schmähl, Himmelreicher und Viebrok (2004) greifen auf empirisch gestützte typisierte Erwerbsbiographien zurück, die sie aus Daten der Untersuchung "Altersvorsorge in Deutschland 1996" (AVID 1996) ableiten. Neben kontinuierlichen Erwerbsbiographien legen sie bei Frauen familien- 0der enwerbsorientierte Biographien zu Grunde, die sich in langen bzw. kurzen Erwerbsunterbrechungen nach Kindergeburten unterscheiden. Erstere treten nach ihren Analysen vor allem bei westdeutschen, letztere bei ostdeutschen Frauen auf. Als Ergebnisgrößen weisen sie Renditen der gesamten Altersvorsorge für Bezieher von Durchschnittseinkommen aus, die Einkommensprofile im Lebensverlauf sind dabei konkav. Zur Bestimmung der Renditen werden die Beitragszahlungen an die gesetzliche und Einzahlungen in private Rentenversicherungen den von diesen beiden Versicherungen empfangenen Leistungen gegenübergestellt. Auch sie gehen damit von Modellfällen aus, die die durch die Rentenreform geschaffene Förderung kapitalgedeckter Altersvorsorge vollumfänglich nutzen. Die von innen angegebenen realen 
Renditen beruhen auf Bruttogrößen, lediglich bei den Beiträgen zur kapitalgedeckten Altersvorsorge wird die Riester-Förderung in Form von Zulagen oder Steuerminderungen von den Brutto-Beiträgen abgezogen. Der intergenerative Vergleich der Renditen über die betrachteten Kohorten von 1945 bis 1970 verläuft ähnlich wie in den oben dargestellten Analysen (vgl. Abbildung 47 und Abbildung 48). Für ledige Frauen sinken die Renditen von etwa 3\% auf 2,2\%, für ledige Männer von rund $2 \%$ auf etwa $0,8 \%$. Ehepaare mit einem Kind erzielen Renditen zwischen 2,8\% (Jahrgang 1945) und 1,8\% (Jahrgang 1970), für Ehepaare mit drei Kindern liegen die Renditen durch die nach Kinderzahl gestaffelte Riester-Förderung und Zuschläge für Kindererziehung in der gesetzlichen Rentenversicherung um rund 0,1 bis 0,2 Prozentpunkte höher. Zu den im Zentrum der Betrachtung stehenden Auswirkungen der Rentenreform 2001 stellen die Verfasser fest, dass jüngere Kohorten von der Reform eher profitieren, intergenerative Renditedifferenzen mithin eingeebnet werden. Bei der Betrachtung intragenerativer Unterschiede sehen die Autoren vorrangig Personen, die durch umverteilende Elemente der gesetzlichen Rentenversicherung belastet werden, als Begünstigte der Reform. Eine aus der Rentenreform 2001 resultierende stärkere Gewichtung des Äquivalenzprinzips führt demnach zu einer relativen Verbesserung von Männern im Vergleich zu Frauen und von Kinderlosen im Vergleich zu Kinderreichen. Bei alleinstehenden Männern liegt die Rendite über dem Niveau vor der Reform für Kohorten ab 1957, maximal beträgt der Vorteil rund 0,2 Prozentpunkte. Bei alleinstehenden Frauen ist der Renditeeffekt hingegen bis zum Geburtsjahr 1967 negativ (mit dem Minimalwert von etwa -0,15 Prozentpunkten für die Kohorte 1945), für die letzten Geburtsjahre minimal positiv. Für Ehepaare treten durchgängig Renditeabnahmen auf von bis zu - 0,15 Prozentpunkten (Jahrgang 1945), zuletzt liegen die Werte bei bis zu -0,1 Prozentpunkten. Mit steigender Kinderzahl verschlechtert sich dabei die Renditebilanz trotz der Kinderzulagen bei der Riester-Förderung.

Grub (2005) schließlich variiert sowohl das Einkommensniveau als auch die Familiengröße bei der Berechnung von Renditen der Altersvorsorge. Seine Arbeit beruht auf einem Entscheidungsmodell, dessen Agenten Sparentscheidungen unter Unsicherheit nutzenmaximierend treffen, womit abweichend von den soeben dargestellten Publikationen an die Stelle der exogenen Vorgabe einer vollständigen Nutzung der Riester-Förderung eine endogen ermittelte Sparquote tritt. Seine hier interessierenden Ergebnisse sind weniger die Gesamtwirkungen der Altersvorsorge aus gesetzlicher und kapitalgedeckter Rente als die inter- und intragenerativen Renditevergleiche nach den Rentenreformen 2001 und 2004. Reale Renditen werden für acht Modellbiographien bestimmt, die sich aus der Kombination von zwei Haushaltstypen (Alleinstehend, Ehepaar mit zwei Kindern) und vier Qualifikationsniveaus mit unterschiedlichen Lebenseinkommensprofilen und Enwerbseintrittsaltern ergeben. Bei der Berechnung der gesetzlichen Renten werden neben den Entgeltpunkten aus Beiträgen auch recht detailgetreu vom Renteneintrittszeitpunkt abhängende Zuschläge für Ausbildung und Kindererziehung sowie die Bewertung von -stochastisch auftretenden- Phasen der Arbeitslosigkeit berücksichtigt. Zum einen kommt Grub (2005) zu dem Schluss, dass die Rentenreformen 2001 und 2004 beide die Spreizung der impliziten Renditen der gesetzlichen Rentenversicherung für die Geburtsjahrgänge 1945 bis 1975 in zweierlei Hinsicht reduzieren. Sowohl inter- als auch intragenerative Renditedifferenzen werden abgebaut, ohne jedoch die übliche Rang- 
folge zwischen Männern und Frauen sowie zwischen Alleinstehenden und Verheirateten zu verändern. ${ }^{226}$

Insoweit decken sich die Befunde von Grub (2005) einerseits und Himmelreicher und Viebrok (2003) sowie Schmähl, Himmelreicher und Viebrok (2004) andererseits, dass mit den jüngeren Reformen umverteilende Wirkungen der Rentenversicherung beschnitten wurden. Zum anderen sind die von Grub (2005) angegebenen Renditeunterschiede zwischen den vier Qualifikationsniveaus bemerkenswert. Für alleinstehende Männer des Geburtsjahres 1945 ohne beruflichen Abschluss wird eine reale Rendite von fast $3,0 \%$ angegeben, für gleichaltrige Hochschulabsolventen hingegen von knapp 1,4\%. Diese Differenz von anfänglich 1,6 Prozentpunkten fällt über die Kohorten bis 1975 monoton, beträgt aber auch zuletzt noch etwa 0,9 Prozentpunkte. Bei Paaren mit zwei Kindern sind die entsprechenden qualifikationsabhängigen Renditeunterschiede geringer, mit Beträgen zwischen rund 0,6 und 1,2 Prozentpunkten je nach Geburtsjahr jedoch immer noch recht hoch. ${ }^{227}$ Als Erklärung für die mit steigendem Einkommen fallenden Renditen wird zum einen auf die Entwicklung von Beitragssätzen und Lohnwachstum verwiesen. Wie bei der Betrachtung eines Akademikers als "gestauchter Eckrentner" im Jahresgutachten 2004/ 05 des Sachverständigenrats (s. o.) wird auf den relativ günstigen Erwerb von frühen Entgeltpunkten im Fall steigender Beitragssätze verwiesen, der die grundsätzlich zu erwartenden Renditevorteile bei näher am Renteneintritt erfolgenden Beitragszahlungen konterkarieren kann (und dies hier auch tut). Zweitens werden die -zumindest partiell intragenerativ wirkenden- umverteilenden Elemente der Rentenversicherung angeführt, von deren Rückbau Geringverdiener relativ stärker betroffen sind.

Einen anderen Ansatz zur Quantifizierung von inter- und intragenerativen Transfers durch die Rentenversicherung verfolgen Börsch-Supan und Reil-Held (2001), die die Paneldaten des SOEP von Beziehern gesetzlicher Renten auswerten. Dabei schätzen sie aus den retrospektiven Einkommensangaben Erwerbseinkommensverläufe und die sich aus diesen ergebenden Entgeltpunkte. Aus der Höhe der Renten wird auf die tatsächlichen Entgeltpunkte rückgeschlossen. Wie beim STM ergeben sich für eine Rentenbiographie somit zum einen die Entgeltpunkte aus Beiträgen und zum anderen die Entgeltpunkte insgesamt. Die oben als Entgeltpunkte aus Transfers vorgestellte Differenz zwischen diesen beiden Größen schlüsseln die Autoren an Hand der biographischen Angaben im SOEP auf in Entgeltpunkte aus Mindesteinkommen, Kindererziehung, (schulischer und beruflicher) Ausbildung, Wehr- und Zivildienst sowie Kriegsfolgen. Vom Einfluss des von Renteneintrittsalter und Geburtsjahr abhängenden Zugangsfaktors wird abstrahiert.

Mit dieser Methode ermitteln Börsch-Supan und Reil-Held (2001) für Männer einen auf versicherungsfremde Leistungen zurückzuführenden Rentenanteil von durchschnittlich 13,6\% (7,3 Entgeltpunkte), wobei die verschiedenen Umverteilungselemente -abgesehen von der für Männer weitgehend bedeutungslosen Kindererziehung - ähnlich stark wirken (Anteile an den Entgeltpunkten insgesamt zwischen $2,0 \%$ und $3,7 \%$ ). Bei Frauen entspricht der durchschnittliche Zuschlag von 8,8 Entgeltpunkten $29,8 \%$ der Entgeltpunkte insgesamt, knapp die Hälfte des Zuschlags

226 Grub (2005), S. 250

227 Grub (2005), S. 202, S. 205. Die genannten Renditen gelten unter den von der Rürup-Kommission getroffenen Annahmen zur zukünftigen Entwicklung. 
folgt aus der Aufwertung niedriger Einkommen (Rente nach Mindesteinkommen). Um von den Entgeltpunkten aus Transfers auf den Umfang intragenerativer Umverteilung zu schließen, definieren die Autoren intragenerative Transfers als Abweichung vom Prinzip relativer Äquivalenz. Da Entgeltpunkte aus Transfers, die jedem Rentenbezieher zu Gute kommen, nach Börsch-Supan und Reil-Held (2001) nicht das Prinzip relativer Äquivalenz verletzen, fassen sie intragenerative Transfers als Differenz der individuellen Entgeltpunkte aus versicherungsfremden Leistungen von dem Durchschnitt dieser Entgeltpunkte aller Versicherten auf. Die intragenerativen Transfers innerhalb der Stichprobe insgesamt sind damit definitionsgemäß null, Untergruppen mit unterdurchschnittlicher (überdurchschnittlicher) Anzahl von Entgeltpunkten aus Transfers weisen negative (positive) Werte auf. ${ }^{228}$ Eine Aufschlüsselung der Stichprobe nach dem Geschlecht bzw. dem Einkommen bzw. der Ausbildung zeigt nach diesem Ansatz eine intragenerative Umverteilung von Männern (rund -0,6 Entgeltpunkte aus Transfers) zu Frauen $(+0,9)$, von Beziehern hoher Einkommen (-0,7 Entgeltpunkte im höchsten Einkommensquintil) zu niedrigen Einkommen (+3,8 Entgeltpunkte im niedrigsten Einkommensquintil) und von Facharbeitern $(-0,5$ Entgeltpunkte) sowohl zu Personen ohne Abschluss $(+0,6)$ als auch insbesondere zu Hochschulabsolventen $(+2,7)$.

Stärker ausgeprägt sind jedoch die Entgeltpunktdifferenzen über verschiedene Geburtsjahrgänge. Während die ältesten Kohorten (1914-1926) 6,4 Entgeltpunkte aus Transfers über dem Gesamtdurchschnitt aufweisen, sind die Werte für alle weiteren Kohorten negativ und fallen monoton über die Geburtsjahre. Die Abweichung der jüngsten Kohorten 1937-1941 vom Gesamtdurchschnitt beläuft sich auf -3,4 Entgeltpunkte. Entsprechend folgern die Autoren, dass von intragenerativer Umverteilung durch die gesetzliche Rentenversicherung einzelne Gruppen zwar profitieren, ihre Bedeutung insgesamt jedoch relativ gering ausfällt. Wie oben bereits als Möglichkeit vorgestellt, überwiegen intergenerative Unterschiede bei der Vergabe von Entgeltpunkten aus versicherungsfremden Leistungen. In der untersuchten Stichprobe, die Daten bis 1997 enthält, zeigt sich eine über die Geburtsjahre zunehmend restriktiver wirkende Anrechnung von versicherungsfremden Leistungen, die nur zum Teil auf auslaufenden Regelungen zur Abmilderung von Kriegsfolgen beruht. Zu untersuchen bleibt, wie sich dieses Bild verschiebt, wenn zum einen die verschiedenen Rechtsänderungen nach 1997 berücksichtigt werden und zum anderen zusätzlich die über die Kohorten tendenziell zunehmenden Abschläge beim Rentenzugangsfaktor eingearbeitet werden.

${ }^{228}$ Die von Börsch-Supan und Reil-Held (2001) an Hand der Entgeltpunktdifferenzen gezogene Nulllinie wirkt damit zwar wie gefordert rangkonservierend, reagiert jedoch nicht auf Verschiebungen der Einkommensrelationen durch versicherungsfremde Leistungen. So würde beispielsweise eine pauschale Anhebung aller Renten um eine konstante Anzahl von Entgeltpunkten nach ihrem Konzept intragenerativ neutral wirken, da die absoluten Entgeltpunktdifferenzen verschiedener Rentner erhalten bleiben. Gleichzeitig schrumpft jedoch der relative Einkommensvorteil von Beziehern höherer Renten, die Einkommensverteilung der Rentner wäre mithin gleichmäßiger als die Verteilung der die Renten begründenden Enwerbseinkommen. Insofern würde eine auf die Anteile -statt auf die Differenzen- der auf Transfers beruhenden Entgeltpunkte bezogene Nullinie Auskunft geben, inwieweit die Einkommensverteilung erhalten bleibt. 


\subsection{Renditerelevante Merkmale: Ergebnisse des STM}

Die Berechnungen mit dem STM zielen zum einen auf eine weitere Untersuchung der soeben beschriebenen intragenerativen Unterschiede ab. Zum anderen werden sowohl für empirisch gestützte typisierende Biographien als auch für Eckrentner interne Renditen der Rentenversicherung unter identischen Annahmen zur zukünftigen Entwicklung ermittelt. Die Ergebnisse zu den Eckrentnern können damit als Referenzgröße oder Nullinie dienen. Abweichungen der betrachteten Biographien von dieser Referenz werden als Indikator herangezogen, wo und in welchem Umfang der Eckrentner intergenerative Vergleiche eher unzureichend abbildet. Den Analysen liegen die fünf qualifikationsspezifischen Einkommensprofile zu Grunde, deren Herleitung in Kapitel 3 beschrieben wurde. Für die fünf Abschlüsse Ohne, Lehre, Meister, FH und Uni ergeben sich bei durchgehender Erwerbstätigkeit bis zu einem Renteneintrittsalter von 65 Jahren zwischen 38,6 (Ohne) und 67,1 (Uni) Entgeltpunkte aus Beiträgen, wobei die Erwerbsphasen auf Grund der Ausbildungsdauern unterschiedlich lang sind (Tabelle 15). Grundsätzlich gelten die aufgeführten Entgeltpunkte auf Grund des gewählten Konstruktionsprinzips der Lebenseinkommensprofile für alle betrachteten Kohorten, bei Hochschulabsolventen unterschreiten die Entgeltpunkte aus Beiträgen für die ältesten Geburtsjahrgänge jedoch die angegebenen Werte um bis zu knapp drei Entgeltpunkte. Durch die zu Beginn des Untersuchungszeitraums vergleichsweise niedrigen Beitragsbemessungsgrenzen sind die Einkommen zum Teil nicht beitragspflichtig, so dass weder von ihnen Versicherungsbeiträge abgeführt noch Entgeltpunkte durch sie begründet werden. In den Jahren um das Renteneintrittsalter von 65 werden je nach Abschluss durchschnittlich zwischen rund 0,8 (Ohne) und 1,8 (Uni) Entgeltpunkte jährlich erzielt, so dass die Gesamtzahl der Entgeltpunkte aus Beiträgen für jedes Jahr eines abweichenden Renteneintritts um Werte dieser Größenordnung ab- oder zunimmt.

Tabelle 15: Entgeltpunkte aus Beiträgen der betrachteten Biographien

\begin{tabular}{|l|r|r|r|r|r|}
\hline Abschluss & Ohne & Lehre & Meister & $\mathrm{FH}^{(1)}$ & Uni $^{(2)}$ \\
\hline Entgeltpunkte aus Beiträgen & 38,6 & 46,8 & 53,7 & 60,3 & 67,1 \\
\hline $\begin{array}{l}\text { Entgeltpunkte/ Jahr } \\
\text { (im Alter von 62-67 J.) }\end{array}$ & 0,78 & 1,05 & 1,29 & 1,57 & 1,84 \\
\hline $\begin{array}{l}\text { (1) Für Kohorten bis } 1935 \text { rund 60,2 Entgeltpunkte aus Beiträgen wegen } \\
\text { Überschreitungen der Beitragsbemessungsgrenze } \\
\text { Für Kohorten bis 1947 zwischen 64,3 und 67,0 Entgeltpunkte aus Beiträgen wegen } \\
\text { Überschreitungen der Beitragsbemessungsgrenze }\end{array}$ \\
Quelle: eigene Berechnungen
\end{tabular}

Bei Renditeberechnungen für die fünf Erwerbsbiographien wird für alle Kohorten einheitlich die fernere Lebenserwartung im Alter von 65 Jahren zu Grunde gelegt. Wie oben dargestellt, sind von dieser Setzung Überschätzungen der Renditen zu erwarten, wobei von größeren Fehlern für ältere Kohorten auszugehen ist. Als Vorteil dieser Annahme zur Lebenserwartung verbleibt eine bessere Vergleichbarkeit mit anderen Untersuchungen zur impliziten Rendite der gesetzlichen Rentenversicherung. Die im Weiteren vorgestellten Ergebnisse beruhen zunächst auf der Annahme eines ge- 
setzlichen Renteneintrittsalters von 65 Jahren, dessen 2007 beschlossene Anhebung auf 67 Jahre wird ab dem Unterkapitel zum Renteneintrittsalter thematisiert.

\subsubsection{Ausbildung und Einkommensprofil}

Die mit dem STM ermittelten Entgeltpunkte insgesamt umfassen unabhängig von weiteren soziodemographischen Merkmalen (wie Familienstand oder Kinderzahl) neben den in Tabelle 15 aufgeführten Entgeltpunkten aus Beiträgen stets zusätzliche Entgeltpunkte für Ausbildungszeiten, soweit diese für die jeweilige Kombination von Ausbildung und Geburtsjahr anfallen. Abbildung 50 zeigt die für Ausbildungszeiten vergebenen Entgeltpunkte aus Transfers bei durchgehend Vollzeiterwerbstätigen. Die meisten Entgeltpunkte für Ausbildungszeiten verzeichnen Hochschulabsolventen (FH und Uni) der ältesten betrachteten Kohorte, 1930, mit 8,4 (Uni) bzw. 7,4 (FH), was einer Anhebung ihrer Rente ohne Transferelemente um 12,4\% (FH) bis $13,0 \%$ (Uni) entspricht. Über die Kohorten bis 1936 sinken diese Zuschläge rasch auf einen Wert von 2,25 Entgeltpunkten ab, für 1945 und später geborene Hochschulabsolventen wirken sich die Ausbildungszeiten nicht mehr rentensteigernd aus. Auch bei den beruflichen Abschlüssen Lehre und Meister schlägt sich die restriktivere Anrechnung von Ausbildungszeiten nieder. Allerdings fällt die Streuung über die Kohorten niedriger aus als bei Hochschulabsolventen, da zum einen die Ausbildungsdauern geringer sind und zum anderen die rechtlichen Einschnitte bei beruflichen Ausbildungszeiten weniger streng ausfallen als im schulischen Bereich. So ergeben sich hier zwischen 3,2 und 1,7 (Lehre) bzw. 4,9 und 2,1 (Meister) Entgeltpunkte aus Transfers. Im Vergleich zu den Renten ohne Transfers entspricht dies Anhebungen um $6,8 \%$ bis $3,5 \%$ (Lehre) bzw. $9,1 \%$ bis $3,8 \%$ (Meister).

Auch ältere Personen ohne beruflichen Abschluss profitieren von Ausbildungszeiten, obwohl bei innen nach dem Konstruktionsprinzip der Lebenseinkommensprofile keine rentenrechtlich relevante Bildungsbeteiligung erfolgt. Ausschlaggebend hierfür ist die ehemals nachweisunabhängige Bewertung der ersten Beitragsjahre als Berufsausbildung. Die geringen Verdienste zu Beginn der Erwerbsphase werden somit bei den Mitgliedern der ältesten Kohorten aufgewertet. Allerdings resultieren hieraus höchstens 1,2 Entgeltpunkte, die einer Rentensteigerung um 3,2\% entsprechen. Für die in Abbildung 50 nicht dargestellten Kohorten bis 1990 gelten dieselben Werte wie für das Geburtsjahr 1945.

Grundsätzliche Überlegungen zum Umlagesystem legen somit aus zwei Gründen eine überdurchschnittliche Rendite von Akademikern nahe. Zum einen wirkt ein näher am Renteneintritt erfolgender Enwerb von Entgeltpunkten renditesteigernd, zumindest solange Beitragssätze und Durchschnittsentgelte nur moderat wachsen (s. o.). Zum anderen ergeben sich für die ältesten betrachteten Akademikerkohorten sowohl absolut als auch relativ die höchsten Entgeltpunkte aus Transfers auf Grund von Ausbildungszeiten. Stattdessen zeigen sich jedoch bei den ältesten Kohorten für die fünf Bildungsabschlüsse fast identische Renditen, bei späteren Jahrgängen weisen Akademiker stets niedrigere Werte auf als die übrigen Gruppen. Unter den zu Grunde gelegten Daten fällt die Renditekurve für alleinstehende Männer über die Geburtsjahre von 1930 bis 1950 deutlich ab (von etwa $4,6 \%$ auf rund $2,2 \%$ bis $2,4 \%$ ) und verläuft für die weiteren Kohorten weitgehend horizontal bei Werten um 2,0\% 
(Abbildung 51). Die Renditen von alleinstehenden Frauen liegen bei ansonsten identischen Bildungs- und Erwerbsverläufen durchgehend um rund 0,7 Prozentpunkte über den in Abbildung 51 dargestellten Werten.

Abbildung 50: Entgeltpunkte aus Transfers: Ausbildung

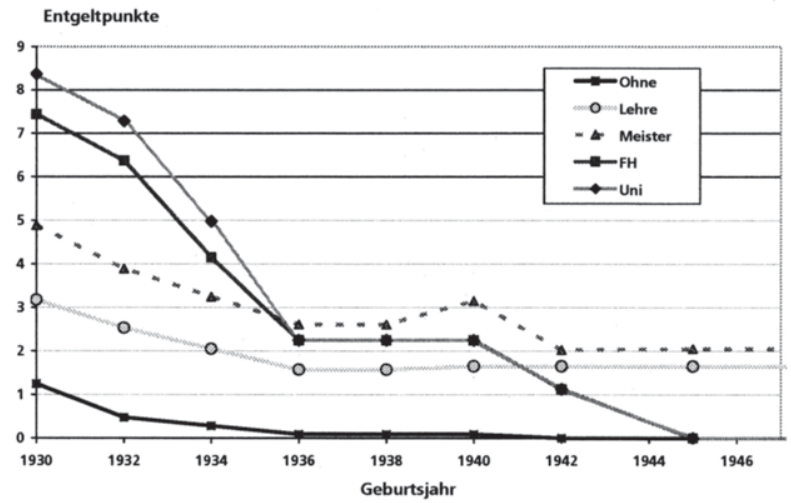

Quelle: $\quad$ eigene Berechnungen

Abbildung 51: Nominale implizite Renditen nach Qualifikation (Männer, alleinstehend)

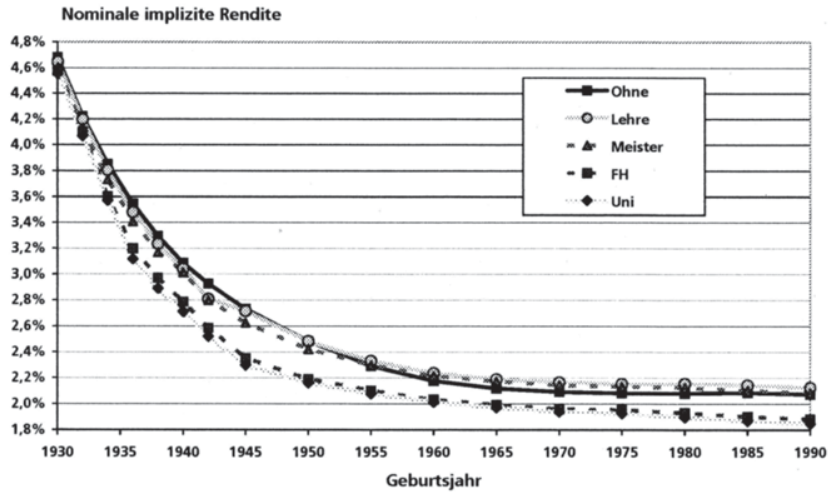

Quelle: $\quad$ eigene Berechnungen 
Wird unter den gleichen Rahmendaten die Rendite des Eckrentners mit seinem flachen statt konkaven Einkommensprofil bestimmt (Einkommen stets in Höhe des Durchschnittsentgelts), liegen die qualifikationsabhängigen Renditen für die 1930 und kurz darauf Geborenen sämtlich über den Standardrenditen $(+0,05$ bis $+0,18$ Prozentpunkte) (Abbildung 52). Über den Eckrentnerrenditen liegende Werte sind auf Grund der Rentenzuschläge für Ausbildungszeiten von mindestens 3,2\% (ohne Abschluss) und bis zu 13,0\% (Universitätsabschluss, jeweils Kohorte 1930) durchaus zu erwarten. Trotz der großzügigen Anrechnung von Ausbildungszeiten bei Hochschulabsolventen liegt ihre Rendite jedoch bereits beim Geburtsjahr 1930 geringfügig unter den Werten der anderen Qualifikationen. Mit der raschen Abschmelzung der Bewertung von schulischen Ausbildungszeiten über die Jahrgänge von 1930 bis 1945 fallen die Renditen der Akademiker um bis zu 0,35 Prozentpunkte unter die Standardrendite (Uni, Geburtsjahr 1936), die Spannweite der qualifikationsabhängigen Renditen beträgt bis zu 0,43 Prozentpunkte (Kohorten 1936 und 1945). Wenn nur die Entgeltpunkte aus Beiträgen bei der Berechnung zu Grunde gelegt werden, resultieren bei Hochschulabsolventen um anfänglich bis zu über 0,5 Prozentpunkte niedrigere Renditen. Paradoxerweise wirkten die grundsätzlich intragenerative Unterschiede begründenden Transferelemente nivellierend. Ohne die Bewertung von Ausbildungszeiten würde die Rendite von Akademikern bereits zu Beginn des betrachteten Zeitraums deutlich unter den übrigen Werten liegen. Für die Geburtsjahre ab 1945, bei denen für Akademiker keine ausbildungsbedingten Entgeltpunkte mehr anfallen, nähern sich die Renditen der Hochschulabsolventen den Eckrentnerrenditen zunächst an (bis zu rund -0,1 Prozentpunkte für die Kohorten von 1960 bis 1975), entfernen sich anschließend jedoch wieder leicht von diesen (bis zu $-0,2$ Prozentpunkte beim Geburtsjahr 1990).

Abbildung 52: Renditevergleich mit dem Eckrentner (Eckrentner: $0 \%$ ) (Männer, alleinstehend)

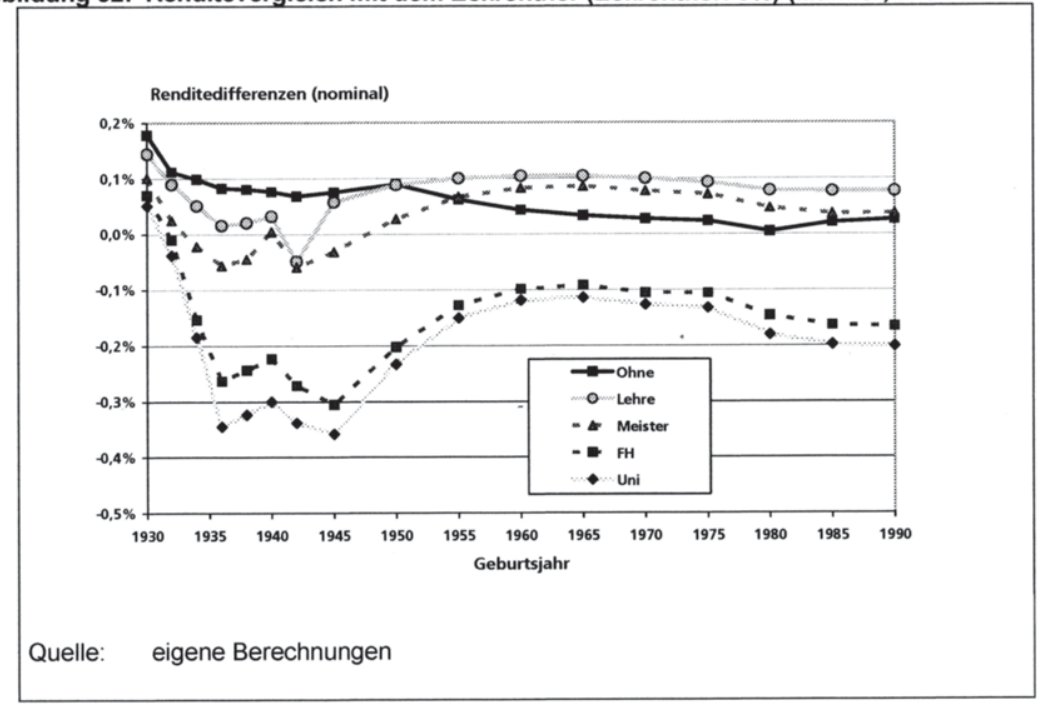


Die Renditen der beiden beruflichen Abschlüssen Lehre und Meister liegen hingegen überwiegend um bis zu 0,1 Prozentpunkte über den Standardrenditen, wozu die durchgehend zu vergebenden Entgeltpunkte für berufliche Ausbildungszeiten beitragen. Für die Kohorten ab 1945 ergibt sich aus innen ein Anstieg der Renditen um etwa 0,1 bis 0,15 Prozentpunkte. Bei Personen ohne beruflichen Abschluss, die abgesehen von den ältesten betrachteten Kohorten keine Entgeltpunkte aus Transfers aufweisen, liegen die Renditen stets zumindest geringfügig über den Werten des Eckrentners. Allerdings verschlechtert sich ihre relative Renditeposition über die Geburtsjahre (von $+0,1$ auf nahezu null Prozentpunkte), wobei die zeitliche Entwicklung in etwa spiegelbildlich zu den Hochschulabschlüssen verläuft.

Ursachen für die Renditedifferenzen in Abbildung 52 sind erstens die Entgeltpunkte aus Transfers für Ausbildungszeiten und zweitens die Verteilung der Periodeneinkommen über die Erwerbsphase. Der grundsätzliche Vorteil eines möglichst kurz vor dem Renteneintritt erfolgenden Erwerbs von Entgeltpunkten bei nicht nach dem Einzahlungszeitpunkt gewichteten Beitragszahlungen kehrt sich unter der historischen und projizierten Entwicklung von Durchschnittsentgelten und Beitragssätzen in einen Renditenachteil um. Besonders sind hiervon Akademiker betroffen, die im Zeitraum von 1935 bis 1945 geboren wurden. Während bei älteren Jahrgängen Renditenachteile durch die Bewertung von Ausbildungszeiten noch kompensiert werden, ergibt sich für Hochschulabsolventen dieser Kohorten die ungünstige Verbindung eines starken Wachstums der Kosten eines Entgeltpunkts bis in die Mitte der 1970er Jahre bei gleichzeitigem Wegfall von bildungsbedingten Rentenzuschlägen. Abbildung 53 zeigt die den Renditeberechnungen zu Grunde liegende Entwicklung des Durchschnittsentgelts der gesetzlichen Rentenversicherung sowie das Wachstum der Kosten eines Entgeltpunkts, das aus der Kombination von Lohnwachstum und Beitragssatzentwicklung folgt. Die Wachstumsrate der Kosten eines Entgeltpunkts im Jahr $t$ $\left(w_{K}(t)\right)$ ist dabei:

$$
w_{K}(t)=\frac{b_{t}^{*} d_{t}}{b_{t-1}{ }^{*} d_{t-1}}
$$

mit $t \quad$ Jahresindex

$d_{t} \quad$ Durchschnittsentgelt der Rentenversicherung

$b_{t} \quad$ Beitragssatz der Rentenversicherung

In einem Jahr, in dem der Beitragssatz des Vorjahres weiterhin gilt, sind die Wachstumsraten des Durchschnittsentgelts und der Kosten eines Entgeltpunkts mithin identisch. Beitragssatzerhöhungen lassen die Kosten hingegen stärker als das Durchschnittsentgelt ansteigen, das Gegenteil tritt bei Beitragssatzsenkungen ein. Von 1950 bis in die Mitte der 1970er Jahre wächst das Durchschnittsentgelt stark an, hinzu treten einige deutliche Beitragssatzerhöhungen. In Analogie zu einer Kapitalmarktbetrachtung formuliert, führt der Erwerb eines Entgeltpunktes in diesem Zeitraum zu realen Jahresrenditen von mehrfach über $10 \%$ und bis zu über $25 \%$. In Hinblick auf die implizite Rendite der gesetzlichen Rentenversicherung sind bei starkem Lohnwachstum und steigenden Beitragssätzen Lebenseinkommensprofile umso nachteiliger, je später der Beginn der Erwerbsphase erfolgt und je steiler das relative 
Einkommen im Enwerbszyklus ansteigt. Beide Aspekte sind bei Hochschulabsolventen am stärksten ausgeprägt.

Abbildung 53: Entwicklung von Durchschnittsentgelt und Beitragssätzen (Reale Größen)

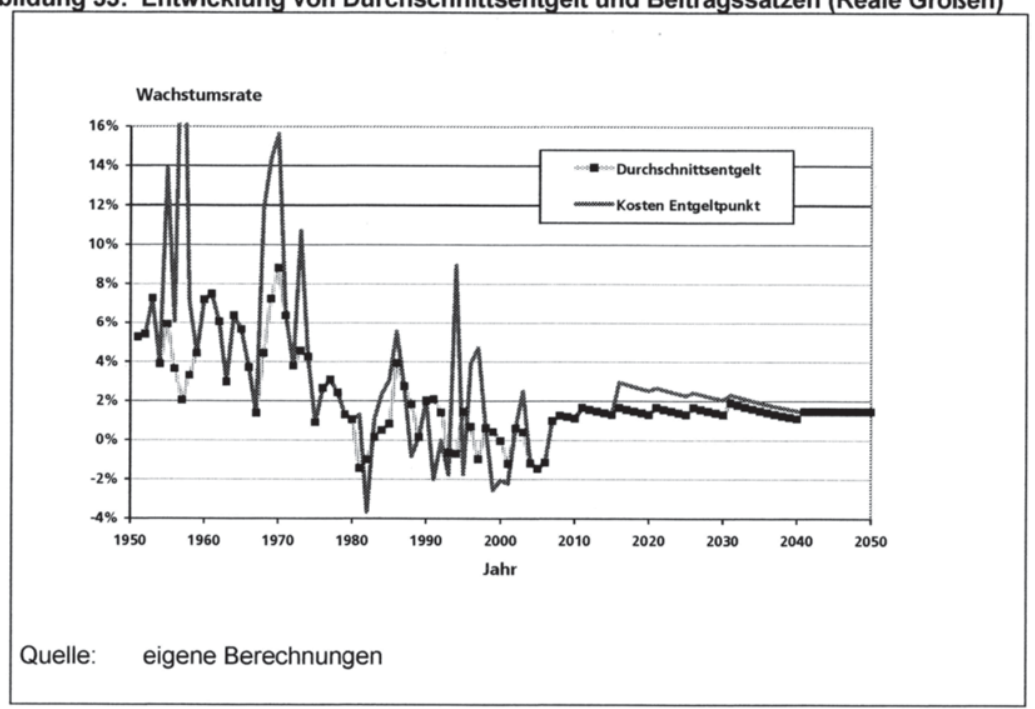

Mit dem Rückgang des Lohnwachstums seit Mitte der 1970er Jahre schrumpft entsprechend der Renditenachteil, der aus den gestauchten Einkommensprofilen der Akademiker resultiert (umgekehrt sinken ebenso die Vorteile von Personen ohne beruflichen Abschluss). Die in Abbildung 52 zu erkennende leichte Zunahme der Renditedifferenz von Hochschulabsolventen im Vergleich zum Eckrentner bei den nach 1975 geborenen Kohorten schließlich lässt sich aus der projizierten Lohn- und Beitragssatzentwicklung erklären: Die angenommenen Parameter führen zu einem stärkeren Wachstum der Kosten eines Entgeltpunkts, als in der historischen Entwicklung seit den 1990er Jahren zu beobachten ist.

Aus der Betrachtung der Entwicklung der impliziten Renditen für die fünf qualifikationsabhängigen Einkommensprofile unter Berücksichtigung von Entgeltpunkten aus Transfers für Ausbildungszeiten verbleiben somit zwei markante Ergebnisse: Zum einen führt eine akademische Erwerbsbiographie für alle betrachteten Kohorten zu unterdurchschnittlichen Renditen, wovon die Kohorten zwischen 1935 und 1945 am stärksten betroffen sind. Zum anderen verstärken die Rechtsänderungen bei der Bewertung von Ausbildungszeiten das bereits beim Eckrentner zu beobachtende rasche Absinken der impliziten Renditen über die Geburtsjahre von 1930 bis 1945 . Für die Kohorte 1930 lassen sich zwischen 0,13 (ohne Abschluss) und 0,57 (Universitätsabschluss) Prozentpunkte der impliziten Renditen auf Transfers zurückführen, über die Geburtsjahre bis 1945 fallen diese Werte auf null (Ohne, FH, Uni) bis 0,14 Prozentpunkte (Lehre, Meister). 
Die unter Renditegesichtspunkten vorteilhafte Position der ältesten Kohorten speist sich für die betrachteten Fälle somit nicht nur aus ihrer relativ günstigen Renten-Beitrags-Relation, sondern wird zusätzlich durch ausbildungsbezogene Transferelemente der Rente gestärkt. In Hinblick auf intragenerative Unterschiede bei den Renditen treten Spannweiten von bis zu 0,43 Prozentpunkten auf, für die jüngeren Kohorten bewegen dich die Differenzen zwischen höchster und niedrigster Rendite der fünf Qualifikationen zwischen 0,2 und 0,3 Prozentpunkten. Im Vergleich zu geschlechtsabhängigen Differenzen, die für alle fünf Qualifikationen und über alle Kohorten einem Renditevorteil von Frauen von etwa 0,7 Prozentpunkten entsprechen, sind die qualifikationsabhängigen Unterschiede deutlich geringer. Dennoch erreichen sie in etwa die Größenordnung von Schätzungen zu Renditeverschiebungen durch verschiedene Reformmaßnahmen im Bereich der Rentenversicherung seit dem Jahr 2001. Neben intergenerativer Umverteilung erzeugt die Rentenversicherung folglich auch intragenerative Unterschiede in einer nach gängigen Maßstäben nicht unerheblichen Größenordnung.

\subsubsection{Gesetzliche Altersgrenzen und Renteneintrittsalter}

Bei den bisherigen Berechnungen wurde stets ein Renteneintritt im Alter von 65 Jahren betrachtet, der bisher durchgehend bestehenden Altersgrenze für eine (abschlagsfreie) Regelaltersrente. Untersuchungen zu den Effekten niedrigerer oder auch höherer Renteneintrittsalter befassen sich vor allem mit zwei Fragestellungen: Zum einen existieren verschiedene mikroökonometrische Schätzungen zu Anreizwirkungen der Rentenberechnung auf Renteneintrittsentscheidungen. Zum anderen wurden Renditeverschiebungen durch die inzwischen beschlossene Anhebung der gesetzlichen Altersgrenze von 65 auf 67 Jahre analysiert.

Größen zur Beurteilung der Anreizwirkungen des Rentensystems auf Rentenzugangsentscheidungen sind Barwerte des Rentenversicherungsvermögens oder der so genannte Optionswert des Verbleibs in der Enwerbsphase in Abhängigkeit vom Renteneintrittsalter. Ein zentraler Punkt dieser Ansätze ist der Vergleich verschiedener Rechtsstände mit einem anreizneutralen Rentensystem. Diese Neutralität wird über eine versicherungsmathematisch faire Rentenberechnung operationalisiert. Ausgehend von der Berechnung der Bruttojahresrente eines Versicherten als

\section{Bruttojahresrente $=($ Entgeltpunkte * Zugangsfaktor * Rentenartfaktor $)$ * aktueller Rentenwert * 12}

ist eine Rente in diesem Sinne fair, wenn der Zugangsfaktor so kalibriert ist, dass der Banwert des Rentenversicherungsvermögens unabhängig vom Verrentungsalter ist. Zu geringe Abschläge bei vorzeitigen Renteneintritten (also unzureichende Herabsetzungen des Zugangsfaktors) wurden verschiedentlich als Anreiz zur Frühverrentung identifiziert, der zusätzlichen Anpassungsdruck auf die gesetzliche Rentenversicherung ausübt. ${ }^{229}$ Vor Wirksamkeit des RRG 1992 betrug der Zugangsfaktor stets 1,0 , seitdem werden für jedes Jahr des Rentenbezugs vor Erreichen der Regel-

${ }^{229}$ S. für Untersuchungen zu Renteneintrittsentscheidungen in Deutschland: Siddiqui (1997); Arnds, Bonin (2002); Berkel, Börsch-Supan (2003); Ohsmann, Stolz, Thiede (2003). 
altersgrenze grundsätzlich Abschläge von 0,036 vorgenommen (vgl. Kapitel 5.2). Ein Rentenzugang mit 63 Jahren führt so etwa zu einem Abschlag von 7,2\% (Zugangsfaktor 0,928 ). Auf Grund von Übergangsregelungen und besonderen Altersrenten waren jedoch nicht alle Rentenzugänge seit 1992 von Abschlägen betroffen. Ein abschlagsfreier Renteneintritt im Alter von 63 Jahren etwa ist für Männer bis zum Geburtsjahr 1937 möglich (Zugangsfaktor 1,0 bei einer Altersrente für langjährig Versicherte), Vergleichbares gilt für Frauen der Kohorten bis 1943 (Zugangsfaktor 1,0 bei einer Altersrente für Frauen).

Umgekehrt gebietet versicherungsmathematische Fairness bei einem Renteneintritt nach Erreichen der Altersgrenze Zuschläge zum Zugangsfaktor. Seit dem RRG 1992 betragen diese 0,06 für jedes Lebensjahr nach Erreichen der Altersgrenze von bisher 65 Jahren, in dem kein Rentenbezug erfolgt. Die mit dem RRG 1992 festgelegten Zugangsfaktoren mit Abschlägen von $3,6 \%$ und Zuschlägen von $6,0 \%$ je Jahr gelten als wichtiger Schritt in Richtung eines anreizneutralen Rentenversicherungssystems, wobei verschiedene Autoren jedoch tendenziell etwas höhere Werte für angemessen halten.

Neben diesen mikroökonometrisch ausgerichteten Arbeiten befassen sich aktuelle Analysen mit Auswirkungen einer veränderten Regelaltersgrenze. Der inzwischen verabschiedete Entwurf des RV-Altersgrenzenanpassungsgesetzes aus dem Dezember 2006 sieht für Renteneintritte ab 2029 eine Regelaltersgrenze von 67 Jahren vor. Nach dem Gesetzesentwurf ist der Geburtsjahrgang 1947 die älteste von der Anhebung der Altersgrenze betroffene Kohorte, der angestrebte Wert von 67 Jahren soll erstmals für den Geburtsjahrgang 1964 erreicht sein. Für die Kohorten dazwischen steigt die Regelaltersgrenze mit jedem Jahr um zunächst einen (Kohorten bis 1957) und anschließend um zwei Monate. ${ }^{230}$ Für das Geburtsjahr 1958 liegt die Regelaltersgrenze somit bei 66 Jahren. Eine Erhöhung der Altersgrenze bewirkt bei einem gegebenen Renteneintrittsalter ein Absinken des Zugangsfaktors. Während ein Rentenbezug im Alter von 65 Jahren nach geltendem Recht zu einem Zugangsfaktor von 1,0 führt, liegt dieser Faktor nach der Reform für die Geburtsjahre ab 1964 bei 0,928 (vgl. Abbildung 54), was einer Rentenkürzung um 7,2\% entspricht. Bei einem Renteneintritt jenseits der geltenden Altersgrenze von 65 Jahren fallen die relativen Rentenminderungen auf Grund der unterschiedlich hohen Ab- und Zuschläge größer aus. Für Renteneintritte im Alter von 67 Jahren sinkt der Zugangsfaktor durch die Reform von 1,12 auf 1,0; es resultiert somit eine Kürzung um 10,7\%. Neben der Übergangsregelung des RV-Altersgrenzenanpassungsgesetzes über die Kohorten von 1947 bis 1964 zeigt Abbildung 54 auch die Folgen des RRG 1992 für Renteneintritte vor Erreichen des Alters von 65 Jahren. Über die Kohorten von 1937 bis 1940 sinkt der Zugangsfaktor für langjährig Versicherte von 1,0 auf 0,928 (bei einem Renteneintrittsalter von 63 Jahren).

${ }^{230}$ Deutscher Bundestag (2006c) 
Abbildung 54: Zugangsfaktoren in Abhängigkeit von Renteneintrittsalter und Geburtsjahr nach dem RV-Altersgrenzenanpassungsgesetz

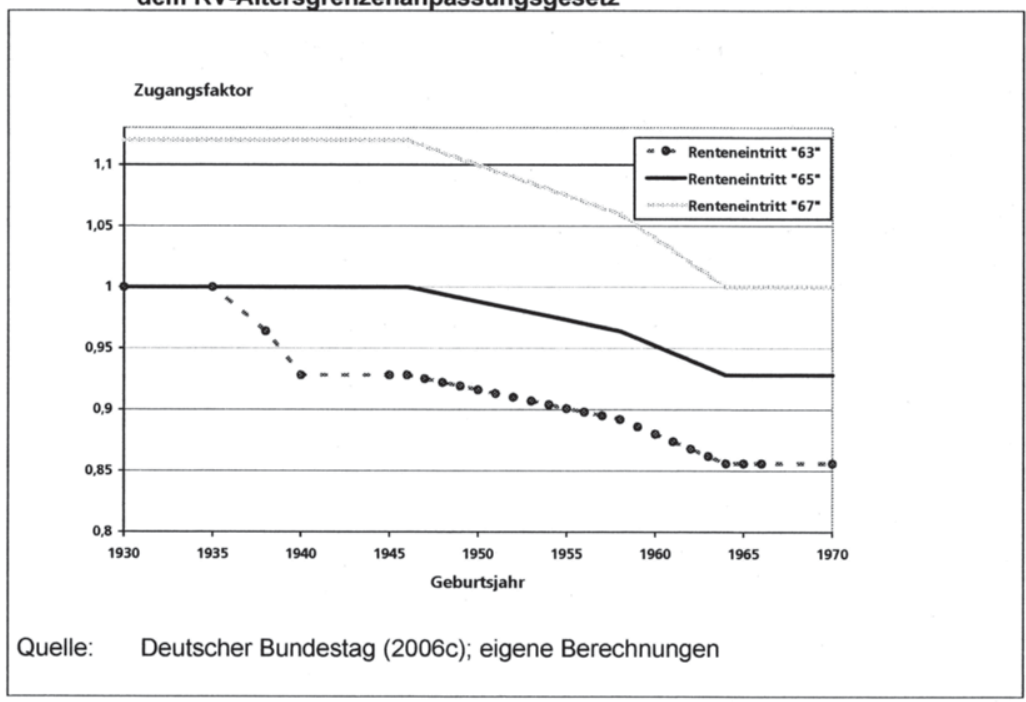

Zur sukzessiven Anhebung des gesetzlichen Renteneintrittsalters auf 67 Jahre liegen zwei Analysen vor, die die Reformen an Hand von Verschiebungen der impliziten Renditen beurteilen. Neben dem Sachverständigenrat, dessen Berechnungen im Jahresgutachten 2006/ 07 oben bereits kurz angesprochen wurden (vgl. Abbildung 47), hat auch der Sozialbeirat hierzu Stellung genommen. ${ }^{231}$ Unter dem Gesichtspunkt intergenerativer Gleichbehandlung wird die Anpassung mit der Zunahme der Lebensenwartung begründet. Eine über die Kohorten ansteigende Regelaltersgrenze wirkt bei steigender Lebenserwartung in Richtung einer Vereinheitlichung der Rentenbezugsdauer, wenngleich nach Ergebnissen des Sachverständigenrats die im RVAltersgrenzenanpassungsgesetz vorgesehene Anhebung Unterschiede in den Dauern nicht vollkommen einebnet; für die Kohorten 1958 bis 1964 ergibt sich eine relativ ungünstige Position. Wie die neuen Altersgrenzen die Renditen einzelner Kohorten beeinflussen werden, hängt unter anderem davon $a b$, wie sich das tatsächliche Renteneintrittsalter und damit der Rentenbestand entwickeln werden. Gesamtwirtschaftlich betrachtet führen eine längere Erwerbs- und eine kürzere Rentenphase zu einem höheren Beitragsaufkommen bei reduziertem Rentenbestand, was in eine Senkung der Beitragssätze und/ oder eine Erhöhung des Rentenwerts münden kann. Durch die Rentenanpassungsformel, nach der zukünftige Rentenwerte an die Entwicklung von Löhnen, Beitragssätzen und Rentnerquotienten gekoppelt sind, zeichnet sich aus der Anhebung der Altersgrenze eine gemischte Wirkung ab, im Vergleich zur Status Quo-Politik resultieren sowohl niedrigere Beitragssätze als auch höhere Ren-

${ }^{231} \mathrm{~S}$. sowohl zu den Ergebnissen als auch zu Implikationen der geplanten Ausgestaltung der Übergangsregelung bis zum Einsetzen der Altersgrenze von 67 Jahren: Deutscher Bundestag (2006d), S. 77ff; Sachverständigenrat zur Begutachtung der gesamtwirtschaftlichen Entwicklung (2006), S. $241 \mathrm{ff}$ 
tenwerte. Aus mikroökonomischer Sicht steigt mit einer längeren Erwerbsphase die Anzahl an Entgeltpunkten, was zu einer höheren Rente führt, die allerdings über weniger Jahre bezogen wird. Inwieweit die Rendite hiervon beeinflusst wird, wird letztlich über die Höhe von $\mathrm{Ab}$ - und Zuschlägen beim Zugangsfaktor entschieden. Wie bei anderen Reformmaßnahmen im Bereich der Rentenversicherung, die mittelfristig belastend und langfristig entlastend wirken, ergeben sich für die Übergangskohorten Renditeeinbußen.

Der Sachverständigenrat und der Sozialbeirat sehen übereinstimmend die stärksten Renditeeinbußen für den Geburtsjahrgang 1964. Dieser ist vollständig von der Anhebung der Altersgrenze betroffen, profitiert jedoch nur vergleichsweise kurz von im Vergleich zum Status Quo niedrigeren Beitragssätzen. Als Renditeminderung für diesen Jahrgang ermittelt der Sachverständigenrat einen Wert von -0,34 (Männer) bzw. -0,24 Prozentpunkten (Frauen), der Sozialbeirat kommt mit weniger als $-0,2$ Prozentpunkten für beide Geschlechter zu einem etwas geringeren Einfluss. In beiden Gutachten ergibt sich mit der Reform für die um 1965 Geborenen die niedrigste Rendite aller betrachteten Kohorten. In Hinblick auf den Renditeeffekt verschiedener Renteneintrittsalter werden in den beiden Arbeiten zwei unterschiedliche Aspekte aufgegriffen: Der Sachverständigenrat ermittelt die Renditen für einen Renteneintritt mit 65 Jahren unter Berücksichtigung von Abschlägen. Für Geburtsjahre ab 1964 beträgt der Zugangsfaktor in diesem Fall also 0,928 statt 1,0. Die Renditekurven für den Renteneintritt bei Erreichen der Regelaltersgrenze und für den Renteneintritt im Alter von 65 Jahren verlaufen ähnlich und weisen nur geringe Differenzen auf. Die Höhe der Rendite ist demnach weitgehend unabhängig von der Wahl des Renteneintrittsalters, was als Hinweis auf die Anreizneutralität der Abschläge von 3,6\% je Jahr des vorzeitigen Renteneintritts gedeutet wird. Der Sozialbeirat betrachtet indessen eine umstrittene Vergünstigung für besonders langjährig Versicherte. Ähnlich wie die frühere Altersrente für langjährig Versicherte, die bei mindestens 35 Versicherungsjahren einen abschlagsfreien Rentenbezug ab dem Alter von 63 Jahren ermöglichte, sieht das RV-Altersgrenzenanpassungsgesetz einen abschlagsfreien Renteneintritt ab 65 Jahren für besonders langjährig Versicherte mit mindestens 45 Versicherungsjahren vor. Der Beirat erkennt in den fehlenden Abschlägen, deren Renditevorteil mit bis zu 0,3 Prozentpunkten beziffert wird, einen starken Anreiz, die Möglichkeit zum Renteneintritt mit 65 Jahren in Anspruch zu nehmen. Absehbare Folge der Ausnahmeregelung für besonders langjährig Versicherte ist demnach eine das Äquivalenzprinzip unterlaufende intragenerative Umverteilung zu Lasten der übrigen Rentenbezieher oder der Beitragszahler.

Aus den beiden Ansätzen, Schätzung anreizneutraler Abschläge einerseits und Ermittlung der Renditeeffekte einer erhöhten Altersgrenze andererseits, ergeben sich Implikationen für die Betrachtung empirisch gestützter Biographien mit dem STM. Relevant für einen intergenerativen Vergleich ist, wie sich die Entwicklung der in Abbildung 51 dargestellten nominalen impliziten Renditen verändert, wenn erstens die Anhebung der Altersgrenze berücksichtigt und zweitens ein anderes Renteneintrittsalter als 65 Jahre angesetzt wird. Unter den Altersgrenzen des RVAltersgrenzenanpassungsgesetzes sinken die Renditen der Kohorten ab 1947 nach den Ergebnissen des STM bei allen fünf Qualifikationen um bis zu etwa 0,25 Prozentpunkte, ein Wert der zwischen den Ergebnissen des Sachverständigenrats und des Sozialbeirats liegt (s. o.). Wenn die Abschläge (und Zuschläge) unter Umständen 
versicherungsmathematisch nicht fair sind (oder waren) und wenn weiterhin das durchschnittliche Renteneintrittsalter beständig unter der gesetzlichen Altersgrenze liegt, bleibt zu prüfen, inwieweit sich die impliziten Renditen verändern, wenn von der Standardannahme eines Rentenzugangs im Alter von 65 Jahren abgewichen wird.

Das durchschnittliche Zugangsalter der Renten wegen Alters schwankte seit den 1990er Jahren um einen Wert von knapp 63 Jahren. ${ }^{232}$ Für die ältesten betrachteten Kohorten, die in den 1930er Jahren geboren wurden, führt ein Renteneintritt mit 63 Jahren zu einem Zugangsfaktor von 1,0 (Altersrente für langjährig Versicherte oder für Frauen), jüngere Jahrgänge haben indessen einen Abschlag von 7,2\% (bei einer Regelaltersgrenze von 65 Jahren) bis $14,4 \%$ (bei einer Regelaltersgrenze von 67 Jahren) hinzunehmen. Mit einem Rentenbezug ab 67 Jahren ergibt sich je nach Kohorte ein Zuschlag von 12\% (Regelaltersgrenze von 65 Jahren) bis $0 \%$ (Regelaltersgrenze von 67 Jahren). Die mit dem STM ermittelten Veränderungen der Renditen bei einer Verschiebung des Renteneintritts um zwei Jahre sind in Abbildung 55 dargestellt.

\section{Abbildung 55: Renditewirkung eines Vorziehens des Renteneintritts um zwei Jahre}

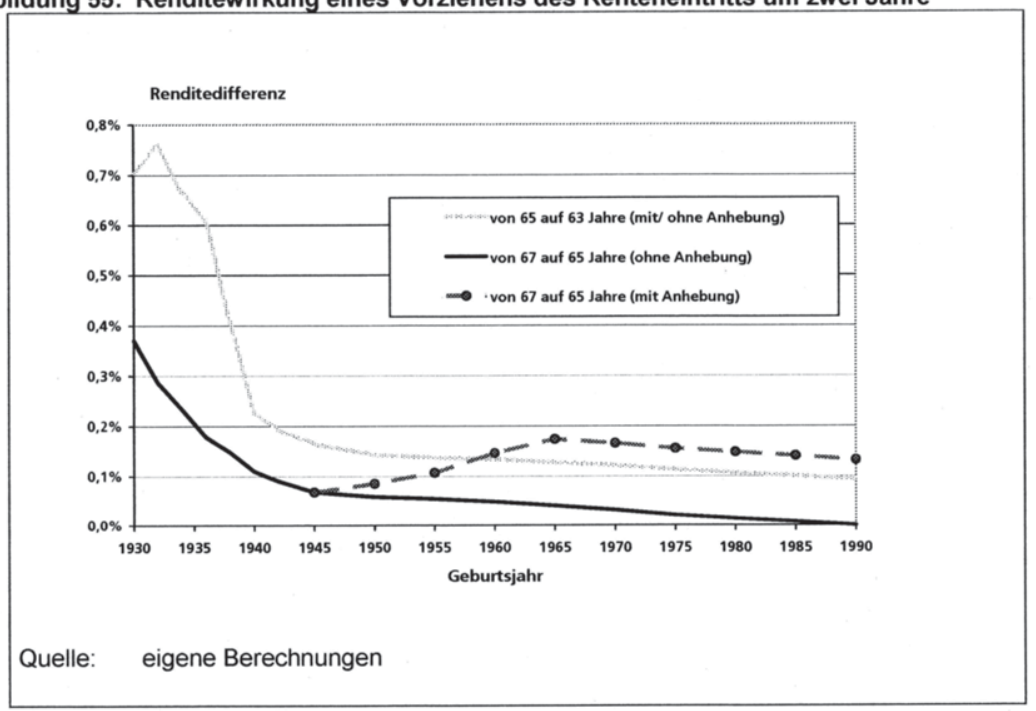

Die Abbildung gibt die Ergebnisse für einen männlichen Versicherten mit dem Einkommensprofil Lehre wieder, für die vier anderen Qualifikationen gelten weitestgehend dieselben Befunde. Grundlage der Abbildung sind sechs implizite Renditen, die sich aus einem Renteneintritt im Alter von 63, 65 oder 67 Jahren mit oder ohne Anhebung der Regelaltersgrenze ergeben. Die Kurve „von 67 auf 65 Jahre (ohne

232 Verband deutscher Rentenversicherungsträger (2007), S. 99. Das meist stärker beachtete durchschnittliche Zugangsalter aller Renten (also neben Altersrenten auch Erwerbsminderungsrenten und andere) liegt um mehrere Jahre niedriger. Für die hier betrachteten typisierten Biographien sind jedoch die Renten wegen Alters relevant. 
Anhebung)" etwa bildet die Differenzen der Renditen eines Renteneintritts mit 65 und mit 67 Jahren $a b\left(r_{65}-r_{67}\right)$, wenn die Regelaltersgrenze unverändert bei 65 Jahren bleibt. Der Vergleich der Renditen bei Renteneintritten im Alter von 65 und 67 Jahren unter den beiden Rechtsständen mit/ ohne Anhebung der Altersgrenze enthält nicht die Renditeminderung von wie enwähnt bis zu -0,25 Prozentpunkten, die aus der Anhebung der Altersgrenze als solcher resultiert. Dargestellt ist ausschließlich die Abhängigkeit der Renditen vom Renteneintrittsalter. Eine Renditedifferenz von null bedeutet, dass die Rendite vom Renteneintrittsalter unabhängig ist, was auf eine anreizneutrale Ausprägung der Ab- und Zuschläge hindeutet. Bei positiven Differenzen ist die implizite Rendite höher, wenn der Renteneintritt früher erfolgt.

Wenn Renteneintritte mit 63 und mit 65 Jahren verglichen werden, verändert die sukzessive Anhebung der gesetzlichen Altersgrenze auf 67 Jahre die Renditedifferenz kaum. Unter beiden Rechtsständen treten Abschläge von 3,6\% je Jahr des vorzeitigen Renteneintritts auf. Eine Altersgrenze von 67 statt 65 Jahren verdoppelt somit unter sonst gleichen Umständen den Abschlag von $7,2 \%$ auf $14,4 \%$, wovon die Renditedifferenzen nahezu unberührt bleiben. Die Kurve "von 65 auf 63 Jahre" in Abbildung 55 gilt daher näherungsweise sowohl mit als auch ohne Anhebung der Altersgrenze. Für vorzeitige Renteneintritte (Renditedifferenzen bei Renteneintritten mit 63 oder 65 Jahren) zeigen sich zum Teil massive Renditevorteile bei früher Verrentung. Für die Kohorten bis 1937 fällt die Rendite bei einem Rentenzugang im Alter von 63 Jahren deutlich höher aus als bei einem Renteneintritt mit 65, die Renditedifferenz beträgt bis zu 0,75 Prozentpunkte. Die oben angegebenen Renditen von rund 4,6\% für den Jahrgang 1930 etwa (vgl. Abbildung 51) liegen im Fall eines vorzeitigen Rentenbezugs ab dem Alter von 63 Jahren bei über 5,3\%. Mit dem Einsetzen der Wirksamkeit der mit dem RRG 1992 eingeführten Abschläge schmilzt der Renditevorteil eines vorzeitigen Renteneintritts rasch ab, für die Kohorte 1945 liegt er noch bei etwa 0,15 Prozentpunkten. Für die weiteren Geburtsjahre erscheinen die Abschläge unter Renditegesichtspunkten zunehmend anreizneutral. Ob der Renteneintritt mit 63 oder 65 Jahren erfolgt, beeinflusst die Renditen nur noch geringfügig, die Differenzen belaufen sich zuletzt auf unter 0,1 Prozentpunkte.

Bei späteren Renteneintritten folgt ein zum Teil abweichendes Bild (Renditedifferenzen bei Renteneintritten mit 65 oder 67 Jahren): Für die Kohorten bis 1947, auf die sich die Anhebung der Altersgrenzen nicht auswirkt, ergibt sich bei einem Renteneintritt mit 67 Jahren stets ein Zuschlag auf den Zugangsfaktor in Höhe von 12\%. Dennoch fällt für diese die Rendite höher aus, wenn das Renteneintrittsalter von 65 statt 67 Jahren gewählt wird, sie liegt dann um bis zu 0,37 Prozentpunkte (Geburtsjahr 1930) höher. Auf Grund der vergleichsweise niedrigen Restlebenserwartung der ältesten Kohorten erscheinen die Zuschläge unzureichend, um den Nachteil einer kürzeren Rentenbezugsphase auszugleichen. Mit dem Anstieg der Lebenserwartung über die Geburtsjahre bis 1947 sinkt der Renditenachteil eines verzögerten Renteneintritts kontinuierlich und beläuft sich zuletzt auf noch 0,07 Prozentpunkte. Auf Grund der höheren Lebenserwartung von Frauen ist bei innen auch für Angehörige der älteren Kohorten ein verspäteter Renteneintritt eher lohnend, hier ergeben sich ab dem Jahrgang 1945 geringfügige Renditesteigerungen, wenn der Rentenbezug erst mit 67 statt mit 65 Jahren beginnt.

Bei den Kohorten ab 1947 zeigen die Ergebnisse des STM zunächst ansteigende Renditenachteile bei einem Aufschub des Rentenbezugs vom 65. auf das 67. Lebensjahr (Kurve "von 67 auf 65 Jahre (mit Anhebung)") von bis zu etwa 0,15 Prozent- 
punkten. Für die ab 1964 Geborenen hingegen nähern sich die Renditen der beiden Renteneintrittsalter wieder an. Ohne RV-Altersgrenzenanpassungsgesetz würden die Renditedifferenzen indessen monoton abnehmen und sich für die jüngsten Kohorten auf ungefähr null belaufen (Kurve „von 67 auf 65 Jahre (ohne Anhebung) “). Die unterschiedlichen Verläufe unter den beiden Rechtsständen beruhen auf der Asymmetrie von $\mathrm{Ab}$ - und Zuschlägen beim Zugangsfaktor. Im Fall einer gleich bleibenden Regelaltersgrenze von 65 Jahren ergibt sich für alle Kohorten bei einem Renteneintrittsalter von 67 Jahren ein Zugangsfaktor von 1,12. Der Aufschub des Rentenzugangs vom 65 . auf das 67 . Lebensjahr wird somit stets mit einer Rentensteigerung um $12 \%$ honoriert. Durch die sukzessive Anhebung der Altersgrenze auf 67 Jahre wird dieselbe Verzögerung zwar weiterhin honoriert (bzw. in der üblichen Sichtweise nicht mit einem Abschlag sanktioniert), die relative Prämie sinkt jedoch. Ab dem Geburtsjahr 1964 betragen die Zugangsfaktoren für 67-Jährige 1,0 und für 65-Jährige 0,928 (Abschlag von 7,2\%). Die Steigerung des Zugangsfaktors beläuft sich somit noch auf rund $7,8 \%(=1 / 0,928)$, über die Kohorten von 1947 bis 1964 sinkt der relative Vorteil folglich von $12 \%$ auf $7,8 \%$. Der zunächst leicht zu- und dann wieder abnehmende geringfügige Renditenachteil eines Renteneintritts mit 67 Jahren nach dem RV-Altersgrenzenanpassungsgesetz folgt demnach aus zwei entgegengesetzt wirkenden Faktoren. Zum einen verringert die steigende Lebenserwartung die Renditedifferenzen. Über die Kohorten von 1947 bis 1964 wird dieser Effekt jedoch von der von $12 \%$ auf $7,8 \%$ sinkenden Anhebung des Zugangsfaktors überkompensiert, die aus der Diskrepanz von $A b$ - und Zuschlägen resultiert.

Aus der Betrachtung der impliziten Renditen verschiedener Renteneintrittsalter bleibt als ein Ergebnis, dass nach den hier ermittelten Ergebnissen die Abschläge und Zuschläge tendenziell geringfügig zu niedrig ausfallen, um die Renditen männlicher Versicherter unabhängig vom Rentenbeginn zu machen. Frühere Renteneintritte heben die Renditen leicht an. Mit der Erhöhung der Altersgrenze auf 67 Jahre wird dieser Effekt verstärkt. Von der Wahl des Renteneintrittsalters gehen nur vernachlässigbare intragenerative Unterschiede aus, ein früherer Rentenbezug wirkt auf alle fünf berücksichtigten qualifikationsabhängigen Einkommensprofile ähnlich. Auf intergenerative Vergleiche übt das angenommene Renteneintrittsalter jedoch zum Teil einen erheblichen Einfluss aus. Für die Kohorten bis 1937 (bei Frauen bis 1942) ergibt sich im Vergleich zur Standardannahme des Rentenbezugs ab dem Alter 65 eine deutlich höhere Rendite, wenn die Rente bereits mit 63 Jahren bezogen wird. Da zudem die Rentenzugänge dieser Kohorten überwiegend vor der gesetzlichen Altersgrenze von 65 Jahren erfolgten, erscheint die Setzung eines vorzeitigen Renteneintritts für intergenerative Vergleiche hier durchaus angemessen. Folge ist, dass der Verfall der Renditen über die Geburtsjahre von 1930 bis 1945 wesentlich stärker ausfält, als in der üblichen Betrachtung von Eckrentnern zum Ausdruck kommt. Wie sich das Renteneintrittsalter der Kohorten ab 1945 entwickeln wird, lässt sich nur mutmaßen. Nach den hier ermittelten Ergebnissen gehen von diesbezüglichen Annahmen leichte Effekte auf das Renditeniveau aus. Renditedifferenzen zwischen Generationen sind indessen kaum betroffen. Für die nach 1945 Geborenen wirkt sich ein vorzeitiger Rentenbezug ab dem Alter von 63 Jahren ebenso wie ein Anstieg des durchschnittlichen Rentenzugangsalters in Folge der Erhöhung der Regelaltersgrenze auf 67 Jahre sehr ähnlich aus. Zwar zeichnet sich durch das RV-Altersgrenzenanpassungsgesetz eine intergenerativ uneinheitliche Wirkung der Ent- 
scheidung zwischen den Zugangsaltern 65 und 67 Jahren ab, die Differenzen zwischen Kohorten betragen jedoch maximal 0,08 Prozentpunkte.

\subsubsection{Familienstand und Kinder}

Die Bestimmung der impliziten Rendite für verheiratete Versicherte lehnt sich bei der Betrachtung von Eckrentnern eng an die Berechnung für Alleinstehende an. Typisierend wird ein Einverdienerpaar angenommen, so dass die Höhe der Beitragszahlungen von Alleinstehenden und Verheirateten identisch ist. Durch die Hinterbliebenensicherung (Renten wegen Todes) verlängert sich jedoch die Rentenbezugsphase um die Zeit, die der nicht erwerbstätige Ehepartner den Versicherten überlebt. In diesen Jahren erhält der Hinterbliebene eine Witwen- bzw. Witwerrente, die grundsätzlich $60 \%$ der Rente des Verstorbenen beträgt. ${ }^{233} \mathrm{Da}$ Männer mehrheitlich älter als ihre Ehefrauen sind und eine geringere Lebenserwartung aufweisen, liegen vor allem bei männlichen Versicherten die Renditen Verheirateter über den Werten Alleinstehender. Tendenziell weisen nach dieser Modellierung die Renditen von alleinstehenden und verheirateten Frauen sowie von verheirateten Männern ähnliche Werte auf, die Renditen alleinstehender Männer liegen darunter. Neben den angesprochenen Unschärfen, die der Eckrentner auch bei alleinstehenden durchgehend Erwerbstätigen aufweist, wird bei Verheirateten von weiteren renditerelevanten Einflüssen abstrahiert:

- Die Renditen beziehen sich ausschließlich auf Einverdienerpaare, eigene Rentenansprüche des zweiten Partners existieren nicht. Vor allem bei Doppelverdienern ist jedoch mit einer Kürzung der Witwenrente wegen des eigenen Einkommens des hinterbliebenen Partners zu rechnen.

- Verschiedene Transferelemente von Renten wie die Berücksichtigung von Kindererziehung und die Aufwertung niedriger Einkommen (Rente nach Mindesteinkommen) kommen typischerweise verheirateten Versicherten zu Gute, fehlen jedoch beim Eckrentner. Die Ausblendung von Umverteilungselementen macht die Rendite von Verheirateten potenziell noch anfälliger für Verzerrungen.

Die beiden Aspekte wirken in entgegengesetzte Richtungen, bei Doppelverdienern ist eine Überschätzung der Rendite durch verheiratete Eckrentner zu erwarten, bei Paaren mit Kindern und/ oder eingeschränkter Erwerbstätigkeit eines Partners eine Unterschätzung. Bei der Berechnung von Renditen verheirateter Versicherter mit dem STM wurde für Ehepaare die Rendite der von innen gemeinsam entrichteten Beiträge und Renten ermittelt, die oben angegebene Kapitalwertformel mithin über zwei Personen aufsummiert. ${ }^{234}$ Die zu diskontierende Zeitreihe umfasst damit die

${ }^{233}$ Zukünftig sinkt einerseits der Wert von $60 \%$ auf $55 \%$, andererseits werden Kindererziehungszeiten bei Hinterbliebenenrenten rentensteigernd berücksichtigt. Weiterhin werden auf die Hinterbliebenenrente Einkommen angerechnet (vgl. Kapitel 5.1).

234 Alternativ möglich aber ungebräuchlich wäre, die Eheleute getrennt zu betrachten und die Rentenzahlungen (eigene Rente plus Witwenrente) separat den anspruchsauslösenden Beitragszahlungen zuzuordnen, so dass statt einer gemeinsamen Rendite des Paares zwei einzelne Renditen resultieren. Dieses Vorgehen führt zu zum Teil sehr hohen Renditen für eingeschränkt er- 
Beitragszahlungen beider Partner und die jeweils bezogenen Renten, die sich aus zwei Altersrenten und der Hinterbliebenenrente des später versterbenden Partners zusammensetzen. Während bei alleinstehenden Versicherten in dieser Arbeit stets durchgehende Erwerbstätigkeit angenommen wird, legen zum einen Analysen von Rentenbeständen und zum anderen die Transferelemente der Rentenversicherung eine weitergehende Differenzierung der Enwerbsmuster bei Ehepaaren nahe. Für den ersten Partner wird weiterhin von durchgehender Vollzeiterwerbstätigkeit ausgegangen. In Anlehnung an Ergebnisse von Schmähl, Himmelreicher und Viebrok (2004) sowie Grub (2005) wurden drei Erwerbsmuster des zweiten Partners -der empirisch in der Regel die Erwerbsbeteiligung von Ehefrauen reflektiert- unterschieden, weiterhin wurde die Altersdifferenz mit zwei Jahren angesetzt: ${ }^{235}$

- Einverdiener. Bei diesem Paartyp beschränkt sich die Erwerbstätigkeit der Ehefrau auf wenige Jahre bis zur Heirat, wodurch sie einen geringen eigenen Rentenanspruch erwirbt. Bei kinderlosen Paaren ähnelt diese Konstellation weitgehend dem Grundmuster verheirateter männlicher Eckrentner.

- Teilzeit: Die Ehefrau ist bis zur Geburt des ersten Kindes vollzeiterwerbstätig, während der ersten drei Lebensjahre eines Kindes beschränkt sie sich auf die Betreuung. Anschließend übt sie bis zum Renteneintritt eine Teilzeitbeschäftigung aus (50\% des Vollzeit-Bruttoeinkommens). Bei diesem Erwerbsmuster ergeben sich rund halb so viele Entgeltpunkte aus Beiträgen wie bei einer durchgehenden Vollzeiterwerbstätigkeit. ${ }^{236}$

- Doppelverdiener. Beide Partner sind unabhängig von der Kinderzahl durchgehend vollzeiterwerbstätig.

Empirisch bestehen Zusammenhänge zwischen der Kinderzahl und diesen Erwerbsmustern, Einverdienerpaare und Teilzeitbeschäftigung treten häufiger bei Paaren mit Kindern auf. Um die Einflüsse verschiedener Vorschriften der Rentenberechnung auf die implizite Rendite von Verheirateten herauszuarbeiten, wurden jedoch auch untypische Kombinationen wie kinderlose Einverdiener analysiert. Weiterhin wird durchgehend von gleich qualifizierten Partnern ausgegangen, Frau und Mann verfügen also über den gleichen Abschluss.

Das Zusammenwirken verschiedener Transferelemente der Rentenversicherung führt zu äußerst uneinheitlichen Verläufen der Begünstigung je nach Qualifikation, Erwerbsmuster und Kinderzahl (Abbildung 56). Die Abbildung zeigt für einige markante Fälle die Entgeltpunkte aus Transfers bei den Altersrenten der Frau, die aus Ausbildung, Kindererziehung und Höherbewertung niedriger Einkommen resultieren. Bei kinderlosen vollzeiterwerbstätigen Frauen entsprechen sowohl die Entgeltpunkte aus eigenen Beiträgen als auch aus Transfers den Werten gleichaltriger Männer mit dem jeweiligen Abschluss (vgl. Tabelle 15 und Abbildung 50). Teilzeiterwerbstätigkeit führt bei Angehörigen der älteren Kohorten mit niedrigen und mittleren Einkommen zu recht

werbstätige Frauen mit Kindem, die allerdings wenig geeignet erscheinen, Verteilungswirkungen der Rentenversicherung zu beschreiben. In diesen Fällen ergeben sich niedrige Entgeltpunktsummen, die einen sehr großen Transferanteil aufweisen.

236 Als Zeitpunkt der ersten Geburt eines Kindes wird das dritte Jahr nach der Heirat angenommen, das seinerseits dem dritten bis fünften Jahr der Erwerbsphase der Frau entspricht. Weitere Kinder folgen in jeweils zweijährigem Abstand. 
hohen Rentenzuschlägen von bis zu acht Entgeltpunkten, ursächlich ist die Vergabe von Mindestentgeltpunkten für Beitragsjahre bis 1991 (Ohne, Teilzeit, kinderlos). Bei Akademikerinnen schlägt sich die Rente nach Mindesteinkommen wegen ihres höheren Verdienstes hingegen nicht nieder (Uni, Teilzeit, kinderlos), als Transfer tritt hier die Bewertung der Ausbildungszeiten bei den ältesten Kohorten auf. Rentenzuschläge wegen der Erziehung von Kindern nehmen über die Kohorten stark zu. Zwei Kinder führen für um 1930 geborene Hausfrauen zu 1,5 Entgeltpunkten aus Transfers, bei Jahrgängen bis etwa 1965 liegt der Wert bei 2,0 Entgeltpunkten (Hausfrau, 2 Kinder). Auf die jüngeren Kohorten wirkt sich die Erhöhung der Kindererziehungszeit von einem auf drei Jahre sowie unter Umständen zusätzlich die Aufwertung von Kinderberücksichtigungszeiten aus, so dass Hausfrauen für zwei Kinder mindestens 6,0 und bis zu 7,3 Entgeltpunkte erhalten.

Abbildung 56: Entgeltpunkte aus Transfers: Kinder und Erwerbsbeteiligung

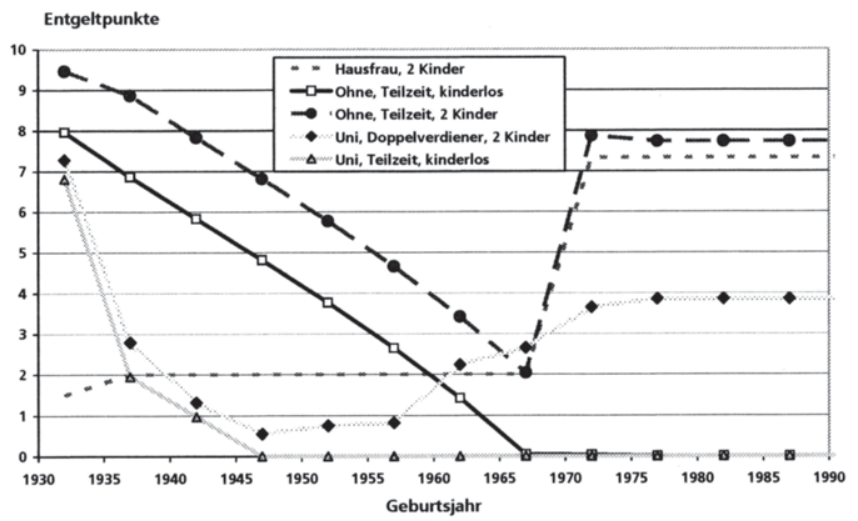

Quelle: eigene Berechnungen

Bei erwerbstätigen Müttern hängt die Anzahl der für Kinder vergebenen Entgeltpunkte wesentlich vom Einkommensniveau ab. Mütter mit niedrigem bis mittlerem Einkommen profitieren am stärksten von der Bewertung der Kindererziehung (Ohne, Teilzeit, 2 Kinder), bei hohen Einkommen wirkt sich hingegen die Begrenzung der Entgeltpunkte auf den sich an der Beitragsbemessungsgrenze ergebenden Maximalwert aus (Uni, Doppelverdiener, 2 Kinder). Für teilzeitbeschäftigte Mütter ohne Abschluss ergeben sich hier 7,7 Entgeltpunkte, für vollzeiterwerbstätige Universitätsabsolventinnen mit 3,9 Entgeltpunkten nur etwa der halbe Wert. ${ }^{237}$ Aus den Vorschriften des SGB VI zur Berücksichtigung von Kindern folgt als Grundmuster eine zunächst mit dem Einkommen ansteigende Anzahl von Entgeltpunkten aus Transfers, womit

${ }^{237}$ S. zu den Spannweiten der effektiven Rentensteigerung auf Grund von Kindererziehung in Abhängigkeit von Kinderzahl und Einkommen auch Schmähl, Rothgang, Viebrok (2006), S. 47ff 
auf eine Begünstigung teilzeiterwerbstätiger Mütter hingewirkt wird, bei gut verdienenden (vollzeit-)erwerbstätigen Frauen mit kurzer Erwerbsunterbrechung ergeben sich hingegen die geringsten kindbedingten Rentenzuschläge.

Abbildung 57 zeigt Spannweiten der nominalen impliziten Renditen für kinderlose Paare mit verschiedenen Einkommensverläufen und Erwerbsmustern auf. Analog zur Darstellung für alleinstehende Männer in Abbildung 52 dienen die Renditen von Eckrentnerpaaren als Referenzpunkt. Für Einverdienerpaare ergeben sich ähnliche Befunde wie bei alleinstehenden Männern. Die qualifikationsabhängig abweichenden Einkommensprofile und der Abbau der Bewertung von Ausbildungszeiten entfalten hier vergleichbare Wirkungen (Renditen oberhalb der Eckrentnerwerte für alle Abschlüsse bei den ältesten Kohorten, Renditenachteile von Akademikern).

\section{Abbildung 57: Renditevergleich mit Eckrentnerpaaren (Eckrentnerpaar: 0\%) (Paare, kinderlos)}

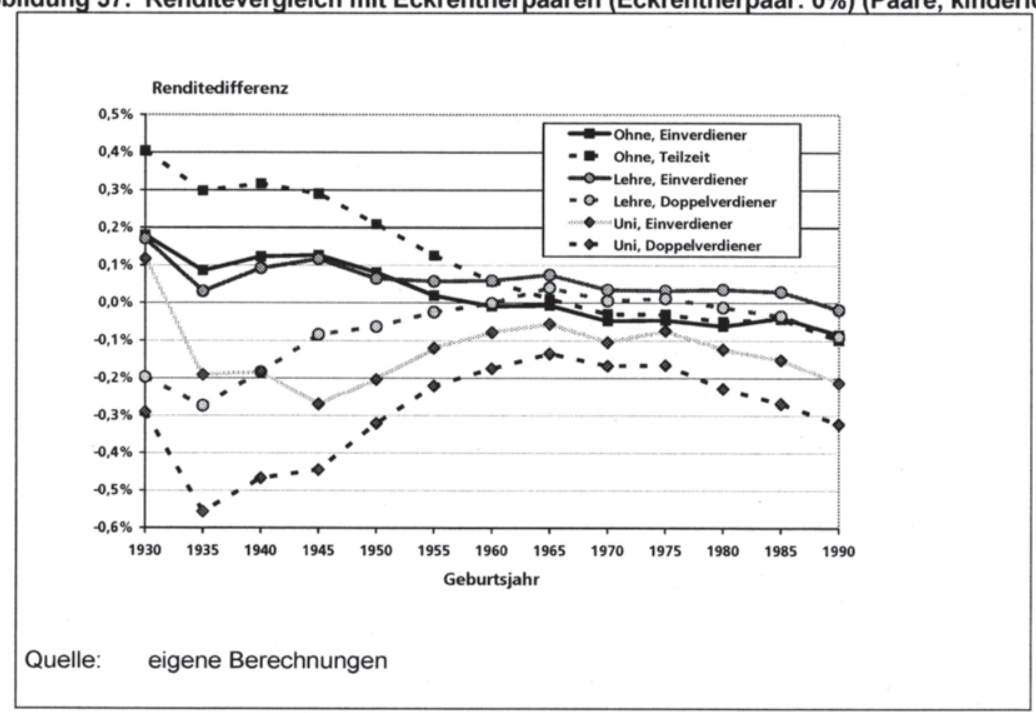

Renditen von Paaren mit zwei Erwerbstätigen liegen wegen der Anrechnung der eigenen Rente auf die Witwenrente grundsätzlich unter den Werten von Einverdienern, allerdings wird dieser Effekt durch die Höherbewertung niedriger Einkommen zum Teil deutlich überkompensiert. Teilzeiterwerbstätigkeit bei niedrigem Einkommen führt hier zu Renditevorteilen gegenüber Einverdienern von bis zu 0,22 Prozentpunkten (Ohne, Teilzeit im Vergleich zu Ohne, Einverdiener, Geburtsjahr 1930). Durch die Beschränkung der Rente nach Mindesteinkommen auf Beitragszeiten bis 1991 nimmt dieser Vorteil über die Kohorten bis etwa 1970 kontinuierlich ab. Der Vergleich von Doppel- mit Einverdienern zeigt zunächst recht starke Renditenachteile von bis zu -0,4 Prozentpunkten der Doppelverdiener für die Kohorten um 1930. Dieser Effekt resultiert jedoch überwiegend aus der angenommenen Altersdifferenz der Partner und nicht aus der Kürzung der Witwenrente. Da in der Abbildung die für das Geburtsjahr 1930 angegebenen Werte für ein Paar gelten, das in den Jahren 1930 und 1932 geboren wurde, folgt der Renditenachteil von Doppelverdienern pri- 
mär aus dem allgemein zu beobachtenden starken Renditeverfall über die Kohorten von 1930 bis 1945. Für die danach Geborenen sind die Renditenachteile von Doppelverdienern gegenüber Einverdienern sehr moderat, sie betragen bei niedrigem Einkommen maximal -0,05 Prozentpunkte (Ohne). Durch die höheren eigenen Renten von Akademikerinnen sind die Differenzen bei innen größer, sie belaufen sich jedoch auch hier auf höchstens $-0,12$ Prozentpunkte (Uni).

Unter Renditegesichtspunkten ist der Einfluss der Einkommensanrechnung auf Hinterbliebenenrenten von überraschend geringer Bedeutung, andere Faktoren wie die Verteilung von Einkommen über den Lebenszyklus und Entgeltpunkte aus Transfers führen zu wesentlich stärker ausgeprägten intragenerativen Unterschieden. In Hinblick auf die Aussagekraft des Eckrentners zur Untersuchung von Verteilungswirkungen der gesetzlichen Rentenversicherung lässt sich hiernach konstatieren, dass die Renditen für Paare annähernd unabhängig vom Erwerbsverhalten des zweiten Partners ausfallen. Aus der Ausblendung eventueller eigener Rentenansprüche von Hinterbliebenen, die zur Minderung der Witwenrente führen, ergeben sich überwiegend nur geringfügige Verzerrungen der impliziten Renditen durch Eckrentnerpaare. Maximal werden die Renditen um gut 0,1 Prozentpunkte überschätzt (bei Doppelverdienern mit hohen Einkommen). Auch die Absenkung des Rentenartfaktors großer Witwenrenten von 0,6 auf 0,55, die sich in der Regel auf ab 1962 Geborene auswirkt, hat nur einen leichten Einfluss auf die implizite nominale Rendite verheirateter Versicherter. Bei einem Eckrentnerpaar ohne Kinder sinkt sie für alle betroffenen Kohorten um rund 0,05 Prozentpunkte.

Zu nur geringen Renditenachteilen von Doppelverdienern im Vergleich zu Einverdienern trägt die gemäßigte Anrechnung von Einkommen auf Witwenrenten bei. Für ein Akademikerpaar der Kohorten ab 1962, dessen Partner jeweils bis zu 67,1 Entgeltpunkte erwerben, ergibt sich eine Kürzung der Hinterbliebenenrente um rund $44 \%$, beim niedrigsten betrachteten Einkommen (Ohne) um 23\%. ${ }^{238}$ Die Bruttorenten der Hinterbliebenen summieren sich damit auf rund $65 \%$ (Uni) bis $71 \%$ (Ohne) des Betrages, den das Paar bezieht, solange beide Partner leben. Das Versorgungsniveau liegt damit um 10 bis 16 Prozentpunkte höher als bei Einverdienerpaaren, bei denen sich die Relation der Bruttorenten vor und nach dem Tod des ersten Partners unmittelbar aus dem Rentenartfaktor ergibt und für jüngere Kohorten qualifikationsunabhängig $55 \%$ beträgt. Im Vergleich zu Alleinstehenden, die nur eine Rente aus eigenen Ansprüchen beziehen, verfügen Hinterbliebene aus Doppelverdienerehen über eine rund $31 \%$ (Uni) bis $42 \%$ (Ohne) höhere Bruttorente.

Als grundlegende Funktion von Hinterbliebenenrenten gilt der Unterhaltsersatz, durch den quasi Unterhaltsansprüche an den Partner über dessen Tod hinaus fingiert werden. Da bei den hier betrachteten Doppelverdienern diese Funktion hinfällig ist, erscheinen die Anrechnungsregeln des SGB VI bei Witwenrenten unangemessen großzügig. Im Vergleich zu Alleinstehenden ergibt sich ein Ehebonus, der weder mit dem Äquivalenzprinzip vereinbar noch aus dem Grundanliegen der Absicherung des

${ }^{238}$ Auf Witwenrenten werden $40 \%$ des Einkommens angerechnet, das 26,4 Entgeltpunkte (zuzüglich 5,6 Entgeltpunkte je Kind) übersteigt ( $\$ 97$ Abs. 2 SGB VI). Bei 67,1 Entgeltpunkten beider Partner ergibt sich daraus überschlägig eine Witwenrente von 20,6 Entgeltpunkten, soweit neben der gesetzlichen Rente kein weiteres Einkommen vorliegt:

$\left(67,1^{*} 0,55\right)-0,4^{*}(67,1-26,4)=20,6$

20,6 Entgeltpunkte sind rund $56 \%$ der ungekürzten Witwenrente in Höhe von 36,9 Entgeltpunkten ( $55 \%$ von 67,1 Entgeltpunkten). 
Langlebigkeitsrisikos ableitbar ist. Im Vergleich zu Einverdienerehen führt die Anrechnung eigener Altersrenten von Doppelverdienern einerseits zwar zu einer Stärkung des Äquivalenzprinzips, da mit der Minderung von Hinterbliebenenrenten der Anteil nicht beitragsgedeckter Leistungen reduziert wird. Andererseits erscheint das wesentlich höhere Versorgungsniveau von verwitweten Doppelverdienern fragwürdig, wenn Hinterbliebenenrenten als bedarfsorientierte Transferzahlung anzusehen sind. ${ }^{239}$

$\mathrm{Zu}$ der Frage, in welchem Ausmaß durch die Eckrentnerbetrachtung intragenerative Renditeunterschiede überdeckt werden, waren für alleinstehende Männer Spannweiten der qualifikationsabhängigen Renditen von bis zu gut 0,4 Prozentpunkten ermittelt worden, die für um 1940 Geborene auftreten (s. o.). Bei kinderlosen Paaren ergeben sich als Folge der unterschiedlichen Erwerbsmuster sowie der hier auftretenden Entgeltpunkte aus Transfers für niedrige Einkommen größere intragenerative Unterschiede. Die Spannweite der Renditen in Abbildung 57 liegt durchgehend über den Spannweiten für Alleinstehende und beträgt bis zu 0,86 Prozentpunkte (Kohorte 1935). Wie bei den Alleinstehenden sind die Renditeunterschiede für die Kohorten von 1965 bis 1975 am geringsten (Spannweiten von gut 0,2 Prozentpunkten), für jüngere Jahrgänge nehmen sie wieder zu und belaufen sich auf etwa 0,3 Prozentpunkte. Diese Entwicklung zunächst großer, dann stark ab- und anschließend wieder leicht zunehmender Spannweiten wird zum einen durch den Abbau von Entgeltpunkten aus Transfers in der Rentenversicherung geprägt. Zum anderen wirkt sich bei den jüngeren Kohorten die oben diskutierte Annahme zum zukünftigen Lohnwachstum aus, die Nachteile von gestauchten (akademischen) Einkommensprofilen verstärkt. Insgesamt bleibt im Vergleich zur Betrachtung alleinstehender Eckrentner als Schlussfolgerung, dass die Verdichtung der Renditen verheirateter Versicherter einer Kohorte zu einem einzelnen Wert zusätzliche intragenerative Unterschiede verwischt. Vor allem innerhalb der älteren Kohorten ergeben sich recht große Abweichungen je nach Qualifikation und Erwerbsmuster.

Die Berücksichtigung von Kindern als weiterem Transferelement der Rentenversicherung führt zu höheren Renditen von Ehepaaren mit Kindern im Vergleich zu kinderlosen Paaren. Abbildung 58 zeigt für dieselben Konstellationen wie in Abbildung 57 wiederum die Abweichungen von kinderlosen Eckrentnerpaaren. Im Vergleich zu kinderlosen Paaren sind neben dem kindbedingt höheren Renditeniveau vor allem zwei Unterschiede festzustellen. Zum einen ergibt sich für ab etwa 1965 Geborene durch die Ausdehnung der Kindererziehungszeit von einem auf drei Jahre (gültig für Geburten nach 1991) eine Verbesserung der Renditeposition im Vergleich zum Eckrentnerpaar, die je nach Qualifikation und Erwerbsmuster zwischen knapp 0,1 (Uni, Doppelverdiener) und gut 0,2 Prozentpunkte (Ohne und Lehre, Einverdiener) ausmacht. Zum anderen sind die intragenerativen Unterschiede stärker ausgeprägt. Für die Kohorte 1935 beträgt die Spannweite der Renditen 1,07 Prozentpunkte, für die Kohorten zwischen 1965 und 1975, die in den bisher betrachteten Fällen (Alleinstehende und kinderlose Paare) relativ homogene Renditen aufweisen, zeigen sich Dif-

${ }^{239} \mathrm{~S}$. zur Einordnung von Hinterbliebenenrenten als versicherungsfremde Leistung (mit der Konsequenz, dass eine Finanzierung über das Steuersystem statt über die Rentenversicherung indiziert wäre) und zu ihrer Charakterisierung als bedarfsorientierter Transfer: Deutscher Bundestag (2002), S. 167 
ferenzen vor mindestens 0,55 Prozentpunkten, die über die weiteren Geburtsjahre auf bis 0,65 Prozentpunkte anwachsen.

Abbildung 58: Renditevergleich mit Eckrentnerpaaren (Eckrentnerpaar: 0\%) (Paare, 2 Kinder)

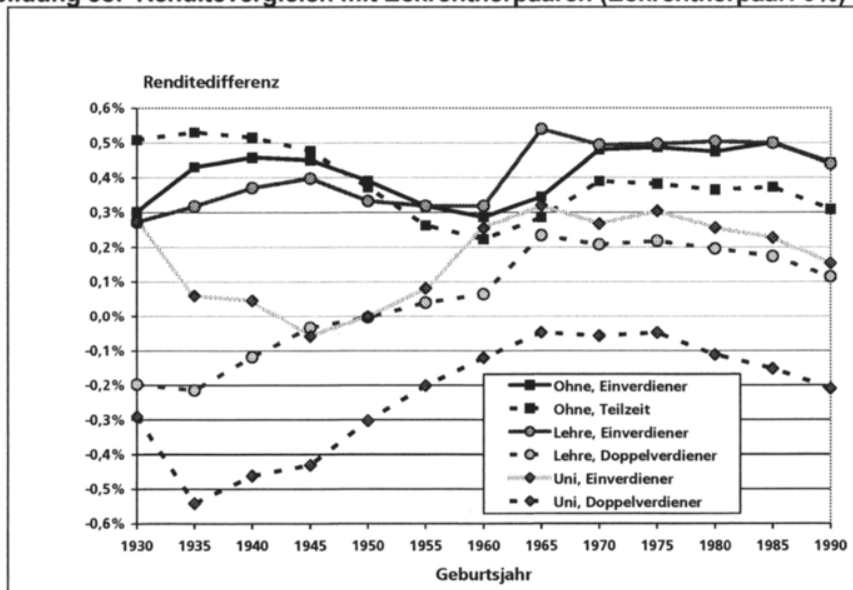

Quelle: $\quad$ eigene Berechnungen

Eine stärkere Auffächerung des Renditespektrums innerhalb einer Kohorte wird von den gesetzlichen Vorgaben zur Berücksichtigung von Kindern vorgeprägt. Dominierende Komponente der Transfers für Kinder sind in der Rentenberechnung additive Zuschläge (Entgeltpunkte für Kindererziehungszeiten, Entgeltpunkte für Kinder bei der Witwenrente für Kohorten ab 1962), dagegen entfalten einkommensabhängige Begünstigungen (Aufwertung von Entgeltpunkten aus Berücksichtigungszeiten) nur geringere Wirkungen. Ein annähernd konstanter absoluter Zuschlag an Entgeltpunkten für alle Angehörigen einer Kohorte wirkt umso stärker renditesteigernd, je weniger Entgeltpunkte aus Beiträgen der Rente zu Grunde liegen. So erhalten Einverdienerpaare der jüngeren Kohorten qualifikationsunabhängig für zwei Kinder rund 7,3 Entgeltpunkte aus Transfers (bei einem aktuellen Rentenwert von 26,13 Euro entsprechend rund 192 Euro), womit die relative Aufwertung der niedrigen Rente von Geringqualifizierten wesentlich stärker ausfällt als bei hohen Renten. ${ }^{240}$ Hieraus folgt, dass erstens für jedes Qualifikationsniveau die Renditewirkung von Kindern bei Einverdienern höher ist als bei Doppelverdienern und zweitens dass die Renditewirkung mit steigendem Einkommen abnimmt. Abbildung 59 zeigt die Differenzen der Abbildung 57 und Abbildung 58 zu Grunde liegenden Renditen von Paaren mit null bzw. zwei Kindern. Die dargestellten Renditedifferenzen entsprechen somit dem Effekt, der ausschließlich von den kindbedingten Rentenzuschlägen ausgeht. Für Teilzeiterwerbs-

240 Die kindbedingten Entgeltpunkte betragen für die hier betrachteten Biographien bis zu 9,1 (Lehre, Teilzeit). Bei niedrigen bis mittleren Einkommen führt die Aufwertung von während Kinderberücksichtigungszeiten entrichteter Beiträge zu höheren Rentenzuschlägen als bei Nichterwerbstätigen. 
tätige liegen die Renditewirkungen von zwei Kindern zwischen den abgebildeten Werten für Ein- und Doppelverdiener.

Abbildung 59: Renditewirkung von 2 Kindern: Paare mit zwei Kindern gegenüber kinderlosen Paaren

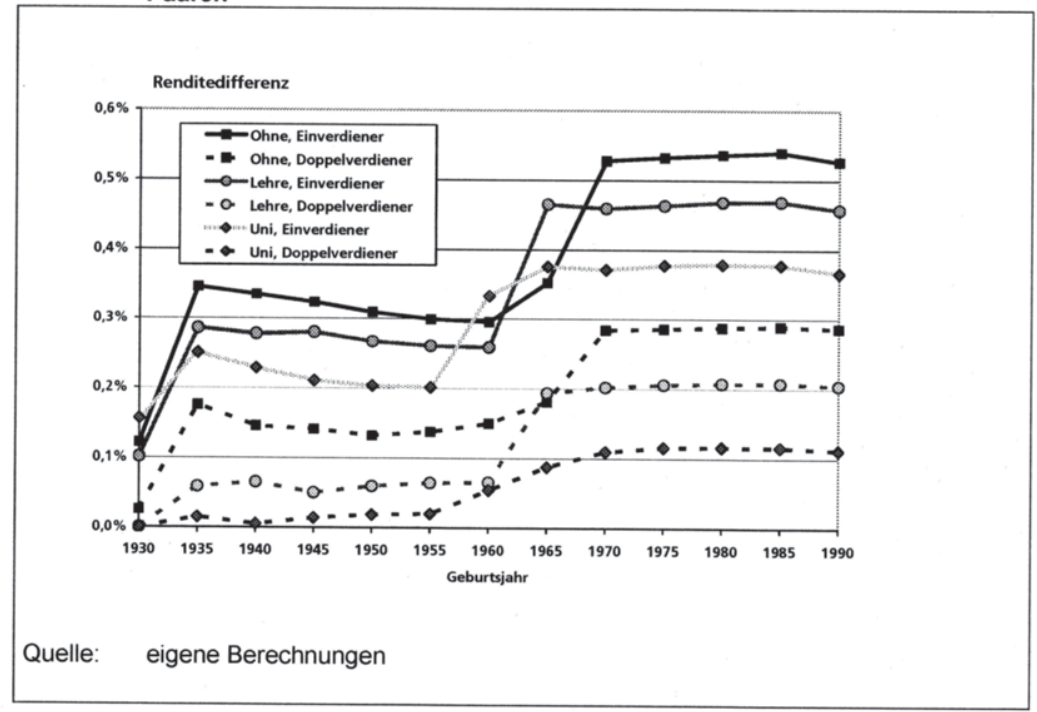

Weiterhin führt die Kappung von Entgeltpunkten an der Beitragsbemessungsgrenze zu einer Verstärkung intragenerativer Renditeunterschiede. Betroffen sind hiervon Paare mit hohem Einkommen und kurzer Erwerbsunterbrechung (rund 3,9 Entgeltpunkte für zwei Kinder von Uni-Absolventinnen). In diesen Fällen wirkt das gesetzgeberische Konzept restringierend, mit kindbedingten Rentenzuschlägen primär durch Erziehungszeiten verlorene Rentenansprüche zu kompensieren. Insgesamt zeigt sich über alle Qualifikationsniveaus ein deutlicher Anstieg des von zwei Kindern ausgehenden Effekts bei den Kohorten, deren Kinder nach 1991 geboren werden. Bei Einverdienerpaaren liegen die Renditewirkungen für Kohorten ab etwa 1965 zwischen rund 0,38 (Uni) und 0,54 Prozentpunkten (Ohne). Für Doppelverdiener mit 0,12 (Uni) bis 0,29 Prozentpunkten (Ohne) sind die Werte aus den genannten Gründen geringer. Es bestehen somit zum einen durchgehend recht ausgeprägte intragenerative Unterschiede in der Renditewirkung von Kindern, zum anderen ergibt sich um den Stichtermin 1991/92 ein nennenswerter kindbedingter Renditeanstieg. Zur Beurteilung intergenerativer Verteilungswirkungen der Rentenversicherung lässt sich aus letzterem Aspekt ableiten, dass eine auf kinderlose Versicherte beschränkte Betrachtung zu einer leichten Verzerrung zu Ungunsten der bis etwa 1965 geborenen Kohorten führt. 


\subsubsection{Renditen nach Steuern}

Die bisher vorgestellten Ergebnisse zu Renditen der gesetzlichen Rentenversicherung beziehen sich ausschließlich auf Bruttogrößen, in die Kapitalwertformel fließen einerseits die Bruttobeitragszahlungen und andererseits die Bruttorenten ein. Alternativ können Renditen nach Steuern bestimmt werden. Abweichungen zwischen Renditen vor und nach Steuern ergeben sich zum einen aus der (begrenzten) steuerlichen Abzugsfähigkeit von Rentenversicherungsbeiträgen als Vorsorgeaufwendungen. Die Bruttobeiträge überzeichnen die effektive Belastung der Versicherten während der Beitragsphase in dem Umfang, in dem aus den entrichteten Beiträgen eine Steuerminderung resultiert. Je stärker die Steuerersparnis für Beitragszahler ausfällt, desto weiter liegen die Renditen nach Steuern über den Werten vor Steuern. Zum anderen wirkt sich in entgegengesetzte Richtung die Besteuerung während der Rentenbezugsphase aus. Die Rendite nach Steuern liegt um so eher unter der Rendite vor Steuern, je stärker der steuerliche Zugriff auf Renten ausfällt. Inter- und intragenerative Unterschiede beim Ausmaß der Abweichung der Rendite nach Steuern vom Wert vor Steuern sind aus mehreren Gründen zu erwarten:

- Intergenerative Unterschiede: Der mit dem Alterseinkünftegesetz angestoßene Systemwechsel von der vor- zur nachgelagerten Besteuerung der gesetzlichen Renten vollzieht sich in langen Übergangsphasen, während derer im Zeitraum von 2005 bis 2025 zunehmende Anteile der Beitragszahlungen steuerfrei gestellt sowie für Renteneintritte zwischen 2005 und 2040 wachsende Anteile der Renten besteuert werden (vgl. Kapitel 4.2.5). Die betrachteten Kohorten sind entsprechend unterschiedlich lange den Systemen der vorund nachgelagerten Besteuerung unterworfen, was selbst bei sorgsam austarierten Übergangsregelungen intergenerativ kaum renditeneutral wirken kann. Zudem zeichnen sich auch ohne diesen Systemwechsel intergenerative Unterschiede durch die unstete Anpassung der Höchstbeträge abziehbarer Vorsorgeaufwendungen nach $\S 10$ Abs. 3 EStG ab. Seit den 1960er Jahren stiegen die Rentenversicherungsbeiträge stärker als die Höchstbeträge, so dass tendenziell zunehmende Anteile der Rentenversicherungsbeiträge steuerlich nicht berücksichtigt wurden (vgl. Kapitel 4.2.4).

- Intragenerative Unterschiede: Diese beiden möglichen Ursachen intergenerativer Unterschiede wirken auch intragenerativ renditedifferenzierend. Bei niedrigen Einkommen gehen von den Beschränkungen der Abzugsfähigkeit der Beiträge in der Erwerbsphase effektiv nur geringe Verschlechterungen aus, bei hohen Einkommen greift diese Restriktion eher. Der stärkere steuerliche Zugriff auf gesetzliche Renten ab 2005 wirkt sich auf hohe Renten unmittelbar aus, bei niedrigen Renten ist erst in einigen Jahren mit einem Anstieg der Steuerbelastung zu rechnen, da mit letzteren sowohl nach der bis 2004 geltenden Ertragsanteilsbesteuerung als auch nach dem AltEinkG ab 2005 der Grundfreibetrag des Steuertarifs unterschritten wird.

Steuerliche Aspekte der gesetzlichen Rentenversicherung wurden in den letzten Jahren vor allem in Hinblick auf den Übergang zur nachgelagerten Besteuerung beachtet, durch den grundsätzlich Steuerbelastungen von der Erwerbsphase in die Rentenbezugsphase verschoben werden, so dass die Verteilung der zu entrichtenden Steuern über den Lebenszyklus geglättet wird. In Untersuchungen zum AltEinkG domi- 
niert die Fragestellung, ob für einzelne Kohorten eine -verfassungsrechtlich unzulässige- Zweifachbesteuerung auftreten kann, darüber hinaus gehende Betrachtungen zu Zusammenhängen von Besteuerung und impliziten Renditen der Rentenversicherung existieren jedoch kaum. Während sich die Annahme vom Einkommensniveau unabhängiger Renditen bei einer Bruttobetrachtung auf das Äquivalenzprinzip der Rentenversicherung stützen kann, gilt dies für die Renditen nach Steuern unter einem progressiven Steuertarif nicht. Das Fehlen von Ergebnissen zu Renditen nach Steuern dürfte sowohl auf die Komplexität ihrer Berechnung als auch auf die starke Fallabhängigkeit zurückzuführen sein. Der Sozialbeirat etwa verzichtet bei seiner Beurteilung des AltEinkG auf eine Quantifizierung von Renditen nach Steuern und beschränkt sich auf Plausibilitätsüberlegungen: „Auf lange Sicht, d. h. nach dem vollständigen Umstieg auf die -für den Steuerzahler grundsätzlich vorteilhaftere- nachgelagerte Besteuerung, dürfte die Rendite nach Steuern allerdings größer ausfallen."241

Für Renditen nach Steuern sind neben den zur Bestimmung der Bruttorenditen erforderlichen Größen zusätzlich erstens die Steuerminderung durch die (begrenzte) Abzugsfähigkeit der Beitragszahlungen und zweitens die durch den Rentenbezug anfallenden Steuern zu ermitteln. In obiger Schreibweise der Kapitalwertformel zur Berechnung der Bruttorendite $C_{0}(z)$ (s. S. 184), wobei hier $Z_{t}$, die Beitragszahlungen während der Erwerbsphase und $R_{t}$ die Renten seien, ergibt sich die Rendite nach Steuern $C_{0}^{y}$ somit in der Form:

$$
C_{0}^{\prime \prime}(z)=C_{0}(z)+\sum_{i=0}^{l:(j)} D_{t}\left(Z_{t}\right)^{*}(1+z)^{-t}+\sum_{t=E(j), 1}^{T(j)} D_{t}\left(R_{j, 1}\right) *(1+z)^{-t}
$$

\section{mit $\quad D_{t}\left(Z_{t}\right) \quad$ Steuerminderung auf Grund von Rentenbeitragszahlungen} $D_{t}\left(R_{j+l}\right)$ Steuermehrbelastung auf Grund des Rentenbezugs

Die Steuerminder- und Steuermehrbelastungen der Versicherten hängen ihrerseits von den Änderungen der steuerlichen Bemessungsgrundlage (zu versteuerndes Einkommen) und den Steuertarifen ab. Zur Bestimmung der Steuerminder- und Steuermehrbelastungen $D_{1}(.$.$) sind jeweils zwei Szenarien zu betrachten: Zum einen ist die$ sich unter dem geltenden Recht festzusetzende Steuer zu ermitteln. In einem zweiten Schritt ist eine fiktive Steuer zu berechnen. Während der Rentenbezugsphase ist dies die zu entrichtende Steuer, wenn die Rente null beträgt (womit bei Alleinstehenden auch die Einkommensteuer null ist). In der Erwerbsphase ergibt sich die fiktive Steuer, indem bei der Berechnung der Einkommensteuer die Sonderausgaben um die auf Rentenversicherungsbeiträgen beruhenden Vorsorgeaufwendungen gekürzt werden. Problematisch an den Rechtsständen bis 2004 ist, dass die den Beitragszahlungen zur Rentenversicherung zuzuordnende Minderung der Bemessungsgrundlage nicht gesetzlich fixiert ist. Sämtliche Vorsorgeaufwendungen, also neben den Rentenversicherungsbeiträgen unter anderem auch Beiträge zu den anderen Zweigen der Sozialversicherung, fielen nach den Fassungen des EStG bis 2004 unter gemeinsame Höchstbeträge. Das EStG ab 2005 kennt hingegen eigene Höchst-

${ }^{241}$ Deutscher Bundestag (2004b), S. 91 
beträge für die Rentenversicherung ( $§ 10 \mathrm{Abs}$. $3 \mathrm{EStG}$ ), so dass seitdem dieses Problem nicht mehr auftritt.

Zur Bestimmung der abzugsfähigen Rentenversicherungsbeiträge bis 2004 sind daher Annahmen zu treffen, welchen Anteil der Höchstbeträge der Gesetzgeber den Rentenversicherungsbeiträgen zudachte. Es existieren verschiedene Lösungsvorschläge zur Modellierung dieses fiktiven Rechtsstands mit separaten Höchstbeträgen für Rentenversicherungsbeiträge, wobei in dieser Arbeit der von der "Sachverständigenkommission zur Neuordnung der steuerlichen Behandlung von Altersvorsorgeaufwendungen und Altersbezügen" vertretene Ansatz übernommen wird. Hiernach wird von einer gleichrangigen Abzugsfähigkeit verschiedener Formen von Vorsorgeaufwendungen ausgegangen, womit der Anteil der abzugsfähigen Rentenversicherungsbeiträge an den Vorsorgeaufwendungen ihrem Anteil am Sozialversicherungsbeitrag insgesamt entspricht. ${ }^{242}$ Wenn etwa der Beitragssatz zur Rentenversicherung die Hälfte der Summe der Beitragssätze zur Sozialversicherung ausmacht, entsprechen die abzugsfähigen Rentenversicherungsbeiträge hiernach auch der Hälfte der steuerlich anerkannten Vorsorgeaufwendungen.

Ob diese nahe liegende Aufteilungsregel angemessen ist, wurde in Hinblick auf die Verfassungskonformität der Übergangsvorschriften des AltEinkG kontrovers diskutiert. ${ }^{243}$ In welchem Umfang Rentenversicherungsbeiträge aus (un-)versteuertem Einkommen stammen, ist eine zentrale Stellgröße zur Diagnose von Verstößen gegen das Verbot einer Zweifachbesteuerung. Diese liegt vor, wenn im Lebenszyklus die Summe der aus versteuertem Einkommen stammenden nominalen Rentenbeiträge die Summe der steuerfrei gestellten nominalen Rentenbezüge übersteigt. ${ }^{244}$ Der unter juristischen Gesichtspunkten aufmerksam verfolgten, ökonomisch jedoch weitgehend irrelevanten Frage nach möglichen Zweifachbesteuerungen wird hier nicht weiter nachgegangen, lediglich die in diesem Kontext begründete Bestimmung der als Vorsorgeaufwendungen abzuziehenden Rentenversicherungsbeiträge wird aufgegriffen. Die Einschätzung einer eng begrenzten Aussagekraft des Konstrukts der Zweifachbesteuerung fußt vor allem auf dem inm zu Grunde liegenden Nominalwertprinzip. Wie sich die nominalen Summen von steuerlich nicht abzugsfähigen Beiträgen und steuerfrei gestellten Rentenbestandteilen zueinander verhalten, zwischen deren Entstehung mehrere Jahrzehnte vergehen, erscheint für intergenerative Belastungsvergleiche nebensächlich.

Die Einflüsse von Beiträgen und Leistungen der Rentenversicherung auf die zu entrichtende Einkommensteuer einschließlich eventueller Zuschlagsteuern sind in Abbildung 60 exemplarisch dargestellt. Die Abbildung zeigt am unteren und oberen Ende der betrachteten Einkommensskala (Ohne Abschluss und Uni) für die älteste (1930) sowie die jüngste (1990) betrachtete Kohorte die für die Renditen nach Steuern relevanten Steueränderungen in Preisen des Jahres 2005. Positive Werte entsprechen Steuerminderungen auf Grund von Rentenbeitragszahlungen, negative Werte den von Rentnern zu entrichtenden Steuern.

${ }^{242}$ S. Bundesministerium der Finanzen (Hrsg.) (2003), S. 43

243 S. zu verfassungsrechtlichen Vorgaben allgemein Papier (1998)

S. zu den Implikationen verschiedener Aufteilungsregeln für die rechtliche Bewertung des AltEinkG Brall, Bruno-Latocha, Lohmann (2003)

244 S. Bundesministerium der Finanzen (Hrsg.) (2003), S. $56 \mathrm{ff}$

Vgl. zur Problematik der Zweifachbesteuerung auch Grub (2005), S. 237ff 
Abbildung 60: Rentenversicherung und Steuerminder-I -mehrbelastungen (Alleinstehende, Preise 2005)

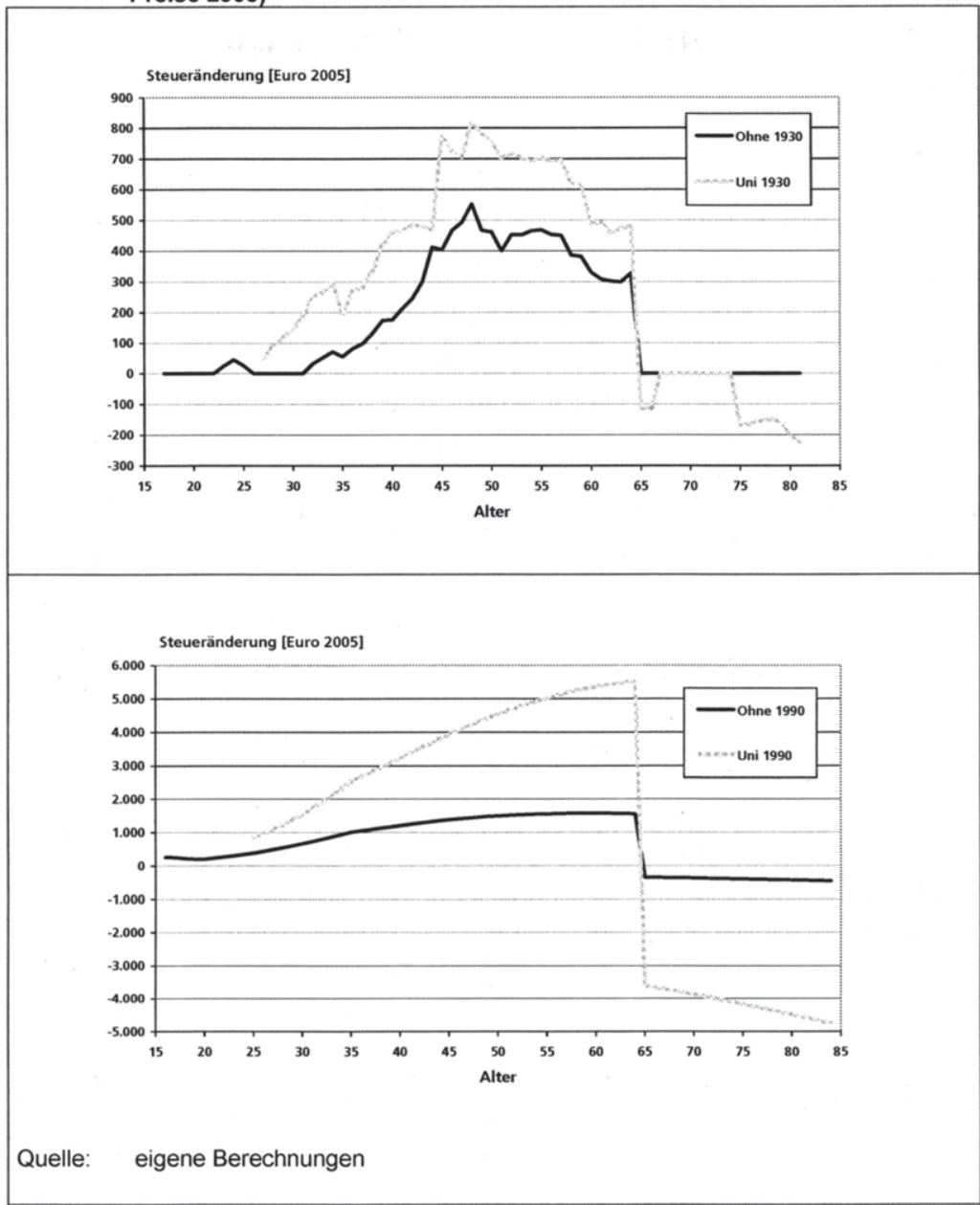

Für Bezieher geringer Einkommen der ältesten Kohorten ist unmittelbar erkennbar, dass die Rendite nach Steuern höher ausfällt als die Bruttorendite (Ohne, 1930). Während der Erwerbsphase führt der Abzug von Rentenversicherungsbeiträgen in den meisten Jahren effektiv zu einer Steuerentlastung, gleichzeitig bleibt die Rente auch nach Einsetzen des AltEinkG ab 2005 steuerfrei, da das sich aus der Rente ergebende zu versteuernde Einkommen stets den Grundfreibetrag des Steuertarifs un- 
terschreitet. ${ }^{245}$ Im Vergleich zur Bruttorendite treten folglich niedrigere (Netto-)Beiträge bei gleich hohen Renten auf, so dass die Rendite nach Steuern zwingend gröBer ist. Bei Angehörigen der ältesten Kohorten mit höheren Einkommen zeichnet sich ebenfalls eine über der Bruttorendite liegende Rendite nach Steuern ab (Uni, 1930). Zwar sind auf die höheren Renten Steuern zu entrichten, deren Beträge unterschreiten jedoch deutlich die vorher in der Beitragsphase auftretenden Steuerminderungen. Universitätsabsolventen des Jahrgangs 1930 haben zu Beginn ihrer Rentenphase Steuern zu entrichten, mit der starken Anhebung des Grundfreibetrags durch die Steuerreform 1996 bleiben dann auch ihre recht hohen Renten steuerlich unbelastet. Mit dem AltEinkG ergibt sich für ihre Renten ab 2005 dann wieder eine moderate Besteuerung.

Bei den ältesten Kohorten führen hiernach zwei Gründe zu Renditen nach Steuern, die über den jeweiligen Bruttorenditen liegen: Zum einen liegt in der Beitragsphase keine vollumfänglich vorgelagerte Besteuerung vor, die Beiträge zur Rentenversicherung werden zumindest teilweise aus unversteuertem Einkommen entrichtet. Zum anderen bewirken verschiedene steuerliche Freibeträge für Rentenbezieher, dass Renten faktisch weitgehend steuerfrei bezogen werden. Beim intragenerativen Vergleich der Steuerminderungen zwischen den Abschlüssen Ohne und Uni wirken mehrere Effekte. Die höheren Grenzsteuersätze von Uni-Absolventen führen auch zu höheren Steuerminderungen. Die ebenfalls höheren Rentenbeiträge der UniAbsolventen schlagen sich hingegen nur beschränkt nieder, da bei ihnen die Begrenzung der Abzugsfähigkeit stärkere Wirkung entfaltet. Die unstete Entwicklung der Steuerminderungen folgt aus verschiedenen Rechtsänderungen (Steuertarife, Vorsorgepauschalen, Beitragssätze der Rentenversicherung) und der Lohnentwicklung.

Für die jüngeren Kohorten ergeben sich einige markante Unterschiede. Erstens zeichnet sich durchgängig eine effektive Besteuerung ihrer Renten ab, auch bei relativ niedrigen Renten ist die Steuerschuld positiv (Ohne, 1990). Zweitens profitieren diese Kohorten in stärkerem Umfang von der zunehmenden Freistellung ihrer Beitragszahlungen. Diese beiden Effekte reflektieren das Grundprinzip des sukzessiven Übergangs zur nachgelagerten Besteuerung. Drittens ergibt sich eine stärkere Spreizung der Steuerminderungen in der Beitragsphase über die Einkommensskala als bei den älteren Kohorten. Unter dem zu Grunde liegenden progressiven Steuertarif dürfte der Umstieg auf die nachgelagerte Besteuerung durch das AltEinkG vor allem für Bezieher höherer Einkommen vorteilhaft sein. Der Anstieg der preisniveaubereinigten Steuerminderungen über die Erwerbsphase wird bei der Kohorte 1990 bis zum Lebensalter von 35 Jahren (Kalenderjahr 2025) vor allem von den bis dahin wachsenden Anteilen der steuerlich abzugsfähigen Rentenversicherungsbeiträge verursacht. Nach 2025 wirken sich noch Reallohnsteigerungen und zunehmende Rentenversicherungsbeiträge aus. Die mittleren Kohorten nehmen eine Position zwischen den für die Jahrgänge 1930 und 1990 dargestellten Verläufen ein.

Das Verhältnis von Renditen nach Steuern und Bruttorenditen wird von einem recht komplizierten Zusammenspiel mehrerer Faktoren geprägt, zu denen der Umfang

245 In den Jahren am Beginn der Erwerbsphase, in denen die Abzugsfähigkeit der Rentenversicherungsbeiträge keine Steuerminderung mit sich bringt, ist entweder die Einkommensteuer auch ohne deren Abzug von der Bemessungsgrundlage bereits null oder recht großzügige Pauschbeträge für Sonderausgaben führen dazu, dass von den Vorsorgeaufwendungen keine weitere Entlastung ausgeht. 
steuerlich abzugsfähiger Rentenversicherungsbeiträge, vom Renteneintrittszeitpunkt abhängender Rentenfreibeträge sowie Grundfreibetrag und Tarifverlauf der Einkommensteuer zählen. Ein wesentliches Ergebnis der Ermittlung von Renditen nach Steuern mit dem STM ist, dass diese für alle betrachteten Fälle höher als die Bruttorenditen ausfallen. In Abbildung 61 sind die Abweichungen der Renditen nach Steuern von den Bruttorenditen für alleinstehende männliche Versicherte dargestellt, bei positiven Werten ist die Rendite nach Steuern größer als die Bruttorendite. Die Abbildung zeigt die Differenzen nominaler Renditen, beim Vergleich realer Renditen ergeben sich nahezu identische Werte.

\section{Abbildung 61: Renditen nach Steuern - Bruttorenditen (Männer, alleinstehend, nominal)}

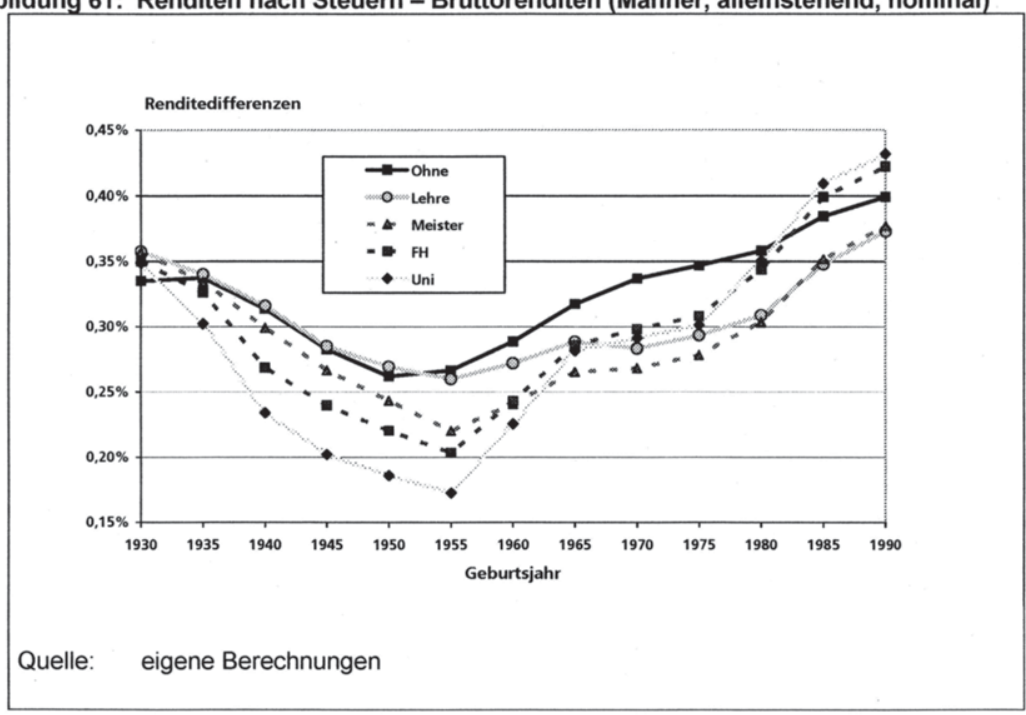

Die Entwicklung der Renditedifferenzen über die Kohorten beschreibt eine leichte u-Kurve, die bei höheren Einkommen eine stärkere Krümmung aufweist. Für um 1930 geborene Versicherte überschreiten die Renditen nach Steuern aller fünf $A b-$ schlüsse die Bruttorenditen um etwa 0,35 Prozentpunkte, über die Kohorten bis etwa 1955 nähern sich die Renditen nach Steuern vor allem bei höheren Einkommen zunehmend den Bruttorenditen an. Für den Jahrgang 1955 liegen die Renditen nach Steuern noch um 0,17 (Uni) bis 0,27 Prozentpunkte (Ohne) über den Bruttorenditen. Bei nach 1955 Geborenen steigen durchgängig die Differenzen wieder an und erreichen für die Kohorte 1990 mit Werten von 0,37 (Lehre, Meister) bis 0,43 (FH, Uni) Prozentpunkten die höchsten Ausprägungen. Über die Kohorten von 1955 bis 1990 ergibt sich damit auch eine Umkehr der Rangfolge der Renditewirkungen der Besteuerung. Bei den vor 1955 Geborenen schlägt sich insbesondere der stärkere steuerliche Zugriff auf Renten durch das AltEinkG nieder, die Verbesserungen der Abzugsfähigkeit der Beiträge wirken indessen für diese Kohorten nur relativ kurze Zeit. Da die Rentenbesteuerung ab 2005 primär für höhere Renten zu effektiven Mehrbelastungen führt, zeigen sich relativ geringe Renditedifferenzen bei Akademi- 
kern $(F H, U n i)$. Umgekehrt verbessert sich die Position von Akademikern, je länger eine Kohorte von der zunehmenden Steuerfreistellung der Beitragszahlungen profitiert.

Ansonsten zeigen sich in den Verläufen der Abbildung 61 noch Auswirkungen der Übergangsregelungen des AltEinkG. Bis zum Geburtsjahrgang 1955 sinkt der so genannte persönliche Rentenfreibetrag jährlich um zwei Prozentpunkte, danach noch um einen Prozentpunkt, was die bis zu diesem Jahrgang fallenden und anschließend steigenden Renditedifferenzen erklärt. Weiterhin ist der Jahrgang 1975 der letzte, bei dem typisierend davon auszugehen ist, dass ein Teil seiner Renten unversteuert bleibt, bei allen jüngeren Jahrgängen sind die Rentenfreibeträge null. Über die Kohorten von 1955 bis 1975 wirken damit zwei Effekte in entgegengesetzte Richtungen: Für die älteren aus diesem Intervall fallen geringere Steuern in der Rentenbezugsphase an, die jüngeren hingegen profitieren stärker von der Freistellung der Beiträge in der Erwerbsphase. Die Kohorten ab 1975 unterscheiden sich indessen nur noch in dem Umfang der steuerfrei gestellten Beiträge. Entsprechend zeigt sich ab dem Geburtsjahr 1975 ein stärkerer Anstieg der Renditedifferenzen.

Abbildung 62: Renditen nach Steuern - Bruttorenditen (Paare, nominal)

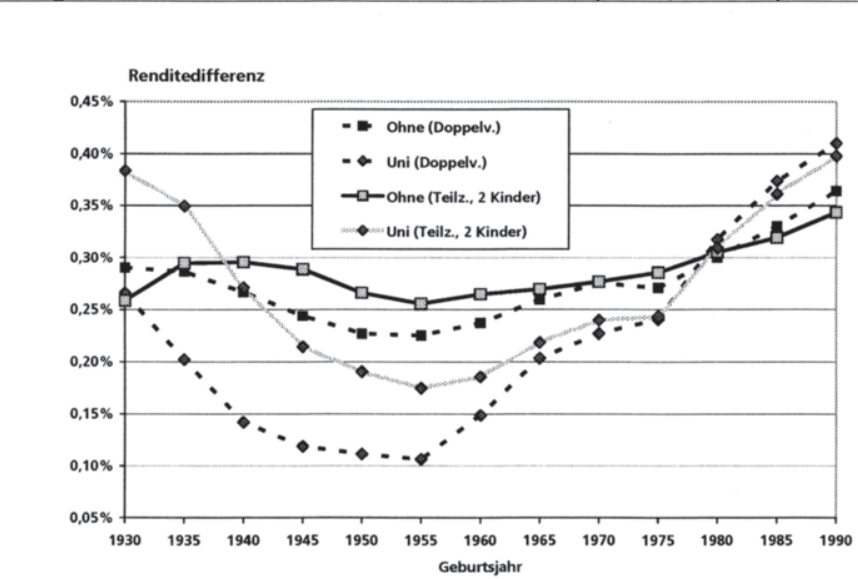

Quelle: eigene Berechnungen

Die Betrachtung von versicherten Paaren führt zu ähnlichen Befunden wie bei alleinstehenden männlichen Versicherten. Auch hier ergeben sich stets positive Differenzen von Renditen nach Steuern und Bruttorenditen sowie der in etwa u-förmige Verlauf mit einer stärkeren Krümmung bei höheren Einkommen (Abbildung 62). Dargestellt sind kinderlose Doppelverdiener sowie Paare mit zwei Kindern und einem teilzeiterwerbstätigen Partner bei den Qualifikationsniveaus Ohne und Uni. Die Renditedifferenzen liegen mit Werten zwischen 0,11 (Uni, Doppelverdiener, 1955) und 0,41 Prozentpunkten (Uni, Doppelverdiener, 1990) auf ähnlichen Niveaus wie bei Alleinstehenden, allerdings ergeben sich über die verschiedenen Paartypen für die zwi- 
schen 1930 und 1955 geborenen Kohorten etwas stärker ausgeprägte intragenerative Unterschiede, die mit maximal 0,17 Prozentpunkten (Geburtsjahr 1945) jedoch weiterhin moderat sind.

Wird die Beziehung von Bruttorenditen und Renditen nach Steuern als Indikator zur Beurteilung der Frage herangezogen, inwieweit die Übergangsregelungen des AltEinkG intergenerativ ausgewogenen wirken, so deutet sich eine relativ ungünstige Position der zwischen 1945 und 1955 Geborenen an. Für diese überwiegen die Nachteile aus dem Übergang zur nachgelagerten Besteuerung von Alterseinkünften. Während die Kohorten vor 1945 von der Änderung nur geringfügig tangiert werden, fallen bei den Geburtsjahren ab 1955 die Vorteile während der Erwerbsphase stärker ins Gewicht. Der Vergleich der Kohorten ab 1955 weist darauf hin, dass die Rechtsänderung wie auch die oben diskutierte Anhebung des Renteneintrittsalters relativ schlecht gestellte Übergangsgenerationen schafft, die von den langfristigen Vorteilen nur partiell profitieren, gleichzeitig jedoch die Verschlechterungen mittragen. Die Renditen nach Steuern übersteigen in zunehmendem Umfang die Bruttorenditen, bis der Übergang abgeschlossen ist.

In Hinblick auf die Leitfrage, inwieweit Ergebnisse der gängigen Eckrentnerbetrachtungen bei differenzierterer Modellierung verzerrt wirken, lässt sich zunächst ein Niveaueffekt konstatieren. Die Renditen nach Steuern liegen für alle Kohorten über den Bruttorenditen. Beim Ausmaß der Renditewirkungen der Besteuerung interagieren Kohorten- und Einkommenseffekte. Bei hohen Einkommen sind die intergenerativen Unterschiede stärker ausgeprägt als bei niedrigen bis mittleren Einkommen. Die stärksten intergenerativen Unterschiede treten beim Abschluss Uni auf, bei dem die Renditen nach Steuern die Bruttorenditen um 0,17 bis 0,43 Prozentpunkte überschreiten. Intragenerative Unterschiede bei den Wirkungen der Besteuerung fallen recht gering aus und betragen bei alleinstehenden Versicherten maximal 0,1 Prozentpunkte (Geburtsjahr 1955). Unter Renditeaspekten dürfte die Umstellung auf eine nachgelagerte Besteuerung langfristig für alle betrachteten Einkommensniveaus vorteilhaft sein, wobei höhere Einkommen stärker profitieren als niedrigere.

\subsection{Renditeberechnungen mit dem STM: Gesamtwirkungen}

In den letzten Abschnitten wurde der Einfluss verschiedener Faktoren auf die implizite Rendite der gesetzlichen Rentenversicherung untersucht. Hierzu wurden die Renditen für empirisch gestützte Versicherungsverläufe den Ergebnissen für Eckrentner gegenübergestellt. Zum einen wurde geprüft, inwieweit sich Abweichungen von der für Eckrentner ermittelten Entwicklung der Renditen über die Kohorten ergeben (intergenerative Unterschiede bei Geburtsjahren von 1930 bis 1990), zum anderen wie stark die Renditen innerhalb einer Kohorte in Abhängigkeit von soziodemographischen Merkmalen streuen (intragenerative Unterschiede). Im Folgenden soll nun die Gesamtwirkung der betrachteten Faktoren auf Renditeschätzungen dargestellt werden. Als markante Effekte der variierten empirischen Größen mit Renditerelevanz (Lebenserwartung, Einkommensprofil, Renteneintrittsentscheidungen) sowie verschiedener Gesetzesparameter (Entgeltpunkte aus Transfers, Altersgrenzen, Hinterbliebenenversorgung, Besteuerung) ergaben sich: 
(1) Lebenserwartung: Die Höhe der Rendite hängt wesentlich von der Rentenbezugsdauer $a b$. Die übliche Methode, Rentenbezugsdauern über kohortenspezifische Restlebenserwartungen ab Renteneintritt abzubilden, ist generell für eine Überschätzung der Renditen anfällig, da über diesen Ansatz Beitragszahlungen von Versicherten, die vor Renteneintritt versterben, ignoriert werden. Über die Kohorten steigt zum einen die fernere Lebenserwartung ab dem typisierenden Renteneintrittsalter von 65 Jahren, ein Effekt der isoliert betrachtet renditesteigernd wirkt und in den gängigen Betrachtungen impliziter Renditen auch erfasst wird. Zum anderen nimmt über die Kohorten aber ebenfalls die Wahrscheinlichkeit zu, dass das Alter von 65 Jahren (oder zukünftig 67 Jahren) überhaupt erreicht wird, so dass der Versicherungsfall eintritt. Diese zweite Entwicklung wird in den meisten Renditeberechnungen jedoch vernachlässigt. Folge ist, dass intergenerative Vergleiche zu Ungunsten älterer Kohorten verzerrt sind. Hier wurde nicht quantifiziert, wie sich die Renditen über die Geburtsjahre unter Berücksichtigung der Sterblichkeit vor Erreichen des Renteneintrittsalters entwickeln, jedoch Hinweise zusammen getragen, dass von einer angemessenen Berücksichtigung der kohortenspezifischen Sterbewahrscheinlichkeiten auch vor Erreichen des Renteneintrittsalters recht deutliche Einflüsse auf die Ergebnisse ausgehen können. Die Annahmen zur Lebenserwartung sind der einzige unter den untersuchten Faktoren, der auf eine Überschätzung der Renditevorteile der ältesten Kohorten hindeutet.

(2) Einkommensprofil: Da bei der Rentenberechnung relative Entgeltpositionen aufsummiert werden, ohne die Beitragssatz- und Lohnentwicklung zu berücksichtigen, hängt die Rendite von der Verteilung der Erwerbseinkommen über den Lebenszyklus ab. Für die mit langen Ausbildungszeiten einhergehenden stärker gestauchten Einkommensprofile ergeben sich durchgängig unterdurchschnittliche Renditen. Intragenerative Renditevergleiche zeigen vor allem für zwischen etwa 1935 und 1945 geborene Akademiker Renditen, die um über 0,3 Prozentpunkte unter den Werten für den Eckrentner liegen, für jüngere Kohorten schmilzt dieser Abstand auf $-0,1$ bis $-0,2$ Prozentpunkte. Der grundsätzliche Renditevorteil verstärkter Beitragszahlungen in zeitlicher Nähe zum Renteneintritt -wie sie bei gestauchten Einkommensprofilen auftreten-erweist sich unter der historischen und projizierten Beitrags- und Einkommensentwicklung als Nachteil.

(3) Ausbildungszeiten: Die Bewertung von Ausbildungszeiten zielt tendenziell auf eine intragenerative Renditedifferenzierung $a b$. Da außerdem von einem positiven Zusammenhang zwischen Ausbildungsdauer und Einkommen auszugehen ist, begünstigt die Bewertung von Ausbildungszeiten tendenziell höhere Einkommen. Auf Grund der starken Einschnitte bei der Anrechnung von Ausbildungszeiten seit den 1990er Jahren, von denen vor allem schulische und universitäre Ausbildungszeiten betroffen sind, dominieren allerdings intergenerative Verteilungswirkungen dieses Transferelements der Rentenversicherung. Die großzügige Bewertung von Ausbildungszeiten führt für alle Angehörigen der ältesten betrachteten Kohorten (1930 bis 1935) zu Renditeanstiegen um mindestens 0,1 Prozentpunkte, bei Universitätsabsolventen erreichen die Werte bis zu über 0,5 Prozentpunkte. Dennoch ergeben sich nur 
geringfügige ausbildungsabhängige Renditeunterschiede für diese Kohorten, da Vorteile aus der Bewertung von Ausbildungszeiten und Nachteile aus einem gestauchten Einkommensprofil einander annähernd ausgleichen. Für die Jahrgänge ab etwa 1945 werden nur noch berufliche Ausbildungen bewertet, die Renditevorteile hieraus belaufen sich auf höchstens 0,1 Prozentpunkte.

(4) Altersgrenzen und Renteneintrittsalter: Bei den Altersgrenzen der Rentenversicherung lassen sich im Wesentlichen drei Rechtsstände unterscheiden: Für die Kohorten bis 1937 (Männer) bzw. bis 1942 (Frauen) bestand die Möglichkeit, bereits vor Vollendung des 65 . Lebensjahrs eine abschlagsfreie Rente zu beziehen. Danach Geborene haben bei einem Rentenbezug vor Erreichen der Regelaltersgrenze Abschläge hinzunehmen, wobei die Altersgrenze für bis 1947 Geborene bei 65 Jahren liegt und danach sukzessive auf 67 Jahre ansteigt. Zum einen wurden Renditeeinbußen durch die unlängst beschlossene Anhebung der Altersgrenze von bis zu -0,26 Prozentpunkten ermittelt (Geburtsjahr 1964). Zum anderen wurde geprüft, wie die Höhe der Renditen von der Wahl des Renteneintrittsalters abhängt. Als wesentlichster Effekt zeigte sich hierbei der Anstieg der Renditen der ältesten Kohorten bei frühzeitiger Verrentung. Die Wahrnehmung der Option einer abschlagsfreien Rente ab dem Alter von 63 Jahren führt zu einer um bis zu 0,7 Prozentpunkte höheren Rendite im Vergleich zu Renteneintritten mit 65 Jahren. Mit der Wirksamkeit der Abschläge wurde die Rendite dann weitgehend unabhängig von der Wahl des Renteneintrittsalters.

(5) Verheiratete Versicherte: Verheiratete Versicherte weisen auf Grund der Hinterbliebenenversorgung bekanntlich Renditevorteile auf. Neben qualifikationsbedingt unterschiedlichen Einkommen wurden für Verheiratete auch verschiedene Enwerbsmuster betrachtet, die für die Anzahl der Entgeltpunkte aus Transfers und die Einkommensanrechnung bei Hinterbliebenenrenten bedeutsam sind. Entgeltpunkte aus Transfers resultieren hier vor allem aus der Aufwertung niedriger Einkommen, die sich bei eingeschränkter Erwerbstätigkeit, kombiniert mit niedrigen bis mittleren Einkommen, auswirkt. Die Rente nach Mindesteinkommen führt bei den hier betrachteten typisierenden Biographien sowohl zu einer Verstärkung inter- als auch intragenerativer Unterschiede. Wegen ihrer zeitlich begrenzten Anwendbarkeit (nämlich auf Beitragsjahre bis 1991) profitieren die ältesten Kohorten am stärksten, die einkommensabhängige Aufwertung begünstigt Bezieher niedriger Renten. Die Einkommensanrechnung bei Witwenrenten führt zu einer geringeren Rendite von Doppelverdienern im Vergleich zu Einverdienern, wobei die Renditeeinbußen mit überwiegend unter -0,1 Prozentpunkten jedoch moderat ausfallen. Im Vergleich zu alleinstehenden Versicherten sind die intragenerativen Unterschiede deutlich stärker ausgeprägt. Für die ältesten Kohorten wurden Spannweiten von bis zu über 0,8 Prozentpunkten ermittelt (Alleinstehende: 0,4 Prozentpunkte), die wie bei Alleinstehenden über die Kohorten deutlich abnehmen.

(6) Kinder: Der Umfang der rentenrechtlichen Bewertung von Kindern hängt vor allem davon ab, ob diese vor oder nach 1991 geboren wurden. Von der starken Ausweitung der kindbedingten Entgeltpunkte aus Transfers profitieren damit Eltern, die den Kohorten ab etwa Mitte der 1960er Jahre angehören. Da 
die Höhe eines kindbedingten Rentenzuschlags weitgehend unabhängig von den hier variierten Merkmalen ist, erhöht er die Rendite umso stärker, je niedriger die zu Grunde liegende Rente ist. Entsprechend groß ist die Spannweite der hiervon ausgehenden Wirkungen, für die Kohorten ab 1965 reichen die kindbedingten Renditesteigerungen für zwei Kinder von gut 0,1 bis zu über 0,5 Prozentpunkten.

(7) Besteuerung: Schließlich wurden neben den Bruttorenditen auch Renditen nach Steuern ermittelt, die die steuerliche Abzugsfähigkeit von Rentenbeitragszahlungen sowie die Besteuerung von Renten erfassen. Die Renditen nach Steuern überschreiten für alle betrachteten Fälle die Bruttorenditen. Als Folge der Übergangsregelung zur nachgelagerten Besteuerung von Renten zeichnet sich dabei eine relativ ungünstige Position der Kohorten von etwa 1945 bis 1955 ab. Langfristig liegen für alle Einkommensniveaus die Renditen nach Steuern um etwa 0,4 Prozentpunkte über den Bruttorenditen. Intergenerative Unterschiede zeigten sich vor allem zwischen Akademikern, für die aus dem Übergang zur nachgelagerten Besteuerung zunächst die stärksten Nachteile, langfristig jedoch die größten Vorteile auftreten.

Zur Darstellung der Gesamtwirkung dieser Faktoren und des von ihnen ausgehenden Renditespektrums sind im Weiteren für Fälle mit über- sowie unterdurchschnittlichen Ergebnissen die Renditen nach Steuern den Bruttorenditen von Eckrentnern gegenübergestellt. Für die Kohorten bis 1945 wird dabei von einem Renteneintritt mit 63 Jahren ausgegangen, was annähernd dem durchschnittlichen $\mathrm{Zu}-$ gangsalter bei Altersrenten seit den 1990er Jahren entspricht. Für die jüngeren Kohorten, bei denen das Renteneinrittsalter die Rendite nur leicht beeinflusst, wird die gängige Annahme eines Rentenbezugs ab dem Alter von 65 Jahren übernommen. Allen im Folgenden besprochenen Renditen liegt die Anhebung der Altersgrenze auf 67 Jahre zu Grunde, von der die Kohorten ab 1947 betroffen sind. Die Rentenbezugsdauer richtet sich nach der ferneren Lebenserwartung im Alter von 65 Jahren, die über die Kohorten abnehmende Sterblichkeit vor Erreichen des Renteneintrittsalters wird damit wie üblich ausgeblendet.

Abbildung 63 zeigt zum einen die nominalen Bruttorenditen alleinstehender weiblicher und männlicher Eckrentner der Geburtsjahre von 1930 bis 1990. Die Entwicklung dieser Renditen und ihre Reaktionen auf Rechtsänderungen dienten in den vergangenen Jahren der Beurteilung verschiedener Reformmaßnahmen im Bereich der Rentenversicherung. Der Verlauf der beiden Kurven in Abbildung 63 reflektiert die historischen und für die Zukunft angenommenen Beitragssätze, Rentenwerte und Lebenserwartungen. Als Folge der geschlechtsabhängigen Lebensenwartungen bewegen sich die Renditen für weibliche Eckrentner über den Werten gleichaltriger Männer, der Renditeabstand liegt durchgängig bei rund 0,7 Prozentpunkten. Beim intergenerativen Vergleich fällt vor allem der starke Rückgang der Renditen über die Geburtsjahre von 1930 bis 1940 um etwa 1,5 Prozentpunkte auf, über die Kohorten von 1940 bis 1950 sinken die Renditen um weitere rund 0,7 Prozentpunkte. Für die zwischen 1955 und 1990 Geborenen ergeben sich im Vergleich hierzu nur geringe Renditeunterschiede, wobei die niedrigsten Werte für Eckrentner der Geburtsjahre um 1965 resultieren. Dieser Verlauf der enwarteten Renditen unterscheidet sich deutlich 
von älteren Schätzungen aus den 1990er Jahren, die einen monotonen Renditeverfall über die Kohorten erwarten ließen. In jüngeren Untersuchungen zur Renditeentwicklung, die die Rentenreformen 2001 und 2004 berücksichtigen, ergeben sich weitgehend konstante Renditen für die Kohorten von etwa 1955 bis 1990, erst für danach Geborene wurde eine weitere Abnahme der Renditen erwartet. Als Effekt der jüngsten Änderung, der Anhebung der Regelaltersgrenze auf 67 Jahre durch das RVAltersgrenzenanpassungsgesetz, zeichnet sich nun ein Renditeminimum für die um 1965 Geborenen ab.

Abbildung 63: Renditen Alleinstehender

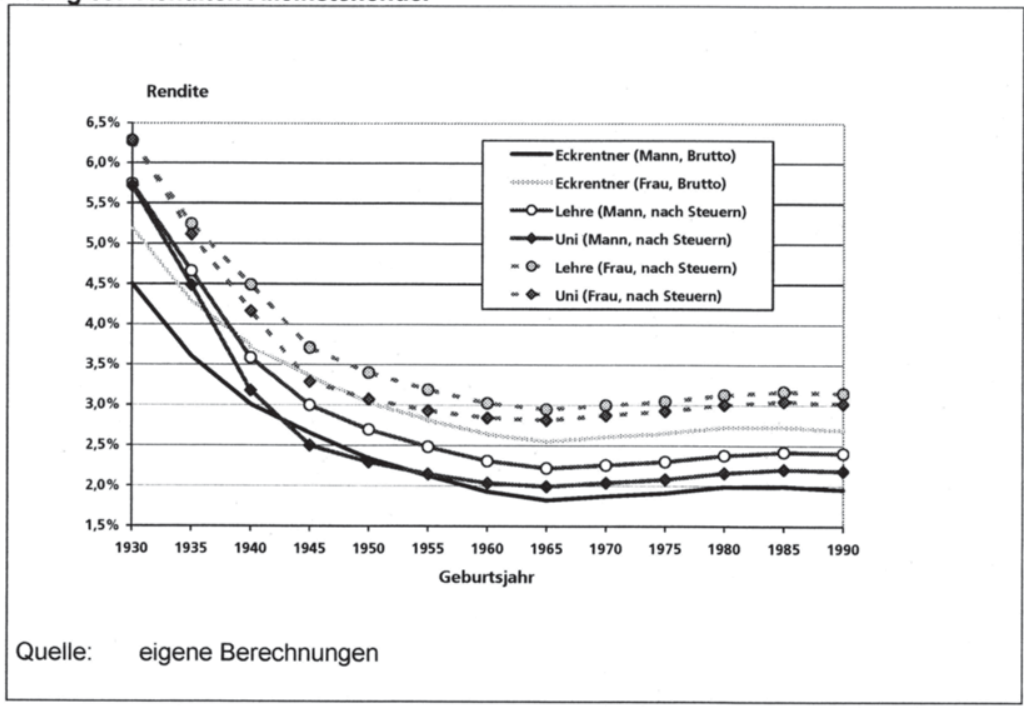

Die Entwicklung der Renditen nach Steuern der in dieser Arbeit betrachteten empirisch gestützten Biographien zeigt ebenfalls einen deutlichen Verfall über die Kohorten von 1930 bis 1950, dem homogenere Renditen folgen. In der Abbildung sind Personen mit vergleichsweise hohen (Abschluss einer Lehre) sowie niedrigen (Uni) Renditen dargestellt. Allerdings sinken die Renditen über die Kohorten von 1930 bis 1945 noch einmal deutlich stärker als beim Eckrentner. Für die Kohorte 1930 überschreiten die Renditen nach Steuern mit Werten von rund 5,7\% (Männer) bis 6,3\% (Frauen) die Bruttorenditen der Eckrentner von 4,5\% (Männer) bzw. 5,2\% (Frauen) um 1,1 bis 1,2 Prozentpunkte. Die massiven Abweichungen lassen sich auf recht großzügige Entgeltpunkte aus Transfers für Ausbildungszeiten sowie insbesondere den abschlagsfreien Rentenbezug ab dem Alter von 63 Jahren zurückführen, in geringerem Umfang trägt auch die Besteuerung zu Renditevorteilen bei. Über die Kohorten bis etwa 1945 wirken sich nun deutliche gesetzgeberische Einschnitte bei den versicherungsfremden Leistungen zunehmend aus. Folge der Wirksamkeit von Abschlägen bei frühzeitigem Rentenbezug sowie restriktiver Vergabe von Entgeltpunkten aus Transfers sind stark schrumpfende Abweichungen zwischen Eckrentnern und empirisch gestützten Biographien. Für den Geburtsjahrgang 1945 über- 
schreiten die Nach-Steuer-Renditen die Eckrentnerergebnisse günstigstenfalls (Lehre) noch um knapp 0,4 Prozentpunkte (Abbildung 64).

Abbildung 64: Renditen nach Steuern Alleinstehender: Abweichungen vom Eckrentner

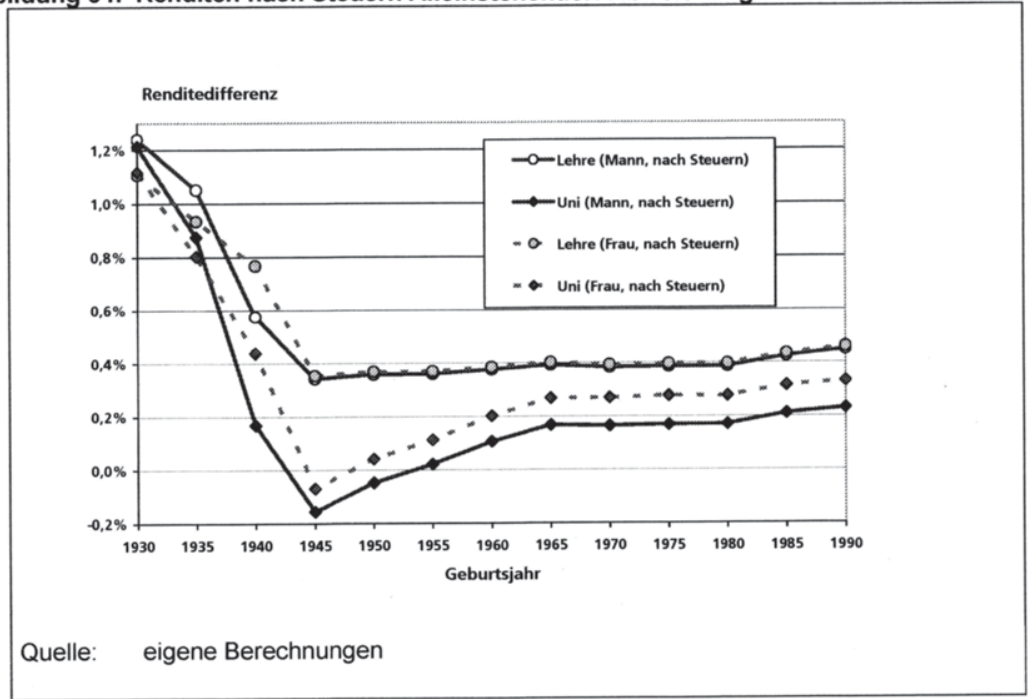

Der aus Eckrentnerberechnungen bekannte Renditeverfall über die Kohorten von 1930 bis 1945 unterzeichnet nach diesen Ergebnissen die tatsächliche Entwicklung deutlich. Neben einer im Lebenszyklus relativ günstigen Relation von Beitragssätzen und Rentenwerten, die auch der Eckrentner erfasst, profitieren die Kohorten um 1930 wesentlich von gesetzgeberischer Großzügigkeit bei der Rentenberechnung. Unter Einschluss der versicherungsfremden Elemente erscheinen nominale Renditen nach Steuern für um 1930 geborene alleinstehende Versicherte von 5,7\% (Männer) bis $6,3 \%$ (Frauen) realistisch. Über die Geburtsjahre bis 1945 fallen diese um etwa drei Prozentpunkte auf Werte von 2,5 bis 3,0\% (Männer) bzw. 3,3 bis 3,7\% (Frauen). Für die Kohorten ab 1945 sind die Abweichungen vom Eckrentner wesentlich geringer. Beim Abschluss Lehre liegen die Renditen nach Steuern für beide Geschlechter ab 1945 um etwa 0,4 Prozentpunkte über den Eckrentnerwerten, wobei die Differenz über die Kohorten leicht aber kontinuierlich ansteigt (von etwa 0,35 auf 0,45 Prozentpunkte). Beim Abschluss Uni indessen ergeben sich deutlicher wachsende Abstände von den Eckrentnerrenditen. Neben den renditerelevanten Annahmen zur Lohn- und Beitragssatzentwicklung schlagen sich hier zunehmende Vorteile durch den Umstieg auf ein System nachgelagerter Rentenbesteuerung nieder. Für Uni-Absolventen des Geburtsjahrs 1990 beträgt die Renditeabweichung vom Eckrentner gut 0,2 (Männer) bis 0,3 (Frauen) Prozentpunkte. Weiterhin weist der Vergleich empirisch gestützter Biographien mit Eckrentnern darauf hin, dass die üblichen Ergebnisse zu Bruttorenditen meist eine Untergrenze typischer Nach-Steuer-Renditen darstellen dürften. Auf Grund der für alle betrachteten Kohorten und Abschlüsse über den jeweiligen Bruttorenditen liegenden Renditen nach Steuern ergeben sich fast ausschließlich po- 
sitive Abweichungen von den Eckrentnerbetrachtungen. Nur bei unter Renditeaspekten sehr ungünstigen Einkommensprofilen, wie sie bei Uni-Absolventen der Kohorten um 1945 auftreten, unterschreiten die Nach-Steuer-Renditen die Werte bei Eckrentnern.

Für verheiratete Versicherte gelten in mehrerlei Hinsicht ähnliche Befunde, insbesondere finden sich bei den hier betrachteten Biographien ebenfalls ein Renditeverfall über die Kohorten von 1930 bis 1945, der weit über das Absinken beim Eckrentner hinausgeht, sowie Nach-Steuer-Renditen, die fast durchgängig über den Eckrentnerwerten liegen (Abbildung 65). Für die Abbildung wurden wiederum Fälle mit recht hohen bzw. niedrigen Renditen ausgewählt, außer in den Qualifikationen unterscheiden sich die Paare in der Kinderzahl und damit einher gehend in den Erwerbsmustern (s. o.).

Abbildung 65: Renditen Verheirateter

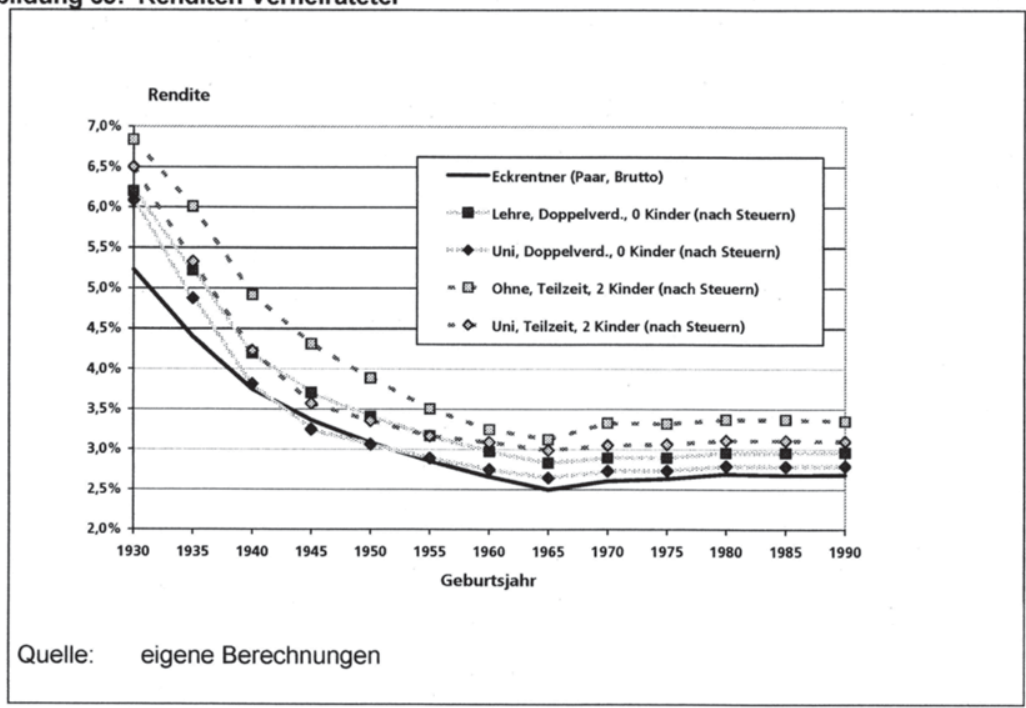

$\mathrm{Zu}$ intragenerativen Renditeunterschieden tragen neben den auch bei Alleinstehenden wirksamen Faktoren (Einkommensprofil, Entgeltpunkte für Ausbildungszeiten und Besteuerung) die Einkommensanrechnung bei Witwenrenten und Entgeltpunkte aus Transfers für Kinder sowie für niedrige Einkommen bei. Im Vergleich zu Eckrentnern ergibt sich bei kinderlosen Doppelverdienern ein ähnliches Bild wie bei Alleinstehenden (Abbildung 66). Durch die Einkommensanrechnung bei Witwenrenten fallen die Abweichungen bei diesen Paaren tendenziell geringer aus, für die jüngeren Kohorten liegen die Renditen nach Steuern um etwa 0,1 (Uni) bis 0,3 (Lehre) Prozentpunkte über den Bruttorenditen der Eckrentner. Als markantes Ergebnis für Paare mit Kindern und eingeschränkter Erwerbstätigkeit ergibt sich zum einen eine sehr hohe Rendite bei Angehörigen älterer Kohorten mit niedrigem Einkommen (Ohne, Teilzeit, 2 Kinder). Zu ihrer Rendite von bis zu 6,8\% (Kohorte 1930), die um 1,6 Pro- 
zentpunkte über der Eckrentnerrendite liegt, trägt neben den bereits angesprochenen Faktoren -wie der vorzeitige abschlagsfreie Rentenbezug - vor allem die Rente nach Mindesteinkommen bei. Indem deren Wirkung über die Kohorten nachlässt, nähern sich die Renditen den Eckrentnerwerten an. Zum anderen zeigt sich bei Paaren vor allem bei niedrigen Einkommen ein Renditeanstieg für Kohorten ab etwa 1965, der aus der verstärkten Bewertung von Kindererziehung resultiert. Für die jüngeren Kohorten liegen die Renditen von Paaren mit Kindern um rund 0,4 (UnI) bis 0,7 (Ohne) Prozentpunkte über den Werten für Eckrentnerpaare.

\section{Abbildung 66: Renditen nach Steuern Verheirateter: Abweichungen vom Eckrentner}

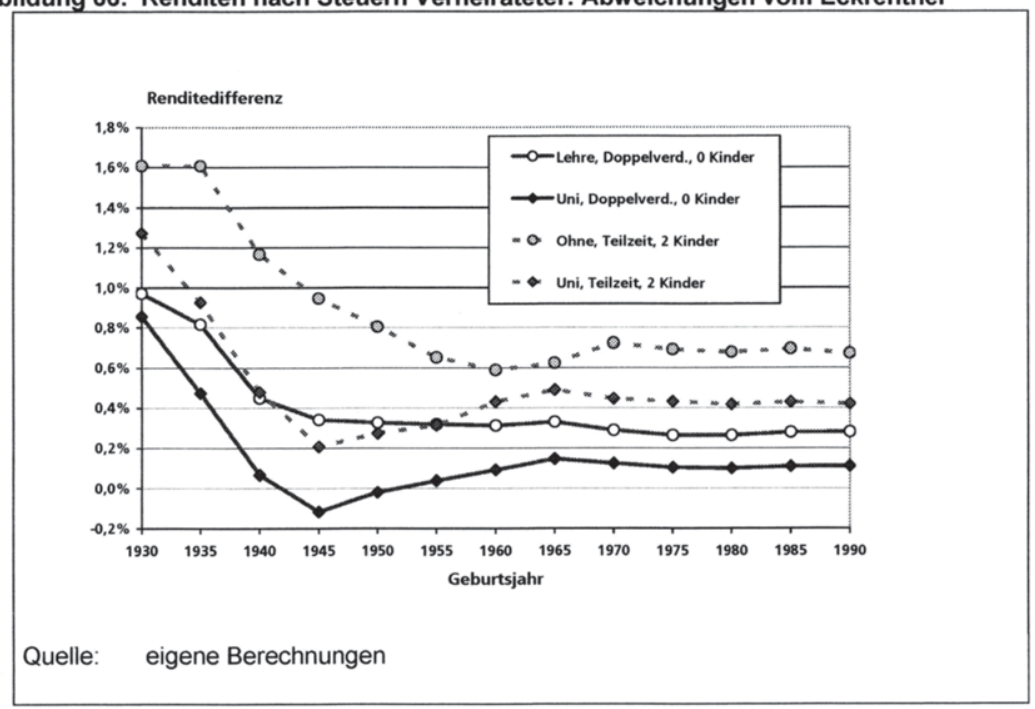

Als Indikator für intragenerative Unterschiede sind in Abbildung 67 die Spannweiten der Renditen der verschiedenen Biographien abgetragen. Für alleinstehende Versicherte sind die qualifikationsbedingten Renditedifferenzen von Frauen sowie von Männern dargestellt (vgl. Abbildung 63). Abbildung 67 erfasst somit intragenerative Unterschiede, die über die bekannten Abweichungen zwischen Geschlechtern und Familienständen hinausgehen. Für verheiratete Versicherte sind zum einen die Differenzen der Renditen kinderloser Doppelverdiener abgetragen, die Kurve "Spannweite Paare ohne Kinder" gibt also die Differenz von Lehre und Uni aus Abbildung 65 wieder. Die in dieser Spannweite erfassten Renditeunterschiede resultieren wie bei Alleinstehenden vor allem aus den unterschiedlichen Einkommensprofilen. Die Kurve „Spannweite Paare" hingegen gibt die Renditedifferenzen zwischen allen betrachteten Paartypen wieder (was der Differenz von Ohne, Teilzeit, 2 Kinder und Uni, Doppelverdiener, 0 Kinder aus Abbildung 65 entspricht). In diese Spannweite gehen zusätzlich die Renditeeffekte verschiedener Entgeltpunkte aus Transfers ein (Kinder sowie Mindesteinkommen).

Abbildung 67 deutet darauf hin, dass bei Vollzeitenwerbstätigen (Mann, Frau, Paare ohne Kinder) die am stärksten ausgeprägten intragenerativen Unterschiede für die 
um das Jahr 1945 Geborenen auftreten. Die Abweichungen der Renditen verschiedener Qualifikationen liegen hier je nach Lebenserwartung bei gut 0,4 (Frau) bis 0,5 Prozentpunkten (Mann). Die geringeren intragenerativen Unterschiede bei älteren Kohorten folgen daraus, dass bei diesen Nachteile eines gestauchten Einkommensprofils durch Entgeltpunkte für Ausbildungszeiten zufällig weitgehend egalisiert werden. Für die Jahrgänge von 1965 bis 1990 sind die intragenerativen Unterschiede weitgehend konstant, die Werte liegen bei gut 0,1 (Frau) bis gut 0,2 Prozentpunkten (Mann). Unter zusätzlicher Berücksichtigung von Kindern -und hier mit diesen assoziierter eingeschränkter Erwerbstätigkeit- ergeben sich erheblich größere intragenerative Unterschiede zwischen verheirateten Versicherten. Unter den getroffenen Annahmen zu kindbedingten Erwerbsunterbrechungen erweist sich vor allem die Aufwertung niedriger Einkommen als renditedifferenzierend. Zwischen verschiedenen Paartypen betragen bei den älteren Kohorten je nach Kinderzahl und Qualifikation die Renditedifferenzen bis zu gut 1,1 Prozentpunkte. Am homogensten sind die Renditen von Paaren, die in der ersten Hälfte der 1960er Jahre geboren wurden, allerdings liegt die Spannweite mit gut 0,5 Prozentpunkten auch hier deutlich über den Werten für Alleinstehende. Als Folge der zunehmenden Bewertung von Kindern nimmt die Spannweite bei ab etwa 1965 geborenen Paaren wieder zu und beläuft sich sodann durchgehend auf knapp 0,6 Prozentpunkte.

Abbildung 67: Intragenerative Renditedifferenzen (Renditen nach Steuern)

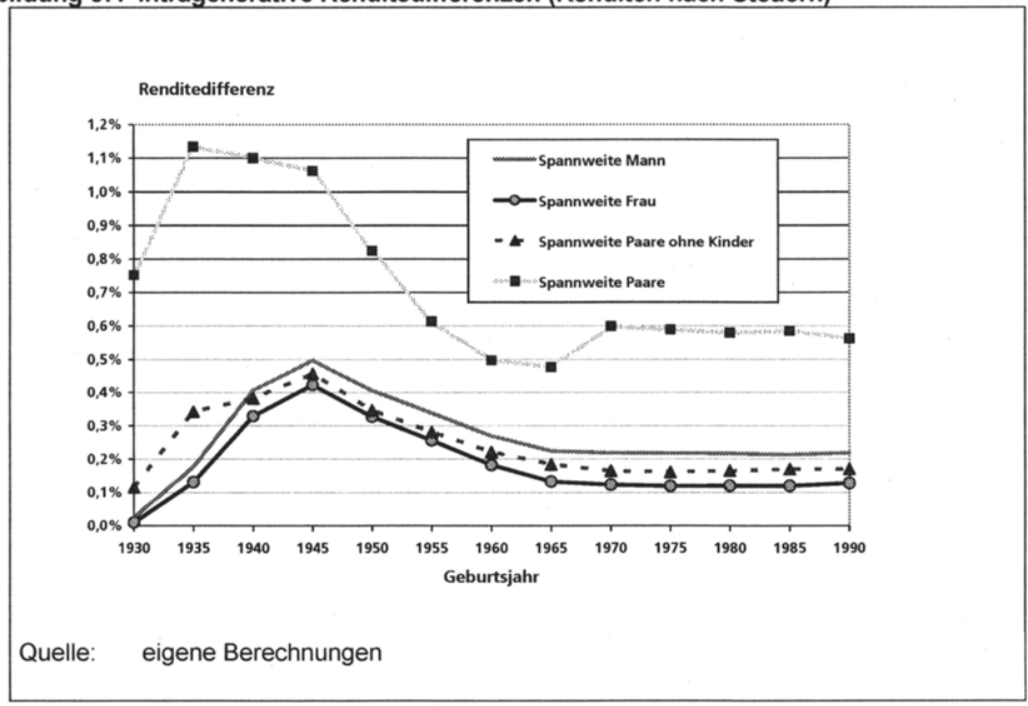




\subsection{Zusammenfassung und Schlussfolgerungen}

Eine der beiden Hauptfragen dieses Kapitels ist, inwieweit die Rentenberechnung für empirisch gestützte Biographien unter detaillierter Berücksichtigung des Steuer- und Sozialrechts zu von üblichen Eckrentnerbetrachtungen abweichenden Einschätzungen der intergenerativen Umverteilung durch die Rentenversicherung führt. Die gravierendsten Unterschiede traten bei den ältesten betrachteten Kohorten auf, die impliziten Renditen der Rentenversicherung von 1930 Geborenen werden nach den hier ermittelten Ergebnissen durch den Eckrentner in der Regel um mehr als einen Prozentpunkt unterschätzt. Die hohen nominalen Renditen von mindestens 5,7\% (für alleinstehende Männer) werden dabei stark von Transferelementen der Rentenversicherung begünstigt. Nachdem im Zuge verschiedener Rentenreformen seit 1999 diese Transfers stark eingegrenzt wurden, führen Renditevergleiche für die Kohorten ab etwa 1945 zu deutlich geringeren Abweichungen zwischen empirisch gestützten Biographien und Eckrentnern. Zwar unterscheidet sich das Renditeniveau, für empirisch gestützte Biographien liegen die Renditen in der Regel höher, was vor allem aus der Berücksichtigung des Steuersystems folgt, der "Fehler" beim Eckrentner streut jedoch nur geringfügig über die Geburtsjahre.

Kohortenvergleiche zu den jüngsten Reformmaßnahmen der Rentenversicherung beschränken sich in der Regel auf die Jahrgänge ab 1940, der drastische Renditeverfall über die in den Jahren davor Geborenen bleibt damit ausgeblendet. Werden nur die ab 1940 Geborenen betrachtet, deuten die Renditen nach Steuern für die hier untersuchten Biographien darauf hin, dass der Eckrentner die Ergebnisse für die 1940 und in den Jahren darauf Geborenen vergleichsweise stark unterschätzt, das Absinken der Renditen über die Geburtsjahre von 1940 bis 1945 wird demnach unterzeichnet. Wenn man dem Ansatz folgt, weitgehend gleichhohe Renditen als Hinweis auf ein intergenerativ ausgewogenes Rentensystem zu interpretieren, so zeichnet sich mit der Anhebung der Regelaltersgrenze auf 67 Jahre als jüngste Reformmaßnahme ein übermäßig starker Einschnitt bei den um 1965 Geborenen ab, bei denen Eckrentnerbetrachtungen ein Renditeminimum aufzeigen. Die in dieser Arbeit betrachteten Faktoren liefern weitere Hinweise auf eine relativ ungünstige Rendite dieser Kohorten. Neben der Übergangsregel bei der Anhebung der Altersgrenze führt auch der Übergang zur nachgelagerten Besteuerung zu einer unterdurchschnittlichen Position dieser Jahrgänge, ebenso profitieren sie nicht oder nur eingeschränkt von der Aufwertung der Kindererziehung. Weiterhin führt die über die Kohorten abnehmende Sterblichkeit während der Erwerbsphase und die infolge dessen zunehmende Wahrscheinlichkeit des Eintretens des Versicherungsfalls dazu, dass intergenerative Vergleiche anfällig sind für Verzerrungen zu Lasten älterer Kohorten. Mit der üblichen und auch im vergangenen Unterkapitel gewählten Modellierung der Rentenbezugsdauer über die fernere Lebenserwartung ab dem Alter von 65 Jahren zeichnet sich damit $a b$, dass der Renditerückstand der um 1965 Geborenen gegenüber den jüngeren Kohorten geringer erscheint, als er tatsächlich ist. Eine weitere Reformmaßnahme mit Bezug zu intergenerativer Umverteilung durch Alterssicherungssysteme ist die hier nicht weiter betrachtete staatliche Förderung einer kapitalgedeckten Altersvorsorge ("Riester-Rente"), deren Einführung mit dem Hinweis erfolgte, dass hierdurch Leistungseinschnitten im Rahmen der umlagefinanzierten Rentenversicherung entgegengewirkt werde. Ein Einschluss der Riester-Förderung in intergenerative Ver- 
gleiche zur Alterssicherung lässt die bis in die 1960er Jahre Geborenen in einer weiteren Hinsicht als Übergangskohorten auftreten, in diesem Fall auf Grund des relativ kurzen Zeitraums, innerhalb dessen die Fördermöglichkeit genutzt werden kann (vgl. hierzu auch Abbildung 47). ${ }^{246}$ Insgesamt deutet sich aus den hier zusammengestellten Einflüssen verschiedener Faktoren an, dass mit den Reformen der vergangenen Jahre nicht nur ein monotoner Verfall der Renditen der gesetzlichen Rentenversicherung gestoppt wurde, sondern dass die Maßnahmen in ihrer Gesamtwirkung über das Ziel einer möglichst gleichartigen Belastung der Kohorten moderat hinausgehen. Aus den Stabilisierungsbemühungen im Bereich der Alterssicherung häufen sich Nachteile aus Übergangsregelungen bei den Kohorten, die sich derzeit in der Mitte des Erwerbslebens befinden. Aus diesem Befund lässt sich nicht zwingend ableiten, dass die Rentenversicherung "überreformiert" wurde, allerdings erscheint es nicht mehr angemessen, mittelfristige Einschnitte zu Gunsten langfristiger Entlastungen mit dem Ziel intergenerativer Ausgewogenheit zu begründen. Anders als bei den stark abfallenden Renditen über die Geburtsjahre von 1930 bis 1950 sind die Renditedifferenzen zwischen den Kohorten ab etwa 1950 allerdings äußerst gering.

Zur zweiten Hauptfrage, in welchem Umfang die Rentenversicherung auch zu intragenerativer Umverteilung führt, ergeben sich zum einen für Kohorten ab Mitte der 1960er Jahre recht konstante intragenerative Renditespannweiten, die sich bei alleinstehenden Versicherten auf bis zu gut 0,2 Prozentpunkte und bei Verheirateten auf knapp 0,6 Prozentpunkte belaufen. Letzterer Wert erreicht damit annähernd die GröBenordnung des Renditevorteils von Frauen gegenüber Männern in Höhe von etwa 0,7 Prozentpunkten. Zumindest bei Paaren wird folglich mit einer Eckrentnerbetrachtung von erheblichen intragenerativen Unterschieden abstrahiert. Diese sind zum Teil unmittelbare Folge explizit der Förderung von Eltern dienender Transferelemente, deren Umfang über die Kohorten wiederholt ausgebaut wurde. Neben direkt an die Elterneigenschaft anknüpfenden Transferelementen führen Einschränkungen der Erwerbstätigkeit auf Grund von Kindererziehung zu weiteren indirekt kindbedingten Renditevorteilen. Qualifikationsabhängige Renditeunterschiede im Bereich von 0,2 Prozentpunkten, wie sie bei Alleinstehenden auftreten, liegen deutlich unter geschlechts- und familienstandsabhängigen Einflüssen. Dennoch erreichen sie in etwa das Niveau der von den verschiedenen Reformschritten der vergangenen Jahre ausgehenden Renditeverschiebungen. Ein aus Sicht der impliziten Rendite ungünstiges Einkommensprofil, das sich mit akademischen Biographien assoziieren lässt, schmälert nach den hier ermittelten Ergebnissen die Rendite zum Teil stärker als die viel beachtete Anhebung der Altersgrenze auf 67 Jahre.

Neben den im Zentrum der Reformdebatten stehenden intergenerativen Belastungsverschiebungen bietet die Rentenversicherung demnach trotz des Äquivalenzprinzips auch intragenerative Unterschiede von quantitativ ähnlicher Bedeutung. Anders als bei den Kohorten ab etwa 1965 zeigen sich über die Geburtsjahre von 1930 bis 1965 wesentliche Schwankungen im Ausmaß intragenerativer Unterschiede. Zum einen nehmen die Spannweiten der Renditen von Paaren massiv ab, eine Folge der Beschneidung von Transferelementen der Rente. Zum anderen ergeben sich für Allein-

${ }^{246} \mathrm{~S}$. zu intergenerativen Vergleichen von Renditen der gesamten Altersvorsorge (gesetzliche Rente und Riester-Rente) neben der Darstellung des Sachverständigenrats (2004) die oben vorgestellten Beiträge von Grub (2005) sowie Schmähl, Himmelreicher und Viebrok (2004). 
stehende zunächst minimale, dann auf bis zu 0,5 Prozentpunkte ansteigende (Jahrgang 1945) und anschließend wie besprochen auf 0,2 Prozentpunkte abfallende Renditedifferenzen. Dieses Muster ist allerdings weniger Folge einer auf intragenerative Differenzierung abzielenden Transferpolitik, geprägt wird dieser Verlauf stattdessen von der eher intergenerative Umverteilung verursachenden Festsetzung der Beitragssätze im Zusammenspiel mit der Einkommensentwicklung. Der auch bei jüngeren Kohorten auftretende Akademikernachteil ist bei den um das Jahr 1945 Geborenen maximal.

Abschließend verbleiben noch einige einschränkende Hinweise zur Aussagekraft von Berechnungen zur Umverteilung durch die Rentenversicherung. Erstens ist auf die Unsicherheit derart weit in die Zukunft ausgerichteter Vorausberechnungen hinzuweisen, die hier bis in die 2080er Jahre hineinreichen. Neue Erkenntnisse zur Entwicklung relevanter Rahmendaten sowie Reaktionen hierauf werden die Ergebnisse jedoch zuvor veralten lassen. Entsprechend sind die Renditeberechnungen auch nicht als Prognose missuverstehen. Ihr Ziel und ihre Berechtigung bestehen darin, sich unter aktuellem Kenntnisstand abzeichnende Fehlentwicklungen zu diagnostizieren und gegebenenfalls zu beheben. Was als "Fehlentwicklung" gilt, unterliegt primär normativen Setzungen, weshalb der Begriff der (Generationen-)Gerechtigkeit in diesem Kapitel gemieden wurde. Neben grundsätzlichen Bedenken in Bezug auf die Operationalisierung von "Gerechtigkeit" erscheint darüber hinaus speziell die Verkürzung von Gerechtigkeitsbegriffen auf den Bereich der Alterssicherung problematisch. Wenn Umverteilung zwischen Kohorten untersucht werden soll, werden mit Analysen der gesetzlichen Rentenversicherung als einzelnem Teilsystem des Steuer-Transfer-Systems intergenerative Unterschiede nur begrenzt erfasst. Die Anfälligkeit von nur auf der Rentenversicherung basierenden Generationenvergleichen für Verzerrungen offenbart sich bereits in den als „Verschiebebahnhofspolitik" bezeichneten Wechselbeziehungen zur Arbeitslosenversicherung. In der Vergangenheit finden sich zahlreiche Beispiele, in denen sich eine gemeinsame Steuerung der Renten- und Arbeitslosenpolitik durch den Gesetzgeber zeigt. Unter anderem durch Variation der Leistungsabgrenzung dieser Sicherungssysteme (wie Bezugsdauern von Arbeitslosengeld und Altersrenten wegen Arbeitslosigkeit) wurden Zuständigkeiten zwischen diesen Versicherungszweigen verschoben. Entsprechend fallen -wie zuletzt auch im Jahr 2007- Beitragserhöhungen bei einer der beiden Versicherungen mit -senkungen bei der anderen zusammen. ${ }^{247}$ Die Entwicklung von Renditen der Rentenversicherung wird demnach nicht nur von der für umlagefinanzierte Systeme maßgeblichen demographischen Entwicklung (genauer gesagt vom Lohnsummenwachstum, wie im Aaron-Paradoxon herausgearbeitet) determiniert, sondern lässt sich in verschiedenerlei Hinsicht vom Gesetzgeber manipulieren. In Kapitel 9 werden intergenerative Belastungsvergleiche vorgestellt, die auf einem umfangreicheren Ausschnitt des Steuer-Transfer-Systems fußen und so weitere intergenerative Unterschiede erfassen. Zwar wird auch damit kein Indikator für eine gerechte Politik geliefert werden können, jedoch ergibt sich ein zutreffenderes Bild der Entwicklung von Belastungen über die untersuchten Kohorten.

${ }^{247}$ S. zu der historischen Entwicklung der "Verschiebebahnhöfe“ Trampusch (2003) 


\section{Monetäre Familienpolitik}

In der familienpolitischen Literatur finden sich zahlreiche Vorschläge, über welche Instrumente und in welchem Umfang Familien im Steuer- und Transfersystem berücksichtigt werden sollten. Dabei herrscht überwiegend die Auffassung vor, dass Familien Benachteiligungen ausgesetzt sind, die durch staatliche Umverteilung nicht hinreichend kompensiert werden. Während eine Familienförderung in älteren Arbeiten vor allem aus sozialpolitischen Motiven abgeleitet wurde und seit den 1990er Jahren, von der Rechtssprechung des Verfassungsgerichts bestärkt, vermehrt steuerpolitisch argumentiert wurde, gewannen zuletzt allokative Begründungen an Bedeutung, die auch in der Umbenennung des Familien/astenausgleichs zum Familien/eistungsausgleich (FLA) seit 1996 Ausdruck finden (vgl. Kapitel 4.3). ${ }^{248}$

Unter dem Eindruck des demographischen Wandels flossen neben intragenerativen Verteilungswirkungen verstärkt auch intergenerative Aspekte in die Diskussion um die Familienpolitik ein. Auf Grund niedriger Geburtenraten -als zweiter Triebfeder eines doppelten Alterungsprozesses neben steigenden Lebenserwartungen- bei zunehmenden Anteilen Kinderloser wurden Zusammenhänge zwischen Familienpolitik und umlagefinanzierter Sozialversicherung zunehmend betont. ${ }^{249} \mathrm{Un}$ ter diesem Gesichtspunkt wurden unter anderem die verstärkte Berücksichtigung von Kindererziehungszeiten bei der Rentenberechnung (vgl. Kapitel 5.2) und die Differenzierung der Beiträge zur Pflegeversicherung zwischen Eltern und Kinderlosen (vgl. Kapitel 4.1) eingeführt.

Zu den zentralen Stellgrößen, die zu einer Kompensation der sich abzeichnenden demographischen Verschiebungen beitragen können, wird neben einer höheren Geburtenrate vor allem auch eine verstärkte Erwerbsbeteiligung gezählt. Da zwischen diesen beiden Zielen ein Konflikt besteht, die Erwerbsbeteiligung von Frauen und inre Kinderzahl hängen negativ zusammen, orientieren sich aktuelle familienpolitische Reformen zudem an einer Verbesserung der Vereinbarkeit von Erwerbstätigkeit und Elternschaft. In diese Richtung zielen unter anderem die Ausweitung der steuerlichen Abzugsfähigkeit erwerbsbedingter Kinderbetreuungskosten seit 2006 (vgl. Kapitel 4.3.2) sowie die Einführung des Elterngelds seit 2007 (vgl. Kapitel 4.4).

Bei zum Teil stark divergierenden Einschätzungen, welche familienpolitischen Ziele anzustreben sind und welche Instrumente dazu geeignet erscheinen, sind den in den letzten Jahrzehnten entwickelten Konzepten großenteils jedoch zwei Punkte gemeinsam. Zum einen wird ein intransparentes und unzweckmäßiges Nebeneinander zahireicher Einzelleistungen im bestehenden System kritisiert, zum anderen laufen die Empfehlungen auf eine Erhöhung des Volumens familienpolitischer Leistungen hinaus, da deren Umfang bisher entweder als nicht (bedarfs-)gerecht eingeschätzt wird oder als nicht ausreichend, um Fehlanreizen zur Kinderlosigkeit entgegen zu wirken. ${ }^{250}$ Abweichendes Fazit einiger jüngerer Stellungnahmen ist, dass

248 Vgl. Lüdeke (2000)

${ }^{249}$ Vgl. Bundesministerium für Wirtschaft und Arbeit (Hrsg.) (2005)

250 So zielen etwa die Empfehlungen des wissenschaftlichen Beirats für Familienfragen seit den 1970er Jahren wiederkehrend in Richtung einer Netto-Ausweitung familienpolitischer Leistungen, vgl.: Bundesministerium für Jugend, Familie, und Gesundheit (Hrsg.) (1971, 1979); Bundesministerium für Jugend, Familie, Frauen und Gesundheit (Hrsg.) (1989); Bundesministerium für Familie, Senioren, Frauen und Jugend (Hrsg.) (2001) 
die Familienpolitik weniger an einem unzureichenden Gesamtvolumen leidet, sondern dass die Mittel über die bestehenden Instrumente nicht zielgerichtet genug eingesetzt werden. ${ }^{251}$

Die Gewichtung verschiedener Kriterien bei der Beurteilung des Steuer-TransferSystems unter familienpolitischen Gesichtspunkten hat sich in den zurückliegenden Jahrzehnten mithin wiederholt verschoben, die grundlegenden Vergleichsmaßstäbe blieben jedoch erhalten: Unterschiede zwischen Eltern und Kinderlosen (sowie zwischen Familien mit unterschiedlicher Kinderzahl) einerseits sowie einkommensabhängige Unterschiede innerhalb der Gruppe der Familien andererseits bilden regelmäßig wesentliche Grundlagen der Bewertung monetärer Familienpolitik. Eine Verknüpfung beider Aspekte findet sich in Arbeiten, die Zusammenhänge zwischen Kinderzahl und Arbeitsangebot berücksichtigen, wodurch Erwerbseinschränkungen als Ursache von niedrigeren Einkommen von Familien in die Betrachtung einbezogen werden. Mit den Zielen wandelten sich auch die Betonungen, unter denen Reformmaßnahmen im Bereich der Familienpolitik erfolgten. Neben Reformen, die allgemein als Verbesserung für Familien im Vergleich zu Kinderlosen deklariert werden, finden sich unter anderem Hinweise auf gezielte Verbesserungen für Mehrkindfamilien oder für ärmere Familien.

Gesamtbewertungen, wie sich der Umfang monetärer Familienpolitik über die zurückliegenden Jahrzehnte entwickelt hat und welche Schwerpunktverlagerungen sich gegebenenfalls dabei abzeichnen, fallen allerdings nicht zuletzt auf Grund der Vielzahl kindbezogener Transfers mit zum Teil widersprüchlich erscheinenden Wechselwirkungen schwer. Zwar existieren einerseits einige langfristige Vergleiche zu den Wirkungen familienpolitischer Instrumente im Querschnitt, die insgesamt auf eine Ausweitung familienpolitisch orientierter Umverteilung über die zurückliegenden Jahrzehnte hinweisen. Diese beschränken sich allerdings weitgehend auf den FLA aus Kindergeld und -freibeträgen, ohne andere Elemente monetärer Familienpolitik wie das Erziehungs- oder Elterngeld zu erfassen. Andererseits liegen seit Mitte der 1990er Jahre ebenfalls mehrere Arbeiten zu den Gesamtwirkungen monetärer Familienpolitik über einen Lebenszyklus vor, in denen jedoch ausschließlich ein Status Quo fortgeschrieben wird. Ein recht typisches Ergebnis dieser Untersuchungen sind monetäre Transfers, die sich auf etwa 35 Tsd. Euro je Kind summieren, wobei jedoch die Möglichkeit fehlt, diesen Wert mit früherer Familienpolitik zu vergleichen.

Ein Hauptanliegen dieses Kapitels besteht darin, diese beiden Ansätze zusammenzuführen. Als Ausgangspunkt dienen die Auswirkungen familienpolitisch orientierter Umverteilung auf das verfügbare Einkommen der begünstigten Familien. Effekte monetärer Familienpolitik seit 1950 werden dann unter den Aspekten betrachtet werden, inwieweit sich über die Jahre generell Verbesserungen für Familien ergeben haben und inwiefern sich die Entwicklung für verschiedene Familientypen unterscheidet. Dabei wird nach dem Grundansatz dieser Arbeit vorgegangen, langfristige inter- und intragenerative Wirkungen des Steuer-Transfer-Systems an Hand des im ersten Teil vorgestellten Steuer-Transfer-Modells (STM) herauszuarbeiten. Ein zentrales Anliegen besteht somit in einer Charakterisierung der derzeitigen Familienpolitik im Vergleich zu früheren Regelungen. Zur Einordnung der dabei berücksichtigten Leistungen werden zunächst die Gesamtheit fiskalisch relevanter Maßnahmen mit Fami-

251 S. etwa Wissenschaftlicher Beirat für Familienfragen (2006); Homburg, Schnabel (2005), S. 12 
lienbezug in einer weiten Abgrenzung besprochen sowie einige Entwicklungslinien seit 1950 in vergleichenden Querschnitten vorgestellt. Daran schließen sich Längsschnittanalysen an, mit denen die summarischen Effekte kindbedingter Leistungen über den Lebenszyklus abgebildet werden. Die Langfristperspektive empfiehlt sich zum einen auf Grund der Vielfalt einkommensrelevanter kindbedingter Transfers mit inren unterschiedlichen Ausmaßen in einzelnen Lebensphasen. Zum anderen schlagen sich Fertilitätsentscheidungen langfristig nieder, so dass das Lebenseinkommen mit Kindern und ohne eine adäquate Größe bildet, um deren Gesamtwirkungen zu erfassen.

Grundlage dieser Analysen bilden die in Kapitel 3 vorgestellten qualifikationsabhängigen Lebenseinkommensprofile, wobei aus der Bildungsvariable fünf Bruttoeinkommensniveaus folgen, an Hand derer intragenerative Unterschiede besprochen werden. Ein Vorteil der Bestimmung einkommensabhängiger Unterschiede auf der Grundlage von Lebenszyklusbetrachtungen besteht darin, die summarischen Wirkungen zum Teil entgegengerichteter Zusammenhänge erfassen zu können. Ein Beispiel hierfür sind mit dem Einkommen steigende Entlastungen durch Steuerfreibeträge bei einem gleichzeitig einkommensabhängig zu mindernden Erziehungsgeld. Die Berechnung von Steuern und Transfers sowie von Renten der gesetzlichen Rentenversicherung erfolgt dabei mit dem STM. Aus intergenerativen Unterschieden zwischen verschiedenen Geburtsjahren lässt sich auf die Entwicklung der monetären Familienpolitik rückschließen, um so eine Basis für einen Vergleich des geltenden Rechts mit früheren Regelungen zu schaffen. Zwar bestehen einige Hinweise, dass die Familienpolitik im Status Quo als relativ großzügig einzustufen ist, es fehlt bisher jedoch eine Analyse, in der die jeweiligen Gesamtwirkungen unter verschiedenen Rechtsständen innerhalb eines einheitlichen Rahmens bestimmt und verglichen werden. Die Entwicklung der Gesamtwirkungen wird dabei differenziert nach Einkommen, Kinderzahl und Erwerbsbeteiligung betrachtet, um nicht nur eine globale Entwicklungslinie sondern auch Schwerpunktverschiebungen herauszuarbeiten.

\subsection{Familienpolitische Maßnahmen: Umfang, Abgrenzung und ausgewählte Entwicklungen seit 1950}

\subsubsection{Umfang insgesamt und Erfassung kindbedingter Mehreinkommen im STM}

Dem Eindruck, dass "die Familienpolitik in der Bundesrepublik stets einen nachrangigen Platz" einnimmt, wie im fünften Familienbericht aus dem Jahr 1994 konstatiert wurde ${ }^{252}$ wirkten in den letzten Jahren einige Zusammenstellungen des Finanzvolumens familienbezogener Leistungen entgegen. Rosenschon (2006) listet gut 100 Maßnahmen aus den Bereichen der Steuergesetzgebung, der Sozialversicherung sowie verschiedener Leistungsgesetze und Realtransfers auf, die sich für das Jahr 2005 auf 247,7 Mrd. Euro summieren. ${ }^{253}$ Dieser Betrag umfasst neben kindbedingten

${ }^{252}$ Deutscher Bundestag (1994), S. 271

253 Rosenschon (2006), S. 72ff 
Leistungen auch ehebezogene Maßnahmen, zu deren quantitativ bedeutsamsten das Ehegattensplitting bei der Einkommensteuer (20,8 Mrd. Euro) und die beitragsfreie Mitversicherung von nicht erwerbstätigen Ehepartnern in Kranken- und Pflegeversicherung (rund $14 \mathrm{Mrd}$. Euro) zählen. Diese ehebezogenen Maßnahmen sind nicht Gegenstand der weiteren Betrachtung dieses Kapitels, die sich ausschließlich auf Unterschiede zwischen Personen mit unterschiedlicher Kinderzahl bezieht. Die größten Positionen kindabhängiger Leistungen sind unentgeltliche Schulbesuche als Realtransfer (50,7 Mrd. Euro) und der Familienleistungsausgleich aus Kindergeld und -freibeträgen (rund 36,3 Mrd. Euro). Alternative Auflistungen kommen zwar zu deutlich geringeren Summen, die großenteils auf engere Abgrenzungen unter Ausschluss ehebezogener Elemente zurückzuführen sind, dennoch ergeben sich auch hier beachtliche Volumina kindbedingter offentlicher Leistungen in einer Größenordnung von gut $150 \mathrm{Mrd}$. Euro. Dieser Umfang dürfte in etwa für die Jahre seit der Jahrtausendwende gelten, wie verschiedene Aufstellungen des Sachverständigenrats, der Bundesbank und des Familienministeriums nahe legen. ${ }^{254}$

Die Zeitreihen des Sozialbudgets zeigen seit den 1990er Jahren eine deutliche Ausweitung der Ausgaben im Bereich "Ehe und Familie", die sich seitdem von rund 60 auf gut 100 Mrd. Euro erhöhten, wobei eine Zunahme vor allem über die Jahre von 1995 bis 2000 zu verzeichnen ist. Allerdings liegen die im Sozialbudget für die Jahre 2000 bis 2005 ausgewiesenen Werte mit 96 bis 103 Mrd. Euro (von denen etwa ein Viertel auf den Bereich Ehe entfällt) deutlich unter dem genannten Niveau kindbedingter Leistungen von über $150 \mathrm{Mrd}$. Euro. ${ }^{255}$ Neben einer weniger detaillierten Zuordnung von Leistungen zu Kindern begründet vor allem das Fehlen von Realtransfers im Sozialbudget die Differenz. Die verschiedenen Quellen weisen somit darauf hin, dass zum einen der Umfang der Leistungen für Familien seit Mitte der 1990er Jahre stark zugenommen hat und zum anderen von erheblicher fiskalischer Bedeutung ist. Ausgehend von einem Volumen von über $150 \mathrm{Mrd}$. Euro in den letzten Jahren entsprechen die Maßnahmen mit Familienbezug gut 7\% des Bruttoinlandsprodukts.

Tabelle 16 schlüsselt den Umfang von 145 kindbedingten Leistungen in der vom Familienministerium gewählten Einteilung in die vier Bereiche steuerliche Maßnahmen, monetäre Transfers, Sozialversicherung und Realtransfers auf. Zu jedem Bereich ist ergänzend der quantitativ bedeutsamste Einzelposten aufgeführt. Über Steuererleichterungen und monetäre Transfers als Elemente einer Familienförderung in engerer Abgrenzung hinaus tragen zum Gesamtbetrag von 158,0 Mrd. Euro in erheblichem Umfang Realtransfers und Leistungen der gesetzlichen Sozialversicherung bei. Zu den steuerlichen Maßnahmen zählen abgesehen vom FLA im engeren Sinne durch Kindergeld und -freibeträge (36,1 Mrd. Euro) unter anderem die kindbedingten Entlastungen durch die Abzugsfähigkeit von Betreuungskosten

${ }^{254}$ Für das Jahr 2000 beziffern sowohl der Sachverständigenrat zur Begutachtung der gesamtwirtschaftlichen Entwicklung als auch die Deutsche Bundesbank den Umfang der Leistungen für Familien mit Kindem auf rund 150 Mrd. Euro (Sachverständigenrat zur Begutachtung der gesamtwirtschaftlichen Entwicklung (2001), S. 171; Deutsche Bundesbank (2002), S. 19). Einen Wert vergleichbarer Größenordnung ermittelte Rosenschon (2001) in einer früheren Untersuchung für das Jahr 2001, in der sie eine Summe von 180,7 Mrd. Euro ausweist (Rosenschon (2001), S. 43f). Eine vom Familienministerium herausgegebene Zusammenstellung 145 kindbedingter Leistungen zu den Basisjahren 2004/2005 summiert sich auf 158 Mrd. Euro, weitere 74 Mrd. Euro fallen für ehebegünstigende Maßnahmen an, vgl. Deutscher Bundestag (2007b).

255 Bundesministerium für Arbeit und Soziales (2007) 
$(0,1 \mathrm{Mrd}$. Euro) sowie die kindbedingten Minderungen beim Solidaritätszuschlag und bei der Kirchensteuer (jeweils 1,0 Mrd. Euro). Den monetären Transfers wurden die Zahlungen des Bundes an die gesetzliche Rentenversicherung für Kindererziehungszeiten zugeschlagen, außerdem befinden sich hierunter das Erziehungsgeld (2,9 Mrd. Euro) sowie die Leistungen nach dem BAföG (2,3 Mrd. Euro) und dem Unterhaltsvorschussgesetz (0,8 Mrd. Euro) ebenso wie kindbedingte Besoldungselemente im öffentlichen Dienst (3,4 Mrd. Euro).

Tabelle 16: Finanzvolumen familienpolitischer Maßnahmen mit Kindbezug 2004/ 2005

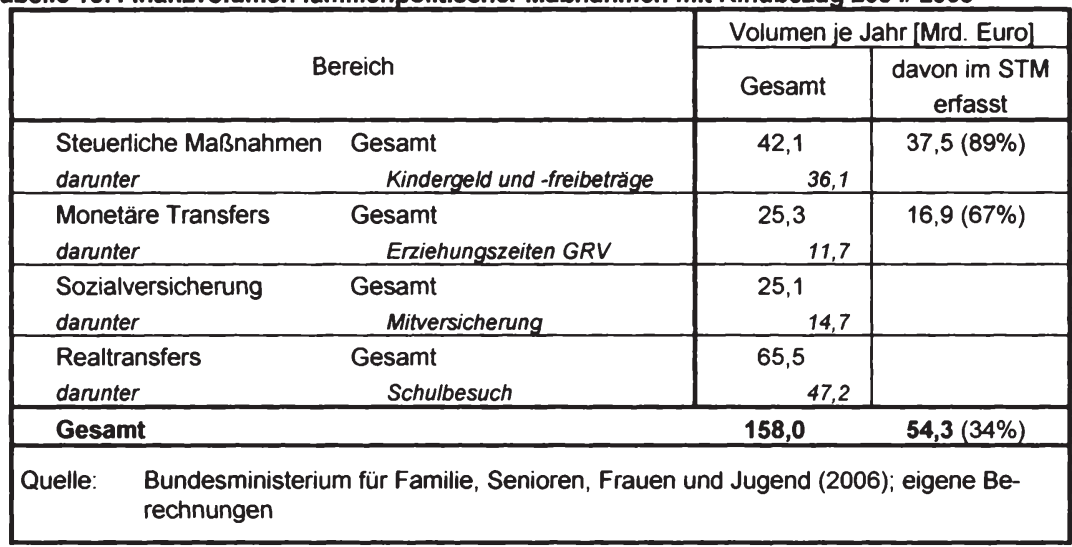

Im Bereich der Sozialversicherung wurde die beitragsfreie Mitversicherung von Kindern in der Kranken- und Pflegeversicherung mit 14,7 Mrd. Euro bewertet, weitere Elemente sind hier Leistungen bei Schwangerschaft und Mutterschaft (3,1 Mrd. Euro), erhöhte Lohnersatzraten für arbeitslose Eltern (0,7 Mrd. Euro) oder Waisenrenten (1,0 Mrd. Euro). Die Realtransfers umfassen neben dem unentgeltlichen Besuch allgemein bildender Schulen (47,2 Mrd. Euro) öffentliche Beiträge zu Betreuungsangeboten (10,2 Mrd. Euro) und die Bereitstellung von Angeboten der Jugendhilfe (7,0 Mrd. Euro). Ob und in welcher Höhe die Gesamtsumme von 158,0 Mrd. Euro sich eventuell um verschiedene Positionen nach oben oder unten korrigieren lässt, ist eine nicht eindeutig zu beantwortende Abgrenzungsfrage. So ist etwa die Aufnahme kindbedingter Besoldungselemente und der Ermäßigung der Kirchensteuer umstritten, umgekehrt ist auch eine Hinzurechnung der gebührenfreien Hochschulausbildung (mit einem Umfang von gut 10 Mrd. Euro) denkbar. ${ }^{256}$

Da eine Größenordnung von 150 Mrd. Euro von verschiedenen Autoren vertreten wird, spiegelt die Tabelle $16 \mathrm{zu}$ Grunde liegende Aufstellung in ihrer Gesamtwirkung jedoch verbreitet akzeptierte Abgrenzungen der fiskalischen Bedeutung familienpolitisch orientierter Maßnahmen wieder. Verschiedentlich wird dieser Form der Zuordnung allerdings vor allem in Bezug auf den FLA mit dem Hinweis widersprochen, dass kein originär familienpolitisches Instrument vorliegt, sondern ausschließlich übergeordnete steuerliche Prinzipien angewandt werden, wie dies verfassungsrechtlich geboten ist (vgl. Kapitel 4.3.1). Für die hier zentrale Frage, in welchem Umfang

${ }^{256}$ Vgl. Bundesministerium für Bildung und Forschung (Hrsg.) (2005), S. 330ff 
staatliche Maßnahmen Familien begünstigen, kann indessen dahingestellt bleiben, auf welcher rechtlichen Ebene die Grundlage für diese Umverteilung gelegt wird und inwieweit sie aus Sicht des Gesetzgebers disponibel ist. Die Zusammenstellung in Tabelle 16 orientiert sich an dem Kriterium, ob effektiv eine Entlastung von Personen mit Kindern eintritt. Diese Sichtweise erscheint vor allem angemessen, um die angestrebten intertemporalen Vergleiche zu den familienpolitischen Regelungen seit 1950 nicht durch uneinheitliche Abgrenzungen zu verzerren.

Nach dem Grundansatz dieser Arbeit, sich auf monetäre Leistungen bei Standardfällen zu beschränken, konzentrieren sich die Berechnungen des STM auf einen Teil der in Tabelle 16 ausgewiesenen Maßnahmen, der mit einem Volumen von 54,3 Mrd. Euro rund $34 \%$ der kindbedingten Leistungen abdeckt. Nicht erfasst sind zum einen "untypische" Transfers wie Waisenrenten oder Kinderkomponenten bei der -derzeit auslaufenden- Eigenheimförderung. Quantitativ bedeutsamer ist das Fehlen von Realtransfers und von Maßnahmen der Sozialversicherung, über die sich die öffentliche Hand an kindbedingten Kosten beteiligt. Inwieweit diese Größen für eine Beurteilung der Familienpolitik relevant sind, hängt von der Art der Fragestellung ab. Wie im nächsten Unterkapitel näher dargelegt wird, sind die von einem Kind ausgehenden Kosten und der von der öffentlichen Hand getragene Anteil hieran unter verschiedenen Gesichtspunkten von zentralem Interesse. Für die in dieser Arbeit gewählte mikroökonomische Perspektive können die Kosten, die etwa im Gesundheits- und Bildungssystem für ein Kind anfallen, unter bestimmten Umständen jedoch ignoriert werden, wenn wie hier Effekte der Familienpolitik auf das verfügbare Einkommen von Eltern untersucht werden. Als Maßstab dient hierbei vor allem das kindbedingte Mehreinkommen $k(n)$ als aus dem Steuer-Transfer-System resultierende Differenz der verfügbaren Einkommen von Eltern und Kinderlosen bzw. als Differenz der verfügbaren Einkommen von Eltern mit unterschiedlicher Kinderzahl:

$$
k(n)=y_{v}\left(y_{B}, n\right)-y_{v}\left(y_{B}, n-1\right)
$$

$y_{v}$ ist das verfügbare Einkommen, $y_{B}$ ein Bruttoeinkommen und $n$ die Anzahl der Kinder. Die kindbedingte Einkommenskomponente ist das Mehreinkommen von Eltern, das sich bei einem gegebenen Bruttoeinkommen aus der Berücksichtigung des $n$-ten Kindes im Steuer-Transfer-System ergibt. In $k(n)$ schlagen sich beim STM unter anderem das Kindergeld, kindbedingte Steuerminderungen und Rentenzuschläge für Kindererziehungszeiten nieder, insgesamt summieren sich die erfassten Maßnahmen auf die genannten 54,3 Mrd. Euro. Die beiden Kategorien "Realtransfers" und "Sozialversicherung" in Tabelle 16 enthalten überwiegend nicht derartige kindbedingte Mehreinkommen sondern stattdessen Minderausgaben von Familien, die aus einer unentgeltlichen oder vergünstigten Bereitstellung von Leistungen resultieren, die anderenfalls das Budget der Eltern belasten würden. Bei den Analysen mit dem STM stehen intergenerative Vergleiche (zwischen Kohorten von Eltern) und intragenerative Vergleiche (insbesondere zwischen Einkommensniveaus) zu den Wirkungen der Familienpolitik im Vordergrund.

Verschiedene Elemente der Familienpolitik auszublenden, erscheint bei intragenerativen Vergleichen hinnehmbar, soweit diese alle gleichaltrigen Kinder eines betrachteten Jahres in annähernd gleichem Umfang begünstigen. Solche Maßnahmen erhöhen das Niveau kindbedingter Leistungen, ohne Unterschiede zwischen 
Familientypen zu begründen. Bei der beitragsfreien Mitversicherung von Kindern in der Kranken- und Pflegeversicherung erscheint diese intragenerativ einheitliche Wirkung weitgehend gegeben. Mit Abstrichen gilt dies auch für Realtransfers in Form öffentlicher Bildungsangebote, positive Zusammenhänge von Elterneinkommen und Bildungsbeteiligung der Kinder führen jedoch dazu, dass durch die auf monetäre Transfers fokussierte Sichtweise beim STM intragenerative Unterschiede zumindest partiell eingeebnet werden. In stärkerem Umfang gilt dies auch für intergenerative Vergleiche. Ein offensichtlicher Verstoß gegen die Annahme einer intergenerativ neutralen Niveauverschiebung folgt aus den verschiedenen Regelungen zur Erhebung von Ausbildungsgebühren seit 1950 (vgl. Kapitel 4.6). Die Abschaffung von Schulgeldern im Laufe der 1950er Jahre etwa entspricht einer Ausweitung von Realtransfers, von der Eltern aus jüngeren Kohorten im Gegensatz zu älteren Eltern profitieren, die sich nicht in der im STM abgebildeten Entwicklung der kindbedingten Mehreinkommen niederschlägt. Die Änderungen bei Ausbildungsgebühren wirken sich jedoch nicht auf die im Zentrum dieses Kapitels stehenden Analysen zu den Wirkungen des Steuer-Transfer-Systems innerhalb vollständiger Lebenszyklen aus, für die wie in dieser Arbeit üblich (Eltern-)Kohorten von 1930 bis 1990 verglichen werden. Die hierbei betrachteten Kinder entstammen Geburtsjahren ab 1954, weiterführende Ausbildungen beginnen für sie somit frühestens ab 1970, so dass Änderungen im Bildungswesen vor dieser Zeit hier ausgeblendet bleiben. Generell wirken Streuungen bei den preisniveaubereinigten öffentlichen Ausgaben je Kind im Bildungs- oder Gesundheitswesen jedoch potenziell verzerrend auf die hier ermittelten Ergebnisse.

Für die weiteren Berechnungen zu kindbezogener Umverteilung mit dem STM bleibt festzuhalten, dass die Ergebnisse vor allem bei intergenerativen Vergleichen Unschärfen enthalten, die überwiegend aus der Ausgrenzung eines Großteils familienpolitisch bedeutsamer Realtransfers folgen. Die Hauptelemente einer familienorientierten Einkommenspolitik sind allerdings recht umfangreich abgebildet, so dass die Ergebnisse die wesentlichen Entwicklungslinien einer Familienförderung in einem engeren Sinne reflektieren.

\subsubsection{Kindbedingte Mehreinkommen im Querschnitt: Entwicklungen seit 1950}

Kindbedingte Mehreinkommen beruhen im deutschen Steuer-Transfer-System zum einen auf breit angelegten Leistungen, die in der Regel dauerhaft gewährt werden, so lange im rechtlichen Sinne die Kindeigenschaft besteht. Hierunter fällt vor allem der FLA im engeren Sinne aus Kindergeld und -freibeträgen sowie seit 2005 die Beitragsermäßigung für Eltern in der Pflegeversicherung. Neben diese universellen Instrumente traten im Zeitraum seit 1950 verschiedene weitere kindbedingte Transfers, die stärker den unterschiedlichen Lebensumständen von Familien gerecht werden sollen. Hierzu existieren auf Familientypen sowie -phasen zugeschnittene Transfers wie steuerliche Freibeträge für Alleinerziehende und Abzugsmöglichkeiten von Betreuungs- oder Ausbildungskosten. In diesem Abschnitt wird zunächst die Entwicklung der kindbedingten Mehreinkommen durch die universell ausgerichteten Instrumente seit 1950 auf der Grundlage von Querschnittsvergleichen präsentiert. Die 
hierüber hinausgehenden Wirkungen weiterer Maßnahmen, die nur in stärker eingegrenzten Lebensphasen wirken, werden dann in den Lebenszyklusbetrachtungen des nächsten Unterkapitels integriert. Die folgende Darstellung weist Parallelen zur Beschreibung des FLA im engeren Sinne in Kapitel 4.3.1 auf, wobei nun jedoch nicht mehr nur Kindergeld und -freibeträge berücksichtigt sind. Die kindbedingten Mehreinkommen als Differenz der Einkommen von Kinderlosen und Eltern unterschiedlicher Kinderzahl setzen sich hier zusammen aus:

- Kindergeld

- Kindergeldzuschlag

- Minderungen der Einkommensteuer durch

- Kinderfreibeträge

- Kinderadditive

- Abzugsbeträge für Alleinerziehende

- Minderungen der Zuschlagsteuern

- Reduzierte Beitragssätze zur Pflegeversicherung

Wie bei Darstellungen zur Wirkung monetärer Familienpolitik gebräuchlich, wird von Arbeitnehmerhaushalten ausgegangen, die ausschließlich Bruttolohn aus sozialversicherungspflichtiger Tätigkeit beziehen. Das verfügbare Einkommen, das für die Bestimmung des kindbedingten Mehreinkommens maßgeblich ist, ergibt sich hier somit aus dem um die Abgaben reduzierten Bruttolohn, ergänzt um das Kindergeld einschließlich eventueller Zuschläge:

$\begin{aligned} \text { Verfügbares Einkommen } \quad= & \text { Bruttolohn } \\ & - \text { Beiträge zur Sozialversicherung } \\ & - \text { Einkommensteuer } \\ & - \text { Zuschlagsteuer } \\ & + \text { Kindergeld einschließlich Kindergeldzuschlag }\end{aligned}$

Für einen intertemporalen Vergleich der relativen Bedeutung der hier betrachteten Maßnahmen sind die kindbedingten Mehreinkommen in Relation zum jeweiligen Einkommens- oder Preisniveau zu betrachten. ${ }^{257}$ Als Ausgangspunkt bieten sich hierfür die nach Familientypen differenzierten Nettoquoten an, die dem Anteil des verfügbaren Einkommens am Bruttolohn entsprechen:

$$
\text { Nettoquote } \quad=\frac{\text { Verfügbares Einkommen }}{\text { Bruttolohn }}
$$

${ }^{257}$ Ein hier nicht weiter verfolgter Aspekt ist, inwieweit die verschiedenen Regelungen des FLA zu der in den 1990er Jahren vom Verfassungsgericht geforderten steuerlichen Freistellung des Existenzminimums von Kindern führen ( $\mathrm{vgl}$. Kapitel 4.3.1). Für erste Kinder ist für den Zeitraum von etwa Mitte der 1960er Jahre bis Mitte der 1990er Jahre von regelmäßigen Verstößen gegen diese Forderung auszugehen. Das Existenzminimum für dritte und weitere Kinder blieb hingegen durchgehend weitgehend steuerlich freigestellt, da für diese überwiegend höhere Kinderfreibeträge und Kindergeldsätze galten. Vgl. zu dieser Fragestellung Hinneburg (2003), S. 33ff 
Abbildung 68: Nettoquoten nach Familientypen und Einkommen seit 1950

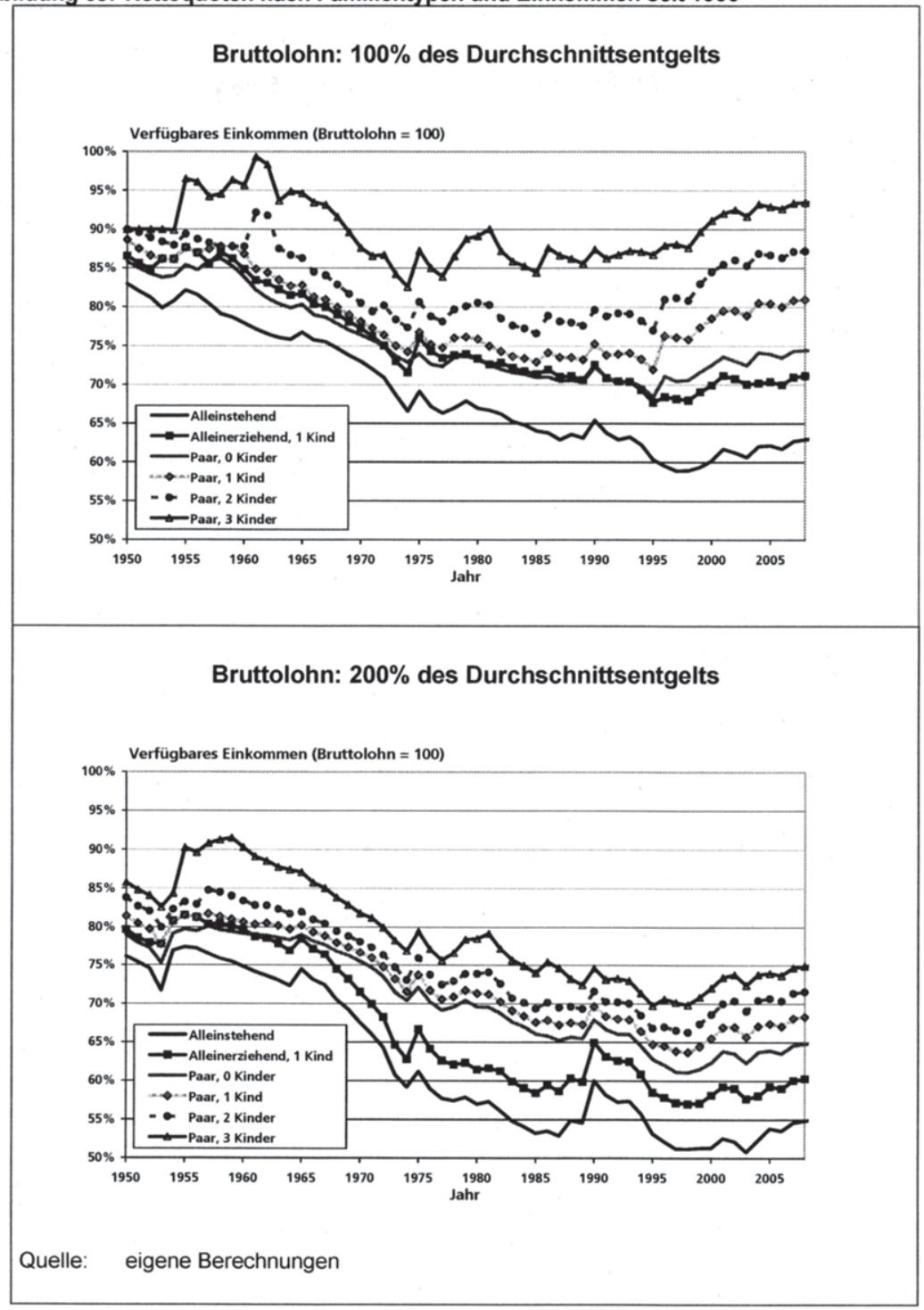

Die so definierten Nettoquoten seit 1950 sind für Einverdienerehepaare mit null bis drei Kindern sowie für Alleinstehende mit und ohne Kind in Abbildung 68 wieder- 
gegeben. ${ }^{258}$ Im oberen Teil der Abbildung liegt ein Bruttolohn in Höhe des Durchschnittsentgelts der gesetzlichen Rentenversicherung zu Grunde, im unteren Teil gilt ein doppelt so hoher Betrag. Beim niedrigeren Einkommen sind die Nettoquoten für jeden Familientyp auf Grund der progressiven Besteuerung größer, wobei dieser Effekt zum Teil durch die Kappung der Sozialversicherungsbeiträge an den Beitragsbemessungsgrenzen kompensiert wird. Hierdurch fällt die Sozialabgabenquote beim doppelten Bruttolohn mitunter geringer aus (vgl. Kapitel 4.1).

Die höchsten Nettoquoten ergeben sich für alle betrachteten Fälle in der Mitte der 1950er Jahre, danach steigt die relative Abgabenbelastung bis zur Mitte der 1970er Jahre überwiegend an. Die Entwicklung im Zeitraum seit 1975 unterscheidet sich je nach Einkommen und Familientyp. Bei Paaren mit Kindern und niedrigerem Einkommen stabilisieren sich die Nettoquoten ab etwa 1975, seit den 1990er Jahren ist ein Anstieg zu verzeichnen. Gegenwärtig liegen die Nettoquoten für diese Fälle mit Werten von gut $80 \%$ (Ehepaar mit einem Kind) bis $93 \%$ (Ehepaar mit drei Kindern) auf einem ähnlichen Niveau wie in den 1960er Jahren. Bei dem höheren der beiden betrachteten Einkommensniveaus setzt sich das Absinken der Nettoquoten nach 1975 fort, deutliche Entlastung bewirkt hier die Steuerreform 1990. In den Jahren seit der Jahrtausendwende steigen die Nettoquoten wieder an und ähneln den Werten aus den Jahren um 1990. Ausgehend von den Nettoquoten führt der hier analysierte Ausschnitt des Steuer-Transfer-Systems im Status Quo zu relativ geringen Belastungen von Ehepaaren mit Kindern und niedrigerem Einkommen. Bei den anderen Fällen sind die gegenwärtigen Belastungen im historischen Vergleich hingegen recht hoch, allerdings sind auch bei diesen nach einem Minimum gegen Mitte der 1990er Jahre die Nettoquoten über die letzten Jahre angestiegen.

Die Differenzen der Nettoquoten von Haushalten mit unterschiedlicher Kinderzahl in Abbildung 68 entsprechen den kindbedingten Mehreinkommen, ausgedrückt als Anteil am jeweiligen Bruttolohn. Je nach Fragestellung lässt sich die kindbedingte Entlastung für intertemporale Vergleiche zu unterschiedlichen Größen in Beziehung setzen. In verschiedenen Untersuchungen zur Entwicklung über die zurückliegenden Jahrzehnte sind kindbedingte Entlastungen in konstanten Preisen, ${ }^{259}$ als Anteil des durchschnittlichen Bruttolohns ${ }^{260}$ oder als Anteil des verfügbaren Einkommens gleichartiger Kinderloser ${ }^{261}$ wiedergegeben. Die dritte Variante, wie in der äußerst umfangreichen und detaillierten Analyse von Willeke und Onken (1990) gewählt, kann aufzeigen, inwieweit das Steuer-Transfer-System bei steigender Kinderzahl kompensierend wirkt, wenn Haushalte mit identischem Bruttoeinkommen verglichen werden. Referenzgröße ist damit das verfügbare Einkommen ohne Kinder, dessen prozentuale Steigerung durch kindbedingte Entlastungen angegeben wird. Bei einer nur schwach nach dem Einkommen differenzierten Wirkung resultiert hierbei eine mit dem Einkommen schrumpfende relative Bedeutung der kindbedingten Komponenten für das Familieneinkommen. Abbildung 69 gibt die kindbedingte Entlastung stattdessen

258 Wie sich ein gegebener Bruttolohn auf zwei Ehepartner aufteilt, wirkt sich seit 1958 auf Grund des Splittingverfahrens mit der Verdoppelung maßgeblicher Abzugsbeträge kaum auf die Nettoquoten aus. Für Doppelverdiener ergeben sich bei gleichem Gesamtbrutto daher äußerst ähnliche Ergebnisse.

259 Cigno, Casolaro, Rosati (2000), S. 4

260 Bahle, Maucher (2003), S. $12 \mathrm{ff}$

261 Willeke, Onken (1990), S. $59 \mathrm{ff}$ 
als Anteil am Durchschnittsentgelt wieder, um einen besseren Vergleich zwischen Einkommensniveaus zu ermöglichen.

Abbildung 69: Kindbedingte Mehreinkommen seit 1950: Ehepaare nach Einkommen und Kinderzahl

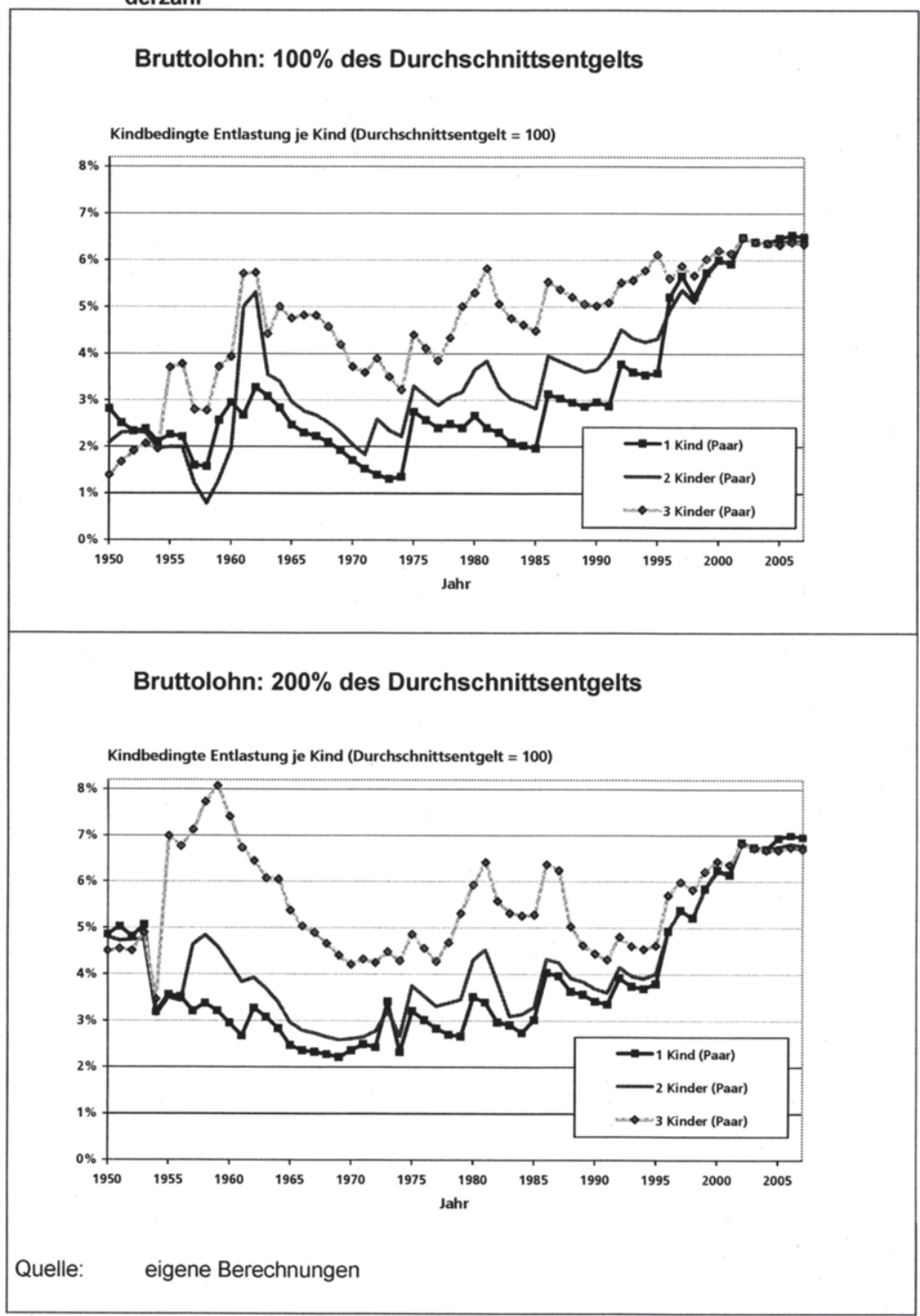


Bei einem Bruttolohn in Höhe des Durchschnittsentgelts stimmen die abgebildeten Werte mit den Differenzen der Nettoquoten überein (wie im oberen Teil von Abbildung 68 der Fall), beim doppelten Durchschnittsentgelt ergibt sich die kindbedingte Entlastung als Zweifaches der Differenz der Nettoquoten. Abgebildet ist die durchschnittliche Entlastung je Kind bei Ehepaaren. Für das Jahr 2006 etwa beläuft sich der Wert für ein Ehepaar mit Durchschnittsverdienst bei einem Kind auf 6,5\%, was bei einem Durchschnittsentgelt von 29.304 Euro einem Betrag von etwa 1.920 Euro entspricht, der sich aus einem Kindergeld von 1.848 Euro und einer Reduktion des Beitragssatzes zur Pflegeversicherung zusammensetzt. Beim zweiten und dritten Kind wirkt sich hingegen ausschließlich das Kindergeld von 1.848 Euro aus, so dass die Werte mit der Kinderzahl geringfügig auf gut bzw. knapp 6,4\% sinken.

Aus dem Vergleich der kindbedingten Entlastungen seit 1950 stechen drei Ergebnisse hervor: Erstens ergibt sich bis 1996 überwiegend eine recht starke Differenzierung nach der Kinderzahl, durch die vorrangig Mehrkindfamilien mit mehr als zwei Kindern gefördert werden. Abweichungen vom Befund einer mit der Kinderzahl überproportional steigenden Entlastung folgen vorrangig bei niedrigeren Einkommen, wenn zusätzliche Freibeträge keine weitere Steuerminderung verursachen. Zweitens bewirken die familienpolitischen Instrumente fast durchgängig eine mit dem Einkommen zunehmende Entlastung, da unter den gegebenen Steuertarifen die progressionsmildernden Wirkungen von Freibeträgen dominieren, eventuelle Einkommensanrechnungen beim Kindergeld werden hiervon überkompensiert. Auch in dieser Hinsicht unterscheiden sich die Regelungen seit 1996 von den früheren Systemen, zuletzt steigt die kindbedingte Entlastung nur noch relativ schwach mit dem Einkommen. Drittens führen die Regelungen des Status Quo zu einer im historischen Vergleich starken effektiven Entlastung von Eltern. Aus den beiden ersten Punkten folgt dabei, dass vor allem Eltern mit niedrigerem Einkommen und/ oder wenigen Kindern im geltenden Recht besser gestellt sind als früher. In der Vergangenheit traten ähnlich großzügige kindbedingte Entlastungen wie heute innerhalb der hier betrachteten Einkommensspanne nur bei gutverdienenden Eltern mit mindestens drei Kindern auf.

Zur besseren Vergleichbarkeit von Eltern mit unterschiedlichem Einkommen ist die kindbedingte Entlastung wie erwähnt nicht als Anteil am verfügbaren Einkommen Kinderloser dargestellt sondern als Anteil des durchschnittlichen Bruttolohns. Eine kindbedingte Entlastung in dieser Formulierung ist umso höher zu gewichten, je niedriger die gleichzeitig auftretenden Nettoquoten sind. Da die hohen kindbedingten Entlastungen der Gegenwart mit relativ niedrigen Nettoquoten einhergehen (vgl. Abbildung 68), ist die Bedeutung des FLA für die Einkommen von Familien eher noch stärker gestiegen, als Abbildung 69 zum Ausdruck bringt.

Für Alleinerziehende bestehen seit 1950 durchgängig zusätzliche steuerliche Abzugsmöglichkeiten (s. Kapitel 4.3.2), die zu einem regelmäßig größeren kindbedingten Mehreinkommen als bei Ehepaaren führen. In Abbildung 70 ist die kindbedingte Entlastung von Alleinerziehenden mit einem Kind wiedergegeben, zum Vergleich ist die Entwicklung bei Ehepaaren mit doppeltem Durchschnittsverdienst aus dem unteren Teil von Abbildung 69 ebenfalls dargestellt. Da die zusätzliche Begünstigung von Alleinerziehenden stets über Abzugsbeträge von der steuerlichen Bemessungsgrundlage erfolgte, wird bei innen die auch für Paare festgestellte Zunahme der kindbedingten Entlastung über die Einkommensskala noch verstärkt. Anders als bei 
Paaren liegt im Status Quo kein Maximum der Entlastungswirkung vor, dieses ist in den Jahren um die Jahrtausendwende gegeben, bevor der Haushaltsfreibetrag gestrichen und der deutlich geringere Entlastungsbetrag für Alleinerziehende eingeführt wurde. Dennoch führen die geltenden Regelungen auch für Alleinerziehende zu einer im historischen Vergleich recht hohen kindbedingten Entlastung, allerdings wurde das heutige Niveau seit Mitte der 1970er Jahre bereits wiederholt erreicht.

Abbildung 70: Kindbedingte Mehreinkommen seit 1950: Alleinerziehende nach Einkommen

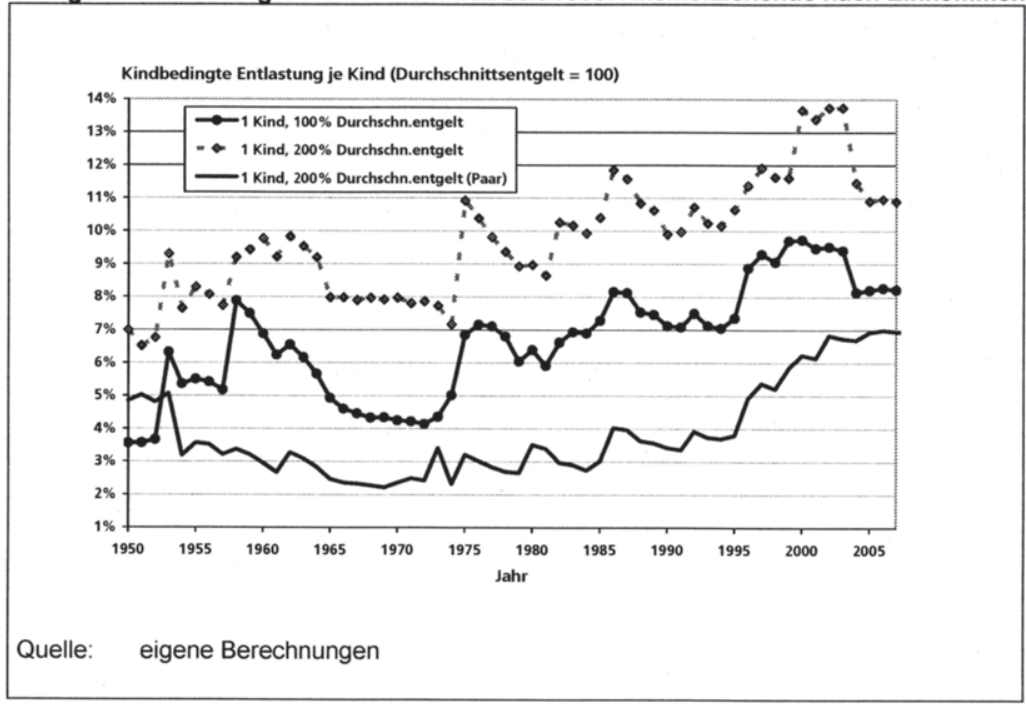

\subsection{Kindbedingte Mehreinkommen im Lebenszyklus}

Vergleichende Querschnittsbetrachtungen zu den Einkommenseffekten familienpolitischer Maßnahmen wie im vorherigen Abschnitt erscheinen vor allem für bedarfsorientierte Ansätze der Familienpolitik relevant. Eine Motivation für diese sind die regelmäßig wiederkehrenden Befunde eines mit der Familiengröße sinkenden bedarfsgewichteten Pro-Kopf-Einkommens sowie eines erhöhten Armutsrisikos bei Familien mit Kindern. ${ }^{262}$ Während für eine distributiv motivierte Familienförderung, die grundsätzlich weitgehend befürwortet wird, die Einkommensverteilung im Querschnitt eine wesentliche Analysegrundlage bildet, verspricht eine Längsschnittperspektive eine vollständigere Abbildung der Familienpolitik, die darüber hinaus für verschiedene allokative Fragestellungen fruchtbarer erscheint. So fallen zum einen in einzelnen Lebensphasen eines Kindes zahlreiche Transfers zeitlich begrenzt an wie etwa das Elterngeld oder die kindbedingten Rentenzuschläge. Eine auf den FLA im engeren Sinne und die inn flankierenden Instrumente beschränkte Betrachtung wie

262 Vgl. etwa Hesse, Scheffer (1995) 
im vorherigen Abschnitt bildet am ehesten die typischen kindbedingten Mehreinkommen $a b$, die sich für Kinder im Schulalter ergeben.

Um die verschiedenen Instrumente in ihrer Gesamtwirkung vollständiger zu erfassen, ist indessen die Betrachtung der Zeitspanne von der Geburt des Kindes bis zum Tod der Eltern erforderlich. Derartige Lebenszyklusbetrachtungen, die auf Zeitreihen der von der Geburt eines Kindes ausgehenden Zahlungsströme abstellen, existieren zum einen aus der Perspektive von (potenziellen) Eltern: Über Differenzen des verfügbaren Lebenseinkommens von Personen mit unterschiedlicher Kinderzahl werden die von Eltern getragenen Kosten der Kindererziehung operationalisiert, die zur Erklärung von Fertilitätsentscheidungen oder als Indikator für einen angemessenen Umfang kindbedingter Transfers genutzt werden. Zum anderen werden aus Sicht der öffentlichen Haushalte die sich über einen Lebenszyklus ergebenden Einnahmen und Ausgaben bestimmt. Ein Einnahmeüberschuss wird dabei als positive fiskalische Externalität gedeutet, die mitunter als ökonomische Begründung für familienfördernde Maßnahmen herangezogen wird. Im folgenden Abschnitt wird zunächst auf in diese Richtung zielende Argumente für eine Familienförderung kritisch eingegangen, die sich auf Lebenszyklusbetrachtungen stützen. Im Weiteren wird dann die Entwicklung der monetären Familienpolitik auf der Grundlage der Lebenszyklen des STM analysiert. Abschließend werden kindbedingte Mehreinkommen im Kontext der von einem Kind ausgehenden Kosten betrachtet, um Anhaltspunkte zu erhalten, in welchem Umfang monetäre Familienpolitik die privaten Kosten von Fertilitätsentscheidungen reduziert.

\subsection{1 Ökonomische Begründungen monetärer Familienpolitik}

Vor dem Hintergrund des Geburtenrückgangs gewannen allokative Begründungen für eine Familienförderung an Bedeutung, die statt auf sozialstaatliche Prinzipien auf eine rationale Politikgestaltung abzielen. Unter dem Modellrahmen der auf Arbeiten Beckers zurückgehenden Theorie endogener Fertilität, ${ }^{263}$ Entscheidungen über die Kinderzahl wie sonstige Konsumentscheidungen als Allokationsproblem der Eltern zu formulieren, erhöhen kindbedingte Transfers den Nettonutzen von Kindern, womit grundsätzlich Anreize für eine erhöhte Reproduktionsrate gesetzt werden. Wenn zudem von Kindern positive externe Effekte ausgehen, ergibt sich so in Kombination mit der Theorie des Marktversagens ein Ansatzpunkt für eine allokative Begründung familienfördernder Maßnahmen. Bei der Frage nach externen Effekten von Kindern lassen sich einerseits reale und andererseits fiskalische externe Effekte trennen. Die Untersuchung realer Externalitäten, die sich grundsätzlich aus interdependenten Nutzenfunktionen bei unvollständigen Tauschbeziehungen ergeben, ${ }^{264}$ nimmt im familienpolitischen Kontext eine eher geringe Rolle ein, ihre theoretische Herleitung ist auf recht spezielle Annahmen angewiesen und ihre empirische Messung kaum möglich. Allerdings erfolgt bisweilen eine Gleichsetzung von Humankapitalproduktion durch Erziehung und Betreuung von Kindern mit (realen) externen Effekten. Da von

\footnotetext{
263 Becker (1960, 1965)

264 Das Vorliegen realer Externalitäten entspricht hiemach der Eigenschaft der Nichtgeltung des Ausschlussprinzips, mit der öffentliche Güter charakterisiert werden.
} 
Familien Reproduktions- und Sozialisationsfunktionen wahrgenommen werden, ohne dass die Eltern hierfür sichtbar kompensiert werden, wird das Vorliegen realer Externalitäten unterstellt. Diese Gleichsetzung wird dem Konzept jedoch nicht gerecht, auch wenn die Steigerung des zukünftigen Produktionspotenzials durch Kinder -zumindest unter einschränkenden Annahmen- unzweifelhaft ist. Die Erträge des Humankapitals werden grundsätzlich privatisiert, sie fallen an in Form der von den Kindern bezogenen Erwerbseinkommen. Ein Marktversagen als allokative Begründung für eine darüber hinaus gehende Kompensation der Eltern bedarf entsprechend weiterer Voraussetzungen, die in der Diskussion um reale Externalitäten jedoch häufig übergangen werden. ${ }^{265}$

Das Vorliegen fiskalischer Externalitäten im familienpolitischen Kontext lässt sich unter weniger strengen Bedingungen herleiten. Sie sind allgemein weit verbreitete Folge staatlichen Handelns und ergeben sich aus dem Auseinanderfallen von Zahlern und Empfängern öffentlicher Leistungen. Auf fiskalische Externaliäten abzielende Argumentationsmuster finden sich zu verschiedenen Zweigen der umlagefinanzierten Sozialversicherung, unter anderem auch im Urteil des Bundesverfassungsgerichts zur Berücksichtigung von Kindern in der Pflegeversicherung aus dem Jahr 2001 (vgl. Kapitel 4.1). Vor allem wird jedoch für die Rentenversicherung auf eine ungleichmäßige Verteilung von Kosten und Erträgen zwischen Eltern und Kinderlosen hingewiesen. Die Argumentation zur Existenz fiskalischer Externalitäten läuft in ihrer vereinfachten Form darauf hinaus, dass Eltern einen doppelten Beitrag zum Umlageverfahren leisten, zum einen unmittelbar in Form ihrer Beitragszahlungen, zum anderen über die Bereitstellung zukünftiger Beitragszahler. Anders ausgedrückt werden Eltern in dieser Sichtweise zweimal Beiträge zugerechnet, sowohl ihre eigenen als auch diejenigen ihrer Kinder; die späteren Ansprüche der Kinder bleiben hingegen ausgeblendet. Umfassender formalisiert wird dieser Grundgedanke einer fiskalischen Externalität von Homburg und Gräff (1988) sowie von Althammer (2000), die jeweils auf das grundlegende Resultat Aarons zurückgreifen, nach dem die interne Rendite einer umlagefinanzierten Rentenversicherung dem Lohnsummenwachstum entspricht. ${ }^{266}$

Die Beurteilung des Ergebnisses bei dieser Vorgehensweise hängt von der Lohnelastizität der Arbeitsnachfrage ab. Althammer (2000) kommt im Gegensatz zu Homburg und Gräff (1988) zu dem Schluss, dass unter den empirisch zu beobachtenden Lohnelastizitäten vom Vorliegen positiver fiskalischer Effekte auszugehen ist: ${ }^{267}$ Bei nicht oder nur schwach nach der Kinderzahl differenzierten Rentenansprüchen ist auch die implizite Verzinsung der Beiträge von der Kinderzahl unabhängig, so dass Eltern und Kinderlose in gleichem Umfang von einer höheren Bevölkerungswachstumsrate profitieren, zu der jedoch nur erstere beisteuern. Das geltende Rentensystem führt hiernach zu einer Umverteilung zu Gunsten von Personen mit unter-

${ }^{265} \mathrm{~S}$. für theoretische Darstellungen sowohl zu realen als auch fiskalischen externen Effekten im Familienkontext Homburg, Gräff (1988) sowie Althammer (2000). Das Vorliegen realer Externalitäten wird jeweils kritisch betrachtet. Allerdings kommen Homburg und Gräff (1988), die wie Althammer (2000) auf der Grundlage von Wachstumsmodellen argumentieren, im Gegensatz zu diesem zu dem Schluss, dass eine Familienförderung allokativ nicht begründbar ist. Althammer (2000, S. 43ff) hingegen sieht die Existenz realer Externalitäten unter nicht unplausiblen Annahmen als gegeben an.

266 S. Aaron (1966)

267 Althammer (2000), S. 49 
durchschnittlicher Kinderzahl, womit zwar noch keine allokative Begründung für eine korrigierend eingreifende Familienpolitik gegeben ist, theoretische Überlegungen jedoch zumindest zur Legitimation eines distributiv motivierten Eingriffs geeignet sind.

Während Althammer (2000) sich auf Hinweise beschränkt, dass diese von Familien generierte fiskalische Externalität grundsätzlich um so stärker ausfällt, je heterogener die Fertilitätsneigung innerhalb des Versichertenkollektivs ist, stellt Sinn (1997) einen Ansatz vor, mit dem der Umfang der Externalität konkretisiert wird. Ausgehend von der Definition einer fiskalischen Externalität als Differenz der Barwerte von Beiträgen und Renten eines Versicherten, wird das überraschende Ergebnis aufgeführt, dass die von einem (zusätzlichen) durchschnittlichen Kind entrichteten Rentenbeiträge in vollem Umfang einem positiven fiskalischen Effekt entsprechen. ${ }^{268}$ Anders als Becker und Barro (1988), nach denen -wie auf Grund des Ergebnisses von Aaron zu erwarten- eine positive fiskalische Externalität umso stärker ausgeprägt ist, je weiter die Kapitalmarktrendite das Lohnsummenwachstum übersteigt, geht Sinn (1997) von einer von diesen Größen unabhängigen Externalität aus. Eine fiskalische Externalität im vollen Umfang des Barwerts der Rentenversicherungsbeiträge wie bei Sinn (1997) tritt trivialenweise ebenfalls bei einem Versicherten auf, der ausschließlich Beiträge entrichtet, ohne je eine Rente zu erhalten. Dass die Versicherungsbilanz eines zusätzlichen durchschnittlichen Kindes mit der Bilanz dieses Versicherten, der keine Leistungen bezieht, übereinstimmt, folgt in Sinns (1997) Argumentation aus dem Einbezug der eigenen Kinder und Kindeskinder des durchschnittlichen Kindes: ${ }^{269} \mathrm{Die}$ Rentenansprüche des Kindes am Ausgangspunkt der Betrachtung werden durch die Nettobeitragszahlungen seiner Nachfahren gedeckt, so dass sich im Vergleich zur Ausgangssituation, dem Zustand ohne Existenz dieses zusätzlichen Kindes, eine Nettomehreinnahme der Rentenversicherung im Umfang der Beiträge des betrachteten Kindes ergibt. Bei dieser Herleitung bleibt zu betonen, dass die ermittelte Externalität nicht mit dem Wert eines Kindes im Allgemeinen gleichzusetzen ist. Die Methode zielt auf den Wert eines zusätzlichen Kindes unter ceteris paribus-Bedingungen $a b$.

Letztlich reflektiert Sinns (1997) Ansatz die Ausgangslage bei Einführung eines umlagefinanzierten Rentenversicherungssystems. Dabei tritt ein Einführungsgewinn der ersten begünstigten Generation auf, die Leistungen empfängt, ohne Beiträge geleistet zu haben, wobei dieser Gewinn zu Lasten sämtlicher weiterer Generationen anfält. Insgesamt ergibt sich ein intergeneratives Nullsummenspiel. ${ }^{270}$ Sinns (1997) Modellierung läuft nun darauf hinaus, dass die von der Einführung profitierende $\mathrm{Ge}$ neration durch das betrachtete zusätzliche durchschnittliche Kind repräsentiert wird. Beschränkt man die Betrachtung auf dieses Kind und die von inm abstammenden Nachfahren, so ergibt sich auch hier die bekannte Nullsumme, mithin auch eine fis-

268 Sinn (1997), S. 14

269 Auch in Lüdeke (1999) findet sich diese Argumentation an Hand dieser Selbstfinanzierung eines Kindes über die späteren Abgaben seiner Kindeskinder (Lüdeke (1999), S. 17).

270 Dieses Ergebnis eines Nullsummenspiels gilt, wenn die Kapitalmarktrendite, wie empirisch regelmäßig zu beobachten, langfristig größer als das Lohnsummenwachstum ist, die Aaron-Bedingung also erfüllt ist. Auch Sinns (1997) Ergebnis einer fiskalischen Externalität durch ein (zusätzliches) Kind in Höhe des Barwerts der von ihm geleisteten Beiträge setzt implizit die Gültigkeit der AaronBedingung voraus. Eine formale Herleitung der Aussage des intergenerativen Nullsummenspiels findet sich ebenfalls bei Sinn (2000). S. Sinn (2000), S. $394 \mathrm{f}$ 
kalische Externalität von null. Wenn nun wie bei Sinn (1997) als Ausgangszeitpunkt nicht der Renteneintritt der ersten Generation (bzw. des betrachteten Kindes) gewählt wird, sondern der Beginn der Erwerbsphase des betrachteten Kindes, so dass unter sonst gleichen Umständen zusätzlich seine Beitragszahlungen in die Bilanzierung einfließen, entspricht deren Barwert vollumfänglich einer fiskalischen Externalität. Ausgehend von Status Quo-Größen des Jahres 1997 beziffert Sinn (1997) diese auf annähernd 90 Tsd. Euro und schlussfolgert, dass eine Transferzahlung dieser Größenordnung geeignet wäre, den Effekt innerhalb des Rentenversicherungssystems zu internalisieren.

Losgelöst von der Frage, ob und in welchem Umfang eine monetäre Familienpolitik grundsätzlich indiziert ist, sprechen mehrere Punkte gegen eine derartige auf die Rentenversicherung fokussierte Berücksichtigung von Kindern im SteuerTransfer-System. Erstens erwächst der potenzielle Interventionsbedarf hier nicht aus einem Marktversagen sondern aus einem vorausgehenden staatlichen Eingriff, nämlich der Einführung des Umlageverfahrens als Zwangsversicherung. Mit einer weiteren Intervention als Reaktion auf eine vorhergehende droht staatliches Handeln selbstlegitimierend zu werden. ${ }^{271}$ So wäre etwa auch eine deutliche Ausweitung der Leistungen der Rentenversicherung bei erhöhten Beiträgen in Hinblick auf das Kriterium fiskalischer Externalitäten neutral zu bewerten, da die Erweiterung ebenso wie die ursprüngliche Einführung ein Nullsummenspiel darstellt. Nach der Argumentation Sinns (1997) steigt mit ihr jedoch der Internalisierungsbedarf, so dass eine fiskalisch neutrale Maßnahme weitere Eingriffe erfordern würde. Zweitens bringen Zwangsabgaben nicht nur in der Sozialversicherung sondern regelmäßig Verzerrungen mit sich. Kapitalbesteuerung etwa hemmt die Kapitalbildung, gleichzeitig wachsen mit dem (Sach-)Kapitalstock die zu erwartenden zukünftigen Steuereinnahmen, so dass auch hier zwischen kurz- und langfristigen Budgetwirkungen abzuwägen ist. Fiskalische Externalitäten sind entsprechend weit verbreitet, so dass es einer gesonderten Begründung bedarf, warum gerade im Bereich der Rentenversicherung eine Korrektur erfolgen soll. ${ }^{272}$ Drittens bleibt die Frage, inwieweit positive Effekte von Kindern insbesondere im Rentensystem anfallen. Wenn eine Volkswirtschaft insgesamt von nachwachsenden Generationen profitiert, indem etwa die Innovationsfähigkeit gesteigert oder der Strukturwandel erleichtert wird, bietet sich eine Finanzierung über das Steuersystem statt über die Sozialversicherung an.

Diese Kritikpunkte werden zum Teil entkräftet, wenn sich auch bei einer umfassenderen Betrachtung des Steuer-Transfer-Systems insgesamt -und nicht nur des Teilsystems Rentenversicherung- ein positiver fiskalischer Nettoeffekt von Kindern herleiten lässt. Nach Sinns (1997) Ergebnissen lassen sich den Rentenversicherungsbeiträgen von 90 Tsd. Euro rund 55 Tsd. Euro an öffentlich getragenen Ausgaben für kindbedingte Transfers (unentgeltliche Bildung sowie monetäre Transfers) gegenrechnen, so dass eine fiskalische (Netto-)Externalität in Höhe von etwa 35 Tsd. Euro verbleibt. Auch aus empirisch verfeinerten Analysen, in denen Ausgaben und Einnahmen der öffentlichen Haushalte bei einer recht umfassenden $\mathrm{Be}$ rücksichtigung des gesamten Steuer-Transfer-Systems über einen typisierten Lebenszyklus saldiert werden, lassen sich Hinweise auf eine positive fiskalische Exter-

271 Vgl. hierzu das Minderheitenvotum des Wissenschaftlichen Beirats beim Bundesministerium für Wirtschaft und Arbeit (Bundesministerium für Wirtschaft und Arbeit (Hrsg.) (2005), S. 45)

272 Vgl. Konrad, Richter (2005), S. 123ff 
nalität ableiten. Das positive Vorzeichen der Bilanz wird dabei bisweilen zum Anlass für recht weit reichende Schlussfolgerungen genommen. Diese laufen auf eine Ausweitung kindbedingter Leistungen hinaus mit dem Ziel, die fiskalische Externalität zu internalisieren. Bei Ausprägungen dieses Effekts in Größenordnungen von mehreren Zehntausend Euro würde sich hieraus eine massive Ausweitung familienpolitischer Maßnahmen ableiten lassen. ${ }^{273}$

In diese Richtung zielenden Forderungen lassen sich zum einen empirische Zweifel entgegenbringen, ob das gegenwärtige deutsche Steuer-Transfer-System für heute geborene Kohorten tatsächlich zu einer Nettobelastung über den Lebenszyklus führt. In Generationenbilanzen für Deutschland, denen bei anderem Untersuchungsziel ebenfalls Barwerte der Zahlungsströme über einen Lebenszyklus zu Grunde liegen, erweisen sich die jüngsten Generationen zum Teil als Netto-Transferempfänger, was sich bei analoger Betrachtung als Hinweis auf eine negative fiskalische Externalität von Kindern deuten lässt. ${ }^{274}$ Umkehrschluss einer Forderung nach Ausweitung familienpolitischer Maßnahmen auf Grund einer positiven Externalität von Kindern wäre hiernach entsprechend die Eindämmung kindbedingter Leistungen wegen ihrer negativen fiskalischen Effekte. Der konkrete Umfang der fiskalischen Bilanz von Angehörigen der jüngsten Kohorten kann recht sensibel auf die zu Grunde gelegten Annahmen wie unter anderem den Zinssatz reagieren, so dass ihr Vorzeichen eher zurückhaltend zu deuten ist. Auch ein weiterer Berührungspunkt der fiskalischen Bilanz eines Kindes mit der Generationenbilanzierung erinnert an die mangelnde Zwangsläufigkeit der Schlussfolgerung vom Vorliegen einer positiven fiskalischen Externalität auf familienpolitische Leistungen. Bei dem üblichen Ergebnis einer Generationenbilanz, dass die gegebene Fiskalpolitik nicht langfristig tragfähig ist, lässt sich das zu begleichende Defizit sowohl in Form einer Ausgabenreduktion als auch einer Einnahmenausweitung quantifizieren. Welche Maßnahmen -wie etwa Erhöhungen der Einkommensteuer oder Einschränkungen der Leistungen der Sozialversicherung- zu welchem Zeitpunkt ergriffen werden, kann dabei offen bleiben. Dieselben Optionen bestehen grundsätzlich, wenn eine externe Wirkung von Kindern internalisiert werden soll, die als positives Vorzeichen einer fiskalischen Bilanz operationalisiert wurde. So wären neben zusätzlichen kindbedingten Leistungen Steuersenkungen ein gleichsam geeignetes Mittel, eine positive Externalität zu korrigieren. Im Fall einer Externalität in Höhe der Rentenversicherungsbeiträge wie oben dargestellt besteht

273 Werding und Hofmann (2005), auf deren Untersuchung im nächsten Abschnitt noch weiter eingegangen wird, ermitteln eine fiskalische Externalität in Höhe von 76.900 Euro. Über den Lebenszyklus eines durchschnittlichen Kindes ergibt sich ein Einnahmeüberschuss mit einem Barwert von 42.800 Euro. Da von den Nachfahren des Kindes weitere Einnahmeüberschüsse ausgehen, diese summieren sich wegen der stärkeren Diskontierung über alle weiteren Generationen auf 34.100 Euro, beläuft sich die fiskalische Externalität nach diesen Ergebnissen auf 76.900 Euro (vgl. Werding, Hofmann (2005), S. 85).

274 Auf Methodik und Ergebnisse von Generationenbilanzen wird in Kapitel 9.1 ausführlicher eingegangen. Ihr Hauptanliegen besteht in der Beurteilung der langfristigen Tragfähigkeit der Fiskalpolitik. Wenn die projizierten Leistungen an die jüngsten Generationen die von ihnen zu entrichtenden Abgaben übersteigen (Nettotransfer), wird die Fiskalpolitik in der Regel nicht nachhaltig sein, so dass zumindest langfristig Korrekturen erforderlich sind. Während sich verschiedene $\mathrm{Ge}-$ nerationenbilanzen zwar im Vorzeichen der Nettobelastung der jüngsten Generationen unterscheiden, bleibt davon jedoch das zentrale Ergebnis unberührt, dass zukünftiger Konsolidierungsbedarf besteht, die Staatsausgaben mithin zu senken und/ oder die Abgabenquoten zu erhöhen sind. 
eine treffsichere Internalisierungsoption darin, einem (zusätzlichen) Kind seine Beitragszahlungen zu erlassen. Auch dann, wenn die Diagnose einer von Kindern ausgehenden positiven fiskalischen Externalität zutrifft, liefert dies keine hinreichende Begründung, warum konkret bei der Familienpolitik anzusetzen ist, um den von ihr ausgehenden möglichen Verzerrungen entgegen zu wirken. Gründe für eine Intervention im Bereich der Familienpolitik könnten sich dann ergeben, wenn sich Transfers an Eltern im Gegensatz zu anderen Maßnahmen hinreichend positiv auf die Fertilität auswirken.

Insgesamt weisen die vorgestellten Ansätze zur Begründung familienfördernder Maßnahmen somit verschiedene Probleme auf, die einer zwingenden Ableitung kindbedingter Leistungen aus ökonomischem Kalkül im Wege stehen. Dennoch existiert ein breiter gesellschaftlicher Konsens darüber, dass eine Umverteilung zu Gunsten von Familien grundsätzlich angemessen ist. Während der von Kindern gestiftete öffentliche Nutzen schwer messbar erscheint, sind die hohen privaten Kosten für Eltern hingegen unbestritten und offenbar für eine weit reichende Akzeptanz familienpolitischer Maßnahmen hinreichend. Höhe und Zusammensetzung dieser Kosten sowie die Frage, wie die familienpolitischen Maßnahmen seit den 1950er Jahren hierauf eingewirkt haben, sind Gegenstand der folgenden Analysen.

\subsubsection{Erfassung kindbedingter Mehreinkommen im Lebenszyklus}

Nach dem gleichen Ansatz wie in der obigen Querschnittsbetrachtung zur Entwicklung der kindbedingten Mehreinkommen $k(n)$ über die zurückliegenden Jahrzehnte werden im Folgenden kindbedingte Leistungen über den Lebenszyklus von Kindern gebildet. Als Bruttoeinkommen liegen fünf qualifikationsspezifische Lebenseinkommensprofile zu Grunde (s. Kapitel 3), aus denen das verfügbare Einkommen abgeleitet wird. Die verfügbaren Lebenseinkommen folgen aus Bruttolöhnen, kindbedingten Transfers und Bruttorenten der gesetzlichen Rentenversicherung. Das kindbedingte Mehreinkommen über den Lebenszyklus eines Kindes $K(q, j, n)$ entspricht der -mit einem Zinssatz z abdiskontierten-Summe der Jahreswerte $k(q, j, n)$, wobei neben den universell ausgerichteten familienpolitischen Instrumenten nun auch unter anderem die kindbedingten Zuschläge bei gesetzlichen Renten zur Erhöhung der verfügbaren Einkommens von Eltern beitragen. $K(q, j, n)$ als Barwert der Summe der kindbedingten Leistungen $k(q, j, n)$ entspricht somit auch der Differenz der verfügbaren Lebenseinkommen von Personen mit unterschiedlicher Kinderzahl:

$$
\begin{aligned}
K(q, j, n) & =\sum_{i=l_{t}}^{T} k_{t}(q, j, n)^{*}(1+z)^{-t} \\
& =\operatorname{LEK}(q, j, n)-\operatorname{LEK}(q, j, n-1)
\end{aligned}
$$

mit $n \quad$ Anzahl von Kindern

$q \quad$ Qualifikation

j Geburtsjahr (des Vaters)

$T$ Todesalter

LEK verfügbares Lebenseinkommen 
Die fünf Qualifikationsniveaus der Eltern reichen von Personen ohne beruflichen Abschluss und mit unterdurchschnittlichen Bruttolöhnen (Mittelwert über die Erwerbsphase in Höhe von knapp $80 \%$ des Durchschnittsentgelts) bis zu Universitätsabsolventen mit überdurchschnittlichem Bruttoeinkommen (knapp 170\% des Durchschnittsentgelts). Von der Art des Bildungsabschlusses gehen zwei weitere Effekte auf den Lebenszyklus der Eltern aus: Mit der Dauer der Ausbildung verkürzt sich zum einen die Erwerbsphase, zum anderen verschieben sich das Heirats- und das Gebäralter nach hinten. ${ }^{275}$ Für die Berechnungen werden dieselben typisierten Lebenszyklen der Eltern zu Grunde gelegt, die auch bei den Renditeberechnungen zur Rentenversicherung gewählt wurden (vgl. Kapitel 7.2.3). Die Väter sind nach diesem Ansatz bei der Geburt eines ersten Kindes zwischen 24 Jahren (Ohne beruflichen Abschluss) und 32 Jahren alt (Universitätsabschluss), die Mütter sind jeweils zwei Jahre jünger und verfügen über dieselbe Qualifikation wie die Väter. Von der Setzung eines früheren oder späteren Alters der Eltern bei der Geburt gehen wie weiter unten noch angesprochen wird ambivalente Wirkungen aus. Die Annahme eines kurzen Geburtsabstands hingegen wirkt eindeutig in Richtung einer Erhöhung des Volumens kindbedingter Mehreinkommen. Ursächlich ist die wiederholt überproportionale Zunahme von Leistungen bei steigender Kinderzahl (vgl. hierzu auch Abbildung 69). Bei rascher Geburtsfolge liegt im rechtlichen Sinne über längere Zeiträume eine Mehrkindfamilie vor (vgl. Kapitel 4.3.1). Indem hier mit zwei Jahren ein recht kurzer Geburtsabstand angenommen wird (tatsächlich beläuft sich der Durchschnittswert in Deutschland auf etwa vier Jahre), erfolgt vor allem für Zeiten eines stark horizontal gestaffelten FLA tendenziell eine leichte Überbewertung der Höhe kindbedingter Mehreinkommen.

Wie auch im Kapitel zur Rentenversicherung werden drei Erwerbsmuster unterschieden, wobei im Weiteren nur die Ergebnisse für Ein- und Doppelverdiener dargestellt sind, da die Befunde für das Erwerbsmuster Teilzeit in aller Regel zwischen diesen beiden Extremen liegen. Bei Einverdienern ist die Frau von der Eheschließung an noch zwei Jahre enwerbstätig, teilzeitbeschäftigte Frauen unterbrechen die Enwerbstätigkeit, solange Kinder unter drei Jahren vorliegen, danach beläuft sich das Arbeitsangebot auf 50\% einer Vollzeitstelle. Bei Doppe/verdienern schließlich sind beide Partner durchgehend vollzeitbeschäftigt, nur nach Geburten ist ein Partner ein Jahr lang nicht erwerbstätig. Weiterhin werden ausschließlich durchgängig bis zum Tod des Vaters miteinander verheiratete Eltern betrachtet, Alleinerziehende sind folglich in den Lebenszyklusbetrachtungen nicht berücksichtigt. Wie oben dargestellt fällt damit ein Teil kindbedingter (steuerlicher) Entlastungen aus der Analyse heraus.

Eine weitere Stellgröße bei der Bestimmung des Umfangs kindbedingter Mehreinkommen in typisierten Lebenszyklen ist die Art der Ausbildung eines Kindes, die darüber entscheidet, in welchem Umfang Leistungen für volljährige Kinder anfallen. Diesbezüglich wird in der Regel von dem Standardfall ausgegangen, dass bis zum Alter von einschließlich 18 Jahren (insgesamt also über 19 Jahre) ein Kind im Sinne des FLA zu berücksichtigen ist, was einem Kind entspricht, das typisierend eine betriebliche Ausbildung (Lehre) durchläuft. Neben dem FLA durch Kindergeld und -freibeträge und die inn flankierenden Maßnahmen, deren Entwicklung im Querschnitt oben nachgezeichnet wurde, erfassen die Lebenszyklusbetrachtungen auch

${ }^{275} \mathrm{Vgl}$. zu diesen Zusammenhängen etwa die Daten in Duschek, Wirth (2005). 
die folgenden, im ersten Teil dieser Arbeit ausführlicher vorgestellten Elemente, bei denen als markante Eckpunkte festgehalten wurden:

Leistungen im Anschluss an die Geburt eines Kindes (vgl. Kapitel 4.4): Die Ausgestaltung eines Zusatz- oder Ersatzeinkommens nach der Geburt eines Kindes durch öffentliche Transfers lässt sich grob in drei Phasen einteilen: Bis 1979, als das Mutterschaftsurlaubsgeld eingeführt wurde, existierte kein breit angelegtes Förderinstrument. Zwischen 1979 und 2006, davon ab 1986 in Form des Erziehungsgelds, bestand eine Förderung, die sich zunehmend auf Eltern mit niedrigerem Einkommen konzentrierte. In den Jahren bis 1993 ergeben sich für diese zunächst Leistungsverbesserungen auf Grund mehrerer Anhebungen der maximalen Bezugsdauer auf bis zu 24 Monate. Bei höheren Einkommen wirkte indessen die Einkommensanrechnung zunehmend restriktiver. Da der monatliche Höchstbetrag zwischen 1986 und 2006 nahezu konstant bei rund 300 Euro blieb, schrumpfte die effektive Bedeutung des Eziehungsgelds für Familieneinkommen ab 1993 kontinuierlich. Mit der Einführung des Elterngelds ab 2007 beginnt die dritte Phase. Da das Elterngeld vor allem eine Lohnersatzfunktion wahrnehmen soll, indem es sich grundsätzlich auf $67 \%$ eines betreuungsbedingt entfallenden Erwerbseinkommens beläuft, profitieren vor allem gut verdienende Elternteile von der Umstellung. Verschlechterungen können bei Familien mit niedrigerem Einkommen auftreten, die von der Herabsetzung der Höchstdauer von 24 auf 12 Monate (unter Umständen auf 14 Monate) betroffen sind. Bis zum Jahr 2006 reichte das Erziehungsgeld von null Euro bei höheren Einkommen bis zu maximal 7.200 Euro (24 Monate mit 300 Euro). Das Elterngeld beläuft sich seit 2007 auf mindestens 3.600 Euro (12 Monate mit 300 Euro) und steigt mit der Höhe des entfallenden Einkommens auf bis zu über 21.600 Euro (12 Monate mit 1.800 Euro). Da das Elterngeld dem Progressionsvorbehalt unterliegt, fließt ein Teil der Zahlungen allerdings an die öffentliche Hand zurück. Wie groß dieser Anteil ist, hängt stark von den Umständen des Falles ab, für die im Weiteren betrachteten Familientypen kann als Faustgröße davon ausgegangen werden, dass rund $10 \%$ des Elterngelds über einen Anstieg der Einkommensteuer wieder entzogen werden.

Steuerliche Anerkennung von Kinderbetreuungskosten (vgl. Kapitel 4.3.2): Erstmals 1980 wurden Kinderbetreuungskosten steuerlich anerkannt, wobei bis 1982 auch ohne Nachweis ein pauschaler Mindestabzug möglich war. Im weiteren Zeitraum bis 2001 wurden Abzugsmöglichkeiten auf Alleinerziehende beschränkt. Erstmals ab 2002 und verstärkt seit 2006 stellt das EStG auf nachweislich erwerbsbedingte Betreuungskosten $a b$, wodurch sich vor allem für Doppelverdiener mit höherem Einkommen Verbesserungen ergeben. Da zum einen in die Berechnungen mit dem STM generell nur nachweisunabhängige Abzüge einfließen und zum anderen die Betrachtung im Weiteren auf verheiratete Eltern beschränkt bleibt, unterzeichnen die Ergebnisse das Ausmaß kindbedingter Entlastungen in den Jahren nach 1982 geringfügig. Vor allem für Eltern mit Kindern im Vorschulalter dürften die relativ großzügigen Regelungen im Status Quo eine Verbesserung im Vergleich zu früheren Rechtsständen bedeuten. 
Kindbedingte Reduktion des Beitragssatzes zur Pflegeversicherung: Seit 2005 wird von Kinderlosen ein zusätzlicher Beitrag zur Pflegeversicherung erhoben, der auch in den Querschnittsergebnissen des vorigen Unterkapitels erfasst ist. Dieser Beitragssatz beläuft sich auf 0,25\% (ohne Beteiligung des Arbeitgebers), Eltern entrichten unabhängig von der Kinderzahl weiterhin ausschließlich den allgemeinen Beitragssatz von 1,7\% (vgl. Kapitel 4.1). Beim Durchschnittsentgelt entspricht die kindbedingte Ersparnis in der Pflegeversicherung derzeit rund 73 Euro im Jahr. Die Beitragsssatzreduktion wirkt sich von der Geburt des ersten Kindes bis zum Tod des zweiten Elternteils einkommenssteigernd aus.

Ausbildungsförderung und Ausbildungsfreibeträge: Bei volljährigen Auszubildenden folgen kindbedingte Mehreinkommen aus der verlängerten Gewährung von Kindergeld und Kinderfreibeträgen (einschließlich sich hieran anlehnender Maßnahemen) sowie aus Ausbildungsförderung und Ausbildungsfreibeträgen (vgl. Kapitel 4.3.2). Die wechselseitigen Abhängigkeiten der ausbildungsbezogenen Instrumente führen zu einer uneinheitlichen Entwicklung der Höhe kindbedingter Mehreinkommen in Abhängigkeit vom Einkommensniveau der Eltern (vgl. hierzu auch Kapitel 6.2.1). Da volljährige Auszubildende zum ejnen wie sonstige Kinder im FLA berücksichtigt werden, gelten auch für sie die im Unterkapitel 8.1.2 vorgestellten Querschnittsergebnisse einer relativ großzügigen Familienpolitik im Status Quo. Die gegenwärtige Ausbildungsförderung erscheint im historischen Vergleich indessen eher knapp bemessen. Für Studenten bestand ab dem Jahr 1957 eine Fördermöglichkeit nach dem Honnefer Modell, die mit der Einführung des BAföG 1971 ausgeweitet wurde (vgl. Kapitel 4.5). Seit Bestehen des BAföG blieben die Anpassungen der Leistung jedoch überwiegend hinter der Preis- und Einkommensentwicklung zurück, so dass die Ausbildungsförderung der 1970er Jahre vergleichsweise großzügig erscheint. Verstärkend wirkt in diese Richtung auch die Förderung im schulischen Bereich. Im Zeitraum von 1971 bis 1982 wurde ein erheblicher Anteil der Schüler an weiterführenden allgemein bildenden Schulen gefördert, danach wurde diese Möglichkeit weitgehend beschnitten. In der Regel erfolgt eine Studenten-Förderung nach dem BAföG über bis zu fünf Jahre und beläuft sich derzeit auf bis zu 6.360 Euro je Jahr, das Kindergeld von 1.848 Euro jährlich kommt additiv hinzu.

Kindbedingte Zuschläge in der Rentenversicherung: Die stärksten Unterschiede in der Rentenversicherung ergeben sich zwischen bis und nach 1991 geborenen Kindern. Für bis 1991 geborene Kinder wird im Allgemeinen ein Entgeltpunkt gut geschrieben, für jüngere Kinder folgen aus der seitdem dreijährigen Kindererziehungszeit drei Entgeltpunkte (vgl. Kapitel 5.2). Auch durch weitere Elemente der Rentenberechnung wie Kinderberücksichtigungszeiten wirken sich Kinder seit den 1990er Jahren verstärkt rentensteigernd aus, wobei der konkrete Umfang wesentlich von der Erwerbsbeteiligung abhängt. Insgesamt ergeben sich für ein Kind bei typisierenden Fällen bis zu etwa vier Entgeltpunkte (vgl. hierzu auch Kapitel 7.2.3). Bei der Bewertung von Kindererziehungszeiten unterscheiden sich öffentliche und private Perspektive deutlich. Während der ersten drei Lebensjahre eines Kindes wird der Bundeshaushalt belastet, da der Bund solange Beiträge an die Rentenversicherung entrichtet, die bei einem Durchschnittsverdienst anfallen würden. Bei gegen- 
wärtigem Beitragssatz und Durchschnittsentgelt beläuft sich die Belastung des Bundeshaushalts während dieser drei Jahre auf rund 17.600 Euro insgesamt. Aus Sicht des begünstigten Elternteils besteht in den Jahren nach der Geburt hingegen kein Einkommenseffekt, stattdessen erhöht sich das Einkommen in der Rentenbezugsphase. Drei Entgeltpunkte für Kindererziehungszeiten entsprechen derzeit einer Erhöhung der Bruttojahresrente um etwa 946 Euro.

Abbildung 71: Kindbedingtes Mehreinkommen nach Lebensalter und Geburtsjahr

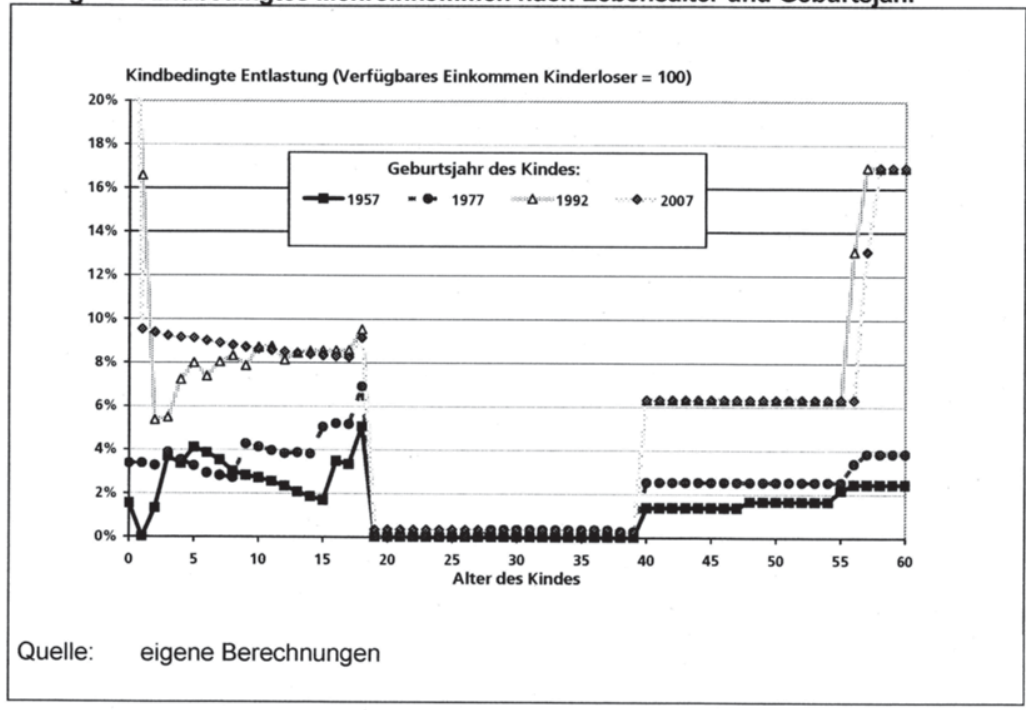

Die sich unter den getroffenen Annahmen im Laufe von Lebenszyklen ergebenden kindbedingten Mehreinkommen sind in Abbildung 71 exemplarisch dargestellt. Der Abbildung liegt die Fallkonstellation eines Einverdienerpaares mit einem Kind und mittlerem Bildungsabschluss (Lehre) und damit auch mittlerem Einkommen (in Höhe von durchschnittlich knapp 105\% des Durchschnittsentgelts) zu Grunde. Die kindbedingten Mehreinkommen sind als Anteil des verfügbaren Einkommens kinderloser Einverdienerpaare gleicher Qualifikation und gleichen Alters angegeben, das Geburtsjahr des Kindes variiert zwischen 1957 und 2007. Für Kinder der Jahrgänge 1992 und 2007 wird in den ersten beiden Lebensjahren Erziehungsgeld (Geburtsjahr 1992) bzw. im ersten Lebensjahr Elterngeld gezahlt, bei den beiden Jahrgängen 1957 und 1977 fallen hingegen keine speziellen Transfers in den beiden ersten Lebensjahren an. Über die Altersspanne von zwei bis 18 Jahren wirken sich die bereits oben im Querschnitt besprochenen familienpolitischen Instrumente aus (überwiegend Kindergeld und -freibeträge), die dabei angesprochene Entwicklung eines im Zeitverlauf steigenden Anteils am Einkommen zeigt sich in Abbildung 71 beim Vergleich der vier Geburtsjahre. ${ }^{276}$ Während das Kind zwischen 19 und 40 Jahren alt ist,

276 Die in der Abbildung nicht ersichtlichen kindbedingten Mehreinkommen im ersten Lebensjahr entsprechen rund 28\% (Geburtsjahr 1992) bzw. 50\% (Geburtsjahr 2007) des verfügbaren Ein- 
führt die Beitragsreduktion in der Pflegeversicherung zu einem kindbedingten Mehreinkommen, soweit es sich dabei um Kalenderjahre ab 2005 handelt. In der Rentenbezugsphase der Mutter wirken sich zusätzlich die jeweiligen kindbedingten Zuschläge auf die Alters- und Witwenrenten aus. Bei den beiden jüngeren der vier abgebildeten Jahrgänge entsprechen die kindbedingten Mehreinkommen rund $6 \%$ der verfügbaren Rente beider Elternteile, während des Bezugs einer Witwenrente entspricht das kindbedingte Mehreinkommen rund $17 \%$ der Nettorente einer kinderlosen Witwe.

Tabelle 17: Summen kindbedingter Mehreinkommen je Kind [1000 Euro]: Vergleich von Ergebnissen

\begin{tabular}{|c|c|c|c|c|}
\hline & \multicolumn{3}{|c|}{ Geburtsjahr des Kindes } \\
\hline & & 1996 & 2000 & 2007 \\
\hline $\begin{array}{l}\text { STM } \\
\text { Verg }\end{array}$ & $\begin{array}{l}\text { (Einverdiener, Lehre, } 1 \text { Kind) } \\
\text { leichswerte }^{*}\end{array}$ & $\begin{array}{r}38,4 \\
34,9^{1} \\
\end{array}$ & $\begin{array}{r}40,0 \\
36,1^{2} \\
\end{array}$ & 43,8 \\
\hline \multicolumn{5}{|c|}{$\begin{array}{l}\text { * Quellen: (1) Bundesministerium für Familie, Senioren, Frauen und Jugend (Hrsg.) } \\
\text { (2001), S.155 } \\
\text { Alle Werte beziehen sich auf die alten Bundesländer. } \\
\text { (2) Werding, Hofmann (2005), S. } 37, \text { S. } 73 \\
\text { und eigene Berechnungen }\end{array}$} \\
\hline
\end{tabular}

Wenn unter der Annahme eines langfristigen Realzinses in Höhe von 4\% der Barwert der kindbedingten Mehreinkommen zum Zeitpunkt der Geburt gebildet wird, ergibt sich für den Abbildung 71 zu Grunde liegenden Familientyp bei einem 1996 geborenen Kind ein Betrag von 38,4 Tsd. Euro (in Preisen des Jahres 2005), für die Geburtsjahre 2000 und 2007 liegen die Werte bei 40,0 Tsd. bzw. 43,8 Tsd. Euro (Tabelle 17). Die Ergebnisse für die Geburtsjahre 1996 und 2000 sind dargestellt, da hierfür Vergleichswerte aus anderen Untersuchungen existieren. Ähnlich wie das kindbedingte Mehreinkommen bestimmte Größen finden sich in einem Gutachten des wissenschaftlichen Beirats des Familienministeriums (2001) und in einer Studie von Werding und Hofmann (2005), auf deren jeweilige Ergebnisse in Kapitel 8.2.3 noch weiter eingegangen wird.

Sowohl der Beirat (2001) mit einer Summe kindbedingter Mehreinkommen für 1996 geborene Kinder von rund 34,9 Tsd. Euro als auch Werding und Hofmann (2005) mit 36,1 Tsd. Euro für im Jahr 2000 Geborene kommen zu um rund drei- bis viertausend Euro niedrigeren Werten. Im Fall der Untersuchung des Beirats liegt die Abweichung zum Teil darin begründet, dass der Rechtsstand 1996 statisch fortgeschrieben wurde, wodurch etwa die Erhöhungen des Kindergelds seit damals oder die Anhebung der Bewertung von Kindererziehungszeiten in der Rentenversicherung (von 0,75 auf 1,0 Entgeltpunkte je Jahr) fehlen. In umgekehrter Richtung wirkt sich aus, dass der Beirat für die kindbedingten Mehreinkommen eine Wachstumsrate in

kommens kinderloser Einverdiener. Der fallende Anteil des kindbedingten Mehreinkommens am Einkommen Kinderloser über die Altersspanne bis zum 19. Lebensjahr bei einem 2007 geborenen Kind ist auf das Alterseinkünftegesetz zurückzuführen (s. a. Kapitel 4.2.4). Mit der zunehmenden steuerlichen Berücksichtigung von Rentenversicherungsbeiträgen fällt die Abgabenquote, so dass der Anteil eines mit der Wachstumsrate des Bruttolohns indexierten Kindergelds am verfügbaren Einkommen sinkt. 
Höhe des Nominalzinses unterstellt (was auf eine Aufsummierung von Nominalwerten des Jahres 1996 hinausläuft). Hierdurch werden spät im Lebenszyklus anfallende Mehreinkommen deutlich höher bewertet als bei gängigen Barwertbildungen. Bei der hier für die Berechnungen mit dem STM getroffenen Annahme einer realen Wachstumsrate kindbedingter Leistungen in Höhe der realen Lohnwachstumsrate von zukünftig 1,5\% wird der Realzins von $4 \%$ deutlich unterschritten. Der Barwert der kindbedingten Rentenzuschläge für ein 1996 geborenes Kind beläuft sich beim STM auf etwa 5,1 Tsd. Euro, ${ }^{277}$ was rund $13 \%$ der kindbedingten Mehreinkommen insgesamt entspricht, nach der Methode des Beirats entfallen auf die Rentenversicherung mit rund 11 Tsd. Euro knapp 31\% des Gesamtbetrages.

Der Vergleichswert von Werding und Hofmann (2005) hingegen beruht auf einer ähnlichen intertemporalen Gewichtung wie beim STM, allerdings nehmen die Autoren einen Realzins von $3,5 \%$ an. Weiterhin gehen sie von einem Kindergeldbezug über 18 Jahre aus (an Stelle von 19 Jahren beim STM) sowie von einem Durchschnittskind (beim STM: Einverdienerpaar mit mittlerem Einkommen und einem Kind als konkreter Familientyp). Trotz der naturgemäß starken Abhängigkeit von Setzungen bei der Berechnung der über den Lebenszyklus eines Kindes anfallenden Mehreinkommen weisen die in Tabelle 17 aufgeführten Ergebnisse ähnliche Größenordnungen auf, wobei sich aus der recht ausführlichen Berücksichtigung von kindbedingten Leistungen beim STM Beträge ergeben, die die aus den beiden Untersuchungen herangezogenen Vergleichswerte jeweils um rund $10 \%$ überschreiten.

Der Anstieg der kindbedingten Mehreinkommen über die Geburtsjahre von 1996 bis 2007 von 38,4 Tsd. auf 43,8 Tsd. Euro basiert überwiegend auf Reformen im Bereich der Familienpolitik wie der Einführung des Elterngelds ab 2007. Generell geht eine Zunahme der realen kindbedingten Mehreinkommen bei parallel steigenden Realeinkommen allerdings nicht zwingend mit einer gezielten Verbesserung der relativen Einkommenslage von Eltern einher, hierzu muss der Einkommensanstieg durch familienpolitische Maßnahmen überproportional ausfallen. Das reale kindbedingte Mehreinkommen, erfasst als Barwert sämtlicher kindbedingter Leistungen im Lebenszyklus zum Zeitpunkt der Geburt, ist über die zurückliegenden Jahrzehnte kontinuierlich gewachsen, beim Tabelle 17 zu Grunde liegenden Familientyp ergibt sich über Kinder der Geburtsjahre von 1957 bis 2007 ein Anstieg von 5,5 Tsd. Euro auf den rund 9,5-fachen Betrag von 43,8 Tsd. Euro. Der Barwert des verfügbaren Lebenseinkommens der Eltern hat sich über diese Zeitspanne in etwa verdoppelt (in Preisen des Jahres 2005: von 450 Tsd. auf 911 Tsd. Euro) (Abbildung 72). Für den betrachteten Familientyp zeigt sich folglich eine über den allgemeinen Einkommensanstieg deutlich hinausgehende Zunahme kindbedingter Mehreinkommen, was eine gewachsene Bedeutung monetärer Familienpolitik widerspiegelt. Mit dieser Relation von kindbedingten Mehreinkommen und verfügbaren Einkommen als Vergleichsmaßstab werden im Folgenden die Entwicklungen im Bereich monetärer Familienpolitik für verschiedene Familientypen verglichen.

277 Durch die Gewichtung über die langfristige Kapitalmarktrendite von real $4 \%$ sind die kindbedingten Rentenzuschläge in den Ergebnissen hier also nicht mit dem Barwert der Einzahlungen erfasst (der sich für ein 1996 geborenes Kind auf annähernd $15 \mathrm{Tsd}$. Euro beläuft) sondern mit dem Barwert der Mehreinkommen aus der Rentenbezugsphase in Höhe der erwähnten 5,1 Tsd. Euro. Je weiter die Kapitalmarktrendite die implizite Rendite des Umlageverfahrens übersteigt, desto stärker unterschreitet die Begünstigung aus Sicht der Eltern die Belastung des Bundeshaushalts. 
Abbildung 72: Kindbedingte Mehreinkommen und Lebenseinkommen nach Geburtsjahr [1000 Euro] (Einverdiener, Lehre, 1 Kind)

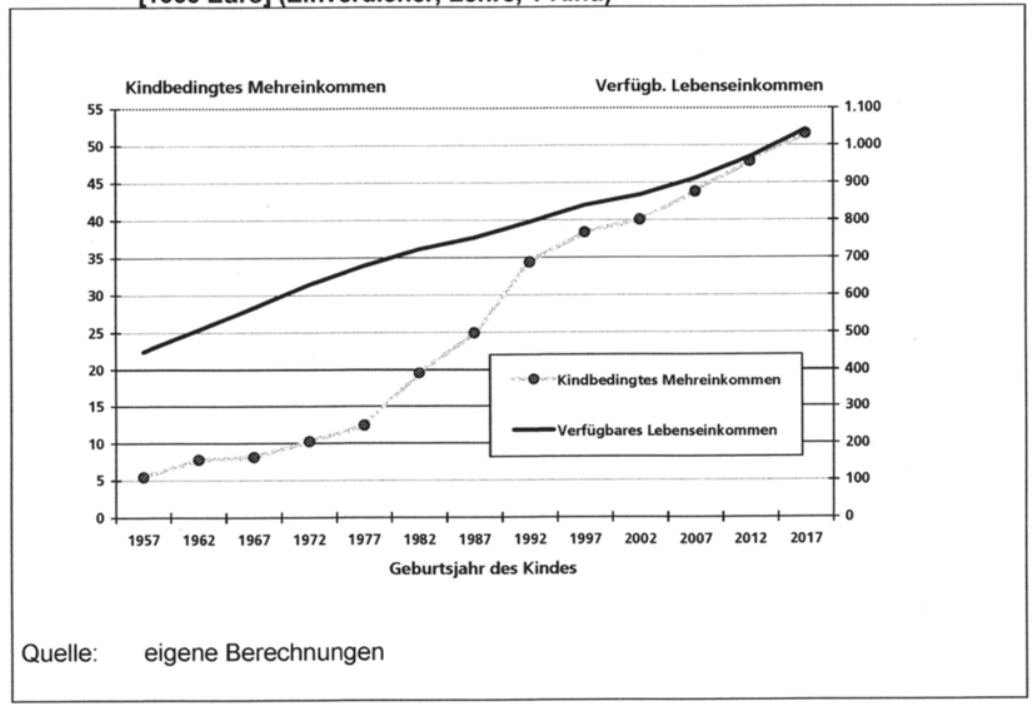

\subsubsection{Kindbedingte Mehreinkommen im Lebenszyklus von Eltern der Kohorten 1930 bis 1990}

Über die betrachteten Geburtsjahre ist beim in Abbildung 72 dargestellten Fall das kindbedingte Mehreinkommen mithin deutlich stärker angestiegen als das verfügbare Einkommen insgesamt, womit auch der auf eine familienpolitisch orientierte Umverteilung entfallende Einkommensanteil gestiegen ist. Als Indikator für die Bedeutung kindbedingter Leistungen sind in Abbildung 73 die kindbedingten Mehreinkommen als Anteil am verfügbaren Lebenseinkommen angegeben. Wie oben wurde dabei von Einverdienerpaaren mit einem Kind, das über 19 Jahre im FLA zu berücksichtigen ist, ausgegangen. Für ein Elternpaar der Qualifikation Lehre entspricht die Darstellung in Abbildung 73 dem Quotienten der beiden Größen aus Abbildung 72, daneben sind die analog gebildeten Werte für Einverdienerpaare mit einem Kind bei den vier übrigen Abschlüssen dargestellt. Abweichend von Abbildung 72 sind die Werte nicht in Abhängigkeit vom Geburtsjahr des Kindes sondern vom Geburtsjahr des Vaters abgetragen. Beim Abschluss Lehre stimmt dies mit einer Verschiebung um 27 Jahre überein, die Eltern eines Kindes des Geburtsjahres 1957 stammen aus den Kohorten 1930 (Vater) und 1932 (Mutter). Bei Eltern derselben Kohorten aber mit anderer Qualifikation ergeben sich hingegen annahmegemäß abweichende Geburtsjahre durch die Kopplung des Gebäralters an die Ausbildungsdauer; die Geburtsjahre erster Kinder von 1930/ 1932 geborenen Eltern liegen zwischen 1954 (Ohne) und 1962 (Uni). 
Eine nach Geburtsjahren der Eltern differenzierte Betrachtung ist für familienpolitische Fragestellungen eher ungewöhnlich. Sie wird hier gewählt, um Vergleiche mit Ergebnissen aus den anderen Kapiteln des zweiten Teils dieser Arbeit zu vereinfachen, in denen sich die intergenerativen Vergleiche stets auf (Eltern-)Kohorten von 1930 bis 1990 beziehen. Intragenerative Vergleiche, normiert auf den Geburtszeitpunkt eines Kindes, schließen sich weiter unten an. Bei einem Vergleich von Eltern gleicher Geburtsjahre jedoch unterschiedlicher Qualifikation besteht für Spätgebärende in Hinblick auf den Einfluss familienpolitischer Leistungen auf das Lebenseinkommen zum einen ein systematischer Nachteil, da die später anfallenden kindbedingten Mehreinkommen bei einer Barwertbetrachtung stärker abdiskontiert werden. ${ }^{278}$ Bei einer im Zeitverlauf zunehmend großzügigeren Familienpolitik kann sich dieser Nachteil jedoch umkehren, da für die Kinder Spätgebärender dann die ausgeweiteten Leistungen anfallen. Auch bei den im nächsten Unterkapitel folgenden Vergleichen von Kindern gleicher Geburtsjahre lassen sich Einkommens- und Zeitpunkteffekte unter den empirisch gestützten Annahmen zu den Zusammenhängen von Ausbildung, Einkommen und Gebäralter der Eltern nicht vollständig trennen. Je höher das Gebäralter ist, desto höher ist auch der Barwert der Rentenzuschläge, da diese im Falle alter Eltern früher im Lebenszyklus des Kindes anfallen.

Die Entwicklung des kindbedingten Mehreinkommens in Abhängigkeit von Geburtsjahr und Qualifikation der Eltern wie in Abbildung 73 dargestellt zeigt über die gesamte betrachtete Einkommensspanne einen deutlichen Zuwachs seines Anteils am verfügbaren Lebenseinkommen. Während bei den 1930 Geborenen zwischen 1,2\% (Ohne) und 1,5\% $(F H)$ des Lebenseinkommens aus kindbedingten Transfers stammen, liegt dieser Anteil nach einem weitgehend monotonen Anstieg über die Kohorten zuletzt bei etwa 4,2\% (Uni) bis 5,5\% (Ohne). Recht deutliche Zunahmen ergeben sich bei niedrigeren Einkommen unter anderem aus der Einführung und Ausweitung von Mutterschuftsurlaubs- und Erziehungsgeld (Ohne, 1950/ 1955 sowie 1960/ 1965). Bei höheren Einkommen zeigen sich Verbesserungen durch die Einführung des Elterngelds 2007, die sich bei Universitätsabsolventinnen auf Grund ihres höheren Gebäralters früher niederschlagen (Uni, 1970/ 1975 sowie $F H, 1975$ / 1980). Ähnlich wirkt sich die Verdreifachung der Dauer von Kindererziehungszeiten für ab 1992 geborene Kinder bei niedriger Qualifikation erstmals auf die Elternkohorte 1970 aus (Ohne, 1965/ 1970), beim Abschluss Lehre hingegen bereits auf die Kohorte 1965 (Lehre, 1960/ 1965). Effekte der zunehmend restriktiveren Einkommensanrechnung beim Erziehungsgeld schlagen sich beim Abschluss Meister nieder, bei dem der Anteil kindbedingter Mehreinkommen am Lebenseinkommen trotz mehrerer Kindergeldanhebungen über die Kohorten von 1965 bis 1975 leicht zurückgeht. Trotz zum Teil auch restriktiver Impulse hat monetäre Familienpolitik über die zurückliegenden Jahrzehnte nach diesen Ergebnissen stark an Bedeutung gewonnen für das Lebenseinkommen von Eltern. Am ausgeprägtesten fallen die relativen Verbesserungen bei unterdurchschnittlichen Einkommen aus, für die der Anteil des kindbedingten Mehreinkommens am Lebenseinkommen über die Kohorten von 1930 bis 1990 auf das 4,7-Fache des Ausgangswerts angestiegen ist (Abbildung 74). Mit der Höhe des Einkommens sinkt die relative Verbesserung, jedoch ergibt sich

${ }^{278}$ Außerdem wirken in diese Richtung Maßnahmen, die wie der Zuschlag zur Pflegeversicherung für Kinderlose unbefristet auf die Elterneigenschaft abstellen. Mit zunehmender Dauer der Erwerbsbeteiligung nach der Erstgeburt steigt das kindbedingte Mehreinkommen aus der Beitragsreduktion. 
auch im ungünstigsten Fall noch eine Steigerung auf das 2,9-Fache des Ausgangswerts (Uni).

Abbildung 73: Kindbedingtes Mehreinkommen : Anteile am verfügbaren Lebenseinkommen (Einverdiener, 1 Kind)

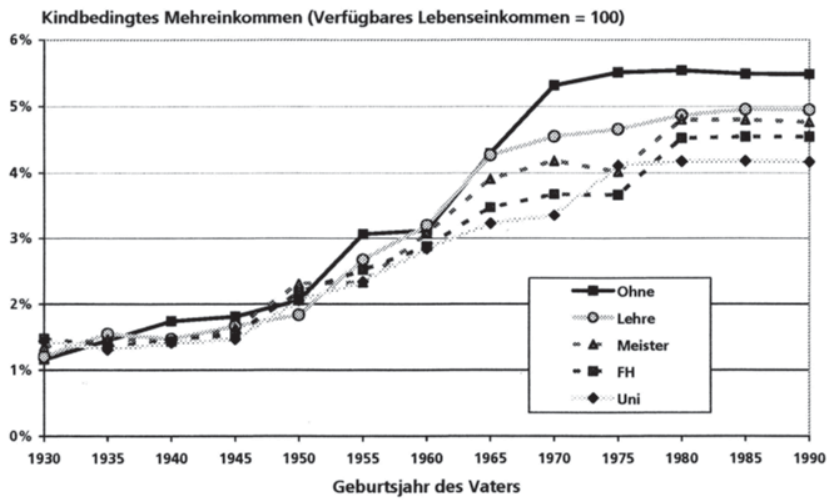

Quelle: $\quad$ eigene Berechnungen

Abbildung 74: Anteile am verfügbaren Lebenseinkommen: Veränderung gegenüber Kohorte 1930 (Einverdiener, 1 Kind)

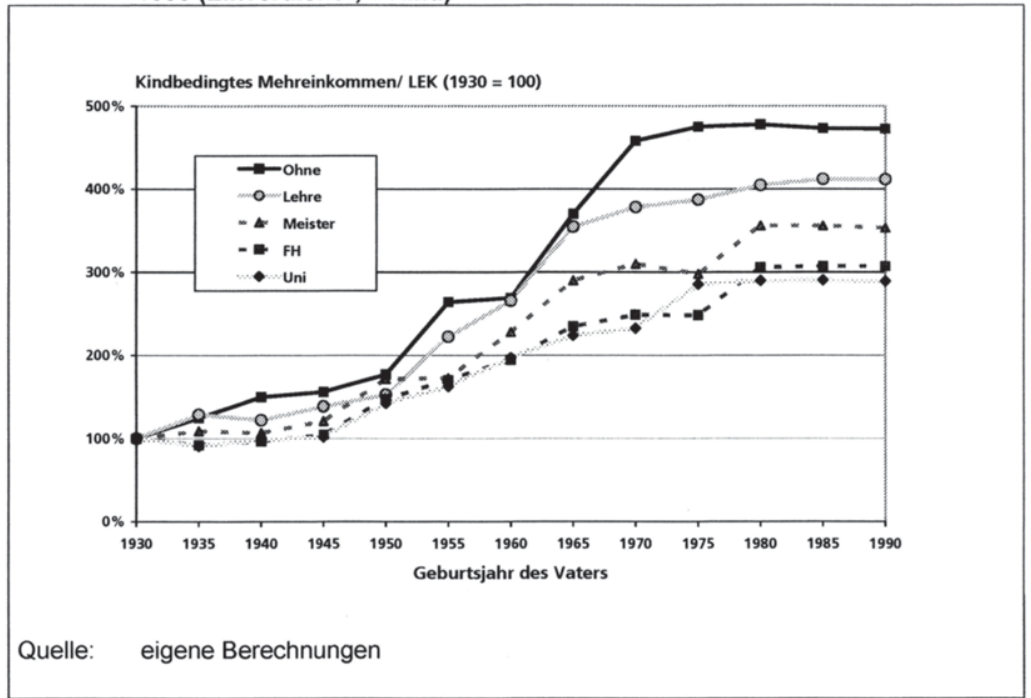


Abbildung 75: Kindbedingtes Mehreinkommen: Ausbildung (Einverdiener, 1 Student)

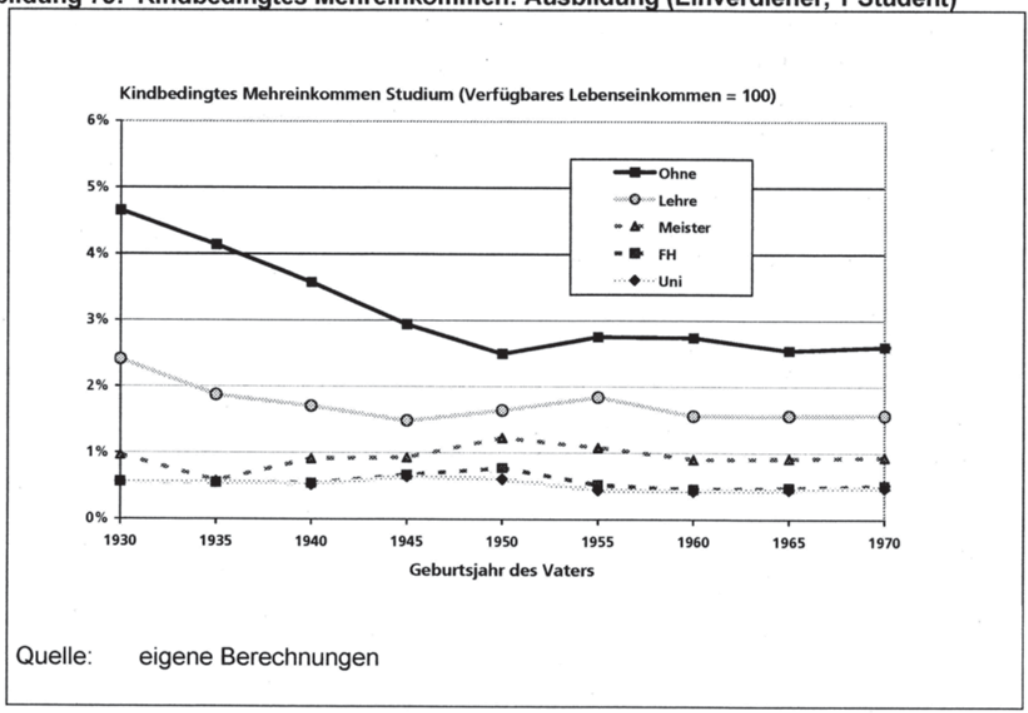

Für ausbildungsbezogene Transfers gilt dieses Ergebnis einer über die Kohorten einkommensübergreifend stark zunehmenden Bedeutung monetärer Familienpolitik nicht. Bei den während eines Studiums anfallenden kindbedingten Mehreinkommen, zu denen Ausbildungsförderung und Ausbildungsfreibeträge beitragen, zeigt sich stattdessen eine je nach Einkommensniveau eher stagnierende bis fallende Tendenz (Abbildung 75). Statt des Standardfalls eines Kindes mit einer Ausbildung bis zum 19. Lebensjahr liegt der Abbildung ein Elternpaar mit einem studierenden Kind zu Grunde, das 25 Jahre lang Kind im Sinne des FLA ist. ${ }^{279}$ In der Abbildung sind ausschließlich die während des Studiums zusätzlich anfallenden kindbedingten Mehreinkommen berücksichtigt. Die Gesamtwirkung aller Transfers für ein studierendes Kind ergibt sich somit als Summe der in Abbildung 73 und Abbildung 75 dargestellten Anteile. Beim niedrigsten der betrachteten Einkommen sinkt das kindbedingte Mehreinkommen aus einer Studiumsphase über die Kohorten von 1930 bis 1950 von 4,7\% auf $2,5 \%$ deutlich, danach pendeln die Werte um ein Niveau von $2,6 \%$ bis $2,9 \%$. Ausschlaggebend für die Entwicklung über die Kohorten bis 1950 sind die insgesamt restriktiv wirkenden Anpassungen der Ausbildungsförderung nach dem BAföG. Während bei mittlerem Einkommen (Lehre) in abgeschwächter Form ein vergleichbarer Verlauf vorliegt, sind die drei höheren Einkommensniveaus von den Änderungen bei der Ausbildungsförderung kaum betroffen, da bei diesen über den gesamten betrachteten Zeitraum keine oder nur geringe Förderungsansprüche bestehen. Bei diesen drei Qualifikationen resultieren die zu beobachtenden moderaten Schwankungen vor allem aus den jeweils geltenden Ausbildungsfreibeträgen. Zu beachten ist, dass bei

279 Für die Phase des Studiums wurden dieselben Typisierungen vorgenommen wie bei der Berechnung von Bildungsrenditen (s. Kapitel 6.2.1). Ausgegangen wird von einem nicht bei den Eltern wohnenden studierenden Kind. 
den dargestellten Elternkohorten ab 1930 die Studienphase des Kindes frühestens zwischen 1974 (Ohne) und 1982 (Uni) beginnt, die Effekte der Rechtsstände davor sich hier also nicht niederschlagen. ${ }^{280}$

Für den intergenerativen Vergleich bleibt aus der Betrachtung eines Kindes mit längerer Ausbildung festzuhalten, dass sich für höhere Elterneinkommen bei Einbezug der Studienphase primär eine Niveauverschiebung ergibt, die kindbedingten Mehreinkommen während eines Studiums schwanken eher geringfügig um Werte in einer Größenordnung von $0,7 \%$ bis $1,1 \%$ (Meister) bzw. von $0,4 \%$ bis $0,7 \%$ ( $F H, U n i)$ des verfügbaren Lebenseinkommens. Bei niedrigeren Einkommen resultiert über Eltern der Kohorten von 1930 bis 1950 hingegen eine Abweichung vom Trend durchgängig wachsender Effekte familienpolitischer Maßnahmen. Der Anteil aller kindbedingter Leistungen am Lebenseinkommen (also die Summe der Anteile aus Abbildung 73 und Abbildung 75 ) fällt bei niedrigerem Einkommen (Ohne) von 5,8\% auf 4,5\%, bei mittlerem Einkommen (Lehre) stagniert der Wert bei rund 3,5\%.

\section{Abbildung 76: Kindbedingtes Mehreinkommen: Erwerbstätigkeit (1 Kind)}

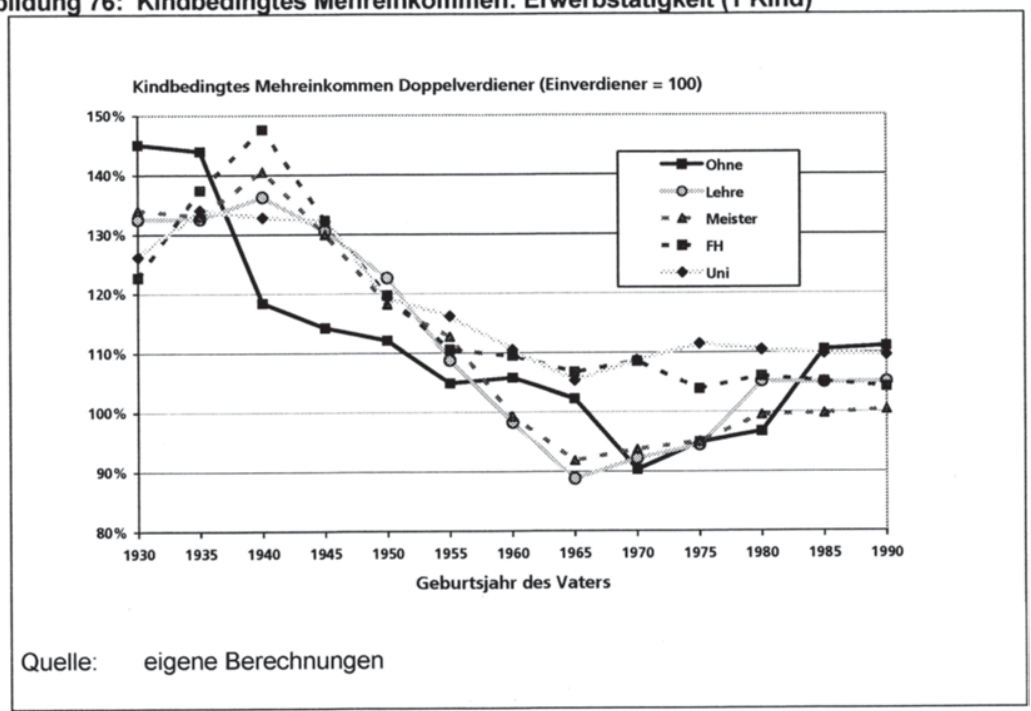

Wenn in Hinblick auf die Erwerbsbeteiligung von der Annahme eines Einverdienerpaares abgewichen wird, steigt mit dem Arbeitsangebot das Einkommen, wovon zum Teil konträre Wirkungen auf einzelne Elemente des kindbedingten Mehreinkommens ausgehen. So nimmt eine Steuerminderung durch Freibeträge zu, negativ einkommensabhängige Leistungen wie die früheren Kindergeldzuschläge und das Erziehungsgeld hingegen sinken, kindbedingte Rentenzuschläge steigen zunächst mit dem Einkommen tendenziell an, werden bei höheren Einkommen jedoch wieder abgeschmolzen. Insgesamt unterscheiden sich die Effekte einer Ausweitung des Ar-

${ }^{280} \mathrm{~S}$. zu den Wirkungen von Transfers in der Ausbildungsphase auch für den Zeitraum ab 1950 Kapitel 4.5 und 6.2.1) 
beitsangebots bei den hier betrachteten typisierten Fällen mit einem Kind nicht wesentlich von anderen Formen eines Einkommensanstiegs. ${ }^{281}$ Da kindbedingte Mehreinkommen bis in die Mitte der 1970er Jahre vor allem aus Steuerminderungen durch Freibeträge resultieren, geht von einem höheren gemeinsamen Einkommen der Eltern auch eine stärkere Entlastung aus. Unter diesen Rechtsständen ergibt sich für Doppelverdiener das höchste kindbedingte Mehreinkommen, für Einverdiener hingegen ein Minimum, die Werte von Teilzeiterwerbstätigen liegen dazwischen. In Abbildung 76 sind die kindbedingten Mehreinkommen von Doppelverdienern in Relation zu den Werten von Einverdienern aus Abbildung 73 dargestellt, womit überwiegend die Extrema des kindbedingten Mehreinkommens in Abhängigkeit von der Erwerbsbeteiligung erfasst sind.

Bei den älteren Elternkohorten übersteigt das kindbedingte Mehreinkommen von Doppelverdienern den Wert bei Einverdienern anfänglich überwiegend um mehr als $30 \%$ (zum Teil um mehr als $40 \%$ ), über die Kohorten bis etwa 1955 schmilzt der relative Vorteil von Doppelverdienern auf rund $5 \%$ bis $15 \%$ ab. Werte von weniger als $100 \%$ und damit ein höheres kindbedingtes Mehreinkommen für Einverdiener treten ausschließlich bei Elternkohorten von 1960 bis 1980 für Fälle mit niedrigerem bis gehobenem Einkommen auf (Ohne, Lehre, Meister). Für diese Konstellationen unterschreitet das kindbedingte Mehreinkommen von Doppelverdienern den Betrag bei Einverdienern um bis zu etwa $7 \%$ bis $11 \%$ (Kohorten 1965 und 1970). Bei den beiden höchsten Einkommensniveaus ( $F H, U n i$ übersteigt das kindbedingte Mehreinkommen von Doppelverdienern hingegen stets die Werte von Einverdienern, für nach etwa 1955 Geborene um rund $5 \%$ bis $10 \%$. Diese Befunde erinnern an die einkommensabhängige Staffelung des Kindergelds und die Kindergeldzuschläge der Jahre von 1983 bis 1995 sowie die Einkommensanrechnung beim Erziehungsgeld. Zunächst führt in diesem Zeitraum ein niedrigeres Einkommen zu einem höheren Transfervolumen, bei überdurchschnittlichen Einkommen hingegen ist der Anspruch auf die maßgeblichen Leistungen verwirkt, so dass dann unter Umständen Steuerfreibeträge zu einer mit dem Einkommen steigenden Entlastung führen. Bei den Kohorten $a b$ 1985, deren Kinder ab 2007 und somit unter dem familienpolitischen Status Quo geboren werden, variiert das Ausmaß kindbedingter Mehreinkommen im Vergleich zu früheren Rechtsständen nur geringfügig mit dem vom Arbeitsangebot abhängenden Bruttoeinkommen, je nach Qualifikation der Eltern ergeben sich beim Vergleich mit Einverdienern Vorteile für Doppelverdiener in einer Größenordnung von $0 \%$ (Meister) bis $10 \%$ (Uni, Ohne). Die Höhe des Elterngelds unterscheidet sich dabei nicht zwischen Ein- und Doppelverdienern auf Grund der getroffenen Annahmen zur Erwerbstätigkeit bis zur Geburt eines ersten Kindes (nur die Wirkung des Progressionsvorbehalts kann zu moderaten Unterschieden führen). Doppelverdiener erzielen geringfügig höhere kindbedingte Mehreinkommen während der Erwerbsphase, bei Einverdienern ergeben sich durch die Einkommensanrechnungen zum Teil höhere kindbedingte Rentenzuschläge.

Insgesamt führt der Vergleich von Ein- und Doppelverdienern zu Ergebnissen, die sich auch in der Querschnittsbetrachtung des FLA abzeichneten. Unter den Regelungen der letzten Jahrzehnte führte monetäre Familienpolitik vor allem zu Beginn

${ }^{281}$ Diese Aussage gilt für die hier betrachteten typisierten Lebenszyklen. Insbesondere in Fällen einer Vollzeiterwerbstätigkeit während des ersten Lebensjahres eines Kindes kann sich indessen eine nennenswerte Minderung des Transfervolumens ergeben, da dann der Bezug von Erziehungsgeld ausgeschlossen ist (1986 bis 2006) oder das Elterngeld null beträgt (ab 2007). 
des betrachteten Zeitraums zu einer stärkeren Begünstigung bei höheren Einkommen, wobei eine Ausweitung des Arbeitsangebots ähnliche Effekte erzeugt wie auch andere Ursachen eines Einkommensanstiegs. Ein abweichender Befund ergibt sich hauptsächlich für Eltern mit niedrigeren bis gehobenen Einkommen, deren Kinder in etwa zwischen 1983 und 2006 geboren wurden. Verglichen mit früheren Rechtsständen gehen im Status Quo vom Arbeitsangebot -zumindest bei den hier betrachteten ersten Kindern- nur leichte Effekte auf das Transfervolumen aus, Doppelverdiener erzielen im Vergleich zu Einverdienern ein höheres kindbedingtes Mehreinkommen, das den Wert bei Einverdienern um $0 \%$ bis $10 \%$ überschreitet, womit der Vorteil von Doppelverdienern im historischen Vergleich moderat ausfällt. Intergenerative Vergleiche auf der Basis von Doppelverdienern führen zu einem ähnlichen Befund wie bei Einverdienern, auch hier steigt der Anteil des kindbedingten Mehreinkommens am verfügbaren Lebenseinkommen für alle fünf Qualifikationsniveaus weitgehend monoton an. Allerdings fällt der Anstieg über die Geburtsjahre etwas geringer aus, für die jüngsten Kohorten ergeben sich Anteile, die sich auf das 2,6- (Uni) bis 4,0-Fache (Ohne) der Ausgangswerte der Kohorte 1930 belaufen (bei Einverdienern: das 2,9- (Uni) bis 4,7-Fache (Ohne), s. o. Abbildung 74).

Für den FLA wurde bereits auf die mit der Kinderzahl häufig überproportional zunehmenden Mehreinkommen hingewiesen, so dass vor allem Mehrkinderfamilien begünstigt wurden. Ähnliches zeigt sich auch bei Lebenszyklusbetrachtungen. An den oberen und unteren Rändern der betrachteten Spannen von Erwerbsbeteiligung und Qualifikation (Ein- und Doppelverdiener mit den Abschlüssen Ohne und Uni) summiert sich das kindbedingte Mehreinkommen für drei Kinder bei Eltern aus den Geburtsjahren bis 1945 auf das 3,6- bis 5,7-Fache des Wertes von Einkindfamilien, besonders stark ausgeprägt ist die überproportionale Begünstigung bei niedrigen Einkommen (Ohne, Einverdiener) (Abbildung 77). Über die Kohorten von etwa 1945 bis 1965 wirkt sich dann die abnehmende horizontale Differenzierung des FLA aus, das kindbedingte Mehreinkommen bei drei Kindern bewegt sich in Richtung des dreifachen Werts von Einkindfamilien. Im Fall einer von der Anzahl der Kinder unabhängigen Wirkung monetärer Familienpolitik ist bei einer Verdreifachung der Kinderzahl (von einem zu drei Kindern) grundsätzlich auch eine Verdreifachung des Umfangs kindbedingter Leistungen anzunehmen, so dass ein Wert von $300 \%$ in der Art der Darstellung von Abbildung 77 als erster Referenzpunkt dienen kann. Allerdings führt die Bewertung kindbedingter Mehreinkommen auf der Grundlage von Barwerten generell dazu, dass Leistungen für später geborene Kinder geringer gewichtet werden, so dass ein streng proportional begünstigendes System familienpolitischer Leistungen unter den getroffenen Annahmen (Realzins von 4\%, Indexierung des SteuerTransfer-Systems mit dem Reallohnwachstum von 1,5\%, Geburtsabstände von zwei Jahren) zu einem etwas niedrigeren Referenzwert von rund $286 \%$ führt. Diese Referenzgröße wird bei den jüngeren Kohorten, auf die das geltende Recht anzuwenden ist, stets unterschritten, die kindbedingten Mehreinkommen bei drei Kindern entsprechen hier dem 2,4- bis 2,7-Fachen des Werts bei einem Kind. Dieses Ergebnis wird im Fall der Einverdienerpaare durch die Regelungen des Elterngelds mitgeprägt, da bei diesen für das zweite und dritte Kind jeweils nur ein geringer Betrag gewährt wird, eine Folge der hier unterstellten Nichterwerbstätigkeit in den berechnungsrelevanten Jahren vor der Geburt. Vor allem für gut verdienende Paare wirkt sich diese Einschränkung negativ auf das Transfervolumen aus (Uni, Einverdiener). 
Abbildung 77: Kindbedingtes Mehreinkommen: Kinderzahl

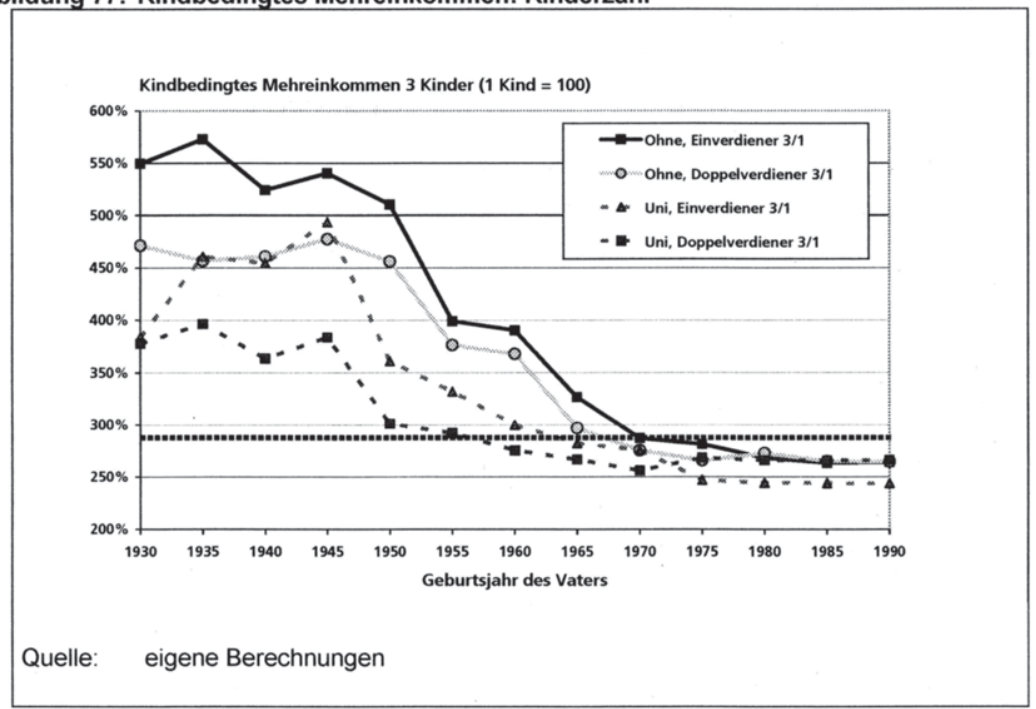

Während bei den abgebildeten Einverdienerfällen in Hinblick auf das Elterngeld ungünstige -und damit durchaus realistische-Voraussetzungen bei der Geburt zweiter und weiterer Kinder zu Grunde liegen, ergibt sich bei den Doppelverdienerfällen umgekehrt für jedes von drei Kindern ein im Rahmen des Möglichen maximales Elterngeld, es bemisst sich stets nach dem Vollzeiteinkommen aus dem jeweiligen Jahr vor der Geburt. Dass dennoch auch bei Doppelverdienern eine leicht unterproportionale Zunahme des Mehreinkommens bei wachsender Kinderzahl eintritt, folgt aus Einflüssen wie der Anrechnung kindbedingter Entgeltpunkte auf Hinterbliebenenrenten oder der mit zweiten und weiteren Kindern nicht weiter zunehmenden Entlastung bei der Pflegeversicherung. Insgesamt führt die Familienpolitik im Status Quo bei den typisierten Biographien dieser Arbeit somit zu einer leicht unterproportionalen Zunahme des kindbedingten Mehreinkommens bei steigender Kinderzahl. Geltendes und früheres Recht unterscheiden sich in dieser Hinsicht deutlich, da unter älteren Rechtsständen Mehrkindfamilien zum Teil massiv überproportional begünstigt waren. Im Status Quo, in dem leistungsrelevante Parameter überwiegend nicht nach der Ordnungszahl von Kindern differenziert sind, wirkt sich der Enwerbsverlauf vor allem bei Mehrkindfamilien auf das Transfervolumen aus. ${ }^{282}$

Da die Ausweitung familienpolitischer Leistungen über die zurückliegenden Jahrzehnte wesentlich auf einer zunehmenden Berücksichtigung von ersten Kindern im

282 Selbstverständlich ist der Umfang der Erwerbstätigkeit auch vor der Geburt erster Kinder entscheidend für die Höhe des Elterngelds, allerdings sind die Erwerbsumfänge von Müttern vor der Geburt erster Kinder homogener als vor der Geburt weiterer Kinder, vor der Geburt erster Kinder ist der Anteil vollzeitbeschäftigter Frauen deutlich größer (Vgl. zur Erwerbsbeteiligung vor und nach der Geburt erster und weiterer Kinder: Gustafsson, Dex, Wetzels, Vlasblom (1996)). Eine zumindest schwache horizontale Differenzierung findet sich im geltenden Recht bei den Kindergeldsätzen, die für erste bis dritte Kinder 154 und für weitere Kinder 179 Euro je Monat betragen. 
Steuer-Transfer-System beruht, hat sich der Anteil kindbedingter Mehreinkommen am verfügbaren Lebenseinkommen vor allem bei Einkindfamilien erhöht. Das obige Ergebnis einer über die betrachteten Kohorten stark steigenden Bedeutung familienpolitisch orientierter Umverteilung ( $\mathrm{vgl}$. Abbildung 74) gilt jedoch auch bei Mehrkindfamilien, wenngleich die intergenerativen Unterschiede wesentlich schwächer ausfallen. Während bei Einkindfamilien der jüngsten Kohorten die kindbedingten Mehreinkommen, gemessen als Anteil am Lebenseinkommen, sich auf das 2,9- (Uni) bis 4,7-Fache (Ohne) des Ausgangswerts belaufen, ergeben sich bei Dreikindfamilien Zunahmen auf das 1,8- (Uni) bis 2,2-Fache (Ohne) (Abbildung 78). Auch der Befund größerer Anstiege für niedrigere Einkommen gilt damit sowohl für Einkind- als auch Dreikindfamilien. Allerdings sind bei mehreren Kindern die Werte für die jüngsten Kohorten nicht mehr durchgehend maximal, hier ergibt sich bei Einverdienern mit niedrigeren bis mittleren Einkommen aus der Einführung des Elterngelds eine Verschlechterung gegenüber dem Erziehungsgeld mit seiner längeren Bezugsdauer. Bei Doppelverdienern mit drei Kindern folgt hingegen für alle fünf Qualifikationen ein Maximum bei den jüngsten Kohorten, wie bei Einverdienern sind auch hier Anstiege auf das 1,8-(Uni) bis 2,2-Fache (Ohne) der Ausgangswerte zu verzeichnen.

Abbildung 78: Anteile am verfügbaren Lebenseinkommen: Veränderung gegenüber Kohorte 1930 (Einverdiener, 3 Kinder)

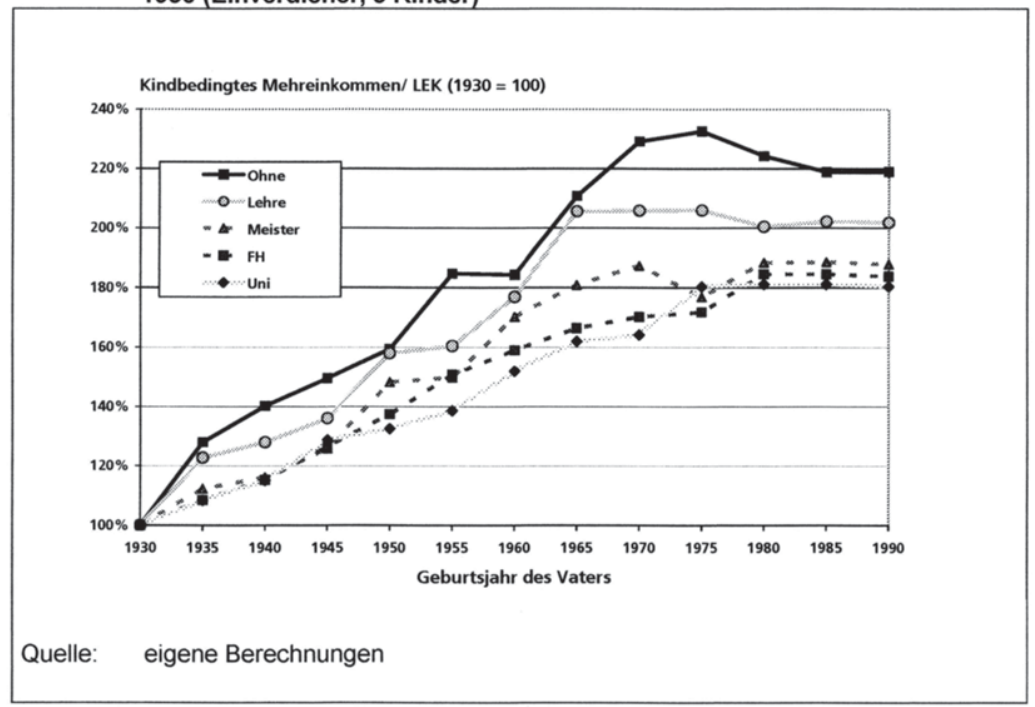




\subsubsection{Vergleiche nach dem Geburtsjahr der Kinder}

Intragenerative Unterschiede können wie oben beschrieben auf unterschiedlicher Erwerbsbeteiligung beruhen. In Hinblick auf qualifikationsabhängige Einkommensunterschiede, der in dieser Arbeit üblichen Basis für intragenerative Vergleiche, folgt aus den Lebenseinkommensprofilen, dass sich Einflüsse des Gebäralters und des Einkommensniveaus überlagern. Die Kinder von im Jahr 1930 (1932) geborenen Vätern (Müttern) mit den Abschlüssen Ohne und Uni etwa gehören den Kohorten 1954 bzw. 1962 an, so dass neben den Einkommensunterschieden auch die zeitliche Verschiebung auf Differenzen der kindbedingten Mehreinkommen einwirkt. Aus einer im Zeitverlauf zunehmenden Umverteilung zu Gunsten von Familien (die wie an Hand der intergenerativen Vergleiche herausgearbeitet bei allen betrachteten Fallkonstellationen auftritt) folgt daraus ein Vorteil von Lebenszyklen mit späterem Gebäralter.

In Abbildung 79 sind die Relationen kindbedingter Mehreinkommen für Eltern gleicher Kohorten bei unterschiedlicher Qualifikation wiedergegeben, als Grundlage dienen Einverdienerpaare mit einem Kind. In den Werten schlagen sich somit die Summen aus einem Einkommens- und einem Zeitpunkteffekt nieder. Bei dieser Betrachtung ergeben sich für die ältesten Kohorten starke qualifikationsabhängige Unterschiede, das kindbedingte Mehreinkommen von um 1930 geborenen Universitätsabsolventen ist im Vergleich zu gleichalten Eltern ohne Abschluss rund doppelt so groß (Unil Ohne 1930), der sich bei mittleren Einkommen ergebende Betrag wird um circa $64 \%$ überschritten (Unil Lehre 1930). Über die Kohorten sinken die Vorteile höher qualifizierter Eltern rasch ab, bei zwischen etwa 1965 und 1975 geborenen Eltern profitieren die niedrigeren Abschlüsse dann stärker von kindbedingten Transfers, das kindbedingte Mehreinkommen von Universitätsabsolventen liegt hier um rund $17 \%$ (Unil Lehre 1970) bis 23\% (Unil Ohne 1970) unter den Beträgen der Vergleichsgruppen. In den jüngeren Elternkohorten unterscheiden sich die kindbedingten Mehreinkommen der verschiedenen Qualifikationen kaum. Bei diesen Ergebnissen wirkt sich ein späterer Geburtszeitpunkt innerhalb des Lebenszyklus auf Grund der Diskontierung grundsätzlich negativ auf den Barwert kindbedingter Leistungen aus. Die qualifikationsübergreifend annähernd gleichhohen kindbedingten Mehreinkommen der Kohorten ab 1980 ergeben sich, indem einerseits für Universitätsabsolventen höhere preisniveaubereinigte Entlastungen anfallen, andererseits diese jedoch stärker abdiskontiert werden. Intragenerative Vergleiche dieser Form, in denen auf das Geburtsjahr der Eltern abgestellt wird, eignen sich entsprechend vorrangig, um die Wirkungen des Steuer-Transfer-Systems auf das Lebenseinkommen von gleichalten aber unterschiedlich qualifizierten Eltern herauszuarbeiten, eine Perspektive die etwa bei Analysen zur Umverteilung durch die gesetzliche Rentenversicherung üblich ist (vgl. Kapitel 7). 
Abbildung 79: Kindbedingtes Mehreinkommen nach Qualifikation und Geburtsjahr des Vaters (Einverdiener, 1 Kind)

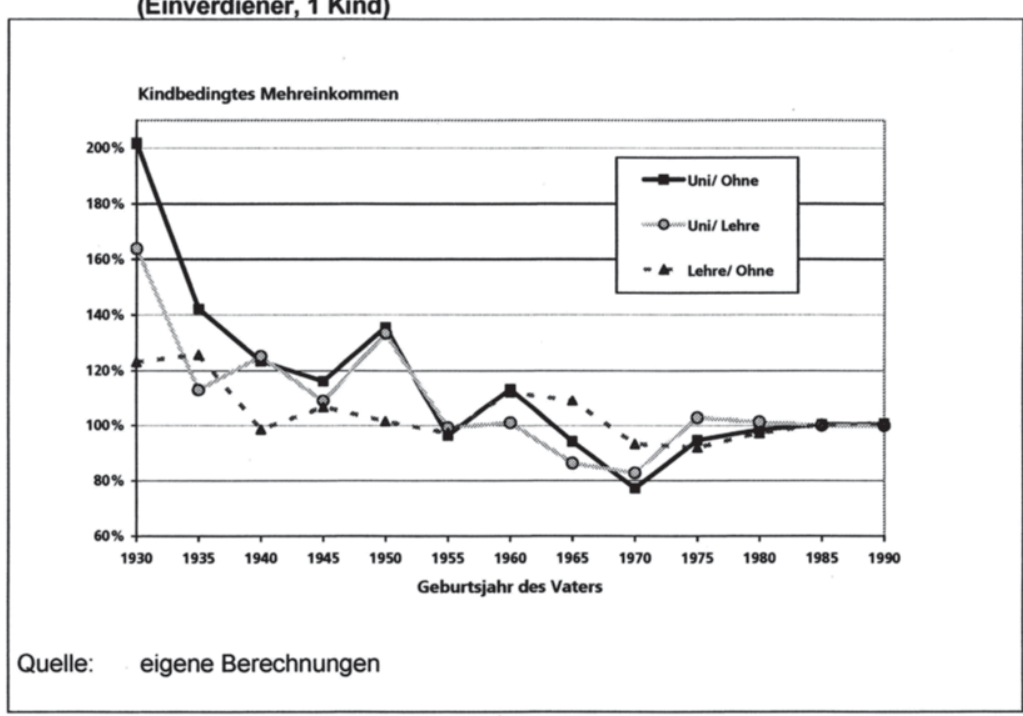

Abbildung 80: Kindbedingtes Mehreinkommen nach Qualifikation und Geburtsjahr des Kindes (Einverdiener, 1 Kind)

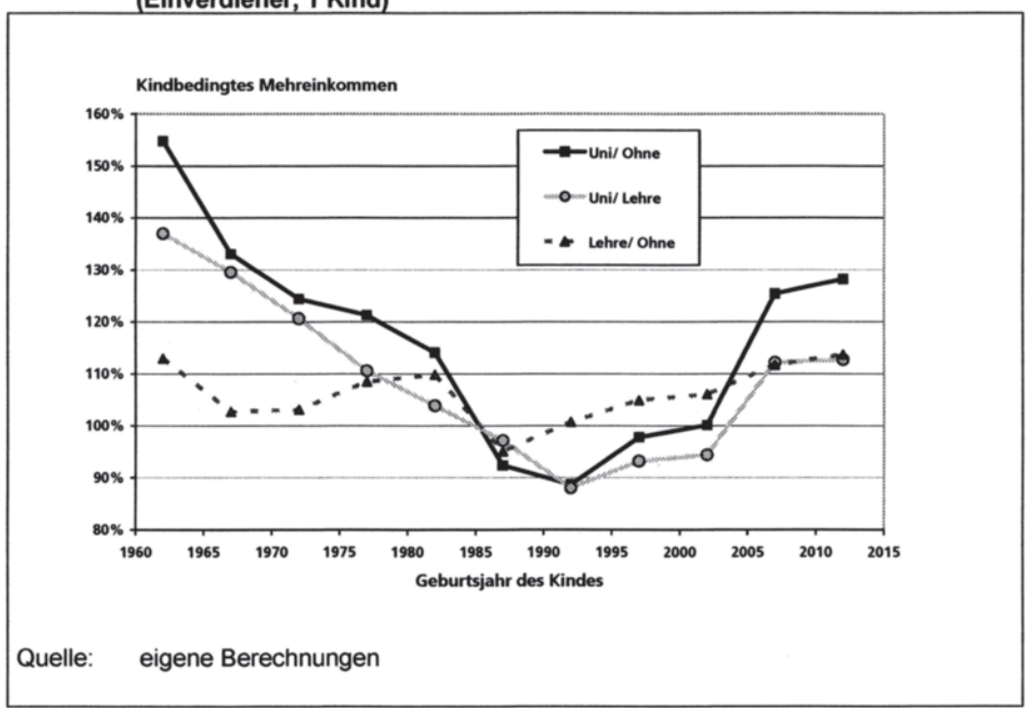

Zur Beurteilung der Verteilungswirkungen familienpolitischer Regelungen eines vorgegebenen Zeitraums oder Zeitpunkts ist hingegen abweichend von der in dieser Ar- 
beit üblichen Kohortenbetrachtung eine Normierung an Hand des Geburtsjahres des Kindes geboten (wie etwa bei den in Tabelle 17 wiedergegebenen Ergebnissen). Übertragen auf die hier genutzten Lebenseinkommensprofile folgt daraus, dass die kindbedingten Mehreinkommen von unterschiedlichen Elternkohorten miteinander zu vergleichen sind, so stammen etwa die Eltern von im Jahr 2007 geborenen Kinder aus Kohorten von 1975 (Uni) bis 1983 (Ohne). Nach diesem Ansatz, die kindbedingten Mehreinkommen in Abhängigkeit vom Geburtsjahr des Kindes zu bestimmen, ergibt sich für um das Jahr 1960 geborene Kinder ein um bis zu $55 \%$ höheres kindbedingtes Mehreinkommen in Fällen mit höheren Bruttoeinkommen (Unil Ohne, 1962) (vgl. Abbildung 80, die auf denselben Setzungen basiert wie Abbildung 79). Der vergleichbare Wert bei der Gegenüberstellung gleichalter Eltern beläuft sich auf $102 \%$ (als Vorteil von 1930 geborenen Universitätsabsolventen gegenüber gleichalten Eltern ohne Abschluss, vgl. Abbildung 79). Die intragenerativen Unterschiede zwischen gleichaltrigen Kindern fallen insgesamt geringer aus als zwischen gleichalten Eltern, wobei die Entwicklungen über die Geburtsjahre allerdings den gleichen Grundmustern folgen. Ausgehend von deutlichen Vorteilen für Eltern mit höherem Einkommen nähern sich die qualifikationsspezifischen Volumina kindbedingter Mehreinkommen zunehmend einander an, für Kinder der Geburtsjahre von etwa 1986 bis 2006 kehrt sich die Rangfolge dann um, Eltern mit niedrigeren Einkommen profitieren in dieser Zeit stärker von familienpolitisch orientierter Umverteilung. Die größten Vorteile für niedrigere Einkommen bestehen bei 1992 geborenen Kindern, hier unterschreitet das kindbedingte Mehreinkommen von Universitätsabsolventen die Werte bei niedrigeren Abschlüssen um rund 12\% (Unil Lehre und Unil Ohne, 1992).

Mit der Einführung des Elterngelds ab 2007 resultiert dann wieder ein höheres Transfervolumen bei höherer Qualifikation, Universitätsabsolventen empfangen ein kindbedingtes Mehreinkommen, das um 13\% (Unil Lehre) bis 27\% (Unil Ohne) über den Werten bei niedrigeren Abschlüssen liegt. Insgesamt ergibt sich somit ein annähernd u-förmiger Verlauf der Relationen kindbedingter Mehreinkommen von höheren gegenüber niedrigeren und mittleren Einkommen (Unil Ohne und Unil Lehre), mit den jüngsten Rechtsänderungen führt der Status Quo wieder zu einem mit dem Einkommen der Eltern steigenden Transfervolumen. Beim Vergleich von mittleren mit niedrigeren Einkommen (Lehre/ Ohne) fallen die Schwankungen über die Geburtsjahre der Kinder schwächer aus, in Ansätzen zeigt sich auch hier der Befund einer zu Beginn und gegen Ende des betrachteten Zeitraums stärker ausgeprägten Begünstigung des höheren Elterneinkommens. Für ab 2007 geborene Kinder übersteigt das kindbedingte Mehreinkommen beim Abschluss Lehre den Wert bei geringer qualifizierten Eltern um 12\%. Ausgehend von einem kindbedingten Mehreinkommen in Höhe von 43,8 Tsd. Euro für das im Jahr 2007 geborene Kind eines Einverdienerpaares mit dem Abschluss einer Lehre (s. o. Tabelle 17) betragen die entsprechenden Werte für Eltern ohne Abschluss 39,2 Tsd. Euro sowie für Universitätsabsolventen 49,1 Tsd. Euro.

Ein u-förmiger Verlauf der Relationen kindbedingter Mehreinkommen von höheren und niedrigeren Qualifikationen ist nicht auf Einverdienerpaare mit einem Kind beschränkt. Die Schwankungen über die Geburtsjahre der Kinder sind bei diesem Familientyp zwar besonders stark ausgeprägt, ein ähnliches Grundmuster zeigt sich jedoch ebenfalls bei anderen Erwerbsmustern und Kinderzahlen (Abbildung 81). In der Abbildung ist zum einen die Relation Unil Lehre für Einverdiener mit einem Kind wie- 
dergegeben, wie sie bereits in Abbildung 80 enthalten ist, daneben finden sich die entsprechenden Werte für Paare mit drei Kindern sowie für Doppelverdiener. Die zeitliche Entwicklung verläuft bei Einverdienerpaaren mit einem und drei Kindern weitgehend gleichartig. Auch bei drei Kindern sind die kindbedingten Mehreinkommen von besser qualifizierten Eltern sowohl zu Beginn als auch gegen Ende des betrachteten Zeitraums höher, zwischen 1986 und 2006 hingegen niedriger. Ähnlich werden auch bei Doppelverdienern höher qualifizierte Eltern sowohl unter den frühen Rechtsständen als auch im Status Quo relativ stark begünstigt. Dazwischen fällt ihr relativer Vorteil zwar geringer aus, anders als bei Einverdienern erzielen sie jedoch durchgängig ein höheres kindbedingtes Mehreinkommen. Für das Geburtsjahr 2007 übersteigt das kindbedingte Mehreinkommen beim Abschluss Uni den Wert beim Abschluss Lehre um rund $8 \%$ ( 3 Kinder, Einverdiener) bis 19\% (1 Kind, Doppelverdiener). Dass im Status Quo der Vorteil von höheren Einkommen bei Einverdienern mit mehreren Kindern am niedrigsten ausfällt, geht vor allem von einem sinkenden Anteil des Elterngelds am Gesamtvolumen aus. Bei Einverdienern bemisst sich das Elterngeld unter den getroffenen Annahmen stets einmalig nach einem Vollzeiteinkommen (nämlich beim ersten Kind), bei zweiten und weiteren Kindern hingegen greift einkommensunabhängig der Grundbetrag von 300 Euro je Monat (zuzüglich Geschwisterboni), die Einkommensvorteile einer höher qualifizierten Mutter schlagen sich bei Einverdienern also unabhängig von der Kinderzahl nur einmal in einem höheren Transfervolumen nieder.

Abbildung 81: Kindbedingtes Mehreinkommen nach Qualifikation und Geburtsjahr des Kindes (Uni gegenüber Lehre)

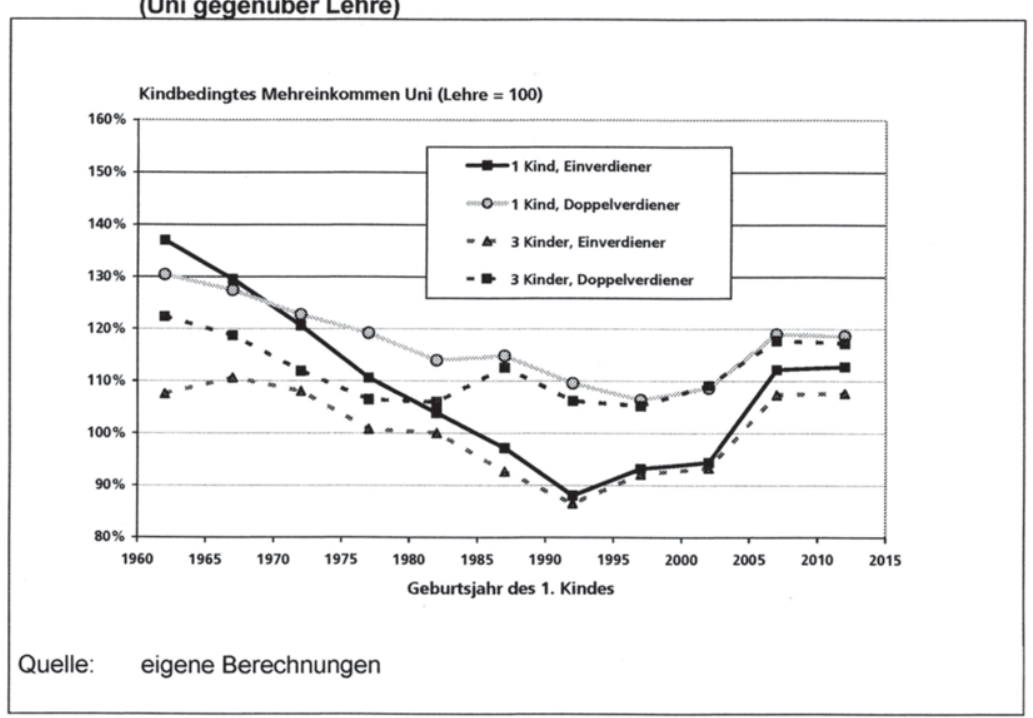

In Hinblick auf die Einkommensabhängigkeit monetärer Familienpolitik lässt sich festhalten, dass im geltenden Recht ein positiver Zusammenhang zwischen Elterneinkommen und Transfervolumen besteht. Hauptursache ist -neben von mit dem Ein- 
kommen moderat steigenden Entlastungen durch den FLA und an inn angelehnte Maßnahmen- das Förderprinzip des Elterngelds. Vor der Ablösung des Erziehungsgelds durch das Elterngeld ab 2007 ergab sich tendenziell der umgekehrte Zusammenhang eines höheren kindbedingten Mehreinkommens bei niedrigeren Einkommen. Der Status Quo deckt sich in dieser Hinsicht mit älteren Rechtsständen, wobei früher jedoch vor allem die Fokussierung monetärer Familienpolitik auf das Steuersystem zu einer mit dem Einkommen steigenden Entlastung führte.

\subsubsection{Kindbedingte Mehreinkommen und Kosten von Kindern}

Die obigen Ergebnisse zu kindbedingten Mehreinkommen zeigten für alle betrachteten Familientypen recht deutliche Anstiege über die Geburtsjahre. Bei den jüngsten Kohorten resultierten für Einverdienerpaare mit einem Kind je nach Qualifikation Anteile am verfügbaren Lebenseinkommen im Bereich von $4,2 \%$ bis $5,5 \%$, während bei den ältesten Kohorten Anteile zwischen 1,2\% und 1,5\% zu verzeichnen waren. Gemessen am verfügbaren Lebenseinkommen ist die Bedeutung kindbedingter Transfers bei Einverdienern mit einem Kind demnach auf das 2,9- bis 4,7-Fache der Ausgangswerte angestiegen. Bei Doppelverdienern ergibt sich überwiegend ein höheres kindbedingtes Mehreinkommen, wobei der Zuwachs über die Kohorten jedoch moderater ausfällt (auf das 2,6- bis 4,0-Fache der Ausgangswerte).

Nicht ersichtlich ist bisher jedoch, welche Relevanz diese Anstiege für Fertilitätsentscheidungen haben könnten. Zur Einordnung, welche Bedeutung die Ausweitung familienpolitisch orientierter Umverteilung für das Lebenseinkommen hat, werden im Folgenden daher die Transfers im Kontext der Gesamtkosten von Kindern betrachtet. Innerhalb der Kohorten variiert das Transfervolumen wie aufgezeigt mit dem Einkommen, das wiederum in Abhängigkeit von Qualifikation und Arbeitsangebot betrachtet wurde. Von der Erwerbsbeteiligung geht somit zum einen ein Einfluss auf das Transfervolumen aus. Ihr wesentlicherer Effekt besteht jedoch darin, dass die empirisch zu beobachtende Erwerbsreduktion von (in der Regel) Müttern maßgeblich die von Fertilitätsentscheidungen ausgehenden Kosten mitbestimmt. In Begründungen familienfördernder Maßnahmen stellen die von Kindern ausgehenden Kosten eine zentrale Größe dar, die als Anhaltspunkt zur Bestimmung eines angemessenen Umfangs kindbedingter Transfers herangezogen wird (vgl. Kapitel 4.3.1). So sind etwa die existenzminimalen Aufwendungen für Kinder relevant, um die Untergrenzen für Kinderfreibeträge im Einkommensteuerrecht zu bestimmen.

Neben diesen direkten Kosten eines Kindes, die für seinen Lebensunterhalt anfallen und für eine am kindbedingten Mehrbedarf oder an Besteuerungsgrundsätzen ausgerichtete Familienpolitik ausschlaggebend sind, werden als indirekte Kosten Einkommensverluste auf Grund von Erwerbseinschränkungen zur Kinderbetreuung erfasst. Einkommensausfälle können zum einen unmittelbar in den Phasen eines reduzierten Arbeitsangebots folgen, zum anderen aber auch über diese Zeiten hinaus, wenn durch Erwerbsunterbrechungen bestehendes Humankapital abgewertet wird (oder im Mincer'schen Sinne weniger Erfahrung akkumuliert wird, vgl. Kapitel 6). ${ }^{283}$ Direkte Kosten von Kindern werden regelmäßig über nach der Haushaltszusammen-

${ }^{283}$ Galler (1988), S. 97ff; Beblo, Wolf (2002); Hufnagel (2002), S. 121 
setzung aufgeschlüsselte Verbrauchsstatistiken ermittelt, in Deutschland insbesondere an Hand der in fünf Jahresabständen erhobenen Einkommens- und Verbrauchsstichprobe (EVS). Zur Quantifizierung von Opportunitätskosten existieren verschiedene Ansätze, die entweder den Zeitaufwand der Erziehung mit den beobachtbaren Löhnen von Erziehern oder Hauswirtschaftern gewichten oder die Einkommen vollzeiterwerbstätiger Vergleichspersonen ansetzen. Bei letzterer Vorgehensweise lässt sich zudem noch unterscheiden, ob Erwerbseinschränkungen nur während entsprechender Phasen Mindereinkommen verursachen oder sich auf sämtliche weitere Erwerbseinkommen negativ niederschlagen ${ }^{284}$ Die erste Vorgehensweise erinnert an eine Ergänzung der volkswirtschaftlichen Gesamtrechnung um den Wert der Haushaltsproduktion, die zweite Variante wird dem Opportunitätsgedanken eher gerecht. Die Nettokosten für ein Kind umfassen aus Sicht der Eltern hiernach die Summe aus direkten Kosten einerseits und Opportunitätskosten andererseits, abzuziehen sind kindbedingte Transfers.

Für Deutschland existieren verschiedene Modellrechnungen, in denen (Netto-)Kosten von Fertilitätsentscheidungen über den Lebenszyklus der Eltern zusammengestellt sind. Direkte Kosten werden üblicherweise für die Zeit von der Geburt bis zur Vollendung des 18. Lebensjahres angesetzt, Transfers wirken den gesetzlichen Vorgaben entsprechend bis zum Tod der Eltern. Bei der Bestimmung von Opportunitätskosten bestehen größere Unterschiede zwischen einzelnen Untersuchungen, die zum einen wie genannt aus den unterschiedlichen Ansätzen zur Bewertung des Zeitaufwands der Erziehung und zum anderen aus divergierenden Annahmen zum Umfang von Erwerbseinschränkungen folgen. In Tabelle 18 sind die bereits oben angesprochenen Ergebnisse zweier recht ausführlicher derartiger Zusammenstellungen der Aufwendungen wiedergegeben, die für ein Kind während der ersten 18 Lebensjahre anfallen. Erstens betrachtet der wissenschaftliche Beirat für Familienfragen verschiedene typisierte Familienzyklen (Ehepaare und Alleinerziehende mit jeweils unterschiedlicher Kinderzahl, getrennt nach alten und neuen Bundesländern). ${ }^{285}$ Zweitens saldieren Werding und Hofmann (2005) in ihren Modellrechnungen die Ausgaben und Einnahmen über einen durchschnittlichen Lebenszyklus, wobei sie für jede als relevant erachtete Hinsicht gewichtete Durchschnittswerte ansetzen. Ihr Hauptanliegen besteht in der Aufstellung der fiskalischen Bilanz eines Kindes (s. o.), die für ein Kind anfallenden Kosten auf Seiten der Eltern und der öffentlichen Haushalte sind dabei Zwischenergebnisse. Ausgehend von alters- und/ oder fertilitätsspezifischen Überlebensraten, Erwerbs- und Bildungsbeteiligungen werden Einnahmenund Ausgabenprofile über das Lebensalter abgetragen. ${ }^{266}$ Anders als bei den empirisch gestützten Profilen von Werding und Hofmann (2005) sind die vom Beirat ausgewiesenen Opportunitätskosten über den mit einem Erzieherlohn bewerteten Zeitaufwand bestimmt. Die Ergebnisse beziehen sich auf die Jahre 1996 (Beirat) bzw. 2000 (Werding und Hofmann).

Die privat getragenen direkten Nettokosten in Tabelle 18 umfassen die Lebenshaltungsaufwendungen, vermindert um die bereits oben vorgestellten kindbedingten

284 Der erste Ansatz findet sich unter anderem bei Lampert (1996), der zweite in erster Ausprägung bei Pfeiffer und Braun (2005), in zweiter Ausprägung bei Werding und Hofmann (2005). S. Lampert (1996), S. 308ff; Pfeiffer, Braun (2005), S. 23ff; Werding, Hofmann (2005), S. $40 \mathrm{ff}$

285 Bundesministerium für Familie, Senioren, Frauen und Jugend (Hrsg.) (2001), S.137ff

286 Werding, Hofmann (2005) 
Mehreinkommen (Kindergeld, Erziehungsgeld etc.), die sich beim öffentlichen Aufwand niederschlagen. Weiterer öffentlicher Aufwand ergibt sich insbesondere über Realtransfers sowie beitragsfreie Leistungen der Sozialversicherung. Die als kindbedingtes Mehreinkommen zusammengefassten Leistungen entsprechen mit Beträgen von rund 35 bis 36 Tsd. Euro etwa $36 \%$ des öffentlichen Aufwands, ein Anteil der sich annähernd auch aus der auf gesamtwirtschaftlichen Jahresdaten beruhenden Betrachtung ergab (Von 158 Mrd. Euro kindbezogener Leistungen insgesamt lassen sich rund $34 \%$ als kindbedingtes Mehreinkommen in den typisierenden Lebenszyklen des STM erfassen, vgl. Tabelle 16).

Tabelle 18: Aufwendungen je Kind von der Geburt bis zum Alter von 18 Jahren [1000 Euro]

\begin{tabular}{|c|c|c|c|c|c|c|}
\hline & \multirow{2}{*}{\multicolumn{4}{|c|}{ Quelle* }} \\
\hline & & & & & & \\
\hline & & & \multicolumn{3}{|c|}{$I(1996)$} & II (2000) \\
\hline & & & Paar, 1 Kind & Paar, 3 Kinder & Durch & nittskind \\
\hline \multirow{3}{*}{$\begin{array}{l}\text { Privater } \\
\text { Aufwand }\end{array}$} & \multicolumn{2}{|c|}{ Opportunitätskosten } & 162 & 110 & 148 & 84 \\
\hline & \multicolumn{2}{|c|}{ Direkte Kosten (Netto) } & 78 & 43 & 69 & 65 \\
\hline & \multicolumn{2}{|c|}{ Gesamt } & 240 & 153 & 217 & 150 \\
\hline \multirow{4}{*}{$\begin{array}{l}\text { Offentlicher } \\
\text { Aufwand }\end{array}$} & \multicolumn{2}{|c|}{ Kindbedingte Mehreink. } & 35 & 36 & 35 & 36 \\
\hline & \multicolumn{2}{|c|}{ Mitversicherung } & 12 & 12 & 12 & 12 \\
\hline & \multicolumn{2}{|c|}{ Realtransfers } & 49 & 50 & 50 & 51 \\
\hline & \multicolumn{2}{|c|}{ Gesamt } & 96 & 98 & 97 & 99 \\
\hline \multirow{3}{*}{$\begin{array}{l}\text { Gesamter } \\
\text { Aufwand }\end{array}$} & \multicolumn{2}{|c|}{ Opportunitätskosten } & 162 & 110 & 148 & 84 \\
\hline & \multicolumn{2}{|c|}{ Direkte Kosten } & 175 & 141 & 166 & 164 \\
\hline & \multicolumn{2}{|c|}{ Gesamt } & 336 & 251 & 314 & 249 \\
\hline \multirow{2}{*}{\multicolumn{2}{|c|}{$\begin{array}{l}\text { Anteil der Opportunitäts- } \\
\text { kosten }\end{array}$}} & Privat & $67,3 \%$ & $72,0 \%$ & $68,3 \%$ & $56,3 \%$ \\
\hline & & Gesamt & $48,1 \%$ & $43,8 \%$ & $47,2 \%$ & $33,9 \%$ \\
\hline \multirow{3}{*}{\multicolumn{3}{|c|}{$\begin{array}{l}\text { Einnahmeausfalle der offentlichen Hand } \\
\text { Gesamt einschl. Einnahmeausfalle } \\
\text { Offentlicher Anteil einschl. Einnahmeausfälle }\end{array}$}} & 30 & 21 & 27 & 58 \\
\hline & & & 366 & 272 & 341 & 307 \\
\hline & & & $34,3 \%$ & $43,9 \%$ & $36,4 \%$ & $51,3 \%$ \\
\hline \multicolumn{7}{|c|}{$\begin{array}{l}\text { *Quelle: (I) Bundesministerium für Familie, Senioren, Frauen und Jugend (Hrsg.) (2001), S.155 } \\
\text { Alle Werte beziehen sich auf die alten Bundesländer. } \\
\text { (II) Werding, Hofmann (2005), S. 37, S. 73 } \\
\text { und eigene Berechnungen }\end{array}$} \\
\hline
\end{tabular}

Ein wesentliches Ergebnis von Zusammenstellungen der Aufwendungen für ein Kind sind die hohen Gesamtbeträge, die für Betreuung und Lebensunterhalt anfallen und die für die in Tabelle 18 wiedergegebenen Konstellationen von 249 Tsd. bis 336 Tsd. Euro reichen. Wenn der öffentlich getragene Anteil an Kinderkosten bestimmt wird, ist es üblich, spiegelbildlich zu den Opportunitätskosten der Eltern (als entgangene Nettoeinkommen) zusätzlich Einnahmeausfälle der öffentlichen Haushalte (als entgangene Abgaben auf die Bruttoeinkommen) einzubeziehen, die aus betreuungsbedingten Erwerbseinschränkungen folgen. Unter Berücksichtigung dieser Einnahmeausfälle ermittelt der Beirat je nach Kinderzahl öffentlich getragene Anteile von $34,3 \%$ bis $43,9 \%$ (jeweils für Ehepaare, bei Alleinerziehenden übersteigen die Anteile 
$50 \%$ ). Bei Werding und Hofmann ergibt sich ein höherer Anteil von gut $50 \%$, Rosenschon (2001) nennt mit rund $46 \%$ bis $47 \%$ vergleichbare Werte. ${ }^{287}$

Während diese beiden Befunde, eine recht starke Beteiligung der öffentlichen Hand an den Aufwendungen für Kinder einerseits und eine dennoch hohe verbleibende Belastung der Eltern andererseits, zu den meist beachteten Ergebnissen in diesem Kontext zählen, ist für die Betrachtung hier auf zwei weitere Aspekte hinzuweisen: die Bedeutung von Skaleneffekten sowie von Opportunitätskosten. Ein plausibles Ergebnis des Beirats sind die mit der Kinderzahl stark fallenden Aufwendungen je Kind (Vergleich von "Paar, 1 Kind" mit „Paar, 3 Kinder"). Die nahe liegende unterproportionale Zunahme der Opportunitätskosten (von 162 Tsd. Euro bei einem Kind auf 330 Tsd. Euro bei drei Kindern (=110 Tsd. Euro je Kind)) weist auf Skalenerträge bei der Haushaltsproduktion hin. Auch beim Haushaltskonsum treten die bekannten Skaleneffekte zu Tage, die Lebenshaltungsaufwendungen je Kind sinken von 113 Tsd. Euro bei einem Kind (= 78 Tsd. Euro direkte Nettokosten der Eltern plus 35 Tsd. Euro kindbedingtes Mehreinkommen) auf 79 Tsd. Euro bei drei Kindern. ${ }^{288}$ Beide Effekte liegen auch bei Alleinerziehenden vor.

Während die Kosten je Kind mit der Kinderzahl demnach abnehmen, sind nach den Ergebnissen des Beirats die kindbedingten Mehreinkommen -ebenso wie die öffentlichen Aufwendungen insgesamt- weitgehend unabhängig von der Ordnungszahl eines Kindes, womit die familienpolitischen Maßnahmen zu einer mit der Kinderzahl steigenden öffentlichen Beteiligung an den Kosten eines Kindes führen. Der Befund sinkender Durchschnittskosten würde bei einer bedarfsorientierten Familienpolitik hingegen für mit der Kinderzahl ebenfalls fallende Leistungen sprechen, so dass der öffentlich getragene Anteil von der Kinderzahl unabhängig wäre. Tatsächlich bestand vor allem in der Vergangenheit jedoch eher der umgekehrte Zusammenhang: Die verstärkte Begünstigung von Mehrkindfamilien, wie für frühere Rechtsstände feststellbar, widerspricht demnach einer am Bedarf orientierten Förderung, stattdessen ergibt sich aus ihr eine tendenziell statuskonservierende Wirkung. Indem der Umfang kindbedingter Mehreinkommen je Kind mit der Ordnungszahl der Kinder zunimmt, wird ein Absinken des bedarfsgewichteten Pro-Kopf-Einkommens bei steigender Kinderzahl abgefedert, so dass sich die relative Einkommensposition weniger stark verschlechtert. Allerdings erscheint der Einfluss dieses Wirkmechanismus bei den festgestellten relativ geringen Anteilen kindbedingter Mehreinkommen am Lebenseinkommen, die für die älteren Rechtsstände festzustellen sind, stark begrenzt.

In Hinblick auf die Opportunitätskosten wurden für einen Vergleich der Studien die nach Kinderzahl und Familientyp differenzierten Angaben aus dem Gutachten des Beirats mit Geburtenhäufigkeiten gewichtet, um so ebenfalls Werte für ein Durchschnittskind abzuleiten. Hiernach ergeben sich in den beiden Untersuchungen trotz diverser methodischer Unterschiede mehrheitlich sehr ähnliche Beträge, nur die Opportunitätskosten unterscheiden sich massiv. Der Wert des Beirats von 148 Tsd. Eu-

287 Rosenschon (2001), S. $42 \mathrm{ff}$

Werding und Hofmann (2005) geben nicht den Anteil von 51,3\% an sondern von 47,4\%. Die Differenz folgt aus Verbrauchsteuern, die auf den Konsum des Kindes erhoben werden. Zur besseren Vergleichbarkeit der verschiedenen Untersuchungen wurde dieser Aspekt hier herausgerechnet.

${ }^{288} \mathrm{Vgl}$. zum Befund mit der Kinderzahl unterlinear zunehmender Kosten: Bundesministerium für Familie, Senioren, Frauen und Jugend (Hrsg.) (2003), S. 177; Hesse, Scheffer (1995), S. $218 f$ 
ro übersteigt die alternative Angabe in Höhe von 84 Tsd. Euro um $76 \%$, Gründe hierfür sind wie erwähnt die Art der Bewertung der Opportunität und der intertemporalen Gewichtung. In weiteren Untersuchungen, in denen die von einem Kind ausgehenden Opportunitätskosten ähnlich wie bei Werding und Hofmann (2005) an Hand von Einkommensausfällen bestimmt werden, finden sich Beträge in Bereichen von etwa 60 Tsd. bis 90 Tsd. Euro, wobei die Höhe unter anderem mit der betrachteten Anzahl von Kindern sowie mit der Qualifikation der Mutter variiert ${ }^{289}$ Opportunitätskosten decken in den Berechnungen des Beirats durchschnittlich 47,2\% der Aufwendungen insgesamt sowie $68,3 \%$ der privaten Aufwendungen ab. Auch wenn die Opportunitätskosten niedriger bewertet werden wie in der Studie von Werding und Hofmann (2005) dominieren sie die privaten Aufwendungen mit einem Anteil von 56,3\% (Anteil insgesamt: $33,9 \%$ ). Wenn ausgehend vom gegebenen Steuer-TransferSystem eine Reduktion der kindbedingten Nettobelastung von Eltern angestrebt wird, bieten sich nach diesen Befunden Maßnahmen an, die auf eine Verringerung der Opportunitätskosten hinwirken.

Derartige Ergebnisse zu den typisierenden Kosten eines Kindes beruhen regelmäßig auf empirischen Durchschnittswerten, wobei vor allem die privaten Kosten der Eltern stark vom zu Grunde gelegten Umfang von Erwerbseinschränkungen abhängen. Die beobachtbaren Werte ihrerseits sind Folge diverser Entscheidungen, bei denen sich unter anderem Fertilität, Erwerbsbeteiligung und die Wirkungen des Steuer-Transfer-Systems wechselseitig beeinflussen, so dass zum einen die Kosten keinen zwangsläufigen Charakter aufweisen und zum anderen eine erhebliche Streuung um die Durchschnittswerte besteht, die wie Tabelle 18 nahe legt unter anderem aus unterschiedlichen Kinderzahlen resultiert. Daneben äußert sich der positive $\mathrm{Zu}$ sammenhang von Einkommen und Konsum ebenfalls in Form von mit dem Einkommen zunehmenden direkten Kosten. Weiterhin steigen mit der Qualifikation der Mutter ihr potenzielles Einkommen und entsprechend auch die Opportunitätskosten. Kompensatorisch kann ein ebenfalls positiv qualifikationsabhängiges Arbeitsangebot wirken. Indem höher qualifizierte Frauen erstens kürzere kindbedingte Erwerbspausen und anschließend größere Erwerbsumfänge zeigen, können bei ihnen einerseits absolut die höchsten Opportunitätskosten auftreten, andererseits die relativen Verluste an Lebenseinkommen jedoch am geringsten ausfallen. ${ }^{290}$

Eine Möglichkeit, solche interindividuellen Unterschiede in typisierenden Modellfällen zu erfassen, besteht in der Betrachtung verschiedener Szenarien, in denen das Einkommensniveau und der Umfang von Erwerbseinschränkungen variiert werden. ${ }^{291}$ Für empirisch gestützte intergenerative Vergleiche zu den von Kindern ausgehenden Kosten wäre zusätzlich die über die Kohorten gestiegene Enwerbsbeteiligung einerseits von Frauen insgesamt sowie andererseits speziell von Frauen mit Kindern zu berücksichtigen. Da gemäß dem Opportunitätsgedanken nur der auf das Vorhandensein von Kindern zurückzuführende Anteil einer Erwerbseinschränkung Kosten im Sinne einer Fertilitätsentscheidung darstellt, bildet das tatsächliche Erwerbseinkommen von kinderlosen Frauen und damit nicht unbedingt ein

${ }^{289}$ Vgl. zu dieser Spannweite die Ergebnisse von: Althammer (2000), S. 90; Hufnagel (2002), S. 121; Pfeiffer, Braun (2005), S. 25

290 Althammer (2000) ermittelt Nettoeinkommensverluste bei zwei Kindern, die von $19,8 \%$ des potenziellen Lebenseinkommens bei niedrigeren Qualifikationen bis zu $16,8 \%$ bei Akademikerinnen reichen (s. Althammer (2000), S. 90).

291 Vgl. etwa Pfeiffer, Braun (2005), S. $23 \mathrm{ff}$ 
Vollzeiteinkommen die Referenzgröße zur Bestimmung von Opportunitätskosten. Für einen intergenerativen Vergleich von Kinderkosten, der auf möglichst durchschnittlichen Erwerbsmustern beruht, wäre entsprechend die Entwicklung des Arbeitsangebots in Abhängigkeit von der Kinderzahl zu berücksichtigen.

Um eine Vergleichsgröße zu generieren, die erstens möglichst frei von diesbezüglichen typisierenden Annahmen ist und zweitens trotzdem geeignet erscheint, den Anteil kindbedingter Leistungen an Kinderkosten für intergenerative Vergleiche verdichtend zu erfassen, wurde mit dem STM ermittelt, in welchem Umfang kindbedingte Mehreinkommen Erwerbsunterbrechungen kompensieren. Anstatt ausgewählte Erwerbsmuster exogen vorzugeben, wird geprüft, bei welcher Erwerbspause die verfügbaren Lebenseinkommen von Eltern und gleichartigen Kinderlosen übereinstimmen. Grundgedanke dieses Ansatzes ist, dass das verfügbare Lebenseinkommen durchgängig doppelt verdienender Paare mit Kindern höher ist als bei kinderlosen Doppelverdienern, die Differenz entspricht dem kindbedingten Mehreinkommen. Umgekehrt zeigt sich, dass das Lebenseinkommen bei dem oben als Einverdiener skizzierten Erwerbstyp (keine Erwerbstätigkeit des zweiten Partners ab der Geburt des ersten Kindes) den Wert von Doppelverdienern ohne Kinder deutlich unterschreitet, die kindbedingten Mehreinkommen gleichen den dauerhaften Wegfall des zweiten Erwerbseinkommens nicht aus. Gesucht ist nun die Dauer einer Erwerbsunterbrechung, bei der das verfügbare Lebenseinkommen von Eltern dem Lebenseinkommen kinderloser Doppelverdiener entspricht, die kindbedingten Mehreinkommen mithin genau den zeitweisen Wegfall eines Erwerbseinkommens kompensieren. Für das Elterngeld etwa gilt vereinfachend, dass es Verdienstausfälle über eine Dauer von rund 0,67 Jahren kompensiert, indem über 12 Monate $67 \%$ des entfallenden Nettoeinkommens ersetzt werden. ${ }^{292}$ Mit dem hier gewählten Ansatz wird der Barwert sämtlicher kindbedingter Leistungen in dieser Form zur kompensierten Dauer einer Erwerbsunterbrechung umgerechnet, wobei die oben beschriebene Abhängigkeit der kindbedingten Mehreinkommen vom Arbeitsangebot berücksichtigt ist.

Diese Sichtweise, mit familienpolitischen Leistungen auf eine Kompensation für kindbedingte Erwerbseinschränkungen hinzuwirken, liegt sowohl dem Elterngeld als auch den Kindererziehungszeiten der Rentenversicherung zu Grunde, die die Folgen eines dreijährigen Verdienstausfalls für die Rentenbezugsphase typisierend ausgleichen sollen. Die hier berechneten kompensierten Dauern entsprechen somit einer Verdichtung der Gesamtwirkung kindbedingter Leistungen unter dieser Perspektive des Verdienstausfalls. Die Erwerbsphase von Paaren mit Kindern setzt sich dabei aus drei Teilphasen zusammen: Bis zur Geburt des ersten Kindes sind beide Partner vollzeiterwerbstätig (1. Phase), danach ist ein Partner vorübergehend nicht erwerbstätig (2. Phase), anschließend arbeiten beide Elternteile wieder in Vollzeit (3. Phase). Die im Folgenden angegebenen kompensierten Dauern entsprechen den gesuchten Dauern der zweiten Phase, als Referenzlebenseinkommen dient der Wert kinderloser Doppelverdiener. Bei den Einkommen der dritten Phase wird unterstellt, dass trotz Erwerbspause das Bruttoeinkommen gleichqualifizierter Kinderloser erzielt wird, der Befund langfristiger negativer Effekte von Erwerbseinschränkungen auf das

292 Tatsächlich fällt die kompensierte Dauer etwas geringer aus, was bei den hier betrachteten Fällen überwiegend an der Wirkung des Progressionsvorbehalts liegt. 
spätere Einkommen wird folglich ignoriert. An die Stelle der Frage, wie groß die Opportunitätskosten von Kindern unter vorgegebenen Erwerbsmustern sind, tritt hier also die Frage, bei welchem Erwerbsmuster die Opportunitätskosten von den kindbedingten Mehreinkommen gedeckt werden.

Die so berechnete kompensierte Dauer beläuft sich für erste Kinder, die zwischen 1960 und 1975 geboren wurden, auf rund 0,9 bis 1,3 Jahre, danach steigen die Werte vor allem in Fällen mit niedrigeren Elterneinkommen stark an. Bei ab 2007 geborenen Kindern gleichen die kindbedingten Mehreinkommen Verdienstausfälle aus, die aus Erwerbsunterbrechungen von rund 2,8 Jahren (Uni) bis 4,1 Jahren (Ohne) resultieren (Abbildung 82).

Abbildung 82: Kompensierte Dauer nach Qualifikation und Geburtsjahr des Kindes (1 Kind)

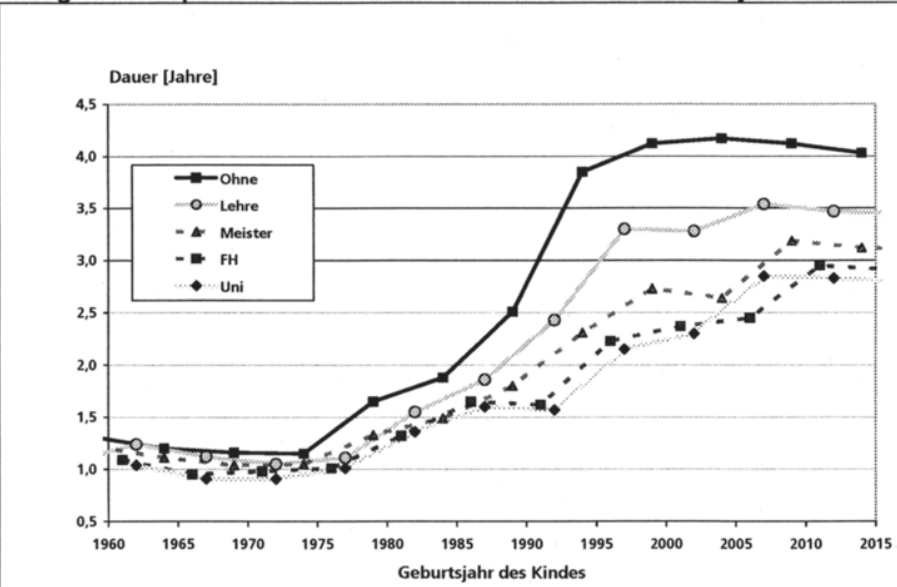

Quelle: eigene Berechnungen

Die Entwicklung der kompensierten Dauern über die Geburtsjahre wird in zentralen Punkten über die Zunahmen der kindbedingten Mehreinkommen geprägt, für die sich ebenfalls vor allem bei niedrigeren Elterneinkommen Verbesserungen im Zeitverlauf abzeichneten (vgl. Abbildung 74). Daneben schlagen sich in den Dauern jedoch verstärkt auch Wirkungen des Steuer-Transfer-Systems abseits familienpolitischer Absichten nieder, wozu insbesondere Progressionseffekte der Besteuerung zählen. Die zu Grunde gelegten Lebenseinkommensprofile sind so konstruiert, dass das Bruttoerwerbseinkommen von (kinderlosen und gleichalten) Doppelverdienern doppelt so groß ist wie von Einverdienern. Wie stark sich die verfügbaren Lebenseinkommen von Doppel- und Einverdienern unterscheiden, hängt somit von der Belastung der zweiten Einkommenshälfte mit Abgaben ab. Je niedriger die Grenzbelastung im relevanten Einkommensbereich ist, desto höher sind die Einkommensnachteile von Einverdienern. Auf die Kosten von Kindern bezogen folgt hieraus, dass mit einer sinkenden Grenzbelastung die Opportunitätskosten zunehmen, was für sich genommen auf eine niedrigere kompensierte Dauer hinwirkt. In welchem Umfang kindbezogene 
Leistungen Einkommensausfälle unter verschiedenen Rechtsständen kompensieren, hängt entsprechend von mehreren Faktoren $a b$, zu denen neben familienpolitischen Maßnahmen auch die Steuertarife und die Lohnwachstumsrate gehören.

Bei den hier betrachteten Einkommensniveaus offenbaren sich vorrangig bei den niedrigeren Qualifikationen Abweichungen zwischen der Entwicklung der kindbedingten Mehreinkommen einerseits und der kompensierten Dauern andererseits (Abbildung 83). In der Abbildung ist zum einen die Entwicklung der kindbedingten Mehreinkommen, ausgedrückt als Anteil am verfügbaren Lebenseinkommen, wie im letzten Unterkapitel besprochenen, dargestellt. Die Kurven für Einverdiener sind dieselben wie in Abbildung 74, für Doppelverdiener sind die entsprechenden Werte dargestellt. Die Kurve "Dauer" gibt analog die kompensierten Dauern als Vielfache der für die Elternkohorte 1930 berechneten Werte wieder. Bei niedrigeren Einkommen (Ohne) fallen die kompensierten Dauern über Eltern der Kohorten von 1930 bis 1950 trotz steigender kindbedingter Leistungen geringfügig ab (von 1,25 auf 1,15 Jahre), danach steigen die Kurven parallel an. Insgesamt vergrößert sich der Anteil der kindbedingten Mehreinkommen am Lebenseinkommen über die Kohorten von 1930 bis 1990 auf das 4,0-Fache (Doppelverdiener) bis 4,7-Fache (Einverdiener) der Ausgangswerte, die kompensierte Dauer nimmt jedoch nur um den Faktor 3,3 zu (von 1,2 auf 4,0 Jahre).

Abbildung 83: Vergleich von Indikatoren zur Entwicklung kindbedingter Leistungen

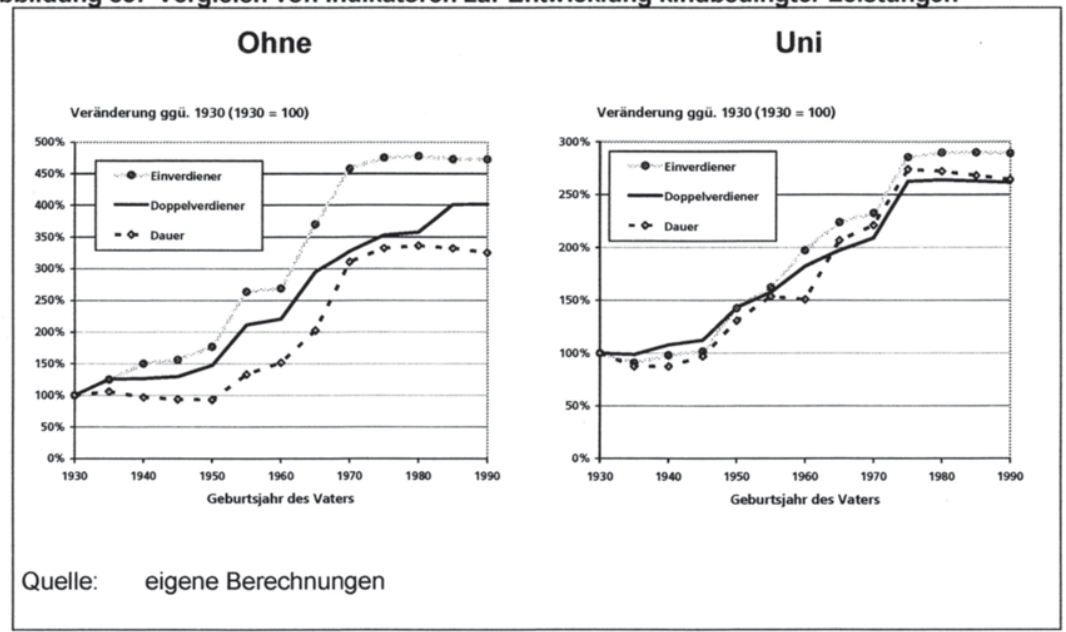

Für höhere Einkommen (Uni) verläuft die Entwicklung der Indikatoren zur Bedeutung kindbezogener Leistungen hingegen weitgehend gleichartig. Nach zunächst geringen Veränderungen über die Elternkohorten von 1930 bis 1945 ist anschließend ein starker Anstieg zu verzeichnen (auf das 2,6-Fache bis 2,9-Fache der Ausgangswerte). ${ }^{293}$

${ }^{293}$ Obwohl im STM für alle ab 2007 geborenen Kinder die gegenwärtigen und damit einheitliche familienpolitischen Regelungen gelten, tritt über die jüngsten Kohorten ein geringer Rückgang sowohl der kindbedingten Mehreinkommen als auch der kompensierten Dauern auf. Dieses Ergebnis folgt aus den Übergangsregelungen des Alterseinkünftegesetzes (vgl. Kapitel 4.2.5), die vor allem bei 
Festhalten lässt sich, dass das Steuer-Transfer-System auch über seine nicht familienpolitisch motivierten Elemente Einfluss auf die bei Fertilitätsentscheidungen zu berücksichtigenden Kosten nimmt, wobei sich diese Effekte je nach Einkommensniveau unterscheiden können und schwerlich systematisieren lassen.

Auch bei Eltern mit drei Kindern ähnelt die Entwicklung der kompensierten Dauern über die Geburtsjahre dem von den kindbedingten Mehreinkommen bekannten Verlauf. Wie bei Eltern mit einem Kind sind über Geburtsjahre von 1960 bis etwa 1975 stagnierende bis leicht schrumpfende Dauern festzustellen, anschließend steigen die Werte qualifikationsübergreifend an (Abbildung 84). Für die Geburtsjahre ab etwa 1995 weichen die Entwicklungen dann je nach Einkommensniveau voneinander ab: Aus der Sicht von Eltern mit bis zu durchschnittlichem Einkommen (Ohne, Lehre) entsprechen die jüngeren Rechtsänderungen Verschlechterungen. Bei drei ab 1999 geborenen Kindern (annahmegemäß also eine Geburtsfolge über die Jahre 1999, 2001 und 2003) erzielen Eltern ohne beruflichen Abschluss dasselbe verfügbare Lebenseinkommen wie kinderlose Doppelverdiener, wenn ein Partner seine Erwerbstätigkeit für 11,5 Jahre unterbricht, im Status Quo ergibt sich eine um 1,3 Jahre geringere implizite kompensierte Dauer von noch rund 10,2 Jahren. Bei Eltern mit dem Abschluss Lehre beläuft sich der Rückgang auf etwa 0,6 Jahre (von 9,2 auf 8,6 Jahre). In den Fällen mit höheren Einkommen, die nicht oder nur gemindert vom Erziehungsgeld profitierten, sind die kompensierten Dauern unter dem geltenden Recht hingegen maximal und belaufen sich auf 6,5 (Uni) bzw. 6,8 (FH) bzw. 7,6 Jahre (Meister). Mit Werten von 6,5 bis 10,2 Jahren haben sich die kompensierten Dauem für drei ab 2007 geborene Kinder gegenüber ab 1960 geborenen auf das 1,7-Fache bis 1,9-Fache erhöht. ${ }^{294}$ Die Anstiege der kompensierten Dauern beruhen überwiegend auf der zunehmenden Berücksichtigung erster -und mit Abstrichen auch zweiterKinder im Steuer-Transfer-System. Die auf ein drittes Kind zurückzuführenden Leistungen decken im geltenden Recht Verdienstausfälle von 1,8 Jahren (Uni) bis 3,0 Jahren (Ohne) ab, was im Vergleich zu den ältesten betrachteten Kindern keinen oder nur leichten Verbesserungen entspricht (Abbildung 85). Gegenüber ersten Kindern, bei denen die Dauern zuletzt 2,8 (Uni) bis 4,1 Jahre (Ohne) betragen, fallen die Werte damit um rund 1,0 bis 1,3 Jahre niedriger aus. Die Leistungen für zweite Kinder führen im geltenden Recht zu ähnlichen Dauern wie bei dritten Kindern (1,9 bis 3,1 Jahre).

höheren Einkommen zu einer steuerlichen Entlastung über den Lebenszyklus insgesamt führen. Da hierdurch die Abgabenquote fällt, während die kindbedingten Leistungen annähernd real konstant bleiben, sinkt die Bedeutung der kindbedingten Mehreinkommen für das Lebenseinkommen.

Wie bereits oben erwähnt bestehen unter dem geltenden Recht in Fällen mit mehreren Kindern zusätzliche Freiheitsgrade bei der Bestimmung der kindbedingten Mehreinkommen und damit auch der kompensierten Dauern. Unter eher unüblichen Erwerbsmustern, bei denen sich mehr als drei Phasen von Enwerbstätigkeit und -unterbrechungen abwechseln, ergibt sich im Status Quo ein höheres Elterngeld und damit auch höhere kompensierte Dauern als in der Abbildung dargestellt, auch entfällt dann die Verschlechterung für Eltern mit niedrigeren Einkommen. 
Abbildung 84: Kompensierte Dauer nach Qualifikation und Geburtsjahr des Kindes (3 Kinder)

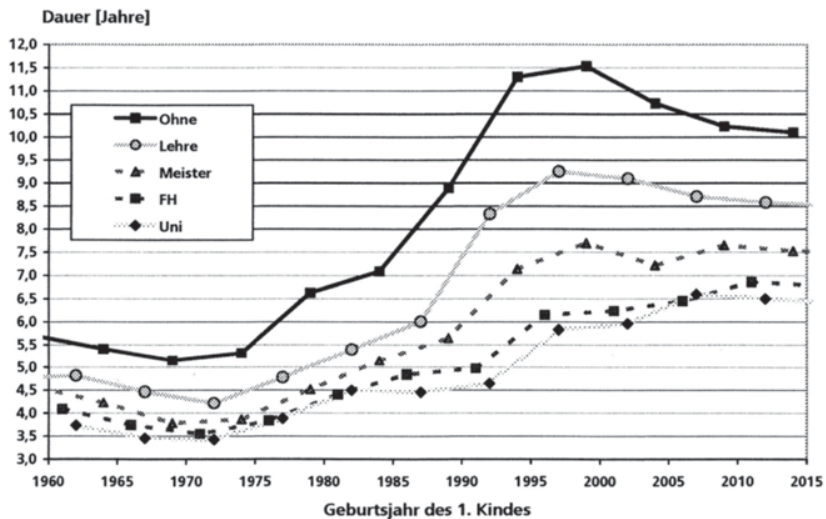

Quelle: eigene Berechnungen

Abbildung 85: Kompensierte Dauer nach Qualifikation und Geburtsjahr des Kindes (3. Kind)

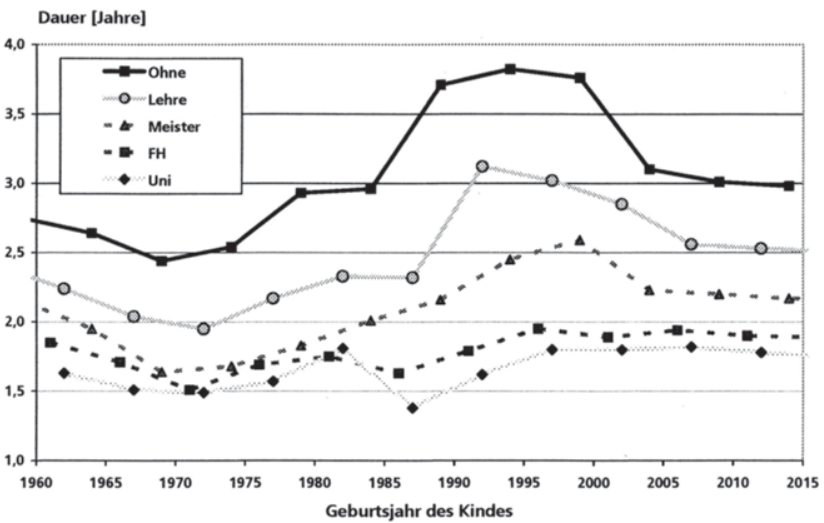

Quelle: $\quad$ eigene Berechnungen 
Die Betrachtung kindbedingter Mehreinkommen unter dem Gesichtspunkt, in welchem Umfang durch sie Opportunitätskosten implizit kompensiert werden, zeigt insgesamt im Wesentlichen vergleichbare Entwicklungslinien auf wie die Analyse der Anteile familienpolitisch orientierter Umverteilung am verfügbaren Lebenseinkommen im vorherigen Unterkapitel. Unter beiden Perspektiven ergeben sich starke Anstiege über die Geburtsjahre, wobei die relativen Verbesserungen jeweils bei Eltern mit wenigen Kindern und/ oder geringen Einkommen am stärksten ausfallen und die jüngsten Reformen je nach Kinderzahl und Einkommen gegensätzliche Effekte mit sich bringen. Als ergänzende Erkenntnis ergab sich, dass die intergenerativen Unterschiede über die Geburtsjahre für niedrigere Einkommen geringer ausfallen, wenn die Opportunitätsperspektive eingenommen wird. Im Zusammenwirken mit Verschiebungen in der Besteuerung schlagen sich die Ausweitungen im Bereich der monetären Familienpolitik bei unterdurchschnittlichen Einkommen nicht vollumfänglich in einem Anstieg der kompensierten Dauern nieder.

Zudem ergänzt die "Umrechnung“ von kindbedingten Mehreinkommen in (Nicht-)Erwerbszeiten die gängige Beobachtung mit der Qualifikation steigender Opportunitätskosten. Auch unter Berücksichtigung der Qualifikationsabhängigkeit der Transfervolumina gilt weiterhin der bekannte Zusammenhang: Zwar empfangen Eltern mit höheren Einkommen höhere Leistungen, dennoch werden Einkommensausfälle in geringerem Maße kompensiert. Bei durchschnittlichen Einkommen (Lehre) werden im Status Quo Erwerbspausen von rund 3,5 Jahren ausgeglichen, bei überdurchschnittlichen Einkommen (Uni) etwa 2,8 Jahre und damit knapp 0,7 Jahre weniger. Kindbedingte Erwerbsunterbrechungen von drei Jahren finden sich wiederholt als Richtgröße in familienpolitischen Planungen, an der sich neben den Kindererziehungszeiten in der Rentenversicherung auch die Regelungen zum Erziehungsurlaub (bzw. zur Elternzeit), die institutionalisierte Kinderbetreuung und das Erziehungsgeld orientieren - bei letzterem wurde jedoch aus fiskalischen Gründen von der geplanten dreijährigen Bezugsdauer abgesehen. Das geltende Steuer-TransferSystem führt nach den Ergebnissen des STM in seiner Gesamtwirkung somit dazu, dass implizit Opportunitätskosten ungefähr in einem Umfang kompensiert werden, der nach normativen Vorstellungen des Gesetzgebers unter verschiedenen Gesichtspunkten als angemessen galt.

Nach üblichen Befunden überschreiten kindbedingte Erwerbsunterbrechungen jedoch überwiegend Dauern dieser Größenordnung. Umfänge von drei Vollzeitjahren gelten als gering und werden am ehesten mit Enwerbsbiographien von Müttern aus der ehemaligen DDR assoziiert. ${ }^{295}$ Ansonsten bilden Arbeitsangebotseinschränkungen in dieser Größenordnung tendenziell die Untergrenze von als typisch erachteten Fällen. In Untersuchungen zu Einkommenseffekten kindabhängiger Erwerbsminderungen summieren sich die betrachteten Erwerbsreduktionen aus Phasen der Nicht- und der Teilzeiterwerbstätigkeit auf Werte von etwa drei bis sechs und bis zu über zehn Vollzeitjahren je Kind. ${ }^{296}$ Auch diese Befunde erinnern daran, dass Ausweitungen des Arbeitsangebots von Eltern wesentlich zur Reduktion der beobachtbaren Kosten von Kindern beitragen können.

295 Vgl. die Auswertungen von Rentenversicherungsverlaufsdaten in: Schmähl, Himmelreicher, Viebrok (2004), S. $48 \mathrm{ff}$

296 Vgl. Galler (1991); Beblo, Wolf (2002) 


\subsection{Zusammenfassung und Schlussfolgerungen}

In diesem Kapitel wurden Entwicklungen im Bereich monetärer Familienpolitik über die zurückliegenden Jahrzehnte unter verschiedenen Aspekten betrachtet, wobei die Analyse von familienpolitisch orientierter Umverteilung im Laufe vollständiger Lebenszyklen im Zentrum stand. Ein wesentlicher Vorteil dieser langfristigen Perspektive ist, die summarischen Effekte der vielfältigen, auf unterschiedliche Lebensphasen ausgerichteten Instrumente verdichtend erfassen zu können. Die Ergebnisse beziehen sich dabei auf Kinder, die seit Mitte der 1950er Jahre geboren wurden. Unter dem Grundansatz dieser Arbeit, inter- und intragenerative Unterschiede in den Wirkungen des Steuer-Transfer-Systems auf der Basis von typisierten Einkommensprofilen zu untersuchen, wurden dazu die Einflüsse monetärer Familienpolitik auf das verfügbare Lebenseinkommen von Eltern herausgearbeitet. Die Betrachtung von kindbedingten Leistungen in Relation zu verfügbaren Einkommen empfiehlt sich vor allem, um die verschiedenen Generationen zukommenden Leistungen vergleichbar zu machen. An Hand der hier ermittelten Ergebnisse lässt sich unter anderem einordnen, wie großzügig die familienpolitischen Elemente des geltenden SteuerTransfer-Systems im Vergleich zu früheren Regelungen wirken und in welchem Umfang sie private Kosten von Fertilitätsentscheidungen reduzieren. In Hinblick auf die in der familienpolitischen Diskussion ebenfalls vielbeachtete Frage, inwieweit Unterschiede in der Förderung reicherer und ärmerer Kinder bestehen, wurde die Entwicklung für Eltern mit qualifikationsbedingt unterschiedlichen Einkommen verglichen. Als wesentliche Ergebnisse lassen sich festhalten (vgl. Tabelle 19):

Tabelle 19: Monetäre Familienpolitik im Lebenszyklus: Ergebnisse im Überblick

\begin{tabular}{|c|r|r|r|r|r|}
\multicolumn{1}{c|}{} & \multicolumn{5}{c|}{ Geburtsjahr des 1. Kindes } \\
\cline { 2 - 6 } \multicolumn{1}{c|}{} & 1962 & 1977 & 1992 & 2002 & 2007 \\
\hline I Kindbed. Mehreinkommen [1000 Euro] ${ }^{*}$ & 7,8 & 12,4 & 34,4 & 40,0 & 43,8 \\
\hline II Abweichungen von I bei & & & & & \\
a) niedrigem Einkommen & $-11 \%$ & $-8 \%$ & $-1 \%$ & $-6 \%$ & $-11 \%$ \\
b) hohem Einkommen & $37 \%$ & $11 \%$ & $-12 \%$ & $-6 \%$ & $12 \%$ \\
\hline III Anteil am verf. Lebenseink. je Kind & & & & & \\
a) 1 Kind & $1,5 \%$ & $1,8 \%$ & $4,3 \%$ & $4,6 \%$ & $4,8 \%$ \\
b) 3 Kinder & $2,4 \%$ & $3,1 \%$ & $4,0 \%$ & $4,0 \%$ & $3,9 \%$ \\
\hline IV Kompensierte Dauer je Kind [Jahre] & & & & & \\
a) 1 Kind & 1,2 & 1,1 & 2,4 & 3,3 & 3,5 \\
b) 3 Kinder & 1,6 & 1,6 & 2,8 & 3,0 & 2,9 \\
\hline * Soweit nicht anders angegeben: Einverdiener, Lehre, 1 Kind & & \\
\hline
\end{tabular}

- Verschiedene Indikatoren weisen übereinstimmend darauf hin, dass die gegenwärtige monetäre Familienpolitik im historischen Vergleich als großzügig einzustufen ist. Dieses Ergebnis gilt für alle betrachteten Familientypen; unabhängig von Einkommen, Erwerbsbeteiligung und Kinderzahl führt das geltende Recht zu einer vergleichsweise hohen kindbedingten Umverteilung. Für Kin- 
der, die zwischen 1955 und 1975 geboren wurden, ergeben sich stagnierende bis moderat steigende Leistungen, danach folgen für alle Familientypen zunehmende Verbesserungen, die sich insbesondere bei seit den 1990er Jahren geborenen Kindern auswirken. Diese Schlussfolgerungen stützen sich weniger auf den feststellbaren Anstieg der preisniveaubereinigten kindbedingten Mehreinkommen, der bei ebenfalls steigenden Realeinkommen nicht zwingend zu einer relativen Verbesserung der Einkommensposition von Familien führen muss. Grundlage bilden stattdessen die Anteile der kindbedingten Mehreinkommen am verfügbaren Lebenseinkommen sowie die hier als kompensierte Dauer beschriebene Größe, mit der die kindbezogenen Leistungen in Jahreserwerbseinkommen umgerechnet werden. Bei Einverdienern mit durchschnittlichem Einkommen, dem für intertemporale oder internationale Vergleiche gebräuchlichsten Familientyp, ${ }^{297}$ entsprechen die Transfers für ein 1962 geborenes erstes Kind 1,5\% des verfügbaren Lebenseinkommens, bei einem 1977 geborenen Kind liegt dieser Anteil bei 1,8\%. Ab 1992 tragen die kindbedingten Mehreinkommen mit über $4 \%$ zum verfügbaren Einkommen bei. Über Kinder der Geburtsjahre von 1962 (1,5\%) bis 2007 (4,8\%) hat sich der Anteil mehr als verdreifacht. Ohne Berücksichtigung der realen Einkommenssteigerungen ergibt sich ein stärkerer Anstieg, das preisniveaubereinigte kindbedingte Mehreinkommen hat über denselben Zeitraum von 7,8 Tsd. Euro auf 43,8 Tsd. Euro um den Faktor 5,6 zugenommen (Zeile I in Tabelle 19).

- Eine starke Zunahme familienpolitischer Leistungen zeigt sich zwar für alle betrachteten Fälle, die Umfänge unterscheiden sich jedoch beträchtlich. Je nach Kinderzahl und Einkommen sind die Anteile kindbedingter Mehreinkommen an den Lebenseinkommen auf das 1,8-Fache bis 4,7-Fache der Ausgangswerte angestiegen. Die stärksten Verbesserungen im Zeitverlauf treten bei Familien mit wenigen Kindern und/ oder niedrigerem Einkommen auf. Für ab 2007 geborene Kinder sind die Leistungen im historischen Vergleich überwiegend maximal, nur bei Mehrkindfamilien mit niedrigem bis durchschnittlichem Einkommen waren die um die Jahrtausendwende geltenden Regelungen vorteilhafter.

- Das Ergebnis einer merkmalsübergreifend deutlichen Ausweitung familienorientierter Umverteilung gilt für Standardfälle von Kindern, die bis zum Alter von 19 Jahren als Auszubildende ihren Eltern gegenüber unterhaltsberechtigt sind. Wenn von einer längeren Ausbildungsphase in Form eines Hochschulstudiums ausgegangen wird, so dass zusätzlich eher der Bildungs- als der Familienpolitik zugeordnete Transfers innerhalb des Lebenszyklus anfallen, ergibt sich ein zum Teil abweichendes Bild. Tendenziell restriktiv wirkende Entwicklungen im Bereich der Ausbildungsförderung führen bei niedrigen Einkommen zu einem Absinken der Summe kindbedingter Leistungen über Kinder der Geburtsjahre von etwa 1955 bis 1975; die in den 1950er Jahren geborenen Kinder profitieren hier von den großzügigen Konditionen des BAföG der 1970er Jahre (vgl. Kapitel 6.2.2.1). Bei höheren Elterneinkommen, für die

297 Bei den mit dem STM betrachteten Fällen ist das Einkommen bei dem Abschluss einer Lehre in etwa mit den gängigen Werten von Facharbeitern oder dem Konstrukt des „average production worker" vergleichbar. 
durchgängig keine oder nur geringe Ausbildungsförderung anfällt, verlängert sich mit der Ausbildung auch die Anwendung der Elemente des FLA (ergänzt um Ausbildungsfreibeträge), so dass sich dort primär der Anstieg allgemeiner ausgerichteter familienpolitischer Leistungen niederschlägt.

- In Hinblick auf den Umfang kindbedingter Mehreinkommen in Abhängigkeit vom (Erwerbs-)Einkommen zeigt sich im Zeitverlauf überwiegend ein positiver Zusammenhang, Eltern mit überdurchschnittlichem Einkommen profitieren stärker von monetärer Familienpolitik als Bezieher von durchschnittlichen oder unterdurchschnittlichen Einkommen. Bei den frühen der untersuchten Rechtsstände, die sich auf in den 1950er Jahren geborene Kinder auswirken, liegt dies an einer auf die Besteuerung konzentrierten Berücksichtigung von Kindern im Steuer-Transfer-System. Der allgemeine Zusammenhang einer mit dem Grenzsteuersatz zunehmenden Steuerminderung durch Freibeträge bewirkt in dieser Phase eine mit dem Einkommen wachsende Entlastung durch monetäre Familienpolitik. Mit einer tendenziell zunehmenden Gewichtung des Kindergelds innerhalb des FLA sinken dann die Vorteile höherer Einkommen, unter dem zunehmend negativ einkommensabhängigen Erziehungsgeld kehrt sich danach die Rangfolge um: Das kindbedingte Mehreinkommen ist in dieser Phase bei niedrigen bis mittleren (Erwerbs-)Einkommen am höchsten. Mit der Einführung des Eltergelds zeigen sich dann wieder Vorteile für Eltern mit überdurchschnittlichen Einkommen. Insgesamt ergeben sich aus den diversen Reformen im Bereich der Familienpolitik keine monotonen Zusammenhänge zwischen Einkommen und Transfervolumen. Für mittlere Einkommen resultieren durchgängig zumindest geringe Vorteile gegenüber unterdurchschnittlichen, beim Vergleich von mittleren mit überdurchschnittlichen Einkommen hingegen wechselt das Vorzeichen wiederholt (Zeilen Ila) und IIb) in Tabelle 19). Während die Familienpolitik für um das Jahr 2002 geborene Kinder zu insgesamt relativ homogenen Wirkungen führte, wächst im Status Quo wieder die Begünstigung mit dem Einkommen.

- Die Staffelung von Leistungen nach der Kinderzahl hat stark abgenommen. Während Kindergeldsätze und Kinderfreibeträge früher vor allem ab dem dritten Kind erhöht waren, gelten seit 1996 sehr ähnliche Werte für jedes Kind. Von den Familien mit Kindern, die bis in die 1980er Jahre hinein geboren wurden, profitierten entsprechend Mehrkindfamilien überproportional von kindbezogenen Leistungen. Unter den Reformen seit den 1990er Jahren hat sich der Zusammenhang zwischen Kinderzahl und kindbedingten Mehreinkommen umgekehrt, seitdem fallen für ein erstes Kind höhere Leistungen an als für weitere Kinder (Zeilen IIla) und IIIb) in Tabelle 19). Anders als im früheren Recht, wo über die Differenzierung der Leistungsparameter gezielt eine Förderung von Mehrkindfamilien angestrebt wurde, ist im Status Quo eine Staffelung jedoch nicht explizit intendiert; sie ist eher Nebeneffekt gängiger Erwerbsmuster, die die Annahme eines höheren Elterngelds für erste Kinder nahe legen. Daneben trägt auch die Methode der Barwertbildung zu einem geringfügigen Absinken der Leistungen mit der Kinderzahl auf Grund der zunehmenden Gebäralter bei.

- Eine Betrachtung der kindbedingten Mehreinkommen unter dem Aspekt der von Kindern ausgehenden Opportunitätskosten zeigt auf, dass im Status Quo die familienpolitischen Leistungen dazu geeignet sind, bei Durchschnitts- 
verdienern Einkommensausfälle aus Erwerbsunterbrechungen von rund dreijähriger Dauer zu kompensieren (Zeilen IVa) und IVb in Tabelle 19). Trotz der wie dargestellt mit dem Einkommen steigenden Transfervolumina ergeben sich für höhere Einkommen größere Opportunitätskosten, die kompensierten Dauern reichen bei einem Kind von 2,8 Jahren (bei überdurchschnittlichen Einkommen) bis zu 4,0 Jahren (bei unterdurchschnittlichen Einkommen).

Nach diesen Ergebnissen lässt sich die geltende monetäre Familienpolitik im intertemporalen Vergleich als großzügige Förderung mit recht einheitlichen Beträgen je Kind charakterisieren. Unter den älteren Rechtsständen gelten eher die umgekehrten Attribute einer knappen Kinderkomponente bei einer Fokussierung auf Mehrkindfamilien. Eine mögliche Deutung dieser Entwicklung ergibt sich aus den in den 1960er und 1970er Jahren stark gefallenen Geburtenraten: Bei einer vergleichsweise homogenen Fertilitätsneigung, unter der Kinderlosigkeit als Ausnahme gelten kann, deutet die Ausgestaltung der damaligen Familienpolitik darauf hin, dass nur ein geringer Bedarf an allgemeiner kindbezogener Umverteilung gesehen wurde, erst bei besonderen Belastungen durch eine überdurchschnittliche Kinderzahl beteiligte sich die öffentliche Hand stärker an den Kosten von Kindern. Unter zunehmenden Abweichungen von einer Biographie mit (mehreren) Kindern als Standardfall verschiebt sich dann die Schwerpunktsetzung. Als zu gering erachtete Geburtenraten bei zunehmender Kinderlosigkeit führen dazu, im Steuer-Transfer-System stärker zwischen Personen mit und ohne Kinder(n) zu differenzieren, wozu zum einen das Leistungsniveau generell erhöht wird und zum anderen bereits erste (und zweite) Kinder verstärkt berücksichtigt werden. Während das ältere Recht hiernach vorrangig auf einen Ausgleich innerhalb der Gruppe der Familien mit Kindern ausgerichtet war, tritt unter dem geltenden Recht der Ausgleich zwischen Eltern und Kinderlosen stärker in den Vordergrund. Vergleichsweise großzügige Regelungen für erste Kinder lassen sich darüber hinaus auch unter Bedarfs- und Anreizaspekten begründen. Hinweise auf mit der Kinderzahl fallende Kosten je Kind sprechen erstens für einen höheren Bedarf bei ersten Kindern sowie zweitens dafür, dass hohe Kosten vor allem bei Entscheidungen für oder gegen erste Kinder fertilitätshemmend wirken können.

Der Versuch, die implizite Antwort des Gesetzgebers auf die normativ geprägte Frage, inwieweit monetäre Familienpolitik Einkommensunterschiede verringern soll, aus den gemeinsamen Wirkungen ihrer einzelnen Maßnahmen abzuleiten, führt zu keinen eindeutigen Ergebnissen. Zwischen kindbezogenen Leistungen und Einkommen bestehen und bestanden sowohl positive (steuerliche Freibeträge, Elterngeld) wie negative (Erziehungsgeld) als auch keine Abhängigkeiten (Kindergeld), die unter anderem mit Steuer- sowie Bedarfsgerechtigkeit oder Marktineffizienzen begründet wurden. Generell wirken Versuche, Familienpolitik gezielt einkommensabhängig zu gestalten, unter Instrumentenmixen mit zum Teil widersprüchlich erscheinenden Zielen anfällig für Inkonsistenzen. Ein Beispiel bieten kindbedingte Mehreinkommen für in den 1990er Jahren geborene Kinder, deren Volumen zunächst mit dem Einkommen steigt, dann fällt und anschließend wieder steigt. Im geltenden Recht entfällt ein recht großer Anteil der kindbedingten Mehreinkommen auf weitgehend einkommensunabhängig wirkende Elemente wie das Kindergeld und die Kindererziehungszeiten der Rentenversicherung. Für eine Familienpolitik, die sich auf externe Effekte von Kindern beruft, erscheinen derartige konstante Leistungen je Kind 
grundsätzlich als angemessene Instrumente. Insgesamt führte das Steuer-TransferSystem hingegen überwiegend zu einer mit dem Einkommen steigenden Entlastung von Eltern, was früher Appendix einer auf steuerliche Gesichtspunkte beschränkten Förderung von Familien war und heute aus der Betonung des Opportunitätsgedankens wie beim Elterngeld folgt. ${ }^{298} \mathrm{Da}$ mit dem Einkommen (in der Regel) der Mutter die Opportunitätskosten von Kindern steigen, was als eine Ursache für geringere Geburtenraten bei höher qualifizierten Frauen gilt, sollen über eine Kompensation von Einkommensausfällen stärkere Anreize für eine Elternschaft gesetzt werden.

Wenn kindbedingte Mehreinkommen im Kontext der Kosten von Fertilitätsentscheidungen betrachtet werden, verbleiben jedoch selbst unter den relativ umfangreichen Leistungen des Status Quo erhebliche private Kosten der Eltern. Verschiedene Ergebnisse zu den von Kindern ausgehenden Kosten deuten darauf hin, dass das Volumen kindbedingter Transfers sich in einer Größenordnung von etwa einem Fünftel der direkten und indirekten Kosten von Kindern bewegt. Wenn monetäre Familienpolitik im Sinne eines Lastenausgleichs auf eine Angleichung der verfügbaren Einkommen von Eltern und Kinderlosen hinwirken soll, wären unter diesem Aspekt weitere massive Ausweitungen familienorientierter Umverteilung denkbar, für eine vollständige Angleichung wäre mit einem Zuwachs in einer Größenordnung von bis zu einer Verfünffachung zu rechnen. Innerhalb realistischer Finanzrahmen werden somit auch weitere Anhebungen kindbezogener Leistungen bestehende private Kosten von Fertilitätsentscheidungen nur zu einem eher geringen Anteil reduzieren können. Wenn von (weiteren) kindbezogenen Transfers Fertilitätsanreize ausgehen sollen, dämpft die Analyse der familienpolitischen Entwicklungen der letzten Jahrzehnte somit diesbezügliche Erwartungen. Für den festgestellten deutlichen Zuwachs kindbedingter Mehreinkommen über die Geburtsjahre zeigt sich keine Entsprechung bei den Geburtenraten, seit den 1970er Jahren bewegen sich die westdeutschen Raten recht konstant auf niedrigem Niveau. Es wäre mithin gesondert zu begründen, ob und inwieweit eine weitere Leistungsexpansion hier zu nachhaltigen Effekten führen kann. Zudem erinnert der hohe Anteil von Opportunitätskosten an einen alternativen Ansatzpunkt für eine Reduktion privater Kosten von Fertilitätsentscheidungen. Beobachtbare Einkommensnachteile von Eltern folgen überwiegend aus kindbedingten Erwerbseinschränkungen. Ein erhöhtes Arbeitsangebot von (in der Regel) Müttern kann demnach die von Kindern ausgehenden Kosten erheblich senken, so dass sich für hierauf hinwirkende Maßnahmen ein höheres Potenzial zum Abbau von Fertilitätshemmnissen abzeichnet.

${ }^{298}$ Einschränkend ist anzumerken, dass die hier ermittelten Ergebnisse das Steuer-Transfer-System für Eltern mit unterdurchschnittlichem Einkommen und mehreren Kindern nur unscharf abbilden, da im STM nicht erfasste Leistungen wie das Wohngeld oder der seit 2005 eingeführte Kinderzuschlag in diesen Fällen maßgeblich zum verfügbaren Einkommen beitragen können. Die kindbedingten Mehreinkommen werden am unteren Rand der betrachteten Einkommensskala in Kombination mit höheren Kinderanzahlen unter Umständen unterschätzt. 


\section{$9 \quad$ Nettobelastungen von Lebenseinkommen}

Die in Kapitel 7 ausführlich behandelte Entwicklung der impliziten Renditen der gesetzlichen Rentenversicherung bildet einen der wesentlichen Indikatoren in der Diskussion um intergenerative Umverteilung unter den sich abzeichnenden demographischen Entwicklungen. Wie dort dargestellt haben die Rentenreformen der letzten Dekade zu einer wesentlichen Vereinheitlichung der Renditen geführt, indem ältere und mittlere Kohorten zu Gunsten jüngerer Jahrgänge stärker belastet werden. Ein anderer Untersuchungsansatz mit einer Fokussierung auf intergenerative Verteilungsfragen ist die Methode der Generationenbilanzierung. Ausgehend von einer gestiegenen öffentlichen Verschuldung und fiskalischen Implikationen demographischer Verschiebungen wird dabei die gegenwärtige Finanzpolitik bei einer alternden Bevölkerung unter Nachhaltigkeitsgesichtspunkten untersucht. Wiederkehrendes Ergebnis von Generationenbilanzen für Deutschland sind langfristig nicht durch die Einnahmeströme gedeckte Staatsausgaben. Die demnach bestehenden Tragfähigkeitslücken gelten als Hinweis auf eine intergenerative Umverteilung zu Lasten junger und zukünftiger Generationen. ${ }^{299}$ Im Gegensatz zu den auf das Teilsystem der Rentenversicherung beschränkten Renditeberechnungen streben Generationenbilanzen dabei eine umfassende Abbildung intergenerativer Umverteilung durch die öffentliche Hand insgesamt an. Allerdings geht dieser Vorteil einer breiten Erfassung fiskalischer Aktivität regelmäßig mit dem Nachteil einer ausschließlich auf die zukünftige Entwicklung ausgerichteten Betrachtung einher. Anders als bei den Renditen der Rentenversicherung bleiben historische Zahlungsreihen ausgeblendet, so dass sich über Generationenbilanzen nicht feststellen lässt, welche Unterschiede zwischen einzelnen Kohorten bestehen.

In diesem Kapitel wird ein Mittelweg zwischen diesen beiden Ansätzen angestrebt, der über die Rentenversicherung hinaus gehende Belastungsvergleiche einzelner Kohorten erlaubt. Dazu werden mit dem im ersten Teil dieser Arbeit vorgestellten Steuer-Transfer-Modell (STM) Lebensnettosteuersätze für die Kohorten von 1930 bis 1990 berechnet, wobei Lebensnettosteuersätze wie aus Generationenbilanzen bekannt als Quotient der Barwerte von Steuer-Transfer-Saldo und Lebenseinkommen bestimmt werden. Ein Schwerpunkt der Betrachtung liegt auf der Veränderung der Zusammensetzung der Nettobelastungen über die Kohorten und der damit einher gehenden intragenerativen Unterschiede zwischen Einkommensniveaus und zwischen Familientypen. Hieraus ergibt sich in verschiedenerlei Hinsicht eine Verknüpfung von Fragestellungen der ersten drei Kapitel des zweiten Teils dieser Arbeit, indem etwa die Vorteile älterer Kohorten bei der Alterssicherung wie in Kapitel 7 vorgestellt und ihre niedrigen kindbedingten Leistungen (vgl. Kapitel 8) jeweils als Beitrag zur Nettobelastung des Lebenseinkommens dargestellt werden.

Da die besondere demographische Anfälligkeit der umlagefinanzierten Sozialversicherung einen Eckpfeiler in der Diskussion um eine intergenerativ ausgewogene Lastenverteilung bildet, werden abweichend vom sonstigen Vorgehen in dieser Arbeit in einer Berechnungsvariante auch die zu erwartenden Beitragssatzanstiege in der Kranken- und Pflegeversicherung berücksichtigt, um die sich abzeichnenden zukünf-

299 S. zur Methodik der Berechnung von Tragfähigkeitsindikatoren Sachverständigenrat zur Begutachtung der gesamtwirtschaftlichen Entwicklung (2003), S. 425ff 
tigen Mehrbelastungen in den Lebensnettosteuersätzen junger Kohorten möglichst umfassend abzubilden. Ein hiermit verbundenes zentrales Anliegen besteht in der vergleichenden Gegenüberstellung der Bedeutung verschiedener Elemente des Steuer-Transfer-Systems für die Belastung im Lebenszyklus. Dabei zeigt sich, dass die zukünftig zu erwartenden Anhebungen der Sozialversicherungsbeiträge weder im Vergleich zu ihrer historischen Entwicklung noch zu nicht unmittelbar demographieabhängigen Rechtsänderungen eine herausragende Größenordnung aufweisen. Anstehende Beitragssatzsteigerungen werden im intergenerativen Vergleich weitgehend über zukünftige Steuersenkungen kompensiert, womit die Umverteilung über die Sozialversicherung statt über das Steuersystem weiter an Bedeutung gewinnt. Nach den hier ermittelten Ergebnissen sind in den jüngeren Kohorten vor allem Personen mit Kindern sowie Bezieher höherer Einkommen relativ gering belastet.

Im ersten Teil dieses Kapitels wird zunächst die Methode der Generationenbilanzierung kurz besprochen, um darauf aufbauend den hier gewählten Ansatz der $\mathrm{Be}$ stimmung von Nettobelastungen sowie seine Beschränkungen vorzustellen. Das anschließende Unterkapitel umfasst eine Übersicht über Beitragssatzprojektionen zur Sozialversicherung und der für das STM hieraus entnommenen Annahmen zur zukünftigen Entwicklung. Außerdem werden die sich aus dem Übergang zur nachgelagerten Besteuerung von Alterseinkünften ergebenden Folgen für die steuerliche Belastung im Zeitverlauf diskutiert. Im darauf folgenden Teil werden dann die Ergebnisse der Berechnung von Lebensnettosteuersätzen vorgestellt, wobei die Einflüsse der einzelnen hier unterschiedenen Komponenten separat bestimmt werden. Das Kapitel schließt danach mit einer Gesamtbetrachtung ab.

\subsection{Ansätze intergenerativer Belastungsvergleiche}

\subsubsection{Generationenbilanzen und Lebensnettosteuersätze}

Die zu Beginn der 1990er Jahre entwickelte Methode der Generationenbilanzierung zielt darauf $a b$, angesichts steigender öffentlicher Verschuldung und sich abzeichnender Bevölkerungsalterung das Ausmaß der in die Zukunft verschobenen Belastungen über die explizite Staatsverschuldung hinaus zu quantifizieren. ${ }^{300} \mathrm{Im}$ Folgenden wird die Methode in ihren Grundzügen kurz unter den hier interessierenden Gesichtspunkten beschrieben, ohne auf diverse Varianten des Ansatzes einzugehen. ${ }^{301}$ Ihren ersten wesentlichen Baustein bilden Alters-Einnahmen- und Alters-AusgabenProfile der öffentlichen Haushalte, in denen Einnahmen und Ausgaben eines Basisjahres nach dem Alter der Zahler bzw. der Empfänger aufgeschlüsselt sind. Generationenkonten werden dann gebildet, indem für jedes Lebensalter zuerst die entrichteten Abgaben abzüglich der empfangenen Leistungen über die verschiedenen öffentlichen Haushalte summiert werden (Nettosteuerzahlung eines Lebensalters) und danach für jeden Geburtsjahrgang unter geeigneter Diskontierung diese Nettosteuerzahlungen für die noch zu durchlebenden Alter aufsummiert werden. Das Generatio-

${ }_{300} \mathrm{Vgl}$. die grundlegende Arbeit von Auerbach, Gokhale, Kotlikoff (1991)

301 S. für umfassendere Darstellungen des Ansatzes: Raffelhüschen (1999); Bonin (2001) 
nenkonto von Neugeborenen des Basisjahres enthält mithin den Barwert sämtlicher Nettosteuerzahlungen über einen gesamten Lebenszyklus unter Status QuoBedingungen, das Generationenkonto des höchsten betrachteten Alters hingegen nur die -regelmäßig negative- Nettosteuerzahlung eines einzelnen Lebensalters, nämlich des maximalen Todesalters. Wenn nun die Generationenkonten der lebenden Generationen addiert werden und für alle zukünftigen Generationen dieselben Nettosteuerzahlungen wie für die jüngste bereits lebende Generation angesetzt werden, wobei eine Bevölkerungsprojektion, das zweite Grundelement, der Gewichtung dient, ergibt sich als Gesamtsumme die implizite Staatsschuld. ${ }^{302}$ Diese Größe entspricht dem Barwert der zukünftigen staatlichen Ausgaben abzüglich der zu ihrer Deckung verfügbaren Einnahmen, wenn die Status Quo-Politik unbefristet beibehalten wird.

Im Kern handelt es sich bei einer Generationenbilanz somit um eine Status QuoProjektion der Fiskalpolitik unter einer alternden Bevölkerung. Die Bezeichnung der Summe aus dieser so bestimmten impliziten Staatsschuld und der expliziten (verbrieften) Staatsschuld als Tragfähigkeitslücke leitet sich dann aus der intertemporalen Budgetrestriktion der öffentlichen Hand als drittem Grundbaustein einer Generationenbilanz ab. Bei hinreichendem Zeithorizont stellt die Budgetgleichung eine Ex Post-Identität dar, langfristig müssen die Einnahmen den Ausgaben zuzüglich Ausgangsvermögen entsprechen. Neben der auch in der klassischen Budgetplanung ausgewiesenen expliziten Staatsschuld umfassen Tragfähigkeitslücken mithin vor allem zukünftige Verpflichtungen aus dem Steuer-Transfer-System als so genannte implizite Schulden, die etwa in Form zukünftiger Renten- oder Pensionsansprüche bestehen.

Verschiedene jüngere Schätzungen der Tragfähigkeitslücken für Deutschland bewegen sich in einer Größenordnung des 3,3-Fachen des Bruttoinlandsprodukts, womit sich bei einer expliziten Staatsschuld in Höhe von gut $60 \%$ die impliziten Schulden auf etwa $270 \%$ des Bruttoinlandsprodukts summieren. ${ }^{303}$ Die impliziten Schulden ergeben sich dabei überwiegend aus der umlagefinanzierten Sozialversicherung. Nach solchen Ergebnissen lässt sich die geltende Politik zumindest langfristig nicht aufrechterhalten, so dass entweder Einnahmen ausgeweitet oder Ausgaben eingeschränkt werden müssen. Eine positive Tragfähigkeitslücke dient so als Indikator für eine intergenerative Umverteilung zu Lasten zukünftiger Generationen. Wie bei langfristigen Prognosen üblich, hängen die Ausprägungen der $\mathrm{Er}$ gebnisse dabei zwangsläufig von zum Teil unsicheren Annahmen ab. Darüber hinaus ist bei der Generationenbilanzierung die Fokussierung auf ein Basisjahr zu beachten, dessen Verhältnisse als zukünftig dauerhaft konstant unterstellt werden, womit sich neben langfristigen Trends auch konjunkturelle Zyklen auf den Umfang von Tragfähigkeitslücken auswirken. ${ }^{304}$ Kurzfristige Entwicklungen können folglich, dem langfristigen Charakter des Ansatzes zuwiderlaufend, die Ergebnisse überlagern. So finden sich etwa für unter einheitlichen Analyserahmen erstellte Generati-

302 Äquivalent aber unter einem anderen Ablauf als hier beschrieben lässt sich die implizite Staatsschuld auch als Summe aller Primärdefizite herleiten. Vgl. für einen Überblick über die Methode Bonin, Patxot (2004).

${ }^{303}$ S. zu der Größenordnung von Tragfähigkeitslücken: Sachverständigenrat zur Begutachtung der gesamtwirtschaftlichen Entwicklung (2003), S. 276; Bundesministerium der Finanzen (2005a)

$304 \mathrm{Vgl}$. zum Problem konjunktureller Einflüsse und für um konjunkturelle Komponenten bereinigte Generationenbilanzen Manzke (2002). 
onenbilanzen mit den Basisjahren 2004 und 2005 Tragfähigkeitslücken von 324\% (2004) bzw. 276\% (2005) des Bruttoinlandsprodukts, wobei der Rückgang vor allem der konjunkturellen Entwicklung zugeschrieben wird. ${ }^{305}$ Um mit Hilfe von Generationenbilanzen eine langfristige politische Planung unterstützen zu können, die auf eine intergenerativ ausgewogene Umverteilung abzielt, sind entsprechend temporäre und dauerhafte Wirkungen von Politikoptionen zu trennen.

Grundsätzlich lassen Generationenbilanzen völlig offen, mit welcher Intervention und zu welchem Zeitpunkt der Diagnose fehlender Nachhaltigkeit zu begegnen ist. An Hand der intertemporalen Budgetrestriktion lassen sich allerdings verschiedene stilisierte Politikvarianten quantifizieren, über die sich die Tragfähigkeitslücke schließen lässt, wobei dauerhafte proportionale Anpassungen gängige Rechenvarianten bilden. Bei einer für Deutschland zum Basisjahr 2002 ermittelten Tragfähigkeitslücke von rund $330 \%$ des Bruttoinlandsprodukts entsprechen unter sonst gleichen Umständen sowohl eine sofortige und dauerhafte Kürzung aller Ausgaben um circa $12 \%$ als auch alternativ eine Erhöhung sämtlicher Einnahmen um gut $14 \%$ einer langfristig tragfähigen Finanzpolitik. ${ }^{306}$

Eine andere Form der "Umrechnung" von Tragfähigkeitslücken, die stärker den Aspekt intergenerativer Umverteilung herausstellt, besteht in der vergleichenden $\mathrm{Ge}-$ genüberstellung verschiedener Kohorten. Eine gängige Variante geht von dem Vergleich der Nettobelastungen der im Basisjahr Geborenen mit dem Wert für zukünftige Generationen aus. Dabei wird unterstellt, dass die Status Quo-Politik über den gesamten Lebenszyklus aller lebenden Generationen unverändert gilt, während für alle zukünftigen Generationen hingegen eine (konstante) nachhaltige Politikvariante angewandt wird. Es wird somit zur Illustration die Fiktion zweier disjunkter Zeiträume (oder Rechtsstände) für lebende und zukünftige Generationen bemüht, nach der die Schließung der Tragfähigkeitslücke ausschließlich zu Lasten zukünftiger Generationen erfolgt. Wenn dabei dann jede Generation durch eine Durchschnittsperson repräsentiert wird, lassen sich die Belastungen in Form von Lebensnettosteuersätzen (Lifetime Net Tax Rates) ausdrücken, definiert als Verhältnis der Barwerte von Steuer-Transfer-Saldo und Lebenseinkommen zum Geburtszeitpunkt:

$$
\text { Lebensnettosteuersatz } \quad=\quad \frac{\text { Barwert (Steuern }- \text { Transfers) }}{\text { Barwert Lebenseinkommen }}
$$

Es werden bei diesem Vorgehen somit zwei Lebensnettosteuersätze bestimmt, erstens der Wert für die jüngste lebende Kohorte, die vollständig unter Status QuoBedingungen weiterlebt, und zweitens ein einheitlicher und konstanter Steuersatz für alle zukünftigen Generationen, der Nachhaltigkeit im Sinne der intertemporalen Budgetrestriktion gewährleistet. Bei nach dieser Vorgehensweise ermittelten Lebensnettosteuersätzen sind Ergebnisse, die mindestens auf eine Verdoppelung der Abgabenquote für zukünftige Generationen hindeuten, nicht unüblich. ${ }^{307}$ Diese Lebens-

${ }^{305}$ S. Hagist, Raffelhüschen, Weddige (2006), S. 6; Hagist, Heidler, Raffelhüschen, Schoder (2007), S. 6 f

${ }^{306}$ Sachverständigenrat zur Begutachtung der gesamtwirtschaftlichen Entwicklung (2003), S. 276

307 Ausgehend vom Basisjahr 1996 gibt die Deutsche Bundesbank Lebensnettosteuersätze an von rund $28 \%$ für Neugeborene und $67 \%$ für zukünftige Generationen (Männer) bzw. von $16 \%$ und $38 \%$ (Frauen) (Deutsche Bundesbank (2001), S. 24). 
nettosteuersätze beschreiben jedoch keine realen Kohorten sondern illustrieren den bestehenden Anpassungsbedarf, wenn Mehrbelastungen willkürlich ausschließlich zukünftigen Generationen angelastet werden. Für alle vor dem Basisjahr geborenen Kohorten unterbleibt in der Regel die Bestimmung ihrer Lebensnettosteuersätze, da die hierzu erforderliche Aufschlüsselung der öffentlichen Budgets aus den bisher durchlebten Jahren einen enormen Datenbedarf mit sich bringt.

Generationenbilanzen folgen in ihren Grundzügen überwiegend dem skizzierten Aufbau und richten ihren Blick wie dargestellt ausnahmslos auf die zukünftige Entwicklung, eine Bewertung der Wirkungen des Steuer-Transfer-Systems vor dem Basisjahr lassen sie nicht zu. Aussagen, inwieweit das Steuer-Transfer-System verschiedene lebende Generationen im Lebenszyklus unterschiedlich behandelt, sind daher nicht möglich. Als Ausnahme bestehen einige so genannte retrospektive $\mathrm{Ge}-$ nerationenbilanzen, die auch historische Daten vor dem Basisjahr berücksichtigen. Ihre geringe Verbreitung dürfte vor allem dem Fehlen langer Zeitreihen hinreichend gegliederter Daten geschuldet sein. Während für Deutschland keine retrospektiven Bilanzen vorliegen, existieren für die USA mehrere derartige Berechnungen. ${ }^{308}$ Allerdings wurden die Daten der Vergangenheit dabei unter zum Teil sehr stark vereinfachenden Annahmen aufbereitet. ${ }^{309}$ In Tabelle 20 sind die in vier retrospektiven Generationenbilanzen mit verschiedenen Basisjahren ermittelten Lebensnettosteuersätze wiedergegeben. Zum einen sind zwei Untersuchungen von Auerbach, Gokhale und Kotlikoff $(1993,1995)$ aufgeführt, zum anderen zwei vom Congressional Budget Office $(1995,2000)$ publizierte Studien ${ }^{310}$ Auerbach, Gokhale und Kotlikoff (1995) finden in der jüngeren ihrer beiden Studien, die vom Basisjahr 1993 ausgeht, frühere Ergebnisse bestärkt, die auf eine massive Zunahme der Nettobelastungen für zukünftige Generationen hindeuten. Die ermittelten Lebensnettosteuersätze für zukünftige Generationen sind sogar noch von $71 \%$ (Basisjahr 1991) auf $84 \%$ (Basisjahr 1993) weiter gestiegen. Über die bereits lebenden Generationen ergeben sich in beiden Untersuchungen monoton wachsende Durchschnittsbelastungen in einem $\mathrm{Be}-$ reich von $22 \%$ bis $34 \%$ (Basisjahr 1991) bzw. $24 \%$ bis $34 \%$ (Basisjahr 1993). In den beiden anderen Studien, die sich untereinander ebenfalls in Hinblick auf Datengrundlagen und Methoden ähneln, weichen die Entwicklungen der Steuersätze über die Geburtsjahre hingegen markant voneinander ab. In der älteren der beiden Arbeiten mit dem Basisjahr 1990 liegt ein vergleichbarer monotoner Anstieg über die Kohorten wie bei Auerbach, Gokhale und Kotlikoff $(1993,1995)$ vor, ebenfalls steigt die Durchschnittsbelastung für zukünftige Generationen wiederum auf mehr als den doppelten Wert der jüngsten lebenden Generation (von $37 \%$ auf $78 \%$ ). In der Bilanz mit dem Basisjahr 1998 ergibt sich hingegen ein Rückgang der relativen Steuerbelastung über die jüngeren lebenden Kohorten (von 30\% beim Geburtsjahr 1970 auf $26 \%$ beim Geburtsjahr 1998). Zukünftige Generationen fallen ebenfalls in diesen Bereich,

${ }^{308}$ Außer für die USA liegt auch für Australien eine retrospektive Generationenbilanz vor. Ablett und Tseggai-Bocurezion (2000) ermitteln dort recht konstante Lebensnettosteuersätze von $37-39 \%$ für Geburtsjahrgänge seit der Mitte der dreißiger Jahre des letzten Jahrhunderts.

309

So wurde beispielsweise in einer Studie des Congressional Budget Office (1995) bei einem bis zum Jahr 1900 zurückgehenden Zeithorizont für die Jahre bis 1964 ein konstanter Altersschlüssel unterstellt.

310 Auerbach, Gokhale, Kotlikoff (1993, 1995); Congressional Budget Office (1995); Gokhale, Page, Potter, Sturrock (2000) 
ihr Lebensnettosteuersatz wird mit 29\% angegeben. Das Ausbleiben der Erwartung einer stark zunehmenden Belastung für zukünftige Generationen in der aktuelleren Berechnung führen die Autoren auf ein unerwartet starkes Wirtschaftswachstum in den 1990er Jahren zurück, kombiniert mit Ausgabenkürzungen im Verteidigungshaushalt. ${ }^{311}$

Tabelle 20: Lebensnettosteuersätze in den USA nach Geburtsjahr

\begin{tabular}{|c|c|c|c|c|}
\hline \multirow{2}{*}{ Geburtsjahr } & \multicolumn{4}{|c|}{ Basisjahr } \\
\cline { 2 - 5 } & $1991^{(7)}$ & $1993^{(2)}$ & $1990^{(3)}$ & $1998^{(4)}$ \\
\hline 1900 & $22 \%$ & $24 \%$ & $24 \%$ & $23 \%$ \\
1930 & $28 \%$ & $30 \%$ & $31 \%$ & $29 \%$ \\
1950 & $31 \%$ & $33 \%$ & $34 \%$ & $30 \%$ \\
1970 & $33 \%$ & $34 \%$ & $36 \%$ & $30 \%$ \\
Basisjahr & $34 \%$ & $34 \%$ & $37 \%$ & $26 \%$ \\
\hline Zukünftig & $71 \%$ & $84 \%$ & $78 \%$ & $29 \%$ \\
\hline Quellen: (1) Auerbach, Gokhale, Kotlikoff (1993), S. 8 \\
(2) Auerbach, Gokhale, Kotlikoff (1995), S. 8 \\
(3) Congressional Budget Office (1995), S. xi \\
(4) Gokhale, Page, Potter, Sturrock (2000), S. 7 \\
\hline
\end{tabular}

Während die konkrete Entwicklung der Lebensnettosteuersätze über die Geburtsjahre in den USA hier nicht weiter verfolgt werden soll, können die Ergebnisse aus Tabelle 20 wiederum an die enwähnte starke Abhängigkeit einer Generationenbilanz von ihrem Basisjahr erinnern, die hier die Einschätzung der erwarteten Belastungen für zukünftige Generationen massiv beeinflusst. Außerdem bleibt festzuhalten, dass ein Vergleich der Wirkungen des Steuer-Transfer-Systems auf verschiedene bereits lebende Generationen nur an Hand retrospektiver Generationenbilanzen möglich ist, die jedoch auf Grund der enormen Datenerfordernisse insgesamt nur selten und für Deutschland bisher gar nicht durchgeführt wurden.

\subsubsection{Verknüpfung bestehender Ansätze im STM}

Generationenbilanzen haben sich zu einem bevorzugten Ansatz entwickelt, Implikationen einer alternden Bevölkerung für die öffentlichen Haushalte zu untersuchen. Daneben existieren zu diesem Thema vor allem Arbeiten zu einzelnen Zweigen der umlagefinanzierten Sozialversicherung, deren Abhängigkeit von der Altersstruktur besonders deutlich ist. Hierzu zählen unter anderem Analysen zur Rentenversicherung wie in Kapitel 7 dieser Arbeit. Ein wesentliches Element dieser Ansätze bilden Beitragssatzprojektionen, die mögliche Entwicklungspfade unter den zukünftigen demographischen Restriktionen aufzeigen. Bei einigen markanten Unterschieden zwischen dieser Art der Projektionen und Generationenbilanzen bestehen in zentralen Punkten jedoch auch Gemeinsamkeiten. Im einfachsten Fall liegen jeweils statische Alters-Einnahmen- und Alters-Ausgaben-Profile zu Grunde, die mit

311 Gokhale, Page, Potter, Sturrock (2000), S. 1 
enwarteten zukünftigen Kohortenstärken multipliziert werden, um darauf aufbauend zukünftige Defizite zu ermitteln.

Auch wenn zur Verfeinerung ergebnisrelevante Fortschreibungsparameter wie gesamtwirtschaftliche Wachstumsraten oder Erwerbsquoten exogen variiert werden, handelt es sich im Kern jeweils um statische Modelle ohne makroökonomische Rückkopplung, die sich im wesentlichen auf die Ermittlung eines Demographieeffekts unter ceteris paribus- Bedingungen beschränken. Ein Hauptunterschied zwischen den beiden Methoden besteht im Umgang mit sich abzeichnenden Defiziten. Während bei der Generationenbilanzierung auf die intertemporale Budgetrestriktion abgestellt wird, greifen Beitragssatzprojektionen auf den für Umlageverfahren charakteristischen permanenten Budgetausgleich zurück, der für jede Periode die Übereinstimmung von Einnahmen und Ausgaben vorsieht, ohne dass eine Verschuldungsoption besteht. Besonders deutlich wird die Überführbarkeit der beiden Ansätze durch Generationenbilanzen, die isoliert für einzelne öffentliche Haushalte aufgestellt werden und unter anderem für die Renten-, Kranken- und Pflegeversicherung vorliegen. $^{312}$ Ergebnisse dieser Berechnungen sind Tragfähigkeitslücken für die einzelnen Versicherungszweige, die sich bei konstanten (oder gegebenenfalls auch modifizierten) Beitragssätzen ergeben. Die Tragfähigkeitslücken in einer Größenordnung des etwa dreifachen des Bruttoinlandsprodukts stammen nach diesen Zusammenstellungen überwiegend aus Renten-, Kranken- und Pflegeversicherung, die zusammen ungefähr zwei Drittel der Tragfähigkeitslücke verursachen.

Im Gegensatz hierzu streben Beitragssatzprojektionen gerade das Ziel an, eine Politikvariante aufzuzeigen, die Nachhaltigkeit gewährleistet, nämlich diejenige, die einen permanenten Budgetausgleich bewirkt (gegebenenfalls auch unter Einbezug exogener (Bundes-)Zuschüsse). Demographischer Druck schlägt sich in der Sichtweise der Generationenbilanzierung mithin in einer Tragfähigkeitslücke nieder, aus der Perspektive von Beitragssatzprojektionen hingegen in Form von Beitragssatzerhöhungen.

Ein Vorteil der Generationenbilanzierung im Vergleich zu Beitragssatzprojektionen besteht in ihrer umfassenderen Betrachtung. Zum einen ist sie nicht auf eine Zuordnung von Einnahmen zu Ausgaben angewiesen sondern lässt im Sinne des Nonaffektationsprinzips Verschiebungen zwischen Haushalten zu. Zum anderen führt gerade der Verzicht auf einen -abseits der umlagefinazierten Systeme unrealistischen- permanenten Budgetausgleich dazu, zukünftige Verschuldung in Relation zu bestehenden Schulden quantifizieren zu können. Ein hiermit verbundener Nachteil ist, dass für Generationenbilanzen als zusätzliche Annahme eine Projektion der Zinsentwicklung erforderlich ist, von der nicht unerhebliche Effekte auf die Ergebnisse ausgehen können. Ein weiterer Nachteil ist empirischer Natur, die Erstellung von Altersschlüsseln für möglichst sämtliche öffentliche Haushalte kommt selbst bei großem Analyseaufwand kaum ohne dezisionistisch anmutende Zuordnungen aus. Schließlich bleibt als Kehrseite einer ausgeprägten Verallgemeinerung eine notwendigerweise recht starke Abstraktion. Diese macht sich unter anderem dann bemerkbar, wenn Tragfähigkeitslücken nicht nur generell geschlossen werden sollen, sondern wenn dabei auch Kriterien einer intergenerativen Ausgewogenheit angelegt werden sollen. Wie oben beschrieben richten Generationenbilanzen in aller Regel ihren Blick ausschließlich in die Zukunft, weshalb üblichenweise generative Unter-

${ }^{312}$ S. Hagist, Heidler, Raffelhüschen, Schoder (2007) 
schiede nur sehr abstrakt zwischen bereits lebenden und zukünftigen Generationen bestimmt werden. Eine Differenzierung zwischen einzelnen lebenden Kohorten unterbleibt. In Hinblick auf intergenerative Belastungsvergleiche lassen sich die Vorteile der umfassenden Abbildung der Finanzpolitik somit nur eingeschränkt nutzen.

Auf Beitragssatzprojektionen und auf innen aufbauende Analysen -wie die Renditeberechnungen zur Rentenversicherung in Kapitel 7- treffen in mehrerlei Hinsicht genau gegenteilige Aussagen zu. An die Stelle einer umfassenden Abbildung der öffentlichen Haushalte tritt eine Fokussierung auf ein Teilsystem. Reformeffekte werden nicht nur global sondern sehr konkret für einzelne Geburtsjahrgänge beziffert; ein Beispiel bilden Renditeverschiebungen wie in Kapitel 7 dargestellt, an Hand derer Gewinner und Verlierer einzelner Maßnahmen identifiziert werden. Rentenkonten sind darauf ausgerichtet, für alle Jahrgänge vollständige Lebensbilanzen zu erfassen, indem auf innen nicht nur die zukünftigen sondern auch die historischen Zahlungen verbucht werden.

Die bestehenden Ansätze weisen entsprechend spezifische Vor- und Nachteile auf, wenn intergenerative Unterschiede in den Wirkungen des Steuer-Transfer-Systems herausgearbeitet werden sollen. Entweder fehlen retrospektive Daten, so dass empirisch gestützte Vergleiche einzelner lebender Kohorten nicht möglich sind, oder es wird nur ein Teilsystem untersucht, so dass mögliche Verschiebungen zwischen Haushalten (wie etwa zwischen Renten- und Arbeitslosenversicherung) ausgeblendet bleiben. Als gemeinsamer Kritikpunkt an beiden Ansätzen kommt die Verdichtung von Generationen auf einen einzigen Durchschnittswert hinzu, wodurch von intragenerativen Unterschieden etwa zwischen Einkommensniveaus oder Familientypen abstrahiert wird. ${ }^{313}$ In diesem Kapitel werden diese Probleme aufgegriffen, indem in Analysen mit dem STM eine Position zwischen den beiden Polen der Generationenbilanzierung und der Analyse einzelner Zweige der Sozialversicherung eingenommen wird. Dabei werden auch intragenerative Unterschiede bestimmt, die wie üblich auf qualifikationsabhängigen Lebenseinkommen beruhen ( $\mathrm{vgl}$. Kapitel 3). Die Charakterisierung als Zwischenposition rührt daher, dass erstens wie bei der $\mathrm{Be}$ stimmung von Renditen der Rentenversicherung in Kapitel 7 die relevanten Zahlungsreihen auch retrospektiv über die kompletten Lebenszyklen abgebildet werden. Zweitens gehen die Zahlungsreihen über die rentenversicherungsinduzierten Beträge hinaus und umfassen weitere Steuern und Transfers. Als Ergebnisgröße dienen die aus der Generationenbilanzierung bekannten Lebensnettosteuersätze, definiert als Anteil der Nettosteuern am Lebenseinkommen. Der Begriff der Steuern ist, wie im hier gegebenen Kontext üblich, weit gefasst und schließt auch die Beiträge zur Sozialversicherung ein. Eine Berechnungsgrundlage ist dabei die grundlegende Darstellung des Barwerts des verfügbaren Lebenseinkommens $L E K$ in Abhängigkeit von Qualifikation $q$ und Geburtsjahr $j$ im STM:

${ }^{313}$ Vgl. Färber (2006), S. 26. Für eine Ausnahme mit nach Einkommensniveaus differenzierten Generationenkonten s. Fehr, Halder (2005), S. 23. 


$$
\begin{aligned}
\operatorname{LEK}(q, j, m)= & \sum_{t=t_{t,}}^{t_{t}-1}\left[\hat{y}(q, t, j)-T_{t}\left(\hat{y}(q, t, j), m_{t}\right)+S_{t}\left(\hat{y}(q, t, j), m_{t}\right)\right]^{*}(1+z)^{-t} \\
& \left.+\sum_{t=t_{t^{\prime}}}^{t_{t}^{*}} R_{t}(q, t, j, m)-T_{t}\left(R_{t}(q, t, j, m), m_{t}\right)+S_{t}\left(R_{t}(q, t, j, m), m_{t}\right)\right]^{*}(1+z)^{-t}
\end{aligned}
$$

mit $\hat{y} \quad$ geschätzter Bruttolohn

$m$ Merkmalsvektor (Familienstand, Anzahl von Kindern ...)

$T_{t}[.$.$] Abgabenfunktion$

$S_{t}[.$.$] Transferfunktion$

$R_{t}[.$.$] Rentenfunktion$

$t_{E} \quad$ Renteneintrittsalter

$t_{N} \quad$ Todesalter

$z \quad$ Zinssatz

Das verfügbare Lebenseinkommen setzt sich zusammen erstens aus den Bruttolöhnen abzüglich der auf sie zu entrichtenden Abgaben (Einkommen- und Zuschlagsteuern, Sozialversicherungsbeiträge) zuzüglich (kindbedingter) Transfers und zweitens aus den Nettorenten zuzüglich Transfers in der Rentenphase. Als (Brutto-)Lebenseinkommen, das bei Lebensnettosteuersätzen den Nenner bildet, wird der Barwert der Bruttolöhne $Y$ herangezogen:

$Y(q, j, m)=\sum_{t=t_{t \mid}}^{t_{t}+1} \hat{y}(q, t, j)^{*}(1+z)^{\prime}$

Der Lebensnettosteuersatz $L$ entspricht damit:

$$
L(q, j, m)=1-\operatorname{LEK}(q, j, m) / Y(q, j, m)
$$

Die Markteinkommen als Grundlage der Besteuerung bestehen folglich ausschließlich aus Bruttolöhnen. Rentenbeiträge werden wie Steuern behandelt, Renten wie sonstige Transfers, die Beziehung zwischen Beiträgen und Leistungen ist hierbei irrelevant. In dieser Darstellung der Lebensnettosteuersätze gehen die Arbeitgeberbeiträge zur Sozialversicherung nicht in die Berechnung ein, die Belastungsquote reflektiert somit die Relation von Netto- und Bruttoeinkommen, wie sie bei Betrachtungen auf der Basis von Jahresdaten gebräuchlich ist. Die im Folgenden präsentierten Ergebnisse beziehen sich regelmäßig auf in dieser Form berechnete Lebensnettosteuersätze. Allerdings kann der Ausschluss der Arbeitgeberanteile vor allem dann verzerrend wirken, wenn der Anteil der Sozialversicherungsbeiträge an den Abgaben im Zeitverlauf stetig zunimmt, wie dies in Deutschland der Fall ist. In einer ergänzenden Variante werden daher später zusätzlich Nettobelastungsquoten angegeben, die sich statt auf den Bruttolohn auf die die Arbeitgeberanteile einschließenden Arbeitskosten beziehen, um auch die hiervon ausgehenden Effekte aufzuzeigen. ${ }^{314}$

314 Deutlich wird die Bedeutung der Frage nach einer angemessenen Zuordnung der Arbeitgeberbeiträge auch, wenn eine implizite Einkommensteuer als Indikator der Verteilungswirkungen der Rentenversicherung bestimmt wird. Als implizite Einkommensteuer gilt in diesem Zusammenhang die 
Dieser Ansatz der Berechnung von Lebensnettosteuersätzen mit dem STM deckt sich grundsätzlich mit dem entsprechenden Vorgehen bei einer Generationenbilanzierung. Ein Hauptunterschied besteht im Umfang der einbezogenen öffentlichen Einnahmen und Ausgaben. Das STM bildet nur einen vergleichsweise kleinen Ausschnitt der öffentlichen Haushalte ab, Generationenbilanzen sind hingegen um eine wesentlich umfangreichere Erfassung bemüht. Allerdings deutet bereits die Verwendung der Größe des Lebensnettosteuersatzes auf die auch dabei verbleibende Begrenztheit der Analyse hin. Im Fall einer vollständigen Abbildung der Ausgaben- und Einnahmeinzidenzen stehen Steuerzahlungen stets in gleichem Umfang Transfers gegenüber, langfristig muss -zumindest in einer geschlossenen Volkswirtschaft- der durchschnittliche Lebensnettosteuersatz bei einer Vollerfassung der Fiskalpolitik null betragen. Einzelne Generationen können zwar positive Nettosteuersätze aufweisen (was dann auf eine intergenerative Umverteilung zu ihren Lasten hindeutet), diese Nettozahlungen müssen jedoch auch einem Empfänger zu Gute kommen, so dass dann zwingend gleichzeitig Generationen mit negativen Lebensnettosteuersätzen existieren müssen. Durchgängig positive Lebensnettosteuersätze, wie sie im Rahmen von (retrospektiven) Generationenbilanzierungen regelmäßig ermittelt werden, verdeutlichen somit, dass auch dort nicht sämtliche Inzidenzen offentlicher Einnahmen und Ausgaben erfasst sind.

Für die im Folgenden aufgeführten, mit dem STM bestimmten Lebensnettosteuersätze gilt durch dessen relativ kleinen Ausschnitt des Steuer-Transfer-Systems in verstärktem Maße, dass die Werte nicht als vollständige Bilanz der geleisteten und empfangenen Zahlungen repräsentativer Individuen zu verstehen sind. Unvollständig ist die Erfassung im STM unter anderem auf Grund der Beschränkung auf ausgewählte direkte Steuern und monetäre Transfers, wodurch etwa intergenerative Unterschiede, die aus Verschiebungen zwischen direkten und indirekten Steuern resultieren können, im STM nicht erfasst sind. Mit dem STM bestimmte Lebensnettosteuersätze sind auch nicht als konkurrierende Werte zu aus Generationenkonten abgeleiteten Ergebnissen zu begreifen. Primär erscheinen sie geeignet, einige sich abzeichnende intergenerative Belastungsunterschiede in Relation zum Lebenseinkommen auszudrücken, ohne sich auf einzelne Zweige der sozialen Sicherungssysteme zu beschränken. Zudem zeigt die intragenerative Differenzierung auf, inwieweit sich die Entwicklung für verschiedene Einkommensniveaus und Familientypen unterscheidet.

Ein zweiter wesentlicher Unterschied zwischen diesem Ansatz des STM und Generationenbilanzen besteht im Umgang mit sich abzeichnenden zukünftigen Finanzierungsdefiziten. Das STM greift wie einleitend erwähnt grundsätzlich auf eine Status Quo-Projektion zurück, bei der abgesehen vom Rentenversicherungssystem die Parameter des Jahres 2007 für die Zukunft fixiert werden. Ob diese Politikvariante nachhaltig ist oder ob sie längerfristig nicht aufrechterhalten werden kann, bleibt dabei unberücksichtigt. In dieser Hinsicht ähnelt die Vorgehensweise dem oben skiz-

Differenz der Barwerte von Beiträgen und Renten, dividiert durch den Barwert des Bruttolebenseinkommens. Wie bei Betrachtungen zur Rentenversicherung angemessen, umfassen die Beiträge sowohl die Arbeitgeber- als auch die Arbeitnehmeranteile. Wenn nun das Bruttolebenseinkommen ohne die Arbeitgeberbeiträge den Nenner der impliziten Einkommensteuer bildet, ist das $M a ß$ in dem Sinne inkonsistent, dass die Arbeitgeberbeiträge einerseits Einkommensbestandteil sind (nämlich im Zähler) andererseits jedoch nicht (im Nenner). S. zur impliziten Einkommensteuer Thum, Weizsäcker (2000) 
zierten Vorgehen, für Generationenkonten bereits lebender Generationen den Fortbestand der Status Quo-Bedingungen zu unterstellen (und Tragfähigkeitslücken gegebenenfalls ausschließlich zu Lasten zukünftiger Generationen zu schließen). Vor allem für die umlagefinanzierte Sozialversicherung ist jedoch nicht von einem Fortbestand der Status Quo-Parameter auszugehen. Für einen realitätsnäheren Vergleich der mutmaßlichen Abgabenbelastungen verschiedener Kohorten werden daher im Folgenden die Ergebnisse verschiedener Beitragssatzprojektionen zur Sozialversicherung aufgegriffen und in einem alternativen Zukunftsszenario zu Grunde gelegt. Im folgenden Unterkapitel werden die diesbezüglichen Annahmen für das Alternativszenario vorgestellt. Bei der Besteuerung wird weiterhin wie bisher ausschließlich das geltende Recht zu Grunde gelegt werden, das vor allem durch die mit dem Alterseinkünftegesetz implementierten Übergangsregelungen einige zukünftige Veränderungen vorsieht. Deren Implikationen für die Steuerbelastung verschiedener Kohorten werden ebenfalls im folgenden Unterkapitel angesprochen.

\subsection{Zukünftige Entwicklung: Annahmen im STM}

\subsubsection{Sozialversicherung: Zwei Szenarien}

Wie im einleitenden Kapitel dieser Arbeit erwähnt, greift das STM bei in die Zukunft reichenden Berechnungen zum einen auf die Annahmen der Rürup-Kommission zurück, zum anderen wird der Rechtsstand 2007 fixiert (s. Kapitel 2.1). In Hinblick auf Einnahmen und Ausgaben der Rentenversicherung beruhen die Parameter damit auf aufeinander abgestimmten Annahmen zur wirtschaftlichen und demographischen Entwicklung. Für die anderen Zweige der Sozialversicherung sind hingegen die Beitragssätze auf dem Stand des Jahres 2007 fixiert, ohne zu berücksichtigen, dass die demographische Entwicklung diese Setzung unrealistisch erscheinen lässt. In den bisherigen Lebenszyklusbetrachtungen des zweiten Teils erscheint diese Einschränkung hinnehmbar, da entweder die hiervon nicht betroffene Rentenversicherung betrachtet wurde (Kapitel 7) oder nicht das Niveau der Abgabenbelastung als solches analysiert wurde, sondern Differenzen zwischen Personen unterschiedlicher Qualifikation (Kapitel 6) oder unterschiedlicher Kinderzahl (Kapitel 8) im Vordergrund standen. Für einen Vergleich der Lebensnettosteuersätze verschiedener Geburtsjahre auf Basis der bisherigen Annahmen zeichnet sich jedoch eine Verzerrung zu Ungunsten jüngerer Kohorten ab. Im Folgenden wird daher nun zweigeteilt vorgegangen: Erstens bleiben in einem Szenario / die Zukunftsparameter dieselben wie in den bisherigen Kapiteln. Die auf dieser Grundlage ermittelten Ergebnisse zeigen für die jüngeren Kohorten eine Untergrenze der Abgabenbelastung an, die sich aus der Status Quo-Politik unter Erfassung der Entwicklungen im Rentensystem abzeichnet. Zweitens werden in einem Szenario // Beitragssatzprojektionen zur Krankenund Pflegeversicherung aufgegriffen, die unter anderem den demographischen Druck auf diese Systeme berücksichtigen. Dieses zweite Szenario basiert auf höheren Sozialversicherungsbeitragssätzen, seine Ergebnisse sollen dadurch eine realitätsnähere Abbildung der mutmaßlichen Belastung der Lebenseinkommen jüngerer Kohorten vermitteln. Die Differenz von Lebensabgabenquoten zwischen den beiden 
Szenarien reflektiert den Einfluss sich abzeichnender Beitragssatzanstiege bei Kranken- und Pflegeversicherung auf das Lebenseinkommen verschiedener Kohorten. Wie oben beschrieben ergeben sich die aus Generationenbilanzen bekannten Tragfähigkeitslücken der Status Quo-Regelungen überwiegend aus der umlagefinanzierten Sozialversicherung. Indem in Szenario II für Renten-, Kranken- und Pflegeversicherung permanent budgetausgleichende Beitragssätze vorgegeben werden, sind diese Tragfähigkeitslücken über die Beitragssatzanstiege dort folglich weitgehend geschlossen. Die im Szenario II bestimmten Lebensnettosteuersätze umfassen somit einen Großteil der aus Generationenbilanzen bekannten Mehrbelastungen junger Kohorten.

Neben der gesetzlichen Rentenversicherung bilden die Kranken- und Pflegversicherung zwei weitere Zweige der umlagefinanzierten Sozialversicherung mit einer ausgeprägten Demographieabhängigkeit. Während die Rentenversicherung durch die relative Beitragsäquivalenz grundsätzlich intragenerativ neutral ausgerichtet ist (vgl. jedoch kritisch hierzu Kapitel 7.1.2), ist für die Krankenversicherung mit ihren einkommensabhängigen Beiträgen bei einheitlichen Leistungen eine intragenerative Umverteilung von hohen zu niedrigen Einkommen konstituierend. Eine zweite Form intragenerativer Umverteilung besteht zwischen Alleinstehenden und Familien, die aus der beitragsfreien Mitversicherung von Familienangehörigen folgt. Darüber hinaus kann sich aus der Altersabhängigkeit von Einnahmen und Ausgaben unter einer alternden Bevölkerung zusätzlich eine intergenerative Umverteilung ergeben, die durch medizinischen Fortschritt noch verstärkt werden kann. Auf der Makroebene äußert sich intergenerative Umverteilung in einem zunehmenden Ausgleich zwischen den beiden Teilsystemen der gesetzlichen Krankenversicherung, der allgemeinen Krankenversicherung (AKV) einerseits, die weitgehend die Erwerbsbevölkerung einschließlich Familienangehöriger sichert, und der Krankenversicherung der Rentner (KVdR) andererseits. Nicht nur die Entwicklung der Versichertenzahlen in den beiden Teilsystemen sondern auch der durchschnittlichen Ausgaben weist dabei auf einen zunehmenden Transfer zwischen den beiden Zweigen hin. Während zu Beginn der 1970er Jahre die durchschnittlichen Leistungsausgaben je Mitglied in der KVdR um rund $10 \%$ den entsprechenden Durchschnitt der AKV überschritten, liegen sie in den letzten Jahren um mehr als $90 \%$ über dem Wert der AKV. ${ }^{315}$ Die Beiträge von Personen im Ruhestandsalter decken derzeit etwa die Hälfte der für sie aufgewandten Leistungsausgaben ab, die andere Hälfte wird von Mitgliedern im Erwerbsalter aufgebracht. ${ }^{316}$

Verschiedene Prognosen zur gesetzlichen Krankenversicherung kommen übereinstimmend zu weiterhin deutlichen Anstiegen der Beitragssätze über die nächsten Jahrzehnte, die im Wesentlichen auf den beiden Faktoren beruhen, die auch die zurückliegende Beitragssatzentwicklung beeinflussten. ${ }^{317}$ Zum einen wächst mit dem Einkommen und dem medizinisch-technischen Fortschritt der Anteil der Ausgaben, der auf den Gesundheitsbereich entfällt, und dieser steigende Trend der Vergangen-

${ }^{315}$ Vgl. zu den Zahlen Sachverständigenrat zur Begutachtung der gesamtwirtschaftlichen Entwicklung (2007), S. 107*

${ }^{316}$ S. Sachverständigenrat zur Begutachtung der gesamtwirtschaftlichen Entwicklung (2005), S. 349, S. 351

317 S. etwa Breyer, Grabka, Jacobs, Meinhardt, Ryll, Schulz, Spieß, Wagner (2001), S. $51 \mathrm{ff}$ 
heit wird in die Zukunft fortgeschrieben. ${ }^{318}$ Zum anderen wirkt eine alternde Bevölkerung auf Grund der Demographieabhängigkeit des Umlageverfahrens beitragssatzerhöhend. Ein steigender Altenquotient übt dabei auf Grund der deutlich höheren Pro-Kopf-Ausgaben für ältere Versicherte zusätzlichen Druck auf die Beitragssätze der Krankenversicherung aus. Zu den Auswirkungen einer höheren Lebenserwartung existieren mit der Medikalisierungs- und der Kompressionsthese zwei alternative Modellierungen. Nach der Medikalisierungsthese ist von einem weiteren überproportionalen Anstieg der Pro-Kopf-Ausgaben für ältere Versicherte auszugehen. Nach der Kompressionsthese treten hingegen grundsätzlich zum Lebensende hin die höchsten Kosten auf, so dass bei einer steigenden Lebenserwartung die Anzahl der kostenintensiven Jahre nicht weiter zunimmt. ${ }^{319}$

Ausgehend von einer Bevölkerungsprojektion und fortgeschriebenen Alters-Ausgaben- sowie Alters-Einnahmen-Profilen als üblichen Grundbausteinen, zeigen sich je nach Konkretisierung der Annahmen zu den beiden Komponenten der Demographie und des medizinischen Fortschritts deutliche Spannweiten zwischen den in verschiedenen Studien prognostizierten Beitragssatzpfaden. Als Ergebnisse reiner Demographie-Szenarien, in denen allein Altersstrukturverschiebungen wirksam werden, finden sich für das Jahr 2050 Beitragssätze, die überwiegend in einem Bereich von etwa $16 \%$ bis $21 \%$ liegen. Wenn von zusätzlichen Ausgabensteigerungen auf Grund des medizinisch-technischen Fortschritts ausgegangen wird, nehmen sowohl das Niveau als auch die Streuung der prognostizierten Werte zu, für 2050 finden sich Angaben im Intervall von etwa $23 \%$ und bis zu $39 \% .{ }^{320}$ Wenn wie hier ein zukünftiger Beitragssatzpfad zur Bestimmung von Lebensnettosteuersätzen gesucht ist, bieten die in der Literatur vertretenen Werte folglich eine erhebliche Spannweite, die je nach getroffener Auswahl die späteren Schlussfolgerungen maßgeblich beeinflussen kann. Da sich die den Modellen mit medizinisch-technischem Fortschritt zu Grunde liegende Setzung einer dauerhaft überdurchschnittlichen Wachstumsrate der Gesundheitsausgaben langfristig logisch zwingend und mittelfristig mutmaßlich politisch nicht aufrechterhalten lässt, orientiert sich die Auswahl an den reinen Demographieprojektionen. Hier wird in Anlehnung an Ergebnisse von Fetzer (2005) für das Szenario II ein Beitragssatzpfad gewählt, der bis zum Jahr 2055 steigt und von da an bei einem Wert von $19,5 \%$ stagniert. Innerhalb der nur die Demographie berücksichtigenden Projektionen, die für das Jahr 2050 die enwähnte Spanne von 16\% bis $21 \%$ aufweisen, bewegt sich diese Setzung im oberen, jedoch nicht im höchsten Bereich.

Prognosen zur Pflegeversicherung beruhen im Wesentlichen auf ähnlichen Ansätzen wie bei der Krankenversicherung, allerdings entfällt eine fortschrittsinduzierte Kostensteigerung, so dass die Beitragssätze weitgehend von der demographischen Entwicklung determiniert werden. Daneben bestehen jedoch Freiheitsgrade bei der Quantifizierung, in welchem Umfang der Gesetzgeber die nach § 30 SGB XI vorgesehene Dynamisierung von Versicherungsleistungen nutzt. Unter von der Rürup-

${ }^{318}$ Die Beobachtung einer überproportionalen Ausgabensteigerung im Gesundheitsbereich wird üblicherweise in Form eines Wachstumsdifferentials ausgedrückt. Ein für Deutschland wiederholt herangezogener Wert stammt aus einer Arbeit von Breyer und Ulich (2000), nach deren Ergebnissen die Wachstumsrate für Gesundheitsausgaben als Folge des medizinisch-technischen Fortschritts die gesamtwirtschaftliche Wachstumsrate um einen Prozentpunkt übersteigt.

319 Vgl. Fetzer (2005)

320 Vgl. die Überblicke in: Cassel (2005), S. 8; Fetzer (2005), S. 26f; Postler (2003), S. 30 
Kommission getroffenen Annahmen steigt der Beitragssatz zur Pflegeversicherung bis zum Jahr 2040 demographiegetrieben auf 3,0\%. ${ }^{321}$ Häcker (2006) kommt zu Beitragssätzen, die je nach Dynamisierung im Jahr 2040 zwischen gut $3 \%$ und knapp 5\% liegen und bis zum Jahr 2060 auf mindestens knapp 4\% und bis zu rund 7,5\% steigen. ${ }^{322}$ In Anbetracht der bisher unterbliebenen Anpassung der Leistungen der Pflegeversicherung an die Preisniveauentwicklung wird für das Szenario II von einer weiterhin eher zurückhaltenden Dynamisierung ausgegangen, die in Anlehnung an die Ergebnisse Häckers (2006) für Szenario II einen Anstieg des Beitragssatzes auf 3,9\% bis zum Jahr 2060 umfasst, ab dann verharrt der Wert auf diesem Niveau.

Während sich die demographische Entwicklung recht eindeutig auf die Beitragssatzentwicklung von Kranken- und Pflegeversicherung auswirkt, erscheint die Arbeitslosenversicherung zwar ebenfalls nicht demographieresistent, die Zusammenhänge sind jedoch unklarer. Grundsätzlich sprechen die prognostizierten Rückgänge der Erwerbsbevölkerung hier für ein Beitragssatzsenkungspotential, dessen Umfang und zeitliche Entwicklung allerdings schwerlich zu beziffern sind. Nach der Herabsetzung von $6,5 \%$ auf $4,2 \%$ ab 2007 gilt seit 2008 ein erneut gesenkter Beitragssatz von $3,3 \%$. Szenario II, dem zukünftig steigende Beitragssätze zur Kranken- und Pflegeversicherung zu Grunde liegen, greift diesen Wert auf und geht für die Jahre ab 2008 von einem konstanten Beitragssatz von 3,3\% aus, was in Anbetracht der aktuellen Planung und der demographiebedingten tendenziellen Entspannung im Bereich der Arbeitslosenversicherung für dieses Zukunftsszenario angemessen erscheint. Für Szenario I bedeutet die Fixierung des Rechtsstandes 2007 hingegen weiterhin die Annahme eines zukünftigen Beitragssatzes von durchgehend 4,2\%.

Für die Beiträge zur Sozialversicherung insgesamt ergibt sich in den Jahren ab 2008 zunächst in Szenario II die geringere Abgabenbelastung, die von dem niedrigeren Beitrag zur Arbeitslosenversicherung herrührt (Abbildung 86). In den Jahren bis 2016 schließt sich dann die Lücke durch die Beitragssatzanstiege in der Kranken- und Pflegeversicherung gemäß Szenario II. In Szenario I bleibt die Abgabenquote ab dem Jahr 2040 konstant bei 22,4\% (Arbeitnehmeranteil) gegenüber $20,7 \% \mathrm{im}$ Jahr 2007, die Anstiege im Zeitraum bis 2040 folgen aus den Rentenversicherungsbeiträgen. In Szenario II verstärken die Anpassungen in der Kranken- und Pflegeversicherung die Zunahme der Abgabenquote, so dass für das Jahr 2040 ein Arbeitnehmeranteil von $24,5 \%$ resultiert. Bis 2060 steigen die Beitragssätze dann weiter an bis auf einen Wert von $25,2 \%$, der ab dann beibehalten wird. Die Setzung konstanter Beitragssätze ab 2060 erscheint nach verschiedenen Prognosen zu den einzelnen Versicherungszweigen nicht unangemessen, da demographische Faktoren ab dann nur noch zu recht geringen Veränderungen führen. ${ }^{323}$ Die Arbeitnehmeranteile in den beiden Szenarien unterscheiden sich folglich um bis zu 2,8 Prozentpunkte, die Beitragssätze einschließlich der Arbeitgeberanteile mithin um den doppelten Wert von 5,6 Prozentpunkten (in den Jahren ab 2060). Wie dargelegt ließen sich aus der Literatur auch stärkere Abgabenanstiege begründen, ohne jedoch dass die in Szenario II

${ }^{321}$ Bundesministerium für Gesundheit und Soziale Sicherung (Hrsg.) (2003), S. 205

322 Häcker (2006), S. 11 f

${ }^{323}$ Auch Ergebnisse von Fehr und Halder (2005), die sie auf der Grundlage eines gesamtwirtschaftlichen Gleichgewichtsmodells ermitteln, stützen die Setzung weitgehend konstanter Beitragssätze in der zweiten Hälfte des 21. Jahrhunderts. 
angenommene Entwicklung unangemessen optimistisch erscheint. Mit Werten von über 50\% (Arbeitgeber- und Arbeitnehmeranteile) liegt die Sozialversicherungsquote des Szenarios II in den Jahren ab 2050 um gut vier Prozentpunkte über dem Niveau, das etwa in Modellrechnungen des Bundesministeriums der Finanzen angesetzt wurde. $^{324}$

Abbildung 86: Beitragssätze zur Sozialversicherung in zwei Szenarien (Arbeitnehmeranteile)

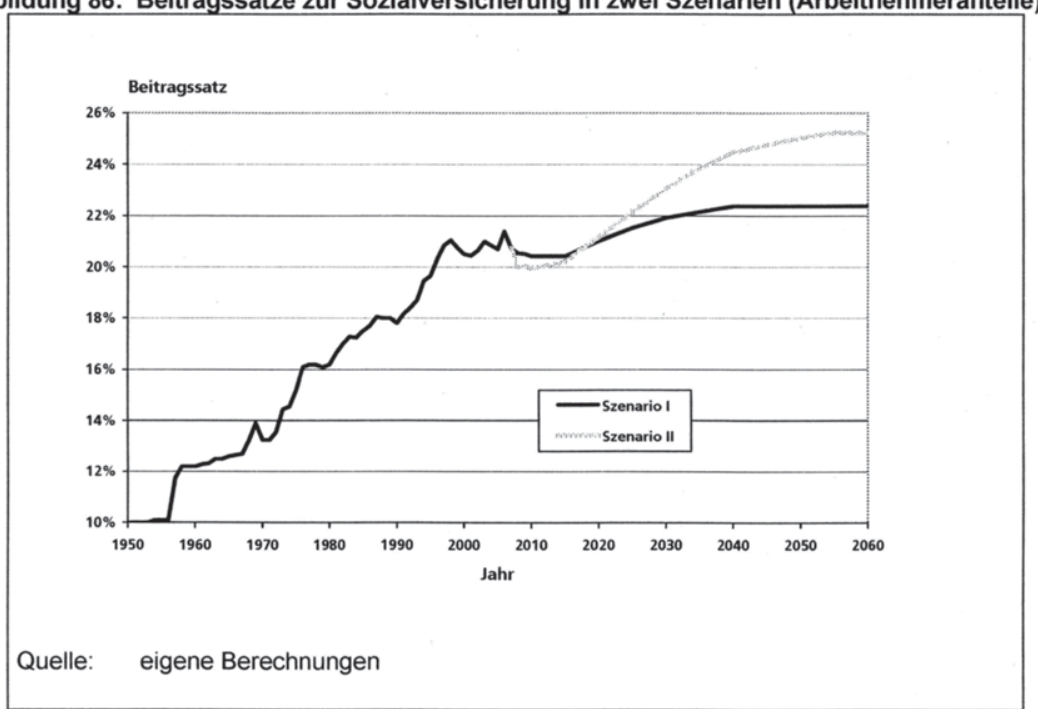

\subsubsection{Besteuerung: Implikationen des geltenden Rechts}

Dem STM liegt für Jahre ab 2007 ein mit dem Lohnwachstum indexiertes SteuerTransfer-System zu Grunde (vgl. Kapitel 2.1), so dass zukünftige geleistete sowie empfangene Zahlungen vom gesamtwirtschaftlichen Lohnniveau unabhängig sind. Grundsätzlich bleibt damit unter anderem der Durchschnittssteuersatz für eine gegebene relative Einkommensposition konstant, soweit im geltenden Recht keine dem widersprechende Regelungen verankert sind. Die für die zukünftige Besteuerung wichtigsten Übergangsregelungen betreffen die nachgelagerte Besteuerung von Alterseinkünften nach dem Alterseinkünftegesetz (AltEinkG). Bis zum Jahr 2025 werden die Rentenversicherungsbeiträge in zunehmendem Umfang als Vorsorgeaufwendungen steuerlich anerkannt, ab 2025 sind sie vollständig abzugsfähig. Bei den hier betrachteten erwerbstätigen Bruttolohnbeziehern führt diese Regelung zu einem beständigen Absinken der Durchschnittsbelastung im Zeitraum bis 2025. Die steuerentlastende Wirkung dieses Übergangs verstärkt sich zudem bei steigenden Beitragssätzen zur Rentenversicherung, da nicht nur der abzugsfähige Anteil sondern

${ }^{324}$ S. Bundesministerium der Finanzen (2005a), S. 26 
auch die entrichteten Beiträge insgesamt ansteigen. Bei einem Alleinstehenden mit einem Bruttolohn in Höhe des Durchschnittsentgelts entspricht die Belastung aus Einkommensteuer und Solidaritätszuschlag im Jahr 2007 einem Durchschnittssteuersatz von 16,6\%. Bis zum Jahr 2025 sinkt dieser Durchschnittssteuersatz um 2,5 Prozentpunkte auf 14,1\% (Abbildung 87). Im Zeitraum danach führen die weiterhin steigenden Beitragssätze zur Rentenversicherung zu einem moderaten weiteren Absinken auf einen Wert von 13,8\%. Bei einem doppelt so großen Bruttolohn ergibt sich bis 2025 ein Rückgang des Durchschnittssteuersatzes um 3,5 Prozentpunkte von $27,0 \%$ auf $23,5 \%$, bis 2040 sinkt der Wert auf $23,2 \%$.

Abbildung 87: Durchschnittssteuersätze in Vergangenheit und Zukunft (Arbeitnehmer)

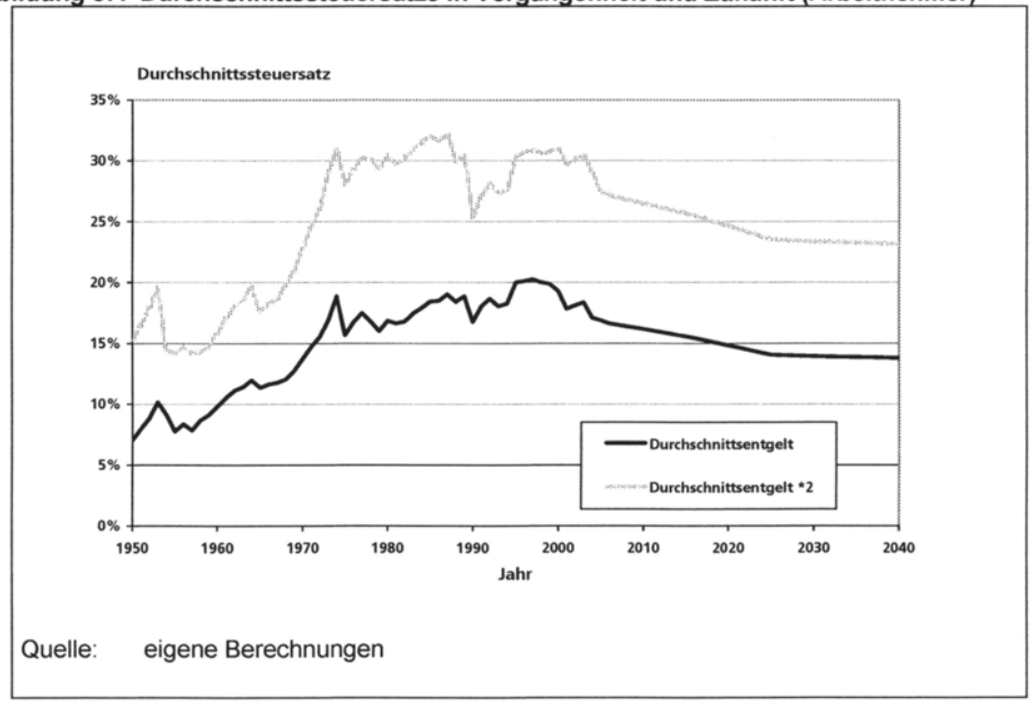

Kehrseite dieses Übergangs ist die zunehmende Besteuerung von Alterseinkünften, die sich bis zum Jahr 2040 vollziehen soll. Bei Renteneintritten bis einschließlich 2005 wird ein nominal fixierter persönlicher Rentenfreibetrag von $50 \%$ festgesetzt, bei Renteneintritten bis 2020 sinkt der steuerfreie Anteil in Schritten von zwei Prozentpunkten je Jahr, danach beträgt die Schrittweite einen Prozentpunkt, bis 2040 der erste Renteneintrittsjahrgang seine Rente vollständig versteuern muss. Wie in Kapitel 4.2.5 angesprochen, zeichnet sich mit dem AltEinkG ein zunehmender steuerlicher Zugriff auf Renten ab, nachdem mit der bis 2004 geltenden Ertragsanteilsbesteuerung Renten faktisch weitgehend steuerfrei gestellt blieben. Im Fall eines Alleinstehenden mit einer Standardrente fiel -soweit wie hier unterstellt keine weiteren Einkünfte vorliegen- in den zurückliegenden Jahrzehnten keine Einkommensteuer an. Trotz der Verschärfung durch das AltEinkG bleiben diese Rentner, auch wenn ihr Rentenbezug zwischen 2005 und 2014 beginnt, steuerlich unbelastet, erstmals folgt beim Renteneintrittsjahrgang 2015 aus einer Standardrente eine positive Ein- 
kommensteuer (Abbildung 88). ${ }^{325}$ Die Durchschnittsbelastung bleibt dabei jedoch moderat und erreicht als Höchstwert 3,8\% bei Renteneintritten ab 2040. Im Fall höherer Renten schlägt sich der Systemwechsel früher und stärker nieder. Bei alleinstehenden Rentnern mit einer Rente in Höhe der 1,5-fachen Standardrente fällt seit 2005 eine relativ geringe positive Steuerschuld an. Für Renteneintritte bis 2020 steigt die Durchschnittsbelastung rasch auf $6,2 \%$ an, danach nehmen die Durchschnittssteuersätze gemäßigt zu, bis erstmals beim Renteneintritt 2040 der Höchstwert von $10,1 \%$ erreicht ist.

Abbildung 88: Durchschnittssteuersätze in Vergangenheit und Zukunft (Rentner)

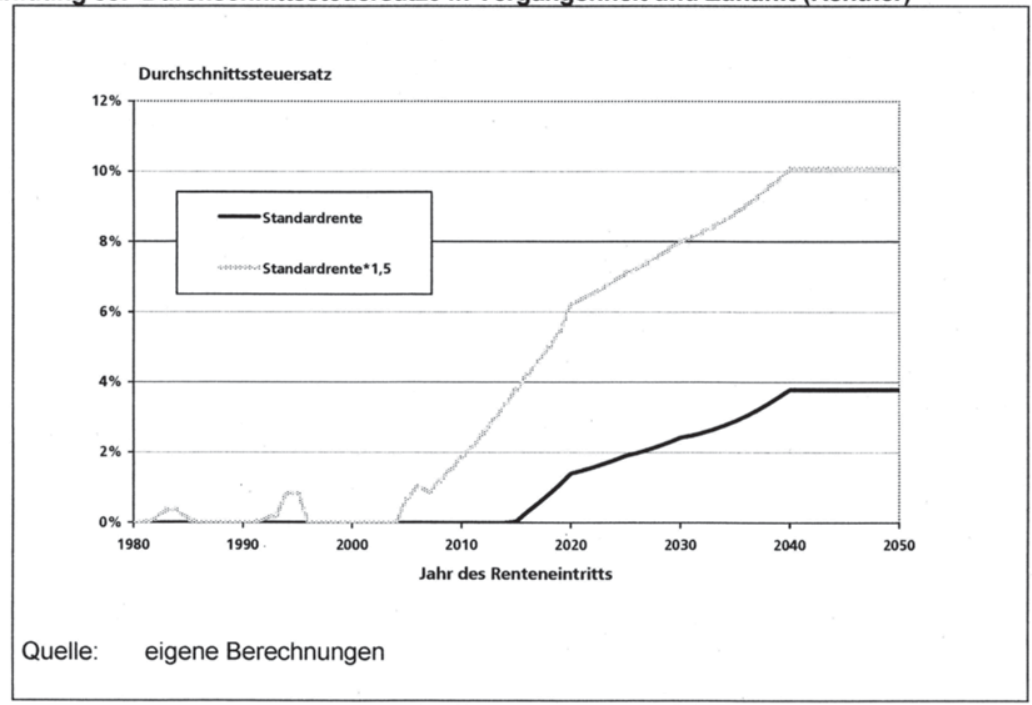

Insgesamt zeichnet sich aus dem Übergang zur nachgelagerten Besteuerung durch das AltEinkG in seiner geltenden Form mittelfristig eine durchaus erhebliche steuerliche Entlastung von Erwerbseinkommen ab. Die für das Jahr 2025 und später zu erwartenden Durchschnittssteuersätze erscheinen im historischen Vergleich moderat und liegen auf ähnlichem Niveau wie letztmals zu Beginn der 1970er Jahre. Auf der Seite der Alterseinkünfte schlägt sich die steuerliche Mehrbelastung tendenziell mit stärkerer Verzögerung nieder und trifft zudem überwiegend Bezieher höherer Renten. Unter Aspekten inter- und intragenerativer Verteilungswirkungen deuten sich aus dem Übergang zur nachgelagerten Besteuerung entsprechend potenziell wesentliche Effekte an, die in den folgenden Lebenszyklusbetrachtungen mit dem STM untersucht werden sollen. In Hinblick auf das Steueraufkommen insgesamt zeichnen sich

${ }^{325} \mathrm{Zu}$ beachten ist, dass durch die nominale Fixierung des persönlichen Rentenfreibetrags im Falle steigender Renten der zu versteuernde Anteil jährlich steigt. Die abgebildeten Durchschnittssteuersätze gelten daher jeweils im Renteneintrittsjahr, in den Folgejahren nehmen sie potenziell zu. 
zudem erhebliche Mindereinnahmen in der Übergangsphase $a b .{ }^{326}$ Bestehende Tragfähigkeitslücken, die in verschiedenen neueren Generationenbilanzen wie oben dargestellt ermittelt wurden, dürften sich durch das AltEinkG weiter vergrößern.

\subsection{Bestimmung von Lebensnettosteuersätzen mit dem STM}

Neben grundsätzlichen Bedenken, Lebensnettosteuersätze oder vergleichbare GröBen für intergenerative Gerechtigkeitsurteile heranzuziehen, stehen beim STM die erwähnten Beschränkungen auf ausgewählte Steuern und Transfers einer Interpretation seiner Ergebnisse als Wohlfahrtsindikator im Wege. Fruchtbar erscheint der Ansatz, Lebensnettosteuersätze mit dem STM zu berechnen, vielmehr aus anderen Gründen: Erstens lassen sich in der Diskussion um eine tragfähige Politik meist unbeachtet bleibende langfristige intragenerative Verschiebungen bestimmen. Die für die Vergangenheit zu beobachtende und für die Zukunft weiterhin zu erwartende wachsende Bedeutung der Sozialversicherungsbeiträge deutet auf eine über die $\mathrm{Ge}$ nerationen abnehmende Progression bei der Abgabenbelastung von Lebenseinkommen hin, ein Aspekt, der sich über den Vergleich der Lebensnettosteuersätze der qualifikationsbedingt unterschiedlichen Einkommensniveaus untersuchen lässt. Eine zweite Form intragenerativer Unterschiede folgt aus der Berücksichtigung von Familien im Steuer-Transfer-System. In eine ähnliche Richtung wie die Auswertungen zu kindbedingten Transfers in Kapitel 8 geht dabei die Untersuchung des Einflusses von Familienstand und Kinderzahl auf die Höhe des Lebensnettosteuersatzes. Zweitens erlaubt die Zerlegung von mit dem STM ermittelten Lebensnettosteuersätzen die vergleichende Gegenüberstellung der Bedeutung einzelner Komponenten für die Belastung des Lebenseinkommens verschiedener Kohorten. So wurden in Kapitel 7 intergenerative Ungleichheiten in Form von Renditedifferenzen in der Rentenversicherung ausgedrückt. Im Rahmen der Bestimmung von Lebensnettosteuersätzen lassen sich die Unterschiede im Rentenbereich in Prozentpunkten des Lebenseinkommens ausdrücken und sich so in Relation zu anderen $\mathrm{Be}$ - oder Entlastungen durch das Steuer-Transfer-System setzen. Neben der Entwicklung der Lebensnettosteuersätze insgesamt interessiert im Folgenden damit vor allem ihre $\mathrm{Zu}$ sammensetzung. Die weitere Darstellung orientiert sich dabei an der Zerlegung des Steuer-Transfer-Saldos in die fünf folgenden Elemente:

$\begin{aligned} \text { Steuer-Transfer-Saldo }= & \text { Einkommen- und Zuschlagsteuern auf Erwerbseinkommen } \\ & + \text { Sozialversicherungsbeiträge auf Erwerbseinkommen } \\ & - \text { Nettorenten der gesetzlichen Rentenversicherung } \\ & - \text { Ehebedingte Mehreinkommen } \\ & - \text { Kindbedingte Mehreinkommen }\end{aligned}$

Der Quotient aus Steuer-Transfer-Saldo und Lebenseinkommen entspricht dem Lebensnettosteuersatz wie oben angegeben, der folglich in fünf Komponenten unterteilt

${ }^{326}$ Nach Ergebnissen von Buslei und Steiner (2006) steigen die jährlichen Einnahmeausfälle bis in die 2020er Jahre hinein an und erreichen dabei Werte von bis zu rund 11 Mrd. Euro je Jahr. Für das Jahr 2050 hingegen rechnen sie dann mit Mehreinnahmen von etwa 2 Mrd. Euro. 
wird. Als Basis wird von männlichen Alleinstehenden ausgegangen, deren SteuerTransfer-Saldo erstens mit den Werten von kinderlosen Verheirateten und zweitens von Ehepaaren mit zwei Kindern verglichen wird. ${ }^{327}$ Bei den beiden Paartypen werden jeweils Einverdiener unterstellt, es handelt sich dabei um dieselben Lebenseinkommensprofile, die unter diesem Typ bereits in den Kapiteln 7 und 8 eingesetzt wurden. ${ }^{328}$ Mit der Beschränkung auf Einverdiener werden die typisierten Wirkungen der ehe- und familienbezogenen Elemente des Steuer-Transfer-Systems bei stilisierten Fällen herausgearbeitet. Bei den Ehepaaren mit Kindern wird wie beim Standardfall des Kapitels 8 von Kindern ausgegangen, die über insgesamt 19 Jahre Kinder im Sinne des EStG sind, ausbildungsbezogene Transfers wie die Förderung nach dem BAföG kommen dabei nicht zum Tragen. ${ }^{329}$ Auch wird von den Transfers abstrahiert, die die betrachteten Fälle während ihrer eigenen Ausbildungszeiten empfangen. Ausbildungsbezogene Transfers sind zu erheblichen Teilen explizit oder implizit an die Eltern der Auszubildenden gerichtet, ihre Entwicklung wird ausführlich in Kapitel 6 analysiert.

Die ehebedingten Mehreinkommen werden analog zu den kindbedingten Mehreinkommen bestimmt, die ihrerseits weiterhin auf der in Kapitel 8 angegebenen Definition beruhen (s. Kapitel 8.2.2). Sie entsprechen der aus dem Steuer-TransferSystem resultierenden Differenz der verfügbaren Einkommen von Alleinstehenden und Verheirateten (ehebedingte Mehreinkommen) bzw. von Ehepaaren mit Kindern und ohne Kinder (kindbedingte Mehreinkommen) bei einem gegebenen Bruttoeinkommen. Die zu den kindbedingten Mehreinkommen beitragenden Elemente des Steuer-Transfer-Systems sind vor allem Kindergeld und -freibeträge, Eltern- oder Erziehungsgeld sowie Kindererziehungszeiten in der Rentenversicherung (vgl. Kapitel 8.1.2 und 8.2.2). Als ehebezogene Maßnahmen ergeben sich nach dem hier vertretenen Ansatz vor allem die Steuerminderungen durch Anwendung des Splittingtarifs (vgl. Kapitel 4.2.1) sowie Hinterbliebenenrenten (vgl. Kapitel 5.2).

Um inter- und intragenerative Unterschiede in den Wirkungen des SteuerTransfer-Systems herauszuarbeiten, werden im Folgenden zunächst an Hand von Alleinstehenden die Einflüsse einzelner Faktoren auf die Entwicklung der Lebensnettosteuersätze über die Kohorten dargestellt. Dazu werden in einem ersten Schritt die Abgabenbelastungen in der Enwerbs- und in der Rentenbezugsphase getrennt betrachtet. Anschließend werden die Wirkungen ehe-sowie kindbezogener Elemente

${ }^{327}$ Das Geschlecht wirkt sich bei Alleinstehenden unter den hier genutzten, nicht nach Geschlechtern differenzierten Einkommensprofilen nur geringfügig auf die Lebensnettosteuersätze aus, weibliche Alleinstehende weisen dabei auf Grund des längeren Rentenbezugs etwas niedrigere Belastungsquoten auf, wobei sich die Differenz für alle betrachteten Kohorten und Einkommensprofile in einer Größenordnung von etwa $1 \%$ des Bruttolebenseinkommens bewegt. Deutlichere Unterschiede gehen von den geschlechtsspezifischen Lebenserwartungen auf die Renditen der gesetzlichen Rentenversicherung aus (vgl. Kapitel 7.1.1)

${ }^{328}$ Bei diesem Paartyp wird von einer auf wenige Jahre bis zur Heirat beschränkten Enwerbstätigkeit des einen Ehepartners ausgegangen, der andere Partner ist durchgängig vollzeiterwerbstätig. Auch in den weiteren berechnungsrelvanten Punkten (Heiratsalter, Geburtsabstand etc.) werden dieselben Annahmen zu Grunde gelegt wie in Kapitel 7 angegeben (s. Kapitel 7.2.3).

329

Die Annahme von Einverdienern führt auf Grund des seit 1958 geltenden Splittingtarifs der Einkommensteuer zu relativ hohen ehebezogenen Transfers. Durch Ausblendung der ausbildungsbezogenen Transfers schlagen sich in diesem Bereich bestehende Vorteile mittlerer Generationen nicht in den Ergebnissen dieses Kapitels nieder (vgl. zur Wirkung ausbildungsbezogener Transfers im Lebenszyklus verschiedener Kohorten Kapitel 6.2.2.1 sowie auch Kapitel 8.2.2.1). 
bestimmt, indem die Lebensnettosteuersätze von Ehepaaren mit den zuvor ermittelten Werten Alleinstehender verglichen werden. Inwieweit die Ergebnisse von den hier getroffenen Annahmen und Abgrenzungen abhängen, wird in zwei sich anschlieBenden Rechenvarianten behandelt. In einer ersten Variante werden die oben als Szenario II vorgestellten höheren Beitragssätze zur Sozialversicherung angesetzt, die nicht nur für die Renten- sondern auch für die Kranken- und Pflegeversicherung die zu erwartenden Beitragssatzanstiege reflektieren. Als Folge zeichnen sich in dieser Variante höhere Lebensnettosteuersätze vor allem der jüngeren Kohorten ab. Der zweiten Variante liegt eine andere Definition der Lebensnettosteuersätze zu Grunde, bei der auch die Arbeitgeberbeiträge zur Sozialversicherung erfasst werden, indem sie sowohl dem Steuer-Transfer-Saldo als auch dem Bruttoeinkommen zugerechnet werden. Diese Abgrenzung ist bei der Bestimmung von Belastungsquoten im Sinne von Brutto-Netto-Berechnungen unüblich. Sie wird hingegen stärker dem Grundansatz der Generationenbilanzierung gerecht, die Einnahmen öffentlicher Haushalte möglichst vollständig zu erfassen. Bei seit den 1950er Jahren überwiegend steigenden Beitragssätzen zur Sozialversicherung zeichnet sich auch hier eine relativ ungünstigere Position für jüngere Kohorten $a b$.

\subsubsection{Steuern und Sozialversicherung}

Da erstens für den Zeitraum von 1950 bis 2080 von weitgehend monoton steigenden Beitragssätzen zur Sozialversicherung auszugehen ist (vgl. Abbildung 86) und zweitens -innerhalb der Beitragsbemessungsgrenzen- durchgängig ein proportionaler Zusammenhang zwischen Bruttoeinkommen und Versicherungsbeiträgen besteht, ist das Ergebnis einer über die Kohorten steigenden Abgabenquote durch die Sozialversicherung vorhersehbar. Die Entwicklung der Belastung der Lebenseinkommen mit Einkommen- und Zuschlagsteuern wird hingegen weniger eindeutig von zunächst tendenziell steigenden und anschließend wieder fallenden Steuersätzen geprägt, wobei aus den geplanten Regelungen durch das AltEinkG zukünttig ein weiteres $A b$ sinken zu enwarten ist (vgl. Abbildung 87). Die Steuerbelastung verschiedener Kohorten in einzelnen Jahren der Erwerbsphase wird zum einen vom jeweils geltenden Steuerrecht und zum anderen von der Konkavität der Einkommensprofile geprägt. Ein Vergleich der Durchschnittssteuersätze aus Einkommen- und Zuschlagsteuern zeigt die niedrigsten Werte für die erste Hälfte der Erwerbsphase der ältesten der betrachteten Kohorten, die ab 1930 geboren wurden. In der zweiten Hälfte der Erwerbszeit bestehen für diese unter den Steuertarifen ab den 1970er Jahren hingegen relativ hohe Belastungen. Für Steuerpflichtige, die in den Jahren um 1950 geboren wurden, so dass sich ihre Erwerbsphase über den Zeitraum von etwa 1970 bis 2015 erstreckt, ergeben sich vergleichsweise hohe Durchschnittssteuersätze, da sie von der moderaten Besteuerung zu Beginn und Ende des Betrachtungszeitraums kaum profitieren. Für die jüngsten Jahrgänge, die mit ihren Geburtsjahren bis 1990 ab etwa 2010 Steuern entrichten, liegen die Durchschnittssteuersätze durchgängig recht niedrig. In Abbildung 89 sind die Durchschnittsbelastungen aus Einkommen- und Zuschlagsteuern für das niedrigste der fünf betrachteten Qualifikations- und damit Einkommensniveaus (Personen ohne beruflichen Abschluss, Ohne) und das höchste Niveau (Personen mit Universitätsabschluss, Uni) abgetragen, deren Einkommen im 
Durchschnitt über eine Erwerbsphase rund $80 \%$ (Ohne) bzw. knapp 170\% (Uni) des Durchschnittsentgelts der gesetzlichen Rentenversicherung betragen. Die Abbildung zeigt für verschiedene Geburtsjahre zwischen 1930 und 1990 die Durchschnittssteuersätze Steuern/ Bruttolohn, die sich bei den gegebenen Jahreseinkommen für alleinstehende Steuerpflichtige im Alter von 16 bis 64 Jahren ergeben. Auf Grund der längeren Ausbildungsdauer verkürzt sich beim Abschluss Uni die Erwerbsphase, so dass erst nach dem Alter von 25 Jahren Steuerzahlungen anfallen.

Abbildung 89: Jährliche Durchschnittssteuersätze nach Qualifikation, Alter und Geburtsjahr

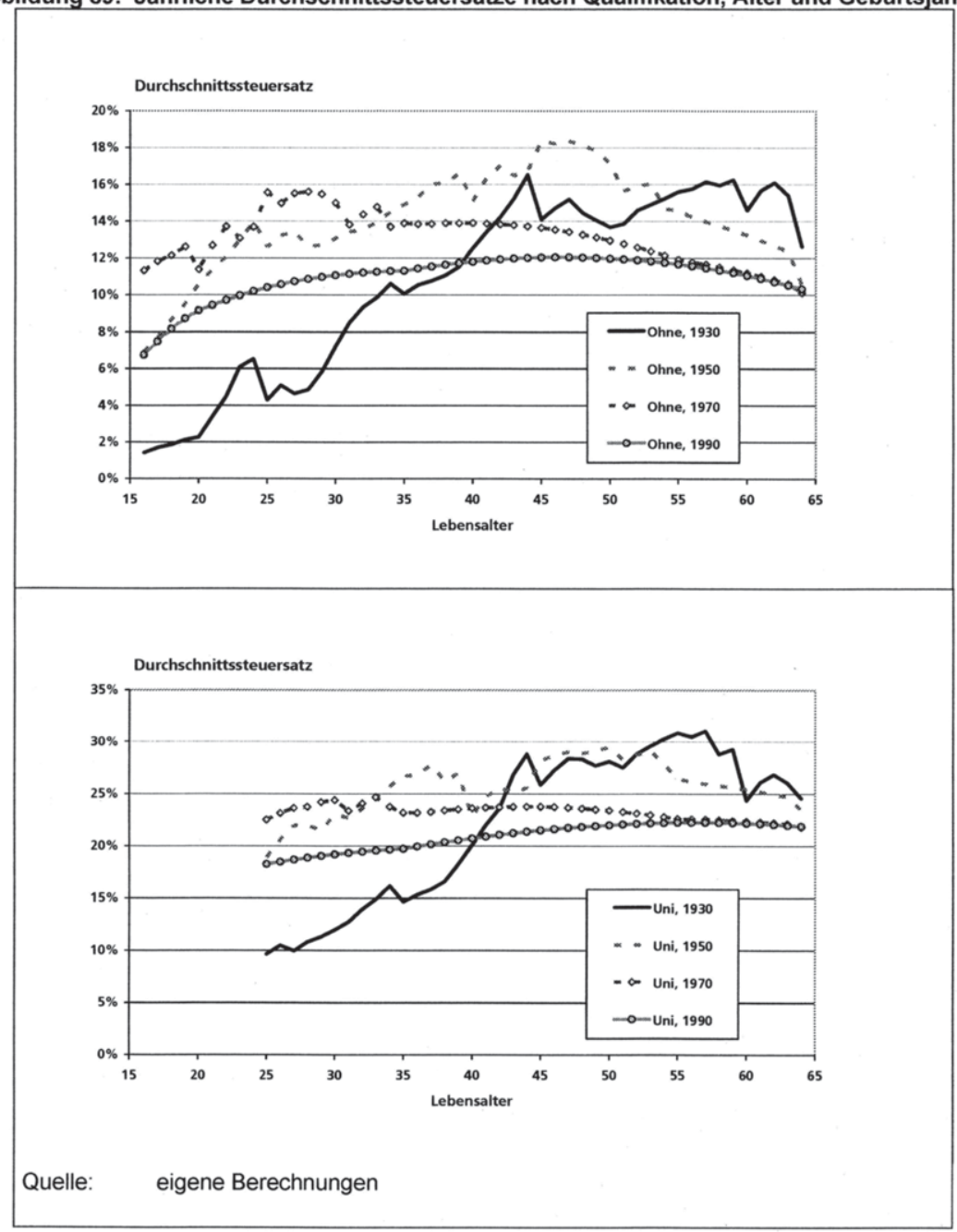


Aus Abbildung 89 lässt sich bereits ableiten, dass die Belastung der Lebenseinkommen mit Steuern bei den jüngsten Kohorten (Geburtsjahr 1990) niedriger ausfällt als bei mittleren Jahrgängen (Geburtsjahre 1950, 1970). Die jährlichen Durchschnittssteuersätze des Geburtsjahres 1990 sind bei beiden dargestellten Qualifikationen für jedes Lebensalter höchstens so groß wie die jeweiligen Werte von Steuerpflichtigen, die 1950 oder 1970 geboren wurden. ${ }^{330}$ Unabhängig davon, mit welchem Zinssatz die monetären Größen zu Barwerten zusammengefasst werden, ergibt sich damit auf jeden Fall eine niedrigere Belastungsquote für die jüngeren Kohorten. Beim Vergleich der ältesten (1930) und der jüngsten (1990) Kohorte hingegen ist die Relation der Steuerquoten über die Erwerbsphase insgesamt nicht offensichtlich, hier liegen einerseits niedrigere Durchschnittssteuersätze der älteren Kohorten in der ersten Hälfte der Erwerbsjahre vor, in der zweiten Hälfte kehrt sich jedoch die Rangfolge um. Die im Weiteren präsentierten Ergebnisse beruhen durchgehend auf einem konstanten Realzins von $4 \%$, der annähernd dem langfristigen Mittelwert über die zurükliegenden Jahrzehnte entspricht. In alternativen Berechnungen wurde stattdessen die tatsächliche Zinsentwicklung zu Grunde gelegt. Über den Zeitraum von 1955 bis 2005 beläuft sich die durchschnittliche reale Rendite auf rund 3,9\%. Die Berücksichtigung der tatsächlichen Jahreswerte mit ihrem geringfügig niedrigeren Mittelwert und der beobachteten Varianz führt zu keinen grundlegend abweichenden Ergebnissen im Vergleich zur Annahme eines konstanten Realzinses von 4\%, so dass hier ausschließlich die Ergebnisse dieser Variante dargestellt sind. ${ }^{331}$

Die sich unter diesem Zinssatz ergebenden Durchschnittssteuersätze für die Erwerbsphase insgesamt (also der Quotient aus den Barwerten sämtlicher Steuern, die im Alter von bis zu 65 Jahren anfallen, und sämtlicher Bruttolöhne) sind in Abbildung 90 dargestellt. Von der oben aufgeführten Zerlegung des Steuer-Transfer-Saldos in fünf Bestandteile ist folglich nur die erste der fünf hier betrachteten Größen enthalten. Die Abbildung zeigt für die fünf in dieser Arbeit unterschiedenen qualifikationsabhängigen Einkommensprofile die Entwicklung der Durchschnittssteuersätze über die Kohorten von 1930 bis 1990. Die niedrigsten Durchschnittssteuersätze treten für jedes Einkommensniveau beim Geburtsjahr 1990 auf, für das sich die Werte auf 10,8\% (Ohne) bis $20,8 \%$ (UnI) belaufen. Für den Jahrgang 1930 liegen die Durchschnittssteuersätze im Intervall von $11,1 \%$ (Ohne) bis $22,7 \%$ (Uni), über die Kohorten zwischen 1930 und 1990 steigen die Quoten zunächst an und fallen anschließend ab. Nach diesen Ergebnissen impliziert das geltende Steuerrecht insbesondere für überdurchschnittliche Einkommen im historischen Vergleich moderate Belastungen des Lebenseinkommens, wobei jüngere Kohorten mit steigendem Geburtsjahr zunehmend besser gestellt sind.

${ }^{330} \mathrm{Ab}$ dem Jahr 2025 ist nach dem geltenden Recht der Übergang zur nachgelagerten Besteuerung von Alterseinkünften in Hinblick auf die Abzugsfähigkeit der Beiträge abgeschlossen, so dass der Geburtsjahrgang $1970 \mathrm{ab}$ dem Alter von 55 Jahren seine Rentenversicherungsbeiträge vollständig steuerlich geltend machen kann. Ab dem Alter von 55 Jahren weisen die abgebildeten Jahrgänge 1970 und 1990 nach den getroffenen Annahmen zur Indexierung des Steuer-Transfer-Systems daher annähernd gleiche Durchschnittssteuersätze auf, da ab diesem Lebensalter für beide dann übereinstimmend die nachgelagerte Besteuerung greift. Geringfügige Unterschiede bleiben auf Grund der über die Jahre zunehmenden Beitragssätze bestehen.

331 Ausgegangen wurde bei diesen Werten von den Umlaufsrenditen inländischer Inhaberschuldverschreibungen. Vgl. zu den langfristigen Realzinsen Deutsche Bundesbank (2001b) 
Die höchsten Durchschnittssteuersätze treten bei Angehörigen der Jahrgänge von etwa 1940 bis 1955 auf, bei welchem Geburtsjahr das Maximum vorliegt, variiert mit dem Abschluss. Für Fälle mit Durchschnittseinkommen reichen die Belastungsquoten je nach Geburtsjahr von $14,1 \%$ (Lehre, 1990) bis $17,2 \%$ (Lehre, 1950), so dass die Spannweite 3,1 Prozentpunkte beträgt. Mit dem Einkommensniveau steigen die Spannweiten auf Werte von bis zu 4,7 Prozentpunkten (Durchschnittssteuersätze beim Abschluss Uni von 20,8\% für den Jahrgang 1990 bis $25,5 \%$ beim Jahrgang 1945). Innerhalb einer Kohorte unterscheiden sich die Durchschnittssteuersätze qualifikationsabhängig um mindestens 9,7 Prozentpunkte für den Jahrgang 1975 (Ohne $12,7 \%$ bis Uni $22,4 \%$ ) und höchstens 12,1 Prozentpunkte beim Jahrgang 1940 (Ohne $12,9 \%$ bis Uni $25,0 \%$ ). Tendenziell nehmen die intragenerativen Differenzen der Durchschnittssteuersätze über die Kohorten ab.

Abbildung 90: Durchschnittssteuersätze nach Qualifikation: Erwerbsphase

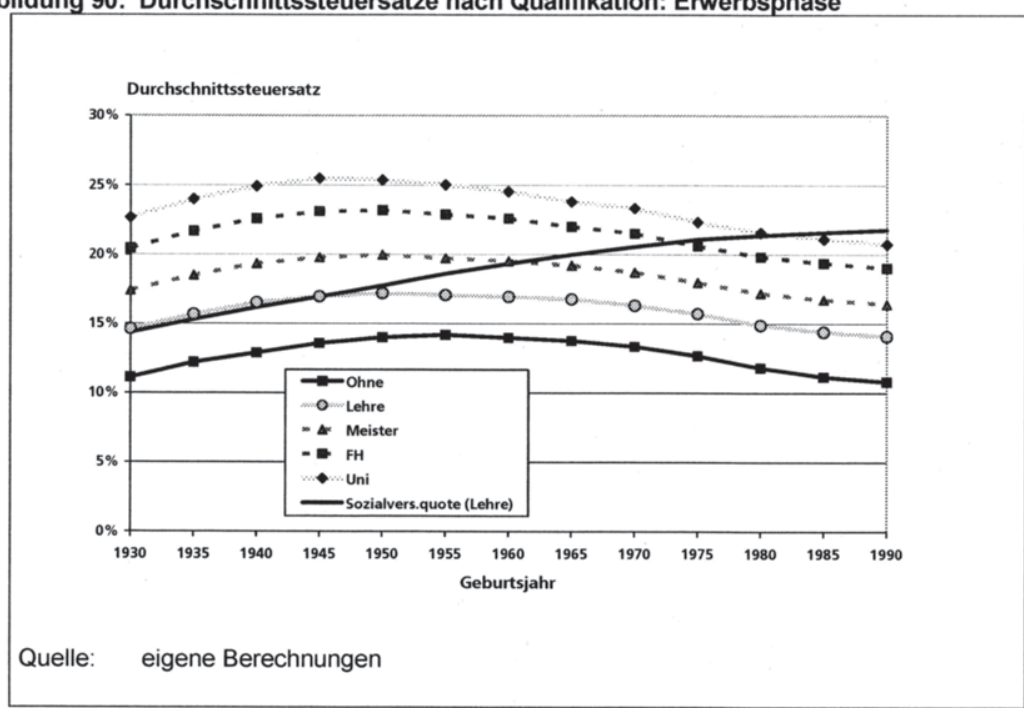

Neben den Durchschnittssteuersätzen für die fünf Abschlüsse ist in Abbildung 90 auch die Sozialversicherungsquote beim Abschluss Lehre angegeben. Die Sozialversicherungsquote als Quotient Sozialversicherungsbeiräge/ Bruttolohn entspricht der zweiten der fünf Komponenten des Steuer-Transfer-Saldos in der obigen Aufstellung. Die Werte umfassen ausschließlich die Arbeitnehmeranteile und beziehen sich wie die Durchschnittssteuersätze nur auf die Erwerbsphase, die Abgaben während der Rentenphase sind nicht erfasst. Auf Grund der je nach Ausbildung unterschiedlichen Alter bei Enwerbsbeginn und der Beitragsbemessungsgrenzen unterscheiden sich die Sozialversicherungsquoten innerhalb einer Kohorte qualifikationsabhängig geringfügig um bis zu gut einen Prozentpunkt, die Entwicklung über die Geburtsjahre ist jedoch für alle fünf Einkommensprofile gleichartig, so dass stell- 
vertretend nur für den Abschluss Lehre der Verlauf abgebildet ist. ${ }^{332}$ Die Sozialversicherungsquoten steigen über die Kohorten monoton um etwa 7,5 Prozentpunkte von $14,3 \%$ (1930) auf 21,8\% (1990), wobei rund zwei Drittel dieser Zunahme auf die erste Hälfte des Betrachtungszeitraums entfallen, die Sozialversicherungsquote für die Kohorte 1960 liegt bei 19,3\%. In der Zunahme um 7,5 Prozentpunkte sind erwartete zukünftige Anstiege der Beitragssätze zur Kranken- und Pflegeversicherung nicht enthalten, deren Wirkung wird wie angekündigt in einer Berechnungsvariante weiter unten besprochen.

\section{Abbildung 91: Abgabenquoten nach Qualifikation: Erwerbsphase}

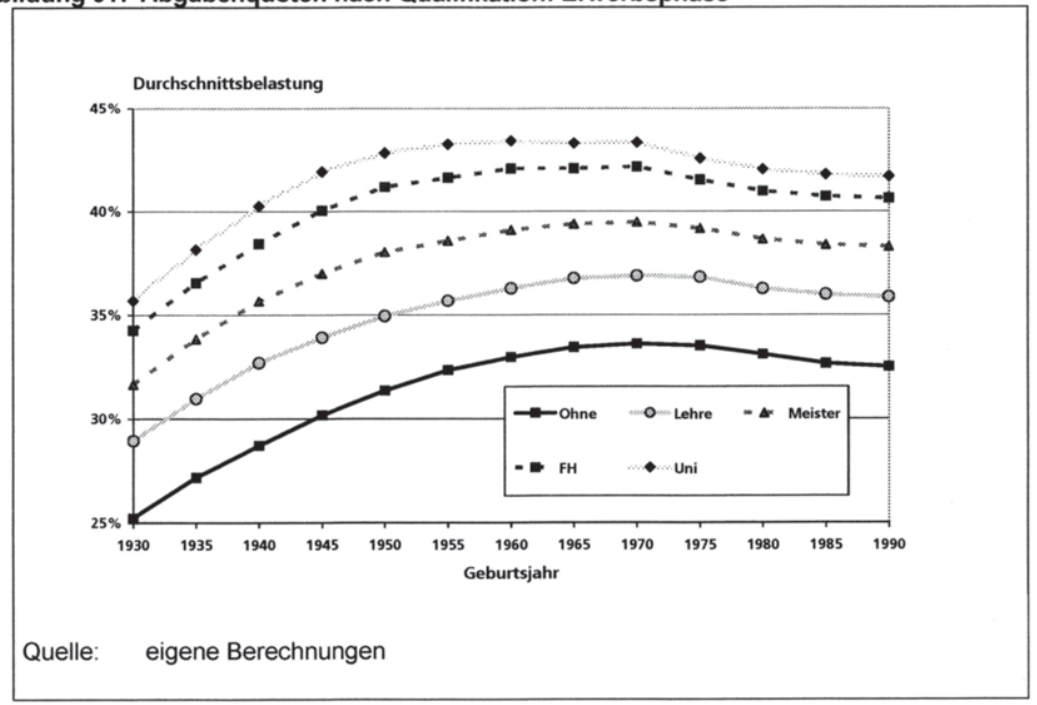

Die Summe aus Durchschnittssteuersätzen und Sozialversicherungsquoten entspricht den sich über die Erwerbsphase ergebenden Abgabenquoten. Niedrige Sozialversicherungsquoten, kombiniert mit recht geringen Durchschnittssteuersätzen, führen dabei zu im Kohortenvergleich moderaten Belastungen der ältesten Jahrgänge (Abbildung 91). Für Angehörige des Jahrgangs 1930 reichen die Abgabenquoten von $25,2 \%$ (Ohne) bis $35,7 \%$ (Uni), bis zum Jahrgang 1950 führen Zunahmen sowohl bei der Sozialversicherung als auch bei der Besteuerung zu stark steigenden Quoten, wonach für 1950 Geborene Werte von $31,4 \%$ (Ohne) bis $42,8 \%$ (Uni) zu verzeichnen sind. Über die Geburtsjahre von 1930 bis 1950 nehmen die Abgaben-

${ }^{332}$ Bei insgesamt in der Tendenz steigenden Beitragssätzen führt ein früherer Erwerbsbeginn zu einer niedrigeren Sozialversicherungsquote, was zu etwas geringeren Werten beim Abschluss Ohne führt. Umgekehrt profitieren vor allem die akademischen Abschlüsse FH und Uni von der Kappung der Beiträge an der Beitragsbemessungsgrenze, was vor allem bei den älteren Kohorten zu Entlastungen führt ( $\mathrm{vgl}$. Kapitel 4.1). Die größte intragenerative Differenz tritt mit 1,2 Prozentpunkten für die Kohorte 1930 auf, deren Sozialversicherungsquoten von $13,1 \%$ (Uni) bis $14,3 \%$ (Lehre) reichen. Auch in den weiteren Geburtsjahren weisen Personen mit akademischen Abschlüssen die niedrigsten Sozialversicherungsquoten auf. 
quoten mithin um gut sechs Prozentpunkte bei bis zu durchschnittlichen Einkommen (Ohne, Lehre) und um rund sieben Prozentpunkte bei höheren Einkommen ( $F H$, Uni) zu. Die anschließende Entwicklung über die Kohorten von 1950 bis 1970 unterscheidet sich dann zwischen den Einkommensniveaus. Für niedrigere und durchschnittliche Einkommen steigen die Abgabenquoten weiter um rund zwei Prozentpunkte an, bei Personen ohne beruflichen Abschluss tritt mit 33,6\% die höchste Belastung für den Jahrgang 1970 auf, beim mit dem Abschluss Lehre verbundenen Durchschnittseinkommen liegt das Maximum ebenfalls beim Jahrgang 1970 und beträgt $36,9 \%$ (nach Werten von $29,0 \%$ für den Jahrgang 1930 und $34,9 \%$ für den Jahrgang 1950). Beim Abschluss Uni unterscheiden sich die Abgabenquoten der Jahrgänge $1950(42,8 \%)$ bis $1970(43,3 \%)$ hingegen nur geringfügig. Über die Kohorten von 1970 bis 1990 fallen die Abgabenquoten dann qualifikationsübergreifend, über diese Jahrgänge wirken sich insgesamt die Steuersenkungen durch den Übergang zur nachgelagerten Besteuerung stärker aus als die weiteren Beitragssatzanstiege in der Rentenversicherung. Für die Abschlüsse Ohne und Lehre sinken die Abgabenquoten um rund einen Prozentpunkt auf $32,5 \%$ bzw. 35,9\%. Bei den überdurchschnittlichen Einkommen reichen die Rückgänge von 1,3 Prozentpunkten (Meister, von $39,6 \%$ auf $38,3 \%$ ) bis zu 1,6 Prozentpunkten (Uni, von $43,3 \%$ auf $41,7 \%$ ).

Als markantestes Ergebnis des intergenerativen Vergleichs von Abgabenquoten bleibt zunächst ein rasches Wachstum der Belastung über die Kohorten von 1930 bis 1950, von dem höhere Einkommen relativ stark betroffen sind. Bei den nächstjüngeren Kohorten bis 1970 bleiben höhere Einkommen hingegen von Mehrbelastungen verschont, während sich für niedrigere Einkommen moderate weitere Zunahmen ergeben. Über die Kohorten von 1970 bis 1990 zeigt sich bei allen betrachteten Einkommensniveaus anschließend ein leichter Rückgang, der für höhere Einkommen geringfügig stärker ausfällt.

\subsubsection{Nettorenten}

Als dritter und letzter Bestandteil der Lebensnettosteuersätze von Alleinstehenden sind die Nettorenten zu ergänzen. Deren Entwicklung hängt zum einen vom Bruttorentenniveau ab, das sich im aktuellen Rentenwert äußert, und zum anderen von den auf die Renten zu entrichtenden Abgaben. Wie in Kapitel 4.1 beschrieben, sind seit 1983 von den Bruttorenten Krankenversicherungsbeiträge abzuführen, die sich seit etwa Mitte der 1990er Jahre wie bei Lohnbeziehern nach dem allgemeinen Beitragssatz der jeweiligen Versicherung richten; seit 1995 kommen die Pflegeversicherungsbeiträge hinzu. Durch die Beschränkung der Besteuerung auf den Ertragsanteil blieben Renten wie oben dargelegt bis 2004 weitgehend steuerlich unbelastet, seit 2005 ist von zunehmenden Durchschnittssteuersätzen bei Rentnern auszugehen (vgl. Abbildung 88 sowie Kapitel 4.2.5). Bei den fünf hier betrachteten Lebenseinkommensprofilen unterscheiden sich die Abgabenquoten in der Rentenbezugsphase für Kohorten bis etwa 1935 kaum, da fast ausschließlich proportionale Sozialversicherungsbeiträge anfallen. Über die Geburtsjahre nehmen dann die Abgabenquoten kontinuierlich zu, wobei Bezieher niedrigerer Renten erst recht spät effektiv belastet werden. Wie für die Erwerbsphase in Abbildung 91 sind in Abbildung 92 für die Renten- 
bezugsphase die Abgabenquoten dargestellt. Die Werte entsprechen somit den Quotienten der Barwerte der in der Rentenbezugsphase zu entrichtenden Abgaben (Einkommen- und Zuschlagsteuern sowie Sozialversicherungsbeiträge) und der Bruttorenten. Über die Kohorten von 1930 bis 1940 steigen die Abgabenquoten hauptsächlich auf Grund zunehmender Sozialversicherungsbeiträge. Da die Beitragssätze zur Kranken- und Pflegeversicherung in der hier dargestellten Grundvariante der Berechnungen ab 2007 fixiert sind, beruhen die weiteren Anstiege über die Geburtsjahre ab 1945 ausschließlich auf dem verstärkten steuerlichen Zugriff.

Abbildung 92: Abgabenquoten nach Qualifikation: Rentenbezugsphase

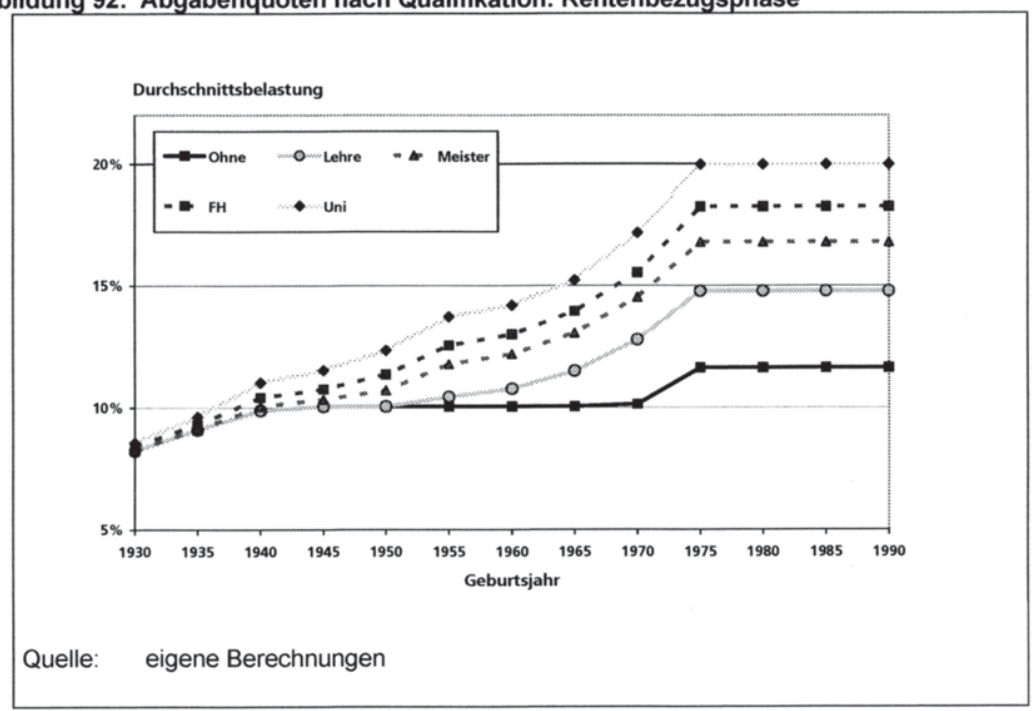

Für die Kohorte 1930 liegen die Abgabenquoten der Rentenbezugsphase bei Werten von $8,2 \%$ (Ohne) bis $8,6 \%$ (Uni). Auch beim Geburtsjahrgang 1940, dessen Renten bei einem typisierenden Renteneintritt im Jahr 2005 durchgängig nach dem AltEinkG zu versteuern sind, unterscheiden sich die Abgabenquoten mit Werten von 9,9\% (Ohne) bis $11,0 \%$ (Uni) nur geringfügig. Auch bei den höchsten Renten, die beim Abschluss Uni anfallen, dessen Erwerbseinkommen bis zum 65. Lebensjahr zu 67,1 Entgeltpunkten führen, bleibt die steuerliche Belastung für den Jahrgang 1940 mit einem Durchschnitssteuersatz von $1,1 \%$ niedrig. Der nominal konstant bleibende persönliche Rentenfreibetrag in Höhe von 50\% der Jahresrente 2005 führt hier annähernd zu einer effektiven Steuerfreistellung. Mit dem über die Renteneintrittsjahre bis 2040 sukzessive auf $0 \%$ fallenden Freibetrag steigen dann die Durchschnittssteuersätze zunächst bei höheren Renten kontinuierlich an. Beim Abschluss Uni nehmen die Werte zu von 1,5\% für den Geburtsjahrgang 1945 auf $9,9 \%$ für Personen, die 1975 oder später geboren sind. Da der Rentenbezug für 1975 Geborene bei einem (nicht abschlagsfreien) Renteneintritt im Alter von 65 Jahren ab 2040 erfolgt, 
ist dies der erste Jahrgang, dessen Rente vollständig zu versteuern ist. ${ }^{333}$ Unter der getroffenen Annahme zur Indexierung des Steuersystems bleiben die Durchschnittssteuersätze ab dann konstant. Auf Bezieher niedrigerer Renten wirkt sich der zunehmende steuerliche Zugriff hingegen erst stark zeitverzögert aus. Beim Abschluss Ohne, aus dessen Erwerbseinkommen 38,6 Entgeltpunkte resultieren, genügen selbst geringe Freibeträge, um keine Steuern entrichten zu müssen, so dass erstmals für Geburtsjahrgänge ab etwa 1975 mit effektiven Belastungen zu rechnen ist, wobei der Durchschnittssteuersatz mit durchgängig 1,6\% moderat ausfällt. Der Übergang zur nachgelagerten Besteuerung von Renten der gesetzlichen Rentenversicherung führt mithin zu einer zunehmenden Spreizung der Abgabenquoten über die Einkommensskala. Während sich bei unterdurchschnittlichen Renten auch für jüngere Kohorten nur geringe steuerliche Belastungen abzeichnen, wächst bei höheren Renten die relative Steuerschuld über die Geburtsjahre. Bei Sozialversicherungsquoten von einheitlich $10,0 \%$ reichen die Abgabenquoten in der Rentenphase für die Jahrgänge ab 1975 von $11,6 \%$ bis $20,0 \%$, so dass die Spannweite 8,4 Prozentpunkte beträgt. Beim Abschluss Lehre, dessen Erwerbseinkommen zu 46,8 Entgeltpunkten führt, so dass durch inn in etwa eine Standardrente repräsentiert wird, haben die Geburtsjahrgänge ab etwa 1955 Steuern zu entrichten, wobei sich der Durchschnittssteuersatz auf bis zu 4,7\% (für Jahrgänge ab 1975) beläuft.

Trotz dieser über die Kohorten wachsenden Belastung der Renten mit Abgaben und trotz des demographischen Drucks auf die umlagefinanzierten Sicherungssysteme kommt es zu keinem kontinuierlichen Verfall der Nettorenten. Ihr Anteil am Lebenseinkommen, ausgedrückt als Relation Nettorente/Bruttolohn, nimmt nach einem starken Absinken über die Kohorten von 1930 bis 1945 für Geburtsjahre ab 1965 wieder leicht zu (Abbildung 93). In der abgebildeten Form lassen sich die Nettotransfers der Rentenphase analog zu den oben beschriebenen Abgabenquoten der Erwerbsphase interpretieren und auch mit innen verrechnen. Der Barwert der Nettorenten beläuft sich bei den untersuchten Fällen auf bis zu 9,3\% des Barwerts des Bruttolebenseinkommens (FH, Geburtsjahr 1930), so dass für diese Konstellation eine Streichung der Rentenansprüche und eine Erhöhung des auf das Erwerbseinkommen erhobenen Durchschnittssteuersatzes um 9,3\% in Hinblick auf die Höhe des verfügbaren Lebenseinkommens äquivalent sind. Der Bezug der gesetzlichen Rente wirkt mithin wie eine Senkung der Abgabenquote (vgl. Abbildung 91) um 9,3\%, so dass der Lebensnettosteuersatz diese um diesen Wert unterschreitet. Bei der Darstellung in Abbildung 93 ist noch einmal daran zu erinnern, dass die Nettorenten hier losgelöst von den Rentenbeiträgen betrachtet werden, diese sind in den oben besprochenen Abgabenquoten enthalten. Eine höhere Nettorente gemäß Abbildung 93 ist daher nicht mit einer vorteilhafteren Behandlung durch das Alterssicherungssystem gleichzusetzen.

${ }^{333}$ Die mit dem Anstieg der Regelaltersgrenze von 65 auf 67 Jahre gegebenenfalls verbundenen Abschläge wirken sich geringfügig auf die Lebensnettosteuersätze aus. Ohne die Anhebung der Altersgrenze würden die Lebensnettosteuersätze um bis zu etwa 0,5 Prozentpunkte niedriger ausfallen. Vgl. zur Übergangsregelung auf die Altersgrenze von 67 Jahren Kapitel 7.2.2. Dort sind Wirkungen der Altersgrenzen auf die implizite Rendite der gesetzlichen Rentenversicherung dargestellt, wobei aus der Anhebung um zwei auf 67 Jahre Renditeminderungen von bis zu einem Viertel Prozentpunkt ermittelt werden. 
Abbildung 93: Nettorenten in Prozent des Bruttolebenseinkommens

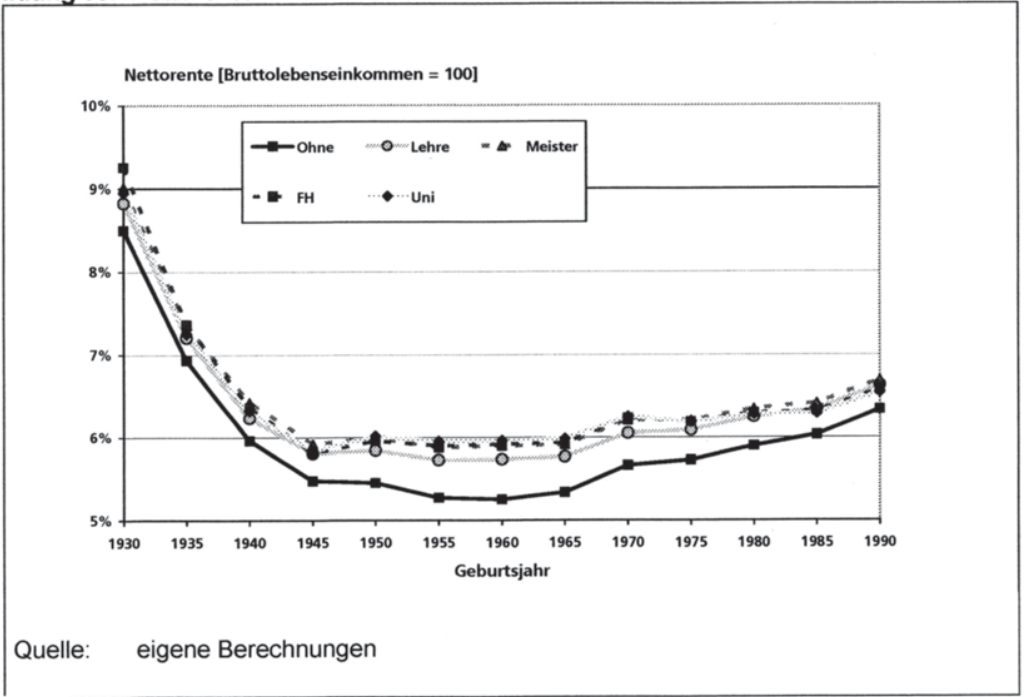

Die als Anteil am Bruttolebenseinkommen ausgedrückten Nettorenten bieten mehrere interessante Interpretationsansätze: Erstens zeigen die Werte an, welcher konstante Beitragssatz zur Rentenversicherung fair ist in dem Sinne, dass er ausschließlich zu einer intertemporalen Umverteilung über den Lebenszyklus führt. Wenn der Barwert einer Nettorente 9,3\% des Bruttolebenseinkommens entspricht, dann decken Nettobeiträge von durchgängig 9,3\% der Erwerbseinkommen diese Leistung genau ab. In dem Umfang, in dem die Nettobeiträge hierüber hinausgehen, findet eine Umverteilung zu Lasten des Versicherten statt. ${ }^{334}$ Zweitens zeigen die Differenzen verschiedener Nettorenten an, in welchem Umfang gegebenenfalls andere Maßnahmen Rentenkürzungen kompensieren oder verstärken. So fällt etwa der Banwert der Nettorenten für Fachhochschulabsolventen über die Geburtsjahre von 1930 bis 1955 von $9,3 \%$ auf $5,9 \%$ um 3,4 Prozentpunkte, für die anderen vier Abschlüsse sind die Rückgänge mit $3,1 \%$ bis $3,2 \%$ etwas geringer. Im Sinne einer gleichartigen Belastung der Kohorten durch das Steuer-Transfer-System wäre entsprechend ein um 3,4 Prozentpunkte niedrigerer Durchschnittssteuersatz geeignet, eine Schlechterstellung des Geburtsjahres 1955 im Vergleich zu 1930 Geborenen zu vermeiden. Drittens lassen sich die Differenzen auch dahin gehend interpretieren, um wie viele Prozentpunkte die Sparquoten jüngerer Generationen ansteigen müssten, um unter sonst gleichen Umständen Rückgänge des Rentenniveaus auszugleichen. Wenn et-

${ }^{334}$ Der Hinweis auf Nettobeiträge bezieht sich auf die steuerliche Abzugsfähigkeit der Beiträge zur Rentenversicherung. Da die entrichteten Beiträge grundsätzlich zu einer Steuerminderung führen, ist die Nettobelastung durch die Rentenversicherung in der Erwerbsphase geringer, als die Beitragssätze suggerieren. Auswirkungen der Besteuerung auf Renditen der gesetzlichen Rentenversicherung werden in Kapitel 7.2.4 untersucht. Die durchschnittlichen (Brutto-)Beitragssätze (Arbeitnehmer- und Arbeitgeberanteile zusammen) über die Enwerbsphase steigen über die Kohorten von knapp $16 \%$ auf gut $21 \%$. 
wa der Anteil der Nettorente am Bruttolebenseinkommen um 3,4 Prozentpunkte niedriger ausfallen wird als derzeit, führt eine zusätzliche Ersparnis über die Erwerbsphase in eben dieser Höhe von 3,4\% des Bruttoeinkommens zu einem vergleichbaren Einkommensniveau in der Rentenbezugsphase. ${ }^{335}$ Die Förderkonditionen der so genannten „Riester-Rente", die Anreize zu einer Stärkung kapitalgedeckter Altersvorsorge bieten soll, sind ab 2008 darauf ausgerichtet, eine Ersparnis in Höhe von $4 \%$ des Bruttoeinkommens anzuregen. Unter Berücksichtigung der steigenden Lebenserwartung erscheint dieser vom Gesetzgeber vorgegebene Wert von $4 \%$ nach den Ergebnissen des STM durchaus angemessen, wenn das heutige Einkommensniveau in der Rentenbezugsphase auch zukünftig gegeben sein soll.

Die in Abbildung 93 gezeigten Nettorenten reichen von 5,3\% (Ohne, 1955) bis 9,3\% $(F H, 1930)$ der jeweiligen Lebenseinkommen, so dass bei (Brutto-)Beitragssätzen von mindestens knapp $16 \%$ die Leistungen der Rentenversicherung stets deutlich geringer ausfallen als die sie begründenden Beiträge. Dieser Befund reflektiert das gängige Ergebnis einer impliziten Rendite des Umlageverfahrens, die unter der Kapitalmarktrendite liegt. ${ }^{336}$ Auch für die ältesten der hier betrachteten Kohorten mit ihren vergleichsweise sehr hohen impliziten Renditen (vgl. Kapitel 7) bewirkt die Rentenversicherung mithin eine Umverteilung zu ihren Ungunsten. Wie weit die Barwerte von Beiträgen und Renten jüngerer Generationen auseinander klaffen, hängt nicht unwesentlich vom angenommenen zukünftigen Zinssatz ab, bei niedrigeren Werten als den hier angesetzten langfristigen Realzinsen von $4 \%$ verbessert sich die Renten-Beitrags-Relation der jüngeren Kohorten, die Grundmuster der intergenerativen Unterschiede bleiben jedoch erhalten. In der Darstellung hier interessiert jedoch weniger das „Preis-Leistungs-Verhältnis" der Rentenversicherung sondern die Nettorenten in ihrer Funktion als Transfer und ihr Einfluss auf die Nettobelastung von Lebenseinkommen.

Intergenerative Vergleiche zeigen über die Kohorten von 1930 bis 1945 starke Rückgänge der Nettorenten, wie sie in ähnlicher Form auch bei den impliziten Renditen der Rentenversicherung auftreten (vgl. Kapitel 7). Die Nettorenten gehen von Werten von $8,5 \%$ bis $9,3 \%$ für den Jahrgang 1930 um 3,0 bis 3,5 Prozentpunkte zurück auf etwa $5,5 \%$ bis $5,9 \%$ des Bruttolebenseinkommens. Über die Kohorten von 1945 bis etwa 1965 zeichnen sich dann nur geringfügige Veränderungen ab, die Nettorenten entsprechen je nach Qualifikation durchgängig knapp 5,5\% bzw. knapp $6,0 \%$ des Bruttolebenseinkommens. Ab dem Jahrgang 1965 steigen die Nettorenten danach moderat aber kontinuierlich um bis zu etwa einen Prozentpunkt an, für 1990 Geborene liegen sie dann bei etwa $6,3 \%$ bis $6,7 \%$. In diesem Punkt unterscheiden sich Nettorenten und implizite Renditen. Bei den Renditen bestehen zwar auch Hinweise auf einen leichten Anstieg nach einem Minimum bei Geburtsjahren um 1965, die Zunahme fällt jedoch zum einen schwächer aus, und zum anderen schließt sich ihr eine Phase stagnierender oder leicht rückläufiger Renditen an (vgl. Kapitel 7.3). Hauptursache dieser Unterschiede sind höhere von den jüngeren Kohorten zu ent-

335 Auf Grund steigender Lebenserwartung reicht dieser Wert von 3,4\% nicht aus, um bei zukünftigen Rentnern das heutige Rentenniveau über die gesamte Rentenbezugsphase zu gewährleisten. Um auch in den zusätzlich zu durchlebenden Jahren ein gleichbleibendes Einkommensniveau zu bewirken, müsste die Sparquote entsprechend stärker ansteigen.

${ }^{336} \mathrm{Vgl}$. zu diesem als Aaron-Paradoxon bezeichneten Ergebnis, nach dem dynamische Effizienz eine Kapitalmarktrendite oberhalb der impliziten Rendite einer umlagefinanzierten Alterssicherung bedingt, Kapitel 8.1.2. 
richtende Beitragssätze, die sich auf die Renditen negativ auswirken, für die Anteile der Nettorenten am Bruttolebenseinkommen jedoch irrelevant sind.

Auf Grund der über die Geburtsjahre steigenden Abgabenbelastung in der Rentenbezugsphase ( $\mathrm{vgl}$. Abbildung 92) ist der wachsende Anteil der Nettorenten über die Kohorten ab 1965 zunächst eher überraschend. Ein Grund für die zunehmenden Anteile der Nettorenten am Lebenseinkommen ist die ebenfalls zunehmende Lebenserwartung. Bei einem gleich bleibenden Rentenniveau steigt der Anteil der Nettorenten am Lebenseinkommen mit der Rentenbezugsdauer, so dass die höhere Lebenserwartung der jüngsten Kohorten zu deren relativ höherer Nettorente beiträgt. Eine zweite Ursache für die in Abbildung 93 zum Ausdruck kommende Entwicklung über die Kohorten ab 1965 sind die historischen und zukünftigen Lohnwachstumsraten. Da zwischen dem Anteil der Nettorente am Lebenseinkommen und dieser Wachstumsrate ein positiver Zusammenhang besteht und da die angenommenen zukünftigen Raten von real 1,5\% (nominal: 3,0\%) über dem historischen Durchschnitt der vergangenen drei Dekaden liegen (vgl. Kapitel 2.2), beruhen die relativen Vorteile junger Kohorten im Vergleich zu mittleren wesentlich auf dieser Annahme.

Die beschriebene Entwicklung der Nettorenten über die Geburtsjahre verläuft für alle fünf qualifikationsabhängigen Einkommensprofile sehr ähnlich. Bei den intragenerativen Unterschieden zwischen den Abschlüssen sticht die durchgängig nachteilige Position von Personen ohne beruflichen Abschluss hervor, deren Nettorente stets etwa 0,4 bis 0,6 Prozentpunkte unter den anderen vier Werten liegt. Dieser Nachteil, der in abgemilderter Form auch beim Abschluss Lehre auftritt, folgt aus einer früher beginnenden Erwerbsphase, durch die die Nettorenten relativ stärker abdiskontiert werden. In Kapitel 7.2.1 wurde auf den grundsätzlichen Vorteil gestauchter "akademischer" Einkommensprofile in Hinblick auf die Rentenversicherung hingewiesen, da die Beiträge nicht versicherungsadäquat nach ihrem Einzahlungszeitpunkt gewichtet werden. Tatsächlich wurden in Kapitel 7.2.1 hingegen umgekehrt Renditenachteile für die akademischen Abschlüsse ermittelt, da sich unter den historischen und erwarteten Beitragssatz- und Einkommensanstiegen die grundsätzlichen Vorteile spät erfolgender Beitragszahlungen in Nachteile umkehrten. Bei der Darstellung der Nettorenten wie in Abbildung 93, bei der ausschließlich die Leistungsseite der Rentenversicherung betrachtet wird, schlagen hingegen die bereits für die Renditen erwarteten Zusammenhänge durch, nach denen früh einsetzende Erwerbsphasen nachteilig sind. Gemäß der Sichtweise, dass die Nettorenten in der dargestellten Form (versicherungsmathematisch) faire Beitragssätze anzeigen, benachteiligt die geltende Form der Rentenberechnung Personen mit (qualifikationsbedingt) längeren Erwerbsphasen. Nach den mit den typisierten Biographien des STM ermittelten Ergebnissen wären an der Dauer der Erwerbsphase orientierte Beitragssatzdifferenzierungen in einer Größenordnung von rund 0,4 bis 0,6 Prozentpunkten gerechtfertigt, wenn von der Rentenversicherung keine intragenerativen Unterschiede ausgehen sollen. ${ }^{337}$.

337 Tatsächlich ist intragenerative Umverteilung durch die Rentenversicherung vom Gesetzgeber durchaus gewollt, diese Absicht schlägt sich unter anderem in den in Kapitel 7.2 als Entgeltpunkte aus Transfers besprochenen versicherungsfremden Leistungen wie der Berücksichtigung von Ausbildung nieder (vgl. auch Kapitel 5.2), daneben wirkt sich die Verteilung der Periodeneinkommen über die Erwerbsphase wie erwähnt aus. 


\subsubsection{Lebensnettosteuersätze Alleinstehender}

Die sich aus den drei dargestellten Komponenten (Steuern, Sozialversicherungsbeiträge, Nettorenten) zusammensetzenden Lebensnettosteuersätze Alleinstehender sind in Abbildung 94 wiedergegeben. Sie entsprechen den Summen der Abgabenquoten aus Abbildung 91 (die sich ihrerseits aus den Durchschnittssteuersätzen und den Sozialversicherunsquoten gemäß Abbildung 90 zusammensetzen) und der Nettorenten aus Abbildung 93. Wie zu erwarten, ergibt sich für die ältesten Kohorten die geringste Nettobelastung ihrer Lebenseinkommen, da bei ihnen die niedrigsten Sozialversicherungsquoten, die höchsten Nettorenten und unterdurchschnittliche Steuersätze zusammentreffen. Die Lebensnettosteuersätze der Kohorte 1930 reichen von $16,7 \%$ (Ohne) bis $26,7 \%$ (Uni). Zu der raschen Zunahme über die darauf folgenden Geburtsjahre tragen alle drei Komponenten bei, steigende Steuern und Sozialversicherungsbeiträge treffen mit fallenden Nettorenten zusammen. Für den Jahrgang 1945 belaufen sich die Lebensnettosteuersätze auf 24,7\% (Ohne) bis $36,1 \%$ (Uni), gegenüber 1930 Geborenen entspricht dies Anstiegen um 8,0 (Ohne) bis 9,3 (Uni) Prozentpunkte.

\section{Abbildung 94: Lebensnettosteuersätze: Alleinstehende}

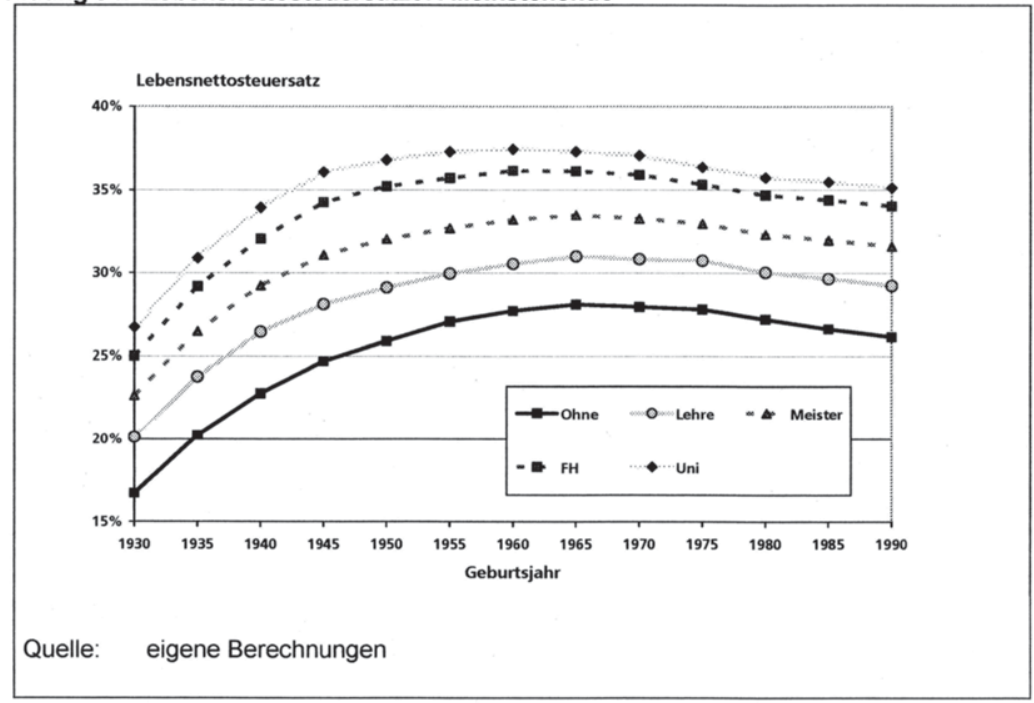

Auch der Verlauf der Lebensnettosteuersätze über die Kohorten von 1945 bis 1965 ähnelt dem durch die Abgabenquoten vorgeprägten Verlauf, nach dem in den unteren Einkommensniveaus die relativen Belastungen weiterhin ansteigen (um bis zu 3,4 Prozentpunkte auf $28,1 \%$ beim Abschluss Ohne), während mit steigendem Einkommen die Lebensnettosteuersätze der Geburtsspanne von 1945 bis 1965 zunehmend ähnlicher werden. Diese Unterschiede zwischen den Einkommensniveaus folgen überwiegend aus steuerlichen Entlastungen, von der vor allem höhere Einkommen profitieren. Während bei den Einkommensprofilen Ohne und Lehre für um 
1965 Geborene Belastungsspitzen auftreten, ist bei den Abschlüssen FH und Uni der maximale Lebensnettosteuersatz früher erreicht (bei Jahrgängen um 1960). Über die Kohorten von 1965 bis 1990 fallen die Nettobelastungen dann qualifikationsübergreifend um rund zwei Prozentpunkte auf $26,2 \%$ bis $35,1 \%$ des Bruttolebenseinkommens. Die Spannweiten der Lebensnettosteuersätze derjenigen Kohorten, die sich derzeit in der Erwerbsphase befinden (was für Jahrgänge ab 1945 typisierend gilt), belaufen sich je nach Abschluss auf 2,1 (FH) bis 3,4 (Ohne) Prozentpunkte. Im Vergleich zu den Veränderungen über die Geburtsjahre von 1930 bis 1945, wo sich wie erwähnt je nach Qualifikation Zuwächse um 8,0 bis 9,3 Prozentpunkte ergeben, erscheinen die intergenerativen Unterschiede zwischen den Kohorten ab 1945 mithin eher gering. Die jüngsten Kohorten sind dabei jeweils relativ geringen Nettobelastungen ausgesetzt.

Die mit dieser Entwicklung einher gehenden intragenerativen Unterschiede, ausgedrückt als qualifikationsabhängige Differenzen der Lebensnettosteuersätze eines Jahrgangs, sind in Abbildung 95 dargestellt; als Referenzgröße dienen in der Abbildung die Lebensnettosteuersätze des Einkommensprofils Ohne. Beispielsweise entspricht somit der für das Geburtsjahr 1930 angegebene Wert beim Abschluss Uni von 10,0\% der Differenz der Nettobelastungen von 26,7\% (Uni, 1930) und 16,7\% (Ohne, 1930), wie sie in Abbildung 94 ersichtlich sind. Die intragenerativen Unterschiede sind überwiegend beabsichtigte Folge der progressiven Besteuerung, daneben wirken in geringerem Umfang auch die Sozialversicherungsquoten und die Nettorenten intragenerativ differenzierend. Zwischen den niedrigeren der hier betrachteten Einkommensniveaus unterscheiden sich die Lebensnettosteuersätze je nach Geburtsjahr um 2,8 bis 3,7 Prozentpunkte, wobei für die Kohorten ab 1950 die Nettobelastungen beim Abschluss Lehre durchgängig um rund drei Prozentpunkte über dem Wert beim Einkommensprofil Ohne liegen, nur bei den älteren Kohorten treten etwas höhere Mehrbelastungen auf. Das qualifikationsbedingte Mehreinkommen bei durchschnittlichem (Lehre) im Vergleich zu unterdurchschnittlichem (Ohne) Einkommen führt mithin zu einer im Zeitverlauf weitgehend einheitlichen relativen Mehrbelastung in Höhe von etwa drei Prozentpunkten des Bruttolebenseinkommens.

Mit steigendem Einkommensniveau schwankt der Umfang, in dem die Lebensnettosteuersätze vom Referenzwert Ohne abweichen, hingegen zunehmend. Dabei zeichnet sich für die Abschlüsse Meister, FH und Uni jeweils dasselbe Muster ab, nach dem die intragenerative Spreizung der Nettobelastungen zunächst bis etwa zum Jahrgang 1945 wächst, danach um das Geburtsjahr 1980 auf ein Minimum fällt und zuletzt wieder leicht zunimmt. Bezogen auf vollständige Lebenszyklen folgt hiernach aus der Entwicklung des betrachteten Ausschnitts des Steuer-TransferSystems zunächst eine Phase zunehmender Differenzierung nach dem Einkommen, anschließend nimmt die vertikale Spreizung deutlich ab. Die zuletzt wieder um bis zu 0,5 Prozentpunkte leicht ansteigende Spannweite der Lebensnettosteuersätze folgt vor allem aus der zunehmenden steuerlichen Belastung höherer Renten, die wie 0ben beschrieben aus dem Übergang zur nachgelagerten Besteuerung folgt. Im Vergleich zu älteren Kohorten sind höhere Einkommen beim Jahrgang 1990 recht geringen Mehrbelastungen ausgesetzt. Der Lebensnettosteuersatz beim Abschluss Meister liegt je nach Geburtsjahr um 5,1 (1980) bis 6,5 (1940) Prozentpunkte über dem Wert Ohne, bei FH-Abschlüssen entsprechen die Differenzen 7,5 (1980) bis 9,5 (1945) Prozentpunkten, bei Uni-Abschlüssen 8,5 (1980) bis 11,4 (1945) Prozent- 
punkten. Wie ausgeprägt intragenerative Unterschiede ausfallen, variiert mithin mit dem Geburtsjahr, wobei sich die Ausmaße qualifikationsbedingter Mehrbelastungen je nach Abschluss um bis zu 1,4 (Meister) bzw. 2,0 (FH) bzw. 2,9 (Uni) Prozentpunkte des Bruttolebenseinkommens unterscheiden. Die oben dargestellten intergenerativen Unterschiede der Lebensnettosteuersätze zwischen den Kohorten 1945 bis 1990 belaufen sich bei einem Durchschnittseinkommen (Lehre) auf 2,9 Prozentpunkte (zwischen $28,1 \%$ beim Jahrgang 1945 und 31,0\% beim Jahrgang 1965, vgl. Abbildung 94). Die Spreizung intragenerativer Unterschiede innerhalb der Kohorten ab 1945 erreicht folglich eine vergleichbare Größenordnung. Das geltende Recht führt dabei zu vergleichsweise geringen intragenerativen Unterschieden, für ältere Kohorten wirkt das Steuer-Transfer-System in deutlich stärkerem Maße progressiv.

Abbildung 95: Lebensnettosteuersätze Alleinstehender: Intragenerative Unterschiede

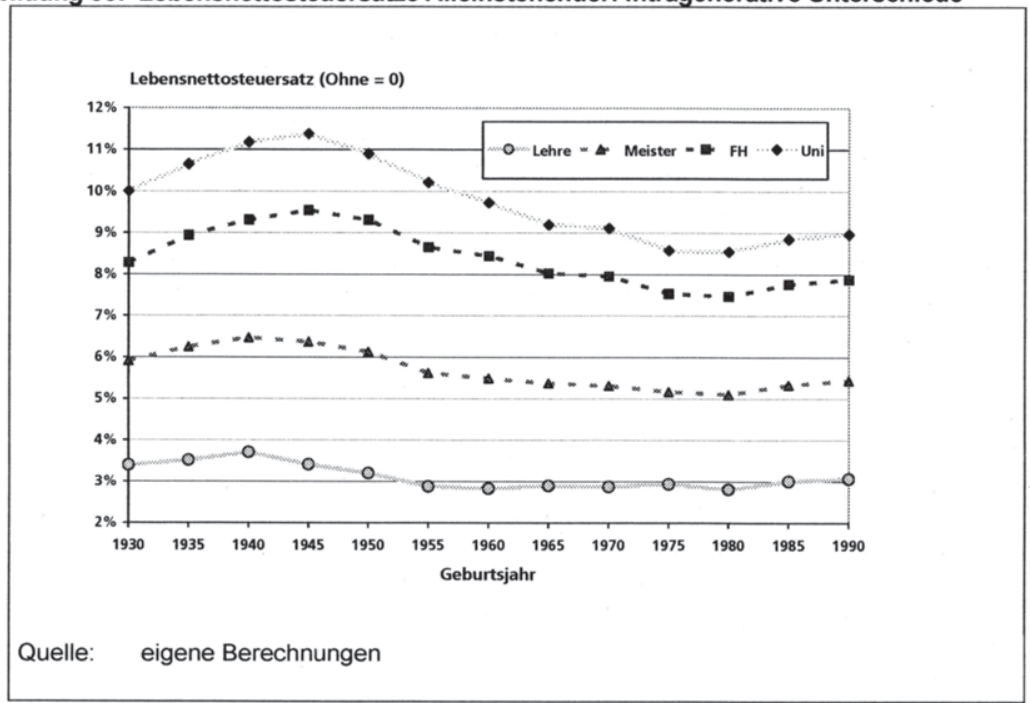

\subsubsection{Familienstand und Kinder}

Nachdem in den letzten Unterkapiteln Lebensnettosteuersätze für durchgehend Alleinstehende bestimmt wurden, wird die Betrachtung nun um Einflüsse des Familienstands und der Kinderzahl ergänzt. Untersucht wird dazu, wie sich der Lebensnettosteuersatz auf Grund der Berücksichtigung von Ehepartnern bzw. Kindern im SteuerTransfer-System ändert, indem bei gleichen Einkommensprofilen wie bisher statt von Alleinstehenden von Ehepaaren ohne bzw. mit zwei Kindern ausgegangen wird. Die Wirkung ehebedingter bzw. kindbedingter Mehreinkommen wird dabei wie in Kapitel 8 an Hand der Differenzen der Barwerte der verfügbaren Einkommen verschiedener Familientypen bei identischen Bruttoeinkommen bestimmt. Als ehebedingte Mehreinkommen werden typisierend die Mehreinkommen verheirateter Einverdienerehe- 
paare im Vergleich zu Alleinstehenden ermittelt. Als kindbedingte Mehreinkommen werden die Differenzen der verfügbaren Einkommen von Elternpaaren mit zwei Kindern und kinderlosen Ehepaaren angegeben. Die beiden Werte entsprechen somit dem vierten und fünften Bestandteil des Steuer-Transfer-Saldos in der oben aufgeführten Zerlegung. Die Quotienten dieser Mehreinkommen und des Bruttolebenseinkommens geben damit an, wie sich die jeweiligen Elemente des Steuer-TransferSystems auf den Lebensnettosteuersatz auswirken. Im Fall der kindbedingten Mehreinkommen fließen damit dieselben Größen in die Berechnungen ein, die bereits in Kapitel 8.2.2.1 bestimmt wurden. Anders als dort werden die Mehreinkommen hier jedoch nicht als Anteil am verfügbaren Einkommen sondern als Anteil am Bruttoeinkommen ausgedrückt. Ehe- und kindbezogene Leistungen lassen sich in dieser Form analog zu den Nettorenten in ihrer Wirkung als negative Steuersätze ausdrücken, wobei von der Belastung Alleinstehender als Referenzpunkt ausgegangen wird. Anders ausgedrückt entspricht die Differenz der Lebensnettosteuersätze von Alleinstehenden und Ehepaaren mit zwei Kindern der Summe aus ehebedingten und kindbedingten Mehreinkommen.

Ehebedingte Mehreinkommen, aufgefasst als Differenz der verfügbaren Einkommen von Alleinstehenden und Verheirateten bei einem gegebenen Einkommen, folgen im STM überwiegend aus der Zusammenveranlagung von Ehepaaren unter Anwendung des Splittingtarifs sowie in geringerem Umfang aus den Hinterbliebenenrenten. ${ }^{338}$ Die Entwicklung der ehebezogenen Transfers über die Kohorten von 1930 bis 1990 deutet auf einige Unterschiede zwischen den Qualifikationsniveaus hin (Abbildung 96). Für die Jahrgänge von 1930 bis 1940 folgen aus der Berücksichtigung des Ehepartners im Steuer-Transfer-System Mehreinkommen von bis zu 9,5\% des Bruttolebenseinkommens (Uni, 1930), wobei der relative Wert ehebedingter Mehreinkommen mit dem Einkommen stark abnimmt auf bis zu 5,7\% des Bruttolebenseinkommens (Ohne, 1930). Zwischen den Kohorten von 1950 bis 1990 lassen sich hingegen keine systematischen intragenerativen Unterschiede ausmachen, auch Abweichungen zwischen den Geburtsjahren sind nur schwach ausgeprägt. In den Jahrgängen ab 1950 bewegen sich die ehebezogenen Transfers für alle Abschlüsse bei nur geringen Schwankungen um einen Wert von $6 \%$, Minimum und Maximum liegen bei $5,4 \%$ ( $F H, 1955)$ bzw. 6,7\% (Lehre, 1970). Eine Erklärung dieser Verläufe an Hand entsprechender gesetzlicher Änderungen erscheint nur sehr begrenzt möglich. Abgesehen von der Einführung des Ehegattensplittings ab 1958, das im Vergleich zur Zeit davor in der Regel zu einer steuerlichen Entlastung führt (vgl. Kapitel 4.2.1), und für den hier gegebenen Kontext eher unbedeutenden Änderungen bei Witwenrenten (vgl. Kapitel 5.1 sowie 7.2.3) erfolgten seit 1950 keine für das STM relevante Eingriffe, mit denen der Gesetzgeber unmittelbar auf Änderungen bei ehebezogenen Transfers abzielte.

${ }^{338}$ Die Nettorentenanteile von Ehepaaren, die über die Nettorenten von Alleinstehenden hinausgehen, sind vollständig in den ehebedingten Mehreinkommen erfasst, neben einer Hinterbliebenenrente also etwa auch eine Steuerminderung, die sich aus der Zusammenveranlagung eines Rentnerpaares ergibt. Als Nettorenten gemäß obiger Zerlegung des Steuer-Transfer-Saldos sind folglich ausschließlich die Nettorenten von Alleinstehenden erfasst. Dieselbe Zuordnung gilt analog für die kindbedingten Mehreinkommen. 
Abbildung 96: Ehebedingte Mehreinkommen (Einverdiener ohne Kinder)

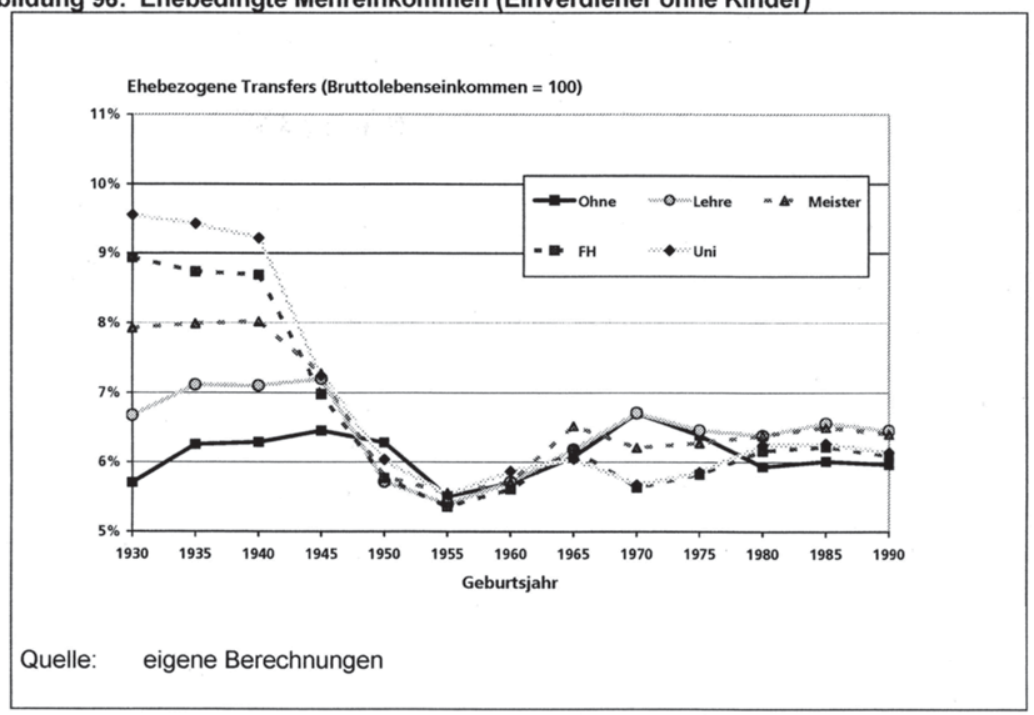

Vorteile älterer Kohorten folgen zum Teil aus dem Rentensystem, da bei ihnen die Witwenrenten -wie auch die Altersrenten- relativ hoch ausfallen, wobei die intergenerativen Unterschiede hieraus jedoch weniger als 0,5 Prozentpunkte des Bruttolebenseinkommens betragen. Die vergleichsweise hohe Besteuerung von Ehepaaren in den Jahren bis 1957 betrifft unter den hier betrachteten Fällen Angehörige der Kohorte 1930 mit den Abschlüssen Ohne und Lehre, was zu ihren im intragenerativen Vergleich niedrigeren ehebedingten Mehreinkommen beiträgt; bei den drei anderen Abschlüssen geht hingegen mit der längeren Ausbildungsdauer die Annahme einer späteren Heirat einher.

Ansonsten hängt die in Abbildung 96 ersichtliche Entwicklung der Umfänge ehebedingter Mehreinkommen über die Kohorten wesentlich vom Lohnwachstum ab. Nach den in den Kapiteln 7 und 8 begründeten Annahmen ist bei Einverdienerpaaren der zweite Partner zunächst einige Jahre bis kurz nach der Heirat enwerbstätig, wodurch ein größerer Anteil des gemeinsamen Bruttolebenseinkommens zu Beginn der Enwerbsphase erzielt wird. Je geringer dieser Anteil des früh erworbenen Einkommens als Doppelverdiener ist, bei dem aus einer Heirat keine oder nur geringe Mehreinkommen folgen, desto höher fallen grundsätzlich die ehebezogenen Transfers aus. Ein starkes Lohnwachstum wie für den Zeitraum bis in die Mitte der 1970er Jahre festgestellt (vgl. Kapitel 2.2) führt mithin zu einem höheren Anteil der ehebezogenen Leistungen am Bruttolebenseinkommen. Die relativ hohen Werte für Angehörige älterer Kohorten mit überdurchschnittlichen Einkommen sind entsprechend primär Begleiterscheinung der gesamtwirtschaftlichen Entwicklung und nicht Folge einer gezielten Förderung der Ehe. Generell führt die Barwertbildung dazu, dass die ehebedingten Mehreinkommen im Lebenszyklus niedriger ausfallen als die durchschnittliche Steuerminderung in der Erwerbsphase. Die Anwendung des Splittings führt unter sämtlichen Steuertarifen seit 1958 bei der hier betrachteteten Einkom- 
mensspanne zu Senkungen des Durchschnittssteuersatzes um etwa $7 \%$ bis $11 \%$, unter dem seit 2005 geltenden Tarif etwa ergeben sich für alle fünf betrachteten Einkommensprofile Splittingvorteile in einer Größenordnung von überwiegend $7-9 \%$ des Bruttojahreslohns. Die ehebedingten Mehreinkommen der jüngeren Kohorten liegen mit Werten von höchstens 6,5\% (von denen rund ein Prozentpunkt auf Witwenrenten zurückzuführen ist) indessen stets niedriger, da die Steuerminderungen auf den Zeitpunkte des Beginns der Erwerbsphase abdiskontiert werden und in den ersten Erwerbsjahren keine ehebedingten Transfers anfallen.

Insgesamt lässt sich aus der Entwicklung festhalten, dass für Kohorten ab etwa 1950 ein Wert von 6\% des Bruttolebenseinkommens als geeignete Faustgröße für ehebedingte Mehreinkommen dienen kann, inter- sowie intragenerative Unterschiede sind dabei eher gering. Die Berücksichtigung der Ehe im Steuer-Transfer-System wirkt mithin wie eine pauschale Herabsetzung des Lebensnettosteuersatzes um etwa sechs Prozentpunkte. Lediglich Angehörige älterer Kohorten mit überdurchschnittlichen Einkommen fallen mit höheren ehebezogenen Transfers von bis zu gut $9 \%$ des Bruttolebenseinkommens auf, diese sind jedoch primär Nebenprodukt der Lohnentwicklung und entspringen keiner gezielten Förderung der Ehe.

Die im Folgenden dargestellten kindbedingten Mehreinkommen entsprechen der Zunahme des verfügbaren Einkommens mit der Kinderzahl bei ansonsten identischen Einverdienerehepaaren wie im letzten Abschnitt. Zu den kindbedingten Mehreinkommen tragen durchgehend Kindergeld und -freibeträge als Elemente des Familienleistungsausgleichs bei, daneben wirken sich zum Teil zeitlich begrenzt verschiedene andere Transfers aus. Hier werden als Standardfall kindbedingte Mehreinkommen von Ehepaaren mit zwei Kindern untersucht, wobei, wie in Kapitel 8 gezeigt wurde, vor allem die Förderung erster Kinder im Zeitverlauf zunahm. ${ }^{339}$ In Hinblick auf die Entwicklung der Anteile der kindbedingten Mehreinkommen am Bruttolebenseinkommen ergeben sich weitgehend ähnliche Befunde wie bereits in Kapitel 8 diskutiert, so dass für eine ausführlichere Darstellung auf dieses verwiesen wird. ${ }^{340}$ Wesentliche Ergebnisse sind zum einen deutliche Zunahmen der kindbedingten Mehreinkommen über die Kohorten für alle Einkommensprofile und zum anderen eine dabei zunehmende Staffelung über die Einkommensskala, womit vor allem für niedrigere Einkommen der Anteil kindbedingter Mehreinkommen am Bruttolebenseinkommen zunimmt (Abbildung 97). Zu diesen Verläufen tragen deutliche Ausweitungen des Familienleistungsausgleichs, die Einführung und Ausweitung von Transfers im Anschluss an die Geburt von Kindern seit 1979 (Mutterschaftsurlaubs-, Erziehungs- und Elterngeld) sowie eine steigende Berücksichtigung von Kindern bei der Rentenberechnung bei. Aus den älteren Rechtsständen, unter denen kindbedingte Mehreinkommen

339 Die heutige monetäre Familienpolitik erscheint im historischen Vergleich insgesamt sehr großzügig, wobei die Förderung insbesondere für erste Kinder im Zeitverlauf deutlich ausgebaut wurde. Für die hier betrachteten Zweikindfamilien ergeben sich entsprechend geringere Zunahmen der kindbedingten Mehreinkommen über die Kohorten als bei Einkindfamilien, umgekehrt fallen die Zuwächse bei Dreikindfamilien geringer aus als hier. Die Entwicklungen im Bereich der monetären Familienpolitik und die Unterschiede in der Differenzierung nach der Kinderzahl sind in Kapitel 8.2.2 ausführlicher besprochen.

${ }^{340} \mathrm{~S}$. vor allem Kapitel 8.2.2.1, in dem wie hier kindbedingte Leistungen im Lebenszyklus gleichalter Eltern untersucht werden. Die hierbei auftretenden intragenerativen Unterschiede folgen zum einen aus einkommensabhängigen Wirkungen familienpolitischer Maßnahmen, zum anderen auch aus den qualifikationsabhängig unterschiedlichen Gebäraltern. 
überwiegend aus steuerlichen Freibeträgen resultieren, folgen für alle fünf Qualifikationen sehr ähnliche kindbedingte Mehreinkommen, für den Jahrgang 1930 entsprechen die für zwei Kinder insgesamt anfallenden Leistungen 2,4\% bis $2,6 \%$ des Bruttolebenseinkommens. Die Mehreinkommen entfalten für diesen Jahrgang mithin dieselbe Wirkung wie eine pauschale Senkung des Durchschnittssteuersatzes um etwa 2,5 Prozentpunkte.

Abbildung 97: Kindbedingte Mehreinkommen (Einverdiener, 2 Kinder)

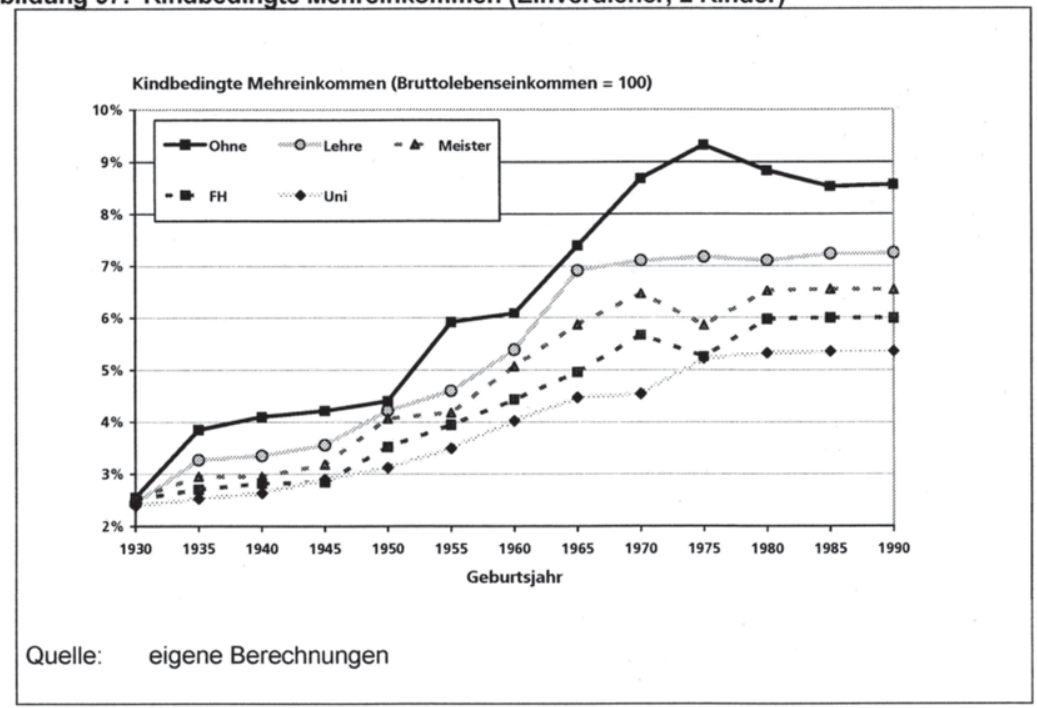

Indem die kindbezogenen Transfers im betrachteten Zeitraum generell zunehmend großzügiger ausgestaltet wurden, ergeben sich für alle fünf Einkommensprofile weitgehend monotone Anstiege. Da weiterhin dabei das Gewicht nicht oder negativ einkommensabhängiger Transfers wie Kinder- oder Erziehungsgeld wuchs, steigt der Anteil der Mehreinkommen für niedrigere Einkommen am stärksten an. ${ }^{341}$ Für die Kohorten ab 1980 ergeben sich überwiegend die höchsten kindbedingten Leistungen, sie entsprechen rund $5,4 \%$ (Uni) bis 7,3\% (Lehre) des Bruttolebenseinkommens. Nur beim Eikommensprofil Ohne, für das sich hier Werte um 8,6\% ergeben, sind leichte Rückgänge erkennbar, dort tritt das Maximum beim Geburtsjahr 1975 mit 9,3\% auf. ${ }^{342}$ Die Spannweiten der kindbedingten Mehreinkommen über die

${ }^{341}$ Die Absolutbeträge der kindbedingten Mehreinkommen hängen hingegen überwiegend positiv vom Einkommen ab (vgl. Kapitel 8.2.2.2). Gemessen am niedrigeren Bruttolebenseinkommen kommt den kindbedingten Mehreinkommen jedoch eine größere Bedeutung bei den niedrigeren Qualifikationsniveaus zu.

342 Ausschlaggebend für den Rückgang über die Kohorten ab 1975 beim Einkommensprofil Ohne ist der Wechsel vom Erziehungs- zum Elterngeld, der sich für die untersuchte Fallkonstellation der Einverdiener mit zwei Kindern nachteilig auswirkt. Für die vier höheren Einkommen ist der Regimewechsel hingegen eher vorteilhaft. Die leicht fallenden Anteile der kindbedingten Mehrein- 
Kohorten von 1930 bis 1990 belaufen sich qualifikationsabhängig auf mindestens 3,0 Prozentpunkte (von $2,4 \%$ bis $5,4 \%$ beim Abschluss Uni) und bis zu 6,7 Prozentpunkte (von 2,6\% bis $9,3 \%$ beim Abschluss Ohne). Sowohl zwischen Kohorten als auch innerhalb der jüngeren Kohorten bestehen folglich erhebliche Unterschiede in der Wirkung kindbedingter Mehreinkommen auf die Nettobelastungsquote des Lebenseinkommens: Erstens werden jüngere Kohorten wesentlich stärker entlastet als ältere (je nach Qualifikation um mindestens 3,0\% des Bruttolebenseinkommens). Zweitens nimmt die vertikale Differenzierung der Lebensnettosteuersätze zu, für Kohorten ab 1965 vergrößern die kindbedingten Leistungen die Spreizung der Belastungsquoten um drei bis vier Prozentpunkte.

Die sich aus den fünf dargestellten Elementen zusammensetzenden Lebensnettosteuersätze von Ehepaaren mit zwei Kindern sind in Abbildung 98 dargestellt. Die abgebildeten Werte umfassen die drei Summanden Lebensnettosteuersätze Alleinstehender (vgl. Abbildung 94), ehebedingte Mehreinkommen (vgl. Abbildung 96) und kindbedingte Mehreinkommen (vgl. Abbildung 97). Wie bereits bei Alleinstehenden treten die niedrigsten Nettobelastungen bei den ältesten Kohorten auf, auch zeigt sich wiederum das bekannte Grundmuster zunächst rasch steigender und anschließend zumindest leicht fallender Lebensnettosteuersätze. Im Umfang der Zu- und Abnahmen der Belastungsquoten über die Kohorten bestehen jedoch recht starke Unterschiede zwischen Alleinstehenden und Ehepaaren mit zwei Kindern. Die Entwicklung der ehebedingten Mehreinkommen führt hauptsächlich bei höheren Einkommen zu einem noch steileren Anstieg der Lebensnettosteuersätze über die Geburtsjahre von 1930 bis 1945, danach bewirken sie im Vergleich zu Alleinstehenden weitgehend ausschließlich eine Niveauverschiebung, die Lebensnettosteuersätze fallen typischerweise um etwa sechs Prozentpunkte geringer aus.

Die über die Kohorten zunehmende Bedeutung kindbedingter Mehreinkommen mildert indessen zunächst die Belastungszunahmen über die Jahrgänge ab und verstärkt anschließend ihren Rückgang. Bei Alleinstehenden mit höheren Einkommen treten die höchsten Lebensnettosteuersätze für die Kohorten von etwa 1950 bis 1975 auf, deren Belastungsquoten sich untereinander nur leicht unterscheiden (Lebensnettosteuersätze von $36,4 \%$ bis $37,4 \%$ beim Abschluss Uni); bei Paaren mit zwei Kindern hingegen setzt bereits ab dem Geburtsjahr 1955 ein moderater aber stetiger Rückgang ein (Lebensnettosteuersätze für zwischen 1955 und 1975 Geborene zwischen zunächst $28,3 \%$ und später $25,3 \%$ beim Abschluss Uni). Auch im Fall durchschnittlicher Einkommen tritt bei Familien die Belastungsspitze beim Jahrgang 1955 auf, während bei Alleinstehenden die höchste relative Belastung für den Jahrgang 1965 anfällt (vgl. Abbildung 99). 
Abbildung 98: Lebensnettosteuersätze: Ehepaare, 2 Kinder

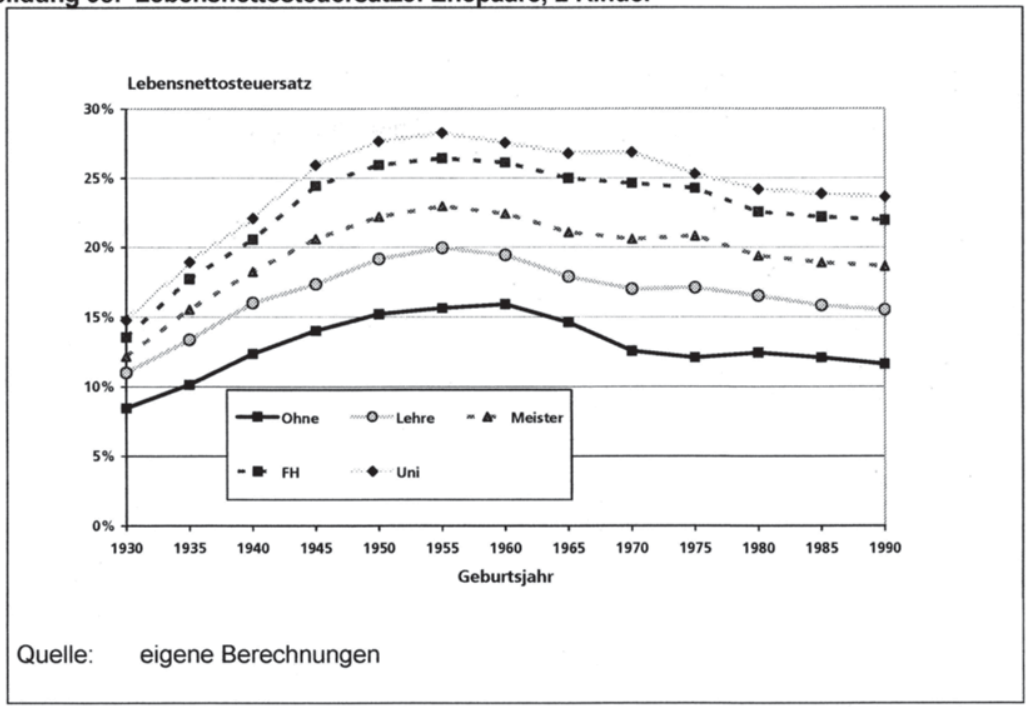

Abbildung 99: Lebensnettosteuersätze bei Durchschnittsverdienst (Lehre) nach Familienstand

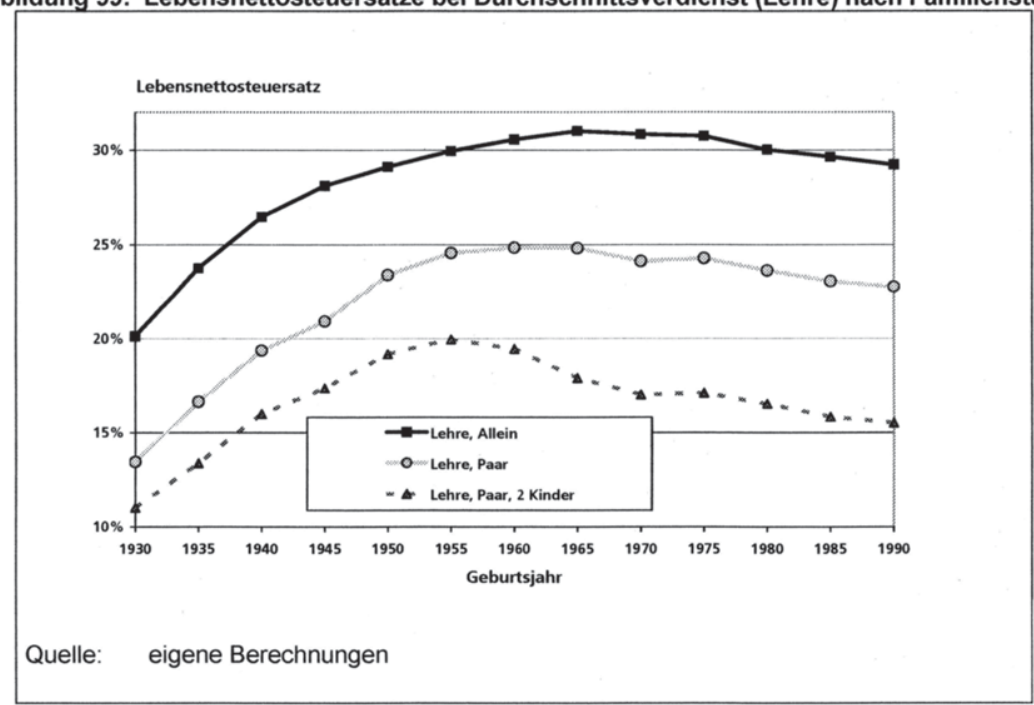

Für welche Kohorten eine besonders hohe Nettobelastung ihres Lebenseinkommens auftritt, variiert folglich mit dem Familienstand, bei Alleinstehenden sind bis in höhere Geburtsjahre hinein Anstiege der Lebensnettosteuersätze zu enwarten. Darüber hinaus tragen die kindbedingten Mehreinkommen dazu bei, dass die Vorteile jüngerer 
Kohorten im Vergleich zu mittleren deutlich stärker ausfallen. Während bei Alleinstehenden die Lebensnettosteuersätze über die Geburtsjahre von 1960 bis 1990 um etwa zwei Prozentpunkte fallen, belaufen sich die entsprechenden Rückgänge bei Zweikindfamilien auf etwa 4,5 Prozentpunkte. Insgesamt erscheinen die intergenerativen Unterschiede der Lebensnettosteuersätze bei Familien weniger stark ausgeprägt als bei Alleinstehenden, da die zunehmenden kindbezogenen Leistungen die deutlich niedrigeren Abgabenquoten der ältesten Kohorten partiell kompensieren. Der Befund der niedrigsten Lebensnettosteuersätze für die ältesten Kohorten bleibt jedoch trotz ihrer relativ geringen kindbedingten Mehreinkommen auch bei Familien erhalten. Die geringste Nettobelastung von Zweikindfamilien unter den ab $1945 \mathrm{Ge}$ borenen ergibt sich für jedes Qualifikationsniveau beim Jahrgang 1990.

\subsubsection{Rechenvarianten: Beitragssatzanstiege und Arbeitgeberanteile}

Die bisher vorgestellten Lebensnettosteuersätze beruhen unter anderem auf der Vorgabe von ab dem Jahr 2007 konstant bleibenden Beitragssätzen zur Krankenund Pflegeversicherung, einer angesichts der zu erwartenden demographischen Entwicklung unrealistischen Setzung, die für die Fragestellungen in den zurückliegenden Kapiteln des zweiten Teils dieser Arbeit jedoch unschädlich erscheint. Da zum einen in der Diskussion um eine intergenerativ ausgewogene Lastenverteilung zukünftige Mehrbelastungen durch die umlagefinanzierten Sicherungssysteme ein zentrales Argument bilden und zum anderen die Ergebnisse dieses Kapitels Aufschluss geben sollen, welcher Anteil der Belastung von Lebenseinkommen auf einzelne Elemente des Steuer-Transfer-Systems entfällt, werden nun in einem Szenario II die sich aus Beitragssatzanstiegen ergebenden Mehrbelastungen ergänzt. Dieses Szennario II greift wie in Kapitel 9.2.1 beschrieben auf Projektionen zur Kranken- und Pflegeversicherung zurück, nach denen bis zum Jahr 2060 die Beitragssätze von derzeit $13,9 \%$ auf $19,5 \%$ (Krankenversicherung) bzw. von 1,95\% (ab Juli 2008) auf 3,9\% (Pflegeversicherung) ansteigen. Außerdem wird in diesem Szenario bei der Arbeitslosenversicherung ebenfalls nicht der Wert des Jahres 2007 von 4,2\% beibehalten sondern der seit 2008 gültige Beitragssatz von 3,3\%. In Hinblick auf die Rentenversicherung weicht Szenario II nicht von den in dieser Arbeit durchgehend getroffenen Annahmen (und somit auch nicht vom Basisszenario) ab. Die Beitragssätze zur Sozialversicherung insgesamt steigen in Szenario II auf Werte von bis zu 50,5\%, im Basisszenario auf $44,8 \%$, die Arbeitnehmeranteile entsprechen jeweils gut der Hälfte dieser Werte (vgl. Abbildung 86).

In welchem Umfang die Lebensnettosteuersätze auf Grund dieser Beitragssatzanstiege bei Kranken- und Pflegeversicherung zunehmen, wird aus Abbildung $100 \mathrm{er}-$ sichtlich. In der Abbildung sind die Differenzen der Lebensnettosteuersätze aus dem Basisszenario und aus Szenario II abgetragen. Die abgebildeten Werte gelten für Alleinstehende, für andere Familientypen ergeben sich jedoch nur minimale Abweichungen. Wie auch in den bisherigen Berechnungen schlagen sich nur die Arbeitnehmeranteile an den Sozialabgaben nieder. Die zusätzlichen Beitragssatzanstiege des Szenario II um langfristig bis zu knapp drei Prozentpunkte (Arbeitnehmeranteile) führen zu Erhöhungen der Lebensnettosteuersätze um höchstens 1,5 Prozentpunkte 
( $F H, 1990)$, wobei die Mehrbelastungen über die Kohorten beständig zunehmen; der Jahrgang 1930 ist annähernd nicht betroffen.

Abbildung 100: Sozialversicherung: Mehrbelastung in Szenario II

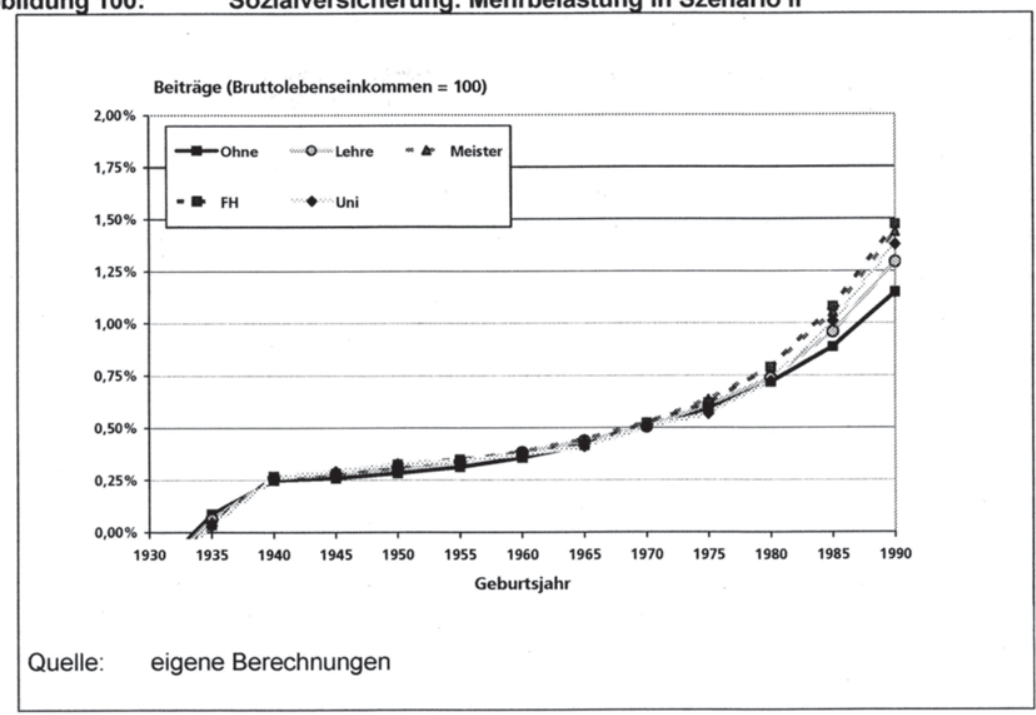

Im Basisszenario mit seinen ab 2007 konstanten Beitragssätzen zu Kranken- und Pflegeversicherung ergeben sich wie oben aufgeführt Anstiege der Sozialversicherungsquoten über die Kohorten von 1930 bis 1990 um etwa 7,5 Prozentpunkte (vgl. Abbildung 90), unter den Annahmen des Szenario II erhöht sich dieser Wert also auf rund 9,0 Prozentpunkte. Zusätzliche intragenerative Unterschiede in Szenario II sind zwar auf Grund der qualifikationsabhängig unterschiedlich langen Erwerbsphasen vorhanden, wirken jedoch vernachlässigbar klein. Im Vergleich zu anderen Bestandteilen der Lebensnettosteuersätze von Kohorten bis 1990 ist der Einfluss des zu erwartenden Beitragssatzdrucks bei Kranken- und Pflegeversicherung gering. Sehr langfristig würden die Belastungsquoten im gleichen Umfang wie die Beitragssätze steigen (bei einer langfristig stationären Entwicklung mithin um knapp drei Prozentpunkte), über die Lebenszyklen der hier betrachteten Kohorten bis 1990 führt der Übergang dorthin jedoch zu Zunahmen von wie erwähnt höchstens 1,5 Prozentpunkten. Für die Kohorten von 1940 bis 1970 zeichnen sich dabei mit rund 0,25 bis 0,5 Prozentpunkten leicht höhere Lebensnettosteuersätze als im Basisszenario ab, über die Geburtsjahre von 1970 bis 1990 steigt die Mehrbelastung in Szenario II dann um einen weiteren Prozentpunkt. Im Vergleich zu Beitragssatzanstiegen der Vergangenheit, durch die etwa die Kohorte 1940 eine um rund zwei Prozentpunkte höhere Belastungsquote aufweist als die Kohorte 1930 (vgl. Abbildung 90), erscheint diese Zunahme moderat.

In einer zweiten Berechnungsvariante wurden die Arbeitgeberanteile an den Sozialabgaben in die Bestimmung der Belastungsquoten des Lebenseinkommens ein- 
bezogen. Formal fallen die Arbeitgeberanteile zu Lasten des Arbeitgebers an, so dass die Lebensnettosteuersätze in der vorgestellten Form, in der ausschließlich die Arbeitnehmeranteile erfasst sind, den rechtlichen Vorgaben entsprechen. Zumindest langfristig ist jedoch davon auszugehen, dass die Arbeitgeberanteile in die Lohnbildung einfließen und damit überwälzt werden, so dass auch sie letztlich von den Arbeitnehmern getragen werden. Nach dieser Inzidenzannahme bildet nicht der Bruttolohn die angemessene Größe zur Bestimmung einer (Lebens-)Abgabenquote sondern die Arbeitskosten, die sich aus Bruttolohn und Arbeitgeberbeiträgen zusammensetzen. ${ }^{343}$ Auf Grund der über weite Strecken paritätischen Finanzierung der Sozialversicherung stimmen Arbeitgeber- und Arbeitnehmerbeiträge annähernd überein, erst durch die Zuschläge ab 2005 fallen die Arbeitnehmerbeiträge seitdem etwas höher aus (vgl. Kapitel 4.1).

Bei einem Barwert des Steuer-Transfer-Saldos $S$ (mit den fünf besprochenen Komponenten Steuern, Sozialversicherungsbeiträge, Nettorenten und ehe- sowie kindbedingte Mehreinkommen) und einem Barwert des Lebensbruttolohns $Y$ entsprechen die vorgestellten Lebensnettosteuersätze $L$ der Form $L=S / Y$. Bei Arbeitgeberbeiträgen zur Sozialversicherung $G$ ergeben sich die von den Arbeitskosten $Y+G$ ausgehenden Lebensnettosteuersätze $L^{\prime}$ demnach als:

$L^{\prime}=\frac{S+G}{Y+G}$

Bei einem Anteil der Arbeitgeberbeiträge am Bruttolohn $g$ mit $g=G / Y$ gilt damit:

$$
L^{\prime}=\frac{L}{1+g}+\frac{g}{1+g}
$$

Im Vergleich zu den bisher diskutierten Lebensnettosteuersätzen $L$ sind die Belastungsquoten auf der Grundlage der Arbeitskosten $L^{\prime}$ stets größer, wobei die Werte umso weiter auseinander liegen, je größer $g$ ist. Bei im Zeitverlauf steigenden Sozialversicherungsquoten wie in Deutschland folgt hieraus, dass $L^{\prime}$ für die jüngeren Kohorten besonders stark über $L$ liegt. Für intragenerative Vergleiche zeichnet sich eine geringere Streuung der Belastungsquoten $\mathrm{ab}$, da erstens die sich in $L$ niederschlagenden intragenerativen Unterschiede in Bezug zu einer höheren Einkommensgröße gesetzt werden (Division durch $1+g$ ) und zweitens ein intragenerativ (annähernd) invarianter Zuschlag $\frac{g}{1+g}$ hinzu kommt. Im Vergleich zu den besprochenen Lebensnettosteuersätzen $L$ weisen die Belastungsquoten auf der Grundlage von Arbeitskosten $L^{\prime}$ folglich die drei Eigenschaften auf, erstens größer zu sein, zweitens im intergenerativen Vergleich nachteiliger für jüngere Kohorten zu sein und drittens intragenerative Unterschiede einzuebnen.

${ }^{343}$ Im Weiteren wird die Summe aus Bruttolohn und Arbeitgeberbeiträgen zu Renten-, Kranken-, Arbeitslosen- und Pflegeversicherung vereinfachend als Arbeitskosten bezeichnet. Tatsächlich gehen die Arbeitskosten in gängiger Abgrenzung über diesen Betrag hinaus, da sie unter anderem noch Beiträge zur Unfallversicherung umfassen. 
Bei Alleinstehenden mit dem Einkommensprofil Ohne übersteigen die von den Arbeitskosten wie beschrieben ausgehenden Lebensnettosteuersätze $L^{\prime}$ um rund 10,3 (Jahrgang 1930) bis 12,6 (1990) Prozentpunkte die oben in Abbildung 94 dargestellten Werte $L$. Für höhere Einkommensniveaus mit ihren höheren Belastungsquoten fallen die Unterschiede zwischen den beiden Abgrenzungen geringer aus, beim Abschluss Uni liegt $L^{\prime}$ um 8,4 (1930) bis 10,8 (1990) Prozentpunkte über $L$. Auch für die drei weiteren Einkommensverläufe gilt, dass der "Zuschlag" zu den Lebensnettosteuersätzen durch den Einbezug der Arbeitgeberbeiträge für die jüngsten Kohorten um etwa 2,3 bis 2,4 Prozentpunkte höher ausfällt als für die ältesten. Da die ehe- und kindbedingten Mehreinkommen in der Abgrenzung $L^{\prime}$ in geringerem Umfang auf die Lebensnettosteuersätze einwirken, unterscheiden sich die Werte von Familien und Alleinstehenden weniger stark als in der bisherigen Betrachtung.

Die Entwicklung der auf die Arbeitskosten bezogenen Lebensnettosteuersätze über die Kohorten weist grundsätzlich dieselben Muster auf wie in der bisherigen Darstellung, einem starken Anstieg über die älteren Kohorten folgt ein mäßiger Rückgang. Auch der Befund einer bei niedrigeren Einkommen später auftretenden Belastungsspitze bleibt erhalten (Abbildung 101). Allerdings führt der zusätzliche Anteil der Sozialversicherungsbeiträge an der Gesamtbelastung dazu, dass der Anstieg über die älteren Kohorten verstärkt wird und der nachfolgende Rückgang erstens später einsetzt und zweitens schwächer ausfällt.

Abbildung 101: Nettobelastung der Arbeitskosten: Alleinstehende

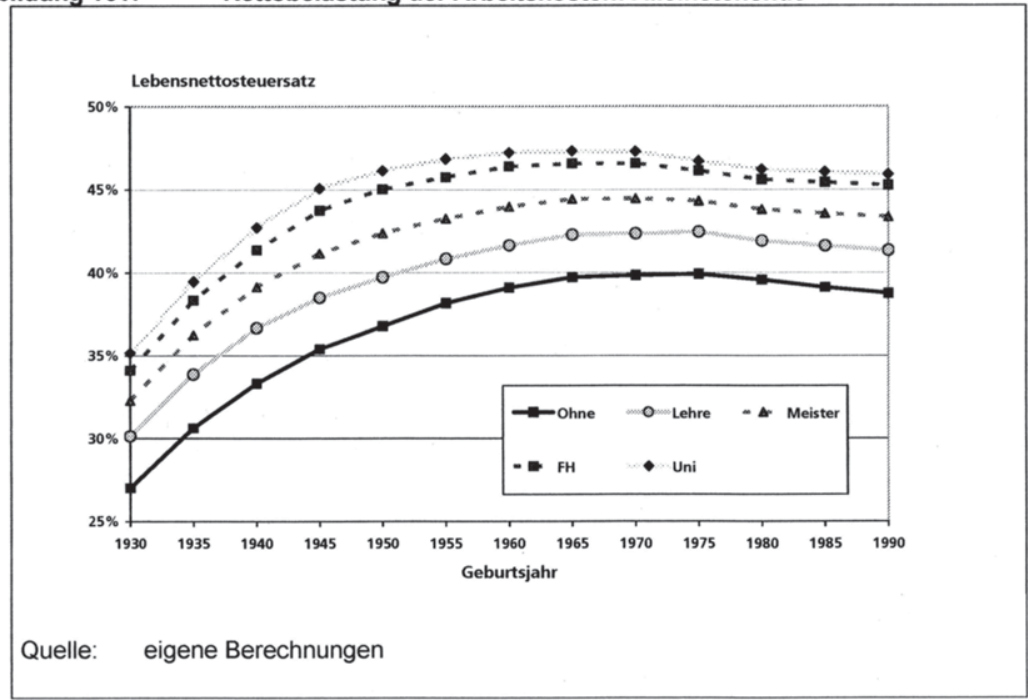

Nach Lebensnettosteuersätzen $L^{\prime}$ von $27,0 \%$ (Ohne) bis 35,2\% (Uni) für den Jahrgang 1930 liegen die Belastungsquoten der Kohorte 1945 mit Werten von 35,4\% (Ohne) bis $45,1 \%$ (Uni) um 8,4 bis 9,9 Prozentpunkte darüber; für die von den Bruttolöhnen ausgehenden Lebensnettosteuersätze $L$ ergaben sich hier von einem niedrigeren Niveau aus vergleichbare Zunahmen um 8,0 bis 9,3 Prozentpunkte (s. o.). Vor 
allem für niedrigere Einkommen wachsen die Lebensnettosteuersätze $L^{\prime}$ danach weiter, bis für die Kohorten von etwa 1965 bis 1975 die Maximalwerte erreicht werden (Lebensnettosteuersätze von knapp $40 \%$ beim Einkommensprofil Ohne). Bei höheren Einkommen tritt die Belastungsspitze wiederum etwas früher auf, Personen der Geburtsjahre von 1960 bis 1970 mit dem Abschluss Uni weisen hier mit Werten von $47,3 \%$ die höchste relative Belastung auf. Für die jüngste Kohorte liegen die Lebensnettosteuersätze $L^{\prime}$ mit $38,8 \%$ (Ohne) bis $45,9 \%$ (Uni) um rund 1,1 bis 1,4 Prozentpunkte unter den jeweiligen Maxima.

Unter den Kohorten, die sich typisierend in der Erwerbsphase befinden und mithin ab etwa 1945 geboren wurden, weisen demnach die ältesten Jahrgänge die niedrigsten Nettobelastungen $L^{\prime}$ auf, wobei vor allem bei Fällen mit höheren Einkommen auch die jüngsten Kohorten relativ moderat belastet werden. Insgesamt lässt sich festhalten, dass die Rechenvariante unter Einbezug der Arbeitgeberbeiträge zur Sozialversicherung zu keinen grundlegenden Abweichungen von den zuvor herausgearbeiteten Hauptbefunden führt, nach denen ältere Kohorten vergleichsweise sehr niedrige Nettobelastungen aufweisen, während eher geringe Unterschiede zwischen den Kohorten ab 1945 bestehen, unter denen die jüngsten Jahrgänge eine recht günstige Position einnehmen. Nachdem für Geburtsjahre zwischen etwa 1960 und 1975 die Lebensnettosteuersätze ein Maximum erreichen, sinken sie danach wieder leicht ab. 


\subsection{Gesamtbetrachtung und Schlussfolgerungen}

Im letzten Unterkapitel wurde die Entwicklung von mit dem STM bestimmten Lebensnettosteuersätzen über die Kohorten von 1930 bis 1990 unter dem Schwerpunkt untersucht, inwieweit Verschiebungen in der Zusammensetzung dieser Nettobelastungen auftreten. Die aus der Generationenbilanzierung bekannte Größe des Lebensnettosteuersatzes entspricht dabei dem Quotienten der Barwerte von SteuerTransfer-Saldo und Bruttolebenseinkommen. Nachdrücklich ist dabei auf den recht knappen Ausschnitt des Steuer-Transfer-Systems hinzuweisen, den das STM abbildet, wodurch die hier ermittelten Werte auch nur einen begrenzten Teil der für die Gesamtbelastung über den Lebenszyklus maßgeblichen Größen erfassen, so dass die Ergebnisse in diesem Sinne unvollständig sind. Auch liegen den vorgegebenen Rahmendaten nur im Bereich der Sozialversicherung Konsistenzprüfungen zu Grunde, ob und inwieweit die angenommene Status Quo-Politik insgesamt längerfristig tragfähig ist, wurde nicht weiter untersucht. Trotz dieser beiden wichtigen Beschränkungen zeigen die Analysen mit dem STM verschiedene Aspekte auf, die in bisherigen Ansätzen zur Untersuchung langfristiger Umverteilungswirkungen fehlen.

Als ein Nachteil von Generationenbilanzen wurde ihre in aller Regel ausschließlich auf eine zukünftige Entwicklung ausgerichtete Betrachtung angesprochen, bei der nur stark abstrahierend zwischen bereits lebenden Kohorten einerseits und zukünftigen Kohorten andererseits unterschieden wird, eine Identifikation einzelner besonders begünstigter oder benachteiligter Jahrgänge fehlt. Entsprechend lassen sie auch keine Beurteilung zu, inwieweit alternative Übergänge zu einer nachhaltigen Politikvariante eventuell bestehende Ungleichheiten zwischen lebenden Generationen einebnen oder verstärken. Als zweiter wichtiger Ansatz zur Untersuchung intergenerativer Umverteilung neben Generationenbilanzen weisen vor allem Renditeberechnungen zur gesetzlichen Rentenversicherung auf eine höhere Belastung junger oder zukünftiger Kohorten hin, die mitunter als Hinweis auf fehlende Generationengerechtigkeit des Steuer-Transfer-Systems in seiner gegenwärtigen Form gedeutet wird. Im Gegensatz zu Generationenbilanzen zeigen die Renditeberechnungen sehr differenziert auf, für welche Kohorten vergleichsweise günstige oder ungünstige Renten-Beitrags-Relationen bestehen; auch lassen sich die Auswirkungen konkreter Reformpfade wie bei der sukzessiven Anhebung der Regelaltersgrenze auf 67 Jahre für alle betroffenen Jahrgänge einzeln ausweisen (vgl. Kapitel 7.1.1). Zu den wesentlichen Befunden von Generationenbilanzen für Deutschland zählt das Fehlen langfristiger Tragfähigkeit der Status Quo-Politik unter der erwarteten Bevölkerungsentwicklung, weshalb irgendwann irgendwelche Generationen zwingend relativ stärker belastet werden müssen als eine synthetische Kohorte, die als Querschnitt aus den heute bereits lebenden Jahrgängen gebildet wird. Ein zentrales Ergebnis jüngerer Renditeberechnungen zur Rentenversicherung ist, dass die wiederholten Reformen seit 1999 einem kontinuierlichen Renditeverfall über die Kohorten entgegengewirkt haben. Nach heutigem Stand verbleiben für um 1930 geborene Kohorten zwar weiterhin deutliche Renditevorteile gegenüber jüngeren, die Renditen der Jahrgänge ab etwa 1945 sind jedoch recht ähnlich. Diese intergenerativ ausbalancierende Wirkung der jüngeren Maßnahmen im Bereich der Rentenversicherung zählte dabei neben kurzfristigen Beitragssatzdämpfungen zu den expliziten Zielen der Reformen der vergangenen Jahre, wobei nach den in Kapitel 7 vor- 
gestellten Ergebnissen für mittlere Kohorten, die etwa in den 1960er Jahren geboren wurden, die niedrigsten Renditen zu erwarten sind.

Eine in Hinblick auf das Bemühen um eine intergenerativ ausgewogene Verteilungspolitik gezogene Schlussfolgerung aus Generationenbilanzen ist, dass die offentlichen Haushalte möglichst bald zu konsolidieren sind, um zukünftige Generationen nicht unangemessen zu belasten. Wie sich die damit verbundenen kurz- bis mittelfristigen Mehrbelastungen auf einzelne Jahrgänge verteilen sollen, wenn eine möglichst gleichartige Belastung der Generationen angestrebt wird, muss jedoch weitgehend offen bleiben, da dazu zunächst bekannt sein müsste, in welchem Umfang Belastungsunterschiede zwischen den lebenden Kohorten bestehen. Für den Teilbereich der Rentenversicherung lässt sich in dieser Hinsicht ergänzen, dass dieses Sicherungssystem inzwischen für die Kohorten, die sich derzeit in der Erwerbsphase befinden, intergenerativ recht ausgewogen wirkt, so dass hierfür derzeit unter $\mathrm{Ge}$ sichtspunkten intergenerativer Gerechtigkeit keine grundlegenden Reformen mehr indiziert erscheinen. ${ }^{344}$

Die mit dem STM bestimmten Lebensnettosteuersätze bieten nun Anhaltspunkte, über das Teilsystem der Rentenversicherung hinaus abzuschätzen, inwieweit das Steuer-Transfer-System in seiner gegenwärtigen Form intergenerativ ausgewogen wirkt. So ist etwa ein Aspekt, ob neben der Rentenversicherung andere Maßnahmen Vorteile älterer Kohorten verstärken oder umgekehrt eventuell kompensieren. Darüber hinaus liefern die Lebensnettosteuersätze des STM Hinweise darauf, dass intergenerative Unterschiede in nicht unerheblichem Umfang von intragenerativen Unterschieden überlagert werden. Auf die Frage, inwieweit Belastungen intergenerativ ausgewogen verteilt erscheinen, bietet sich eine differenzierte Antwort an, da die Entwicklungen je nach Einkommensniveau oder Familientyp nicht unerheblich voneinander abweichen. Während bei der Untersuchung langfristiger Wirkungen des Steuer-Transfer-Systems Kohorten überwiegend nur über eine einzelne Durchschnittsperson repräsentiert werden, werden hier mehrere Lebensläufe unterschieden. Durch die Zerlegung der Lebensnettosteuersätze des STM in einzelne Bestandteile lassen sich dabei auch verschiedene Aspekte der Themen der drei ersten Kapitel des zweiten Teils dieser Arbeit zusammenführen. In Kapitel 6 wird auf die moderate Besteuerung von Humankapital im Status Quo hingewiesen, Kapitel 7 behandelt die erheblichen Vorteile älterer Kohorten in der Alterssicherung, in Kapitel 8 werden hingegen deutliche Vorteile jüngerer Kohorten aufgezeigt, wenn staatliche Leistungen für Familien verglichen werden. Mit den hier bestimmten Lebensnettosteuersätzen lassen sich diese Ergebnisse in Beziehung zueinander setzen, indem sowohl eine höhere Rente als auch niedrigere kindbedingte Transfers jeweils als Beitrag zum Lebensnettosteuersatz ausgedrückt und miteinander verrechnet werden, womit sich aus Untersuchungen zur Rentenversicherung bekannte Vorteile älterer Kohorten zum Teil relativieren. Ein zentrales Anliegen bei diesem Vorgehen ist, die sich abzeichnenden zukünftigen Beitragssatzanstiege in der Sozialversicherung in Relation zu anderen Gesetzesänderungen zu betrachten. Dabei zeigt sich, wie je nach Einkommensniveau und Familientyp verschiedene andere Maßnahmen für die

${ }^{344} \mathrm{Vgl}$. Sachverständigenrat zur Begutachtung der gesamtwirtschaftlichen Entwicklung (2006), S. 241 
Nettobelastung von Lebenseinkommen durchaus größere Bedeutung haben als die im Zentrum der Diskussion um intergenerative Gerechtigkeit stehende umlagefinanzierte Sozialversicherung.

Tabelle 21: Zusammensetzung der Nettobelastung von Lebenseinkommen [1000 Euro] (Durchschnittseinkommen, in Preisen von 2005)

\begin{tabular}{|l|r|r|r|r|}
\cline { 2 - 5 } \multicolumn{1}{c|}{} & \multicolumn{4}{c|}{ Geburtsjahr } \\
\cline { 2 - 5 } \multicolumn{1}{c|}{} & 1930 & 1950 & 1970 & 1990 \\
\hline Bruttolohn & 292 & 469 & 566 & 702 \\
\hline III Steuern & 43 & 81 & 92 & 99 \\
III Nozialvers. (Arbeitnehmeranteil) & 42 & 83 & 116 & 153 \\
IV Ehebenten & 26 & 27 & 34 & 47 \\
V Kindbed. Mehreink. (2 Kinder) & 20 & 27 & 38 & 45 \\
\hline Anstiege Kranken-/ Pflegev. ab 2007 & 7 & 20 & 40 & 51 \\
Sozialvers. (Arbeitgeberanteil) & 0 & 1 & 3 & 9 \\
\hline Bruttolohn & $100,0 \%$ & $100,0 \%$ & $100,0 \%$ & $100,0 \%$ \\
\hline I Steuem & $14,6 \%$ & $17,2 \%$ & $16,3 \%$ & $14,1 \%$ \\
II Sozialvers. (Arbeitnehemeranteil) & $14,3 \%$ & $17,8 \%$ & $20,6 \%$ & $21,8 \%$ \\
III Nettorenten & $8,8 \%$ & $5,8 \%$ & $6,1 \%$ & $6,6 \%$ \\
IV Ehebedingte Mehreinkommen & $6,7 \%$ & $5,7 \%$ & $6,7 \%$ & $6,5 \%$ \\
V Kindbed. Mehreink. (2 Kinder) & $2,4 \%$ & $4,2 \%$ & $7,1 \%$ & $7,3 \%$ \\
\hline Anstiege Kranken-/ Pflegevers. ab 2007 & $0,0 \%$ & $0,3 \%$ & $0,5 \%$ & $1,4 \%$ \\
Sozialvers. (Arbeitgeberanteil) & $14,3 \%$ & $17,6 \%$ & $20,0 \%$ & $20,7 \%$ \\
\hline Mehrbelastung ${ }_{n}$ Uni“, Alleinstehend & $+6,6 \%$ & $+7,7 \%$ & $+6,2 \%$ & $+5,9 \%$ \\
\hline Quelle: eigene Berechnungen & & & & \\
\hline
\end{tabular}

In Tabelle 21 sind für verschiedene Geburtsjahre einige Kennwerte zur Zusammensetzung der Nettobelastung von Lebenseinkommen zusammengestellt, die im letzten Unterkapitel vorgestellt wurden. Im oberen Teil der Tabelle sind für das Einkommensprofil Lehre mit seinem durchschnittlichen Verdienst die Barwerte des Bruttolohns, der fünf Bestandteile des Steuer-Transfer-Saldos sowie der in den beiden Berechnungsvarianten (Anstiege der Beitragssätze zu Kranken- und Pflegeversicherung einerseits sowie Berücksichtigung der Arbeitgeberbeiträge zur Sozialversicherung andererseits) aufgenommenen Größen wiedergegeben ${ }^{345} \mathrm{Im}$ unteren Teil der Tabelle sind diese Größen jeweils als Anteil am Bruttolohn ausgedrückt. Ergänzend ist in der letzten Zeile angegeben, um wie viele Prozentpunkte der Lebensnettosteuersatz beim Abschluss Uni mit seinem höheren Einkommen den Wert beim Abschluss Lehre überschreitet, die Größen entsprechen somit den Differenzen der

345 Angegeben sind die Barwerte zum Zeitpunkt, in dem potenziell das erste Erwerbseinkommen erzielt wird, das beim Abschluss Lehre aus den ersten Ausbildungsvergütungen im Alter von 16 Jahren besteht. Die im Kapitel 8 zur monetären Familienpolitik angegebenen Barwerte beziehen sich hingegen wie dabei üblich auf das Geburtsjahr der Kinder, so dass die hier ausgewiesenen Absolutbeträge kindbedingter Mehreinkommen nicht unmittelbar mit den Werten aus Kapitel 8 vergleichbar sind. 
Lebensnettosteuersätze, wie dies in Abbildung 95 im Vergleich zum Einkommensprofil Ohne dargestellt ist.

Tabelle 21 erinnert an einige wesentliche Befunde der letzten Abschnitte: Die Belastung mit Einkommen- und Zuschlagsteuern ist für die ältesten (14,6\% des Bruttolohns) und die jüngsten Kohorten (14,1\% des Bruttolohns) vergleichsweise niedrig, vor allem für die Kohorten um 1950 mit Durchschnittssteuersätzen von 17,2\% ergeben sich um bis zu gut drei Prozentpunkte höhere Anteile. Die relative Belastung mit Sozialversicherungsbeiträgen steigt monoton, über die Kohorten von 1930 bis 1990 insgesamt um 7,5 Prozentpunkte (von $14,3 \%$ auf $21,8 \%$ ), wobei unter den vier Vergleichswerten der Tabelle die stärkste Zunahme über die Jahrgänge von 1930 bis 1950 auftritt. Die Arbeitnehmerbeiträge des Jahrgangs 1950 entsprechen 17,8\% dessen Bruttolebenseinkommens, womit die Quote der 1930 Geborenen im Basisszenario um etwa 3,5 Prozentpunkte überschritten wird, steigende Beiträge zu Kranken- und Pflegeversicherung im alternativen Szenario II erhöhen diese Differenz um 0,3 auf 3,8 Prozentpunkte. Die Sozialversicherungsquoten der Kohorten 1950 und 1970 unterscheiden sich um 2,8 (Basisszenario) bzw. 3,0 Prozentpunkte (Alternativszenario), zwischen 1970 und 1990 Geborenen ergibt sich eine Differenz von noch 1,2 (Basisszenario) bzw. 2,1 Prozentpunkten (Alternativszenario). Gemessen an früheren Beitragssatzanstiegen, die sich vorrangig in der Differenz zwischen den Jahrgängen 1930 und 1950 niederschlagen, wirken die sich für die Zukunft abzeichnenden weiteren Zunahmen bei Renten-, Kranken- und Pflegeversicherung folglich eher gering. Die Ausweitungen der relativen Belastung durch Sozialversicherungsbeiträge aus der Vergangenheit fallen in der Lebenszyklusperspektive stärker aus als die wegen des demographischen Drucks zu erwartenden weiteren Zuwächse.

Bei den Nettorenten bestehen die größten Unterschiede zwischen den $1930 \mathrm{Ge}-$ borenen einerseits und den drei jüngeren Kohorten andererseits. Mit $8,8 \%$ des Bruttolebenseinkommens überschreitet die Nettorente für den Jahrgang 1930 die Werte der übrigen Geburtsjahre um 2,2 bis 3,0 Prozentpunkte, zwischen den Kohorten von 1950 bis 1990 beträgt die Spannweite mithin vergleichsweise geringe 0,8 Prozentpunkte, wobei auf Grund des niedrigen Lohnwachstums der letzten Dekaden -das unter den angenommenen zukünftigen Raten liegt- die 1950 Geborenen die niedrigste Nettorente erzielen ( $5,8 \%$ des Bruttolebenseinkommens).

Während die ehebedingten Mehreinkommen stets etwa $5,7 \%$ bis $6,7 \%$ des Bruttolebenseinkommens ausmachen, ohne dass sich eine systematische Entwicklung im Zeitverlauf andeutet, offenbart sich bei den kindbedingten Mehreinkommen hingegen eine deutliche Zunahme. Für Kohorten ab 1970 entspricht der Barwert der kindbedingten Mehreinkommen für zwei Kinder bis zu 7,3\% des Bruttolebenseinkommens, für den Jahrgang 1930 ergibt sich hier mit 2,4\% ein um 4,9 Prozentpunkte niedrigerer Wert. Beim höchsten der hier betrachteten Einkommen, das bei einem Universitätsabschluss auftritt, übersteigen die Lebensnettosteuersätze vornehmlich auf Grund der Steuerprogression die in der Tabelle angegebenen Werte, die für einen nach Abschluss einer Lehre auftretenden Durchschnittsverdienst gelten. Für die jüngste betrachtete Kohorte, 1990, fällt diese Mehrbelastung höherer Einkommen mit $5,9 \%$ des Lebenseinkommens am niedrigsten aus; beim Jahrgang 1950, der die höchsten einkommensabhängigen intragenerativen Unterschiede aufweist, ist dieser Wert mit 7,7\% um knapp 1,9 Prozentpunkte größer. 
Je nach Abgrenzung lassen sich die in Tabelle 21 aufgeführten Werte zu verschiedenen Lebensnettosteuersätzen zusammenfassen. In Tabelle 22 sind die Werte für die sich aus den hier variierten Faktoren ergebenden Minimal- und Maximalvarianten wiedergegeben, die sich in dem zu Grunde gelegten Einkommen (Bruttolohn oder Arbeitskosten) und in der Beitragssatzentwicklung der Kranken-, Pflegeund Arbeitslosenversicherung (Basisszenario oder Szenario II) unterscheiden. In der Minimalvariante gehen die Lebensnettosteuersätze erstens vom Bruttolohn als Einkommensgröße aus, die Arbeitgeberbeiträge zur Sozialversicherung schlagen sich also nicht als Belastung nieder. Zweitens sind die Beitragssätze zu Kranken-, Pflegeund Arbeitslosenversicherung auf dem Stand von 2007 fixiert (Basisszenario). In der Maximalvariante werden zum einen die Arbeitgeberbeiträge sowohl den Abgaben als auch den Einkommen zugerechnet, zum anderen wird gemäß Szenario II von zukünftigen Anstiegen der Beitragssätze zu Kranken- und Pflegeversicherung ausgegangen. Das in Tabelle 22 ersichtliche generell höhere Niveau der Lebensnettosteuersätze in der Maximalvariante resultiert vor allem aus dem Einschluss der Arbeitgeberbeiträge. Für den Jahrgang 1930 unterscheiden sich die Werte in den beiden Varianten um 9,8 Prozentpunkte, bei der Kohorte 1990 um 13,4 Prozentpunkte (jeweils Alleinstehende). Die über die Kohorten zunehmende Diskrepanz zwischen den beiden Varianten folgt aus den im Zeitverlauf weitgehend monoton steigenden Beitragssätzen, wodurch die Position der jüngeren Kohorten in der Maximalvariante ungünstiger ausfällt.

Ein herausstechendes Ergebnis intergenerativer Vergleiche sind die sehr niedrigen Lebensnettosteuersätze der Kohorte 1930, die mit Werten von 20,1\% (Minimalvariante) bzw. 29,9\% (Maximalvariante) um rund 9 bis 12 Prozentpunkte unter den Belastungsquoten der anderen drei aufgeführten Jahrgänge liegen (jeweils Alleinstehende). Zwischen den Kohorten ab 1950 bestehen im Vergleich hierzu nur geringe Unterschiede. Tendenziell weist die Entwicklung der Lebensnettosteuersätze für ab etwa 1945 Geborene einen umgekehrt u-förmigen Verlauf mit leichter Krümmung auf, wobei die höchste Belastung je nach Variante, Einkommensniveau und Familientyp bei einem der zwischen 1950 und 1970 geborenen Jahrgänge vorliegt. Bei Personen mit höherem Einkommen und/ oder Kindern tritt der Maximalwert relativ früh innerhalb dieser Geburtsspanne auf, unter kinderlosen Alleinstehenden mit niedrigerem Einkommen kommt es hingegen erst ab den Jahrgängen um 1970 zu einem Rückgang der Lebensnettosteuersätze. Allerdings ergibt sich unter allen betrachteten Konstellationen, auch unter der wesentliche zukünftige (Mehr-)Belastungen antizipierenden Maximalvariante, zu zumindest leichten Vorteilen der jüngsten Kohorten im Vergleich zu den zwischen 1950 und 1970 Geborenen. Trotz der in die Berechnungen eingespeisten erwarteten weiteren Anstiege der Beitragssätze zur Sozialversicherung auf bis zu über $50 \%$ (Arbeitgeber- und Arbeitnehmeranteile insgesamt) führt der betrachtete Ausschnitt des geltenden Rechts unter den getroffenen Annahmen zu keinem monotonen Anstieg der Lebensnettosteuersätze über die Kohorten bis 1990.

Wie bei den Berechnungen von impliziten Renditen der Rentenversicherung (vgl. Kapitel 7.3) ergibt sich somit auch bei den hier bestimmten Belastungsquoten für mittlere Kohorten die ungünstigste Position, wobei die Nachteile gegenüber jüngeren Generationen jedoch moderat bleiben. Nur über die ältesten der hier untersuchten Kohorten, die Jahrgänge von 1930 bis 1945, sind gravierende Zunahmen der Netto- 
belastungen im Lebenszyklus zu verzeichnen, danach verläuft die Entwicklung über die Geburtsjahre vergleichsweise flach.

Tabelle 22: Lebensnettosteuersätze in verschiedenen Varianten

\begin{tabular}{|c|c|c|c|c|}
\hline & \multicolumn{4}{|c|}{ Geburtsjahr } \\
\hline & 1930 & 1950 & 1970 & 1990 \\
\hline & \multicolumn{4}{|c|}{ Bruttolohn, Basisszenario } \\
\hline Alleinstehend, "Lehre" & $20,1 \%$ & $29,1 \%$ & $30,8 \%$ & $29,2 \%$ \\
\hline Mehrbelastung ${ }_{n}$ Uni“ & $+6,6 \%$ & $+7,7 \%$ & $+6,2 \%$ & $+5,9 \%$ \\
\hline \multirow[t]{2}{*}{ Ehepaar, 2 Kinder, „Lehre ${ }^{4}$} & $11,0 \%$ & $19,2 \%$ & $17,0 \%$ & $15,5 \%$ \\
\hline & \multicolumn{4}{|c|}{ Arbeitskosten, Szenario II } \\
\hline Alleinstehend, "Lehre" & $29,9 \%$ & $40,0 \%$ & $42,8 \%$ & $42,6 \%$ \\
\hline Mehrbelastung ${ }_{n}$ Uni“ $^{\prime \prime}$ & $+5,0 \%$ & $+6,4 \%$ & $+4,9 \%$ & $+4,6 \%$ \\
\hline Ehepaar, 2 Kinder, " Lehre ${ }^{4}$ & $21,9 \%$ & $31,6 \%$ & $31,3 \%$ & $31,2 \%$ \\
\hline Quelle: eigene Berechnungen & & & & \\
\hline
\end{tabular}

Diesem Befund einer ab etwa 1950 recht flach verlaufenden Kurve der Lebensnettosteuersätze lassen sich selbstverständlich die beiden eingangs eingeräumten Einschränkungen entgegenhalten, die in der Fokussierung auf einen Ausschnitt des Steuer-Transfer-Systems und im Fehlen von Konsistenzprüfungen zur längerfristigen Tragfähigkeit des Status Quo bestehen. Jedoch können die mit dem STM ermittelten Ergebnisse für sich beanspruchen, über die Projektionen zu Renten-, Kranken- und Pflegeversicherung die Hauptursachen von in Generationenbilanzen ermittelten Tragfähigkeitslücken zu berücksichtigen. Die mittels Generationenbilanzen für Deutschland typischerweise bestimmten impliziten Schulden in einer Größenordnung des etwa 2,5-fachen des Bruttoinlandsprodukts entspringen größtenteils der Sozialversicherung und folgen dann, wenn wie im ersten Teil dieses Kapitels (Kapitel 9.1.1) beschrieben deren Beitragssätze zukünftig auf dem geltenden Stand fixiert werden. ${ }^{346}$ Indem im STM nicht von konstanten sondern von aus verschiedenen Beitragssatzprojektionen übernommenen permanent budgetausgleichenden Sätzen ausgegangen wird, sind die sich aus der Sozialversicherung ergebenden zukünftigen Mehrbelastungen in den hier vorgestellten Lebensnettosteuersätzen folglich erfasst. ${ }^{347}$ Insofern überrascht das hier ermittelte Ergebnis einer über die Kohorten ab etwa 1950 weitgehend flachen Belastungskurve angesichts der sonstigen Hinweise auf die demographiebedingt höheren Belastungen junger und zukünftiger Generationen. Gemessen an den Lebensnettosteuersätzen in der hier vertretenen Abgrenzung existieren eher moderate Unterschiede zwischen denjenigen Kohorten, die sich derzeit in der Erwerbsphase befinden, wenn am gegenwärtigen Steuerrecht festgehalten wird.

${ }^{346}$ Als Orientierung können Tragfähigkeitslücken aus der Sozialversicherung in einer Größenordnung von etwa $200 \%$ des Bruttoinlandsprodukts dienen, die in etwa hälftig aus der Rentenversicherung einerseits und der Kranken- und Pflegeversicherung gemeinsam andererseits erwachsen. Vgl. zur Zusammensetzung von Tragfähigkeitslücken: Hagist, Heidler, Raffelhüschen, Schoder (2007), S. 8

347 Neben den Beitragssätzen richten sich beim STM auch die zukünftigen Rentenwerte nach einer in sich konsistenten Projektion der zukünftigen wirtschaftlichen und demographischen Entwicklung. 
Für eine auf intergenerative Ausgeglichenheit abzielende Politik, die möglichst gleichhohe Lebensnettosteuersätze der Generationen anstrebt, besteht hiernach kein dringender Handlungsbedarf, der Status Quo erscheint intergenerativ recht ausgewogen. Insbesondere deutet sich kein Spielraum an, unter Aspekten des intergenerativen Ausgleichs Belastungen von den jüngsten auf mittlere Kohorten zu verschieben. Lediglich für Jahrgänge, die sich schon weit in der Rentenphase befinden, zeichnen sich nach diesem Kriterium deutliche Vorteile ab, doch diese sind über zukünftige Reformen nur noch sehr begrenzt revidierbar.

Über die projizierten Sozialversicherungsbeiträge berücksichtigen die dargestellten Lebensnettosteuersätze zwar wesentliche Ursachen zukünftiger Abgabensteigerungen, grundsätzlich sind sie wegen ihrer genannten Beschränkungen jedoch nur bedingt geeignet, Belastungsniveaus adäquat abzuschätzen. Insofern soll hier statt des Verlaufs der Belastungskurve über die Kohorten vor allem die von diesen Problemen unberührte Entwicklung der Zusammensetzung der Lebensnettosteuersätze herausgestellt werden. Hauptursache der trotz steigender Sozialbeiträge gleich bleibenden oder sogar leicht zurück gehenden Nettobelastungen sind die über die jüngeren Kohorten schrumpfenden Durchschnittssteuersätze. Über die Kohorten von 1950 bis 1990 nimmt die Belastung mit Einkommen- und Zuschlagsteuern bei Durchschnittseinkommen um 3,1 Prozentpunkte des Bruttolohns ab, bei höheren Einkommen beläuft sich der Rückgang gar auf 4,6 Prozentpunkte (vgl. Tabelle 21). Zu dieser Entwicklung tragen zum einen die im historischen Vergleich niedrigen Steuertarife im Status Quo bei, zum anderen führt der Übergang zur nachgelagerten Besteuerung von Alterseinkünften hier zu weiteren zukünftigen Entlastungen. Während für Durchschnittsverdiener der Kohorte 1950 Steuern mit 17,2\% und Arbeitnehmerbeiträge zur Sozialversicherung mit $17,8 \%$ des Bruttolebenseinkommens annähernd gleiche Umfänge aufweisen, belaufen sich beim Jahrgang 1990 die Sozialversicherungsbeiträge mit einem Anteil von 21,8\% auf mehr als das 1,5-fache der Steuern $(14,1 \%)$.

Eine Folge dieses gravierenden Zuwachses der proportionalen Sozialbeiträge bei schrumpfender Bedeutung der progressiven Steuern sind die relativ geringen einkommensabhängigen Unterschiede innerhalb der jüngeren Kohorten. Vor allem Bezieher höherer Einkommen werden in den jüngeren Kohorten folglich recht moderat belastet. Zu ergänzen ist dabei, dass die hier betrachtete Einkommensspanne keine Hoch- oder Höchsteinkommen umfasst, sie endet beim Einkommensprofil (durchschnittlicher) Universitätsabsolventen mit einem Verdienst von knapp $170 \%$ des Durchschnittsentgelts. Für Bezieher hierüber hinausgehender Einkommen, die verstärkt von der Kappung der Sozialversicherungsbeiträge an der Bemessungsgrenze profitieren (vgl. Kapitel 4.1), dürfte das geltende Recht damit noch weitaus vorteilhafter sein. Ebenso zeichnet sich für Angehörige junger Kohorten, die nicht sozialversicherungspflichtige Einkünfte beziehen, auf Grund der moderaten Besteuerung im Status Quo eine im historischen Vergleich minimale Belastung ihrer Lebenseinkommen ab. Im geltenden Recht werden Grundsteine für eine niedrige steuerliche Belastung junger Kohorten bei nur geringer Progression ihrer Lebensnettosteuersätze gelegt.

Insgesamt liefern die hier ermittelten Ergebnisse Anhaltspunkte dafür, dass sich aus dem Status Quo des Steuer-Transfer-Systems einige kompensierend wirkende Ele- 
mente ergeben, die einem Anstieg der Nettoabgabenquoten junger Kohorten trotz der sich ankündigenden demographischen Verschiebungen entgegenwirken. Während in der Diskussion um eine intergenerativ ausgewogene Politik vor allem auf die umlagefinanzierte Sozialversicherung Bezug genommen wird, folgen etwa aus den Entwicklungen im Steuersystem ebenfalls erhebliche intergenerative Unterschiede, die in vergleichbarem Umfang auf die Nettobelastung von Lebenseinkommen einwirken. So liegt etwa vor allem durch den Übergang zur nachgelagerten Besteuerung von Alterseinkünften der Durchschnittssteuersatz der Kohorte 1990 um über zwei Prozentpunkte unter dem Wert des Jahrgangs 1970, die Differenz der Arbeitnehmerbeiträge zur Sozialversicherung dieser beiden Kohorten weist bei umgekehrtem Vorzeichen annähend denselben Betrag auf. Ähnlich übersteigt die Sozialversicherungsquote des Jahrgangs 1970 den Wert der 1950 Geborenen um bis zu drei Prozentpunkte, bei 1970 geborenen Eltern entspricht die Ausweitung kindbedingter Leistungen fast exakt einer Kompensation dieser Mehrbelastung. Verschiedene Rechtsänderungen ohne unmittelbar intergenerativen Bezug führen mithin dazu, dass die intergenerativen Unterschiede der Lebensnettosteuersätze nach derzeitiger Rechtslage recht moderat bleiben. Anders betrachtet gehen die demographiebedingten Mehrbelastungen junger Kohorten, die sich großenteils in Form von zukünftig steigenden Sozialversicherungsbeiträgen ausdrücken lassen, in ihren Größenordnungen nicht zwingend über die Effekte sonstiger umverteilend wirkender Reformmaßnahmen wie bei Steuerrechtsänderungen hinaus. Auch im Vergleich zu Beitragssatzanhebungen der Vergangenheit fallen die projizierten weiteren Zunahmen nicht besonders hoch aus. Damit ist zwar keineswegs ausgeschlossen, dass Reformen der sozialen Sicherungssysteme gerade angesichts einer alternden Bevölkerung vorteilhaft sein können. Die hier gegebenen Hinweise sollen jedoch dem Eindruck entgegenwirken, dass zukünftige Mehrbelastungen die Größenordnungen bisher da gewesener Veränderungen sprengen.

Im historischen Vergleich erweist sich das geltende Recht vor allem für Bezieher höherer Einkommen und für Personen mit Kindern als recht günstig. Während für die hier untersuchten Fälle sozialversicherter Arbeitnehmer steigende Sozialabgaben bei fallenden Steuern in etwa als Nullsummenspiel erscheinen, impliziert diese Entwicklung für Einkommen außerhalb der Sozialversicherungspflicht hingegen äußerst niedrige Belastungen in den jüngsten Kohorten. Aus den hier untersuchten Ausschnitten des Steuer-Transfer-Systems zeichnet sich damit weniger ein permanentes Ansteigen der Belastungsquoten über die Kohorten als Problem ab. Vielmehr erscheint die steigende Umverteilung über die an den Faktor Arbeit gekoppelte Sozialversicherung bei niedrigen Steuern unter Verteilungsgesichtspunkten zunehmend fragwürdig. 


\section{Schlussbemerkungen}

In dieser Arbeit wurden Entwicklungen im deutschen Steuer-Transfer-System seit 1950 unter verschiedenen Aspekten inter- und intragenerativer Umverteilung untersucht. Zum einen finden sich im ersten Teil vergleichende Querschnittsbetrachtungen, die aufzeigen, in welchen Jahren Reformen zu Mehrbelastungen oder Entlastungen führten und in welche Richtung sich einzelne Steuern oder Transfers entwickelten. In dieser Form werden unter anderem der Familienleistungsausgleich dargestellt -mit dem Ergebnis einer deutlichen Zunahme vor allem für niedrigere Einkommen- oder die Besteuerung von Renten der gesetzlichen Rentenversicherung, die bisher effektiv kaum und zukünftig zwar zunehmend aber moderat steuerlich belastet werden. Im zweiten Teil der Arbeit werden dann die Wirkungen dieser Entwicklungen unter verschiedenen Fragestellungen im Längsschnitt betrachtet, indem die Einflüsse von Steuern und Transfers auf das verfügbare Lebenseinkommen von Angehörigen der Jahrgänge 1930 bis 1990 untersucht werden. Ausgehend von Bruttoeinkommen, die aus qualifikationsabhängigen Alters-Einkommens-Profilen Mincer'scher Art und dem Lohnniveau gebildet werden, werden dazu mit einem SteuerTransfer-Modell die verfügbaren Einkommen abgeleitet, wobei intragenerative Unterschiede über nach Einkommen und Familienstand differenzierte Analysen herausgearbeitet werden. Diese Längsschnittperspektive bietet sich unter mehreren $\mathrm{Ge}-$ sichtspunkten an: Erstens bezieht sich die Diskussion um eine intergenerativ ausgewogene Umverteilung im Wesentlichen auf Gesamtbelastungen über den Lebenszyklus. Zweitens sind zentrale mikroökonomische Fragestellungen wie Bildungs- und Fertilitätsentscheidungen langfristiger Natur. Drittens addieren sich im SteuerTransfer-System verschiedene Leistungen über den gesamten Lebenszyklus, wodurch sich etwa die Gesamtwirkung monetärer Familienpolitik erst im Lebenseinkommen erfassen lässt. Vergleiche der Belastungen verschiedener Kohorten, wie sie bei Untersuchungen zur Alterssicherung üblich sind, lassen sich so auch auf weitere Elemente des Steuer-Transfer-Systems anwenden. Die im ersten Teil aufgezeigten Entwicklungen über die Kalenderjahre seit 1950 werden folglich im zweiten Teil unter dem Aspekt untersucht, welche Kohorten von welchen Änderungen betroffen sind und wie sich verschiedene Maßnahmen in ihrer Summe auswirken. Zum einen dient diese Vorgehensweise intergenerativen Vergleichen, inwieweit sich einzelne Elemente des Steuer-Transfer-Systems auf ältere, mittlere und junge Kohorten unterschiedlich auswirken und ob über die Alterssicherung hinaus weitere Indikatoren für Vorteile älterer Jahrgänge sprechen. Zum anderen gilt der Kohorte 1990 besondere Aufmerksamkeit, für die von Beginn ihrer Erwerbsphase an durchgehend das derzeit geltende Recht fortgeschrieben wird. Auf ihre Lebenseinkommen schlägt sich folglich durchgängig die Status Quo-Politik nieder, wodurch die Unterschiede zu älteren Jahrgängen aufzeigen, in welche Richtungen sich Wirkungen des Steuer-TransferSystems langfristig verschoben haben und welche weiteren Verschiebungen sich aus der zu erwartenden zukünftigen Entwicklung abzeichnen. Die Darstellungen im ersten und zweiten Teil bieten somit unterschiedliche Perspektiven auf identische Sachverhalte, wie die vier folgenden Punkte illustrieren:

- Die Entwicklungen des BAföG und des Erziehungsgelds zeigen im vergleichenden Querschnitt Folgen von fehlender Kontinuität gesetzgeberischen 
Handelns bei der Anpassung von Leistungsgesetzen auf. Beide Leistungen waren bei ihrer Einführung in den Jahren 1971 (BAföG) bzw. 1986 (Erziehungsgeld) vergleichsweise großzügig bemessen, blieben jedoch zunehmend hinter der Einkommensentwicklung zurück. Während die Ausbildungsförderung in mehreren Reformen zumindest unregelmäßig angepasst wurde (vgl. Abbildung 27 und Abbildung 28), blieb der Erziehungsgeldsatz von 300 Euro je Monat 20 Jahre lang (von 1986 bis 2006) unverändert (Abbildung 24). In der Längsschnittperspektive erzeugt solch unstetiges gesetzgeberisches Handeln mitunter nahezu erratisch wirkende Unterschiede in den Entlastungen benachbarter Kohorten. Beispiele hierfür finden sich in den Effekten der Ausbildungsförderung auf Bildungsrenditen (vgl. Abbildung 41) oder in der Entlastung von Eltern nach der Ablösung des Erziehungsgelds durch das Elterngeld ab 2007 (vgl. Abbildung 73). Der Einfluss markanter Gesetzeseinschnitte auf das verfügbare Lebenseinkommen kann dabei durchaus Größenordnungen deutlich oberhalb des Niveaus annehmen, das von Maßnahmen eines intergenerativen Ausgleichs wie der Anhebung des Rentenalters auf 67 Jahre ausgeht.

- Auch die Belastungen mit Steuern und Sozialversicherungsbeiträgen werden sowohl in ihrer Entwicklung über die Kalenderjahre als auch in ihrem Einfluss auf das Lebenseinkommen verschiedener Kohorten untersucht. Zu großen Teilen beruht die Diskussion um ein intergenerativ ausgewogenes SteuerTransfer-System auf dem demographischen Druck, der auf den umlagefinanzierten Sicherungssystemen lastet. Die Beitragssätze zur Sozialversicherung haben sich seit 1950 von 20\% (Arbeitnehmer- und Arbeitgeberanteil) auf über $40 \%$ mehr als verdoppelt (vgl. Abbildung 11), und verschiedene Projektionen lassen Anstiege auf über $50 \%$ in der zweiten Hälfte dieses Jahrhunderts erwarten (Abbildung 86). Im Kohortenvergleich führt diese Entwicklung zu einer besonders starken Zunahme der Belastung des Lebenseinkommens über die Kohorten von 1930 bis 1950 . Die projizierten weiteren Zuwächse verursachen mithin schwächere intergenerative Unterschiede als die historischen Beitragserhöhungen.

Während über die Generationen monoton wachsende Abgabenquoten im Bereich der Sozialversicherung eindeutig sind, zeigt sich bei der Besteuerung ein differenzierteres Bild. Nach -für die hier betrachtete Einkommensspannesehr niedrigen steuerlichen Belastungen in den 1950er Jahren stiegen die Durchschnittssteuersätze vor allem für gehobene Einkommen bis in die 1970 er Jahre hinein stark an. Seitdem sind die Durchschnittssteuersätze wieder vor allem für hohe sowie niedrigere Einkommen gefallen (Abbildung 16), wobei erstere von Absenkungen der Steuertarife und letztere von der Anhebung des Grundfreibetrags profitieren. Seit 1989 wurde einerseits der Spitzensteuersatz in mehreren Schritten von $56 \%$ auf $42 \%$ gesenkt, andererseits setzt er seit Jahrzehnten bei zunehmend niedrigeren Einkommen ein, so dass er nicht mehr nur bei Hoch- oder Höchsteinkommen wirksam wird (Abbildung 14). Die Progression im Bereich von Hocheinkommen hat mit den jüngeren Steuerreformen deutlich abgenommen. Im Vergleich der Jahre ab etwa 1970 erscheint die derzeitige Belastung mit Einkommensteuern insgesamt recht gering, wobei das Alterseinkünftegesetz weitere Steuerminderungen in den nächsten Jahren erwarten lässt (Abbildung 87). Besonders vorteilhaft wirkt der 
Status Quo für sehr hohe Einkommen, die in dieser Arbeit allerdings nicht weiter untersucht wurden. Dieser über die Jahre seit 1950 auftretende Verlauf zuerst steigender und später fallender Belastungen führt bei der Besteuerung von Lebenseinkommen der Kohorten von 1930 bis 1990 ebenfalls zu einer näherungsweise umgekehrt u-förmigen Entwicklung. Angehörige der ältesten sowie der jüngsten Jahrgänge weisen die niedrigsten Durchschnittssteuersätze auf, für die 1990 Geborenen ist die Besteuerung des Lebenseinkommens minimal (Abbildung 90).

- Die Regelungen des Familienleistungsausgleichs aus Kindergeld und -freibeträgen zeigen eine seit den 1950er Jahren deutlich reduzierte Staffelung nach der Kinderzahl bei einem insgesamt steigenden Leistungsniveau. Seit 1996 gelten vom ersten Kind an ähnlich hohe Leistungen, während früher vor allem Mehrkindfamilien begünstigt wurden (Abbildung 19). Auch lässt die Entwicklung über die Kalenderjahre erkennen, wie vor allem zu Beginn des Betrachtungszeitraums Eltern mit hohem Einkommen verstärkt profitierten, während mit der wachsenden Bedeutung des Kindergelds die einkommensabhängigen Unterschiede abgenommen haben (Abbildung 20). In der Längsschnittperspektive lässt sich die gemeinsame Wirkung des Ausbaus des Familienleistungsausgleichs und weiterer kindbedingter Leistungen wie Elterngeld oder Rentenzuschläge erfassen. Im intergenerativen Vergleich zeigt sich ein hohes Transfervolumen für heute geborene Kinder, wobei neben einem enweiterten Familienleistungsausgleich weitere Leistungen zu dieser Entwicklung beitragen. Über Eltern der Kohorten von 1930 bis 1990 steigt der Anteil kindbedingter Leistungen am Lebenseinkommen auf das Zwei- bis annähernd Fünffache an (Abbildung 74 und Abbildung 78).

- Zahlreiche restriktive Änderungen im Bereich der Rentenversicherung sehen längerfristige Übergänge vor, in denen entweder nach Renteneintrittsjahren oder nach Geburtsjahren differenzierte Regelungen gelten; Beispiele umfassen die Anhebungen von Altersgrenzen oder die Kürzung von nicht beitragsgedeckten Leistungen wie der Anrechnung von Ausbildungszeiten (Abbildung 31). Über die Kalenderjahre zeichnet sich hieraus ein Absinken des Anteils nicht beitragsgedeckter Leistungen an den Rentenausgaben ab (Tabelle 7). Im Vergleich der Geburtsjahre offenbart sich hingegen ein deutlich schnelleres Wirksamwerden dieser Leistungskürzungen (Abbildung 50). Da sich der Rückbau versicherungsfremder Leistungen auf die Bestandsrenten nicht auswirkt, schlagen sich die Einschnitte erst allmählich in den jährlichen Ausgaben nieder, wenn die betroffenen Kohorten -überwiegend bei Renteneintritten ab etwa 2001- einen zunehmenden Anteil der Rentner stellen.

Die Lebenszyklusperspektive im zweiten Teil dieser Arbeit wird unter verschiedenen Gesichtspunkten eingenommen, wobei sich die vier Kapitel an unterschiedliche Forschungsbereiche anlehnen. Unter anderem dient der Einsatz eines in dieser Form neuartigen Steuer-Transfer-Modells, das auch die Rechtshistorie abbildet, dem Vergleich mit bestehenden Ergebnissen. So gelten Bildungsrenditen in Deutschland als tendenziell recht stabil, die Analyse hier weist jedoch auf deutliche Unterschiede zwischen den Kohorten hin. Ebenso sind Vorteile älterer Kohorten in Hinblick auf das Preis-Leistungs-Verhältnis der Rentenversicherung hinlänglich bekannt, die Ergeb- 
nisse hier zeigen ergänzend auf, dass diese Vorteile noch deutlicher ausfallen als üblicherweise angegeben wird. Als eine Folge der Anwendung eines einheitlichen Ansatzes auf verschiedene Themengebiete bleibt, dass die jeweiligen Ergebnisse eher nebeneinander stehen, als sich zu ergänzen. In Teilaspekten bietet das letzte Kapitel mit seiner Betrachtung von Lebensnettosteuersätzen eine Zusammenführung von Ergebnissen der anderen drei Kapitel, indem einzelne Leistungen wie Renten und familienpolitische Transfers jeweils normiert als Anteil am Bruttolebenseinkommen dargestellt sind. In den abschließenden Abschnitten dieser Arbeit sollen nun noch einige weitere verdichtende Schlussfolgerungen aus den verschiedenen Befunden dieser Arbeit gezogen werden:

Einen der Ausgangspunkte der Diskussion um eine intergenerative Balance des Steuer-Transfer-Systems bilden mutmaßliche Vorteile älterer Kohorten, die angesichts der demographischen Entwicklungen zu Lasten jüngerer Kohorten angehäuft werden und/ oder jüngeren Kohorten versagt bleiben werden. Ein Ergebnis des Kapitels zur Rentenversicherung ist, dass die Gesetzgebung im Bereich der Alterssicherung tatsächlich über die sich aus den demographischen Entwicklungen ergebenden Beschränkungen hinaus zu einer Begünstigung älterer Jahrgänge führt. Indem die gesetzlichen Renten in erheblichem Umfang über ihre beitragsbegründeten Anteile hinaus gehen, fallen die Leistungen für die heutigen Rentnergenerationen relativ großzügiger aus, was sich für die Generationen der Erwerbstätigen in höheren Beiträgen niederschlägt. Da im Rahmen der Konsolidierungsbemühungen diese nicht beitragsgedeckten Leistungen deutlich beschnitten wurden, entrichten die derzeit Erwerbstätigen Beiträge für Leistungselemente, die ihnen selbst verwehrt werden. Die Vorteile älterer Kohorten beruhen also nicht nur auf günstigen Rahmendaten wie einem hohen Lohnsummenwachstum, sondern werden zusätzlich vom Gesetzgeber verstärkt. Zudem haben die älteren Kohorten für ihr höheres Rentenniveau nur relativ geringe Versicherungsbeiträge entrichtet, was zusammengenommen ihre hohen impliziten Renditen begründet.

Mit Lebensnettosteuersätzen, verstanden als Anteil des Steuer-Transfer-Saldos am Lebenseinkommen, wurde ein weiterer Indikator vorgestellt, mit dem über das Rentenversicherungssystem hinaus gehende intergenerative Unterschiede erfasst werden. Ähnlich wie bei den impliziten Renditen der Rentenversicherung gelten auch bei Lebensnettosteuersätzen über die Kohorten möglichst gleich bleibende Werte als Hinweis auf intergenerative Ausgewogenheit. Ein Hauptnutzen der hier ermittelten Werte besteht in der Möglichkeit, die aus der Alterssicherung bekannten Vorteile älterer Kohorten in Relation zu anderen Effekten des Steuer-Transfer-Systems setzen zu können. Die Reformen der letzten Jahre im Bereich der Rentenversicherung bewirken einerseits Kürzungen von Leistungen und andererseits geringere Beitragssatzanstiege. Auf Grund des fallenden Sicherungsniveaus wurden begleitend Anreize für ein verstärktes Vorsorgesparen gesetzt, damit zukünftige Rentnergenerationen eine vergleichbare Alterssicherung aufbauen können wie heutige. Ein durch die Beitragssatzdämpfungen verfügbares Mehreinkommen in der Enwerbsphase wird dabei als Quelle zusätzlicher Ersparnisbildung gesehen. Mit den im Kapitel zur Nettobelastung von Lebenseinkommen vorgestellten Lebensnettosteuersätzen wird diese Perspektive auf weitere Elemente des Steuer-Transfer-Systems ausgedehnt, nach der niedrigere Abgabenquoten oder höhere Transfers in der Erwerbsphase als Kompensation für eine geringere Rente betrachtet werden können. Unter dem Aspekt der 
Nettobelastung von Lebenseinkommen ergibt sich hiernach, dass von niedrigen Steuern und sehr niedrigen Sozialversicherungsbeiträgen der älteren Kohorten gewichtigere Einflüsse ausgehen als von ihren hohen Renten. Wenn Lebensnettosteuersätze als Indikator herangezogen werden, sind Vorteile älterer Kohorten im intergenerativen Vergleich deutlich stärker ausgeprägt als bei einer auf die Rentenversicherung beschränkten Betrachtung. Großzügigere Leistungen der Rentenversicherung zu Gunsten von älteren Kohorten, die als eines der Hauptindizien für eine intergenerative Schieflage gelten, verursachen weniger als ein Drittel der Unterschiede in der Nettobelastung von Lebenseinkommen. Daneben ergeben sich aus den Lebensnettosteuersätzen allerdings auch Hinweise auf weitere Entwicklungen im Steuer-Transfer-System, die zu einer ungünstigen Position älterer Kohorten führen. Für ihre Kinder empfingen die Angehörigen der älteren Jahrgänge relativ geringe Leistungen, wobei die Nachteile niedriger kindbezogener Transfers die Vorteile einer hohen Rente, jeweils gemessen als Anteile am verfügbaren Lebenseinkommen, durchaus überwiegen können.

Eine Unschärfe, die zahlreichen Betrachtungen intergenerativer Umverteilung anhaftet, besteht in der Abgrenzung begünstigter oder benachteiligter Kohorten. Häufig findet sich nur eine vage Trennung in junge und alte oder in lebende und zukünftige Generationen wie etwa in Generationenbilanzen. Eine Konkretisierung, wer in diesem Sinne "alt" oder "jung" ist und wie gegebenenfalls der Übergang zwischen diesen Polen verläuft, findet sich vorwiegend in Arbeiten zur Rentenversicherung. Wenn in den beiden letzten Absätzen von „älteren Kohorten" gesprochen wird, sind damit die in den Jahren um 1930 Geborenen gemeint, die ältesten der hier untersuchten Jahrgänge. Diese unterscheiden sich gravierend von den nächstjüngeren Kohorten, über die Geburtsspanne von 1930 bis etwa 1945 weichen nicht nur die Renditen der gesetzlichen Rentenversicherung sondern auch die Lebensnettosteuersätze erheblich voneinander $a b$. Wenn gleichmäßige Nettobelastungen im Lebenszyklus als Kriterium für intergenerativ ausgewogene Umverteilung herangezogen werden, dann besteht die schwerstwiegende Schieflage in der Entwicklung über die Kohorten von 1930 bis 1945, über die die Lebensnettosteuersätze rasch ansteigen. Die Kohorten, die sich derzeit am Übergang von der Erwerbs- zur Rentenphase befinden, sind zum einen in doppelter Hinsicht von den Kürzungen im Bereich der Rentenversicherung betroffen, da sich auf sie die Niveausenkungen sowohl über die Rentenformel als auch über die Reduktion versicherungsfremder Leistungen auswirken. Zum anderen ergeben sich für sie in ihrer Erwerbsphase deutlich höhere Abgabenquoten als bei älteren Jahrgängen, die nicht nur weniger Sozialversicherungsbeiträge sondern auch geringere Steuern zu entrichten hatten. Mit den Reformen der Rentenversicherung in den letzten Jahren wurden mithin bestehende intergenerative Unterschiede zwischen den Kohorten von 1930 bis 1945 verschärft. Unter dem Aspekt der Vereinheitlichung von Nettobelastungen wurde folglich der Zeitraum verpasst, in dem Reformen eine Angleichung innerhalb der Kohorten bis 1945 hätten bewirken können. Anders ausgedrückt waren Argumente, die Reformen zum Zweck eines intergenerativen Ausgleichs nahe legen, vor Jahren bereits mindestens so stichhaltig wie heute.

Zwischen den Kohorten, die im Zeitraum von 1945 bis 1990 geboren wurden und die sich damit derzeit in der Erwerbsphase befinden, bestehen hingegen eher geringe Differenzen ihrer Lebensnettosteuersätze. Die um 1945 Geborenen weisen dabei relativ hohe steuerliche Belastungen bei niedrigen Sozialabgaben und geringen kind- 
bedingten Leistungen auf, für die um 1990 Geborenen gelten die jeweils gegenteiligen Attribute. Auch unter Berücksichtigung des demographischen Drucks, der zukünftige Beitragssatzanstiege bei Renten-, Kranken- und Pflegeversicherung erwarten lässt, weichen die Lebensnettosteuersätze der jüngsten Kohorten nicht wesentlich von den Werten ab, die für die ab 1945 Geborenen gelten. Insgesamt deutet sich aus dem Status Quo des Steuer-Transfer-Systems ein leichtes Absinken der Nettobelastungen über die jüngeren Kohorten an, die ungünstigsten Werte treten im Geburtszeitraum von 1950 bis 1970 auf. In diesem Punkt ähnelt der Verlauf der Lebensnettosteuersätze der Entwicklung bei den Renditen der gesetzlichen Rentenversicherung, wo ebenfalls zumindest geringe Nachteile bei mittleren Jahrgängen festzustellen sind. Wenn Nachteile jüngerer Generationen auf eine Gegenüberstellung von "Jung" und "Alt" zugespitzt werden sollen, dann verläuft die Trennlinie zwischen diesen beiden Gruppen folglich in etwa beim Geburtsjahr 1945. Ungefähr ab diesem Geburtszeitpunkt ergeben sich Nettobelastungen des Lebenseinkommens, die auch für die heute am Beginn ihrer Erwerbsphase stehenden Generationen Bestand haben könnten. In den 1930er Jahren Geborene weisen sehr niedrige Lebensnettosteuersätze auf, alle später Geborenen unterscheiden sich untereinander nur moderat.

Wenn intergenerative Ausgewogenheit sich an dem Kriterium möglichst geringer Schwankungen von Indikatoren wie Rentenrenditen oder Lebensnettosteuersätzen orientiert, dann bestehen folglich Hinweise auf ausgeprägte Ungleichheiten zu Gunsten älterer Kohorten, wobei bereits ab etwa Mitte der 1940er Jahre Geborene nicht mehr zu den derart begünstigten "Alten" zählen. In dieser Arbeit wurde jedoch bewusst vermieden, aus diesen Befunden Gerechtigkeitsurteile abzuleiten. Geeignetes Kriterium hierfür wären das Wohlfahrtsniveau verschiedener Kohorten und der Einfluss umverteilender Maßnahmen auf dieses, was sich mit den hier diskutierten GröBen jedoch nur sehr begrenzt erfassen lässt. Zum einen sprechen grundlegende Indikatoren wie steigende Lebenserwartungen und Realeinkommen oder sinkende Arbeitszeiten für eine wachsende Wohlfahrt, was grundsätzlich gegen die These einer Besserstellung älterer Kohorten spricht. Zum anderen erweisen sich Wachstumsraten wiederholt als wesentliche Ursache für die vorgestellten intergenerativen Unterschiede, wobei Vorteile älterer Kohorten auf dem hohen Lohnwachstum im Zeitraum bis etwa 1975 basieren. Sowohl die impliziten Renditen der gesetzlichen Rentenversicherung als auch Bildungsrenditen hängen positiv vom Lohn(summen-)wachstum $a b$, was jeweils zu günstigeren Werten für die älteren Kohorten beiträgt. Hohe Wachstumsraten bedeuten gleichzeitig aber ein vergleichsweise niedriges Einkommensniveau zu Beginn der Erwerbsphase. Die Bewertung intergenerativer Unterschiede berührt somit auch die Frage, ob ein Lebenszyklus vorzuziehen ist, der sich über Phasen einer stark wachsenden Wirtschaft erstreckt oder über daran anschließende Phasen einer Stagnation auf höherem Niveau. Mit der Interpretation bekannter Unterschiede zu Gunsten älterer Kohorten als Wohlfahrtsvorteil wird dieses Problem üblicherweise ausgeblendet.

Abgesehen von den nur normativ zu lösenden Bewertungsfragen bestehen zudem erhebliche empirische Probleme, wenn langfristige Umverteilungswirkungen politisch gesteuert werden sollen. Eine Ursache dieser Probleme besteht in diskretionären Eingriffen des Gesetzgebers, die eine Bilanzierung vergangener und voraussichtlicher zukünftiger Zahlungen erschweren. Während Änderungen im Bereich der Ren- 
tenversicherung wie die Anhebung von Altersgrenzen regelmäßig unter dem Aspekt ihrer intergenerativen Verteilungswirkungen betrachtet werden, wird bei Reformen aus anderen Politikfeldern selten ein generativer Bezug hergestellt. Dieses Problem wurde in dieser Arbeit aufgegriffen, indem mit einem Steuer-Transfer-Modell gearbeitet wurde, das die historischen Rechtsstände erfasst, wodurch unter anderem auch Entwicklungen in der Bildungs- und Familienpolitik einzelnen Kohorten zugeordnet werden konnten. Nach diesen Ergebnissen ergeben sich aus diesen Bereichen Nachteile älterer Kohorten, die ihre Vorteile in der Alterssicherung zum Teil relativieren. Ein weiteres Problem besteht bei Fragen intergenerativer Verteilungswirkungen in ihrem langen Zeithorizont, der über Jahrzehnte oder Jahrhunderte in die Zukunft reicht. Ihrem Ansatz, langfristige politische Planung zu unterstützen, widerspricht jedoch eine bisweilen erstaunende Kurzlebigkeit ihrer Ergebnisse. Zum einen spiegeln Anpassungen gewollte Effekte vollzogener Reformen wider, durch die etwa Projektionen der Beitragssätze zur Rentenversicherung aktuell zu deutlich niedrigeren Werten kommen als noch vor einigen Jahren. Die Ergebnisse von Berechnungen mit weitem Zeithorizont können sehr sensibel auf Reformen reagieren, womit Zukunftserwartungen stärker schwanken, als langfristige Konzepte wie der Begriff der Generationengerechtigkeit suggerieren. Zum anderen zeichnet sich auch eine mitunter starke Abhängigkeit vom Prognosezeitpunkt ab, durch die etwa Generationenbilanzen für die USA, die im Abstand weniger Jahre erstellt wurden, zu fundamental abweichenden Einschätzungen der Belastungen junger und zukünftiger Kohorten kommen. Auch für Deutschland publizierte Werte zeigen deutliche Reaktionen auf kurzfristige Entwicklungen. Wenn jedoch bereits konjunkturelle Einflüsse Anlass geben, Ergebnisse in nennenswerter Größenordnung zu revidieren, erscheint die Möglichkeit, Umverteilung über derart lange Zeiträume sinnvoll zu planen, begrenzt.

Trotz dieser in den letzten Abschnitten geäußerter Bedenken aus grundsätzlicher sowie aus empirischer Sicht, Reformen im Steuer-Transfer-System auf Argumente intergenerativer Gerechtigkeit zu stützen, erscheinen Analysen langfristiger Verteilungswirkungen nicht hinfällig. Über sie lassen sich zumindest grobe Entwicklungslinien antizipieren, die die geltende Politik unter zukünftigen Rahmendaten impliziert, womit sich Möglichkeiten einer frühzeitigen Intervention eröffnen. Inwieweit dabei Belange verschiedener Generationen gegeneinander aufzurechnen sind, bleibt eine normative Frage. Die in dieser Arbeit zusammengetragenen Ergebnisse enthalten allerdings verschiedene Hinweise, dass Argumente eines intergenerativen Ausgleichs weniger geeignet sind, kurz- bis mittelfristige Einschnitte zu begründen, als üblicherweise angenommen wird. Die sich abzeichnenden Mehrbelastungen jüngerer Kohorten aus der umlagefinanzierten Sozialversicherung sind nicht so groß, dass sie eine gesonderte Begründung für Eingriffe bieten. Sie bleiben durchaus im Rahmen der intergenerativen Unterschiede, die der Gesetzgeber über andere Maßnahmen schafft. Auch strebt die Abgabenbelastung im Lebenszyklus keinen Höchstwerten entgegen, geplante Steuersenkungen kompensieren steigende Sozialbeiträge.

Jedoch auch ohne auf einen intergenerativen Ausgleich zu rekurrieren, lassen sich aus der Analyse der historischen Entwicklung und des Status Quo samt seiner Implikationen für die Zukunft einige Anhaltspunkte für mögliche Reformrichtungen ableiten. Die Einflüsse des Steuer-Transfer-Systems in seiner geltenden Form auf ein vollständiges Lebenseinkommen zeigen sich beim Jahrgang 1990. Dieser unter- 
scheidet dich nach den in den vier Kapiteln des zweiten Teils dargestellten Ergebnissen von früheren Kohorten in folgenden Punkten:

- Hohe Sozialversicherungsbeiträge (im Vergleich zu allen früheren Kohorten)

- Niedrige Steuern (vor allem im Vergleich zu mittleren Kohorten)

- Hohe kindbedingte Leistungen (im Vergleich zu älteren und mittleren Kohorten)

- Mittlere Nettorenten (niedriger als bei älteren, höher als bei mittleren Kohorten)

- Mittlere Ausbildungsförderung (schwankende Verläufe bei älteren und mittleren Kohorten)

- Moderate Studiengebühren (niedriger als bei älteren, höher als bei mittleren Kohorten)

Die Kombination dieser Merkmale führt zu intragenerativen Unterschieden mit einigen markanten Abweichungen von früheren Rechtsständen. Die Belastungen der Lebenseinkommen sind bei niedrigen Steuern und hohen Sozialabgaben vergleichsweise nur schwach progressiv. Die Mehrbelastung höherer Einkommen fällt im historischen Vergleich gering aus, vor allem für Einkommen außerhalb der Sozialversicherungspflicht steuert das geltende Recht auf sehr niedrige Durchschnittsbelastungen zu. Für die auch unter der Perspektive eines generativen Ausgleichs geforderten Reformen im Bereich der Sozialversicherung lassen sich hiernach andere Gründe anführen. Zum einen wirkt unter Verteilungsgesichtspunkten fragwürdig, Umverteilung zunehmend in die Sozialsysteme zu verlagern statt in das umfassendere und progressive Steuersystem. Zum anderen gilt unter arbeitsmarktpolitischen Gesichtspunkten die Abgabenbelastung vor allem bei niedrigen Einkommen als $\mathrm{Be}-$ schäftigungshemmnis. Eine Auslagerung versicherungsfremder Leistungen aus der Sozialversicherung eröffnet entsprechend Spielräume für Beitragssenkungen, von denen positive Arbeitsmarkteffekte enwartet werden. Weiterhin enthält das geltende Recht vergleichsweise großzügige Begünstigungen von Eltern. Der Ausbau kindbedingter Transfers hat allerdings weder verhindert, dass sich die Geburtenraten auf einem anhaltend niedrigen Niveau bewegen noch dass Elternschaft weiterhin gravierende Kosten mit sich bringt. Unter distributiven Gesichtspunkten erscheint der Umfang familienpolitischer Leistungen zwar nicht unangemessen, ein Einfluss auf die weitere demographische Entwicklung ist jedoch zumindest mittelfristig nicht zu erwarten. Ein Schnittpunkt von Familienpolitik und demographiebedingten Belastungen, von dem hingegen unmittelbar Wirkungen ausgehen können, besteht in der Frauenerwerbstätigkeit. Verbesserte Möglichkeiten der Erwerbsbeteiligung für Mütter können dabei in zwei Schritten entlastend wirken: Erstens können sie auch kurzfristig zu einem erhöhten Arbeitsangebot führen, zweitens können sie fertilitätssteigernd wirken, wenn sie zu einem Abbau der von Kindern ausgehenden Opportunitätskosten beitragen. Anders als in der Familienpolitik, deren Ausweitung auch als Fertilitätsanreiz und mit Verweis auf die demographischen Entwicklungen erfolgte, sticht das geltende Recht in der zweiten Stufe der Humankapitalproduktion, der Bildungspolitik, nicht durch vergleichsweise großzügige Leistungen hervor. Wenn die demographische Entwicklung zu quantitativen Engpässen bei der Erwerbsbevölkerung 
führt, dann zeigen anhaltend hohe Bildungsrenditen sowie auch mit steigender Qualifikation sinkende Arbeitslosigkeitsrisiken nachdrücklich die Bedeutung eines qualifizierten Arbeitsangebots an. Letztlich weisen damit die sich aus den drei hier betrachteten Politikfeldern der Sozial-, Familien- und Bildungspolitik ergebenden Schlussfolgerungen in eine gemeinsame Richtung: Zentrale Stellgrößen zur Kompensation der demographischen Verschiebungen bestehen in der Lösung von Arbeitsmarktproblemen. 
Tobias Arens - 978-3-631-75164-0

Downloaded from PubFactory at 01/11/2019 07:33:05AM

via free access 


\section{Anhang}

\section{A 1: Korrekturfaktor für Lebenseinkommensprofile}

Grundsätzlich bestimmt sich das Durchschnittsentgelt als Mittelwert des Bruttoeinkommens der sozialversicherungspflichtig Beschäftigten:

$d=\sum_{i=1}^{n} b_{i} / n$

Wird die Einkommensverteilung durch ein Mincer-Modell in der hier gewählten Form beschrieben, bei dem fünf Qualifikationen $q$ unterschieden werden und bei dem $n(q, a)$ für die Anzahl der Erwerbstätigen einer Alters-Qualifikations-Kombination stehe, entspricht das geschätzte Durchschnittsentgelt eines Jahres $\hat{d}_{1}$ demgemäß:

$\hat{d}_{t}=\left(\sum_{q=1}^{5} \sum_{a=a_{\min }}^{a_{m i n}} \hat{b}_{t}(q, a)^{*} n_{t}(q, a)\right) /\left(\sum_{q=1}^{5} \sum_{a=a_{\min }}^{a_{\min }} n_{t}(q, a)\right)$

Die Grundgesamtheit der $n$ Erwerbstätigen wird also in $\left(a_{\max }-a_{\min }\right)^{*} 5$ Alters-Einkommens-Kombiantionen (bei einer Zeitspanne vom 15. bis 64 . Lebensjahr beispielsweise 250) zerlegt. Deren mit ihren Häufigkeiten gewichtete Bruttoeinkommen entsprechen dem geschätzten Durchschnittsentgelt. Werden statt ihrer Anzahlen die Gewichte der einzelnen Kombinationen $w_{t}(q, a)=n_{t}(q, a) / n_{t}$ eingesetzt, ergibt sich unter dem Grundansatz (3), die Einkommen auf der Grundlage des Durchschnittsentgelts fortzuschreiben

$\hat{b}(q, t, a)=d(t)^{*} \hat{y}(q, a)$

aus (2):

$\hat{d}_{t}=d(t) * \sum_{q=1}^{j} \sum_{a=a_{\min }}^{a_{\min }} \hat{y}_{t}(q, a)^{*} w_{t}(q, a)$

Unter der Annahme identischer Gewichtungen der Alter innerhalb jeder Qualifikationsstufe im Zeitverlauf $((w(q, a) \mid t)=w(q, a))$ lässt sich (4) vereinfachen zu:

$\hat{d}_{t}=d(t)^{*} \sum_{q=1}^{j} \hat{y}_{t}\left(q, \bar{a}_{4}\right)^{*} w_{t}(q)$ 
wobei $\bar{a}_{q}$ das Alter ist, dessen Durchschnittseinkommen mit dem Durchschnittseinkommen aller Erwerbstätigen derselben Qualifikationsstufe übereinstimmt. Annahmegemäß ist $\bar{a}_{4}$ zeitlich invariant. (5) entspricht damit (2), wenn davon ausgegangen wird, dass Änderungen des Durchschnittsentgelts abgesehen von allgemeinen Einkommenssteigerungen ausschließlich auf sich wandelnde Qualifikationsstrukturen zurückzuführen sind.

Weiterhin lässt sich nach Mincers Ansatz bei gleich bleibenden Bildungsrenditen das Durchschnittseinkommen verschiedener Qualifikationen als konstante Relation $r_{q} \mathrm{zu}$ einer Basisqualifikation $q=1$ ausdrücken:

$\hat{y}_{t}\left(q, \bar{a}_{q}\right)=r_{4} * \hat{y}_{t}\left(1, \bar{a}_{1}\right) \forall q$

Nach (5) und (6) ist das geschätzte Durchschnittsentgelt eines Jahres:

$\hat{d}_{t}=d_{t} * \hat{y}_{t}\left(1, \bar{a}_{t}\right) * \sum_{q=1}^{5} r_{q} * w_{t}(q)$

$\hat{y}_{t}\left(1, \bar{a}_{1}\right)$ ist nur für das Basisjahr $\mathrm{t}=2003$, aus dem die geschätzten Parameter der EVS stammen, grundsätzlich bekannt, für andere Jahre fehlt zu seiner Bestimmung die Kenntnis der Konstanten $\beta_{0}$ der Mincer-Gleichung. Da sowohl die weiteren Parameter als auch die $\bar{a}_{q}$ als unveränderlich gelten, muss $\beta_{0}$ für jedes Jahr zur Erfüllung folgender Bedingung führen:

$\frac{\hat{d}_{t}}{d_{t}}=\frac{\hat{d}_{2003}}{d_{2003}}$

Gemäß (8) wird nicht gefordert, dass das geschätzte Durchschnittsentgelt des Jahres 2003 den tatsächlichen Wert reproduziert, was in Anbetracht der Selektionskriterien bei der Schätzung (insbesondere nur Vollzeitbeschäftigte) auch nicht zu erwarten ist. (8) besagt hingegen, dass der relative Fehler für das Jahr 2003 auch in anderen Jahren gelten soll.

Nach (8) lässt sich $\hat{d}_{t}$ ausdrücken als

$$
\begin{aligned}
\hat{d}_{t} & =\frac{d_{t}}{d_{2003}} * \hat{d}_{20013} \\
& =\frac{d_{t}}{d_{20013}} *\left(d_{2003} * \hat{y}_{2013}\left(1, \bar{a}_{1}\right) * \sum_{q=1}^{5} r_{q} * w_{2003}(q)\right)
\end{aligned}
$$

wobei der letzte Ausdruck dem geschätzten Durchschnittsentgelt 2003 gemäß (7) entspricht. Da die aus der Definitionsgleichung (2) unter zusätzlichen Annahmen ab- 
geleitete Gleichung (7) für jedes Jahr t gilt, muss $\hat{d}_{t}$ sowohl (7) als auch (9) erfüllen. Aus (7) und (9) gemeinsam folgt somit:

$\frac{d_{t}}{d_{2(003}} * d_{20033} * \hat{y}_{2003}\left(1, \bar{a}_{1}\right) * \sum_{q=1}^{5} r_{q} * w_{2(0) 3}(q)=d_{t} * \hat{y}_{t}\left(1, \bar{a}_{t}\right) * \sum_{q=1}^{5} r_{q} * w_{t}(q)$

oder

$\hat{y}_{t}\left(1, \bar{a}_{t}\right)=\frac{\sum_{q=1}^{5} r_{q} * w_{20033}(q)}{\sum_{q=1}^{5} r_{4}{ }^{*} w_{t}(q)} * \hat{y}_{2(1) 3}\left(1, \bar{a}_{1}\right)$

und es sei:

$k_{t}:=\frac{\sum_{q=1}^{5} r_{q}{ }^{*} w_{2003}(q)}{\sum_{q=1}^{5} r_{q}{ }^{*} w_{t}(q)}$

$\hat{y}_{t}\left(1, \bar{a}_{t}\right)$ entspricht folglich dem Produkt aus dem Verhältnis der mit den bildungsspezifischen Einkommensunterschieden gewichteten Qualifikationsstrukturen und seinem analogen Wert des Jahres 2003, $\hat{y}_{2003}\left(1, \bar{a}_{1}\right)$. Da schließlich dieser Faktor $k_{t}$ im Mincer-Modell für alle $\hat{y}_{t}(q, a)$ gilt, ist $\beta_{0}(t)=\beta_{0}(2003)+\ln \left(k_{t}\right)$. 


\section{A 2: Tabellarische Übersichten}

Tabelle 23: Sozialversicherung: Beitragssätze, Bemessungsgrenzen und Durchschnittsentgelte 1950 bis 2007 (Monetäre Werte in Euro/ Jahr, früheres Bundesgebiet)

\begin{tabular}{|c|c|c|c|c|c|c|c|}
\hline \multirow{2}{*}{$\begin{array}{c}\text { Jahre } a b \\
\ldots \\
\end{array}$} & \multicolumn{4}{|c|}{ Beitragssätze $^{(1)}$} & \multicolumn{2}{|c|}{ Bemessungsgrenzen $^{(2)}$} & \multirow{2}{*}{$\begin{array}{l}\text { Durchschn.- } \\
\text { entgelt }^{(3)}\end{array}$} \\
\hline & AV & $\mathrm{KV}^{(4)}$ & RV & $\mathrm{PV}^{(5)}$ & $\mathrm{KV}, \mathrm{PV}$ & $\mathrm{RV}$ & \\
\hline 1950 & $2,00 \%$ & $3,00 \%$ & $5,00 \%$ & & 2.301 & 3.681 & 1.616 \\
\hline 1953 & $2,00 \%$ & $3,00 \%$ & $5,00 \%$ & & 3.068 & 4.602 & 2.076 \\
\hline 1954 & $2,00 \%$ & $3,10 \%$ & $5,00 \%$ & & 3.068 & 4.602 & 2.165 \\
\hline 1955 & $1,63 \%$ & $3,10 \%$ & $5,38 \%$ & & 3.068 & 4.602 & 2.325 \\
\hline 1956 & $1,50 \%$ & $3,10 \%$ & $5,50 \%$ & & 3.068 & 4.602 & 2.477 \\
\hline 1957 & $1,08 \%$ & $3,90 \%$ & $6,75 \%$ & & 3.068 & 4.602 & 2.578 \\
\hline 1958 & $1,00 \%$ & $4,20 \%$ & $7,00 \%$ & & 4.049 & 4.602 & 2.725 \\
\hline 1959 & $1,00 \%$ & $4,20 \%$ & $7,00 \%$ & & 4.049 & 4.908 & 2.864 \\
\hline 1960 & $1,00 \%$ & $4,20 \%$ & $7,00 \%$ & & 4.049 & 5.215 & 3.119 \\
\hline 1961 & $0,58 \%$ & $4,70 \%$ & $7,00 \%$ & & 4.049 & 5.522 & 3.437 \\
\hline 1962 & $0,53 \%$ & $4,80 \%$ & $7,00 \%$ & & 4.049 & 5.829 & 3.747 \\
\hline 1963 & $0,70 \%$ & $4,80 \%$ & $7,00 \%$ & & 4.049 & 6.136 & 3.975 \\
\hline 1964 & $0,65 \%$ & $4,85 \%$ & $7,00 \%$ & & 4.049 & 6.749 & 4.329 \\
\hline 1965 & $0,65 \%$ & $4,95 \%$ & $7,00 \%$ & & 4.049 & 7.363 & 4.719 \\
\hline 1966 & $0,65 \%$ & $5,00 \%$ & $7,00 \%$ & & 5.522 & 7.976 & 5.058 \\
\hline 1967 & $0,65 \%$ & $5,05 \%$ & $7,00 \%$ & & 5.522 & 8.590 & 5.225 \\
\hline 1968 & $0,65 \%$ & $5,10 \%$ & $7,50 \%$ & & 5.522 & 9.817 & 5.543 \\
\hline 1969 & $0,65 \%$ & $5,25 \%$ & $8,00 \%$ & & 5.522 & 10.430 & 6.053 \\
\hline 1970 & $0,65 \%$ & $4,10 \%$ & $8,50 \%$ & & 7.363 & 11.044 & 6.822 \\
\hline 1971 & $0,65 \%$ & $4,10 \%$ & $8,50 \%$ & & 8.743 & 11.657 & 7.634 \\
\hline 1972 & $0,85 \%$ & $4,20 \%$ & $8,50 \%$ & & 9.663 & 12.885 & 8.352 \\
\hline 1973 & $0,85 \%$ & $4,60 \%$ & $9,00 \%$ & & 10.584 & 14.112 & 9.354 \\
\hline 1974 & $0,85 \%$ & $4,70 \%$ & $9,00 \%$ & & 11.504 & 15.339 & 10.421 \\
\hline 1975 & $1,00 \%$ & $5,20 \%$ & $9,00 \%$ & & 12.885 & 17.179 & 11.150 \\
\hline 1976 & $1,50 \%$ & $5,60 \%$ & $9,00 \%$ & & 14.265 & 19.020 & 11.931 \\
\hline 1977 & $1,50 \%$ & $5,70 \%$ & $9,00 \%$ & & 15.646 & 20.861 & 12.754 \\
\hline 1978 & $1,50 \%$ & $5,70 \%$ & $9,00 \%$ & & 17.026 & 22.701 & 13.417 \\
\hline 1979 & $1,50 \%$ & $5,60 \%$ & $9,00 \%$ & & 18.407 & 24.542 & 14.155 \\
\hline 1980 & $1,50 \%$ & $5,70 \%$ & $9,00 \%$ & & 19.327 & 25.769 & 15.075 \\
\hline 1981 & $1,50 \%$ & $5,90 \%$ & $9,25 \%$ & & 20.247 & 26.996 & 15.799 \\
\hline 1982 & $2,00 \%$ & $6,00 \%$ & $9,00 \%$ & & 21.628 & 28.837 & 16.463 \\
\hline 1983 & $2,30 \%$ & $5,90 \%$ & $9,08 \%$ & & 23.008 & 30.678 & 17.022 \\
\hline 1984 & $2,30 \%$ & $5,70 \%$ & $9,25 \%$ & & 23.928 & 31.905 & 17.533 \\
\hline 1985 & $2,15 \%$ & $5,90 \%$ & $9,45 \%$ & & 24.849 & 33.132 & 18.041 \\
\hline 1986 & $2,00 \%$ & $6,10 \%$ & $9,60 \%$ & & 25.769 & 34.359 & 18.727 \\
\hline 1987 & $2,15 \%$ & $6,30 \%$ & $9,60 \%$ & & 26.229 & 34.972 & 19.289 \\
\hline 1988 & $2,15 \%$ & $6,50 \%$ & $9,35 \%$ & & 27.610 & 36.813 & 19.887 \\
\hline 1989 & $2,15 \%$ & $6,50 \%$ & $9,35 \%$ & & 28.070 & 37.427 & 20.484 \\
\hline 1990 & $2,15 \%$ & $6,30 \%$ & $9,35 \%$ & & 28.990 & 38.654 & 21.447 \\
\hline 1991 & $3,09 \%$ & $6,10 \%$ & $8,98 \%$ & & 29.911 & 39.881 & 22.712 \\
\hline 1992 & $3,15 \%$ & $6,40 \%$ & $8,85 \%$ & & 31.291 & 41.721 & 23.939 \\
\hline 1993 & $3,25 \%$ & $6,70 \%$ & $8,75 \%$ & & 33.132 & 44.176 & 24.633 \\
\hline 1994 & $3,25 \%$ & $6,60 \%$ & $9,60 \%$ & & 34.972 & 46.630 & 25.126 \\
\hline 1995 & $3,25 \%$ & $6,60 \%$ & $9,30 \%$ & $0,50 \%$ & 35.893 & 47.857 & 25.905 \\
\hline
\end{tabular}


Fortsetzung Tabelle 23

\begin{tabular}{|c|c|c|c|c|c|c|c|}
\hline \multirow{2}{*}{$\begin{array}{c}\text { Jahre ab } \\
\ldots\end{array}$} & $\mathrm{AV}$ & $\mathrm{KV}^{(4)}$ & $\mathrm{RV}$ & $\mathrm{PV}^{(5)}$ & $\mathrm{KV}, \mathrm{PV}$ & $\mathrm{RV}$ & Burchschn.- $^{\text {entgelt }}{ }^{(3)}$ \\
\hline 1996 & $3,25 \%$ & $6,80 \%$ & $9,60 \%$ & $0,68 \%$ & 36.813 & 49.084 & 26.423 \\
\hline 1997 & $3,25 \%$ & $6,60 \%$ & $10,15 \%$ & $0,85 \%$ & 37.733 & 50.311 & 26.660 \\
\hline 1998 & $3,25 \%$ & $6,80 \%$ & $10,15 \%$ & $0,85 \%$ & 38.654 & 51.538 & 27.060 \\
\hline 1999 & $3,25 \%$ & $6,80 \%$ & $9,85 \%$ & $0,85 \%$ & 39.114 & 52.152 & 27.358 \\
\hline 2000 & $3,25 \%$ & $6,75 \%$ & $9,65 \%$ & $0,85 \%$ & 39.574 & 52.765 & 27.741 \\
\hline 2001 & $3,25 \%$ & $6,80 \%$ & $9,55 \%$ & $0,85 \%$ & 40.034 & 53.379 & 27.959 \\
\hline 2002 & $3,25 \%$ & $7,00 \%$ & $9,55 \%$ & $0,85 \%$ & 40.500 & 54.000 & 28.518 \\
\hline 2003 & $3,25 \%$ & $7,15 \%$ & $9,75 \%$ & $0,85 \%$ & 41.400 & 61.200 & 28.938 \\
\hline 2004 & $3,25 \%$ & $7,00 \%$ & $9,75 \%$ & $0,85 \%$ & 41.850 & 61.800 & 29.060 \\
\hline 2005 & $3,25 \%$ & $6,85 \%$ & $9,75 \%$ & $0,85 \%$ & 42.300 & 62.400 & 29.202 \\
\hline 2006 & $3,25 \%$ & $6,85 \%$ & $9,75 \%$ & $0,85 \%$ & 42.750 & 63.000 & 29.304 \\
\hline 2007 & $2,10 \%$ & $6,85 \%$ & $9,95 \%$ & $0,85 \%$ & 42.750 & 63.000 & 29.488 \\
\hline
\end{tabular}

(1) Bei unterjährigen Veränderungen entsprechen die Beitragssätze gewichteten Mittelwerten.

AV: Arbeitslosenversicherung

KV: Krankenversicherung

Durchschnittliche Beitragssätze für Mitglieder

- mit sofortigem Anspruch auf Barleistungen (bis 1969)

- mit Entgeltfortzahlungsanspruch für mindestens 6 Wochen (ab 1970)

RV: Rentenversicherungen der Arbeiter und Angestellten

PV: Pflegeversicherung

(2) Die jährliche Beitragsbemessungsgrenze der Arbeitslosenversicherung entsprach

- derjenigen der Krankenversicherung

- $\quad 9.000 \mathrm{DM}$ (4.602 Euro) bis 15.600 DM (7.976 Euro)

(1950 bis 1956)

- derjenigen der Rentenversicherung

(1957 bis 1969)

(seit 1970).

(3) Durchschnittsentgelt der gesetzlichen Rentenversicherung nach Anlage 1 SGB VI

(4) Ab Juli 2005 zuzüglich $0,9 \%$

(5) Ab Januar 2005 zuzüglich 0,25\% bei mindestens 23-jährigen Kinderlosen

Quelle: Anlage 1 SGB VI; Bundesministerium für Arbeit und Soziales (Hrsg.) (2007) 
Tabelle 24: Kindergeld und Kinderfreibeträge seit 1950

\begin{tabular}{|c|c|c|c|c|c|c|c|}
\hline \multirow{2}{*}{$\begin{array}{c}\text { Jahre } a b \\
\ldots\end{array}$} & \multicolumn{4}{|c|}{ Kindergeld [Euro/ Jahr] } & \multicolumn{3}{|c|}{ Kinderfreibetrag [Euro/ Jahr] ${ }^{(1)}$} \\
\hline & 1. Kind & 2. Kind & 3. Kind & ab 4. Kind & 1. Kind & 2. Kind & ab 3. Kind \\
\hline 1950 & 0 & 0 & 0 & 0 & 307 & 307 & 307 \\
\hline 1953 & 0 & 0 & 0 & 0 & 307 & 307 & 378 \\
\hline 1954 & 0 & 0 & 0 & 0 & 307 & 307 & 429 \\
\hline 1955 & 0 & 0 & 153 & 153 & 368 & 368 & 859 \\
\hline 1957 & 0 & 0 & 153 & 153 & 368 & 736 & 859 \\
\hline 1958 & 0 & 0 & 184 & 184 & 460 & 859 & 920 \\
\hline 1959 & 0 & 0 & 245 & 245 & 460 & 859 & 920 \\
\hline 1961 & 0 & $153^{*}$ & 245 & 245 & 460 & 859 & 920 \\
\hline 1962 & 0 & $153^{*}$ & 245 & 245 & 614 & 859 & 920 \\
\hline $1964^{(2)}$ & 0 & $153^{*}$ & 307 & 368 & 614 & 859 & 920 \\
\hline $1971^{(2)}$ & 0 & $153^{*}$ & 368 & 368 & 614 & 859 & 920 \\
\hline 1975 & 307 & 429 & 736 & 736 & 0 & 0 & 0 \\
\hline 1978 & 307 & 491 & 920 & 920 & 0 & 0 & 0 \\
\hline 1979 & 307 & 552 & 1.227 & 1.227 & 0 & 0 & 0 \\
\hline 1980 & 307 & 614 & 1.227 & 1.227 & 0 & 0 & 0 \\
\hline 1981 & 307 & 736 & 1.473 & 1.473 & 0 & 0 & 0 \\
\hline 1982 & 307 & 614 & 1.350 & 1.473 & 0 & 0 & 0 \\
\hline 1983 & 307 & $614^{\star \star}$ & $1.350^{\star \star}$ & $1.473^{\star \star}$ & 221 & 221 & 221 \\
\hline $1986^{(3)}$ & 307 & $614^{\star *}$ & $1.350^{\star *}$ & $1.473^{\star \star}$ & 1.270 & 1.270 & 1.270 \\
\hline $1990^{(3)}$ & 307 & $614^{\star *}$ & $1.350^{\star \star}$ & $1.473^{\star \star}$ & 1.546 & 1.546 & 1.546 \\
\hline $1991^{(3)}$ & 307 & $798^{\star \star}$ & $1.350^{\star \star *}$ & $1.473^{\star \star}$ & 1.546 & 1.546 & 1.546 \\
\hline $1992^{(3)}$ & 429 & $798^{\star \star}$ & $1.350^{\star \star}$ & $1.473^{\star \star}$ & 2.098 & 2.098 & 2.098 \\
\hline 1996 & 1.227 & 1.227 & 1.841 & 2.147 & 3.203 & 3.203 & 3.203 \\
\hline 1997 & 1.350 & 1.350 & 1.841 & 2.147 & 3.534 & 3.534 & 3.534 \\
\hline 1999 & 1.534 & 1.534 & 1.841 & 2.147 & 3.534 & 3.534 & 3.534 \\
\hline $2000^{(4)}$ & 1.657 & 1.657 & 1.841 & 2.147 & 5.080 & 5.080 & 5.080 \\
\hline 2002 & 1.848 & 1.848 & 1.848 & 2.148 & 5.808 & 5.808 & 5.808 \\
\hline
\end{tabular}

(1) Bis 1957: Ausgewiesen sind die im EStG nicht explizit genannten sondern in die Einkommensteuertabellen eingearbeiteten Freibeträge für Kinder.

1958 bis 1999: Angegeben sind die Kinderfreibeträge nach § 32 EStG.

Ab 2000: Angegeben ist die Summe der Freibeträge nach $\S 32$ Abs. 6 EStG für (I) das sächliche Existenzminimum eines Kindes (Kinderfreibetrag) und (II) Betreuungs- und Erziehungs- oder Ausbildungsbedarf eines Kindes

(2) Von 1964 bis 1974 betrug das Kindergeld für 5. und weitere Kinder 429 Euro/ Jahr.

(3) Zwischen 1986 und 1995 wurde daneben bei geringeren Einkommen ein Kindergeldzuschlag gewährt, der je nach Jahr maximal 282 bis 399 Euro/ Jahr betrug.

(4) In den Jahren 2000 und 2001 umfassen die angegebenen Kinderfreibeträge auch den Betreuungsfreibetrag, der nur für Kinder bis zum vollendeten 16. Lebensjahr gewährt wurde. Für Kinder im Alter von mindestens 17 Jahren betrug der Kinderfreibetrag 3.534 Euro.

* Betrag entfällt bei Überschreiten der Einkommensgrenze

** Betrag wird bei steigendem Einkommen bis zu einem Sockelbetrag (Mindestwert) gemindert

Quelle: Bundesministerium der Finanzen (2007) 
Tabelle 25: Altersgrenzen für Kindergeld und Kinderfreibeträge seit 1950

\begin{tabular}{|l|c|c|c|c|}
\hline \multirow{2}{*}{ Zeitraum } & \multicolumn{2}{|c|}{ Kindergeld $^{*}$} & \multicolumn{2}{c|}{ Kinderfreibetrag* $^{*}$} \\
\cline { 2 - 5 } & Allgemein & Auszubildende & Allgemein & Auszubildende \\
\hline bis 1954 & -- & -- & 18 & 25 \\
\hline $1955-1964$ & 18 & 25 & 18 & 25 \\
\hline $1965-1974$ & 18 & 25 & 18 & 27 \\
\hline $1975-1981$ & 18 & 27 & 18 & 27 \\
\hline 1982 & 16 & 27 & 18 & 27 \\
\hline $1983-1991$ & 16 & 27 & 16 & 27 \\
\hline $1992-1995$ & 16 & 27 & 18 & 27 \\
\hline $1996-2006$ & 18 & 27 & 18 & 27 \\
\hline ab 2007 & 18 & 25 & 18 & 25 \\
\hline
\end{tabular}

(1) In den Jahren 2000 und 2001 galten für Kinder ab Vollendung des 16. Lebensjahrs niedrigere Freibeträge.

-- Kein allgemeines Kindergeld vorgesehen

* Kindergeld/ Kinderfreibetrag bis zur Vollendung des ...-ten Lebensjahres

Quelle: KGG, BKGG, EStRG 1974, 9. BKGG, 2. HStruktG, StÄndG 1991, JStG 1996, StÄndG 2007

Tabelle 26: Ausbildungsfreibeträge seit 1954 [Euro/ Jahr]

\begin{tabular}{|c|r|r|r|r|}
\hline \multirow{2}{*}{ Jahre ab ... } & \multirow{2}{*}{$\begin{array}{c}\text { Minderung ab } \\
{ }^{*}\end{array}$} & $\begin{array}{c}\text { Minderjährig, } \\
\text { auswärts }\end{array}$ & $\begin{array}{c}\text { Volljährig, } \\
\text { bei den Eltern }\end{array}$ & $\begin{array}{c}\text { Volljährig, aus- } \\
\text { wärts }\end{array}$ \\
\hline 1954 & - & 245 & 0 & 245 \\
\hline 1957 & - & 368 & 0 & 368 \\
\hline 1958 & - & 460 & 0 & 460 \\
\hline 1961 & - & 614 & 0 & 614 \\
\hline 1977 & 1.227 & 920 & 1.227 & 2.147 \\
\hline 1984 & 1.227 & 460 & 614 & 1.074 \\
\hline 1986 & 1.227 & 614 & 920 & 1.534 \\
\hline 1988 & 1.841 & 920 & 1.227 & 2.147 \\
\hline 2002 & 1.848 & 0 & 0 & 924 \\
\hline
\end{tabular}

* Minderung der Ausbildungsfreibeträge wenn eigene Einkünfte und Bezüge des Kindes den angegebenen Betrag übersteigen. Ab 1977 war der Ausbildungsfreibetrag um die Zuschüsse aus Ausbildungshilfen aus öffentlichen Mitteln in voller Höhe zu kürzen (mit Ausnahme von 1981).

-- Keine Anrechnung vorgesehen

Quelle: Onken (1993), S .176; EStG 
Tabelle 27: Abzugsbeträge für Alleinerziehende und Kinderadditive seit 1950 [Euro/ Jahr]

\begin{tabular}{|c|c|c|c|}
\hline Jahre $a b$. & Anmerkungen & $\begin{array}{l}\text { Abzugsbeträge } \\
\text { Alleinerziehende }\end{array}$ & $\begin{array}{l}\text { Kinder- } \\
\text { additive }\end{array}$ \\
\hline 1950 & \multirow{3}{*}{$\begin{array}{l}\text { Abzugsbetrag in } \\
\text { Einkommensteuer- } \\
\text { tabellen }\end{array}$} & 77 & $205^{*}$ \\
\hline 1953 & & 409 & $205^{*}$ \\
\hline 1955 & & 460 & $256^{*}$ \\
\hline 1958 & \multirow{7}{*}{$\begin{array}{l}\text { Sonder- bzw. Haus- } \\
\text { haltsfreibetrag } \\
\S 32 \text { EStG }\end{array}$} & 614 & $256^{*}$ \\
\hline 1975 & & 1.534 & 307 \\
\hline 1982 & & 2.154 & 307 \\
\hline 1986 & & 2.319 & \multirow{5}{*}{$\begin{array}{l}\text { nicht vor- } \\
\text { gesehen }\end{array}$} \\
\hline 1988 & & 2.430 & \\
\hline 1990 & & 2.871 & \\
\hline 2002 & & 2.340 & \\
\hline 2004 & $\begin{array}{l}\text { Entlastungsbetrag } \\
\S 24 \text { b EStG }\end{array}$ & 1.308 & \\
\hline
\end{tabular}

* Verdoppelung bei mindestens 50-jährigen Steuerpflichtigen

Quelle: Bundesministerium für Familie, Senioren, Frauen und Jugend (Hrsg.) (2001), S.22f; EStG

Tabelle 28: Abzug von Kinderbetreuungskosten seit 1980 [Euro/ Jahr]

\begin{tabular}{|c|c|c|c|c|c|c|}
\hline \multirow[b]{2}{*}{ Zeitraum } & \multirow{2}{*}{$\begin{array}{l}\text { Alters- } \\
\text { grenze } \\
\text { (1) }\end{array}$} & \multicolumn{3}{|c|}{ Alleinerziehende } & \multicolumn{2}{|c|}{ Ehepaare } \\
\hline & & 1. Kind ${ }^{(2)}$ & ab 2. Kind ${ }^{(2)}$ & $\begin{array}{l}\text { ohne Nach- } \\
\text { weis }^{(3)}\end{array}$ & $\begin{array}{l}\text { Höchst- } \\
\text { betrag }\end{array}$ & $\begin{array}{l}\text { Anzur. } \\
\text { Betrag }\end{array}$ \\
\hline $1980-1982^{(4)}$ & 18 & \multicolumn{3}{|c|}{ Wie Ehepaare } & 307 & 0 \\
\hline 1983-1984 & - & \multicolumn{3}{|c|}{ Kein Abzug } & \multirow{3}{*}{\multicolumn{2}{|c|}{ Kein Abzug }} \\
\hline $1985-1999$ & 16 & 2.045 & 1.023 & 245 & & \\
\hline $2000-2001$ & - & \multicolumn{3}{|c|}{ Kein Abzug } & & \\
\hline $2002-2005^{(5)}$ & 14 & \multicolumn{3}{|c|}{ Wie Ehepaare } & 1.500 & 1.548 \\
\hline$a b 2006^{(6)}$ & 14 & \multicolumn{3}{|c|}{ Wie Ehepaare } & 4.000 & $1 / 3$ \\
\hline
\end{tabular}

(1) Bis zur Vollendung des jeweiligen Lebensjahres

(2) Höchstbeträge für nachgewiesene erwerbsbedingte Kinderbetreuungskosten, zu mindern um die zumutbare Belastung.

(3) Mindestbetrag für jedes Kind bei enwerbstätigen Alleinerziehenden

(4) Höchstbetrag gegen Nachweis, ohne Nachweis 153 Euro. Für zusammen veranlagte Ehepaare Verdoppelung beider Beträge.

(5) Beträge gelten je vollen Kinderfreibetrag. Nur enwerbsbedingte Kinderbetreuungskosten (Doppelverdienerpaare). Der anzurechnende Betrag entspricht dem in den Kinderfreibetrag eingearbeiteten Betreuungsfreibetrag.

(6) Zwei Drittel der nachgewiesenen Kosten sind abzugsfähig. Die Altersgrenze gilt für erwerbsbedingte Betreuungskosten.

Quelle: Bundesministerium für Familie, Senioren, Frauen und Jugend (Hrsg.) (2001), S.22f; EStG 
Tabelle 29: Leistungsparameter von Mutterschaftsurlaubs- und Erziehungsgeld 1979 bis 2004

\begin{tabular}{|c|c|c|c|c|c|c|}
\hline \multirow[t]{2}{*}{ Jahre ab } & \multirow{2}{*}{ Anmerkungen } & \multicolumn{3}{|c|}{ Bezugsdauer [Monate] } & \multicolumn{2}{|c|}{$\begin{array}{c}\text { Leistung [Euro/ Mo- } \\
\text { nat] }\end{array}$} \\
\hline & & 1. Phase & $\begin{array}{l}\text { 2. Phase } \\
\text { Regel }\end{array}$ & $\begin{array}{l}\text { 2. Phase } \\
\text { Budget }\end{array}$ & Regel & Budget \\
\hline 1979 & Mutterschafts- & 6 & - & -- & 383 & -- \\
\hline 1984 & urlaubsgeld & 6 & - & -- & 261 & -- \\
\hline 1986 & \multirow{6}{*}{$\begin{array}{l}\text { Erziehungs- } \\
\text { geld }\end{array}$} & 6 & 4 & -- & 307 & -- \\
\hline 1988 & & 6 & 6 & -- & 307 & -- \\
\hline 1990 & & 6 & 12 & -- & 307 & - \\
\hline 1993 & & 6 & 18 & - & 307 & - \\
\hline 2001 & & 6 & 18 & 6 & 307 & 460 \\
\hline 2004 & & 6 & 18 & 6 & 300 & 450 \\
\hline
\end{tabular}

-- nicht vorgesehen

Quelle: Deutscher Bundestag (1986a); Bundeserziehungsgeldgesetz

Tabelle 30: Einkommensanrechnung beim Erziehungsgeld 1986 bis 2004

\begin{tabular}{|c|c|c|c|c|c|c|}
\hline \multirow[t]{2}{*}{ Jahre $a b$} & \multicolumn{3}{|c|}{ Einkommensgrenzen Verheiratete $^{(1)}$} & \multirow{2}{*}{\begin{tabular}{|c|}
$\begin{array}{c}\text { Minderungs- } \\
\text { satz }^{(3)}\end{array}$ \\
\end{tabular}} & \multicolumn{2}{|c|}{ Abzugsbetrag ${ }^{(4)}$} \\
\hline & 1. Phase ${ }^{(2)}$ & 2. Phase & je Kind & & $\S 10 c$ Abs. 3 EStG & Sonst \\
\hline 1986 & -- & 15.032 & 2.147 & $3,3 \%$ & & \\
\hline 1994 & 51.129 & 15.032 & 2.147 & $3,3 \%$ & $27 \%$ & $22 \%$ \\
\hline 2001 & 51.129 & 16.464 & 2.454 & $4,2 \%$ & $27 \%$ & $22 \%$ \\
\hline 2002 & 51.129 & 16.470 & 2.797 & $4,2 \%$ & $27 \%$ & $22 \%$ \\
\hline 2003 & 51.129 & 16.470 & 3.140 & $4,2 \%$ & $27 \%$ & $22 \%$ \\
\hline 2004 & 30.000 & 16.500 & 3.140 & $5,2 \%$ & $24 \%$ & $19 \%$ \\
\hline
\end{tabular}

(1) Einkommensgrenzen nach § 5 BErzGG in Euro/ Jahr für Verheiratete. Der entsprechende Wert für allein Erziehende ist rund $20 \%$ niedriger.

(2) Für die Budgetleistung bestehen seit 2004 gemäß § 5 Abs. 3 BErzGG niedrigere Einkommensgrenzen (22.086 Euro bei Verheirateten).

(3) Minderung des Erziehungsgelds um den die Einkommensgrenzen übersteigenden Betrag gemäß $\S 5$ Abs. 3 (bis 2003 einschließlich) bzw. § 5 Abs. 4 BErzGG. Für das Budget gelten bzw. galten Minderungssätze von 6,2\% (bis 2003 einschließlich) bzw. 7,2\%.

(4) Pauschaler relativer Abzugsbetrag von der Summe der positiven Einkünfte nach $\S 6$ Abs. 1 BErzGG. Der erste Wert (Personenkreis des §10c Abs. 3 EStG) gilt für sozialversicherungspflichtige Arbeitnehmer.

(5) Bis einschließlich 1993 wurden statt eines pauschalen Abzugsbetrags die entrichtete Einkommensteuer und die steuerlich anerkannten Vorsorgeaufwendungen abgezogen.

-- nicht vorgesehen

Quelle: Bundeserziehungsgeldgesetz 
Tabelle 31: Entwicklung der Förderung durch Mutterschaftsurlaubs- und Erziehungsgeld 1979 bis 2004

\begin{tabular}{|c|c|c|c|c|c|}
\hline Jahr & Anmerkungen & $\begin{array}{l}\text { Lebend- } \\
\text { geborene } \\
{[1000]^{(3)}}\end{array}$ & $\begin{array}{l}\text { Leistungs- } \\
\text { empfänger }{ }^{(4)} \\
{[1000]}\end{array}$ & $\begin{array}{l}\text { Inanspruch- } \\
\text { nahme }\end{array}$ & $\begin{array}{l}\text { Ausgaben } \\
\text { [Mio. Euro] }\end{array}$ \\
\hline $1979^{(1)}$ & \multirow{7}{*}{$\begin{array}{l}\text { Mutter- } \\
\text { schafts- } \\
\text { urlaubs- } \\
\text { geld nach } \\
\S 200 \mathrm{~d} \\
\text { Abs. } 3 \\
\text { RVO }\end{array}$} & 582,0 & 38,3 & 1 & 53 \\
\hline 1980 & & 620,7 & 294,0 & $88,6 \%$ & 427 \\
\hline 1981 & & 624,6 & 320,6 & $93,3 \%$ & 469 \\
\hline 1982 & & 621,2 & 321,8 & $93,4 \%$ & 473 \\
\hline 1983 & & 594,2 & 301,9 & $91,8 \%$ & 453 \\
\hline 1984 & & 584,2 & 275,0 & $91,3 \%$ & 351 \\
\hline 1985 & & 584,8 & 270,1 & $89,9 \%$ & 279 \\
\hline $1986^{(2)}$ & \multirow{19}{*}{$\begin{array}{c}\text { Erzie- } \\
\text { hungsgeld }\end{array}$} & 626,0 & 1 & 1 & 1.001 \\
\hline 1987 & & 642,0 & 614,0 & $97,0 \%$ & 1.596 \\
\hline 1988 & & 677,3 & 639,9 & $95,6 \%$ & 1.699 \\
\hline 1989 & & 681,5 & 649,8 & $96,5 \%$ & 2.067 \\
\hline 1990 & & 905,7 & 680,9 & $95,2 \%$ & 2.347 \\
\hline 1991 & & 830,0 & 789,7 & $96,5 \%$ & 3.020 \\
\hline 1992 & & 809,1 & 769,7 & $96,7 \%$ & 3.693 \\
\hline 1993 & & 798,4 & 703,4 & $90,4 \%$ & 3.489 \\
\hline 1994 & & 769,6 & 788,6 & $103,8 \%{ }^{(6)}$ & 3.410 \\
\hline 1995 & & 765,2 & 723,5 & $95,9 \%$ & 3.698 \\
\hline 1996 & & 796,0 & 725,5 & $92,5 \%$ & 3.553 \\
\hline 1997 & & 812,2 & 751,2 & $93,9 \%$ & 3.640 \\
\hline 1998 & & 785,0 & 732,4 & $94,8 \%$ & 3.653 \\
\hline 1999 & & 770,7 & 715,3 & $94,3 \%$ & 3.517 \\
\hline 2000 & & 767,0 & 703,1 & $93,2 \%$ & 3.407 \\
\hline 2001 & & 734,5 & 650,0 & $91,0 \%$ & 3.322 \\
\hline 2002 & & 719,3 & 653,4 & $92,4 \%$ & 3.310 \\
\hline 2003 & & 706,7 & 647,0 & $93,1 \%$ & 3.167 \\
\hline 2004 & & 705,6 & 571,4 & 1 & 3.061 \\
\hline
\end{tabular}

(1) ab 3. Quartal

(2) Mutterschaftsurlaubs- (151 Mio. Euro) und Erziehungsgeld (850 Mio. Euro)

(3) bis 1989 früheres Bundesgebiet, danach Deutschland

(4) Entspricht den bewilligten Anträgen, ab 1995 bewilligte Erstanträge

(5) Leistungsempfänger/ Leistungsberechtigte (Lebendgeborene korrigiert um Mehrlingsgeburten). Entspricht dem Anteil der bewilligten Erstanträge.

(6) Wert $>100 \%$ wegen Nachbearbeitung von Anträgen des Vorjahres

1 nicht publiziert

Quelle: Deutscher Bundestag (1981a); Deutscher Bundestag (1986a); Bundesministerium für Familie, Senioren, Frauen und Jugend (o.J.); Fendrich, Fischer, Schilling (2005); eigene Berechnungen 
Tabelle 32: Bedarfe nach dem BAföG und dem Honnefer Modell [Euro/ Monat]

\begin{tabular}{|c|c|c|c|c|}
\hline \multirow{2}{*}{ Jahre $a b \ldots$} & \multirow{2}{*}{ Anmerkungen } & \multicolumn{2}{|c|}{ Grundbedarfe $^{(1)}$} & \multirow{2}{*}{$\begin{array}{c}\text { Gesamtbedar } \\
\text { Maximal }^{(2)}\end{array}$} \\
\hline & & Minimal & Maximal & \\
\hline 1957 & \multirow{5}{*}{$\begin{array}{l}\text { Förderung nach } \\
\text { dem Honnefer } \\
\text { Modell (nur Stu- } \\
\text { dierende) }\end{array}$} & -- & 102 & 102 \\
\hline 1961 & & -- & 125 & 125 \\
\hline 1964 & & -- & 128 & 128 \\
\hline 1966 & & -- & 148 & 148 \\
\hline 1969 & & - & 164 & 164 \\
\hline 1970 & $\begin{array}{c}\text { AföG (Schüler)/ } \\
\text { Honnefer M. (Stu- } \\
\text { dierende) }\end{array}$ & 77 & 179 & 179 \\
\hline 1971 & & 82 & 215 & 215 \\
\hline 1973 & & 82 & 215 & 230 \\
\hline 1974 & & 102 & 256 & 291 \\
\hline 1975 & & 102 & 256 & 297 \\
\hline 1976 & & 102 & 281 & 324 \\
\hline 1977 & & 120 & 297 & 341 \\
\hline 1979 & & 133 & 317 & 363 \\
\hline 1980 & & 133 & 317 & 373 \\
\hline 1982 & & 141 & 337 & 405 \\
\hline 1983 & & - & 337 & 388 \\
\hline 1984 & Entfall des Be- & - & 353 & 403 \\
\hline 1985 & darfssatzes für im & -- & 353 & 403 \\
\hline 1986 & Elternhaus unter- & -- & 363 & 421 \\
\hline 1987 & gebrachte Schüler & -- & 363 & 421 \\
\hline 1988 & nach dem HBegIG & -- & 371 & 432 \\
\hline 1989 & & - & 371 & 432 \\
\hline 1990 & & 159 & 383 & 455 \\
\hline 1991 & & 159 & 383 & 455 \\
\hline 1992 & & 169 & 406 & 481 \\
\hline 1993 & & 169 & 406 & 481 \\
\hline 1995 & Geue änder & 176 & 424 & 506 \\
\hline 1996 & & 176 & 424 & 509 \\
\hline 1998 & & 179 & 432 & 516 \\
\hline 1999 & & 182 & 440 & 527 \\
\hline 2001 & Einheitliche Be- & 192 & 465 & 583 \\
\hline 2002 & $\begin{array}{c}\text { darfe im gesamten } \\
\text { Bundesgebiet }\end{array}$ & 192 & 466 & 585 \\
\hline
\end{tabular}

(1) Bedarfe nach $\S \S 12$ und 13 BAföG

Der Minimalwert entspricht dem Bedarf von bei den Eltern wohnenden Schülern an allgemein bildenden Schulen ( $\$ 12$ Abs. $1 \mathrm{Nr}$. 1 BAföG). Der Maximalwert gilt für Studierende, die nicht bei den Eltern wohnen ( $\$ 13$ Abs. $1 \mathrm{Nr}$. 1 und $\S 13$ Abs. 2 Nr. 2 BAföG).

(2) Der maximale Gesamtbedarf umfasst neben dem Bedarf für auswärtig untergebrachte Studierende zusätzliche Zuschläge für Miete, Fahrtkosten, eigenständige Versicherungen.

Quelle: Rothe, Blanke (2005), Einführung, Rn. 10 
Tabelle 33: Sozialpauschalen und Freibeträge vom Elterneinkommen nach dem BAföG [Euro/ Monat]

\begin{tabular}{|c|c|c|c|c|c|c|c|}
\hline \multirow{2}{*}{$\begin{array}{l}\text { Jahre } \\
\text { ab ... }\end{array}$} & \multicolumn{2}{|c|}{ Sozialpauschale ${ }^{(1)}$} & \multicolumn{3}{|c|}{ Absolute Freibeträge ${ }^{(2)}$} & \multicolumn{2}{|c|}{$\begin{array}{c}\text { Relative Freibe- } \\
\text { träge }^{(5)}\end{array}$} \\
\hline & $\begin{array}{l}\text { Prozent- } \\
\text { satz }\end{array}$ & $\begin{array}{c}\text { Maximal- } \\
\text { betrag }\end{array}$ & $\begin{array}{l}\text { Verhei- } \\
\text { ratete }^{(3)}\end{array}$ & $\begin{array}{c}\text { Allein Ste- } \\
\text { hende }\end{array}$ & $\begin{array}{l}\text { zusätzl. } \\
\text { Kinder }^{(4)}\end{array}$ & Basis & $\begin{array}{l}\text { zzgl. je } \\
\text { Kind }^{(6)}\end{array}$ \\
\hline 1971 & $15,0 \%$ & 136 & 409 & 256 & 138 & $40 \%$ & $5 \%$ \\
\hline 1974 & $16,0 \%$ & 187 & 491 & 327 & 164 & $40 \%$ & $5 \%$ \\
\hline 1976 & $16,0 \%$ & 187 & 491 & 327 & 164 & $25 \%$ & $10 \%$ \\
\hline 1977 & $19,0 \%$ & 315 & 578 & 389 & 189 & $25 \%$ & $10 \%$ \\
\hline 1979 & $19,0 \%$ & 354 & 624 & 424 & 199 & $25 \%$ & $10 \%$ \\
\hline 1980 & $19,0 \%$ & 375 & 649 & 445 & 205 & $25 \%$ & $10 \%$ \\
\hline 1982 & $18,0 \%$ & 409 & 716 & 491 & 220 & $25 \%$ & $10 \%$ \\
\hline 1983 & $18,0 \%$ & 422 & 741 & 506 & 225 & $25 \%$ & $10 \%$ \\
\hline 1984 & $18,5 \%$ & 452 & 772 & 527 & 235 & $25 \%$ & $10 \%$ \\
\hline 1985 & $18,5 \%$ & 469 & 787 & 537 & 240 & $25 \%$ & $10 \%$ \\
\hline 1986 & $18,7 \%$ & 494 & 803 & 550 & 248 & $25 \%$ & $10 \%$ \\
\hline 1987 & $18,7 \%$ & 511 & 818 & 562 & 256 & $25 \%$ & $10 \%$ \\
\hline 1988 & $19,0 \%$ & 533 & 844 & 580 & 286 & $25 \%$ & $10 \%$ \\
\hline 1989 & $19,0 \%$ & 554 & 869 & 598 & 294 & $25 \%$ & $10 \%$ \\
\hline 1990 & $19,0 \%$ & 554 & 895 & 619 & 302 & $50 \%$ & $5 \%$ \\
\hline 1991 & $19,0 \%$ & 571 & 920 & 634 & 312 & $50 \%$ & $5 \%$ \\
\hline 1992 & $19,2 \%$ & 571 & 946 & 652 & 320 & $50 \%$ & $5 \%$ \\
\hline 1993 & $19,4 \%$ & 656 & 971 & 670 & 327 & $50 \%$ & $5 \%$ \\
\hline 1995 & $20,8 \%$ & 758 & 1.012 & 698 & 343 & $50 \%$ & $5 \%$ \\
\hline 1996 & $21,4 \%$ & 797 & 1.033 & 711 & 348 & $50 \%$ & $5 \%$ \\
\hline 1998 & $22,1 \%$ & 865 & 1.094 & 754 & 368 & $50 \%$ & $5 \%$ \\
\hline 1999 & $22,1 \%$ & 865 & 1.161 & 800 & 391 & $50 \%$ & $5 \%$ \\
\hline 2001 & $21,5 \%$ & 861 & 1.411 & 941 & 424 & $50 \%$ & $5 \%$ \\
\hline 2002 & $21,5 \%$ & 867 & 1.440 & 960 & 435 & $50 \%$ & $5 \%$ \\
\hline
\end{tabular}

(1) Abzugsbeträge für Pflichtbeiträge zur Sozialversicherung von rentenversicherungspflichtigen Arbeitnehmern nach $\S 21$ Abs. $2 \mathrm{Nr}$. 1 BAföG. Für nicht sozialversicherungspflichtige Arbeitnehmer gelten andere Werte.

(2) Freibeträge nach § 25 Abs. 1 BAföG

(3) Für Doppelverdiener galt zwischen 1971 und 1983 ein zusätzlicher Freibetrag nach § 25 Abs. 2 BAföG, der bis zu rund 95 Euro/ Monat betrug.

(4) Zusätzliche Kinder neben dem zu fördernden Auszubildenden. In § 25 Abs. 3 BAföG wurden im Zeitverlauf bis zu drei Freibeträge für Geschwister des Auszubildenden aufgeführt, die nach dem Alter und dem Ausbildungsstatus gestaffelt waren. Angegeben ist der jeweils höchste Betrag.

(5) Anrechnungsfreier Anteil des die Freibeträge übersteigenden Einkommens der Eltern nach $\S 25$ Abs. 4 BAföG. Für Eltern ohne weitere Kinder neben dem zu fördernden Auszubildenden gilt der als Basis angegebene Wert, der sich für jedes weitere Kind erhöht.

(6) Im Zeitraum von 1981 bis 1989 wurde der auf relativen Freibeträgen für weitere Kinder beruhende anrechnungsfreie Einkommensteil auf Maximalwerte beschränkt, die je nach Kinderzahl und Jahr zwischen 26 (für 1. Kinder) und 133 Euro je Monat (für 3. Kinder) lagen.

Quelle: Rothe, Blanke (2005), Einführung, Rn. 10 
Tabelle 34: Darlehensregelungen für das Studenten-BAföG und das Honnefer Modell

\begin{tabular}{|l|r|r|r|}
\hline \multirow{2}{*}{ Zeitraum } & \multirow{2}{*}{ Darlehensanteil } & \multicolumn{2}{|c|}{ Darlehen maximal [Euro] } \\
\cline { 3 - 4 } & & je Monat & insgesamt \\
\hline $1957-1970^{(1)}$ & $50 \%$ & $\infty$ & 767 \\
\hline $1971-1973$ & $0 \%$ & 0 & 0 \\
\hline $1974-1982$ & $100 \%$ & $41-77^{(2)}$ & $\infty$ \\
\hline $1983-1989$ & $100 \%$ & $\infty$ & $\infty$ \\
\hline $1990-2000$ & $50 \%$ & $\infty$ & $\infty$ \\
\hline 2001 & $50 \%$ & $\infty$ & 10.226 \\
\hline ab 2002 & $50 \%$ & $\infty$ & 10.000 \\
\hline
\end{tabular}

$\infty \quad$ keine Begrenzung

(1) Honnefer Modell. Der Maximalbetrag gilt bei erfolgreicher Abschlussprüfung und erhöht sich ansonsten auf 1.278 Euro.

(2) Die Beträge gelten für auswärtig untergebrachte Studierende. Im Fall der Unterbringung bei den Eltern liegen die Werte etwa $15 \%$ niedriger. 
Tabelle 35: Entwicklung der Förderung nach dem BAföG 1972 bis 2005 (Studenten)

\begin{tabular}{|c|c|c|c|c|c|c|c|}
\hline \multirow{4}{*}{ Jahr } & \multirow{4}{*}{$\begin{array}{l}\text { Finanz- } \\
\text { aufwand } \\
\text { [Mio. Euro] }\end{array}$} & \multicolumn{3}{|c|}{ Studierende $[1000]^{(1)}$} & \multirow{2}{*}{\multicolumn{3}{|c|}{ Quoten }} \\
\hline & & \multirow[b]{2}{*}{ Gesamt } & \multicolumn{2}{|c|}{ Davon } & & & \\
\hline & & & $\begin{array}{l}\text { Anspruchs- } \\
\text { berechtigte }\end{array}$ & Geförderte & \multirow[t]{2}{*}{ IIII } & \multirow[t]{2}{*}{$\|I I /\|^{(2)}$} & \multirow[t]{2}{*}{$\mid I I / I^{(3)}$} \\
\hline & & 1 & II & III & & & \\
\hline 1972 & 547 & 606 & 1 & 270 & 1 & 1 & $44,6 \%$ \\
\hline 1973 & 588 & 675 & 1 & 310 & 1 & I & $45,9 \%$ \\
\hline 1974 & 614 & 736 & 1 & 300 & 1 & 1 & $40,8 \%$ \\
\hline 1975 & 874 & 792 & 1 & 345 & 1 & 1 & $43,6 \%$ \\
\hline 1976 & 793 & 830 & 1 & 325 & 1 & 1 & $39,2 \%$ \\
\hline 1977 & 823 & 860 & 695 & 318 & $80,8 \%$ & $45,8 \%$ & $37,0 \%$ \\
\hline 1978 & 911 & 894 & 1 & 325 & 1 & 1 & $36,4 \%$ \\
\hline 1979 & 882 & 940 & 1 & 330 & 1 & 1 & $35,1 \%$ \\
\hline 1980 & 1.021 & 976 & 722 & 341 & $74,0 \%$ & $47,2 \%$ & $34,9 \%$ \\
\hline 1981 & 1.037 & 1046 & 760 & 344 & $72,7 \%$ & $45,3 \%$ & $32,9 \%$ \\
\hline 1982 & 1.026 & 1122 & 808 & 338 & $72,0 \%$ & $41,8 \%$ & $30,1 \%$ \\
\hline 1983 & 1.027 & 1200 & 867 & 327 & $72,3 \%$ & $37,7 \%$ & $27,3 \%$ \\
\hline 1984 & 940 & 1240 & 899 & 302 & $72,5 \%$ & $33,6 \%$ & $24,4 \%$ \\
\hline 1985 & 966 & 1260 & 912 & 291 & $72,4 \%$ & $31,9 \%$ & $23,1 \%$ \\
\hline 1986 & 929 & 1290 & 900 & 276 & $69,8 \%$ & $30,7 \%$ & $21,4 \%$ \\
\hline 1987 & 923 & 1347 & 900 & 273 & $66,8 \%$ & $30,3 \%$ & $20,3 \%$ \\
\hline 1988 & 909 & 1394 & 916 & 259 & $65,7 \%$ & $28,3 \%$ & $18,6 \%$ \\
\hline 1989 & 945 & 1438 & 947 & 263 & $65,9 \%$ & $27,8 \%$ & $18,3 \%$ \\
\hline 1990 & 1.028 & 1493 & 985 & 291 & $66,0 \%$ & $29,5 \%$ & $19,5 \%$ \\
\hline 1991 & 1.522 & 1697 & 1145 & 442 & $67,5 \%$ & $38,6 \%$ & $26,0 \%$ \\
\hline 1992 & 1.553 & 1754 & 1186 & 442 & $67,6 \%$ & $37,3 \%$ & $25,2 \%$ \\
\hline 1993 & 1.425 & 1806 & 1198 & 408 & $66,3 \%$ & $34,1 \%$ & $22,6 \%$ \\
\hline 1994 & 1.241 & 1836 & 1201 & 355 & $65,4 \%$ & $29,6 \%$ & $19,3 \%$ \\
\hline 1995 & 1.111 & 1829 & 1157 & 311 & $63,3 \%$ & $26,9 \%$ & $17,0 \%$ \\
\hline 1996 & 1.047 & 1814 & 1108 & 274 & $61,1 \%$ & $24,7 \%$ & $15,1 \%$ \\
\hline 1997 & 889 & 1794 & 1080 & 237 & $60,2 \%$ & $21,9 \%$ & $13,2 \%$ \\
\hline 1998 & 845 & 1780 & 1059 & 225 & $59,5 \%$ & $21,2 \%$ & $12,6 \%$ \\
\hline 1999 & 847 & 1755 & 1063 & 225 & $60,6 \%$ & $21,2 \%$ & $12,8 \%$ \\
\hline 2000 & 884 & 1741 & 1086 & 232 & $62,4 \%$ & $21,4 \%$ & $13,3 \%$ \\
\hline 2001 & 1.109 & 1777 & 1135 & 265 & $63,9 \%$ & $23,3 \%$ & $14,9 \%$ \\
\hline 2002 & 1.343 & 1845 & 1203 & 304 & $65,2 \%$ & $25,3 \%$ & $16,5 \%$ \\
\hline 2003 & 1.382 & 1916 & 1274 & 326 & $66,5 \%$ & $25,6 \%$ & $17,0 \%$ \\
\hline 2004 & 1.514 & 1961 & 1344 & 340 & $68,6 \%$ & $25,3 \%$ & $17,3 \%$ \\
\hline 2005 & 1.555 & 1925 & 1372 & 345 & $71,3 \%$ & $25,1 \%$ & $17,9 \%$ \\
\hline
\end{tabular}

(1) Jahresdurchschnitt

(2) Gefördertenquote nach neuerer Definition der Berichte nach § 35 BAföG

(3) Gefördertenquote nach älterer Definition der Berichte nach § 35 BAföG nicht publiziert

Quelle: Deutscher Bundestag. 2.bis 17. Bericht nach § 35 BAföG; Statistisches Bundesamt (2006d); eigene Berechnungen 
Tabelle 36: Entwicklung der Förderung nach dem BAföG 1972 bis 2005 (Schüler und Gesamt)

\begin{tabular}{|c|c|c|c|c|c|c|}
\hline \multirow[b]{2}{*}{ Jahr } & \multicolumn{4}{|c|}{ Schüler } & \multicolumn{2}{|c|}{ Gesamt } \\
\hline & $\begin{array}{c}\text { Finanz- } \\
\text { aufwand } \\
\text { [Mio. Euro] }\end{array}$ & $\begin{array}{c}\text { Anspruchs- } \\
\text { berechtig- } \\
\text { te*[1000] }\end{array}$ & $\begin{array}{l}\text { Geför- } \\
\text { derte } \\
{[1000]}\end{array}$ & $\begin{array}{l}\text { Geförder- } \\
\text { tenquote }\end{array}$ & $\begin{array}{l}\text { Finanz- } \\
\text { aufwand } \\
\text { [Mio. Euro] }\end{array}$ & $\begin{array}{l}\text { Geför- } \\
\text { derte }\end{array}$ \\
\hline 1972 & 269 & 720 & 225 & $31,3 \%$ & 817 & 495 \\
\hline 1973 & 307 & 800 & 240 & $30,0 \%$ & 895 & 550 \\
\hline 1974 & 333 & 858 & 250 & $29,1 \%$ & 946 & 550 \\
\hline 1975 & 469 & 1.080 & 320 & $29,6 \%$ & 1.343 & 665 \\
\hline 1976 & 454 & 985 & 300 & $30,5 \%$ & 1.247 & 625 \\
\hline 1977 & 465 & 970 & 305 & $31,4 \%$ & 1.288 & 623 \\
\hline 1978 & 533 & 1.135 & 360 & $31,7 \%$ & 1.444 & 685 \\
\hline 1979 & 677 & 1.330 & 440 & $33,1 \%$ & 1.559 & 770 \\
\hline 1980 & 854 & 1.440 & 490 & $34,0 \%$ & 1.874 & 831 \\
\hline 1981 & 853 & 1.535 & 485 & $31,6 \%$ & 1.890 & 829 \\
\hline 1982 & 829 & 1.635 & 455 & $27,8 \%$ & 1.854 & 793 \\
\hline 1983 & 657 & 1 & 123 & 1 & 1.684 & 450 \\
\hline 1984 & 233 & 1 & 100 & 1 & 1.172 & 402 \\
\hline 1985 & 219 & 1 & 73 & 1 & 1.185 & 364 \\
\hline 1986 & 211 & 1 & 68 & 1 & 1.140 & 344 \\
\hline 1987 & 228 & 1 & 68 & 1 & 1.151 & 341 \\
\hline 1988 & 235 & 1 & 69 & 1 & 1.144 & 328 \\
\hline 1989 & 242 & 1 & 70 & 1 & 1.188 & 333 \\
\hline 1990 & 259 & 1 & 80 & 1 & 1.287 & 371 \\
\hline 1991 & 483 & 1 & 164 & 1 & 2.004 & 606 \\
\hline 1992 & 437 & 1 & 144 & 1 & 1.990 & 586 \\
\hline 1993 & 373 & 1 & 124 & 1 & 1.798 & 532 \\
\hline 1994 & 346 & 1 & 112 & 1 & 1.587 & 467 \\
\hline 1995 & 347 & 1 & 108 & 1 & 1.458 & 419 \\
\hline 1996 & 345 & 1 & 106 & 1 & 1.392 & 380 \\
\hline 1997 & 344 & 1 & 109 & 1 & 1.233 & 346 \\
\hline 1998 & 355 & 1 & 116 & 1 & 1.200 & 341 \\
\hline 1999 & 377 & 1 & 122 & 1 & 1.224 & 347 \\
\hline 2000 & 381 & 1 & 127 & 1 & 1.265 & 359 \\
\hline 2001 & 497 & 1 & 143 & 1 & 1.606 & 408 \\
\hline 2002 & 606 & 1 & 163 & 1 & 1.949 & 467 \\
\hline 2003 & 647 & 1 & 179 & 1 & 2.029 & 505 \\
\hline 2004 & 698 & 1 & 192 & 1 & 2.212 & 532 \\
\hline 2005 & 726 & 1 & 199 & 1 & 2.280 & 544 \\
\hline
\end{tabular}

* Jahresdurchschnitt

I nicht publiziert

Quelle: Deutscher Bundestag. 2.bis 17. Bericht nach § 35 BAföG; Statistisches Bundesamt (2006d); eigene Berechnungen 
Tabelle 37: Ermittlung der Entgeltpunkte bei Altersrenten im STM

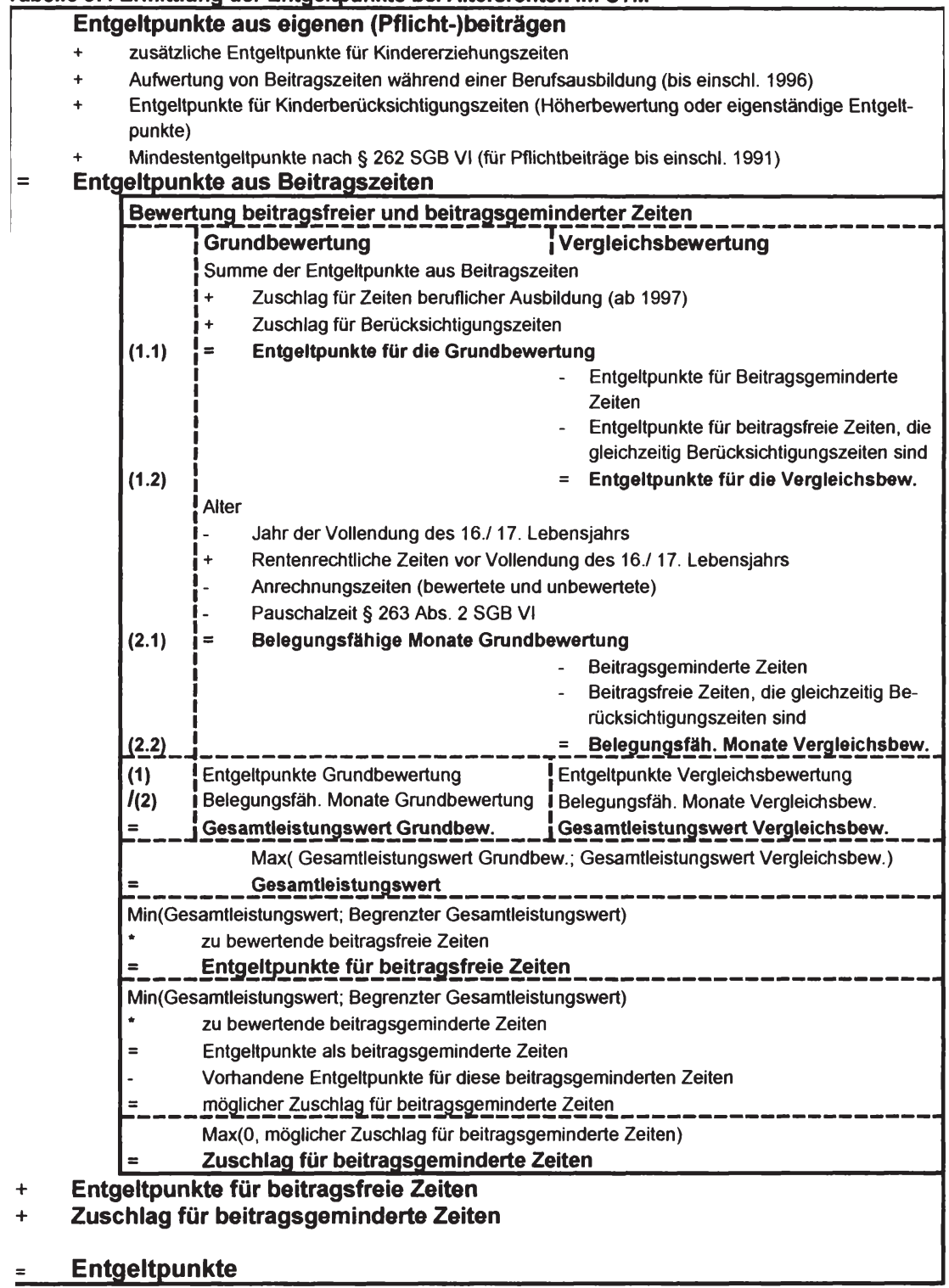




\section{Literaturverzeichnis}

Aaron, Henry (1966). The social insurance paradox. Canadian Journal of Economics and Political Science. 1966 Vol. 32. S.371-374.

Ablett, John; Tseggai-Bocurezion, Zaid (2000). Lifetime Net Average Tax Rates in Australia since Federation. The Economic Record, 76. S. 139-151.

Althammer, Jörg (2000). Ókonomische Theorie der Familienpolitik. Heidelberg: Physica.

Ammermüller, Andreas; Kuckulenz, Anja; Lauer, Charlotte; Zwick, Thomas (2005). The case for Germany. In: Committee of the Regions (2005). Human capital as a factor of growth and promotion of employment at the regional level: the case of France and Germany. CoR Studies E Bd. 2/2005. Brussels. S. 53113.

Arens, Tobias; Quinke, Hermann (2003): Bildungsbedingte öffentliche Transfers und Investitionspotentiale privater Haushalte in Deutschland. Bielefeld: wbv.

Arnds, Pascal; Bonin, Holger (2002). Frühverrentung in Deutschland: Ökonomische Anreize und institutionelle Strukturen. IZA Discussion Paper No. 666.

Auerbach, Alan J.; Gokhale, Jagadeesh; Kotlikoff, Laurence J. (1991). Generational Accounts: A Meaningful Alternative to Deficit Accounting. In: Bradford, David (Hrsg.) (1991). Tax policy and the economy. Cambridge: MIT Press. S. 55110.

Auerbach, Alan J.; Gokhale, Jagadeesh; Kotlikoff, Laurence J. (1993). Generational Accounts and Lifetime Tax Rates, 1900-1991. Federal Reserve Bank Cleveland Economic Review, 29. S. 2-13.

Auerbach, Alan J.; Gokhale, Jagadeesh; Kotlikoff, Laurence J. (1995). Restoring Generational Balance in U.S. Fiscal Policy: What Will It Take? Federal Reserve Bank Cleveland Economic Review, 31. S. 2-12.

Bahle, Thomas; Maucher, Mathias (2003). Kindergeldsysteme und Steuererleichterungen für Kinder in Westeuropa: institutionelle Merkmale und quantitative Indikatoren im Ländervergleich, 1950-2000. Mannheimer Zentrum für Europäische Sozialforschung, Arbeitspapier Nr. 72, 2003

Beblo, Miriam; Wolf, Elke (2002). How much does a year off cost? Estimating the Wage Effects of Employment Breaks and Part-Time Periods. Cahiers Économique de Bruxelles 45(2). S. 191-217.

Beck'sche Textausgaben (1957). Einkommensteuer 1956/57, Körperschaftsteuer, Lohnsteuer, Notopfer. Gesetze, Durchführungsverordnungen, Ergänzungsvorschriften und Tabellen (19. Aufl.). München: Beck.

Becker, Gary S. (1960). An Economic Analysis of Fertility. NBER Conference Series, Vol. 11. Demographic and Economic Change in Developed Countries. Princeton: National Bureau of Economic Research. S. 209-231 
Becker, Gary S. (1965). A Theory of the Allocation of Time. The Economic Journal Vol. 75. S. 493-517.

Becker, Gary S.; Barro, Robert J. (1988). A Reformulation of the Economic Theory of Fertility. Quarterly Journal of Economics Vol. 103. S. 1-25

Becker, Gary S.; Chiswick, Barry R. (1966). Education and the distribution of earnings. The American Economic Review 56 (2). S. 358-369.

Becker, Sascha O; Fenge, Robert (2005). Gerechtigkeit und Effizienz nachgelagerter Studiengebühren. ifo Schnelldienst 58 (02). S. 16-22.

Bellmann, Lutz; Gartner, Hermann (2003). Fakten zur Entwicklung der qualifikatorischen und sektoralen Lohnstruktur. Mitteilungen aus der Arbeitsmarkt- und Berufsforschung 4/ 2003. S. 493-508.

Bellmann, Lutz; Reinberg, Alex; Tessaring, Manfred (1994). Bildungsexpansion, Qualifikationsstruktur und Einkommensverteilung - Eine Analyse mit Daten des Mikrozensus und der Beschäftigtenstatistik. In: Lüdeke, Reinar (Hrsg.) (1994). Bildung, Bildungsfinanzierung und Einkommensverteilung II. Schriften des Vereins für Socialpolitik, Neue Folge, Band 221/ll. Berlin: Duncker \& Humblot.

Berkel, Barbara; Börsch-Supan, Axel (2003). Renteneintrittsentscheidungen in Deutschland: Langfristige Auswirkungen verschiedener Reformoptionen. MEA Discussion Paper 31-03.

Blaug, Mark (1973). An Introduction to the Economics of Education. Harmondsworth: Penguin.

Blöndal, Sveinbjörn; Field, Simon; Girouard, Nathalie (2002). Investment in human capital through post-compulsory education and training: Selected efficiency and equity aspects. OECD Economics Department Working Papers, No. 333.

Bonin, Holger (2001). Generational Accounting: Theory and Application. Berlin: Springer.

Bonin, Holger; Patxot, Concepcio (2004). Generational Accounting as a Tool to Assess Fiscal Sustainability: An Overview of the Methodology. IZA Discussion Paper No. 990

Boockmann, Bernhard; Steiner, Viktor (2000). Cohort effects and the returns to education in West Germany. ZEW Discussion Paper No. 00-05, Mannheim.

Börsch-Supan, Axel (1997). Sozialpolitik. In: Hagen, Jürgen von; Welfens, Paul J.J.; Börsch-Supan, Axel (Hrsg.). Handbuch der Volkswirtschaftslehre 2. Wirtschaftspolitik und Weltwirtschaft. Berlin: Springer. S. 181-234.

Börsch-Supan, Axel (2003). Zum Konzept der Generationengerechtigkeit. Zeitschrift für Wirtschaftspolitik, Band 2 2003. S. 221-226.

Börsch-Supan, Axel; Lusardi, Annamaria (2003). Saving: A Cross-National Perspective. In: Börsch-Supan, Axel (Hrsg.) (2003). Life Cycle Savings and Public Policy. San Diego: Academic Press. S .1-32. 
Börsch-Supan, Axel; Reil-Held, Anette (2001). How Much is Transfer and How Much is Insurance in a Pay-as-you-go System? The German Case. Scandinavian Journal of Economics 103 (3). S. 505-524.

Brall, Natalie; Bruno-Latocha, Gesa; Lohmann, Albert (2003). Abschlussbericht der Besteuerungskommission - Kritik und Lösungsvorschlag. Deutsche Rentenversicherung, Heft 8/2003. S. 465-487

Brall, Natalie; Bruno-Latocha, Gesa; Lohmann, Albert (2004). Neuordnung der Rentenbesteuerung - Auswirkungen für Versicherte, Rentner und Rentenversicherungsträger. Deutsche Rentenversicherung, Heft 6-7/2004. S. 409445

Breyer, Friedrich; Grabka, Markus M.; Jacobs, Klaus; Meinhardt, Volker; Ryll, Andreas; Schulz, Erika; Spieß, C. Katharina; Wagner, Gert G. (2001). Wirtschaftliche Aspekte der Märkte für Gesundheitsdienstleistungen. Gutachten im Auftrag des Bundesministeriums für Wirtschaft und Technologie.

Breyer, Friedrich; Ulrich, Volker (2000). Gesundheitsausgaben, Alter und medizinischer Fortschritt: eine Regressionsanalyse. Jahrbuch für Nationalökonomie und Statistik, 1. S. 1-17.

Bundesministerium der Finanzen (2004). Materialien zur Neuordnung der einkommensteuerrechtlichen Behandlung von Altersvorsorgeaufwendungen und Altersbezügen. Berlin: BMF - I A 5, 23. Januar 2004.

Bundesministerium der Finanzen (2005a). Bericht zur Tragfähigkeit der öffentlichen Finanzen. Berlin.

Bundesministerium der Finanzen (2005b). Darstellung der geltenden Familienförderung. Monatsbericht September 2005. S. 45-52.

Bundesministerium der Finanzen (2007a). Datensammlung zur Steuerpolitik. Ausgabe 2007.

Bundesministerium der Finanzen (2007b). Übersicht über die Steuerrechtsänderungen seit 1964. Stand: August 2007.

http://www.bundesfinanzministerium.de/ 01.03 .2008

Bundesministerium der Finanzen (Hrsg.) (1967). Gutachten zur Reform der direkten Steuern in der Bundesrepublik Deutschland des wissenschaftlichen Beirats beim Bundesministerium der Finanzen. BMF-Schriftenreihe, Heft 9. Bonn: Stollfuß.

Bundesministerium der Finanzen (Hrsg.) (1986). Gutachten zur einkommensteuerlichen Behandlung von Alterseinkünften. Erstattet vom wissenschaftlichen Beirat beim Bundesministerium der Finanzen. BMF-Schriftenreihe, Heft 38. Bonn: Stollfuß.

Bundesministerium der Finanzen (Hrsg.) (1997). Bericht zur steuerlichen Berücksichtigung von Vorsorgeaufwendungen (Aktualisierte Fassung). BMFSchriftenreihe, Heft 62. Bonn: Stollfuß. 
Bundesministerium der Finanzen (Hrsg.) (2003). Abschlussbericht der Sachverständigenkommission zur Neuordnung der steuerlichen Behandlung von Altersvorsorgeaufwendungen und Altersbezügen. Berlin: BMF-Schriftenreihe, Heft 74.

Bundesministerium für Arbeit und Soziales (2007). Sozialbudget 2006. Tabellenauszug. Bonn.

Bundesministerium für Arbeit und Soziales (Hrsg.) (2007). Statistisches Taschenbuch 2007. Arbeits- und Sozialstatistik. Stand: Juni 2007.

Bundesministerium für Bildung und Forschung (Hrsg.) (2005). Grund- und Strukturdaten 2005. Bonn.

Bundesministerium für Bildung und Wissenschaft (Hrsg.) (1988). Vorschläge zur Reform des Bundesausbildungsförderungsgesetzes (BAföG). Bericht des Beirats für Ausbildungsförderung. Schriftenreihe Grundlagen und Perspektiven für Bildung und Wissenschaft Nr. 21. Bonn: BMBW.

Bundesministerium für Familie, Senioren, Frauen und Jugend (Hrsg.) (2001). Gerechtigkeit für Familien. Zur Begründung und Weiterentwicklung des Familienlasten- und Familienleistungsausgleichs. Schriftenreihe des Bundesministeriums für Familie, Senioren, Frauen und Jugend Band 202. Stuttgart: Kohlhammer.

Bundesministerium für Familie, Senioren, Frauen und Jugend (Hrsg.) (2003). Die Familie im Spiegel der amtlichen Statistik.

Bundesministerium für Familie, Senioren, Frauen und Jugend. (o.J.). Bundesstatistik Erziehungsgeld 2002 http://www.bmfsfj.de/bmfsfj/generator/Politikbereiche/familie, did=5928.html 16.02.2008.

Bundesministerium für Gesundheit und Soziale Sicherung (Hrsg.) (2003). Nachhaltigkeit in der Finanzierung der Sozialen Sicherungssysteme. Bericht der Kommission.

Bundesministerium für Gesundheit und Soziale Sicherung (Hrsg.) (2005). Übersicht über das Sozialrecht. Nürnberg: BW.

Bundesministerium für Jugend, Familie und Gesundheit (Hrsg.) (1971). Reform des Familienlastenausgleichs. Gutachten des Wissenschaftlichen Beirats für Familienfragen. Bonn: Bundes-Verlag.

Bundesministerium für Jugend, Familie und Gesundheit (Hrsg.) (1979). Leistungen für die nachwachsende Generation in der Bundesrepublik Deutschland. Gutachten des Wissenschaftlichen Beirats für Familienfragen. Schriftenreihe des Bundesministers für Jugend, Familie und Gesundheit Band 73. Stuttgart: Kohlhammer. 
Bundesministerium für Jugend, Familie, Frauen und Gesundheit (Hrsg.) (1989). Erziehungsgeld, Erziehungsurlaub und Anrechnung von Erziehungszeiten in der Rentenversicherung. Gutachten des Wissenschaftlichen Beirats für Familienfragen. Schriftenreihe des Bundesministers für Jugend, Familie, Frauen und Gesundheit Band 243. Stuttgart: Kohlhammer.

Bundesministerium für Jugend, Familie, und Gesundheit (Hrsg.) (1971). Reform des Familienlastenausgleichs. Gutachten des Wissenschaftlichen Beirats für Familienfragen. Bonn: Bundes-Verlag.

Bundesministerium für Wirtschaft (Hrsg.) (1998). Grundlegende Reform der gesetzlichen Rentenversicherung. Gutachten des wissenschaftlichen Beirats beim Bundesministerium für Wirtschaft vom 20./21. Februar 1998. BMWAStudienreihe 99 .

Bundesministerium für Wirtschaft und Arbeit (Hrsg.) (2005). Alterung und Familienpolitik. Gutachten des Wissenschaftlichen Beirats. Dokumentation des BMWA Nr. 548.

Bundesrat (1985). Entwurf eines Gesetzes über Erziehungsgeld und Erziehungsurlaub (Bundeserziehungsgeldgesetz - BErzGG). Drucksache 350/ 85 16.08.1985

Buslei, Hermann; Steiner, Viktor (2006). Reform der Besteuerung von Alterseinkünften. DIW Wochenbericht 5/ 2006. S. 57-63.

Cassel, Dieter (2005). Wege zur nachhaltigen Finanzierung der Gesetzlichen Krankenversicherung. In: Nordrhein-Westfälische Akademie der Wissenschaften (Hrsg.) (2005). Vorträge Ingenieur- und Wirtschaftswissenschaften. Paderborn: Schöningh.

Chiswick, Barry R. (2003). Jacob Mincer, Experience and the Distribution of Earnings. IZA Discussion Paper No. 847.

Cigno, Alessandro; Casolaro, Luca; Rosati, Furio C. (2000). The Role of Social Security in Household Decisions: VAR Estimates of Saving and Fertility Behaviour in Germany. CESifo Working Paper Series No. 394.

Clement, Werner; Tessaring, Manfred; Weißhuhn, Gernot (1980). Zur Entwicklung der qualifikationsspezifischen Einkommensrelationen in der Bundesrepublik Deutschland. Mitteilungen aus der Arbeitsmarkt- und Berufsforschung 2/1980, S. 184-212.

Congressional Budget Office (1995). Who Pays and When? An Assessment of Generational Accounting. CBO Study. Washington, D.C.

Corneo, Giacomo (2005). The Rise and Likely Fall of the German Income Tax, 19582005. CESifo Economic Studies, Vol. 51, 1/2005. S. 159-186.

Dahnen, Josef (1970). Taschenbuch der Ausbildungsförderung. Taschenbücher für die Wirtschaft Nr. 19. Heidelberg: Sauer. 
De la Fuente, Angel; Jimeno, Juan F. (2005). The Private and Fiscal Returns to Schooling and the Effect of Public Policies on Private Incentives to Invest in Education: A General Framework and Some Results for the EU. CESifo Working Paper Series No. 1392.

Deutsche Bundesbank (2001). Realzinsen: Entwicklung und Determinanten. Monatsbericht Juli 2001. S. 33-50

Deutsche Bundesbank (2001). The fiscal burden on future generations - an analysis using generational accounting. Monthly Report November 1997.

Deutsche Bundesbank (2001b). Realzinsen: Entwicklung und Determinanten. Monatsbericht Juli 2001.

Deutsche Bundesbank (2002). Staatliche Leistungen für die Förderung von Familien. Monatsbericht April 2002. S. 15-32.

Deutscher Bundestag (1965). Bundesbericht Forschung I. Unterrichtung durch die Bundesregierung Drucksache 4/2963 28.06.1965.

Deutscher Bundestag (1974a). Entwurf eines Dritten Steuerreformgesetzes. Drucksache $7 / 1470$ 09.01.1974.

Deutscher Bundestag (1974b). Das soziale Bild der Studenten in der Bundesrepublik Deutschland. Ergebnisse der 7. Sozialerhebung des Deutschen Studentenwerks im Sommersemester 1973. Drucksache 7/2803.

Deutscher Bundestag (1976). Zweiter Bericht nach $§ 35$ des Bundesausbildungsförderungsgesetzes zur Überprüfung der Bedarfssätze, Freibeträge sowie Vomhundertsätze und Höchstbeträge nach $\S 21$ Abs. 2. Drucksache 8/28 30.12.1976.

Deutscher Bundestag (1978). Dritter Bericht nach $§ 35$ des Bundesausbildungsförderungsgesetzes zur Überprüfung der Bedarfssätze, Freibeträge sowie Vomhundertsätze und Höchstbeträge nach § 21 Abs. 2. Drucksache $8 / 2269$ 09.11.1978.

Deutscher Bundestag (1981a). Bericht über den Mutterschaftsurlaub. Drucksache 9/1210 16.12.1981.

Deutscher Bundestag (1981b). Vierter Bericht nach $\S 35$ des Bundesausbildungsförderungsgesetzes zur Überprüfung der Bedarfssätze, Freibeträge sowie Vomhundertsätze und Höchstbeträge nach § 21 Abs. 2. Drucksache 9/206 26.02.1981.

Deutscher Bundestag (1982). Situation der Schülerausbildungsförderung (BAföG). Drucksache 9/2203. 01.12.1982.

Deutscher Bundestag (1983). Fünfter Bericht nach $\S 35$ des Bundesausbildungsförderungsgesetzes zur Überprüfung der Bedarfssätze, Freibeträge sowie Vomhundertsätze und Höchstbeträge nach § 21 Abs. 2. Drucksache 10/835 21.12.1983. 
Deutscher Bundestag (1985). Entwurf eines Gesetzes zur leistungsfördernden Steuersenkung und zur Entlastung der Familie (Steuersenkungsgesetz StSenkG). Drucksache 10/ 2884 21.02.1985.

Deutscher Bundestag (1986a). Bericht über den Mutterschaftsurlaub. Drucksache $10 / 5327$ 16.04.1986.

Deutscher Bundestag (1986b). Sechster Bericht nach $\S 35$ des Bundesausbildungsförderungsgesetzes zur Überprüfung der Bedarfssätze, Freibeträge sowie Vomhundertsätze und Höchstbeträge nach $\S 21$ Abs. 2. Drucksache 10/4617 02.01.1986.

Deutscher Bundestag (1987). Siebter Bericht nach $§ 35$ des Bundesausbildungsförderungsgesetzes zur Überprüfung der Bedarfssätze, Freibeträge sowie Vomhundertsätze und Höchstbeträge nach $\S 21$ Abs. 2. Drucksache 11/877 02.10.1987.

Deutscher Bundestag (1989). Achter Bericht nach $\S 35$ des Bundesausbildungsförderungsgesetzes zur Überprüfung der Bedarfssätze, Freibeträge sowie Vomhundertsätze und Höchstbeträge nach $\S 21$ Abs. 2. Drucksache $11 / 5524$ 02.10.1989.

Deutscher Bundestag (1992a). Entwurf eines Gesetzes zur Neuregelung der Zinsbesteuerung (Zinsabschlaggesetz). Drucksache 12/ 2501 30.04.1992.

Deutscher Bundestag (1992b). Neunter Bericht nach § 35 des Bundesausbildungsförderungsgesetzes zur Überprüfung der Bedarfssätze, Freibeträge sowie Vomhundertsätze und Höchstbeträge nach §21 Abs. 2. Drucksache 12/1920 14.01.1992.

Deutscher Bundestag (1994). Familien und Familienpolitik im geeinten Deutschland - Zukunft des Humanvermögens. Fünfter Familienbericht. Drucksache $12 / 756015.6 .1994$

Deutscher Bundestag (1994). Zehnter Bericht nach $\S 35$ des Bundesausbildungsförderungsgesetzes zur Überprüfung der Bedarfssätze, Freibeträge sowie Vomhundertsätze und Höchstbeträge nach $\S 21$ Abs. 2. Drucksache 12/6605 17.01.1994.

Deutscher Bundestag (1995a). Entwurf eines Jahressteuergesetzes (JStG) 1996. Drucksache 13/ 901 27.03.1995.

Deutscher Bundestag (1995b). Elfter Bericht nach $\S 35$ des Bundesausbildungsförderungsgesetzes zur Überprüfung der Bedarfssätze, Freibeträge sowie Vomhundertsätze und Höchstbeträge nach $\S 21$ Abs. 2. Drucksache 13/3413 28.12.1995.

Deutscher Bundestag (1996). Entwurf eines Gesetzes zur Umsetzung des Programms für mehr Wachstum und Beschäftigung in den Bereichen der Rentenversicherung und Arbeitsförderung (Wachstums- und Beschäftigungsförderungsgesetz - WFG). Drucksache 13/ 4610 10.05.1996

Deutscher Bundestag (1997a). Schriftliche Fragen. Drucksache 13/ 8162 04.07.1997 
Deutscher Bundestag (1997b). Zwölfter Bericht nach § 35 des Bundesausbildungsförderungsgesetzes zur Überprüfung der Bedarfssätze, Freibeträge sowie Vomhundertsätze und Höchstbeträge nach $\S 21$ Abs. 2. Drucksache 13/9515 18.12.1997.

Deutscher Bundestag (1998). Bedeutungsschwund des Erziehungsgeldes. Drucksache 13/9794 05.02.1998.

Deutscher Bundestag (1999). Familienförderung und Alleinerziehende. Drucksache $14 / 1888$ 28.10.1989.

Deutscher Bundestag (2000). Dreizehnter Bericht nach $\S 35$ des Bundesausbildungsförderungsgesetzes zur Überprüfung der Bedarfssätze, Freibeträge sowie Vomhundertsätze und Höchstbeträge nach § 21 Abs. 2. Drucksache 14/1927 04.01.2000.

Deutscher Bundestag (2001a). Lebenslagen in Deutschland - Erster Armuts- und Reichtumsbericht. Drucksache 14/5990. 08. 05. 2001.

Deutscher Bundestag (2001b). Vierzehnter Bericht nach $\S 35$ des Bundesausbildungsförderungsgesetzes zur Überprüfung der Bedarfssätze, Freibeträge sowie Vomhundertsätze und Höchstbeträge nach § 21 Abs. 2. Drucksache 14/7972 20.12.2001.

Deutscher Bundestag (2002). Schlussbericht der Enquête-Kommission „Demographischer Wandel - Herausforderungen unserer älter werdenden Gesellschaft an den Einzelnen und die Politik". Drucksache 14/ 8800 28.03.2002.

Deutscher Bundestag (2003). Fünfzehnter Bericht nach $\S 35$ des Bundesausbildungsförderungsgesetzes zur Überprüfung der Bedarfssätze, Freibeträge sowie Vomhundertsätze und Höchstbeträge nach §21 Abs. 2. Drucksache $15 / 890$ 22.04.2003.

Deutscher Bundestag (2004a). Entwurf eines Gesetzes zur Berücksichtigung der Kindererziehung im Beitragsrecht der sozialen Pflegeversicherung (KinderBerücksichtigungsgesetz - KiBG). Drucksache 15/ 3671 03.09.2004

Deutscher Bundestag (2004b). Gutachten des Sozialbeirats zum Rentenversicherungsbericht 2004. Drucksache 15/4498 01.12.2004

Deutscher Bundestag (2005). Sechzehnter Bericht nach $\S 35$ des Bundesausbildungsförderungsgesetzes zur Überprüfung der Bedarfssätze, Freibeträge sowie Vomhundertsätze und Höchstbeträge nach §21 Abs. 2. Drucksache 15/4995 25.02.2005.

Deutscher Bundestag (2006a). Leistungen für Familien. Drucksache 16/ 771 27.02.2006

Deutscher Bundestag (2006b). Entwurf eines Gesetzes zur Einführung des Elterngeldes. Drucksache 16/ 1889 20.06.2006.

Deutscher Bundestag (2006c). Entwurf eines Gesetzes zur Anpassung der Regelaltersgrenze an die demografische Entwicklung und zur Stärkung der Finanzierungsgrundlagen der gesetzlichen Rentenversicherung (RV-Altersgrenzenanpassungsgesetz). Drucksache 16/3794 12.12.2006 
Deutscher Bundestag (2006d). Gutachten des Sozialbeirats zum Rentenversicherungsbericht 2006. Drucksache 16/3700 05.12.2006.

Deutscher Bundestag (2007a). Siebzehnter Bericht nach $\S 35$ des Bundesausbildungsförderungsgesetzes zur Überprüfung der Bedarfssätze, Freibeträge sowie Vomhundertsätze und Höchstbeträge nach $\S 21$ Abs. 2. Drucksache $16 / 412318.01 .2007$

Deutscher Bundestag (2007b). Bewertung der familienbezogenen Leistungen und Maßnahmen des Staates. Drucksache 16/5394 22.05.2007

Deutsches Studentenwerk (2008). Übersicht: Studiengebühren in den 16 Bundesländern (Stand: 08. Januar 2008).

http://www.studentenwerke.de/pdf/Uebersicht\%20Details\%20Studiengebueh ren.pdf 12.03.2008

Deutsches Studentenwerk (Hrsg.) (1957). Das Soziale Bild der Studentenschaft in Westdeutschland und Berlin. Sommersemester 1956. Berlin: Colloquium.

Deutsches Studentenwerk (Hrsg.) (1964). Das Soziale Bild der Studentenschaft in Westdeutschland und Berlin. Sommersemester 1963. Berlin: Colloquium.

Deutsches Studentenwerk (Hrsg.) (1969). Das Soziale Bild der Studentenschaft in der Bundesrepublik Deutschland. Wintersemester 1967/68. Bonn: Deutsches Studentenwerk.

Diehl, Peter (1971). Umverteilungswirkungen im Familienlastenausgleich. Ein Vergleich des bestehenden Systems mit zwei Vorschlägen zu seiner Reform. Meisenheim am Glan: Hain.

Dohmen, Dieter (1999). Ausbildungskosten, Ausbildungsförderung und Familienlastenausgleich. Eine ökonomische Analyse unter Berücksichtigung rechtlicher Rahmenbedingungen. Berlin: Duncker \& Humblot.

Dresdner Bank AG (1976). Einkommensteuer 1975, Körperschaftsteuer, Gewerbesteuer. Niederkassel-Mondorf: Titz.

Dresdner Bank AG (Hrsg.) (1966). Einkommensteuer 1965, Körperschaftsteuer, Gewerbesteuer. Mondorf: Titz.

Dünn, Sylvia; Lohmann, Albert ; Stahl, Helmut; Stegmann, Michael (2004). Die Neuregelung zur Bewertung schulischer und beruflicher Ausbildungszeiten. Deutsche Rentenversicherung, 6-7/2004. S. 364-383

Duschek, Klaus-Jürgen; Wirth, Heike (2005). Kinderlosigkeit von Frauen im Spiegel des Mikrozensus. Eine Kohortenanalyse der Mikrozensen 1987 bis 2003. Wirtschaft und Statistik 8/ 2005. S. 800-820.

Ehmann, Christoph (2003). Bildungsfinanzierung und soziale Gerechtigkeit. 2. Aufl. Bielefeld: wbv.

Engstler, Heribert; Menning, Sonja (2003) Die Familie im Spiegel der amtlichen Statistik. Lebensformen, Familienstrukturen, wirtschaftliche Situation der Familien und familiendemographische Entwicklung in Deutschland. Bonn: Bundesministerium für Familie, Senioren, Frauen und Jugend. 
Essig, Lothar; Reil-Held, Anette (2003). Chancen und Risiken der "Riester-Rente". MEA Discussion Paper 35-03.

Färber, Gisela (1996). Alternativen der Finanzierung des Lebenseinkommens von StudentInnen. Lorenz-von-Stein-Institut für Verwaltungswissenschaften an der Christian-Albrechts-Universität zu Kiel. Arbeitspapier Nr. 41.

Färber, Gisela (1997). Besteuerung von Alterseinkünften - ein überfälliger Regimewechsel! Hamburger Jahrbuch für Wirtschafts- und Gesellschaftspolitik, 42. S. $183-207$

Färber, Gisela (2006). Generationengerechtigkeit - Teil I. Nachrichten der Deutschen Rentenversicherung Hessen 4/2006. S. 24-31.

Fehr, Hans; Halder, Gitte (2005). Alternde Bevölkerung, öffentliche Budgets und intergenerative Wohlfahrt. In: Genser, Bernd (Hrsg.) (2005). Haushaltspolitik und öffentliche Verschuldung. Berlin: Duncker u. Humblot. S. 11-52.

Fendrich, Sandra; Fischer, Jörg; Schilling, Matthias (2005). Erziehungsgeld und Elternzeit. Bericht des Jahres 2003 im Auftrag des Bundesministeriums für Familie, Senioren, Frauen und Jugend.

http://www.bmfsfj.de/bmfsfj/generator/Politikbereiche/familie, did=5928.html 16.02.2008.

Fetzer, Stefan (2005). Determinanten der zukünftigen Finanzierbarkeit der GKV: Doppelter Alterungsprozess, Medikalisierungs- vs. Kompressionsthese und medizinisch-technischer-Fortschritt. Diskussionsbeiträge des Instituts für Finanzwissenschaft der Albert-Ludwigs-Universität Freiburg 130/ 05.

Franz, Wolfgang (2003). Arbeitsmarktökonomik (5. Auflage). Berlin: Springer.

Frerich, Johannes; Frey, Martin (1996). Handbuch der Geschichte der Sozialpolitik in Deutschland. Band 3: Sozialpolitik in der Bundesrepublik Deutschland bis zur Herstellung der Deutschen Einheit. 2. Aufl. München: Oldenbourg.

Galler, Heinz P. (1988). Familiale Lebenslagen und Familienlastenausgleich. In: Felderer, Bernhard (Hrsg.) (1988). Familienlastenausgleich und demographische Entwicklung. Schriften des Vereins für Socialpolitik, Neue Folge, Band 175. Berlin: Duncker \& Humblot.

Galler, Heinz P. (1991). Opportunitätskosten der Entscheidung für Familie und Haushalt. In: Gräbe, Sylvia (Hrsg.). Der private Haushalt als Wirtschaftsfaktor. Frankfurt a. M.: Campus. S. 118-152.

Göbel, Dieter (1983). Lebenseinkommen und Erwerbsbiographie. Eine Längsschnittuntersuchung mit Daten der gesetzlichen Rentenversicherung. Frankfurt: Campus.

Gokhale, Jagadeesh; Page, Benjamin; Potter, Joan; Sturrock, John (2000). Generational Accounts for the United States: An Update. Congressional Budget Office Technical Paper Series 2000 - 1.

Grub, Martin (2005). Verteilungswirkungen anreizorientierter Sozialpolitik. Das deutsche Rentenversicherungs- und Steuersystem in der Perspektive dynamischer Lebenszyklusmodelle. Aachen: Shaker. 
Gustafsson, Siv S.; Dex, Shirley; Wetzels, Cecile; Vlasblom, Jan D. (1996). Women's labor force transitions in connection with childbirth: A panel data comparison between Germany, Sweden and Great Britain. Journal of Population Economics 9 (3). S. 223-246

Häcker, Jasmin (2006). Dynamisierung der Pflegeleistungen: Vergangenheit - Gegenwart - Zukunft. Diskussionsbeiträge des Forschungszentrums Generationenverträge, Albert-Ludwigs-Universität Freiburg No. 8.

Hagist, Christian; Heidler, Matthias; Raffelhüschen, Bernd; Schoder, Jörg (2007). Die Generationenbilanz - Brandmelder der Zukunft. Update 2007: Demografie trifft Konjunktur. Diskussionsbeiträge des Forschungszentrums Generationenverträge, Albert-Ludwigs-Universität Freiburg No. 17.

Hagist, Christian; Raffelhüschen, Bernd; Weddige, Olaf (2006). Brandmelder der Zukunft - Die Generationenbilanz 2004. Diskussionsbeiträge des Forschungszentrums Generationenverträge, Albert-Ludwigs-Universität Freiburg No. 12.

Hain, Winfried; Lohmann, Albert; Lübke, Eckhard (2004). Veränderungen bei der Rentenanpassung durch das „RV-Nachhaltigkeitsgesetz". Deutsche Rentenversicherung, 6-7/2004, S. 333-349

Haug, Volker (1999). Das Kolleggeld - die Geschichte eines Leistungselements in der Hochschullehrerbesoldung. Zeitschrift für Beamtenrecht. S. 113-116.

Heckman, James J.; Lochner, Lance J.; Todd, Petra E. (2003). Fifty Years of Mincer Earnings Regressions. IZA Discussion Paper No. 775.

Heckman, James J.; Lochner, Lance J.; Todd, Petra E. (2005). Earnings Functions, Rates of Return and Treatment Effects: The Mincer Equation and Beyond. IZA Discussion Paper No. 1700.

Heine, Wolfgang (1990). Die Rentenreform 1992. In: Ruland, Franz (Hrsg.) (1990). Handbuch der gesetzlichen Rentenversicherung. Neuwied: Luchterhand. S. $141-170$

Henman, Barbara (2002): Familienpolitik im deutschen Steuer- und Transfersystem. Köln: Institut für Wirtschaftspolitik.

Hermann, Christopher (1990). Die Zeit von 1957-1991. In: Ruland, Franz (Hrsg.) (1990). Handbuch der gesetzlichen Rentenversicherung. Neuwied: Luchterhand. S. 105-139

Hesse, Klaus; Scheffer, Martin (1995). Die Ermittlung des Einflusses von Kindern auf den privaten Verbrauch mit Hilfe des "Functionalized Extended Linear Expenditure System" (FELES). Bundesministerium für Familie, Senioren, Frauen und Jugend (Hrsg.) (1995). Lebenshaltungsaufwendungen für Kinder. Schriftenreihe des Bundesministeriums für Familie, Senioren, Frauen und Jugend Band 43. Stuttgart: Kohlhammer.

Himmelreicher, Ralf K.; Viebrok, Holger (2003). „Riester-Rente“ und Rentabilität in der Altersvorsorge". Deutsche Rentenversicherung, 6-7 2003. S. 332-350. 
Himmelreicher, Ralf K.; Viebrok, Holger (2003). Die „Riester-Rente“ und einige Folgen für die Alterseinkünfte. ZeS-Arbeitspapier Nr. 4/2003. Bremen: Zentrum für Sozialpolitik, Universität Bremen.

Hinneburg, Heike (2003). Die Entwicklung der Familienbesteuerung - einschließlich Kindergeld -. IFSt-Schrift Nr.402

Hockerts, Hans-Günter (1990). Die Rentenreform 1957. In: Ruland, Franz (Hrsg.) (1990). Handbuch der gesetzlichen Rentenversicherung. Neuwied: Luchterhand. S. 93-104.

Homburg, Stefan (1988). Theorie der Alterssicherung. Berlin: Springer.

Homburg, Stefan (1996). Steuerrecht für Ökonomen. München: Vahlen.

Homburg, Stefan; Gräff, Carsten (1988): Zur ökonomischen Begründbarkeit eines Familienlastenausgleichs. In: Felderer, Bernhard (Hrsg.) (1988). Familienlastenausgleich und demographische Entwicklung, Schriften des Vereins für Socialpolitik Bd. 175: Berlin: Duncker \& Humblot. S. 13-28

Homburg, Stefan; Schnabel, Reinhold (2005). Reform der Familienpolitik. Gütersloh: Bertelsmann-Stiftung.

Hufnagel, Rainer (2002). Die Kosten von Kindern und die Kosten einer egalitären Partnerschaft. DIW Vierteljahrshefte zur Wirtschaftsforschung 71 (2002), 1. S. $114-125$

Kaltenborn, Bruno (1998). SimTrans - Mikrosimulation des deutschen SteuerTransfer-Systems und alternativer Reformvarianten. Johannes-GutenbergUniversität Mainz, Fachbereich Rechts- und Wirtschaftswissenschaften, Beiträge zur Wirtschaftsforschung, Nr. 56.

Kammann, H. Werner (1988). Analyse des bestehenden Familienlastenausgleichs und seine Weiterentwicklung. In: Felderer, Bernhard (Hrsg.) (1988). Familienlastenausgleich und demographische Entwicklung. Schriften des Vereins für Socialpolitik, Neue Folge, Band 175. Berlin: Duncker \& Humblot.

Kath, Gerhard (1967). Die monatlichen Ausgaben der Studierenden. Eine Untersuchung über die Richtbeträge für eine Förderung aus öffentlichen Mitteln. Bonn: Deutsches Studentenwerk.

Kirchhof, Paul (2005). EStG Kompaktkommentar. Einkommensteuergesetz. (5. Aufl.). Heidelberg: C. F. Müller

Köhler, Alo (1958). Das neue Einkommensteuergesetz mit der neuen Ehegattenbesteuerung und den für die Veranlagung 1956 und 1957 geltenden Durchführungsbestimmungen, Richtlinien, Erläuterungen und Beispielen sowie den Gesetzesentwürfen zur Steuerreform 1958. Neuwied: Luchterhand.

Köhler-Rama, Tim (2003). Grundprinzipien der gesetzlichen Rentenversicherung aus versicherungsökonomischer Sicht. Die Angestellten-Versicherung Jg. 50, Heft 8. S. 1-7. 
Konrad, Kai A.; Richter, Wolfram F. (2005). Zur Berücksichtigung von Kindern bei umlagefinanzierter Alterssicherung. Perspektiven der Wirtschaftspolitik 2005 6(1). S. $115-130$

Kowalski, Matthias (1994). Die Vergessenen. Focus 4/ 1994. S. 149

Lampert, Heinz (1996). Priorität für die Familie - Plädoyer für eine rationale Familienpolitik. Berlin: deGruyter

Lauer, Charlotte; Steiner, Viktor (1999). Returns to Human Capital in Germany: Review of the Empirical Literature. In: Asplund Rita; Pereira, Pedro T. (Hrsg.) (1999). Returns to Human Capital in Europe. A Literature Review. B Series Bd. 156. Helsinki: ETLA. S. 126-146.

Lauer, Charlotte; Steiner, Viktor (2000). Returns to Education in West Germany. An Empirical Assessment. ZEW Discussion Paper No. 00-04, Mannheim.

Lüdeke, Reinar (1999). Familienlastenausgleich, Elternleistungsausgleich und die Neufundierung der umlagefinanzierten Altersversorgung. Wirtschaftswissenschaftliche Fakultät der Universität Passau: Passauer Diskussionspapiere Nr. 17

Lüdeke, Reinar (2000). Vom Familienlastenausgleich zum Elternleistungsausgleich: Von der interpersonellen Bedarfsgerechtigkeit zur intergenerativen Leistungsgerechtigkeit. In: Lüdeke, Reinar (Hrsg.) (2000). Wirtschaftswissenschaft im Dienste der Verteilungs-, Geld- und Finanzpolitik. Festschrift für Alois Oberhauser zum 70. Geburtstag. Berlin: Duncker \& Humblot. S. 193219

Lüdeke, Reinar; Werding, Martin (1996). Die Reform des Dualen Familienlastenbzw. Familienleistungsausgleichs 1996. Wirkungen und Ziele einkommensteuerlicher Kinderfreibeträge und des Kindergelds nach altem und neuem Recht. Jahrbücher für Nationalökonomie und Statistik, Bd. 215. S. 419-443

Maddala, G.S. (1983). Limited-Dependent and Qualitative Variables in Econometrics. Cambridge: Cambridge University Press.

Manzke, Bernhard (2002). Zur langfristigen Tragfähigkeit der öffentlichen Haushalte in Deutschland - eine Analyse anhand der Generationenbilanzierung. Volkswirtschaftliches Forschungszentrum der Deutschen Bundesbank Diskussionspapier 10/02.

Mincer, Jacob (1958). Investment in Human Capital and Personal Income Distribution. Journal of Political Economy, 66, S. 281-302.

Mincer, Jacob (1974). Schooling, Experience, and Earnings. New York: National Bureau of Economic Research.

Müller, Eugen; Nachtigal, Gert; Hansen, Volker (1990). Rentenreformgesetz 1992 Erläuterungen für die Praxis mit vollem Gesetzestext. Köln: Wirtschaftsverlag Bachem. 
o.V. (1952). Einkommensteuergesetz 1951 (EStG 1951), Einkommensteuer-Durchführungsverordnung 1951 (EStDV) in der Fassung vom 17. Januar 1952. Schriftenreihe der Steuerbriefe für Unternehmer, Heft 1. Bad Wörishofen: Hans Holzmann.

o.V. (2004). Bericht der Bundesregierung zur Entwicklung der nicht beitragsgedeckten Leistungen und der Bundesleistungen an die Rentenversicherung vom 13. August 2004. Deutsche Rentenversicherung, Heft 10. S. 569-585.

OECD (2003). Education at a Glance. Paris.

Oehler, Christoph; Scheuch, Anne M. (1965). Der Erfolg der allgemeinen Studienförderung nach dem Honnefer Modell an der Universität in Marburg und der Technischen Hochschule in Darmstadt. Bonn: Deutsches Studentenwerk.

Ohsmann, Sabine; Stolz, Ulrich (2004). Entwicklung der Rendite in der gesetzlichen Rentenversicherung. Die Angestellten Versicherung Jg. 52, Heft 2. S. 56-62.

Ohsmann, Sabine; Stolz, Ulrich; Thiede, Reinhold (2003). Rentenabschläge bei vorgezogenem Rentenbeginn: Welche Abschlagssätze sind "richtig"? Die Angestellten Versicherung Jg. 50, Heft 4. S. 1-9.

Onken, Ralph (1993). Ausbildungsförderung im Rahmen des Familienlastenausgleichs in der Bundesrepublik Deutschland von 1970 bis 1990 : eine empirische Analyse. Frankfurt a.M.: Lang.

Ott, Notburga (2002). Luxusgut Kind zwischen Privatinteresse und gesellschaftlicher Verpflichtung - Zu den Kontroversen in der familienpolitischen Debatte. DIW. Vierteljahrshefte zur Wirtschaftsforschung 71 (2002), 1. S. 11-25.

Papier, Hans-Jürgen (1998). Verfassungsrechtliche Vorgaben für die Alterssicherung. In: Cramer, Jörg-Engelbrecht; Förster, Wolfgang; Ruland, Franz (Hrsg.) (1998). Handbuch zur Altersversorgung. Gesetzliche, betriebliche und private Vorsorge in Deutschland. Frankfurt a. M.: Knapp.

Pfeiffer, Ulrich; Braun, Reiner (2005). Expertise "Lebensökonomie als (mögliches) Leitbild einer nachhaltigen Familienpolitik" im Auftrag des Bundesministeriums für Familie, Senioren, Frauen und Jugend. Berlin: empirica.

Postler, Andreas (2003). Modellrechnungen zur Beitragssatzentwicklung in der Gesetzlichen Krankenversicherung: Auswirkungen von demographischem Wandel und medizinisch-technischem Fortschritt. Diskussionsbeiträge der Fakultät Wirtschaftswissenschaft der Universität Duisburg-Essen Nr. 298.

Psacharopoulos, George (1995): The Profitability of Investment in Education. Concepts and Methods. Washington, D. C.: Worldbank.

Psacharopoulos, George; Patrinos, Harry A. (2004). Returns to Investment in Education: A Further Update. Education Economics 12 (2), S. 111-134.

Raffelhüschen, Bernd (1999). Generational Accounting: Method, Data and Limitations. European Economy: Reports and Studies, Number 6. S. 17-28. 
Reinberg, Alexander (1999). Der qualifikatorische Strukturwandel auf dem deutschen Arbeitsmarkt - Entwicklungen, Perspektiven und Bestimmungsgründe. Mitteilungen aus der Arbeitsmarkt- und Berufsforschung 4/1999, S. 434-447.

Riphahn, Regina T. (2004). The Enrollment Effect of Secondary School Fees in PostWar Germany. IZA Discussion Paper No. 1295.

Rosenschon, Astrid (2001). Familienförderung in Deutschland - eine Bestandsaufnahme. Kieler Arbeitspapier Nr. 1071.

Rosenschon, Astrid (2006). Finanzpolitische Maßnahmen zugunsten von Familien Eine Bestandsaufnahme für Deutschland. Kieler Arbeitspapier Nr. 1273.

Rothe, Friedrich; Blanke, Ernst August (2005). Bundesausbildungsförderungsgesetz. Kommentar, Loseblattsammlung, 5. Auflage. Stuttgart. Kohlhammer.

Rürup, Bert (2004). Generationengerechtigkeit und Rentenversicherung. Verband deutscher Rentenversicherungsträger (Hrsg.) (2004). Generationengerechtigkeit - Inhalt, Bedeutung und Konsequenzen für die Alterssicherung. DRVSchriften Band 51. S. 39-44.

Sachverständigenrat zur Begutachtung der gesamtwirtschaftlichen Entwicklung (2001). Für Stetigkeit - Gegen Aktionismus. Jahresgutachten 2001/ 02.

Sachverständigenrat zur Begutachtung der gesamtwirtschaftlichen Entwicklung (2003). Staatsfinanzen konsolidieren - Steuersystem reformieren. Jahresgutachten 2003/ 04.

Sachverständigenrat zur Begutachtung der gesamtwirtschaftlichen Entwicklung (2004). Erfolge im Ausland - Herausforderungen im Inland. Jahresgutachten 2004/ 05.

Sachverständigenrat zur Begutachtung der gesamtwirtschaftlichen Entwicklung (2005). Die Chancen Nutzen - Reformen mutig voranbringen. Jahresgutachten 2005/ 06.

Sachverständigenrat zur Begutachtung der gesamtwirtschaftlichen Entwicklung (2006). Widerstreitende Interessen - Ungenutzte Chancen. Jahresgutachten 2006/ 07

Sachverständigenrat zur Begutachtung der gesamtwirtschaftlichen Entwicklung (2007). Das Erreichte nicht verspielen. Jahresgutachten 2007/ 08.

Schieckel, Horst (1965). Bundeskindergeldgesetz (BKGG) vom 14. April 1964 (BGBL. 1964 | S.265); Textausgabe mit Einführung, amtlicher Begründung und Verweisungen. München: Schulz.

Schmähl, Winfried (2004). Anmerkungen zu "Generationengerechtigkeit" und Alterssicherung aus ökonomischer Perspektive. Verband deutscher Rentenversicherungsträger (Hrsg.) (2004). Generationengerechtigkeit - Inhalt, Bedeutung und Konsequenzen für die Alterssicherung. DRV-Schriften Band 51. S. 74-84. 
Schmähl, Winfried; Göbel, Dieter (1983). Lebenseinkommensverläufe aus Daten der Rentenversicherungsträger. In: Schmähl, Winfried (Hrsg.) (1983). Ansätze der Lebenseinkommensanalyse. Tübingen: Mohr.

Schmähl, Winfried; Himmelreicher, Ralf K.; Viebrok, Holger (2004). Private Vorsorge statt gesetzlicher Rente: Wer gewinnt, wer verliert? Beiträge zur Sozial- und Verteilungspolitik, Band 3. Münster: Lit.

Schmähl, Winfried; Rothgang, Heinz; Viebrok, Holger (2006). Berücksichtigung von Familienleistungen in der Alterssicherung. Analyse und Folgerungen aus ökonomischer Sicht. Deutsche Rentenversicherung Bund (Hrsg.). DRV Schriften Band 65.

Schmidt, Klaus-Dieter; Baumgarten, Peter (1967). Berufliche Ausbildung und Einkommen. In: Ott, Alfred Eugen (Hsrg.) (1967). Theoretische und empirische Beiträge zur Wirtschaftsforschung. Tübingen: Mohr. S. 155-182.

Schmidt, Ludwig (Hrsg.) (2002). Einkommensteuergesetz: Kommentar (21. Aufl.). München: Beck.

Schnabel, Reinhold (1998). Rates of Return of the German Pay-As-You-Go Pension System. Working Paper. Department of Economics, University of Mannheim.

Siddiqui, Sikandar (1997). The pension incentive to retire: Empirical evidence for West Germany. Journal of Population Economics, 10 (4), S. 463-486.

Sinn, Hans-Werner (1997). The Value of Children and Immigrants in a Pay-as-you-go Pension System: A Proposal for a Partial Transition to a Funded System. CESifo Working Paper No. 141.

Sinn, Hans-Werner (1999). The Crisis of Germany's Pension Insurance system and How it Can be Resolved. CESifo Working Paper No. 191.

Sinn, Hans-Werner (2000). Why a Funded Pension System is Useful and Why It is Not Useful. International Tax and Public Finance Vol 7. S. 389-410

Spence, Michael (1973). Job market signaling. Quarterly Journal of Economics, 87. S. 355-379.

Stahl, Helmut; Stegmann, Michael (2001). Änderungen der Hinterbliebenenrentenreform. Deutsche Rentenversicherung, 6-7/2001. S. 387-400.

Statistisches Bundesamt (2004). Fachserie 18/ Reihe S. 21: Volkswirtschaftliche Gesamtrechnungen. Revidierte Ergebnisse 1970 bis 2003. Stuttgart: MetzlerPoeschel.

Statistisches Bundesamt (2005a). Generationensterbetafeln für Deutschland. Modellrechnungen für die Geburtsjahrgänge 1871-2003. Wiesbaden

Statistisches Bundesamt (2005b). Bildung im Zahlenspiegel 2005. Wiesbaden.

Statistisches Bundesamt (2006a). Verbraucherpreisindex und Index der Einzelhandelspreise. Lange Reihe ab 1948 bis 2005 - Jahresdurchschnitte -. 
Statistisches Bundesamt (2006b). Fachserie 1: Bevölkerung und Erwerbstätigkeit. Reihe 1.1: Natürliche Bevölkerungsbewegung 2004. Stuttgart: Metzler Poeschel.

Statistisches Bundesamt (2006c). Fachserie 11: Bildung und Kultur. Reihe 4.3: Monetäre hochschulstatistische Kennzahlen 2004. Stuttgart: Metzler Poeschel.

Statistisches Bundesamt (2006d). Fachserie 11: Bildung und Kultur. Reihe 7: Ausbildungsförderung nach dem Bundesausbildungsförderungsgesetz (BAföG) 2005. Stuttgart: Metzler Poeschel.

Stephany, Gerda (1968). Das Honnefer Modell. Schriften zum Offentlichen Recht Bd. 77. Berlin: Duncker \& Humblot.

Strate, Gregor; Meyer, Sebastian (2006). Studienfinanzierung - Modelle und Möglichkeiten. Studiendarlehen, Studienkredite, Bildungsfonds, Studiengebührenausnahmereglungen und Stipendiendatenbanken. Wissenschaftliche Dienste des Deutschen Bundestages. WF VIII - 39/2006.

Thum, Marcel; Weizsäcker, Jakob von (2000). Implizite Einkommensteuer als Messlatte für die aktuellen Rentenreformvorschläge. Perspektiven der Wirtschaftspolitik, 1. S. 453-468.

Thurow, Lester C. (1975). Generating Inequality: Mechanisms of Distribution in the U.S. Economy. New York: Basic Books.

Tipke, Klaus; Lang, Joachim (2002). Steuerrecht (17. Aufl.). Köln: Otto Schmidt.

Trampusch, Christine (2003). Ein Bündnis für die nachhaltige Finanzierung der Sozialversicherungssysteme: Interessenvermittlung in der bundesdeutschen Arbeitsmarkt- und Rentenpolitik. Max-Planck-Institut für Gesellschaftsforschung: Discussion Paper 03/1.

Verband deutscher Rentenversicherungsträger (2005). Rentenversicherung in Zahlen 2005. Frankfurt a. M.

Verband deutscher Rentenversicherungsträger (2007). Rentenversicherung in Zeitreihen. DRV-Schriften Band 22.

Verband deutscher Rentenversicherungsträger (Hrsg.) (2001a). Rentenstrukturreform - Teil I. Deutsche Rentenversicherung, 5/ 2001.

Verband deutscher Rentenversicherungsträger (Hrsg.) (2001b). Rentenstrukturreform - Teil II. Deutsche Rentenversicherung, 6-7/ 2001.

Verband deutscher Rentenversicherungsträger (Hrsg.) (2004). Reformen der Alterssicherung. Deutsche Rentenversicherung, 6-7/ 2004.

Viebrok, Holger (1997). Das Arbeitsangebot im Übergang von der Beschäftigung in den Ruhestand - Eine Analyse der Arbeitsanreize durch sozialrechtliche Regelungen in der Spätphase des Erwerbslebens. Frankfurt: Lang. S. 103ff

Wagner, Gert G. (2002). Kinderbetreuung und Vorschulerziehung sollten flexibel gestaltet werden - Erziehung muss für Eltern keine ökonomische Last sein. DIW. Vierteljahrshefte zur Wirtschaftsforschung 71 (2002), 1. S. 43-51 
Weißhuhn, Gernot; Clement, Werner (1982). Analyse der qualifikationsspezifischen Verdienstrelationen in der Bundesrepublik Deutschland auf der Basis der Beschäftigtenstatistik1974/1977. Mitteilungen aus der Arbeitsmarkt- und Berufsforschung 1/1982, S. 36-49.

Werding, Martin; Hofmann, Herbert (2005). Die fiskalische Bilanz eines Kindes im deutschen Steuer- und Sozialsystem. Studie im Auftrag der Robert-BoschStiftung. ifo Forschungsberichte Nr. 27.

Wickenhagen, Ernst; Krebs, Heinrich (1994). Bundeskindergeldgesetz. Kommentar, Loseblattsammlung. Köln: Heymann.

Wilke, Christina B. (2005). Rates of Return of the German PAYG System - How they can be measured and how they will develop. MEA Discussion Paper 97-05.

Willeke, Franz-Ulrich; Onken, Ralph (1990). Allgemeiner Familienlastenausgleich in der Bundesrepublik Deutschland - eine empirische Analyse zu drei Jahrzehnten monetärer Familienpolitik. Frankfurt: Campus.

Wissenschaftlicher Beirat für Familienfragen (2006). Mehr Transparenz im monetären Familienleistungsausgleich - Familienfreundliche Reform der sozialen Sicherungssysteme.

http://www.bmfsfj.de/RedaktionBMFSFJ/Abteilung2/Pdf-

Anlagen/stellungnahme-reform-soziale-sicherungssysteme 11.06.2007.

Zimmerer, Thomas (1996). Zur Kurzlebigkeit deutscher Einkommensteuertarife: Eine Replik über 50 Jahre deutsche Einkommensbesteuerung. Regensburger Diskussionsbeiträge zur Wirtschaftswissenschaft Nr. 286. 


\section{FINANZWISSENSCHAFTLICHE SCHRIFTEN}

Band 1 Werner Steden: Finanzpolitik und Einkommensverteilung. Ein Wachstums- und Konjunkturmodell der Bundesrepublik Deutschland. 1979.

Band 2 Rainer Hagemann: Kommunale Finanzplanung im föderativen Staat. 1976.

Band 3 Klaus Scherer: Maßstäbe zur Beurteilung von konjunkturellen Wirkungen des öffentlichen Haushalts. 1977.

Band 4 Brita Steinbach: "Formula Flexibility" - Kritische Analyse und Vergleich mit diskretionärer Konjunkturpolitik. 1977.

Band 5 Hans-Georg Petersen: Personelle Einkommensbesteuerung und Inflation. Eine theoretisch-empirische Analyse der Lohn- und veranlagten Einkommensteuer in der Bundesrepublik Deutschland. 1977.

Band 6 Friedemann Tetsch: Raumwirkungen des Finanzsystems der Bundesrepublik Deutschland. Eine Untersuchung der Auswirkungen der Finanzreform von 1969 auf die Einnahmenposition der untergeordneten Gebietskörperschaften und ihrer regionalpolitischen Zieladäquanz. 1978.

Band 7 Wilhelm Pfähler: Normative Theorie der fiskalischen Besteuerung. Ein methodologischer und theoretischer Beitrag zur Integration der normativen Besteuerungstheorie in der Wohlfahrtstheorie. 1978.

Band 8 Wolfgang Wiegard: Optimale Schattenpreise und Produktionsprogramme für öffentliche Unternehmen. Second-Best Modelle im finanzwirtschaftlichen Staatsbereich. 1978.

Band 9 Hans P. Fischer: Die Finanzierung des Umweltschutzes im Rahmen einer rationalen Umweltpolitik. 1978.

Band 10 Rainer Paulenz: Der Einsatz finanzpolitischer Instrumente in der Forschungs- und Entwicklungspolitik. 1978.

Band 11 Hans-Joachim Hauser: Verteilungswirkungen der Staatsverschuldung. Eine kreislauftheoretische Inzidenzbetrachtung. 1979.

Band 12 Gunnar Schwarting: Kommunale Investitionen. Theoretische und empirische Untersuchungen der Bestimmungsgründe kommunaler Investitionstätigkeit in NordrheinWestfalen 1965-1972. 1979.

Band 13 Hans-Joachim Conrad: Stadt-Umland-Wanderung und Finanzwirtschaft der Kernstädte. Amerikanische Erfahrungen, grundsătzliche Zusammenhänge und eine Fallstudie für das Ballungsgebiet Frankfurt am Main. 1980.

Band 14 Cay Folkers: Vermögensverteilung und staatliche Aktivität. Zur Theorie distributiver Prozesse im Interventionsstaat. 1981.

Band 15 Helmut Fischer: US-amerikanische Exportförderung durch die DISC-Gesetzgebung. 1981.

Band 16 Günter Ott: Einkommensumverteilungen in der gesetzlichen Krankenversicherung. Eine quantitative Analyse. 1981.

Band 17 Johann Hermann von Oehsen: Optimale Besteuerung. (Optimal Taxation). 1982.

Band 18 Richard Kössler: Sozialversicherungsprinzip und Staatszuschüsse in der gesetzlichen Rentenversicherung. 1982.

Band 19 Hinrich Steffen: Zum Handlungs- und Entscheidungsspielraum der kommunalen Investitionspolitik in der Bundesrepublik Deutschland. 1983.

Band 20 Manfred Scheuer: Wirkungen einer Auslandsverschuldung des Staates bei flexiblen Wechselkursen. 1983. 
Band 21 Christian Schiller: Staatsausgaben und crowding-out-Effekte. Zur Effizienz einer Finanzpolitik keynesianischer Provenienz. 1983.

Band 22 Hannelore Weck: Schattenwirtschaft: Eine Möglichkeit zur Einschränkung der öffentlichen Verwaltung? Eine ökonomische Analyse. 1983.

Band 23 Wolfgang Schmitt: Steuern als Mittel der Einkommenspolitik. Eine Ergänzung der Stabilitätspolitik? 1984.

Band 24 Wolfgang Laux: Erhöhung staatswirtschaftlicher Effizienz durch budgetäre Selbstbeschränkung? Zur Idee einer verfassungsmäßig verankerten Ausgabengrenze. 1984.

Band 25 Brita Steinbach-van der Veen: Steuerinzidenz. Methodologische Grundlagen und empirisch-statistische Probleme von Länderstudien. 1985.

Band 26 Albert Peters: Ökonomische Kriterien für eine Aufgabenverteilung in der Marktwirtschaft. Eine deskriptive und normative Betrachtung für den Allokationsbereich. 1985.

Band 27 Achim Zeidler: Möglichkeiten zur Fortsetzung der Gemeindefinanzreform. Eine theoretische und empirische Analyse. 1985.

Band 28 Peter Bartsch: Zur Theorie der längerfristigen Wirkungen 'expansiver' Fiskalpolitik. Eine dynamische Analyse unter besonderer Berũcksichtigung der staatlichen Budgetbeschrănkung und ausgewählter Möglichkeiten der öffentlichen Defizitfinanzierung. 1986.

Band 29 Konrad Beiwinkel: Wehrgerechtigkeit als finanzpolitisches Verteilungsproblem. Möglichkeiten einer Kompensation von Wehrungerechtigkeit durch monetäre Transfers. 1986.

Band 30 Wolfgang Kitterer: Effizienz- und Verteilungswirkungen des Steuersystems. 1986.

Band 31 Heinz Dieter Hessler: Theorie und Politik der Personalsteuern. Eine Kritik ihrer Einkommens- und Vermőgensbegriffe mit Blick auf die Leistungsfähigkeitstheorie. 1994.

Band 32 Wolfgang Scherf: Die beschäftigungspolitische und fiskalische Problematik der Arbeitgeberbeiträge zur Rentenversicherung. Eine Auseinandersetzung mit der Kritik an der lohnbezogenen Beitragsbemessung. 1987.

Band 33 Andreas Mästle: Die Steuerunion. Probleme der Harmonisierung spezifischer Gütersteuern. 1987.

Band 34 Günter Ott: Internationale Verteilungswirkungen im Finanzausgleich der Europäischen Gemeinschaften. 1987.

Band 35 Heinz Haller: Zur Frage der zweckmäßigen Gestalt gemeindlicher Steuern. Ein Diskussionsbeitrag zur Gemeindesteuerreform. 1987.

Band 36 Thomas Kuhn: Schlüsselzuweisungen und fiskalische Ungleichheit. Eine theoretische Analyse der Verteilung von Schlüsselzuweisungen an Kommunen. 1988.

Band 37 Walter Hahn: Steuerpolitische Willensbildungsprozesse in der Europäischen Gemeinschaft. Das Beispiel der Umsatzssteuer-Harmonisierung. 1988.

Band 38 Ulrike Hardt: Kommunale Finanzkraft. Die Problematik einer objektiven Bestimmung kommunaler Einnahmemöglichkeiten in der gemeindlichen Haushaltsplanung und im kommunalen Finanzausgleich. 1988.

Band 39 Jochen Michaelis: Optimale Finanzpolitik im Modell überlappender Generationen. 1989.

Band 40 Bernd Raffelhüschen: Anreizwirkungen der sozialen Alterssicherung. Eine dynamische Simulationsanalyse. 1989.

Band 41 Berend Diekmann: Die Anleihe- und Darlehenstransaktionen der Europäischen Gemeinschaften. 1990.

Band 42 Helmut Kaiser: Konsumnachfrage, Arbeitsangebot und optimale Haushaltsbesteuerung. Theoretische Ergebnisse und mikroökonometrische Simulation für die Bundesrepublik Deutschland. 1990. 
Band 43 Rüdiger von Kleist: Das Gramm-Rudman-Hollings-Gesetz. Ein gescheiterter Versuch der Haushaltskonsolidierung. 1991.

Band 44 Rolf Hagedorn: Steuerhinterziehung und Finanzpolitik. Ein theoretischer Beitrag unter besonderer Berücksichtigung der Hinterziehung von Zinserträgen. 1991.

Band 45 Cornelia S. Behrens: Intertemporale Verteilungswirkungen in der gesetzlichen Krankenversicherung der Bundesrepublik Deutschland. 1991.

Band 46 Peter Saile: Ein ökonomischer Ansatz der Theorie der intermediären Finanzgewalten Die Kirchen als Parafisci. 1992.

Band 47 Peter Gottfried: Die verdeckten Effizienzwirkungen der Umsatzsteuer. Eine empirische allgemeine Gleichgewichtsanalyse. 1992.

Band 48 Andreas Burger: Umweltorientierte Beschäftigungsprogramme. Eine Effizienzanalyse am Beispiel des "Sondervermögens Arbeit und Umwelt". 1992.

Band 49 Jeanette Malchow: Die Zuordnung verteilungspolitischer Kompetenzen in der Europäischen Gemeinschaft. Eine Untersuchung aufgrund einer Fortentwicklung der ökonomischen Theorie des Föderalismus. 1992.

Band 50 Barbara Seidel: Die Einbindung der Bundesrepublik Deutschland in die Europäischen Gemeinschaften als Problem des Finanzausgleichs. 1992.

Band 51 Ralph Wiechers: Markt und Macht im Rundfunk. Zur Stellung der öffentlich-rechtlichen Rundfunkanstalten im dualen Rundfunksystem der Bundesrepublik Deutschland. 1992.

Band 52 Klaus Eckhardt: Probleme einer Umweltpolitik mit Abgaben. 1993.

Band 53 Oliver Schwarzkopf: Die Problematik unterschiedlicher Körperschaftsteuersysteme innerhalb der EG. 1993.

Band 54 Thorsten Giersch: Bergson-Wohlfahrtsfunktion und normative Ökonomie. 1993.

Band 55 Li-Fang Chou: Selbstbeteiligung bei Arzneimitteln aus ordnungspolitischer Sicht. Das Beispiel der Bundesrepublik Deutschland. 1993.

Band 56 Harald Schlee: Einkommensteuerliche Behandlung von Transferzahlungen. Zur Neuordnung der Familienbesteuerung sowie der Besteuerung von Versicherungsleistungen und Sozialtransfers. 1994.

Band 57 Alexander Spermann: Kommunales Krisenmanagement. Reaktionen baden-württembergischer Stadtkreise auf steigende Sozialhilfekosten und Einnahmenausfälle (198092). 1993.

Band 58 Otto Roloff / Sibylle Brander / Ingo Barens / Claudia Wesselbaum: Direktinvestitionen und internationale Steuerkonkurrenz. 1994.

Band 59 Claudia Wesselbaum-Neugebauer: Internationale Steuerbelastungsvergleiche. 1994.

Band 60 Stephanie Miera: Kommunales Finanzsystem und Bevölkerungsentwicklung. Eine Analyse des kommunalen Finanzsystems vor dem Hintergrund der sich abzeichnenden Bevölkerungsentwicklung am Beispiel Niedersachsens unter besonderer Berücksichtigung des Landkreises Wolfenbüttel und seiner Gemeinden. 1994.

Band 61 Wolfgang Schert: Die Bedeutung des kaldorianischen Verteilungsmechanismus für die gesamtwirtschaftlichen Wirkungen der staatlichen Neuverschuldung. 1994.

Band 62 Rainer Volk: Vergleich der Vergünstigungseffekte der verschiedenen investitionsfördernden Maßnahmen. 1994.

Band 63 Hans-Georg Napp: Kommunale Finanzautonomie und ihre Bedeutung für eine effiziente lokale Finanzwirtschaft. 1994. 2., unveränderte Auflage 1994.

Band 64 Bernd Rahmann / Uwe Steinborn / Günter Vornholz: Empirische Analyse der Autonomie lokaler Finanzwirtschaften in der Europäischen Gemeinschaft. 1994. 
Band 65 Carsten Kühl: Strategien zur Finanzierung der Altlastensanierung. 1994.

Band 66 Stephan Boll: Intergenerationale Umverteilungswirkungen der Fiskalpolitik in der Bundesrepublik Deutschland. Ein Ansatz mit Hilfe des Generational Accounting. 1994.

Band 67 Karl Justus Bernhard Neumärker: Finanzverfassung und Staatsgewalt in der Demokratie. Ein Beitrag zur konstitutionellen Finanztheorie. 1995.

Band 68 Christian Haslbeck: Zentrale versus dezentrale Internalisierung externer Effekte bei unvollständiger Information. 1995.

Band 69 Regina Müller: Horizontale oder vertikale Transfers zur Durchsetzung eines horizontalen Finanzausgleichs. 1995.

Band 70 Christian Hockenjos: Öffentliche Sportförderung in der Bundesrepublik Deutschland. Darstellung und finanztheoretische Analyse. 1995.

Band 71 Manfred Rosenstock: Die Kontrolle und Harmonisierung nationaler Beihilfen durch die Kommission der Europäischen Gemeinschaften. 1995.

Band 72 Christian Rüsch: Wohnungsbau- und Wohneigentumspolitik im Rahmen der Einkommensteuer. Eine Analyse unter steuersystematischen, verteilungspolitischen und fiskalischen Aspekten. 1996.

Band 73 Stephan Winters: Die kollektive Vorsorge für den Pflegefall im Alter. Eine Untersuchung am Beispiel der gesetzlichen Pflegeversicherung in den Niederlanden. 1996.

Band 74 Knut Blind: Allokationsineffizienzen auf Sicherheitsmärkten: Ursachen und Lösungsmöglichkeiten. Fallstudie: Informationssicherheit in Kommunikationssystemen. 1996.

Band 75 Barbara Petrick-Rump: Ökonomische Wirkungen von Steueramnestien. Untersuchung konkreter Erfahrungen ausgewählter Länder mit dem Einsatz von Steueramnestien anhand eines effizienten Steueramnestieprogramms. 1996.

Band 76 Georg Hirte: Effizienzwirkungen von Finanzausgleichsregelungen. Eine Empirische Allgemeine Gleichgewichtsanalyse für die Bundesrepublik Deutschland. 1996.

Band 77 Ulrike Kirchhoff: Die rheinland-pfälzischen Gemeinden im System des Finanzausgleichs. 1996.

Band 78 Kerstin Keil: Der soziale Mietwohnungsbau: Mängel und Alternativen. 1996.

Band 79 Bernhard Manzke: Kinderlastenausgleich versus verstärkte Einwanderung. Alternative Ansätze zur langfristigen Sicherung der Gesetzlichen Rentenversicherung. 1997.

Band 80 Hariolf M. Wenzler: Institutionenökonomik und öffentliche Finanzkontrolle. Eine Analyse am Beispiel der Europäischen Union. 1997.

Band 81 Joachim Nagel: Supply-Side Policy in den USA. Eine theoretische und empirische Analyse der angebotsorientierten Wirtschaftspolitik Reagans unter besonderer Berücksichtigung steuerlicher Aspekte. 1997.

Band 82 Heinz Lampert: Krise und Reform des Sozialstaates. 1997.

Band 83 Monika Hanswillemenke / Bernd Rahmann: Zwischen Reformen und Verantwortung für Vollbeschäftigung. Die Finanz- und Haushaltspolitik der sozial-liberalen Koalition von 1969 bis 1982.1997.

Band 84 Berthold Fürst: Die Maastrichter Budgetkriterien im Konflikt mit der Verschuldungsautonomie der deutschen Gebietskörperschaften. 1997.

Band 85 Burkhard Pahnke: Einkommensorientierte Förderung des sozialen Mietwohnungsbaues. Bestandsaufnahme und Kritik. 1998.

Band 86 Judith Safford: Staatsverschuldung im Vereinigten Königreich. Die öffentliche Verschuldung unter der Konservativen Regierung von 1979-1994. Ursachen und Auswirkungen. 1998. 
Band 87 Ralf Oberheide: Die Bekämpfung der Steuerumgehung. 1998.

Band 88 Achim Truger: Die neue Finanzwissenschaft zwischen Realitätsferne und Irrelevanz der Annahmen. Eine methodologische Analyse potentieller Verteidigungsstrategien der neuen Finanzwissenschaft gegen den Vorwurf der Realitätsferne ihres entscheidungstheoretischen Fundamentes. 1998.

Band 89 Karin Bickel: Familienbezogene Elemente im System der gesetzlichen Rentenversicherung. Unter besonderer Berücksichtigung von Ein-Eltern-Familien. 1999.

Band 90 Wolfgang Schert: Schlüsselzuweisungen und Kreisumlage. Die Problematik der Finanzierung der Landkreise am Beispiel des kommunalen Finanzausgleichs von RheinlandPfalz. 1998.

Band 91 Sandra Ehmann: Familienpolitik in Frankreich und Deutschland - ein Vergleich. 1999.

Band 92 Hendrik Suermann: Einkommensteuerliche Behandlung von Währungsgewinnen und -verlusten. Eine finanzwissenschaftliche Analyse des Steuerrechts in den USA und in Deutschland. 1999.

Band 93 Rolf Bösinger: Die Neuordnung des bundesstaatlichen Finanzausgleichs 1995. Eine theoretische und empirische Analyse unter Berūcksichtigung von allokationstheoretischen und polit-ökonomischen Gesichtspunkten. 1999.

Band 94 Ulrich Ermschel: Finanzwirtschaftliche Konsequenzen beim Übergang auf das Ursprungslandprinzip im Europäischen Binnenmarkt. Eine Untersuchung am Beispiel des unvollkommenen oligopolistischen Neufahrzeugmarktes. 1999.

Band 95 Ute Hansen: Überwälzte Leistungen der Administration. Eine empirische und theoretische Analyse. 2000.

Band 96 Hans-Werner Seiler: Zur Durchsetzung der Einmalbesteuerung deutscher Körperschaftsgewinne. Strategien zur Vermeidung der im deutschen Körperschaftsteuersystem angelegten Benachteiligung ausländischer Anteilseigner. Eine finanzwissenschaftliche Analyse. 2000.

Band 97 Steffen Meyer: Zwischenstaatliche Finanzzuweisungen im zusammenwachsenden Europa. Zur Gestaltung eines Finanzausgleichs für die Europäische Union. 2000.

Band 98 Marion Hübner: Ökodumping? Umweltpolitik in internationalen Oligopolmärkten. 2000.

Band 99 Christhart Bork: Steuern, Transfers und private Haushalte. Eine mikroanalytische Simulationsstudie der Aufkommens- und Verteilungswirkungen. 2000.

Band 100 Norbert Eichler: Die Probleme des Gemeindefinanzausgleichs im Kooperativen Föderalismus. Eine ökonomische Analyse am Beispiel des Bundeslandes Nordrhein-Westfalen. 2000.

Band 101 Wolfgang Scherf: Der Länderfinanzausgleich in Deutschland. Ungelöste Probleme und Ansatzpunkte einer Reform. 2000.

Band 102 Stefan Dietrich Josten: Staatsverschuldung, intertemporale Allokation und Wirtschaftswachstum. Eine theoretische Analyse staatlicher Verschuldungspolitik in Modellen exogenen und endogenen Wachstums. 2000.

Band 103 Axel Breitbach: Steuerhinterziehung und Schattenwirtschaft aus gesamtwirtschaftlicher Sicht. 2000.

Band 104 Alexander Spermann: Negative Einkommensteuer, Lohnsubventionen und Langzeitarbeitslosigkeit. 2001.

Band 105 Michael Broer: Der kommunale Finanzausgleich in Hessen. Historische Darstellung und ökonomische Analyse unter besonderer Berücksichtigung der Schlüsselzuweisungen. 2001.

Band 106 Jan-Paul Ritscher: Der Einsatz von Finanzderivaten unter einer modernisierten Schuldenstrukturpolitik des Bundes. 2002. 
Band 107 Martin Gasche: Dynamische Fiskalpolitik. Makroökonomische Wirkungen der Fiskalpolitik in einem Real Business Cycle-Modell. 2003.

Band 108 Felix Brosius: Internationaler Steuenwettbewerb und Koordination der Steuersysteme. 2003.

Band 109 Claudia Hensberg: Eigennützige Regierungen im fiskalischen Wettbewerb um Kapital. 2003.

Band 110 Hans-Martin Grambeck: Konsumsteuerreformen und Konsumbesteuerung. Eine verglejchende Analyse und Bewertung verschiedener Konsumsteuermodelle unter besonderer Berücksichtigung der Probleme in offenen Volkswirtschaften. 2003.

Band 111 Antje Draheim: Probleme der finanzpolitischen Willensbildung in Europa. Eine kritische Analyse der europäischen Haushalts- und Finanzverfassung. 2004.

Band 112 Robert Nuscheler: On Competition and Regulation in Health Care Systems. 2005.

Band 113 Guido K. Raddatz: Das Eigenmittelsystem der Europäischen Union. 2005.

Band 114 Markus Euler: Ansatzpunkte für eine Reform des Finanzierungssystems der Europäischen Union. 2005.

Band 115 Marco Penske: Finanzierung der Gesetzlichen Krankenversicherung - Probleme und Reformoptionen. 2006.

Band 116 Pascal Krimmer: Demographie, Erwerbsbeteiligung, Steuerreformen und Steueraufkommen. Langfristige Auswirkungen von Steuerreformen. 2008.

Band 117 Frank Blasch: Steuerreformen und Unternehmensentscheidungen. Eine empirische Analyse der deutschen Steuerpolitik mit besonderem Schwerpunkt auf die Steuerreform 2000. 2008.

Band 118 Tobias Arens: Inter- und intragenerative Umverteilung im deutschen Steuer-TransferSystem. Langfristige Wirkungen im Lebenszyklus. 2009.

www.peterlang.de 


\section{Demographie, Erwerbsbeteiligung, Steuerreformen und Steueraufkommen}

\section{Langfristige Auswirkungen von Steuerreformen}

Frankfurt am Main, Berlin, Bern, Bruxelles, New York, Oxford, Wien, 2008. XVI, 228 S., zahlr. Tab. und Graf.

Finanzwissenschaftliche Schriften.

Verantwortlicher Herausgeber: Bernd Raffelhüschen. Bd. 116

ISBN 978-3-631-57577-2 · br. $€ 42.50$ *

Das zukünftige Einkommensteueraufkommen hängt außer von der

Ausgestaltung des Steuersystems auch von der zahlenmäßigen und strukturellen Entwicklung der Bevölkerung ab. Anders als die Problematik der langfristigen Finanzierbarkeit der sozialen Sicherungssysteme wurde die Entwicklung des Steueraufkommens aufgrund des demographischen Wandels bisher kaum thematisiert. Ausgangspunkt der Arbeit ist daher die Darstellung der Entwicklung von Demographie und Erwerbsbeteiligung in Deutschland. Dafür werden neben den Determinanten der Bevölkerungsentwicklung (Geburtenrate, Lebenserwartung, Zuwanderung) auch Definitionen zur Messung der Erwerbsbeteiligung untersucht. Auf dieser Basis erfolgt eine Analyse der Steueraufkommens- und Verteilungswirkungen verschiedener aktueller Steuerreformvorschläge. Dabei kommt ein Mikrosimulationsmodell und die Methode der Generationenbilanzierung zur Anwendung.

Aus dem Inhalt: Demographie und Erwerbsbeteiligung · Simulationsmodelle und empirische Grundlagen - Das deutsche Steuersystem im Überblick . Auswirkungen von Steuerreformen

Frankfurt am Main - Berlin - Bern - Bruxelles - New York - Oxford - Wien Auslieferung: Verlag Peter Lang AG

Moosstr. 1, CH-2542 Pieterlen

Telefax 0041 (0) $32 / 3761727$

«inklusive der in Deutschland gültigen Mehrwertsteuer Preisänderungen vorbehalten

Homepage http://www.peterlang.de 
Tobias Arens - 978-3-631-75164-0

Downloaded from PubFactory at 01/11/2019 07:33:05AM

via free access 